OAK RIDGE

NATIONAL LABORATORY

MANAGED BY UT-BATTELLE

FOR THE DEPARTMENT OF ENERGY

\title{
Durability-Based Design Criteria for a Quasi-Isotropic Carbon-Fiber- Reinforced Thermoplastic Automotive Composite
}

D. J. Naus

J. M. Corum

L. B. Klett

M. S. Davenport

R. L. Battiste

W. A. Simpson

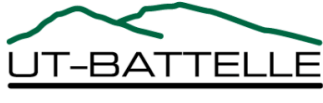

ORNL-27 (4-00) 


\section{DOCUMENT AVAILABILITY}

Reports produced after January 1, 1996, are generally available free via the U.S. Department of Energy (DOE) Information Bridge.

Web site http://www.osti.gov/bridge

Reports produced before January 1, 1996, may be purchased by members of the public from the following source.

National Technical Information Service

5285 Port Royal Road

Springfield, VA 22161

Telephone 703-605-6000 (1-800-553-6847)

TDD 703-487-4639

Fax 703-605-6900

E-mail info@ntis.fedworld.gov

Web site http://www.ntis.gov/support/ordernowabout.htm

Reports are available to DOE employees, DOE contractors, Energy Technology Data Exchange (ETDE) representatives, and International Nuclear Information System (INIS) representatives from the following source.

Office of Scientific and Technical Information

P.O. Box 62

Oak Ridge, TN 37831

Telephone 865-576-8401

Fax 865-576-5728

E-mail reports@adonis.osti.gov

Web site http://www.osti.gov/contact.html

This report was prepared as an account of work sponsored by an agency of the United States Government. Neither the United States Government nor any agency thereof, nor any of their employees, makes any warranty, express or implied, or assumes any legal liability or responsibility for the accuracy, completeness, or usefulness of any information, apparatus, product, or process disclosed, or represents that its use would not infringe privately owned rights. Reference herein to any specific commercial product, process, or service by trade name, trademark, manufacturer, or otherwise, does not necessarily constitute or imply its endorsement, recommendation, or favoring by the United States Government or any agency thereof. The views and opinions of authors expressed herein do not necessarily state or reflect those of the United States Government or any agency thereof. 


\title{
DURABILITY-BASED DESIGN CRITERIA FOR A CARBON-FIBER-REINFORCED THERMOPLASTIC AUTOMOTIVE COMPOSITE
}

\author{
D. J. Naus \\ J. M. Corum \\ L. B. Klett \\ M. S. Davenport \\ R. L. Battiste \\ W. A. Simpson
}

Date Published: April 2006

Prepared by the OAK RIDGE NATIONAL LABORATORY

Oak Ridge, Tennessee 37831

managed by

UT-BATTELLE, LLC

for the

U.S. DEPARTMENT OF ENERGY

under contract DE-AC05-00OR22725 


\section{CONTENTS}

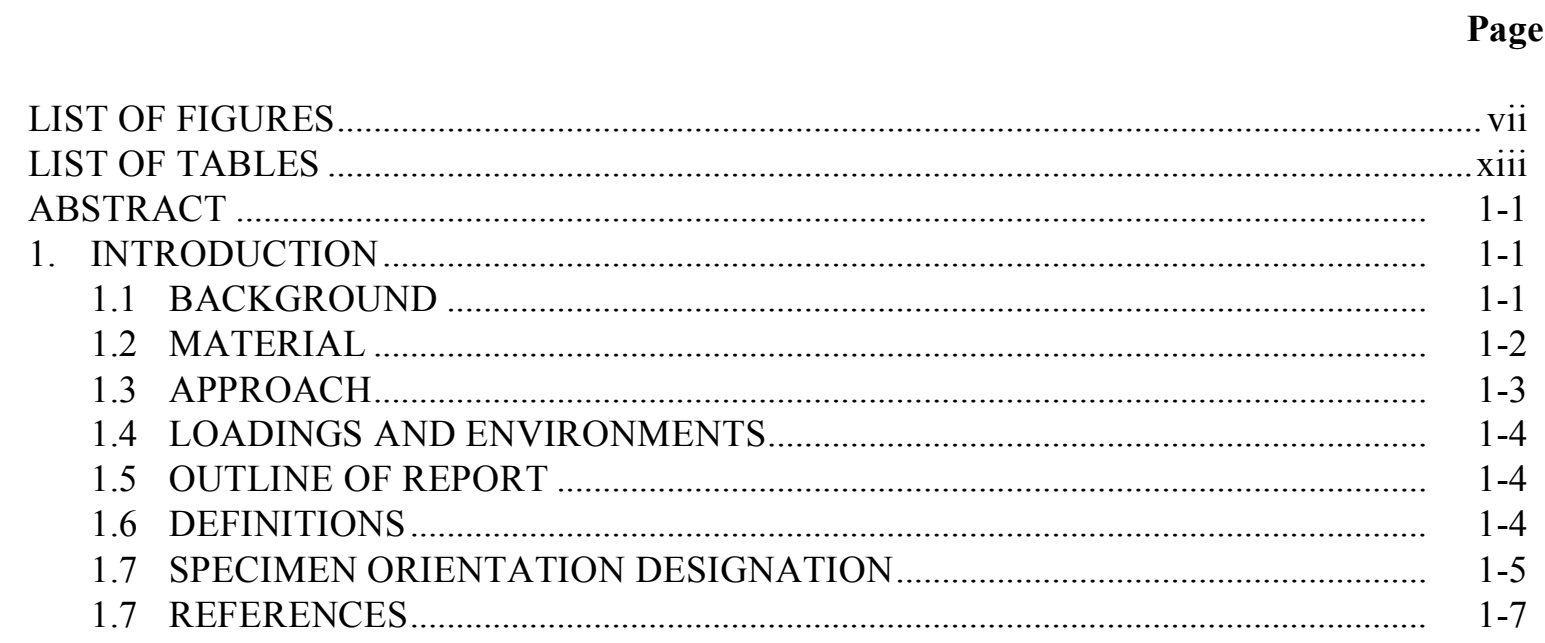

\section{PART 1. DESIGN CRITERIA}

2. ELASTIC AND CREEP PROPERTIES FOR DESIGN ANALYSIS …......................... $2-1$

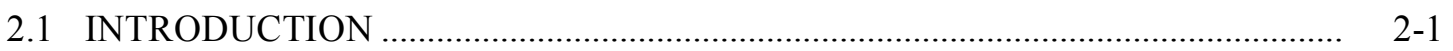

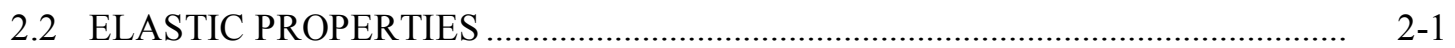

2.2.1 Effects of Temperature .............................................................................. 2- 2-1

2.2.2 Effect of Sequential and Prior Loading ........................................................ 2-2

2.2.3 Effect of Fluids............................................................................................. 2-3

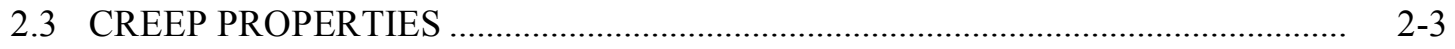

2.3.1 Basic Room-Temperature Creep Equation.................................................. 2-3

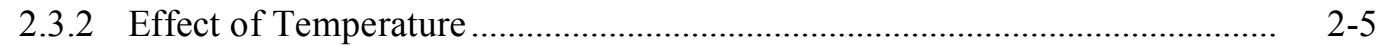

2.3.3 Effect of Fluids ........................................................................................ 2 2-5

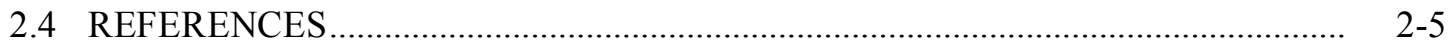

3. DESIGN ALLOWABLES FOR STATIC LOADINGS ……............................................

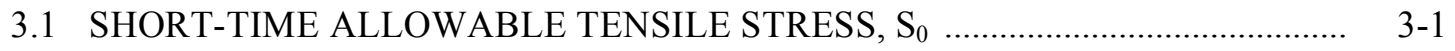

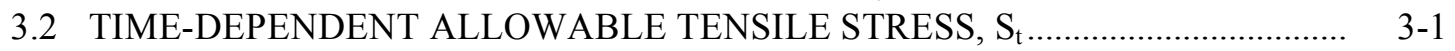

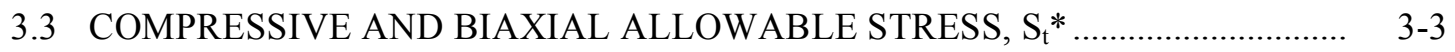

3.3.1 Biaxial Strength Criteria .............................................................................. $3-3$

3.3.2 Allowable Stresses ............................................................................... $\quad 3-5$

3.4 TREATMENT OF MEMBRANE AND BENDING STRESSES............................. 3- 3

3.5 TREATMENT OF INCREMENTS OF CHANGING LOADS …............................ 3-9

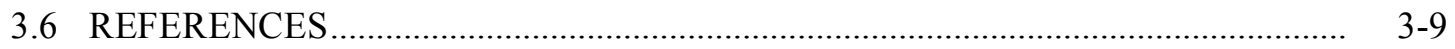

4. DESIGN LIMITS FOR CYCLIC LOADINGS ….......................................................

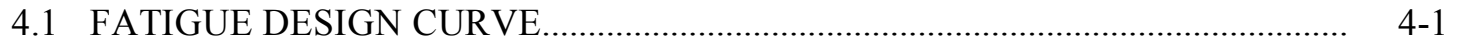

4.2 EFFECTS OF TEMPERATURE ....................................................................... 4-2

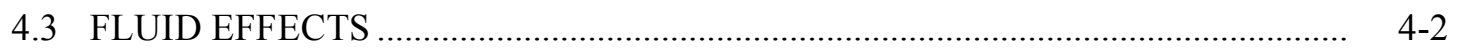

4.4 TREATMENT OF VARYING STRESS AMPLITUDES....................................... $4-3$

4.5 REFERENCES ........................................................................................ $4-3$

5. DAMAGE TOLERANCE ASSESSMENT FOR LOW-ENERGY IMPACTS

AND OTHER DEFECTS AND DISCONTINUITIES....................................................... $5-1$

5.1 GENERAL REQUIREMENTS .................................................................. $5-1$

5.2 EFFECTS OF CIRCULAR HOLES AND CRACKS ……......................................... $5-1$

5.3 DETERMINATION OF IMPACT DAMAGE AREAS …….................................. $5-2$ 
5.4 DETERMINATION OF STRENGTH AND STIFFNESS DEGRADATION .......... $5-3$

5.5 REFERENCE ...........................................................................................

6. SUMMARY AND COMPARISON WITH QUASI-ISOTROPIC THERMOSET

CARBON-FIBER COMPOSITE ............................................................................ 6-1

6.1 ELASTIC AND CREEP PROPERTIES FOR DESIGN ANALYSIS ...................... $6-1$

6.2 ALLOWABLE STRESSES FOR STATIC LOADINGS ............................................. $6-2$

6.3 ALLOWABLE STRESSES FOR CYCLIC LOADINGS …........................................ $6-4$

6.4 SIMPLIFIED SUMMARY OF ALLOWABLE STRESSES …................................... 6

6.5 DAMAGE TOLERANCE EVALUATION.......................................................... 6

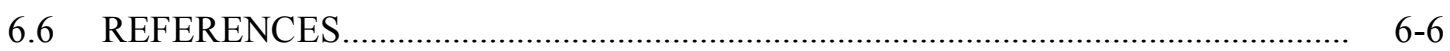

\section{PART 2. BACKGROUND DATA AND MODELS}

7. BASIC TENSILE, COMPRESSIVE, AND SHEAR PROPERTIES ................................. 7-1

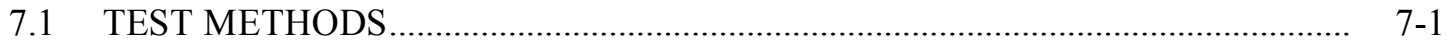

7.2 ROOM-TEMPERATURE BASIC PROPERTIES ……..........................................

7.3 PROPERTIES VS PRECONDITIONINGTEMPERATURE ....................................

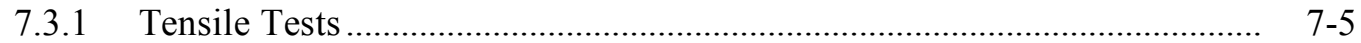

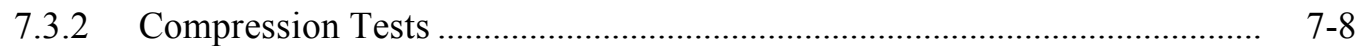

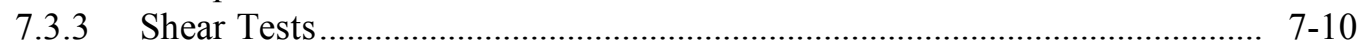

7.3.4 Temperature Multiplication Factors................................................................. 7-11

7.4 EFFECT OF SEQUENTIAL AND PRIOR LOADING ON STIFFNESS ............... 7-15

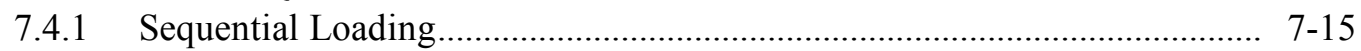

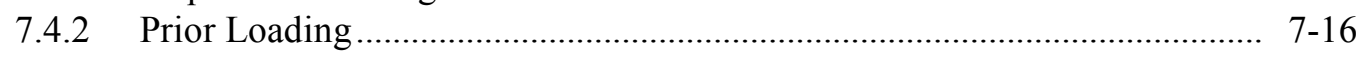

7.5 EFFECT OF STRAIN RATE ON TENSILE PROPERTIES ……......................... 7-18

7.6 EFFECTS OF THERMAL CYCLING …....................................................... 7-19

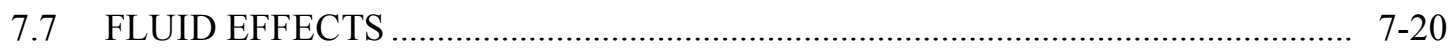

7.7.1 Environmental Screening .................................................................... 7-20

7.7.2 Distilled Water and Windshield Washer Fluid Effects............................... 7-24

7.7.2.1 Tensile Properties ................................................................ 7-24

7.7.2.2 Compressive Strength........................................................... 7-26

7.7.2.3 Shear Strength ................................................................... 7-26

7.7.2.4 Fluid Effect Multiplication Factors .......................................... 7-27

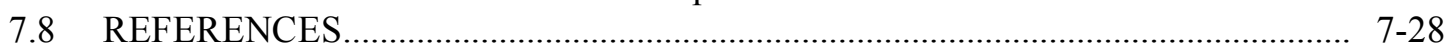

8. UNIAXIAL AND BIAXIAL FLEXURAL PROPERTIES …...........................................

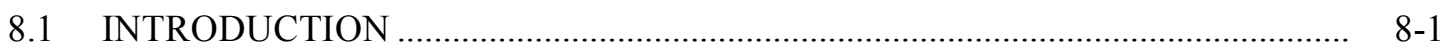

8.2 UNIAXIAL FLEXURAL STRENGTH ........................................................ 8

8.2.1 Temperature Effects ............................................................................. 8-1

8.2.2 Fluid Effects ................................................................................. 8-3

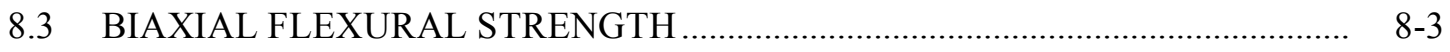

8.4 COMPARISON OF STRENGTH MULTIPLICATION FACTORS …................... $8-4$

8.5 PREDICTABILITY OF BENDING DEFORMATIONS .......................................... $8-5$

8.5.1 Uniaxial Flexure - Three-Point Bending ................................................ 8-6

8.5.2 Uniaxial Flexure - Cantilever Beams …….................................................... 8-6

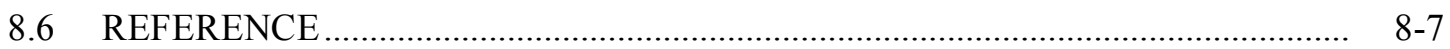

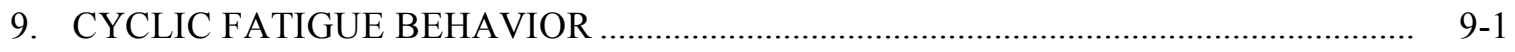

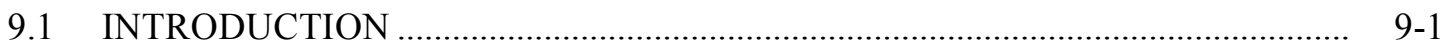

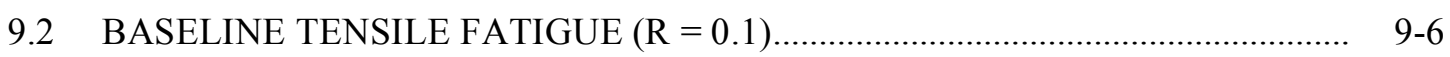

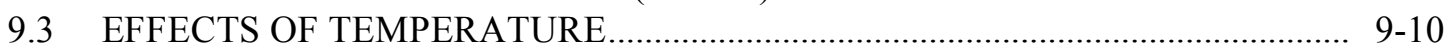

9.4 FLUID EFFECTS ..................................................................................... 9-16 
9.5 EXTENSION TO OTHER TYPES OF CYCLES …........................................... 9-19

9.6 SUMMARY AND RECOMMENDATIONS …................................................. 9-25

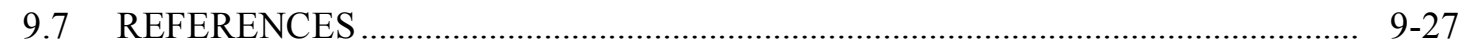

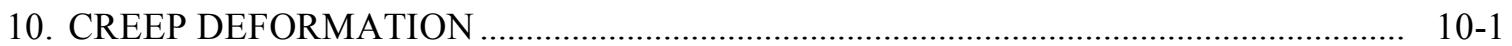

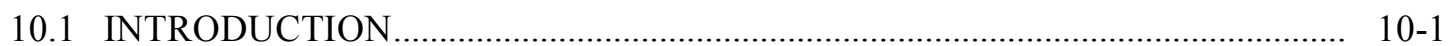

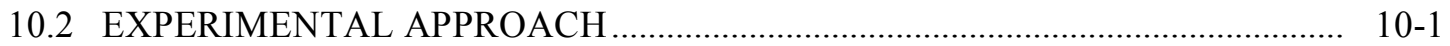

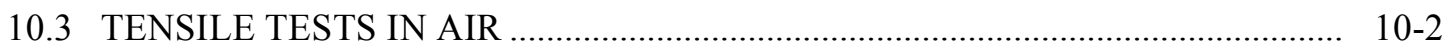

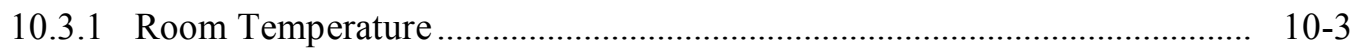

10.3.2 Elevated Temperature .......................................................................... 10-14

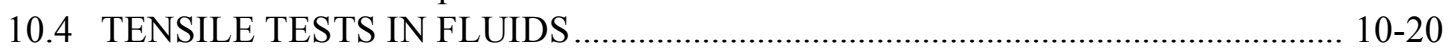

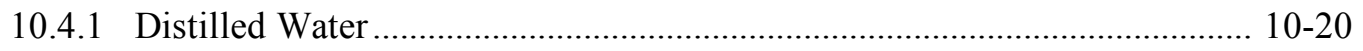

10.4.2 Windshield Washer Fluid...................................................................... 10-21

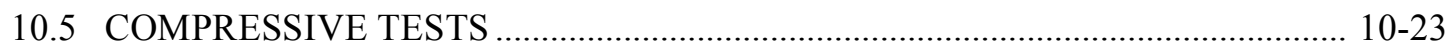

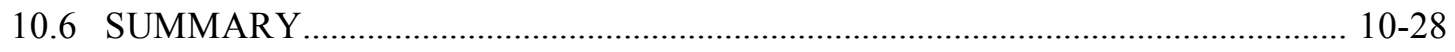

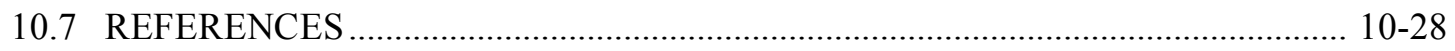

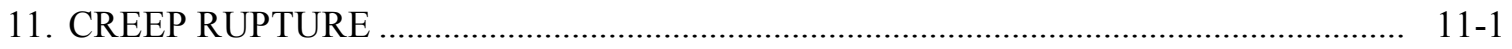

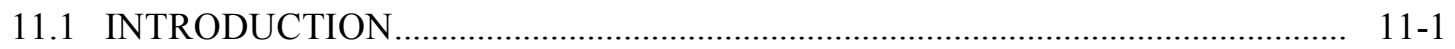

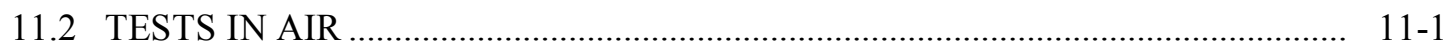

11.2.1 Tensile Failures at Room Temperature and $120^{\circ} \mathrm{C}$................................... 11-1

11.2.2 Compressive Failures at Room Temperature and $120^{\circ} \mathrm{C}$........................... 11-4

11.2.3 Time-Temperature Creep-Rupture Parameter ........................................... 11-4

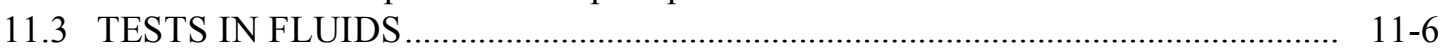

11.3.1 Distilled Water ...................................................................................... $11-7$

11.3.2 Windshield Washer Fluid................................................................... 11-7

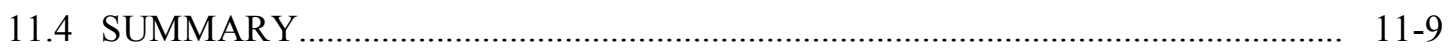

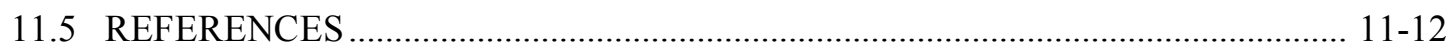

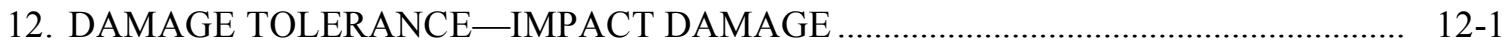

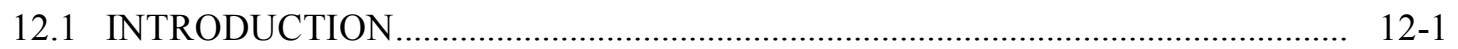

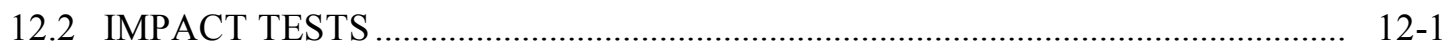

12.2.1 Baseline Results ...................................................................... 12-2

12.2.2 Effects of Annealing and Low Temperature ................................................ 12-10

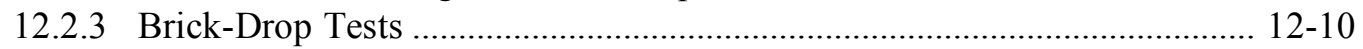

12.3 DEGRADATION OF STRENGTH PROPERTIES …............................................. 12-12

12.3.1 Introduction.................................................................................. 12-12

12.3.2 Compression-After-Impact ............................................................ 12-13

12.3.3 Tension-After-Impact ........................................................................... 12-16

12.3.4 Similarity to Hole Effects......................................................................... 12-16

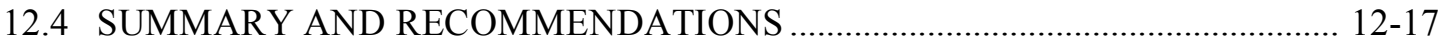

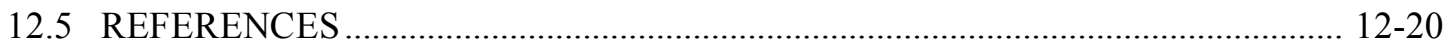

13. DAMAGE TOLERANCE—CIRCULAR HOLES AND CRACKS …............................ 13-1

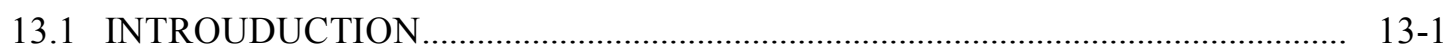

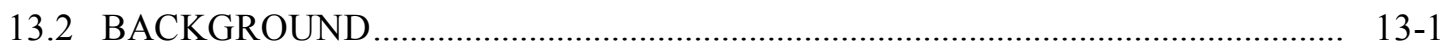

13.3 TEST PROGRAM AND DATA ANALYSIS …............................................... 13-2

13.4 TEST RESULTS AND CORRELATIONS ….................................................... 13-4

13.5 SUMMARY AND CONCLUSIONS …............................................................. $13-7$

13.6 REFERENCES .............................................................................................. 13-7

APPENDIX A: SUMMARY OF PLAQUE SPECIMEN DISTRIBUTION …................... A-1

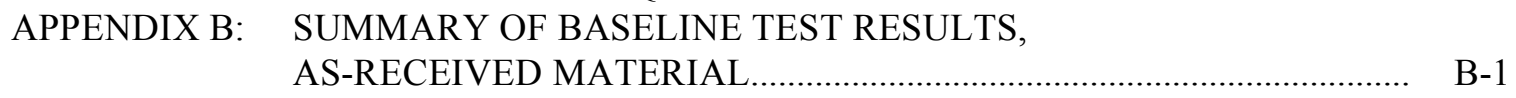


APPENDIX C: SUMMARY OF BASELINE TEST RESULTS, ANNEALED MATERIAL

C-1

APPENDIX D: SUMMARY AND COMPARISON OF RESULTS FOR AS-RECEIVED AND ANNEALED MATERIALS ON THE EFFECT OF SPECIMEN ORIENTATION ON TENSILE, COMPRESSIVE, AND SHEAR PROPERTIES

D-1

APPENDIX E: SUMMARY AND COMPARISON OF RESULTS FOR AS-RECEIVED AND ANNEALED MATERIALS ON THE EFFECT OF ELEVATED TEMPERATURE AND SPECIMEN ORIENTATION $\left(0^{\circ}\right.$ AND $\left.22.5^{\circ}\right)$ ON TENSILE, COMPRESSIVE, AND SHEAR PROPERTIES E-1 APPENDIX F: TENSILE CREEP TEST RESULT SUMMARY F-1 APPENDIX G: SUMMARY OF CREEP POST-TEST TENSILE PROPERTY RESULTS G-1 


\section{LIST OF FIGURES}

Figure

Page

1.1 Composite materials investigated $1-2$

1.2

Effect of specimen orientation on tensile properties $1-6$

Comparison of plaque unidirectional tape layup and specimen

orientation designation used throughout investigation: $0^{\circ}$ and $90^{\circ}$ correspond to longitudinal and transverse orientations, respectively

2.1 Multiplication factor for determining elastic in-plane modulus of elasticity at a given temperature from room-temperature value

Allowable tensile stresses, $\mathrm{S}_{\mathrm{t}}$, without environmental and prior load effects ............. 3-2

Allowable tensile stresses, $S_{t}$, with fluid effects

Candidate failure criteria compared with available room-temperature fracture data.

3.4 Allowable compressive and nontensile biaxial stresses, $\mathrm{S}_{\mathrm{t}}{ }^{*}$, without environmental and prior load effects.

3.5 Allowable compressive and nontensile biaxial stresses, $\mathrm{S}_{\mathrm{t}}{ }^{*}$, with estimated fluid effects

4.1 Final recommended design fatigue curve for

loads involving a positive mean stress.

4.2 Final recommended design fatigue curve for loads involving a zero or negative mean stress.

Strength reduction factor for circular holes and cracks in an infinitely wide, uniaxially loaded plate...

Design assessment curve for estimating impact damage area ..................................... 5-3

5.3 Design assessment curve for estimating tensile and compressive strength degradation as a function of impact damage area.

Closeup of IITRI test fixture ...................................................................................

Effect of specimen width tensile failure strain ....................................................... 7-4

Baseline tensile strength values adjusted for width effect ............................................. 7-4

7.11 Typical tensile stress-strain curves: tests at room temperature ……........................... 7-5

7.12 Effect of preconditioning temperature on ultimate tensile strength .............................. 7-5

7.13 Effect of preconditioning temperature on tensile modulus of elasticity ..................... 7-5

7.14 Effect of preconditioning temperature on tensile failure strain ................................... 7-5

7.15 Effect of preconditioning temperature on Poisson's ratio ............................................ 7-6

7.16 Effect of exposure period on ultimate tensile strength: $50^{\circ} \mathrm{C}$................................... 7-6

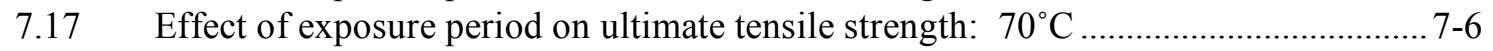

7.18 Effect of exposure period on ultimate tensile strength: $90^{\circ} \mathrm{C}$................................... 7-7

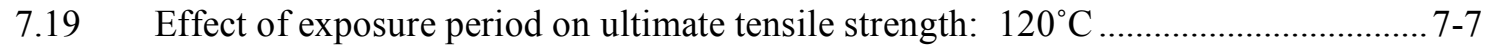

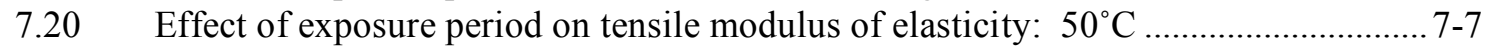


7.29 Examples of compressive stress vs strain curves:

specimens tested at temperature

Effect of sequential loading on stress vs strain results obtained

Stiffness change relative to baseline stiffness due to prior loading

Test specimen positioned in slack adapter prior to conduct of test...........

Short-beam shear test fixture............................................................................. 7-22

Summary of short-beam shear strength results .................................................... 7-22

Effect of 1000 hour exposure time to typical automotive fluids

on tensile properties

7.54 Effect of exposure time in windshield washer fluid on UTS ................................. 7-24

7.55 Effect of exposure time in windshield washer fluid on tensile stiffness ................... 7-24

7.56 Effect of exposure time in windshield washer fluid on tensile failure strain ............ 7-24

7.57 Effect of exposure time in distilled water on ultimate tensile strength...................... 7-25

7.58 Effect of exposure time in distilled water fluid on tensile stiffness ........................... 7-25

7.59 Effect of exposure time in distilled water on tensile failure strain ........................... 7-25

7.60 Effect of exposure time in windshield washer fluid on compressive strength .......... 7-26

7.61 Effect of exposure time in distilled water compressive strength ............................. 7-26

7.62 Effect of exposure time in windshield washer fluid on shear strength ..................... 7-27

7.63 Effect of exposure time in distilled water on shear strength .................................... 7-27

8.1a Flexural strength test setup ................................................................................. 8-1 


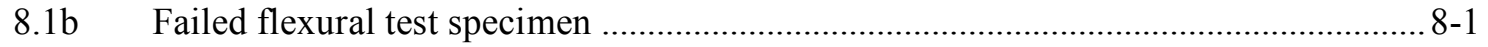

8.2 Effect of preconditioning and test temperatures on flexural strength ........................ 8-2

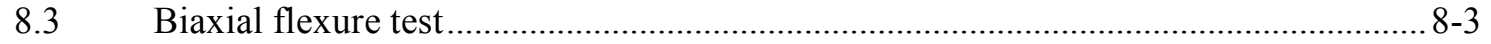

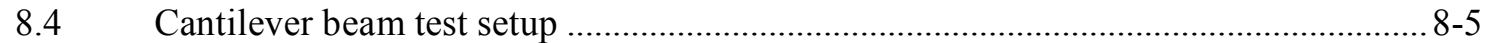

8.5 Load vs deflection, three-point bend test: $0^{\circ}$ orientation ........................................... $8-6$

8.6 Load vs deflection, three-point bend test: $90^{\circ}$ orientation ........................................ 8-6

8.7 Load vs deflection, cantilever beam test: $0^{\circ}$ orientation ............................................. 8-7

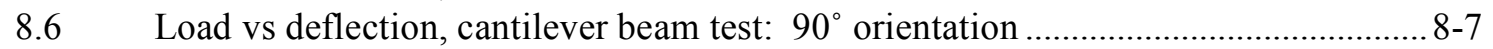

9.1 Cyclic fatigue test specimen geometry..................................................................... 9-5

9.2 Tensile fatigue $(\mathrm{R}=0.1)$ curves at $23^{\circ} \mathrm{C}$ for specimens

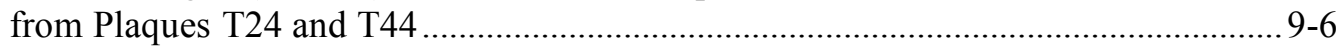

9.3 Maximum strain vs fatigue cycles for specimens at room temperature ........................ 9-7

9.4 Stiffness loss vs cycle fraction, $\mathrm{n} / \mathrm{N}_{\mathrm{f}}$, for specimens tested at room temperature........ 9-8

9.5 Temperature vs cycle fraction, $\mathrm{n} / \mathrm{Nf}$, for room temperature fatigue tests ................... 9-9

9.6 Typical failed specimen for room temperature fatigue test ...................................... 9-10

9.7 Tensile fatigue curves for Plaques T24 and T34 specimens at various temperatures: (a) using maximum stress and

(b) using $\%$ of plaque room temperature UTS.

. $9-10$

9.8 Maximum strain behavior at $-40^{\circ} \mathrm{C}$ for specimens from Plaque T24 ........................9-11

9.9 Maximum strain behavior at $70^{\circ} \mathrm{C}$ for specimens from Plaque T24 ........................9-12

9.10 Maximum strain behavior at $120^{\circ} \mathrm{C}$ for specimens from Plaque T34 ......................9-12

9.11 Stiffness loss vs cycle fraction, $\mathrm{n} / \mathrm{N}_{\mathrm{f}}$, for Plaque T24 and T34 specimens

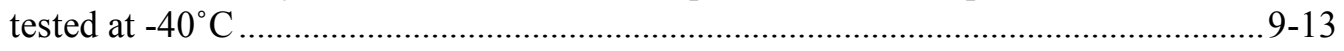

9.12 Stiffness loss vs cycle fraction, $\mathrm{n} / \mathrm{N}_{\mathrm{f}}$, for Plaque T24 specimens

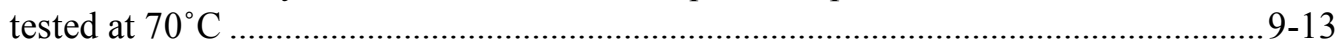

9.13 Stiffness loss vs cycle fraction, $\mathrm{n} / \mathrm{N}_{\mathrm{f}}$, for Plaque T34 specimens

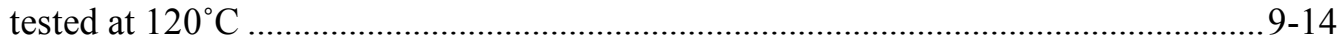

9.14 Average specimen temperature vs cycle fraction: Plaque T24 and T34

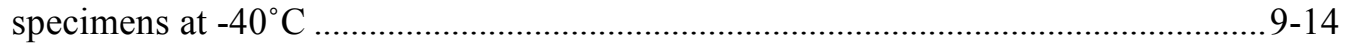

9.15 Average specimen temperature vs cycle fraction: Plaque T24

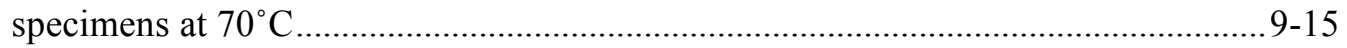

9.16 Average specimen temperature vs cycle fraction: Plaque T34

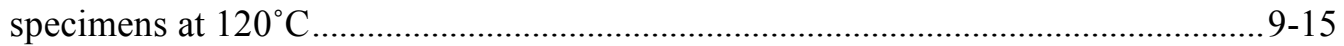

9.17 Effect of fluids on room temperature fatigue strength for Plaque T44 specimens.... 9-16

9.18 Stiffness loss vs cycle fraction, $\mathrm{n} / \mathrm{N}_{\mathrm{f}}$, for Plaque T44 specimens

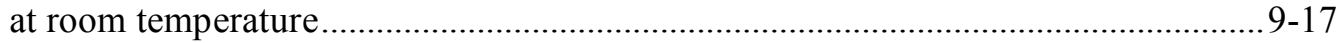

9.19 Maximum strain behavior for Plaque T44 specimens .............................................. 9-18

9.20 Four cyclic stress histories used to examine mean-stress effects ...............................9-19

9.21 Tensile S-N curve for hourglass specimens $(\mathrm{R}=0)$ compared with

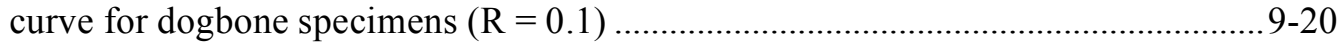

9.22 Fatigue curves from four different mean-stress cycle types compared on basis of maximum, or absolute value of minimum stress .....................................9-21

9.23 Fatigue curves from four different mean-stress cycle types compared on basis of stress amplitude, $\mathrm{S}_{\mathrm{a}}$

9.24 Fatigue curves from four different mean-stress cycle types

compared on basis of stress parameter $\sqrt{\mathrm{S}_{\max } \times \mathrm{S}_{\mathrm{a}}}$ or $\sqrt{\left|\mathrm{S}_{\min }\right| \times \mathrm{S}_{\mathrm{a}}} \quad \cdots \ldots \ldots \ldots \ldots . . . .9-23$

9.25 Comparison of Goodman predictions (based on $\mathrm{R}=-1$ correlation)

with experimental data and curve for tensile mean-stress cycle types. 
9.26 Comparison of Goodman prediction (based on $\mathrm{R}=-1$ correlation) with experimental data and curve for compressive mean-stress

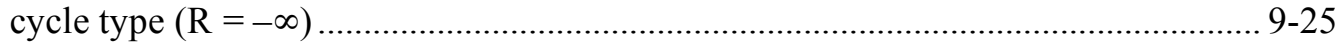

9.27 Comparison of room-temperature, in-air S-N curves from mean-stress tests with $\mathrm{R}=0.1 \mathrm{~S}-\mathrm{N}$ curve using $\mathrm{S}=\sqrt{\mathrm{S}_{\max } \times \mathrm{S}_{\mathrm{a}}}$ as the cyclic stress parameter........ 9-26

9.28 Construction of final recommended design fatigue curve for loads involving a positive mean stress $9-26$

9.29 Construction of final recommended design fatigue curve for loads involving a zero or negative mean stress ................................................... 9-27

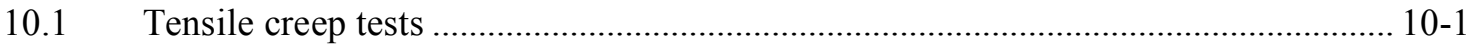

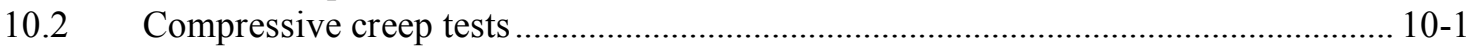

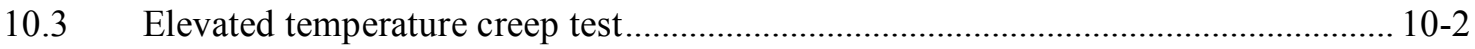

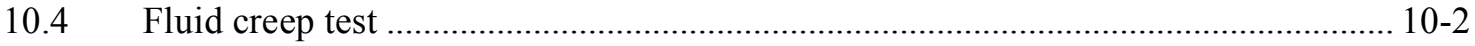

10.5 Loading strains measured in room-temperature, in-air creep tests .......................... 10-3

10.6 Examples of room temperature total strain versus time results.............................. 10-11

10.7 Examples of room temperature time-dependent strain versus time results ............. 10-11

10.8 Time-dependent, room temperature creep data .................................................... 10-11

10.9 Power-law coefficient A and exponent $\mathrm{n}$ as functions of applied stress at room temperature..................................................................... 10-12

10.10 Comparison of measured and predicted in-air room temperature creep strains ...... 10-12

10.11 Time-dependent room-temperature creep strains predicted by power-law creep equation ........................................................... 10-13

10.12 Predicted room-temperature isochronous stress-strain curves ................................. 10-13

10.13 Comparison of predicted creep response of quasi-isotropic carbon-fiber reinforced thermoplastic (T material) and quasi-isotropic carbon-fiber reinforced thermoset (Q material) composites................................... 10-14

10.14 Loading strains measured in $120^{\circ} \mathrm{C}$, in-air creep tests ...................................... 10-15

10.15 Examples of elevated temperature total strain versus time results.......................... 10-15

10.16 Examples of elevated temperature time-dependent strain versus time results ........ 10-15

10.17 Time-dependent, elevated temperature creep data ............................................. 10-16

10.18 Power-law coefficient $\mathrm{A}$ and exponent $\mathrm{n}$ as functions of applied stress at elevated temperature .............................................................................10-16

10.19 Comparison of measured and predicted $120^{\circ} \mathrm{C}$ creep strain .................................. 10-17

10.20 Time-dependent, $120^{\circ} \mathrm{C}$ creep strains predicted by creep equation ........................ 10-17

10.21 Predicted $120^{\circ} \mathrm{C}$ isochronous stress-strain curves ............................................... 10-18

10.22 Examples of temperature effect on total strain versus time results: $70 \%$ UTS .................................................................................... 10-19

10.23 Examples of temperature effect on time-dependent strain versus

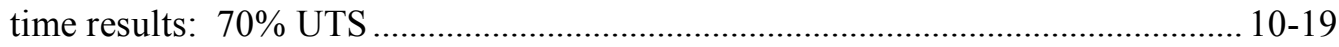

10.24 Examples of temperature effect on time-dependent creep data ............................. 10-19

10.25 Comparison of measured and predicted time-dependent creep strains: $70^{\circ} \mathrm{C} \ldots \ldots . .10-20$

10.26 Comparison of measured and predicted time-dependent strains: $90^{\circ} \mathrm{C}$.................. 10-20

10.27 Examples of room temperature total strain versus time results: distilled water exposure ..................................................................................... 10-20

10.28 Examples of room temperature time-dependent strain versus time results: distilled water exposure ........................................................................... 10-20

10.29 Time-dependent creep response of specimens tested in distilled water compared to predicted response in air. $10-21$ 
10.30 Examples of room temperature total strain versus time results:

windshield washer fluid

10.31 Examples of room temperature time-dependent strain versus time results:

windshield washer fluid exposure

10.32 Time-dependent creep response of specimens tested in windshield washer fluid compared to predicted response in air

10.33 Typical failed compressive creep specimens.

10.34 Room temperature total creep strain versus log time results $10-24$

10.35 Time-dependent creep strain versus time: (a) short-time test results

(b) longer duration test results.

10.36 Comparison of compressive creep strain with

laboratory daily temperature fluctuations

10.37 Time-dependent compressive creep response compared to

predicted tensile creep at room temperature (dashed curve) ....................................10-25

10.38 Thermal strain during heat up of $120^{\circ} \mathrm{C}$ creep specimens.....................................10-26

$10.39 \quad 120^{\circ} \mathrm{C}$ total creep strain versus $\log$ time results .................................................. 10-26

$10.40120^{\circ} \mathrm{C}$ time-dependent creep strain versus time: (a) short-time test results, longer duration test results

10.41 Time-dependent compressive creep response at $120^{\circ} \mathrm{C}$ compared to predicted tensile creep at room temperature (solid curve) and at $120^{\circ} \mathrm{C}$ (dashed curve)

11.1 Tensile creep-rupture data and average curve at room temperature in air.................. 11-2

11.2 Development of design curve for tensile creep-rupture at room temperature in-air

11.3 Tensile creep-rupture data, average curve, and design curve at temperature of $120^{\circ} \mathrm{C}$ in air.

11.4 Compressive creep-rupture data and average curves at room temperature and $120^{\circ} \mathrm{C}$

11.4 Compressive creep-rupture data and curve at $120^{\circ} \mathrm{C}$ compared with room-temperature and $120^{\circ} \mathrm{C}$ tensile curves

11.5 Manson-Haferd construction for tensile creep rupture ............................................11-5

11.6 Manson-Haferd construction for compressive creep rupture..................................... 11-6

11.7 Manson-Haferd curve for tensile creep-rupture design stresses ................................ 11-7

11.8 Manson-Haferd curve for compressive creep-rupture design stresses........................ 11-8

11.9 Final tensile and compressive creep-rupture design curves........................................ 11-8

11.10 Creep-rupture data and average curve for specimens tested in distilled water compared to in-air curve

11.11 Creep-rupture data and average curve for specimens tested in windshield-washer fluid compared to in-air curve

12.1 Visible damage on back face of impact specimen T51-21, which was subjected to a pendulum impact that produced significant damage

12.2 Visible damage on back face of impact specimen T49-74, which was subjected to an air-gun impact that produced significant damage.

12.3 Schematic of impact damage state

12.4 Low-magnification photomicrographs of full thickness of specimen

T51-21, which was subjected to pendulum impact

12.5 Low-magnification photomicrographs of full thickness of specimen

T49-74, which was subjected to air-gun impact. 
12.6 Typical C-scan images of specimens impacted at increasing energy levels

12.7 Baseline impact damage areas vs kinetic energy .....

12.8 Baseline impact damage area vs mass ${ }^{0.465} \mathrm{x}$ velocity

(mass in $\mathrm{kg}$ and velocity in $\mathrm{m} / \mathrm{s}$ ).

12.9 Comparison of peak impact forces measured in pendulum tests of three candidate carbon-fiber composites

12.10 Impact damage in annealed specimens in compared to results for baseline, as-received specimens .....

12.11 Impact damage in specimens tested at $-40^{\circ} \mathrm{C}$ compared to room-temperature baseline results

12.12 Impact damage in specimens subjected to brick drops compared to baseline correlation

12.13 Layout used for cutting CAI-type specimens from impacted plate specimens ....... 12-12

12.14 "CAI-type" specimen used for both tension- and compression-after-impact strength tests

12.15 Relative retained CAI strength vs damage area for as-received specimens 12-14

12.16 Relative retained CAI strength in annealed specimens compared with results for as-received specimens (curves)

12.17 Relative retained CAI strength in specimens impacted at $-40^{\circ} \mathrm{C}$ compared with results for as-received specimens impacted at room temperature (curves)..... 12-15

12.18 Relative retained CAI strength in specimens impacted by bricks compared with baseline results (curves).

12.19 Relative retained tensile strength after impact (solid curves) compared to CAI results (dashed curves)

12.20 Comparison of relative retained strength for specimens with holes compared to results for specimens with impact damage

12.21 Construction of design curve for conservatively estimating damage from impactor mass and velocity

12.22 Construction of lower-bound curve for estimating strength degradation due to impact damage.

13.1 Schematic representation of predicted axial stress distributions at large and small holes in a uniaxially loaded, infinitely wide plate

13.2 Layout of tensile specimens for hole and crack studies: (a) holes (Plaque T32) and (b) cracks (Plaque T33)....

13.3 Experimentally determined factor for adjusting UTS to account for specimen width

13.4 Results of tensile hole study compared to results of similar study on quasi-isotropic urethane composite.

13.5 Comparison of the effect of cracks on tensile strength degradation to that of holes $13-6$

13.6 Comparison of tensile hole results (from Fig. 13.4) with CAI-type compressive hole results (from Chap. 12) 


\section{LIST OF TABLES}

Table

2.1 Elastic properties for design

3.1 Basic $\mathrm{S}_{\mathrm{t}}(\mathrm{MPa})$ allowable stresses (applicable to tensile loadings).....

Allowable time-dependent tensile stresses, $\mathrm{S}_{\mathrm{t}}(\mathrm{MPa})$, with reductions to account for fluid effects...

Basic $\mathrm{S}_{\mathrm{t}}$ * (MPa) allowable stresses applicable to compressive and nontensile biaxial stress states.

Allowable time-dependent compressive and nontensile biaxial stresses,

$\mathrm{S}_{\mathrm{t}} *(\mathrm{MPa})$, with estimated reductions to account for fluid effects

Cyclic stress reduction factors for use with Fig. 4.1 to evaluate cycles with

a compressive mean stress

Elastic constants.

Time-dependent tensile creep strains due to a stress of $60 \mathrm{MPa}$ applied

for $5000 \mathrm{~h}$ at room temperature

Tensile $\mathrm{S}_{\mathrm{t}}$ values in air $(\mathrm{MPa})$.

Key allowable tensile stresses, expressed as a percentage of average

room-temperature UTS

Average properties from temperature dependence study..

Temperature multiplication factors for determining at-temperature modulus

and strength from room-temperature values

Average tensile properties obtained from groups of

specimens subjected to prior short-time static loads

Test series 1: tensile fatigue tests of Plaques T24 and T34 specimens at various

Fatigue strength factors for two bounding fluid environments.................................... 4-3

$\mathrm{S}_{\mathrm{t}} *(\mathrm{MPa})$ allowable stresses applicable to nontensile biaxial stress states ................. 6-3

Allowable maximum cyclic stresses for tensile cycling $(\mathrm{R}=0)$................................. 6-4

Bounding fluid multiplication factors for allowable cyclic stresses ........................... 6-4

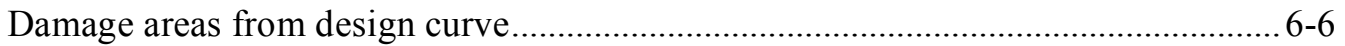

Estimated strength-reduction ratios caused by impact damage ................................ 6-6

Average in-air room-temperature baseline properties ................................................ 7-3

Maximum and minimum in-air room-temperature baseline property values .............. 7-3

Calculated baseline properties at different temperatures ............................................ 7-14

Calculated and measured shear moduli at different temperatures .............................. 7-15

Summary of sequential loading test results for final load cycle to failure................. 7-15

Effect of thermal cycling on tensile, compressive, and shear properties .................. 7-20

Details of automotive fluids used in environmental screening................................. 7-21

Effects on stiffness and strength of 100-h exposure in windshield washer fluid ...... 7-27

Effects on stiffness and strength of 1000 -h exposure in $23^{\circ} \mathrm{C}$ distilled water ........... 7-27

Fluid multiplication factors: comparison of $\mathrm{T}$ and $\mathrm{Q}$ materials................................ 7-28

Average uniaxial flexural properties at various temperatures ................................. 8-2

Effects of environment on flexural properties ....................................................... 8-3

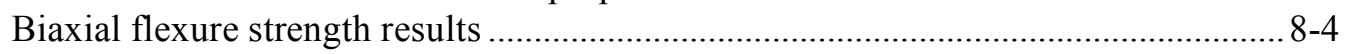

Strength multiplication factors relative to in-air room-temperature values ................. 8-4 temperatures ............................................................................................... 9-2

Tests series 2: tensile fatigue tests of Plaque T44 in air and fluids ............................ 9-3

Test series 3: mean stress fatigue tests of specimens from Plaque T38 ....................... 9-4 
9.4 Temperature fatigue multiplication factors ............................................................ 9-11

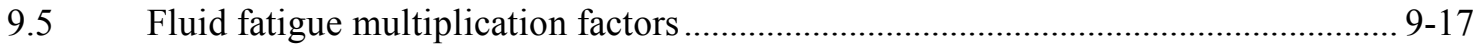

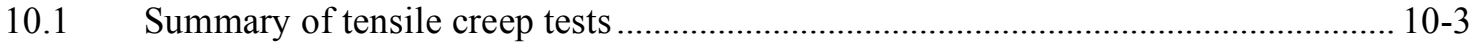

$10.2 \quad$ Matrix of tensile creep and creep-rupture tests ..................................................... 10-4

10.3 Factors for predicting tensile creep strains at $120^{\circ} \mathrm{C}$ from room-temperature

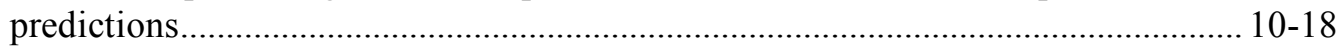

10.4 Matrix of compressive creep and creep-rupture tests .......................................... 10-23

11.1 Allowable tensile stresses at room temperature in air.............................................. 11-10

11.2 Creep-rupture strength multiplication factors (relative to in-air,

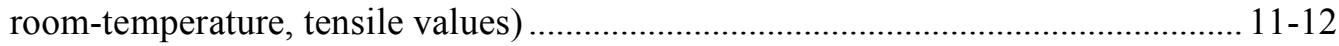

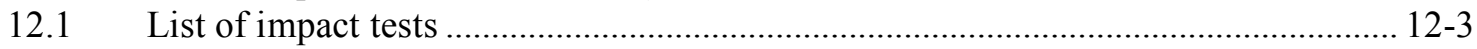

APP A Summary of plaque specimen distribution ................................................................

APP B Summary of baseline test results: as-received material ...............................................

APP C Summary of baseline test results: annealed material ..................................................

APP G Creep post-test tensile property results ........................................................................ 


\title{
DURABILITY-BASED DESIGN CRITERIA FOR A QUASI-ISOTROPIC CARBON-FIBER-REINFORCED THERMOPLASTIC AUTOMOTIVE COMPOSITE
}

\author{
D. J. Naus \\ J. M. Corum \\ M. S. Davenport \\ L. B. Klett \\ R. L. Battiste \\ W. A Simpson
}

\begin{abstract}
This report provides recommended durability-based design properties and criteria for a quaisisotropic carbon-fiber thermoplastic composite for possible automotive structural applications. The composite consisted of a PolyPhenylene Sulfide (PPS) thermoplastic matrix (Fortron's PPS - Ticona 0214B1 powder) reinforced with 16 plies of carbon-fiber unidirectional tape, $\left[0^{\circ} / 90^{\circ} /+45^{\circ} /-45^{\circ}\right]_{2 \mathrm{~S}}$. The carbon fiber was Hexcel AS-4C and was present in a fiber volume of 53\% (60\%, by weight).

The overall goal of the project, which is sponsored by the U.S. Department of Energy's Office of Freedom Car and Vehicle Technologies and is closely coordinated with the Automotive Composites Consortium, is to develop durability-driven design data and criteria to assure the long-term integrity of carbon-fiber-based composite systems for automotive structural applications.

This document is in two parts. Part 1 provides design data and correlations, while Part 2 provides the underlying experimental data and models. The durability issues addressed include the effects of shorttime, cyclic, and sustained loadings; temperature; fluid environments; and low-energy impacts (e.g., tool drops and kickups of roadway debris) on deformation, strength, and stiffness. Guidance for design analysis, time-independent and time-dependent allowable stresses, rules for cyclic loadings, and damagetolerance design guidance are provided.
\end{abstract}

\section{INTRODUCTION}

\subsection{BACKGROUND}

This report is the seventh in a series providing durability-based design data and criteria for polymeric composites suitable for producing large structural automotive components. The first three reports addressed two random-glass-fiber composites - one with swirled continuous-strand-mat reinforcement and one with chopped-fiber reinforcement. ${ }^{1-3^{*}}$ The fourth report was the first to address a carbon-fiber composite, and focused on a reference continuous-fiber $\left[ \pm 45^{\circ}\right]_{3 \mathrm{~S}}$ crossply composite. ${ }^{4}$ The fifth report addressed a quasi-isotropic, $\left[0 / 90 / \pm 45^{\circ}\right]_{\mathrm{S}}$ version of the crossply. ${ }^{5}$ The matrix and individual $\pm 45^{\circ}$ stitchbonded mats were the same in both cases. The basic ply information from the reference crossply composite could thus be used as a basis for predicting and better understanding the behavior of the quasiisotropic material. The sixth report ${ }^{6}$ addressed a random chopped-carbon-composite. The matrix was the same as used in the other two carbon-fiber composites, but the 50.8-mm-long fiber bundles came from a large, flat tow split into eight parts. Figure 1.1 presents a summary description of composite materials investigated under this program.

\footnotetext{
${ }^{*}$ The report for the swirled-mat composite consisted of two separate documents.
} 


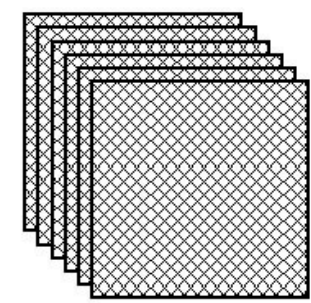

REFERENCE CROSSPLY, $\left[ \pm 45^{\circ}\right]_{38}$ $\pm 45^{\circ} \mathrm{T} 300 \mathrm{Stt}$ tch-Bonded MatsNrethane Matix

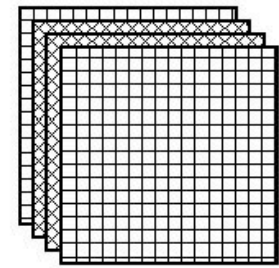

QUASI-ISOTROPIC, $\left[0 / 90 / 445^{\circ}\right]_{\mathrm{S}}$ $\pm 45^{\circ} \mathrm{T} 300$ Stitch-Bonded MatsNrethane Matrix

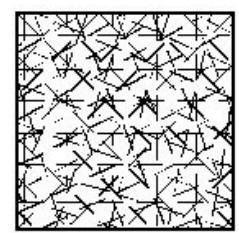

CHOPPED FIBER, Zoltek Panex 33 -
seven-split, $46 \mathrm{~K}$ Urethane Matrix

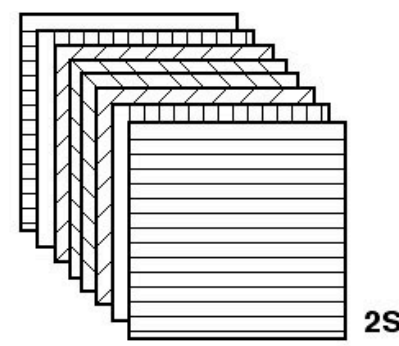

QUASI-ISOTROPIC, $\left[0 / 90 /+45^{\circ} / 45^{\circ}\right]_{2 S}$ AS-4C Unidrectional tape Polvphen vene Sulfide (PPS) Matrix

Figure 1.1 Composite materials investigated.

The work reported here was part of a project at Oak Ridge National Laboratory (ORNL) entitled Durability of Carbon-Fiber Composites. The project is sponsored by the U.S. Department of Energy's (DOE's) Office of Freedom Car and Vehicle Technologies and is closely coordinated with the Automotive Composites Consortium (ACC), an R\&D partnership between Daimler-Chrysler, Ford, and General Motors.

The current project has two primary goals. The first is to develop experimentally based, durabilitydriven guidelines to assure the long-term (15-year) integrity of representative carbon-fiber-based composite systems that can be used to produce large structural automotive components. The second goal is to provide a design criteria framework and test protocol that can be used by automakers and their suppliers for durability characterization of future carbon-fiber composites. The durability issues considered here include the potentially degrading effect that both cyclic and sustained loadings, exposure to automotive fluids, temperature extremes, and low-energy impacts from such things as tool drops and kickups of roadway debris can have on structural strength, stiffness, and dimensional stability.

\subsection{MATERIAL}

The ACC supplied 49 plaques, $510 \mathrm{~mm}$ by $610 \mathrm{~mm}$ by about 3-mm thick, for use in durability studies." The composite consisted of a PolyPhenylene Sulfide (PPS) thermoplastic matrix (Fortron's PPS - Ticona $0214 \mathrm{~B} 1$ powder) reinforced with 16 plies of carbon-fiber unidirectional tape, $\left[0 \% / 90^{\circ} /+45^{\circ} /\right.$ $\left.45^{\circ}\right]_{2 S}$. The carbon fiber was Hexcel AS-4C and was present in a fiber volume of $53 \%$ (60\%, by weight). A PPS-based scrim-reinforced coating was applied to the plaque faces during the manufacturing process. The scrim coatings made up about $10 \%$ the plaque thickness.

Processing conditions are very important in that they affect the crystallinity of a semicrystalline polymer such as PPS. Crystallinity changes of thermoplastic materials can result in significant changes in the mechanical behavior of composites containing them, particularly with respect to matrix-dominated properties such as compressive strength and creep. For this reason the ability to precisely characterize the polymer crystallinity in a thermoplastic material becomes an important requirement. Unfortunately, due to the proprietary nature of the material processing, only limited information has been provided by the material supplier on processing of the as-received material.

* Thirty-six of the plaques were used to provide the data used to develop the design criteria. Six additional plaques were heated at $230^{\circ} \mathrm{C}$ for two hours prior to specimen fabrication in an effort to enhance the material crystallinity. Appendix A presents a summary of the plaque specimen distribution. Plaque stiffness results, and a summary of baseline tensile, compression, and shear test results are presented in Appendix B for the as-received material and Appendix $\mathrm{C}$ for the annealed material. 
Differential scanning calorimetry (DSC) results, over the temperature range from $40^{\circ}$ to $320^{\circ} \mathrm{C}$, have been obtained from several samples of the quasi-isotropic material to investigate crystallinity of the asreceived material. The first scan indicated that the degree of crystallization was less than optimum about $85 \%$ of maximum crystallinity or about $32 \%$ crystallinity assuming a $40 \%$ resin content. The crystallization peak was not present during the second scan indicating a higher degree of crystallinity due to the first scan test temperature. Additional ramp and hold experiments were run in which samples were either heated from $40^{\circ}$ to $90^{\circ} \mathrm{C}$ at $20^{\circ} \mathrm{C}$ per minute, held at $90^{\circ} \mathrm{C}$ for 60 minutes and then permitted to return to room temperature; or heated to $120^{\circ} \mathrm{C}$ and held for 60 minutes prior to cooling to room temperature. After the $90^{\circ} \mathrm{C} \mathrm{ramp}$, the scan (sample ran at $40^{\circ}$ to $320^{\circ} \mathrm{C}$ at $20^{\circ} \mathrm{C}$ per minute) showed a $\mathrm{T}_{\mathrm{g}}$ and crystallization peak signifying less than an optimum degree of crystallinity. The second scan exhibited a flat baseline, indicating a high degree of crystallinity. Additional testing conducted by the University of Tennessee using x-ray diffraction produced crystallinity results in agreement with those obtained at ORNL.

A review of literature and contacts with industry has been conducted to provide data and information that addresses the relationship between processing of PPS materials and crystallinity as well as the relationship between crystallinity and material properties. A secondary objective of this review was to broaden the understanding of low-cost, semi-crystalline thermoplastic resins and composites for use in potential future automotive applications. Results of this review are provided in a report that has been published. $^{7}$ PPS has an excellent combination of attributes including good mechanical properties and thermal stability, high chemical resistance, low moisture absorption, good weathering resistance, high dimensional stability, low flammability, and excellent processability. Specific areas addressed in the report include: structure of PPS; techniques for measuring crystallinity; crystallinity as a function of prior treatment; crystallization kinetics and morphology; effect of variation of crystallinity on properties of PPS and its composites; environmental stability; unusual effects of cooling rates and degree of crystallinity on mechanical properties of AS4/PPS composites; recent PPS laminate data (Ten Cate Advanced Composites); and recommendations for future research.

\subsection{APPROACH}

The general project approach used for the current composite, and for each of the previous glass- and carbon-fiber composites, has been to first replicate on-road conditions in the laboratory specimens to generate data to form the basis for developing correlations and models. These correlations and models were then used to formulate design criteria. In the case of the current quasi-isotropic carbon-fiberreinforced thermoplastic composite, over 2,000 tests were performed." The tests included the following:

- basic, short-time tension, compression, and shear;

- uniaxial and biaxial flexure;

- cyclic fatigue, including mean stress effects;

- tensile and compressive creep and creep rupture;

- hole and crack effects;

- low-energy impact; and

- tension- and compression-after-impact (CAI).

In most cases, characterization of the effects of temperature and fluid exposure was included in the test effort.

* A number of tests was conducted investigating the effects of specimen orientation and annealing. Appendix D presents a summary of these effects on tensile, compressive, and shear properties; and Appendix E, a summary of these effects when elevated temperature effects are included. 
Despite the large number of tests performed, more extensive testing would be recommended in several areas to provide sufficient data for developing completely defensible correlations, models, and design criteria. For example, most of the factors developed to account for the effects of fluids and prior loading conditions are based on somewhat limited test results. The approach taken in the present study was to perform as many carefully planned tests as possible within time and budget constraints. Then the design criteria were developed with the philosophy of providing the best engineering design guidance possible based on the limited information available. This sometimes required assumptions and extrapolations beyond the range of existing data and ignoring possible synergisms. Clearly, while the information in this report should be adequate for preliminary designs undertaken with this material and for comparative purposes with other materials, more information would likely be required for final design purposes.

\subsection{LOADINGS AND ENVIRONMENTS}

From a durability standpoint, it is assumed here that an automobile with a composite structure must last for 15 years $(131,500 \mathrm{~h})$ and 150,000 miles. It is further assumed that during the 15 years, the vehicle will actually be operated between 3,000 and $5,000 \mathrm{~h}$ (at an average speed of 30 to $50 \mathrm{mph}$ ). The design temperature range is assumed to vary from a minimum of $-40^{\circ} \mathrm{C}$ to a maximum of $120^{\circ} \mathrm{C}$, with the higher temperatures occurring only during operation. The effects of thermal cycling are also a concern.

In addition to functional stiffness and deformation requirements, structures must support and resist a variety of live and dead loads. During operation, for example, live loads might include a combination of pothole impact, hard turn, and maximum acceleration. Dead loads during the 15-year life would include those from the weight of the vehicle or more importantly, sustained loads in the bed of a light truck.

Structures will also be subjected to common vehicle fluids and operating atmospheres, and design limits must take the resulting property degradation into account. The effects of a variety of fluids and moisture conditions were examined in the case of the glass-fiber composites and in screening tests, reported here, on the carbon-fiber composite. Based on the combined findings, the fluids most extensively examined were reduced primarily to distilled water and windshield washer fluid (a methanol/water mix).

\subsection{OUTLINE OF REPORT}

This report is divided into two parts, in a manner analogous to the arrangement used in the previous composite reports. Part 1, which consists of five chapters, provides guidelines for (1) the properties to be used in structural analysis, (2) design allowables for static loadings, (3) design rules for cyclic loadings, and (4) damage tolerance design for low-energy impacts. A final Part 1 chapter summarizes the quasiisotropic carbon-fiber thermoplastic composite ( $\mathrm{T}$ material) criteria and compares the allowables with the corresponding values for a previously investigated quasi-isotropic thermoset composite (Q material).

Part 2 provides the experimental data and models on which the guidance and criteria of Part 1 are based. Those readers wishing to understand the basic behavioral characteristics of the quasi-isotropic carbon-fiber thermoplastic composite should read Part 2 prior to reading Part 1. Part 2 has chapters on basic properties, including flexure, cyclic fatigue, time-dependent creep and creep rupture, prior load effects, and impact.

\subsection{DEFINITIONS}

A Impact damage area

A, $n \quad$ Creep law constants

a Hole diameter or crack length

CAI Compression after impact

E Elastic modulus (often referred to simply as stiffness) 


\begin{tabular}{|c|c|}
\hline $\mathrm{E}_{\mathrm{t}}$ & Time-dependent "pseudoelastic modulus" \\
\hline G & Shear modulus \\
\hline $\mathrm{K}$ & Temperature-dependent factor on allowable bending stress \\
\hline $\mathrm{k}_{\mathrm{b}}$ & Statistical factor used in determining R-basis minimum UTS \\
\hline $\mathrm{m}$ & Mass of impacting object \\
\hline MOR & Modulus of rupture \\
\hline $\mathrm{n}$ & Number of applied fatigue cycles for a given stress \\
\hline $\mathrm{N}_{\mathrm{d}}$ & Number of allowable design cycles for a given stress \\
\hline $\mathrm{P}$ & Calculated membrane stress at a point in the plane of a plate or shell structure \\
\hline $\mathrm{P}_{\mathrm{MH}}$ & Manson-Haferd creep-rupture parameter \\
\hline Q & Calculated bending stress at a point \\
\hline $\mathrm{R}^{2}$ & Coefficient of determination in curve fitting \\
\hline $\mathrm{R}$ & Ratio of minimum to maximum stress in a fatigue cycle \\
\hline $\mathrm{RH}$ & Relative humidity \\
\hline $\mathrm{S}$ & Stress parameter in fatigue cycle or equivalent intensity of combined stress \\
\hline $\mathrm{S}_{\mathrm{a}}$ & Alternating stress in fatigue cycle \\
\hline SCF & Stress concentration factor \\
\hline SD & Standard deviation \\
\hline $\mathrm{S}_{\max }$ & Maximum stress in fatigue cycle \\
\hline $\mathrm{S}_{0}$ & Basic short-time allowable stress (time $\mathrm{t}=0$ ) \\
\hline $\mathrm{S}_{0} *$ & $\begin{array}{l}\text { Short-time allowable stress applicable to compressive and biaxial stresses with a } \\
\text { compressive component }\end{array}$ \\
\hline $\mathrm{S}_{\mathrm{r}}$ & Minimum creep-rupture strength at a given time \\
\hline $\mathrm{Sr}^{*}$ & Minimum compressive creep-rupture strength at a given time \\
\hline $\mathrm{S}_{\mathrm{t}}$ & Time-dependent allowable stress \\
\hline $\mathrm{S}_{\mathrm{t}}^{*}$ & $\begin{array}{l}\text { Time-dependent allowable stress applicable to compressive and biaxial stresses with a } \\
\text { compressive component }\end{array}$ \\
\hline $\mathrm{T}$ & Temperature in Manson-Haferd parameter \\
\hline $\mathrm{t}$ & Time at a given stress \\
\hline $\mathrm{t}_{\mathrm{r}}$ & Rupture time in Manson-Haferd parameter \\
\hline $\mathrm{T}_{\mathrm{d}}$ & Allowable design time at a given stress \\
\hline UTS & Ultimate tensile strength \\
\hline $\mathrm{v}$ & Velocity of impacting object \\
\hline $\mathrm{w}$ & Plate width \\
\hline$\varepsilon$ & Normal strain \\
\hline$\varepsilon_{\mathrm{c}}$ & Normal creep strain \\
\hline$\dot{\varepsilon}_{m}$ & Steady-state creep rate \\
\hline$\sigma$ & Normal stress \\
\hline$\sigma_{1}, \sigma_{2}$ & Principal stress components \\
\hline $\bar{\sigma}$ & Applied stress in plate with hole \\
\hline $\bar{\sigma}_{\infty}$ & Applied stress in infinitely wide plate with hole \\
\hline$\sigma_{\mathrm{r}}$ & Average creep-rupture strength at a given time \\
\hline & Poisson's ratio \\
\hline
\end{tabular}

\subsection{SPECIMEN ORIENTATION DESIGNATION}

Prior to conduct of the in-depth testing required to provide the information utilized to develop the durability-based design data and criteria for the quasi-isotropic carbon-fiber thermoplastic composite, a limited number of tensile tests were conducted to investigate the effect of specimen orientation. Results 
from this series of tests were utilized to select the specimen orientation for the majority of testing conducted over the course of the testing program. Figure 1.2 presents a summary of the effect of specimen orientation on tensile properties. Figure 1.3 provides a description of the specimen orientations used throughout the test program and compares it to the AS-4C unidirectional carbon tape layup for the quasi-isotropic carbon-fiber thermoplastic material. Although the $22.5^{\circ}$ orientation provided the lowest tensile strength values as it was the orientation that was not aligned with a principal carbon-fiber orientation, the longitudinal (designated as the $0^{\circ}$ direction) was selected as the primary direction utilized for specimen orientation throughout the test program. A number of specimens, however, were fabricated in the $22.5^{\circ}$ orientation and tested over the duration of the test program. Results for specimens having the $22.5^{\circ}$ orientation are provided in Appendices D and E.

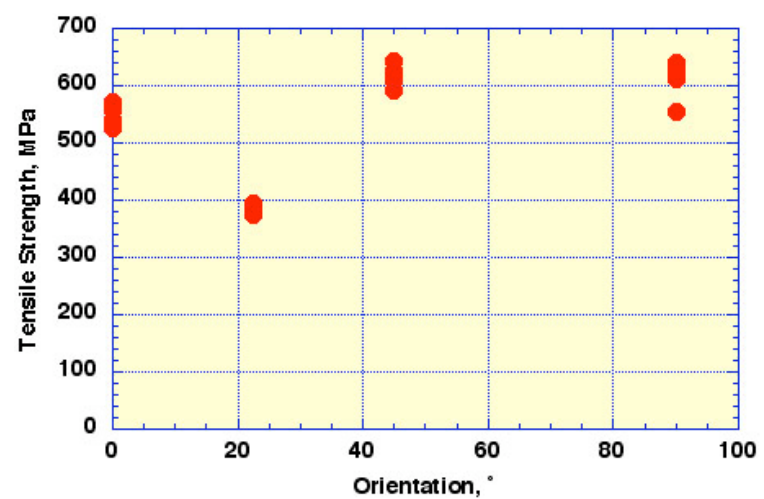

Effect of specimen orientation on ultimate tensile strength.

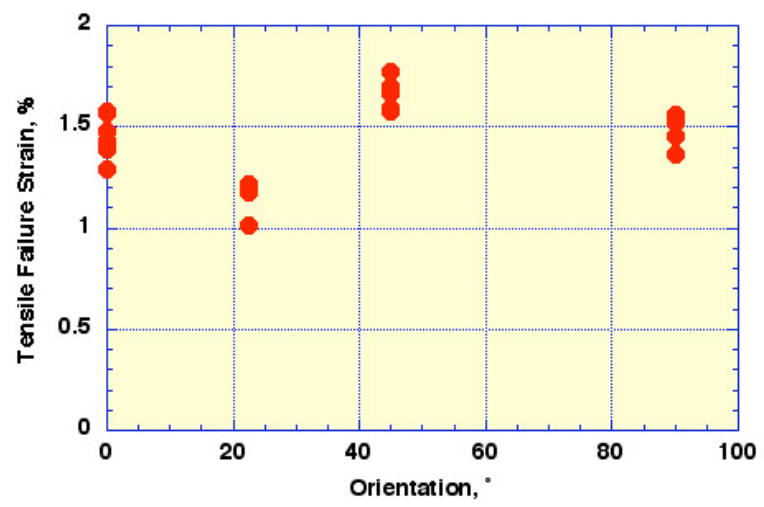

Effect of specimen orientation on tensile failure strain.

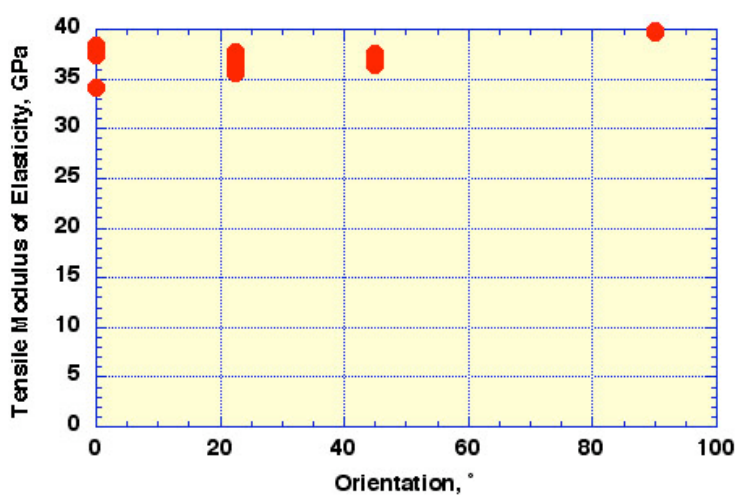

Effect of specimen orientation on tensile modulus of elasticity.

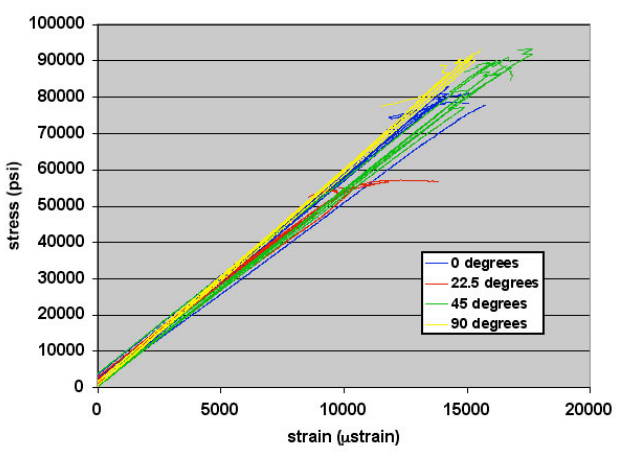

Effect of specimen orientation on tensile stress-strain curve.

Figure 1.2 Effect of specimen orientation on tensile properties. 


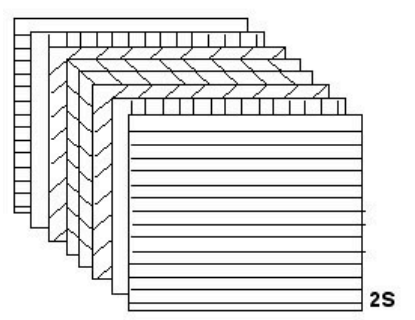

Quasi-Isotropic $\left[0 / 90 /+45^{\circ} /-45^{\circ}\right]_{45}$ AS-4C Unidirectional Tape Polyphenylene Sulfide (PPS) Matrix

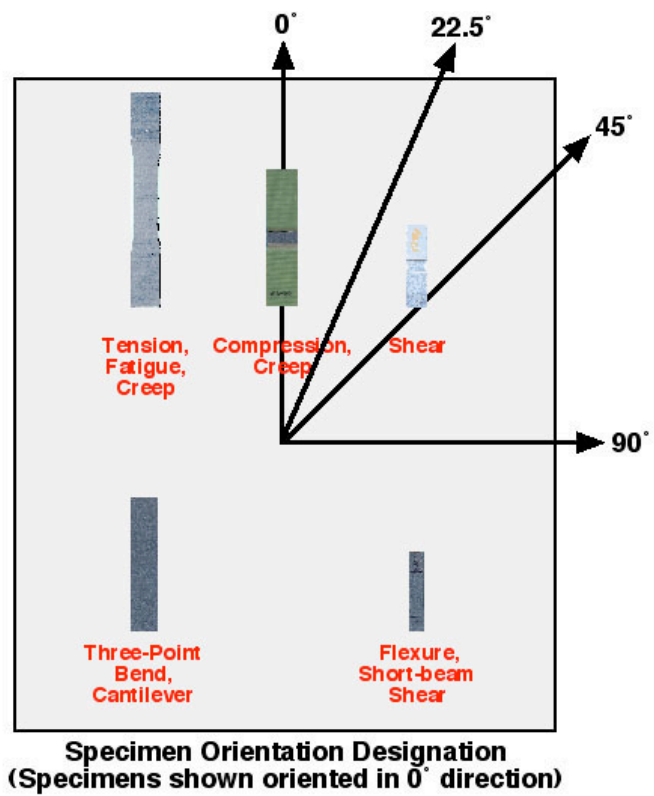

(Specimens shown oriented in $0^{\circ}$ direction)

Figure 1.3 Comparison of plaque unidirectional tape layup and specimen orientation designation used throughout the investigation: $0^{\circ}$ and $90^{\circ}$ correspond to the longitudinal and transverse plaque orientations, respectively.

\subsection{REFERENCES}

1. J. M. Corum et al., Durability-Based Design Criteria for an Automotive Structural Composite: Part 1. Design Rules, ORNL-6930, Oak Ridge National Laboratory, Oak Ridge, Tenn., February 1998.

2. J. M. Corum et al., Durability-Based Design Criteria for an Automotive Structural Composite: Part 2. Background Data and Models, ORNL-6931, Oak Ridge National Laboratory, Oak Ridge, Tenn., February 1998.

3. J. M. Corum, R. L. Battiste, W. Ren, and M. B. Ruggles, Durability-Based Design Criteria for a Chopped-Glass-Fiber Automotive Structural Composite, ORNL/TM-1999/182, Oak Ridge National Laboratory, Oak Ridge, Tenn., November 1999.

4. J. M. Corum et al., Durability-Based Design Properties of Reference Crossply Carbon-Fiber Composite, ORNL/TM-2000/322, Oak Ridge National Laboratory, Oak Ridge, Tenn., April 2001.

5. J. M. Corum et al., Durability-Based Design Criteria for a Quasi-Isotropic Carbon-Fiber Automotive Composite, ORNL/TM-2002/39, Oak Ridge National Laboratory, Oak Ridge, Tenn., March 2002.

6. J. M. Corum et al., Durability-Based Design Criteria for a Choped-Carbon-Fiber Automotive Composite, ORNL/TM-2003/86, Oak Ridge National Laboratory, May 2003.

7. J. Spruiell and C. Janke, Measurement and development of Crystallinity and Its Relation to Properties in Neat Poly (Phenylene Sulfide) and It Fiber Reinforced Composites, ORNL/TM-2004/304 Report, Oak Ridge National Laboratory, Oak Ridge, Tenn., August 2004. 


\section{ELASTIC AND CREEP PROPERTIES FOR DESIGN ANALYSIS}

\section{$2.1 \quad$ INTRODUCTION}

The carbon-fiber-reinforced thermoplastic composite is intended to exhibit in-plane isotropy. Limited strength data were obtained for the $0^{\circ}, 22.5^{\circ}, 45^{\circ}$, and $90^{\circ}$ specimen orientations (see Figure 1.3). Tensile strength results in the $22.5^{\circ}$ specimen orientation were 25 to $30 \%$ below those in the primary test orientation of $0^{\circ}$, whereas tensile strength results in the $90^{\circ}$ specimen orientation were approximately 10 to $15 \%$ greater than those obtained in the $0^{\circ}$ orientation. Stiffness test results, also presented in Appendix D, were consistent for each of the four specimen orientations examined. The elastic and creep properties given in this chapter are for in-plane response to in-plane loads.

Both simple beam and plate theory provided relatively good predictions of the beam deflections for specimens loaded in three-point bending. Comparing results in the $0^{\circ}$ and $90^{\circ}$ specimen orientations, beam deflections at comparable loads for the transverse beam specimens $\left(90^{\circ}\right.$ orientation) were less than those for the longitudinal beams $\left(0^{\circ}\right.$ specimen orientation). For the transverse beams the outer ply of fibers was aligned along the beam length where it is more effective in resisting applied loads. Both simple beam and plate theory generally provided good predictions of the cantilever beam deflections, although somewhat less than actual at a given load. Cantilever beam deflections at comparable loads for the transverse beam specimens $\left(90^{\circ}\right.$ specimen orientation) were less than those for the longitudinal beams $\left(0^{\circ}\right.$ specimen orientation). Again the outer ply of fibers for the transverse beams was aligned along the beam length where it is more effective in resisting applied loads. Shear deformations may also play a role because of a low out-of-plane shear stiffness.

\subsection{ELASTIC PROPERTIES}

For a composite that possesses in-plane isotropy, the linearly elastic response to in-plane applied loads is characterized by two constants, $\mathrm{E}$ and $\mathrm{G}$, or alternatively, $\mathrm{E}$ and $v$, where $\mathrm{E}$ and $\mathrm{G}$ are the Young's and shear moduli, and $v$ is Poisson's ratio. The constants are related by the following equation:

$$
G=\frac{E}{2(1+v)}
$$

Using measured values of $\mathrm{E}$ and $v$ to calculate $\mathrm{G}$ by Eq. (2.1) results in an overprediction compared to the measured in-plane $\mathrm{G}$ from shear tests. While the error is not large at room temperature and below, it increases with temperature to $23 \%$ at $120^{\circ} \mathrm{C}$ (see Chap. 7). The discrepancy may be due, at least in part, to an artifact of the Iosipescu shear test used to determine G. ${ }^{\dagger}$

The average in-plane, room-temperature elastic modulus and Poisson's ratio values for the carbonfiber-reinforced thermoplastic composite are $\mathrm{E}=36.45 \mathrm{GPa}$, and $v=0.29$. These basic values should be adjusted in accordance with the recommendations of the following subsections.

\subsubsection{Effects of Temperature}

Poisson's ratio exhibited a slight increase with increasing temperature $\left(\sim 4 \%\right.$ increase at $120^{\circ}$ relative to value at $23^{\circ} \mathrm{C}$ ), while the modulus of elasticity exhibited a very slight decrease with increasing temperature $\left(\sim 4 \%\right.$ decrease at $120^{\circ}$ relative to value at $\left.23^{\circ} \mathrm{C}\right)$ (see Chap. 7$)$. The latter decrease is shown

\footnotetext{
†See, for example, Ref. 1 for a discussion of shear stress and strain nonuniformities across an Iosipescu specimen and the possible effect of matrix plasticity. The agreement has been better, over the full temperature range, for previous isotropic composites. $^{2,3}$
} 
graphically in Figure 2.1 as a multiplication factor on the room-temperature modulus value of $36.45 \mathrm{GPa}$. Values of modulus of elasticity tabulated from the relation presented in Figure 2.1 are shown in Table 2.1 for specific temperatures. Poisson's ratio values are also presented in the table as a function of temperature.

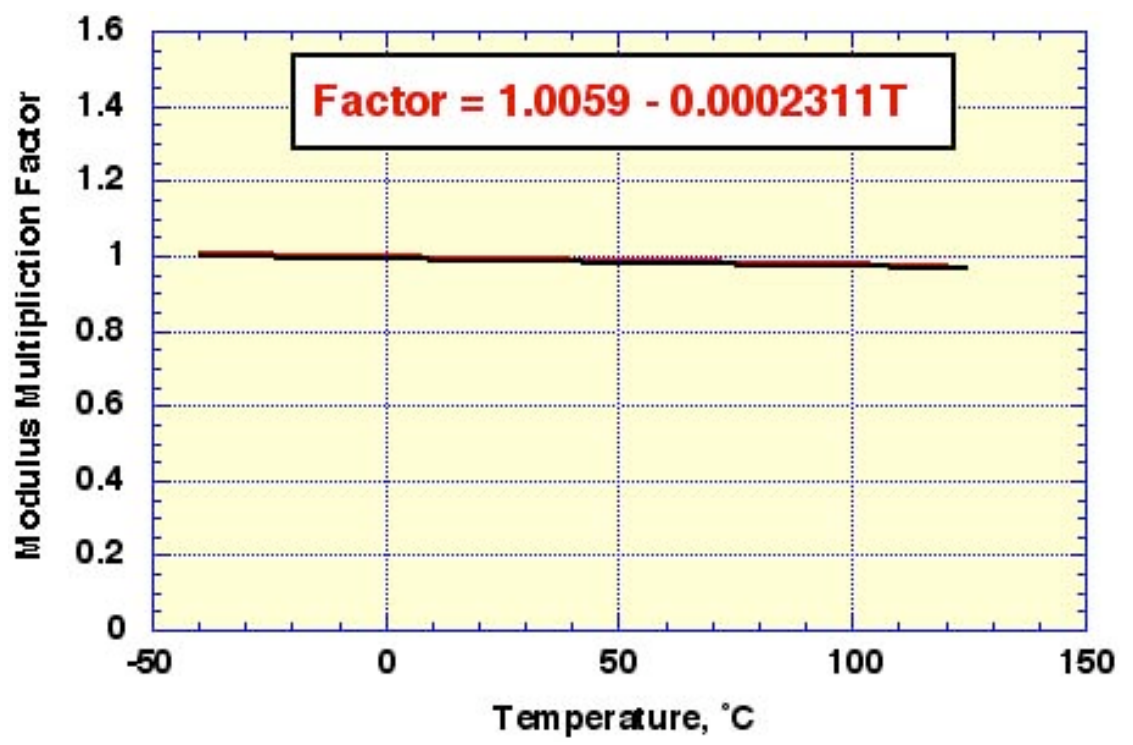

Fig. 2.1. Multiplication factor for determining elastic in-plane modulus of elasticity at a given temperature from room-temperature value.

Table 2.1. Elastic properties for design

\begin{tabular}{ccc}
\hline $\begin{array}{c}\text { Temperature } \\
\left({ }^{\circ} \mathbf{C}\right)\end{array}$ & $\begin{array}{c}\text { Modulus of elasticity } \\
(\mathbf{G P a})\end{array}$ & $\begin{array}{c}\text { Poisson's } \\
\text { ratio }\end{array}$ \\
\hline-40 & 37.00 & 0.284 \\
23 & 36.47 & 0.289 \\
70 & 36.08 & 0.308 \\
90 & 35.91 & 0.303 \\
120 & 35.65 & 0.301
\end{tabular}

Temperature cycling has some effect on elastic properties, as reported in Chap. 7. Tensile, compressive, and shear specimens were cycled between $-40^{\circ}$ and $120^{\circ} \mathrm{C}$ for up to 25 times prior to determining tensile, compressive, and shear properties at room temperature. After 25 thermal cycles, tensile strength increased $(<9.2 \%)$, compressive strength decreased $(<8.4 \%)$, and shear strength increased $(<6.6 \%)$. The tensile, compressive, and shear modulii decreased as a result of thermal cycling with the largest decrease occurring for the shear modulus $(<4.2 \%)$.

\subsubsection{Effect of Sequential and Prior Loading}

In general prior loads tend to introduce microdamage and a resultant loss of stiffness. As shown in Chap. 7, the effect of a limited number of loadings is small in the carbon-fiber-reinforced thermoplastic composite.

For sequential loading, the first load increment did not produce a change in stiffness, but succeeding load increments produced increased reductions in the modulus of elasticity relative to specimen baseline 
values. When loaded to failure following application of the sequential loadings, the ultimate tensile strength was relatively unaffected $(<3.7 \%$ increase relative to baseline), the stiffness values were reduced $(<8.3 \%)$, and failure strains increased slightly $(<6.6 \%)$.

For the prior loading tests, the change in stiffness relative to specimen baseline values was approximately $3 \%$ or less. When loaded to failure following application of the prior loading cycles, there was little effect on the average tensile property values relative to specimen baseline results $(\leq 4.1 \%)$.

It is shown in Chap. 9 that larger numbers of cyclic loadings, even when the number of cycles is within the allowable range (see Chap. 4), can reduce subsequent stiffness.

\subsubsection{Effect of Fluids}

Chapter 7 presents the results of several test series that assess the effects of distilled water and windshield washer fluid $(70 \%$ methanol $/ 30 \%$ distilled water) on stiffness. Preexposure for $1000 \mathrm{~h}$ to distilled water, which is one of two standard fluid exposures adopted in the durability studies, resulted in a tensile stiffness loss of $<3.3 \% .^{\dagger}$ The other standard preexposure- $100 \mathrm{~h}$ in windshield washer fluidexhibited little effect on modulus. Thus, to bound fluid effects on stiffness, a $4 \%$ value is recommended.

\subsection{CREEP PROPERTIES}

In the case of long-term sustained loadings - either those associated with the 3000- to 5000-h operating life of a vehicle or the nominally 15-year overall life-time-dependent creep deformations may become an important consideration and need to be accounted for in design analysis. This can be done at one of two levels of sophistication:

- $\quad$ using a creep equation in an inelastic (elastic-creep) analysis, or

- using a pseudo-elastic modulus from isochronous stress-strain curves in an elastic analysis.

Provisions for both approaches are given below.

\subsubsection{Basic Room-Temperature Creep Equation}

Many finite-element analysis programs allow for specification of a creep equation for use in an inelastic analysis. The following equation is developed in Chap. 10 for predicting time-dependent creep strains at room temperature.

$$
\varepsilon_{c}=A t^{n}
$$

where

$$
\begin{aligned}
& \mathrm{A}=1.056 \times 10^{-7} \sigma^{2.0614} \\
& \mathrm{n}=-4.1316 \times 10^{-7} \sigma^{2}+3.4953 \times 10^{-4} \sigma+0.062324
\end{aligned}
$$

Here, $\varepsilon_{\mathrm{c}}$ is time-dependent strain in percent, $\mathrm{t}$ is time in hours, and $\sigma$ is applied stress in megapascals. As a reminder, a creep equation is just one ingredient of a constitutive theory. The design analyst should be mindful of the other ingredients incorporated into an analysis program; for example, the hardening law and multiaxial flow rule.

\footnotetext{
${ }^{\dagger}$ Chapter 7 presents stiffness (tension only) and strength multiplication factors for tension, compression, and shear resulting from preconditioning in the two standard fluid exposures.
} 
Total strain is obtained by adding the creep strain predicted by Eq. (2.2) to the predicted elastic loading strain. Total strains predicted in this manner are displayed in Figure 2.2 in the form of isochronous stress-strain curves. Each curve gives the total strain that would be accumulated at a given constant stress level over the time period for which the curve was constructed. The longest-time curve, $131,000 \mathrm{~h}$, corresponds to the 15-year life of a vehicle.

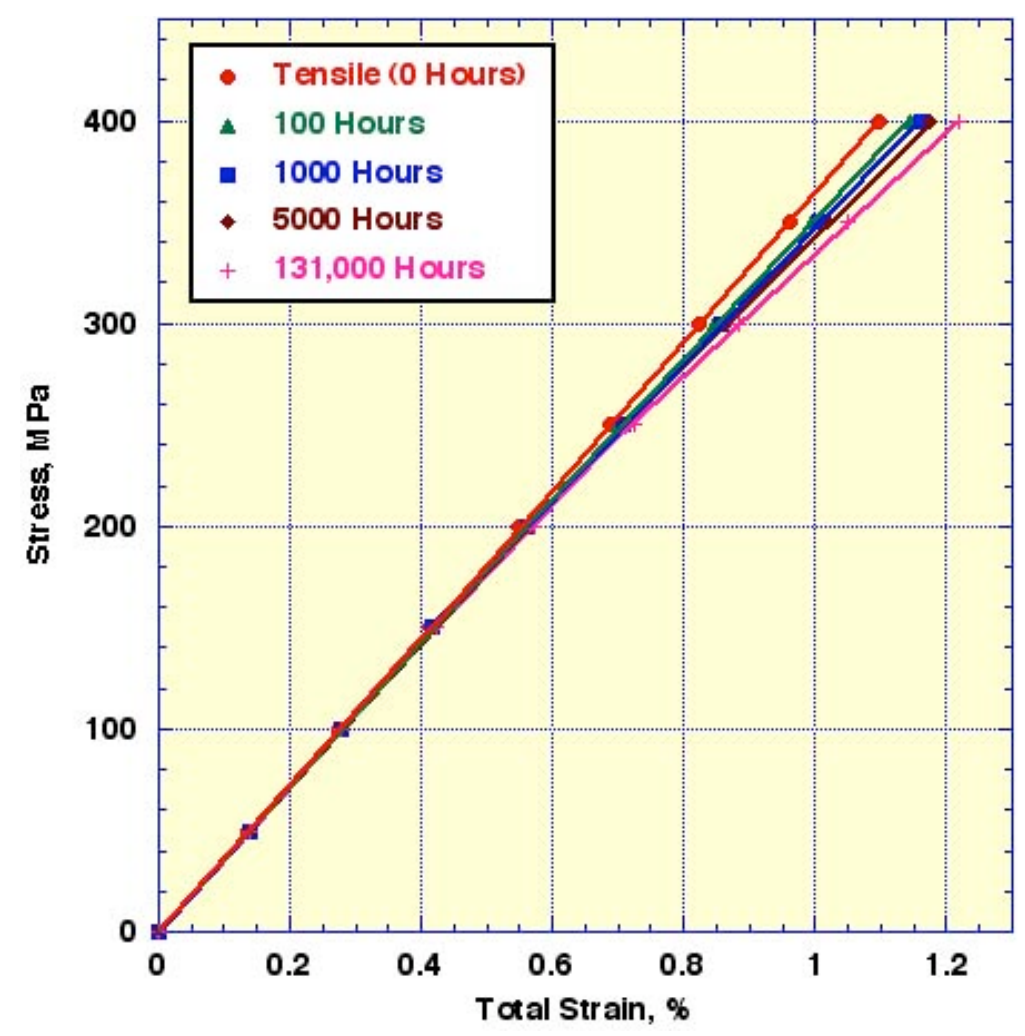

Fig. 2.2. Isochronous stress-strain curves for room-temperature ambient air.

Although a slight curvature exists for the curves in Figure 2.2, a straight line approximation to a given curve can be used to obtain a pseudo-elastic modulus for approximately determining strains corresponding to the time of the curve." Pseudo-modulus values obtained in this manner for the curves plotted in Figure 2.2 are tabulated below.

\begin{tabular}{rrrr} 
Time (h) & & $\mathbf{E}_{\mathbf{t}}(\mathbf{G P a})$ \\
\cline { 1 - 1 } 100 & & 36.45 \\
1,000 & & 35.04 \\
5,000 & & 33.46 \\
131,000 & & 32.90 \\
& &
\end{tabular}

\footnotetext{
*This approach usually gives reasonable approximations for non-time-varying loadings, and providing stress redistribution is minimal.
} 


\subsubsection{Effect of Temperature}

As noted in Chap. 10, the creep strain-time response at $120^{\circ} \mathrm{C}$ did not exhibit both a primary and secondary, or steady-state, creep component as was observed for the prior material investigated (i.e., chopped-carbon fiber composite). Therefore, the same basic equation as used for predicting room temperature creep strain-time response can be used $\left(\varepsilon_{c}=A t^{n}\right)$, where $\mathrm{A}$ and $\mathrm{n}$ are now

$$
\begin{aligned}
& \mathrm{A}=8.366 \times 10^{-9} \sigma^{2.5834} \\
& \mathrm{n}=-2.0172 \times 10^{-6} \sigma^{2}+1.5173 \times 10^{-3} \sigma
\end{aligned}
$$

and $\sigma$ is stress in megapascals, $\varepsilon_{\mathrm{c}}$ in Eqn. (2.3) is time-dependent strain in percent, and time, $t$, is in hours. The ratios of strains predicted using A and $\mathrm{n}$ from Eqn. (2.3) for $120^{\circ} \mathrm{C}$ to those predicted by Eqn. (2.2) for room temperature were determined in Chapter 10 and presented in Table 10.3. As noted in the table, the $120^{\circ} \mathrm{C}$ creep strain multiplier was much less than that obtained from previous materials investigated. The factor also did not appear to vary significantly with time. Therefore, time-dependent strains were compared at 1500 hours and provided creep strain multipliers of 1.30 at $70^{\circ} \mathrm{C}$ and 1.7 at $90^{\circ} \mathrm{C}$ and above.

Creep under compressive stresses is much more matrix-dominated, and, at least at higher temperatures and stress levels, probably involves local buckling. Limited compressive creep data presented in Chapter 10 indicate at room temperature, compressive creep is similar to tensile creep. Eqns. (2.2) and (2.3) for room-temperature creep apply to both tensile and compressive loadings at room temperature. It is shown in Chap. 10 that compressive creep at $120^{\circ} \mathrm{C}$ is about six times the predicted tensile creep at room temperature. Clearly, long-term compressive loadings at elevated temperature should be carefully considered in design.

\subsubsection{Effect of Fluids}

The effect on creep strain of the two standard fluid exposures - the 1000-h presoak in distilled water, followed by testing in distilled water, and the 100-h presoak in windshield washer fluid, followed by testing in windshield washer fluid-is reported in Chap. 10. Multiplication factors obtained for the distilled water and windshield washer fluid exposures were 1.4 and 2.2 , respectively. A single multiplication factor of 2.2 on predicted room-temperature creep strain is recommended to bound fluid effects.

\subsection{REFERENCES}

1. M-J. Pindera, P. Ifju, and D. Post, "Iosipescu Shear Characterization of Polymeric and Metal Matrix Composites," Experimental Mechanics, 101-108 (March 1990).

2. J. M. Corum, R. L. Battiste, W. Ren, and M. B. Ruggles, Durability-Based Design Criteria for a Chopped-Glass-Fiber Automotive Structural Composite, ORNL/TM-1999/182, Oak Ridge National Laboratory, Oak Ridge, Tenn., November 1999.

3. J. M. Corum et al., Durability-Based Design Criteria for a Quasi-Isotropic Carbon-Fiber Automotive Composite, ORNL/TM-2002/39, Oak Ridge National Laboratory, Oak Ridge, Tenn., March 2002. 


\section{DESIGN ALLOWABLES FOR STATIC LOADINGS}

The allowable stresses provided in this chapter are time-dependent. The applicable allowable, $\mathrm{S}_{\mathrm{t}}$, depends on the duration of the applied loading and is defined as

$$
S_{t} \leq\left\{\begin{array}{c}
S_{0} \\
0.67 \sigma_{r}
\end{array},\right.
$$

where $S_{0}$ is derived from short-time data in Chap. 7, and $\sigma_{\mathrm{r}}$ is the expected average creep-rupture strength at time t, developed in Chap. 11.

Actually, two sets of allowable stresses, $S_{t}$ and $S_{t}{ }^{*}$, are used in this chapter. The first is derived from uniaxial tensile test data and is only applicable to tensile stress states - when normal stress components in a biaxial stress state are positive. The second, $\mathrm{S}_{\mathrm{t}}{ }^{*}$, is derived primarily from compressive test data and is applicable to biaxial stress states containing a compressive normal stress component. The tensile allowables are first presented. Then the treatment of compressive stresses and biaxial stress states is discussed.

\subsection{SHORT-TIME ALLOWABLE TENSILE STRESS, $\mathbf{S}_{0}$}

The basic short-time, or instantaneous, allowable stress is based on the minimum room-temperature ultimate tensile strength (UTS), which is defined as the "B-basis stress" specified in MIL-HDBK-17. ${ }^{1}$ The minimum room-temperature value is based on statistical treatment of $n=207$ UTS values from 36 plaques, such that the survival probability at the minimum stress is $90 \%$ at a confidence level of $95 \%$. This statistically minimum stress was calculated to be ${ }^{1}$

$$
\mathrm{UTS}_{\min }=\mathrm{UTS}_{\mathrm{avg}}-\mathrm{k}_{\mathrm{B}}(\mathrm{SD})=490 \mathrm{MPa}
$$

where (see Chap. 7) the average UTS is $551 \mathrm{MPa}$, the standard deviation (SD) is $42.1 \mathrm{MPa}$, and the factor $\mathrm{k}_{\mathrm{B}}$ for 207 data points is 1.447 (see Ref. 1).

The basic time-independent allowable stress, $\mathrm{S}_{0}$ is defined as two-thirds $\mathrm{UTS}_{\min }$. At room temperature, $\mathrm{S}_{0}$ thus becomes $327 \mathrm{MPa}$, which is $59 \%$ of the average UTS. Values of $\mathrm{S}_{0}$ for other temperatures are obtained by multiplying the room-temperature $S_{0}$ value by the UTS temperature factors tabulated in Table 7.4 of Chap. 7 and plotted in Fig. 7.37.

\subsection{TIME-DEPENDENT ALLOWABLE TENSILE STRESS, $\mathrm{S}_{\mathrm{t}}$}

For sustained loadings, creep-rupture stress (see Chap. 11) is the basis for time-dependent allowable stresses, provided, as specified in Eq. (3.1), that $\mathrm{S}_{0}$ is not lower than the creep-rupture-derived values. A design margin of two-thirds of the average stress to produce rupture in time $t$ is used.

Values of $\mathrm{S}_{\mathrm{t}}$ [see Eq.(3.1)], without any of the environmental and prior loading effects described in Chap. 7, are tabulated in Table 3.1 and plotted in Fig. 3.1.

While the designer must ultimately judge which environmental and prior loading reduction factors developed in Part 2 are appropriate for an application, a bounding fluid effect on allowable stress is introduced here. Fluid exposure is common in automotive applications, and tests on the previously investigated quasi-isotropic carbon-fiber thermoset composite showed that even high humidity can have a deleterious effect on strength. ${ }^{2}$ While the effects of several fluids that were screened are reported in Chap. 7, two particular bounding exposures were used for more thorough investigations, as reported in Chaps. 7 and 11: 
Table 3.1. Basic $S_{t}$ (MPa) allowable stresses (applicable to tensile loadings)

\begin{tabular}{rccccc}
\hline & \multicolumn{4}{c}{ Temperature $\left({ }^{\circ} \mathbf{C}\right)$} \\
\cline { 2 - 5 } Time (h) & $\mathbf{- 4 0}$ & $\mathbf{2 3}$ & $\mathbf{7 0}$ & $\mathbf{1 2 0}$ \\
\hline 0 & 340 & 327 & 322 & 314 \\
10 & & $\Downarrow$ & 309 & 295 \\
100 & & 322 & 304 & 291 \\
1000 & $\downarrow$ & 316 & 299 & 287 \\
5000 & $\downarrow$ & 311 & 295 & 284 \\
131,000 & 337 & 302 & 287 & 279 \\
\hline
\end{tabular}

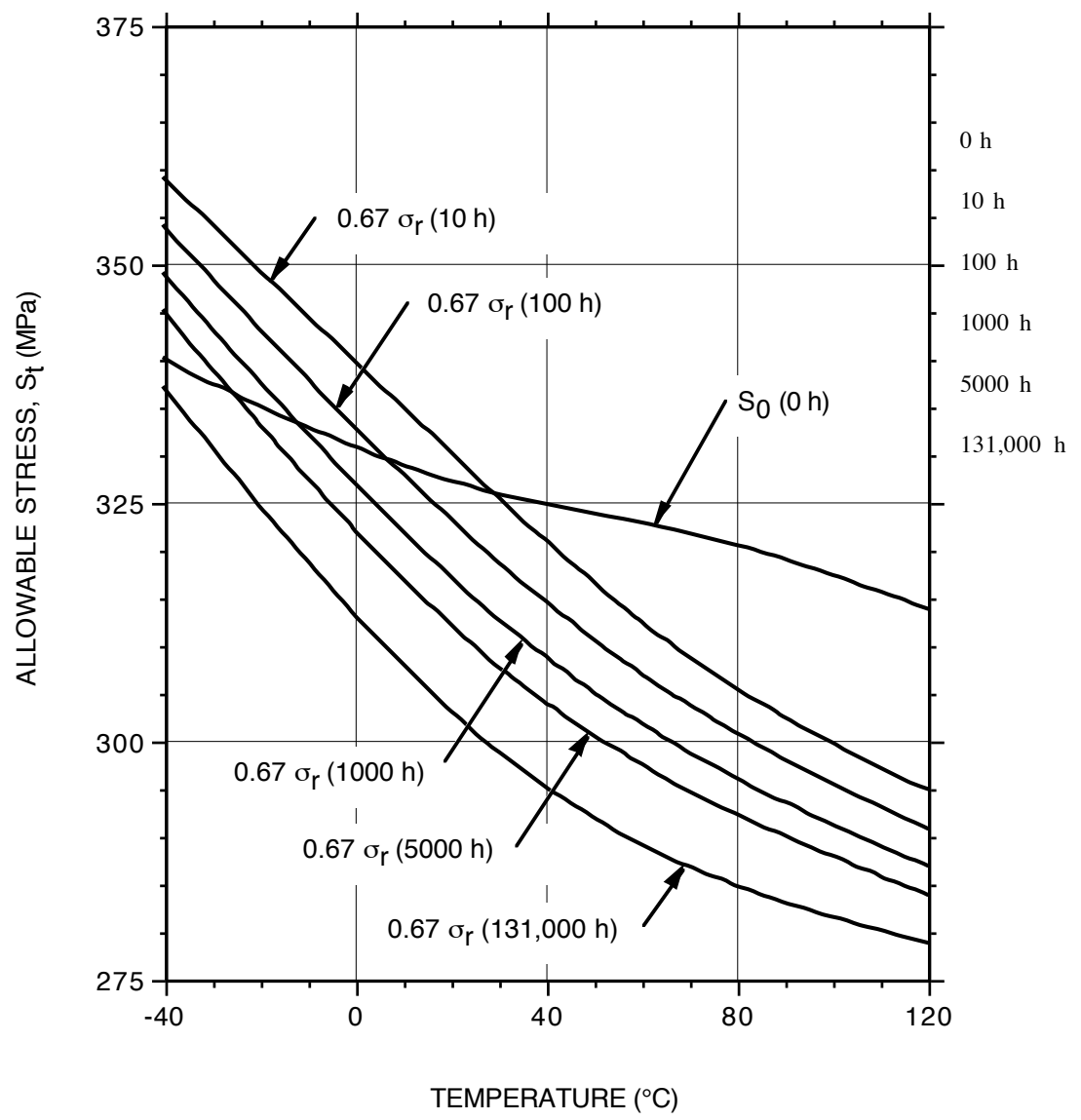

Fig. 3.1. Allowable tensile stress, $S_{t}$, without environmental and prior load effects. Note that $S_{t}$ is the lower of $S_{0}$ and $0.67 \sigma_{\mathrm{r}}$.

- pre-exposure to distilled water for $1000 \mathrm{~h}$

- pre-exposure to windshield-washer fluid for $100 \mathrm{~h}$.

The creep-rupture tests reported in Chap. 11 were performed in the fluids after the pre-exposure. The resulting creep-rupture strength-reduction factors are tabulated in Table 11.2 of Chap. 11 for various times, including $\mathrm{t}=0$. To bound the effects, the lowest factor at each time was used. At $\mathrm{t}=0$ the windshieldwasher fluid factor was lowest; for all other times, the distilled-water factor was lowest. It should be emphasized that the fluid reduction factors in Table 11.2 are for room-temperature, and since data at other temperatures do not exist, the room-temperature factors were used to reduce the allowable stresses at all 
temperatures. This is probably unconservative at elevated temperatures because of the likely synergistic effect between temperature and fluid absorption.

Table 3.2 tabulates the tensile allowable stresses with the bounding fluid effects factored in. The allowables are plotted in Fig. 3.2. For tensile stresses, the fluid effects are seen to be relatively small.

\section{Table 3.2. Allowable time-dependent tensile stresses, $S_{t}(M P a)$, with reductions to account for fluid effects}

\begin{tabular}{rrcccc}
\hline & \multicolumn{4}{c}{ Temperature $\left({ }^{\circ} \mathbf{C}\right)$} \\
\cline { 2 - 6 } Time (h) & $\mathbf{- 4 0}$ & $\mathbf{2 3}$ & $\mathbf{7 0}$ & $\mathbf{1 2 0}$ \\
\hline 0 & 310 & 298 & 293 & 285 \\
10 & $\downarrow$ & $\Downarrow$ & 284 & 271 \\
100 & & 296 & 280 & 268 \\
1000 & & 294 & 278 & 267 \\
5000 & $\downarrow$ & 289 & 274 & 264 \\
131,000 & $\Downarrow$ & 284 & 270 & 262 \\
\hline
\end{tabular}

\subsection{COMPRESSIVE AND BIAXIAL ALLOWABLE STRESS, $\mathrm{S}_{\mathrm{t}}$ * $^{*}$}

\subsubsection{Biaxial Strength Criterion}

To this point, the allowable stresses were based on, and are only applicable to, uniaxial tensile stress states. Failure stresses in compression, for example, are considerably lower than in tension for the current composite, so the magnitude of the allowable stresses must be appropriately reduced. In design, where a variety of stress states can exist, a simple biaxial strength criterion is needed. Because the current composite is considered to be isotropic in the plane of the material, a rule as simple as the maximum stress criterion, which was used for the quasi-isotropic and chopped-carbon-fiber thermoset composites ${ }^{2,3}$ as well as for the chopped-glass thermoset composite, ${ }^{4}$ or the maximum shear stress criterion, which was used for the swirled-glass-mat composite, ${ }^{5,6}$ may be adequate.

The only truly in-plane biaxial failure data available are from shear specimens (see Chap.7). Biaxial bending failures were obtained from tests of circular disks (see Chap. 8), but the actual bending stresses at failure in the disks can only be estimated from nonlinear large-deflection analysis. The available shorttime, room-temperature, average failure stress data are plotted in principal stress space in Fig. 3.3, where they are compared with the two common strength theories mentioned in the previous paragraph and with the more complex maximum energy theory. The solid points in the figure are the basic tensile, compressive, and shear strengths reported in Chap. 7. The two open compressive points are the average compressive strength value reported in Chap. 12 from tests of undamaged wide compression-after-impact specimens.

Clearly, a single failure criterion passing through all of the solid points would be complex. In the first quadrant where both principal stresses are tensile, it seems reasonable to assume that the maximum principal stress criterion (the solid square) governs in this quasi-isotropic, continuous-fiber composite. In the other three quadrants, where there is a compressive stress component, the maximum shear criterion (dashed) based on compressive strength, appears to be conservative. Thus, for tensile stress states (both 


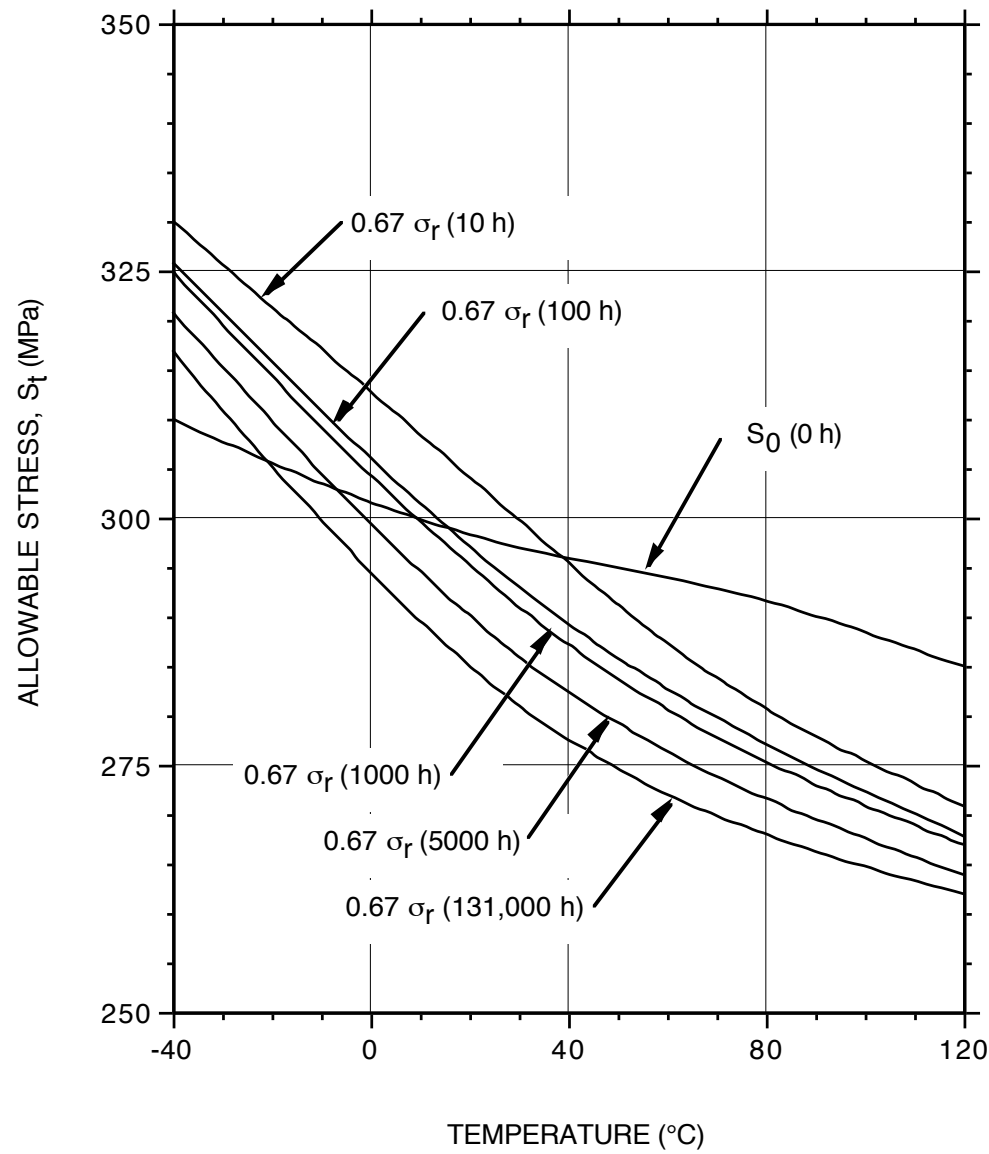

Fig. 3.2. Allowable tensile stresses, $S_{t}$, with fluid effects.

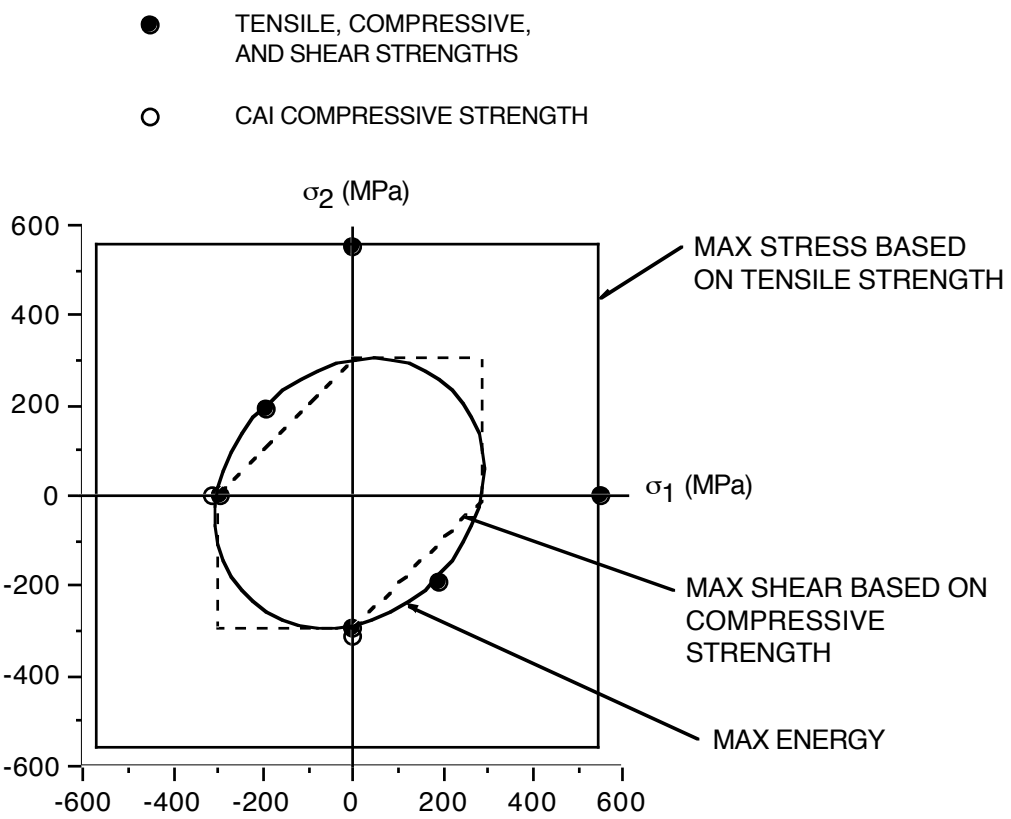

Fig. 3.3. Candidate failure criteria compared with available room-temperature fracture data. 
principal stress components positive) the maximum stress criterion is recommended for use. Tensile stresses should be compared to the $\mathrm{S}_{\mathrm{t}}$ allowables given in Sect. 3.2.

For quadrants 2, 3, and 4, where there is a compressive principal stress component, the maximum shear stress criterion is recommended for use. A single equivalent stress quantity is used to represent the biaxial stress state in these quadrants. That quantity is the stress intensity, S. This equivalent intensity of combined stresses is defined as twice the maximum shear stress and is equivalent to the difference between the algebraically largest principal stress and the algebraically smallest principal stress at a given point in a structure. Tensile stresses are considered positive and compressive stresses are considered negative. The stress intensity is limited to $\mathrm{S}_{\mathrm{t}}{ }^{*}$ allowable stresses, which are based primarily on compressive strength.

\subsubsection{Allowable Stresses}

Table 3.3 tabulates the $\mathrm{S}_{\mathrm{t}}$ * allowable stresses, and they are plotted in Fig. 3.4. The $\mathrm{S}_{0} *(\mathrm{t}=0)$ allowables were derived as follows. The average room-temperature ultimate compressive strength from Chap. 7 is $295 \mathrm{MPa}$. An allowable room-temperature compressive strength was obtained by multiplying the tensile allowable by the ratio of this value to the average tensile strength: ${ }^{\dagger}$

$$
S_{0}^{*}=\frac{295}{551} \times 327=175 \mathrm{MPa}
$$

Values for other temperatures were obtained using the temperature factors for compressive strength tabulated in Table 7.4 and plotted in Fig. 7.37.

Table 3.3. Basic $S_{t}^{*}$ (MPa) allowable stresses applicable to compressive and non-tensile biaxial stress states

\begin{tabular}{rrrccc}
\hline & \multicolumn{4}{c}{ Temperature $\left({ }^{\circ} \mathbf{C}\right)$} \\
\cline { 2 - 6 } Time (h) & $\mathbf{- 4 0}$ & $\mathbf{2 3}$ & $\mathbf{7 0}$ & $\mathbf{1 2 0}$ \\
\hline 0 & 184 & 175 & 151 & 93 \\
10 & 183 & 153 & 120 & 66 \\
100 & 178 & 146 & 112 & 60 \\
1000 & 172 & 139 & 105 & 55 \\
5000 & 167 & 134 & 100 & 52 \\
131,000 & 159 & 125 & 91 & 46 \\
\hline
\end{tabular}

With the exception of the $120^{\circ} \mathrm{C}$ values, the time-dependent allowable stresses are simply two-thirds of the average compressive creep-rupture strengths developed in Chap. 11 . The $120^{\circ} \mathrm{C}$ values have been adjusted downward to make them conservative for pure shear. As temperature is increased, the ratio of shear strength to compressive strength decreases until, at $120^{\circ} \mathrm{C}$ the shear point in Fig. 3.3 moves inside the dashed maximum shear strength boundary. The following procedure was used to approximately correct for this.

\footnotetext{
* In pure uniaxial compression, the maximum shear stress is one-half the compressive stress. The stress intensity is thus equal to the compressive stress in magnitude. In pure shear, the tensile and compressive principal stresses are equal to the shear stress in absolute value. The stress intensity is equal to twice the compressive stress in magnitude.

${ }^{\dagger}$ The tensile allowable was introduced because it has a much larger statistical basis.
} 


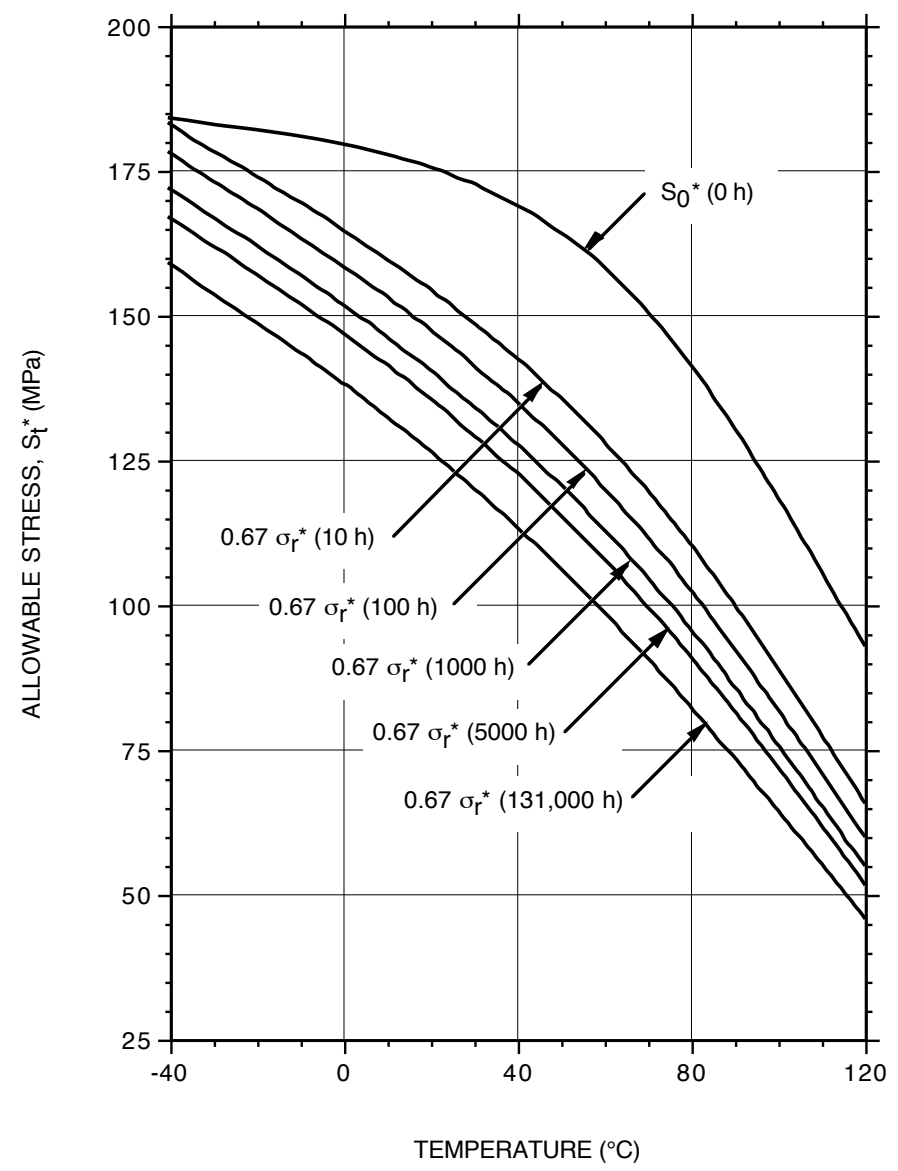

Fig. 3.4. Allowable compressive and non-tensile biaxial stresses, $S_{t}{ }^{*}$, without environmental and prior load effects.

- The average room-temperature shear strength of $193 \mathrm{MPa}$ (from Chap. 7) was used to determine an allowable shear strength from the tensile allowable, as follows

$$
\frac{193}{551} \times 327=115 M P a^{*}
$$

- The temperature factors tabulated in Chap. 7 (Table 7.4, Fig. 7.37) were used to obtain values at other temperatures.

- These shear allowables were multiplied by two (maximum shear criterion) and compared to the compressive allowable at $\mathrm{t}=0$ for each temperature.

- At $120^{\circ} \mathrm{C}$, the shear stress intensity was less than the compressive allowable; the ratio was 0.90 .

- Since no shear creep-rupture data were available, each time dependent allowable compressive stress at $120^{\circ} \mathrm{C}$ was multiplied by the $\mathrm{t}=0$ ratio of 0.90 .

To approximately account for fluid effects on the $\mathrm{S}_{\mathrm{t}}$ * allowables, a similar procedure had to be used. Not only are there no shear creep-rupture data, there are no compressive or shear fluid creeprupture data — only tensile data.

\footnotetext{
${ }^{*}$ This is the same procedure as used to obtain a compressive allowable.
} 
- To account for fluids, the short-time fluid factors given in Tables 7.9 and 7.10 for the two bounding exposures were used for all times and temperatures. For compression, windshieldwasher fluid produced the lowest factor- 0.74 . For shear, distilled water produced the lowest factor- 0.65 .

- A table of compressive allowables was prepared in which all values were multiplied by 0.74 .

- A second table of stress intensity allowables based on shear was prepared as previously described. All of the values were multiplied by 0.65 .

- The final table of $\mathrm{S}_{\mathrm{t}}{ }^{*}$ values with fluid effects is made up of the lower of the compressive and shear-based values at each time and temperature. Shear again governed only at $120^{\circ} \mathrm{C}$.

Table 3.4 is a tabulation of the St* allowables incorporating fluid effects, and Fig. 3.5 is a plot of the values.

Table 3.4. Allowable time-dependent compressive and non-tensile biaxial stresses, $S_{t} *(\mathrm{MPa})$, with estimated reduction to account for fluid effects

\begin{tabular}{rccccc}
\hline & \multicolumn{4}{c}{ Temperature $\left({ }^{\circ} \mathbf{C}\right)$} \\
\cline { 2 - 6 } Time (h) & $\mathbf{- 4 0}$ & $\mathbf{2 3}$ & $\mathbf{7 0}$ & $\mathbf{1 2 0}$ \\
\hline 0 & 136 & 130 & 111 & 61 \\
10 & 135 & 113 & 89 & 43 \\
100 & 132 & 108 & 83 & 40 \\
1000 & 127 & 103 & 78 & 36 \\
5000 & 124 & 99 & 74 & 34 \\
131,000 & 118 & 93 & 67 & 30 \\
\hline
\end{tabular}

\subsection{TREATMENT OF MEMBRANE AND BENDING STRESSES}

The $\mathrm{S}_{\mathrm{t}}$ and $\mathrm{S}_{\mathrm{t}}$ * allowable stresses given in the previous two sections establish limits on allowable inplane membrane stresses, P. Elastically-calculated bending stresses, Q, must also be considered. ${ }^{*}$ For bending alone, flexure test results presented in Chap. 8 indicate that failures occur in compression at a calculated bending stress that ranges from 1.5 to 1.7 times the ultimate compressive strength. Thus for pure bending, without a superimposed membrane stress, an appropriate stress limit is

$$
\frac{Q}{1.5} \leq S_{t}^{*}
$$

where 1.5 conservatively covers the 1.5 to 1.7 range mentioned above. With this built-in conservatism, the drop in $\mathrm{S}_{\mathrm{t}}$ * with temperature for $\mathrm{t}=0$ adequately covers the drops in flexural strength with temperature reported in Chap. 8. Also, the fluid effects built into $\mathrm{S}_{\mathrm{t}}{ }^{*}$ (Table 3.4 and Fig. 3.5) are adequate for flexure.

The choice of an appropriate allowable stress becomes more problematic when a membrane stress is imposed on a bending stress. Depending on the sign and magnitude of the membrane stress, the stress intensity at either surface could govern, and both should be checked against the following limits.

\footnotetext{
* The bending stress, Q, is calculated from a bending moment in isotropic, homogeneous beam, plate, or shell theory. It is not the ply stress calculated using classical lamination theory. It is shown in Chap. 8 that, at least for beam bending, the simple bending theory predicts deformations reasonably well.
} 


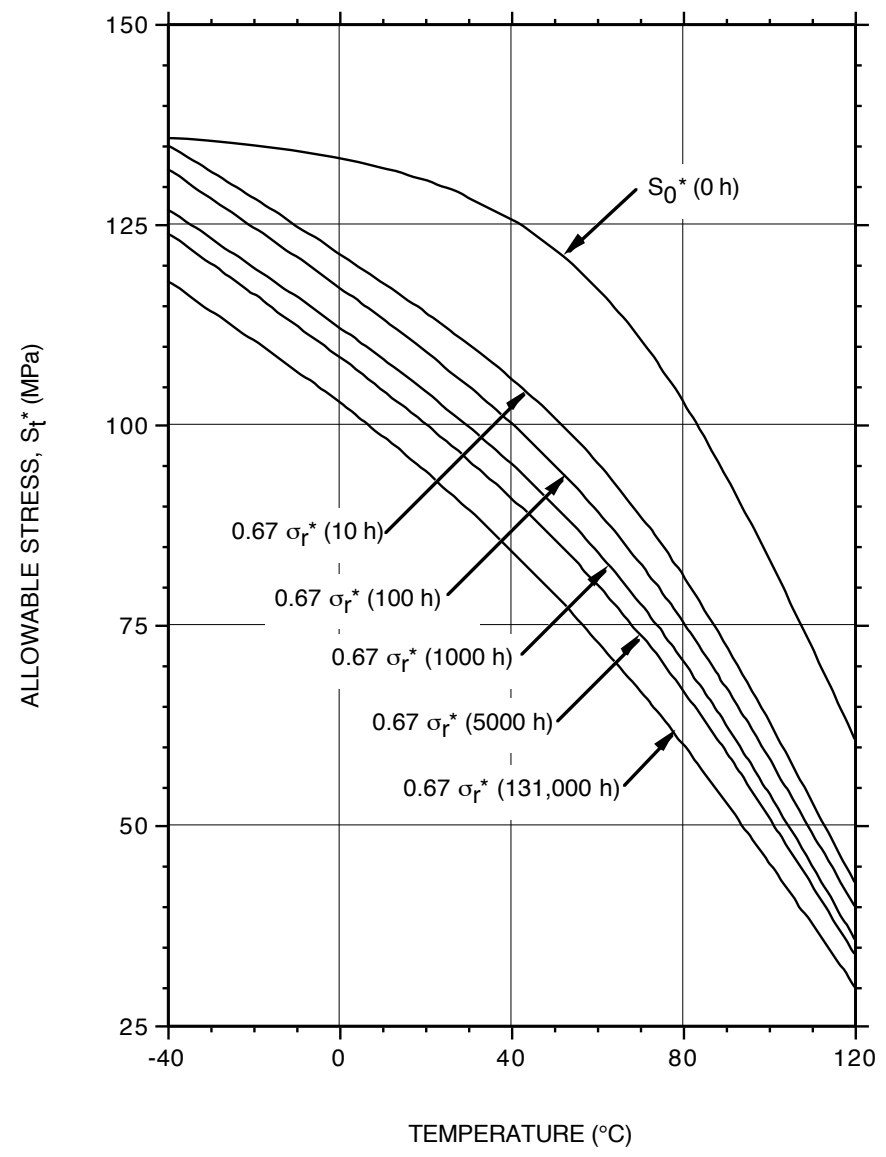

Fig. 3.5. Allowable compressive and non-tensile biaxial stresses, $S_{t}{ }^{*}$, with estimated fluid effects.

$$
P+\frac{Q}{1.5} \leq S_{t}^{*}
$$

or

$$
P+\frac{Q}{K} \leq S_{t}
$$

where $\mathrm{K}$ is a temperature-dependent factor, with the values tabulated below.

$\begin{array}{cc}\mathbf{T}\left({ }^{\circ} \mathbf{C}\right) & \mathbf{K} \\ -40 & .97 \\ 23 & .89 \\ 70 & .80 \\ 120 & .51\end{array}$

* The $\mathrm{K}$ values are the ratios of maximum calculated bending stress at failure to UTS that are tabulated in Table 8.1 of Chap. 8 . 
Geometric discontinuities include corners and bends. At such locations, the fiber distribution across the thickness of a composite plate or shell structure is likely to be less uniform. More importantly, new failure modes (i.e., delaminations) can be introduced. The bending stress limits given above do not apply at these locations.

\subsection{TREATMENTS OF INCREMENTS OF CHANGING LOADS}

For stress levels that vary with time, the time-fraction summation method should be used to assess cumulative damage. The sum of the use fractions associated with the primary plus bending stresses for all increments of loading should not exceed a value of 1.0:

$$
\sum_{i}\left(\frac{t}{T_{d}}\right)_{i} \leq 1.0
$$

Here, $t_{i}$ is the specified duration of a given load increment $i$, and $T_{d_{i}}$ is the allowable design time for the stress associated with that load increment.

\subsection{REFERENCES}

1. The Composite Materials Handbook-MIL 17, Volume 1, Guidelines for Characterization of Structural Materials, Revision MIL-HDBK-17-1E, Technomic Publishing Co., Inc., Lancaster, Pennsylvania, January 1997.

2. J. M. Corum et al., Durability-Based Design Criteria for a Quasi-Isotropic Carbon-Fiber Automotive Composite, ORNL/TM-2002/39, Oak Ridge National Laboratory, Oak Ridge, Tenn., March 2002.

3. J. M. Corum et al., Durability Based Design Criteria for a Chopped-Carbon Fiber Automotive Composite, ORNL/TM-2003/86, May 2003.

4. J. M. Corum, R. L. Battiste, W. Ren, and M. B. Ruggles, Durability Based Design Criteria for a Chopped-Glass-Fiber Automotive Structural Composite, ORNL/TM-1999/182, November 1999.

5. J. M. Corum et al., Durability-Based Design Criteria for an Automotive Structural Composite: Part 1. Design Rules, ORNL-6930, Oak Ridge National Laboratory, Oak Ridge, Tenn., February 1998.

6. J. M. Corum et al., Durability-Based Design Criteria for an Automotive Structural Composite: Part 2, Background Data and Models, ORNL-6931, Oak Ridge National Laboratory, Oak Ridge, Tenn., February 1998. 


\section{DESIGN LIMITS FOR CYCLIC LOADINGS}

\subsection{FATIGUE DESIGN CURVE}

Two room-temperature design fatigue curves are provided for the T material composite. The first curve is directly applicable to all cycles having a positive mean stress. The second curve is applicable to all cycles having a zero or negative mean stress. The basis for these curves and for the approach recommended is provided in Chap. 9 of Part 2.

A special stress parameter that combines the maximum stress, $S_{\max }$, or in the case of a compressive cycle the absolute value of the minimum stress, $\left|\mathrm{S}_{\min }\right|$, with the alternating component of the stress, $\mathrm{S}_{\mathrm{a}}$, is used for all fatigue evaluations.

$$
S=\sqrt{S_{\max } \times S_{a}}
$$

The design curve, which gives the design allowable number of cycles for a given value of the parameter $\mathrm{S}$, is shown in Figure 4.1 and is applicable to all cycles having a positive mean stress. As explained in Chap. 9, the design curve was derived from fatigue data by first placing a margin of 20 on cycles to failure (applied to the average S-N curve) and then multiplying stress by an additional reduction factor of 0.89 . The latter factor is the ratio of the minimum to average UTS of the material.

If the cycle being evaluated involves a zero or compressive mean stress, then the stress in Figure 4.1 must be reduced. Figure 4.2 should be used if any principal stress component has a zero or compressive mean stress. In the absence of definitive biaxial fatigue test data, maximum or minimum principal stresses should be used for the evaluation of biaxial cyclic stresses.

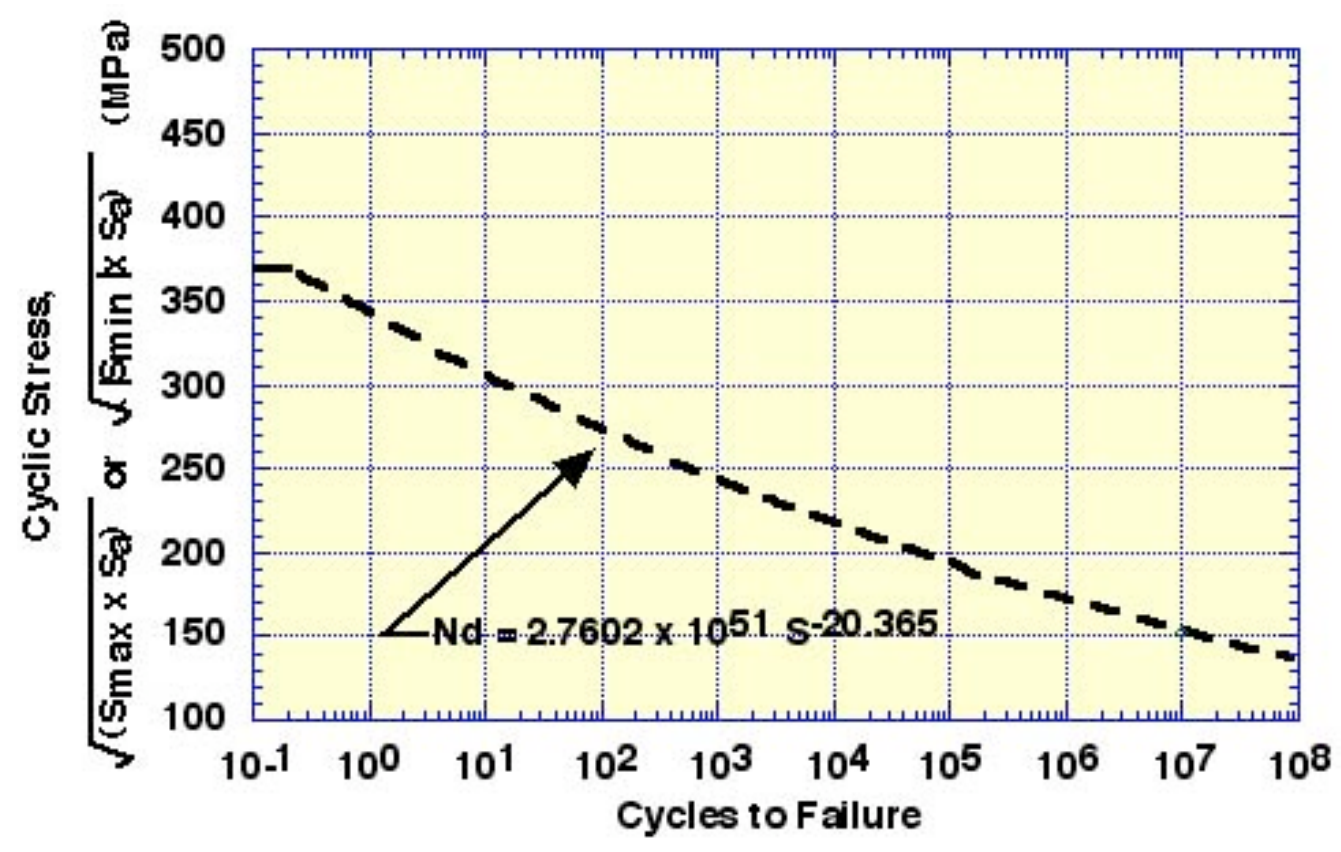

Fig. 4.1. Final recommended design fatigue curve for loads involving a positive mean stress. 


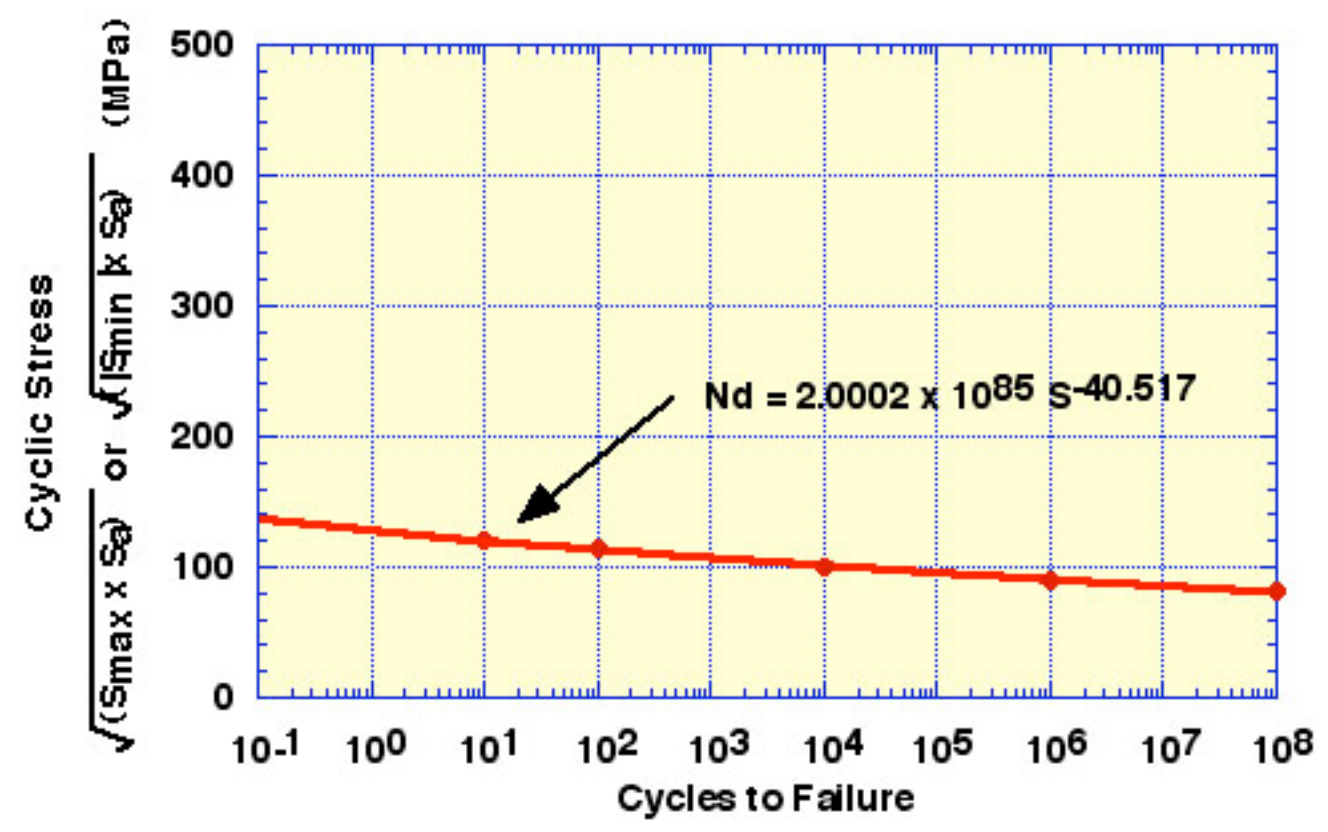

Fig. 4.2. Final recommended design fatigue curve for loads involving a zero or negative mean stress.

\subsection{EFFECTS OF TEMPERATURE}

The design fatigue curve in Fig 4.1 is for room temperature. For other temperatures, the fatigue strength values in Fig. 4.1 should be multiplied by the reduction factors developed in Sect. 9.3 and repeated here in Table 4.1.

Table 4.1. Fatigue strength factors to account for temperature

\begin{tabular}{ccccc}
\hline Temperature & \multicolumn{4}{c}{ Cycles } \\
\cline { 2 - 5 }$\left({ }^{\circ} \mathbf{C}\right)$ & $\mathbf{1 0}^{\mathbf{2}}$ & $\mathbf{1 0}^{\mathbf{4}}$ & $\mathbf{1 0}^{\mathbf{6}}$ & $\mathbf{1 0}^{\mathbf{8}}$ \\
\hline-40 & 1.03 & 1.03 & 1.04 & 1.04 \\
23 & 1.00 & 1.00 & 1.00 & 1.00 \\
70 & 0.93 & 0.96 & 0.98 & 1.00 \\
120 & 0.77 & 0.79 & 0.82 & 0.85 \\
\hline
\end{tabular}

\subsection{FLUID EFFECTS}

Fluid effects on fatigue are discussed in Sect. 9.4. The two standard exposures discussed earlier were used for fatigue:

- specimens soaked for $1000 \mathrm{~h}$ at room temperature and then tested in distilled water, and

- specimens soaked for $100 \mathrm{~h}$ at room temperature and then tested in windshield washer fluid $(70 \%$ methanol $/ 30 \%$ distilled water).

The fatigue strength multiplication factors are tabulated in Table 4.2. Like the temperature effects factors, the fluid factors were derived from tensile fatigue data. In the absence of other data, it is assumed that they apply to other uniaxial and biaxial cycle types as well. 
Table 4.2. Fatigue strength factors for two bounding

fluid environments

\begin{tabular}{ccccc}
\hline \multirow{2}{*}{ Environment } & \multicolumn{4}{c}{ Cycles } \\
\cline { 2 - 5 } & $\mathbf{1 0}^{\mathbf{2}}$ & $\mathbf{1 0}^{\mathbf{4}}$ & $\mathbf{1 0}^{\mathbf{6}}$ & $\mathbf{1 0}^{\mathbf{8}}$ \\
\hline $\begin{array}{c}\text { Distilled Water, } \\
\text { 1000-h presoak }\end{array}$ & 0.91 & 0.86 & 0.81 & 0.77 \\
$\begin{array}{c}\text { Windshield washer } \\
\text { fluid, 100-h } \\
\text { presoak }\end{array}$ & 0.85 & 0.88 & 0.91 & 0.95 \\
\hline
\end{tabular}

\subsection{TREATMENT OF VARYING STRESS AMPLITUDES}

Cumulative damage under varying stress amplitudes is an important consideration in designing for cyclic loadings. For the random-glass-fiber composites previously evaluated, Miner's rule was recommended. ${ }^{1-3}$ The choice for the glass composites was based on a very limited number of block loading tests in each case and was thus not well based statistically.

No block loading tests have been performed for the carbon-fiber composites. It is recommended that in the absence of definitive data, Miner's rule again be adopted. For a design to be acceptable, the fatigue damage should satisfy the following relation:

$$
\sum_{i}\left(n / N_{d}\right)_{i} \leq 1.0
$$

where $n_{i}$ is the number of specified cycles of type $i$, and $N_{d i}$ is the number of design-allowable cycles for cycle i determined from the design curve in Fig. 4.1 (only applicable for positive mean stress). The curve should be adjusted when fatigue involves a zero or compressive mean stress (i.e., Fig. 4.2) and to correspond to the maximum temperature of the cycle, as well as to account for the environment.

\subsection{REFERENCES}

1. J. M. Corum et al., Durability-Based Design Criteria for an Automotive Structural Composite: Part 1. Design Rules, ORNL-6930, Oak Ridge National Laboratory, Oak Ridge, Tenn., February 1998.

2. J. M. Corum et al., Durability-Based Design Criteria for an Automotive Structural Composite: Part 2. Background Data and Models, ORNL-6931, Oak Ridge National Laboratory, Oak Ridge, Tenn., February 1998.

3. J. M. Corum, R. L. Battiste, W. Ren, and M. B. Ruggles, Durability-Based Design Criteria for a Chopped-Glass-Fiber Automotive Structural Composite, ORNL/TM-1999/182, Oak Ridge National Laboratory, Oak Ridge, Tenn., November 1999. 
4-4 


\section{DAMAGE TOLERANCE ASSESSMENT FOR LOW-ENERGY IMPACTS AND OTHER DEFECTS AND DISCONTINUITIES}

\subsection{GENERAL REQUIREMENTS}

A two-part design assessment procedure is recommended.

1. Assume the presence of a 6.4-mm-diam circular hole in the worst possible location in the structure, and demonstrate through analysis or use of experimental data and models, that the structure maintains its integrity. This evaluation will ensure that the structure can tolerate minor impacts and structural flaws at least up to a size of 6.4-mm-diam or length, no matter where they are located. Guidance for this evaluation is provided in the next section.

2. For specific low-energy impacts such as kickups of roadway debris, tool drops, or load drops in a pickup truck box, the procedures described in Sects. 5.3 and 5.4 may be used to assess damage tolerance for damage areas larger than that corresponding to a 6.4 -mm-diam hole $\left(32 \mathrm{~mm}^{2}\right)$.

\subsection{EFFECTS OF CIRCULAR HOLES AND CRACKS}

Several series of tests are reported in Chap. 12 and 13 of Part 2 in which specimens with center circular holes were tested in tension or compression, and other specimens with center cracks were tested in tension. The trend is the same in each set of results-the reduction in strength vs hole diameter or crack length is very similar. The quasi-isotropic PPS/carbon-fiber composite is much more tolerant of these discontinuities than would be predicted for a homogeneous, isotropic material. The effective stress concentration factor (SCF) for holes is not nearly as high as theoretically predicted.* Furthermore, the smaller the hole, the smaller the effective SCF. The curve in Fig. 5.1, which is provided for preliminary design assessments, is a lower-bound correlation for the effects of holes or lateral cracks in either a tensile or compressive uniaxial stress field. The ordinate gives the gross failure stress in an infinitely-wide, uniaxially loaded plate with a hole or crack as a fraction of the strength of a plate with no hole-the ultimate tensile or compressive strength. The basis for this curve is given in Chap. 13 of Part 2.

For the standard 6.4-mm-dia hole, the strength reduction factor predicted by Fig. 5.1 is 0.63 compared to a theoretical reduction factor of $0.33(\mathrm{SCF}=3.0)$ for a homogeneous, isotropic material.

While Fig. 5.1 is for an infinitely-wide plate, real structures will often have sections where the width-to-hole-diameter (or crack length) is relatively small. In those cases, the following equations (from Chap. 13) can be used to determine the applied failure-causing stress, $\bar{\sigma}$, in a finite-width plate that corresponds to an applied failure-causing stress, $\bar{\sigma}_{\infty}$, in an infinitely-wide plate.

$$
\frac{\bar{\sigma}}{\bar{\sigma}_{\infty}}=\frac{3(1-a / w)}{2+(1-a / w)^{3}},
$$

where $w$ is the plate width, and $a$ is the hole diameter. This equation is only accurate for values of $a / w \leq 1 / 2$.

For center cracks of length $a$,

\footnotetext{
* This is a common characteristic of composites and was observed in each of the five urethane thermoset composites previously characterized.
} 


$$
\frac{\bar{\sigma}}{\bar{\sigma}_{\infty}}=\left[\frac{2 w}{\pi a} \tan \left(\frac{\pi a}{2 w}\right)\right]^{-1 / 2} .
$$

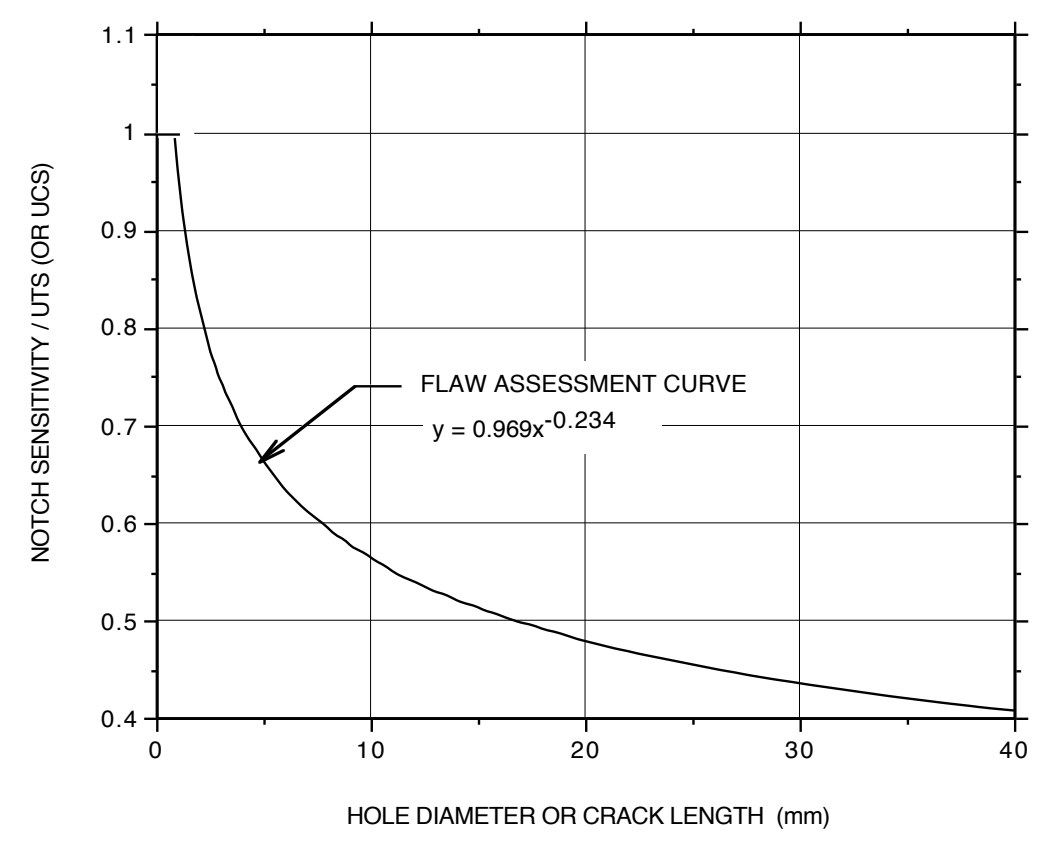

Fig. 5.1. Strength reduction factor for circular holes and cracks in an infinitely-wide, uniaxiallyloaded plate. Curve is derived from results of tensile tests of plates with a center hole or lateral crack and compressive tests of plates with a center hole.

While no fatigue or creep-rupture test results were generated on quasi-isotropic PPS/carbon-fiber composite specimens with holes or cracks, such tests of specimens with holes were performed in the case of the previously-characterized urethane/chopped-glass-fiber composite. ${ }^{1}$ Tensile, fatigue, and creeprupture results all showed about the same strength reduction. Thus, in the absence of data, it is assumed that Fig. 5.1 can also be applied to fatigue and creep rupture, as well as to the short-time failures.

To reliably predict stiffness reductions in structures with circular holes or cracks, finite-element analyses should be employed.

\subsection{DETERMINATION OF IMPACT DAMAGE AREAS}

For a given object (e.g., roadway debris or dropped tool) of mass, m, impacting a structure with velocity, $\mathrm{v}$, in the most highly stressed location, away from structural discontinuities, the impact damage should be estimated by the curve in Fig. 5.2. This curve is an upper bound of data generated from air-gun and pendulum impact tests on clamped $203-\mathrm{mm}$-diam by $2.8-\mathrm{mm}$-thick circular plates. Development of this curve and its applicability to real events, typified by bricks dropped in a pickup box, are discussed in Chap. 12 of Part 2. Also, as shown in Chap. 12, the curve applies to impacts at a low temperature of $-40^{\circ} \mathrm{C}$, and to annealed as well as as-received materials.

Once the impact damage area has been estimated, the procedures recommended in the following section can be used to assess the likely effect on properties and structural integrity. 


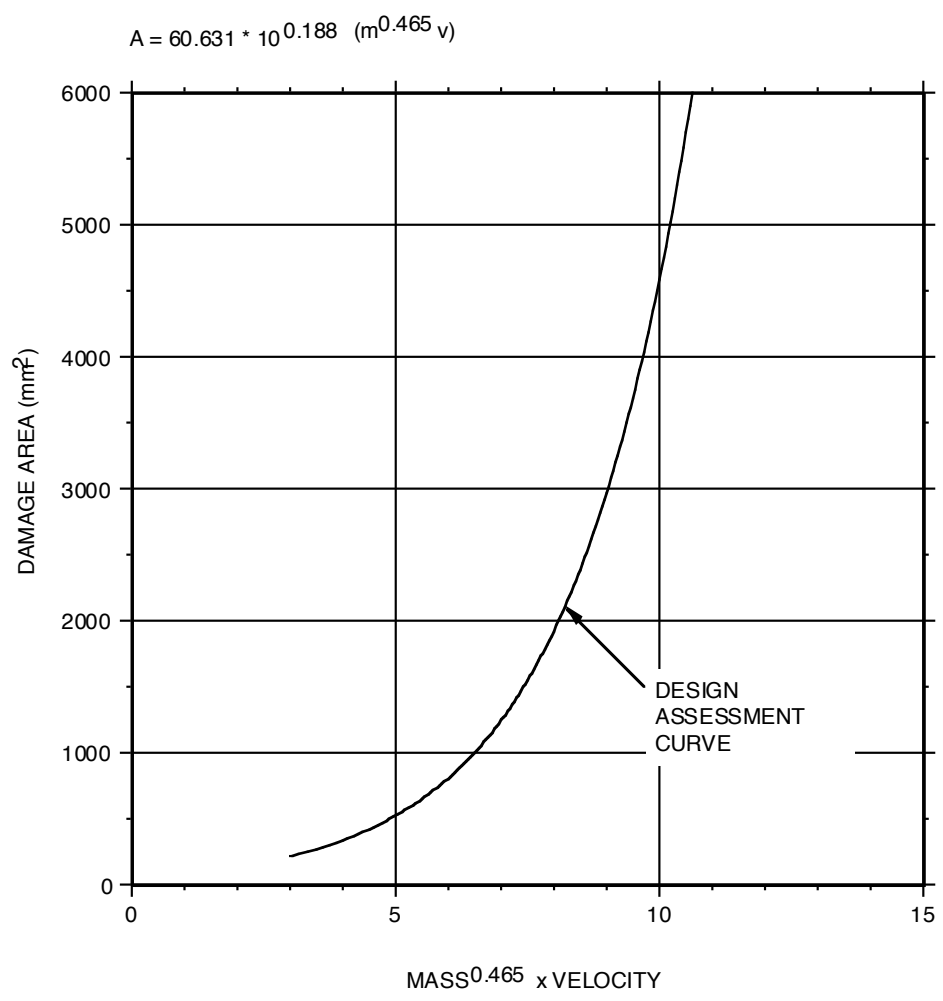

Fig. 5.2. Design assessment curve for estimating impact damage area. Mass, $m$, is in kilograms, and velocity, $\mathrm{v}$, is in meters/second. Note that this curve becomes invalid near the ballistic limit, above which complete penetration occurs. At the lower end, some threshold likely exists below which no damage occurs.

\subsection{DETERMINATION OF STRENTH AND STIFFNESS DEGRADATION}

For a given predicted damage area determined from Fig. 5.2, the resulting tensile or compressive strength degradation can be estimated from Fig. 5.3. This curve was derived from tensile and compressive strength-after-impact data obtained from 75.2-mm-wide CAI (compression-after-impact)-type specimens cut from impacted plates (see Chap. 12).

In using Fig 5.3 to estimate strength reductions, it should be kept in mind that the curve is for finitewidth $(76.2 \mathrm{~mm})$ specimens. To approximately convert the results to an infinitely-wide plate or to other finite widths, it is recommended that the damage area be represented by an equivalent circular hole and that Eq. (5.1) be used.

While the strength reduction due to circular holes is generally supposed to bound that due to impact damage, the difference between the two in the quasi-isotropic PPS/carbon-fiber composite is considerably larger than it was in the previously characterized urethane thermoset composites-for a given damage area, hole strength reduction data fall significantly below impact, strength reduction data. This is believed to be due to the fact that the PPS composite exhibits a greater propensity for delaminations and matrix cracking, which is considerably less degrading than is the complete absence of material. Despite the difference, it is recommended that structural stiffness degradation due to impacts can best be estimated by the equivalent circular hole method. 


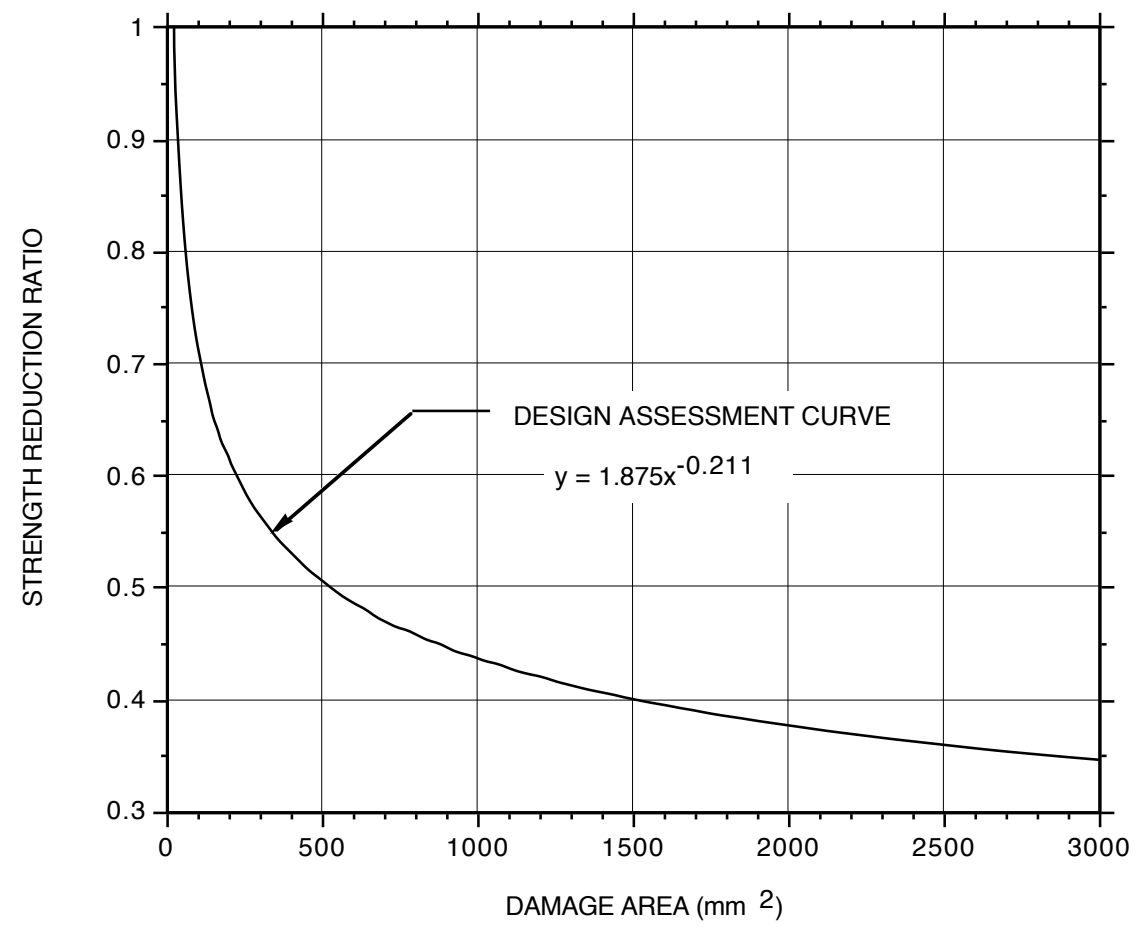

Fig. 5.3. Design assessment curve for estimating tensile and compressive strength degradation as a function of impact damage area. This figure directly applies only to 76.2-mm-wide strength specimens. Guidance is given for approximately converting the curve to other widths.

\subsection{REFERENCE}

1. J. M. Corum, R. L. Battiste, W. Ren, and M. B. Ruggles, Durability-Based Design Criteria for a Chopped-Glass-Fiber Automotive Structural Composite, ORNL/TM-1999/182, Oak Ridge National Laboratory, Oak Ridge, Tenn., November 1999. 


\section{SUMMARY AND COMPARISON WITH QUASI-ISOTROPIC THERMOSET CARBON-FIBER COMPOSITE}

This chapter is intended to summarize the key parts of the guidance and criteria presented in the previous four chapters for the quasi-isotropic carbon-fiber-reinforced thermoplastic composite (T material). It also provides a convenient forum for comparing the quasi-isotropic carbon-fiberreinforced thermoplastic composite with a previously characterized quasi-isotropic carbon-fiber reinforced thermoset composite (Q material). ${ }^{1}$

The T material consisted of a PolyPhenylene Sulfide (PPS) thermoplastic matrix reinforced with 16 plies of carbon-fiber unidirectional tape, $\left[0^{\circ} / 90^{\circ} /+45^{\circ} /-45^{\circ}\right]_{2 \mathrm{~S}}$. The carbon fiber was Hexcel AS-4C and was present in a fiber volume of $53 \%(60 \%$, by weight). Nominal plaque thickness of the T material was $2.9 \mathrm{~mm}$. The Q material had a 40\% volume fraction and a Baydur 420 IMR urethane matrix. Carbon fiber reinforcement for the Q material was a $[0 / 90 / \pm 45]_{S}$ layup of continuous $6 \mathrm{~K}$ tow aerospace-grade fibers. Nominal plaque thickness of the Q material was $2 \mathrm{~mm}$. The comparisons in this chapter help bring into focus the trade-offs associated with using a thermoplastic versus a thermoset resin matrix composite.

In Sect. 6.4, the allowable stresses for static and cyclic loadings are reduced to a simplified table of values expressed as percentages of the room-temperature, ambient air, UTS value. Values for both quasiisotropic composites are shown in the simplified table to facilitate direct comparisons between the two materials.

\subsection{ELASTIC AND CREEP PROPERTIES FOR DESIGN ANALYSIS}

In-plane elastic constants for the quasi-isotropic thermoplastic composite ( $\mathrm{T}$ material) are listed in Table 6.1, where they are compared with the quasi-isotropic thermoset composite (Q material) values. The $\mathrm{T}$ material composite stiffness is about $13 \%$ larger than the $\mathrm{Q}$ material value at room temperature, and it is slightly less affected by an increase in temperature to $120^{\circ} \mathrm{C}$ than is the Q material.

Table 6.1. Elastic constants

\begin{tabular}{ccc}
\hline $\begin{array}{c}\text { Temperature } \\
\left({ }^{\circ} \mathbf{C}\right)\end{array}$ & $\begin{array}{c}\text { Elastic modulus, E } \\
(\mathbf{G P a})\end{array}$ & $\begin{array}{c}\text { Poisson's } \\
\text { ratio, } \boldsymbol{v}\end{array}$ \\
\hline Quasi-isotropic & thermoplastic composite & $($ T material) \\
23 & 36.5 & 0.29 \\
120 & 35.7 & 0.30 \\
Quasi-isotropic & thermoset composite & $($ Q \\
23 & 32.4 & 0.31 \\
120 & 29.8 & 0.34 \\
\hline
\end{tabular}

Prior thermal cycling had a small effect on the T material. After 25 thermal cycles between $-40^{\circ}$ and $120^{\circ} \mathrm{C}$ the tensile strength increased $9.2 \%$, compressive strength decreased $8.4 \%$, and shear strength increased $6.6 \%$. With respect to the Q material, the tensile strength decreased $6.6 \%$, the compressive strength increased 19.7\%, and shear strength decreased $3.4 \%$. The loss in shear stiffness was more significant for the Q material (25.1\%) than for the T material (4.2\%).

A few prior mechanical loadings within the allowable stress range degraded the modulus of elasticity slightly for both materials. For the T material there was no loss of stiffness during the first load cycle, but the stiffness decreased slightly with succeeding load cycles reaching a maximum of about $4 \%$ during the last load cycle. Both the T and Q materials exhibited no degradation in ultimate tensile strength during the final load cycle to failure. However, larger numbers of cyclic loads, within the design allowable cycle numbers, can lead to a gradual stiffness loss (see Chap. 9). There was no general indication that the 10\% level would be exceeded in either quasi-isotropic composite. 
The bounding effect of fluids on elastic modulus was the same for both the thermoplastic and thermoset quasi-isotropic composites - a reduction of $4 \%$.

Time-dependent tensile creep strains at room-temperature were significantly less in the $\mathrm{T}$ material composite than they were in the Q material composite. This is illustrated in Table 6.2 by the timedependent creep strains predicted to result from the application of a $60 \mathrm{MPa}$ stress for $5000 \mathrm{~h}$.

Table 6.2. Time-dependent tensile creep strains due to a stress of $60 \mathrm{MPa}$ applied for $5000 \mathrm{~h}$ at room temperature

\begin{tabular}{ccc}
\hline Composite & $\begin{array}{c}\text { Creep strain } \\
(\%)\end{array}$ & $\begin{array}{c}\text { Temperature } \\
\text { multiplication factor } \\
\text { at } \mathbf{1 2 0}^{\circ} \mathbf{C}\end{array}$ \\
\hline T material & 0.000981 & 1.7 \\
Q material & 0.014684 & $4.3^{a}$ \\
\hline$a_{\text {The actual stress-dependent factor is } 2.9 \text { for } 60 \mathrm{MPa},}$ \\
but a single bounding factor of 4.3 was used in Ref. 1.
\end{tabular}

Time-dependent creep strain for the condition chosen is about 14 times larger at room temperature in the Q material composite than in the T material composite. At $120^{\circ} \mathrm{C}$, the factor jumps to 37.9 using the information in Table 6.2.

At room temperature, compressive creep is the same as tensile creep for both the quasi-isotropic composites. At $120^{\circ} \mathrm{C}$. compressive creep is about six times the predicted tensile creep for the T material. For the Q material, the factor ranges from 8 to 18 for the stresses examined. In either case, compressive loadings at $120^{\circ} \mathrm{C}$ should be carefully considered in design.

A single creep-strain multiplication factor of 2.2 is recommended to account for fluid effects in the $\mathrm{T}$ material composite. The corresponding factor for the $\mathrm{Q}$ material composite was 1.7.

\subsection{ALLOWABLE STRESSES FOR STATIC LOADINGS}

The basic time-dependent allowable stress quantity used in Chap. 3 is the same as that used in Ref. 1 except that the design factor on creep rupture strength was changed from 0.8 to 0.67

$$
\mathrm{S}_{\mathrm{t}} \leq\left\{\begin{array}{l}
\mathrm{S}_{0} \\
0.67 \sigma_{\mathrm{r}}(\mathrm{T} \text { material }) ; 0.8 \mathrm{~S}_{\mathrm{r}} \text { (Q material) }
\end{array}\right.
$$

Here, $\mathrm{S}_{\mathrm{t}}$ is the time-dependent allowable stress applicable to tensile stress components, $\mathrm{S}_{0}$ is the shorttime (time-independent) allowable stress, $\sigma_{\mathrm{r}}$ is the average creep-rupture strength, and $\mathrm{S} r$ is the minimum creep-rupture strength corresponding to time $t$. Representative values of $S_{t}$ are tabulated in Table 6.3 for both the $\mathrm{T}$ material composite and the $\mathrm{Q}$ material composite. The room-temperature $\mathrm{S}_{0}$ value for the $\mathrm{T}$ material composite is $169 \%$ of the value for the $\mathrm{Q}$ material composite. This percentage increases to $200 \%$ at $120^{\circ} \mathrm{C}$, so the short-time strength of the T material composite is degraded less by temperature than is that of the Q material composite. At 5000 hours, the corresponding percentages are $160 \%$ and $200 \%$, so temperature has about the same affect on both materials.

\footnotetext{
${ }^{*}$ The 60 -MPa stress level is below the allowable stress levels, even at $120^{\circ} \mathrm{C}$.
} 
Table. 6.3. Tensile $S_{t}$ values in air (MPa)

\begin{tabular}{|c|c|c|c|}
\hline \multirow{2}{*}{$\begin{array}{c}\text { Temperature } \\
\left({ }^{\circ} \mathrm{C}\right)\end{array}$} & \multicolumn{3}{|c|}{ Time } \\
\hline & $\mathbf{O} \mathbf{h}$ & $5000 \mathrm{~h}$ & 15 years \\
\hline \multicolumn{4}{|c|}{ Quasi-isotropic composite (T Material) } \\
\hline 23 & 327 & 311 & 302 \\
\hline 120 & 314 & 284 & $279^{a}$ \\
\hline \multicolumn{4}{|c|}{ Quasi-isotropic composite (Q Material) } \\
\hline 23 & 194 & 194 & 194 \\
\hline 120 & 157 & 142 & $130^{a}$ \\
\hline
\end{tabular}

$a_{\text {Unrealistic condition. }}$

Prior mechanical loads, thermal cycles, and fluid exposure each degrade the allowable stress, $\mathrm{S}_{0}$. Bounding reductions given in Chap. 3 are summarized and compared with the corresponding reductions for the Q material composite below.

\begin{tabular}{|c|c|c|}
\hline \multirow[b]{2}{*}{ Effect } & \multicolumn{2}{|c|}{ Strength reduction $(\%)$} \\
\hline & $\begin{array}{c}\text { Quasi-isotropic } \\
\text { composite } \\
\text { (T Material) }\end{array}$ & $\begin{array}{c}\text { Quasi-isotropic } \\
\text { composite } \\
\text { (Q Material) }\end{array}$ \\
\hline Prior loads & 4 & 15 \\
\hline $\begin{array}{l}\text { Prior thermal } \\
\text { cycles }\end{array}$ & 3 & 7 \\
\hline Fluid exposure & 35 & 0 \\
\hline
\end{tabular}

For tensile biaxial stress states, the maximum principal stress theory is recommended for design with both composites. The principal stress theory is also recommended for compressive and other nontensile biaxial stress states for the Q material composite. However, the maximum shear strength criterion is recommended for the $\mathrm{T}$ material composite for compressive and other nontensile biaxial stress states. For these latter stress states, the stress is limited to the quantity $\mathrm{S}_{\mathrm{t}}{ }^{*}$, which is based on short-time compressive strength and compressive creep-rupture results. Representative $\mathrm{St}_{\mathrm{t}}{ }^{*}$ values for the $\mathrm{T}$ material composite are tabulated and compared with Q material composite values in Table 6.4.

Table 6.4. $\mathrm{S}_{\mathrm{t}} *(\mathrm{MPa})$ allowable stresses applicable to nontensile biaxial stress states

\begin{tabular}{cccc}
\hline Temperature & \multicolumn{3}{c}{ Time } \\
\cline { 2 - 4 }$\left({ }^{\circ} \mathbf{C}\right)$ & $\mathbf{0 ~ h}$ & $\mathbf{5 0 0 0} \mathbf{~ h}$ & $\mathbf{1 5}$ years \\
\hline \multicolumn{2}{c}{ Quasi-isotropic composite } & $($ T & Material) \\
23 & 175 & 134 & 125 \\
120 & 93 & 52 & $46^{a}$ \\
\multicolumn{4}{c}{ Quasi-isotropic composite $($ Q } \\
23 & 130 & 130 & 130 \\
120 & 76 & 17 & $10^{a}$ \\
\hline
\end{tabular}

$a_{\text {Unrealistic condition. }}$

The T material allowables in Table 6.4 are reduced $26 \%$ by fluid exposure at room temperature, and $35 \%$ at $120^{\circ} \mathrm{C}$. These are much larger than the values used for the $\mathrm{Q}$ material. 


\subsection{ALLOWABLE STRESSES FOR CYCLIC LOADINGS}

Two room-temperature design fatigue curves are provided for the $T$ material composite. The first curve is directly applicable to all cycles having a positive mean stress. The second curve is applicable to all cycles having a zero or negative mean stress. The governing stress parameter is $\mathrm{S}=\sqrt{S_{\max } \times S_{a}}$, where $S_{\max }$ is the maximum stress reached in the cycle, or in the case of a compressive cycle, the absolute value of the minimum stress, $\left|S_{\min }\right|$, and $S_{a}$ is the alternating stress component. To account for the effect of temperature and fluid effects, stress-reduction factors are provided.

Table 6.5 compares representative allowable maximum cyclic stresses for tensile cycling for the $\mathrm{T}$ material composite with the corresponding stresses for the $\mathrm{Q}$ material composite. At room temperature, the allowable cyclic tensile stress at $10^{8}$ cycles for the T material composite is $22 \%$ greater than that for the $\mathrm{Q}$ material composite. The percentage is $106 \%$ at $120^{\circ} \mathrm{C}$.

Bounding fluid effects multiplication factors for the two composites are tabulated in Table 6.6. The $\mathrm{T}$ material composite factors are somewhat lower than are those for the Q material composite.

Table 6.5. Allowable maximum cyclic stresses for tensile cycling $(R=0)$

\begin{tabular}{ccc}
\hline Temperature & \multicolumn{2}{c}{ Maximum stress $(\mathbf{M P a})$} \\
\cline { 2 - 3 }$\left({ }^{\circ} \mathbf{C}\right)$ & $\mathbf{1 0}^{\mathbf{2}}$ cycles & $\mathbf{1 0}^{\mathbf{8}}$ cycles \\
\hline Quasi-isotropic composite & $($ T & material) \\
23 & 379 & 192 \\
120 & 292 & 163 \\
Quasi-isotropic composite & $($ Q & material $)$ \\
23 & 267 & 157 \\
120 & 259 & 79 \\
\hline
\end{tabular}

Table 6.6. Bounding fluid multiplication factors for allowable cyclic stresses

\begin{tabular}{lcc}
\hline Composite & $\mathbf{1 0}^{\mathbf{2}}$ cycles & $\mathbf{1 0}^{\mathbf{8}}$ cycles \\
\hline T material & 0.85 & 0.77 \\
Q material & 0.92 & 0.98 \\
\hline
\end{tabular}

\subsection{SIMPLIFIED SUMMARY OF ALLOWABLE STRESSES}

As a way of further simplifying and summarizing the allowable design stresses for static and cyclic loadings, Table 6.7 gives the key allowable stress values for various conditions as percentages of the average room-temperature UTS value-551 MPa for the T material composite and $336 \mathrm{MPa}$ for the $\mathrm{Q}$ material composite. The table shows that while the two sets of values are fairly similar, temperature and time had a greater relative effect on the $\mathrm{Q}$ material composite than they did on T material composite.

A strain limit of 0.3 to $0.4 \%$ has often been used, at least for glass-fiber composites for design of composite automotive structures. ${ }^{*}$ The strain limit is intended to cover all effects. For the T material composite, strain limits of 0.3 and $0.4 \%$ correspond to elastic stresses of $19 \%$ and $26 \%$ of the average room-temperature UTS, respectively (the corresponding values for the Q material composite are 29 and

\footnotetext{
* In the aerospace industry, fixed wing and rotocraft composite structures have been successfully designed to operate at strains up to $0.4 \%{ }^{2}$
} 
$39 \%$, respectively). Comparison of the $19 \%$ and $26 \%$ stress levels for the T material composite with the allowable values in Table 6.7 shows that the $0.3 \%$ strain limit covers all the listed conditions, while the $0.4 \%$ limit covers all conditions except $10^{8}$ cycles at $120^{\circ} \mathrm{C}$ with fluid effects. For the Q material, the strain limits would cover all the realistic conditions except for high-cycle fatigue at $120^{\circ} \mathrm{C}$.

\subsection{DAMAGE TOLERANCE EVALUATION}

For specific low-energy impacts such as roadway kickups, tool drops, and load drops in a pickup box, experimentally derived correlations are given for (1) estimating the damage area from the mass and velocity of the impacting object and (2) determining, from the estimated damage area, the resulting degradation in strength. While these correlations are clearly tied to the specific sizes and geometries of the impacted plate specimens and of the specimens used for mechanical property evaluations, it is thought that they do provide useful information. This is particularly true when comparing the relative response of two different composites.

Table 6.7. Key allowable tensile stresses, expressed as a percentage of average room-temperature UTS $a$

\begin{tabular}{|c|c|c|c|c|}
\hline \multirow{2}{*}{$\begin{array}{c}\text { Stress } \\
\text { allowable }\end{array}$} & \multicolumn{2}{|c|}{ Without fluid effects } & \multicolumn{2}{|c|}{ With fluid effects $b$} \\
\hline & $23^{\circ} \mathrm{C}$ & $120^{\circ} \mathrm{C}$ & $23^{\circ} \mathrm{C}$ & $120^{\circ} \mathrm{C}$ \\
\hline \multicolumn{5}{|c|}{ Quasi-isotropic composite (T Material) } \\
\hline $\mathrm{S}_{0}(0 \mathrm{~h})$ & 59 & 57 & 54 & 52 \\
\hline \multicolumn{5}{|l|}{$\mathrm{S}_{\mathrm{t}}$} \\
\hline $5000 \mathrm{~h}$ & 56 & 52 & 52 & 48 \\
\hline 15 years & 55 & $51^{c}$ & 52 & $48^{c}$ \\
\hline \multicolumn{5}{|l|}{$\mathrm{S}_{\max }(\mathrm{R}=0)$} \\
\hline $10^{2}$ cycles & 69 & 53 & 59 & 45 \\
\hline $10^{8}$ cycles & 35 & 30 & 27 & 23 \\
\hline \multicolumn{5}{|c|}{ Quasi-isotropic composite (Q Material) } \\
\hline $\mathrm{S}_{0}(0 \mathrm{~h})$ & 58 & 47 & 54 & 44 \\
\hline \multicolumn{5}{|l|}{$\mathrm{S}_{\mathrm{t}}$} \\
\hline $5000 \mathrm{~h}$ & 58 & 42 & 54 & 40 \\
\hline 15 years & 58 & $39^{c}$ & 54 & $36^{c}$ \\
\hline \multicolumn{5}{|l|}{$\mathrm{S}_{\max }(\mathrm{R}=0)$} \\
\hline $10^{2}$ cycles & 79 & 77 & 73 & 71 \\
\hline $10^{8}$ cycles & 47 & 24 & 46 & 23 \\
\hline \multicolumn{5}{|c|}{ 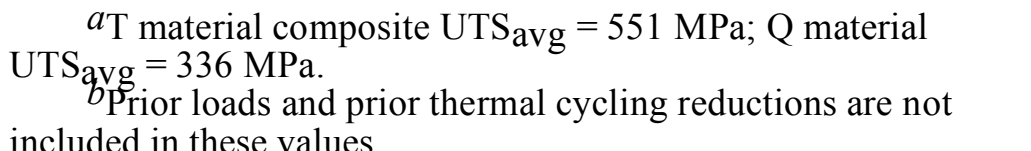 } \\
\hline
\end{tabular}

Table 6.8 gives the predicted impact damage area from the design curves (e.g., Fig. 5.2) for four representative combinations of impactor mass and velocity for the quasi-isotropic thermoplastic composite ( $\mathrm{T}$ material), the quasi-isotropic thermoset composite ( $\mathrm{Q}$ material), and the $\pm 45^{\circ}$ crossply laminate. $^{3}$ The latter continuous-fiber thermoset composite is added to the comparison because it has roughly the same thickness $(3.2 \mathrm{~mm})$ as the T composite, whereas the Q composite was thinner $(2 \mathrm{~mm}$ vs $2.9 \mathrm{~mm}$ ). With one exception, the damage areas for the $\mathrm{T}$ composite are larger than those for the other 
two composites. As pointed out in Chapter 12, this material has a greater propensity to delaminate than did the previous composites.

Table 6.8. Damage areas from design curve (e.g., Fig. 5.2)

\begin{tabular}{ccccc}
\hline \multirow{2}{*}{$\begin{array}{c}\text { Mass } \\
\mathbf{k g})\end{array}$} & $\begin{array}{c}\text { Velocity } \\
(\mathbf{m} / \mathbf{s})\end{array}$ & $\begin{array}{c}\text { Quasi-isotropic } \\
\text { Composite } \\
\text { (T Material) }\end{array}$ & $\begin{array}{c}\text { Quasi-isotropic } \\
\text { Composite } \\
\text { (Q Material) }\end{array}$ & $\mathbf{\pm \mathbf { 4 5 } ^ { \circ } \text { Crossply }}$ \\
\hline 11.52 & 0.8 & 178 & 168 & 72 \\
11.52 & 1.3 & 350 & 891 & 338 \\
0.0227 & 22.4 & 321 & 168 & 84 \\
0.0227 & 36.4 & 911 & 891 & 396 \\
\hline
\end{tabular}

The $\mathrm{T}$ composite is somewhat more damage tolerant than the Q composite. For both composites, 76.2-mm-wide mechanical property specimens containing the impact damage area were cut from impacted plate specimens. The T composite specimens were used for both tension and compression tests. This lower bound is depicted in Figure 5.3. Only compression tests were performed for the Q composite. Typical strength reduction ratios from the lower-bound curves (e.g., Fig. 5.3) are tabulated in Table 6.9.

Table 6.9. Estimated strength-reduction ratios caused by impact damage

\begin{tabular}{ccc}
\hline Damage area & \multicolumn{2}{c}{ Strength-reduction ratio } \\
\cline { 2 - 3 }$\left(\mathbf{m m}^{\mathbf{2}}\right)$ & T material & $\mathbf{Q}$ material \\
\hline 100 & 0.71 & 0.60 \\
500 & 0.51 & 0.45 \\
\hline
\end{tabular}

\subsection{REFERENCES}

1. J. M. Corum et al., Durability-Based Design Criteria for a Quasi-Isotropic Carbon-Fiber Automotive Composite, ORNL/TM-2002/39, Oak Ridge National Laboratory, Oak Ridge, Tenn., March 2002.

2. National Materials Advisory Board, Life Prediction Methodologies for Composite Materials, NMAB-4600, National Research Council, Washington, D.C., October 1991.

3. J. M. Corum et al., Durability-Based Design Properties of Reference Crossply Carbon-Fiber Composite, ORNL/TM-2000/322, Oak Ridge National Laboratory, Oak Ridge, Tenn., April 2001. 
Part 2

BACKGROUND DATA AND MODELS 



\section{BASIC TENSILE, COMPRESSIVE, AND SHEAR PROPERTIES}

\subsection{TEST METHODS}

Basic properties were established from stiffness, tensile, compressive, and in-plane shear tests. Untabbed dogbone-shaped tensile specimens were used in all stiffness and tensile tests, which were performed according to the test method described in Ref. 1. Figure 7.1 presents the tensile test setup with averaging extensometer positioned for determining axial strains, and Figure 7.2 presents typical stressstrain curves for specimens from three different plaques. Straight-sided specimens with tabs were used in compression tests. ${ }^{1}$ The tab material was $1.6-\mathrm{mm}$-thick G-11 composite, an epoxy reinforced with woven

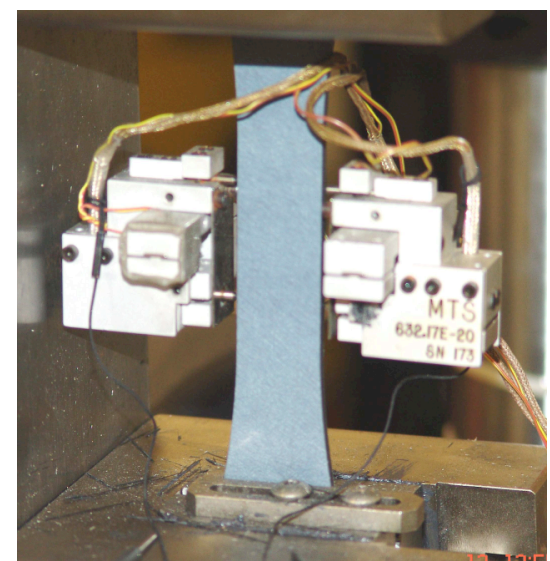

Figure 7.1 Tensile test setup showing averaging extensometer.

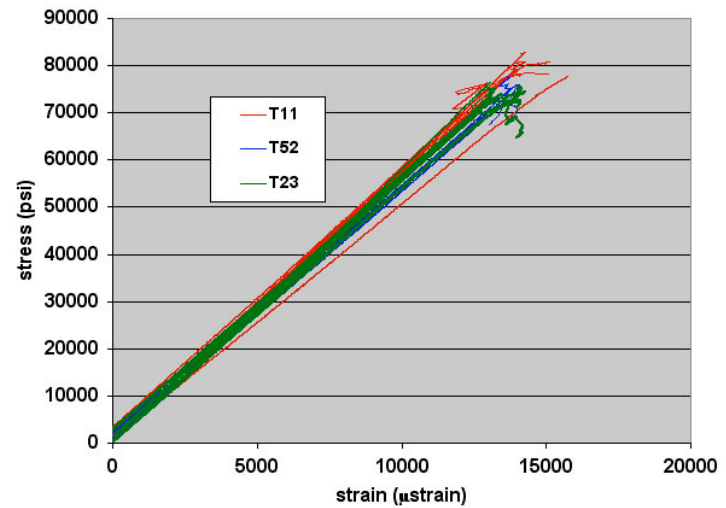

Figure 7.2 Typical tensile stress-strain curves.

fiberglass cloth. The adhesive used for bonding the tabs to the test specimens was Hysol EA 9394 A/B cured under contact pressure at room temperature for 24 hours. Compression tests employed an IITRI fixture (Procedure B in ASTM D 3410²). The test method was as described in Ref. 1, and Figure 7.3

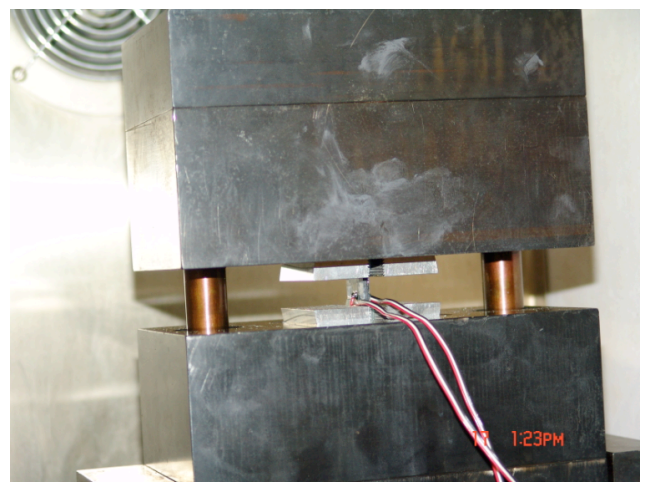

Figure 7.3 Closeup of IITRI test fixture.

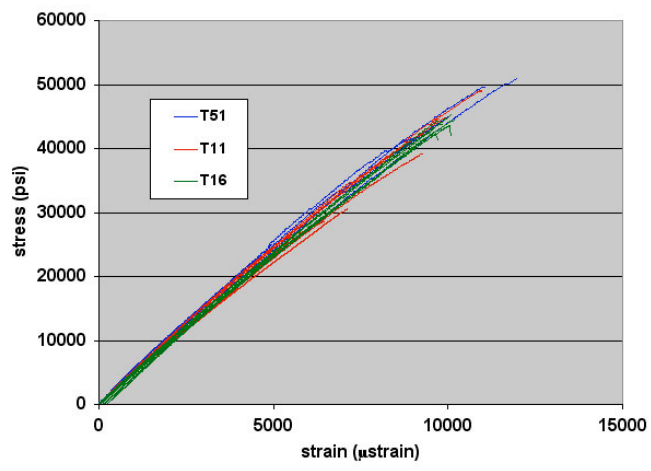

Figure 7.4 Typical compressive stressstrain curves.

presents a closeup of a specimen positioned in the IITRI test fixture. Figure 7.4 presents typical compressive stress-strain curves for specimens from three different plaques. Compression specimens were instrumented on front and back surfaces with $6.35-\mathrm{mm}$ gage length wire-resistance strain gages (Micro-measurements EA-06-250AE-350). The strain gages were attached to the compression specimens using Micro-measurements M-Bond 200 adhesive with M-Coat A polyurethane protective coating. The 
V-notched beam (Iosipescu) shear specimens and shear test method were as described in Ref. 1. The tab material was 3-mm-thick steel plate. The steel tabs were bonded to the shear specimens by lightly abrading the test specimen and using "J B Weld" under pressure for 24 hours at room temperature. Prior to testing, the tabs and specimen edges were machined to produce flat bearing surfaces. Specimens were instrumented with Iosipescu specialty gages (Micromeasurements Group N2P-08-C032A-500) on front and back faces (500 $\boldsymbol{\Omega} \pm 45^{\circ}$ shear gage, planar configuration with side-by-side grids). The Iosipescu strain gages were attached using the same procedure as for the compression gages. Figure 7.5 presents a closeup of an instrumented test specimen.

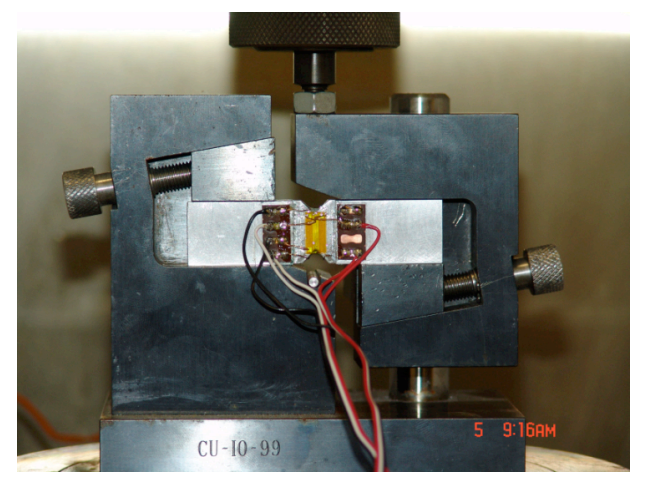

Figure 7.5 Instrumented shear specimen positioned in Iosipescu test fixture.

Poisson's ratio measurements were carried out using untabbed dogbone-shaped tensile specimens. Each Poisson's ratio specimen was instrumented with an averaging extensometer to determine axial strain and a 6.35-mm gage length strain gage (Micro-measurements EA-06-250AE-350) to determine transverse strain. The procedure for installation of the strain gages was the same as that used for the compression gages. Poisson's ratio values were determined at temperatures of $-40^{\circ}, 23^{\circ}, 70^{\circ}, 90^{\circ}$, and $120^{\circ} \mathrm{C}$ by plotting transverse versus axial strains and determining the slope of a straight line fit to the data. A minimum of three specimens was tested at each temperature.

In addition to presenting baseline properties at room temperature, this chapter provides strength and stiffness properties for $-40^{\circ}, 70^{\circ}, 90^{\circ}$, and $120^{\circ} \mathrm{C}$. Multiplication factors for determining elastic constants and strength properties at different temperatures from room-temperature values are developed. Furthermore, effects of sequential and prior loading, strain rate, and thermal cycling on properties are discussed. Finally, the effects of typical automotive fluids are considered, and multiplication factors to account for exposures in distilled water and windshield washer fluid are presented.

\subsection{ROOM-TEMPERATURE BASIC PROPERTIES}

In-air room-temperature tensile properties were established from 753 stiffness tests (each test represents average of three load cycles) and 207 tensile tests on specimens from 36 different plaques. Compressive properties were based on 57 tests of specimens from 10 plaques, and in-plane shear properties were based on 34 Iosipescu shear tests on specimens from 7 plaques. Baseline roomtemperature properties are summarized in Table 7.1, with the corresponding percent coefficients of variation $(\mathrm{COV})$ given in parentheses."

Compressive properties in Table 7.1 were obtained from the 25.4-mm-wide reference compression specimens. It is noteworthy that very similar compressive strength values were also obtained

\footnotetext{
* Additional testing has been conducted to determine the effect on tensile, compressive and shear properties of specimen orientation and annealing the thermoplastic composite at $230^{\circ} \mathrm{C}$ for $2 \mathrm{~h}$ in an attempt to enhance material crystallinity. Appendix C summarizes these results.
} 
from the 76.2-mm-wide compression after impact (CAI) specimens (see Chap. 12). Sixteen CAI specimens, without impact damage, cut from 9 different plaques produced an average compressive strength of $307 \mathrm{MPa}$ with a COV of $13.8 \%$. This indicates that the short-gage-length compressive specimen used here provides representative results.

Table 7.1. Average in-air room-temperature baseline properties

\begin{tabular}{lccc}
\hline \multicolumn{1}{c}{ Property } & Tension & Compression & Shear \\
\hline Modulus, GPa & $36.45(4.22)$ & $34.26(4.38)$ & $13.40(5.22)$ \\
Poisson's ratio & $0.29(4.80)$ & & \\
Strength, MPa & $551(7.64)$ & $295(12.63)$ & $193(5.73)$ \\
Failure strain, \% & $1.53(10.45)$ & $0.95(13.47)$ & $1.63(7.30)$ \\
\hline
\end{tabular}

Average tensile and compressive strength, stiffness, and failure strain values obtained for the quasi-isotropic PPS composite (T material) are greater than those obtained for the quasi-isotropic (Q material) composite. For the Q composite, the average tensile stiffness, strength, and failure strain values were $32.4 \mathrm{GPa}, 336 \mathrm{MPa}$, and $1.02 \%$, respectively; and the compressive stiffness, strength, and failure strain values were $32.1 \mathrm{GPa}, 225 \mathrm{MPa}$, and $0.72 \%$, respectively. The average shear strength and failure strain values of the T composite were less than those obtained for the Q composite (226 MPa and 2.32\%), but the average shear modulus for the T composite was greater than that for the Q composite (12.2 GPa). Poisson's ratio of the T composite was slightly less than that of the Q composite (0.31).

Maximum and minimum property values, which are given in Table 7.2 , indicate that basic properties, including outlying points, can vary by as much as a factor of 1.91. For the Q composite, with the exception of the compressive failure strain which had a ratio of maximum to minimum of 4.9 , the basic properties varied by as much as a factor of 2.7. These results indicate improved plaque to plaque as well as within plaque consistency of properties for the $\mathrm{T}$ composite relative to the $\mathrm{Q}$ composite.

Table 7.2. Maximum and minimum in-air room-temperature baseline property values

\begin{tabular}{|c|c|c|c|c|c|c|}
\hline \multirow[t]{2}{*}{ Property } & \multicolumn{2}{|c|}{ Tension } & \multicolumn{2}{|c|}{ Compression } & \multicolumn{2}{|c|}{ Shear } \\
\hline & Max & Min & Max & Min & Max & Min \\
\hline Modulus, GPa & 39.78 & 30.69 & 37.19 & 31.22 & 14.43 & 12.08 \\
\hline Strength, MPa & 654 & 473 & 350 & 159 & 207 & 163 \\
\hline Failure strain, \% & 1.943 & 1.276 & 1.22 & .64 & 1.81 & 1.32 \\
\hline
\end{tabular}

The Q composite strength in compression was $67 \%$ of the ultimate tensile strength (UTS); however, compressive strength for the T composite is only $53.5 \%$ of the UTS. Fiber volume fraction of the $\mathrm{T}$ composite was $53 \%$ versus $40.0 \%$ for the $\mathrm{Q}$ composite. Coefficients of variation for the T composite in Table 7.1 ranged from 4.38 to $13.47 \%$, while those for the Q composite, with one exception (i.e., shear strength), ranged from 15 to $32 \%$.

Since prior studies indicated a definite width effect on tensile results, a series of tensile tests on specimens of various widths was performed. Four sets of three tensile specimens having widths of 10.2, 20.3, 40.6, and $73.7 \mathrm{~mm}$ were cut from Plaque T4 and tested. Tensile strength, stiffness, and failure strain versus specimen width are shown in Figures 7.6 -7.8, respectively. 


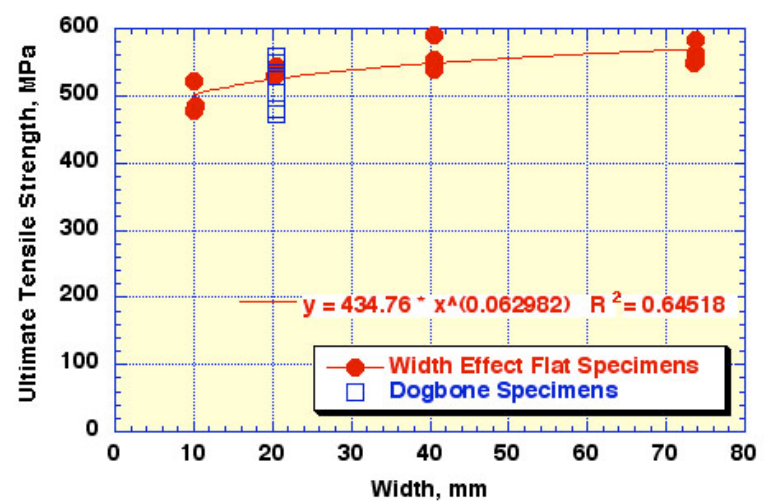

Figure 7.6 Effect of specimen width on ultimate tensile strength.

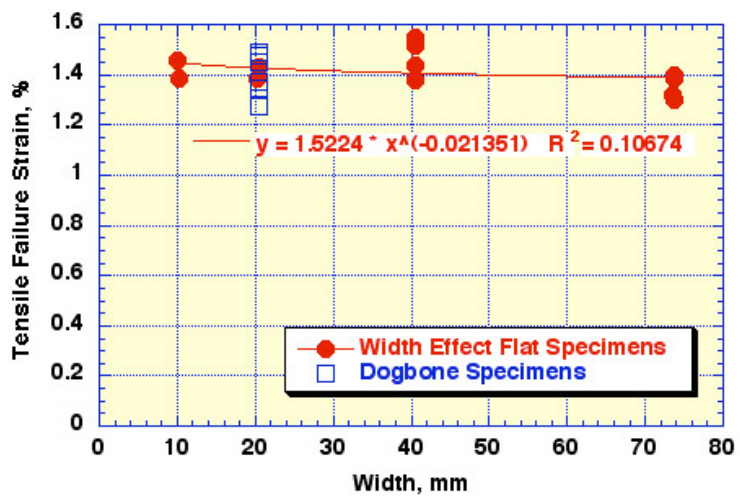

Figure 7.8 Effect of specimen width on tensile failure strain.

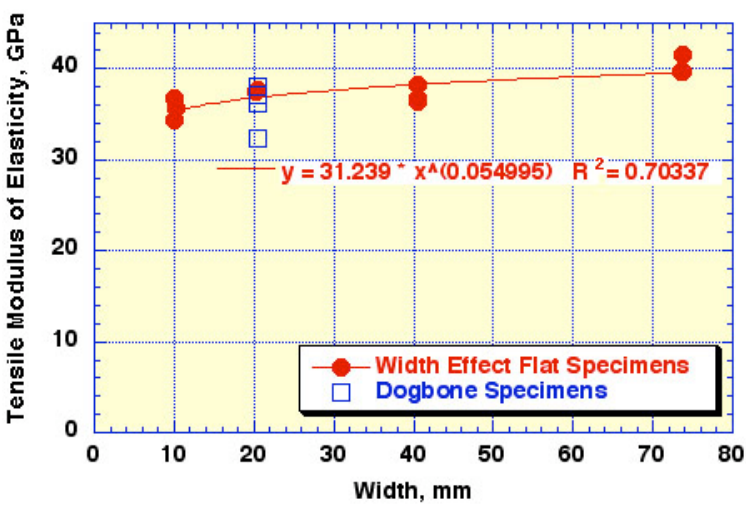

Figure 7.7 Effect of specimen width on tensile modulus of elasticity.

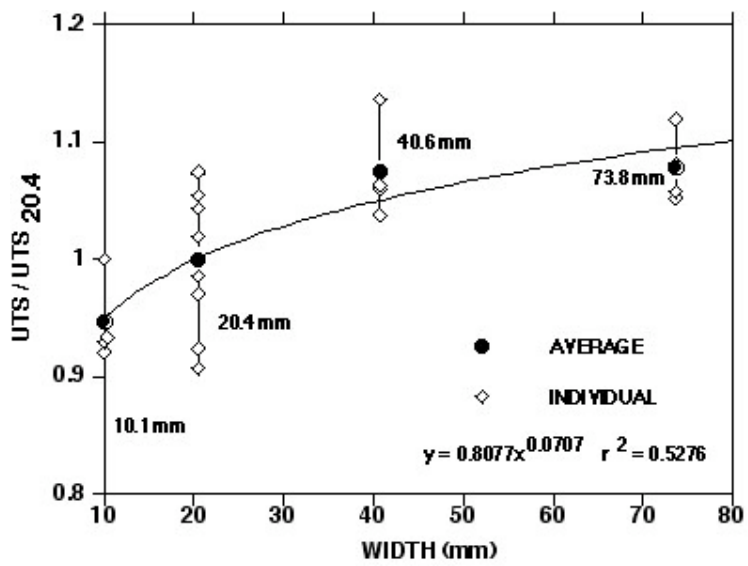

Figure 7.9 Baseline tensile strength values adjusted for width effect.

Baseline tensile strength values adjusted for width effect are presented in Figure 7.9. Results, presented in Fig. 7.6 and Fig. 7.7, indicate that both tensile strength and stiffness increase with specimen width; however, results in Figure 7.8 show that the tensile failure strain decreases slightly with specimen width. Specimens of 20.2-mm width were chosen for baseline tensile and fatigue tests with the knowledge that they would give relatively conservative stiffness and strength values while being sufficiently wide to be representative of the composite. A width factor (Fig. 7.9) was established to permit ultimate tensile strength adjustment for specimens of various widths (see, for example, Chap. 13).

\subsection{PROPERTIES VS PRECONDITIONING TEMPERATURE}

The effect of elevated temperature exposure on tensile, compressive, and shear properties was determined. Prior to testing, the specimens were subjected to a preconditioning temperature versus time exposure as illustrated in Figure 7.10. Preconditioning temperatures of $-40^{\circ}, 70^{\circ}, 90$ and $120^{\circ} \mathrm{C}$ were employed to quantify the effects of short-term thermal exposure. Preconditioning period at temperature was 60 minutes for each of the tension, compression, and shear tests. Six specimens were tested for each temperature with three of the specimens tested at temperature and three tested after returning and 
stabilizing at room temperature. The effect of time at preconditioning temperature on tensile properties was also evaluated for exposure periods up to 1000 hours.

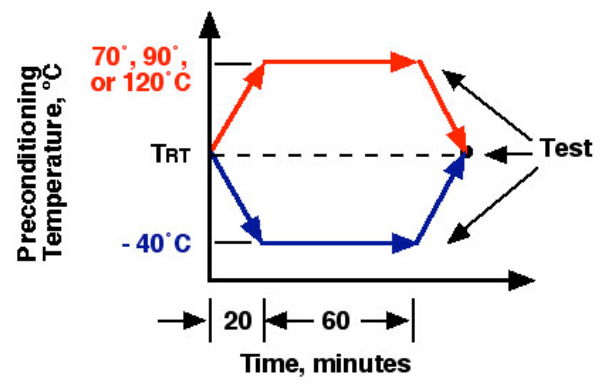

Figure 7.10 Specimen short-term temperature preconditioning history.

\subsubsection{TENSILE TESTS}

All 30 of the short-term thermal exposure specimens were cut from a single plaque (T17). Figure 7.11 presents typical tensile stress-strain curves for specimens tested at room temperature after preconditioning for one hour at various temperatures. Figures $7.12-7.14$ present ultimate tensile strength, tensile modulus of elasticity, and tensile failure strain, respectively, as a function of preconditioning temperature for specimens tested at temperature and after returning to room temperature.

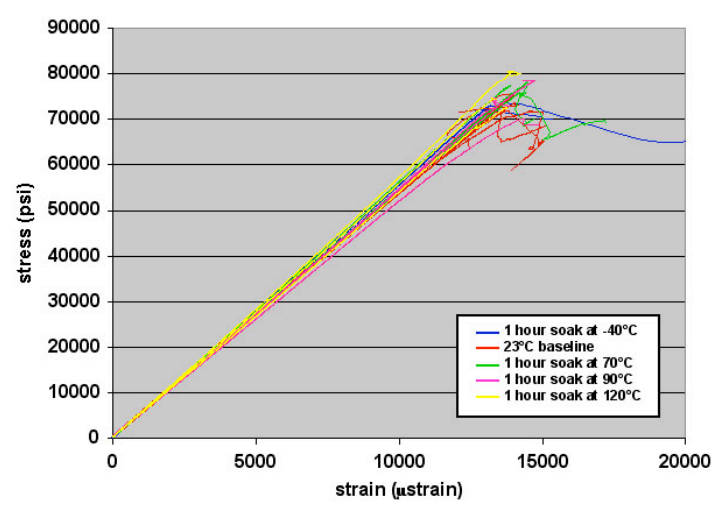

Figure 7.11 Typical stress-strain curves: tests at room temperature.

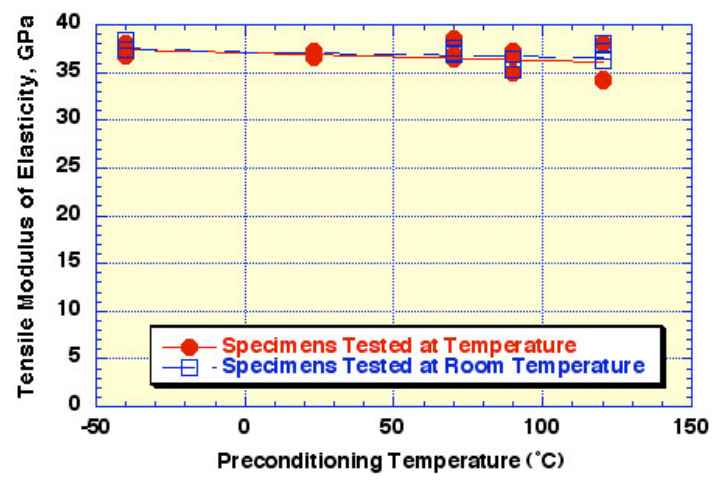

Figure 7.13 Effect of preconditioning temperature on tensile modulus of elasticity.

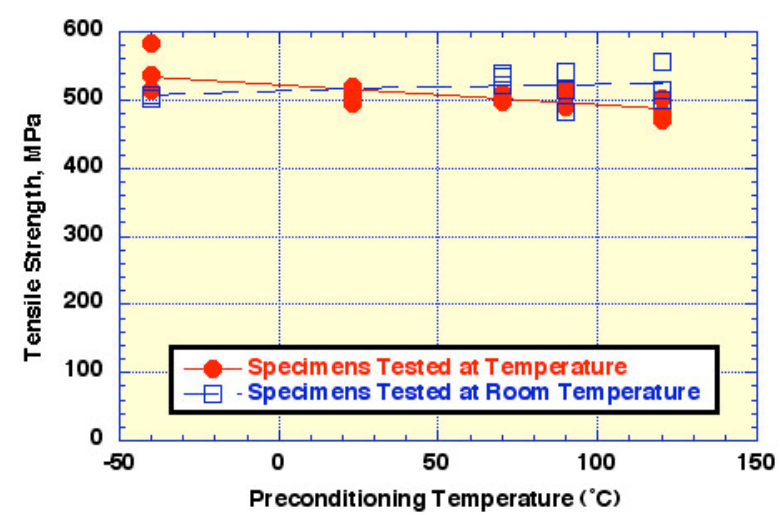

Figure 7.12 Effect of preconditioning temperature on ultimate tensile strength.

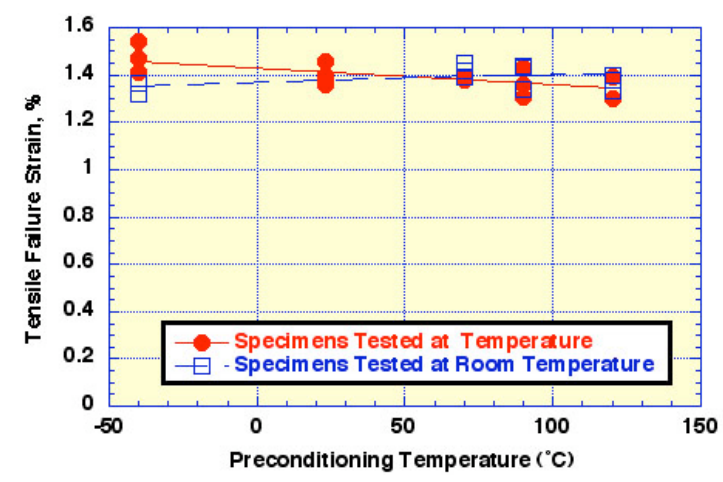

Figure 7.14 Effect of preconditioning temperature on tensile failure strain. 
Results presented in Figure 7.12 indicate that, except for the $-40^{\circ} \mathrm{C}$ preconditioning temperature, specimens tested at temperature tended to exhibit a slight decrease in average ultimate tensile strength (i.e., 1 to $7 \%$ ) relative to specimens permitted to return to room temperature prior to testing. The preconditioning and testing temperature had little effect on tensile modulus of elasticity and failure strain as noted in Figures 7.13 and 7.14, respectively.

Twenty-four specimens fabricated from Plaque T34 were instrumented with strain gages in order to determine the effect of elevated temperature exposure on Poisson's ratio. Six tensile specimens each were subjected to thermal conditioning at temperatures either of $-40^{\circ}, 70^{\circ}, 90^{\circ}$, or $120^{\circ} \mathrm{C}$ for one hour prior to testing. Three of the specimens at each preconditioning temperature were tested at temperature with the remaining three permitted to cool to room temperature prior to testing. Figure 7.15 presents the effect of preconditioning temperature on Poisson's ratio. As noted in the figure, both specimens tested at temperature and after returning to room temperature exhibited little effect of preconditioning temperature on Poisson's ratio.

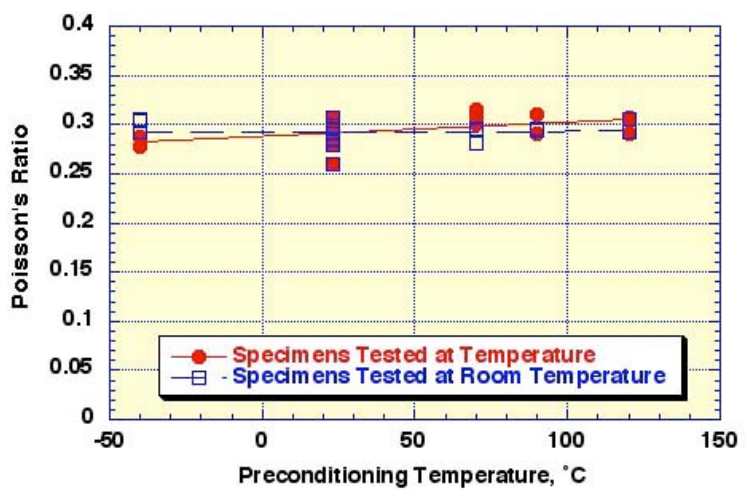

Figure 7.15 Effect of preconditioning temperature on Poisson's ratio.

Tensile specimens fabricated from Plaque T36 were subjected to preconditioning temperatures of $50^{\circ}, 70^{\circ}, 90^{\circ}$, and $120^{\circ} \mathrm{C}$ for up to 1000 hours. After exposure periods of $100,200,500$, and 1000 hours, two or three specimens that had been maintained at each of the preconditioning temperatures were removed from their oven, permitted to slowly cool to room temperature, and tested. The effect of exposure period on ultimate tensile strength of specimens maintained either at $50^{\circ}, 70^{\circ}, 90^{\circ}$, or $120^{\circ} \mathrm{C}$, are presented in Figures 7.16 - 7.19, respectively. Figures 7.20-7.23 and Figures 7.24-7.27 present the effect of exposure period on tensile modulus of elasticity and tensile failure strain, respectively, for specimens maintained at these exposure temperatures for period up to 1000 hours. As noted in Figures $7.16-7.20$, the ultimate tensile strength either changed little $\left(50^{\circ} \mathrm{C}\right)$ or decreased slightly $\left(70^{\circ}\right.$ and $90^{\circ} \mathrm{C}$ ) for preconditioning temperatures at or below the T material glass transition temperature but

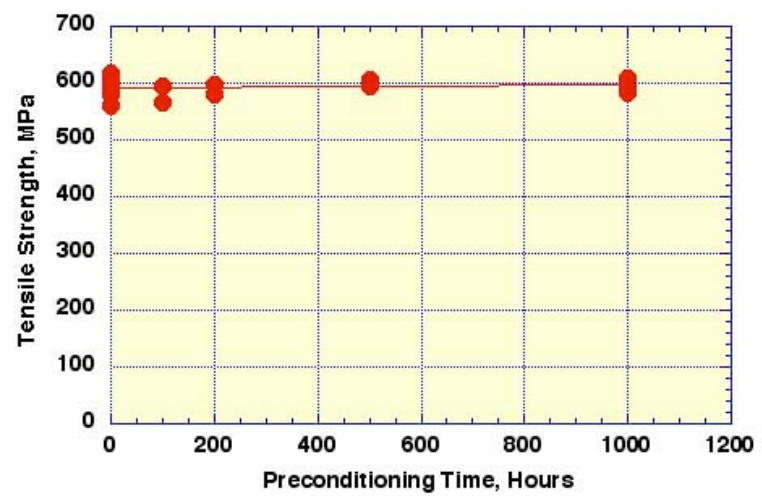

Figure 7.16 Effect of exposure period on ultimate tensile strength: $50^{\circ} \mathrm{C}$.

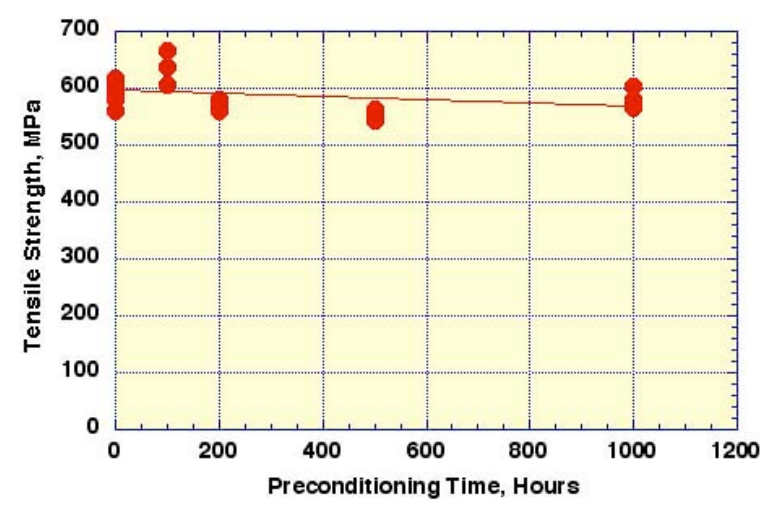

Figure 7.17 Effect of exposure period on ultimate tensile strength: $70^{\circ} \mathrm{C}$. 


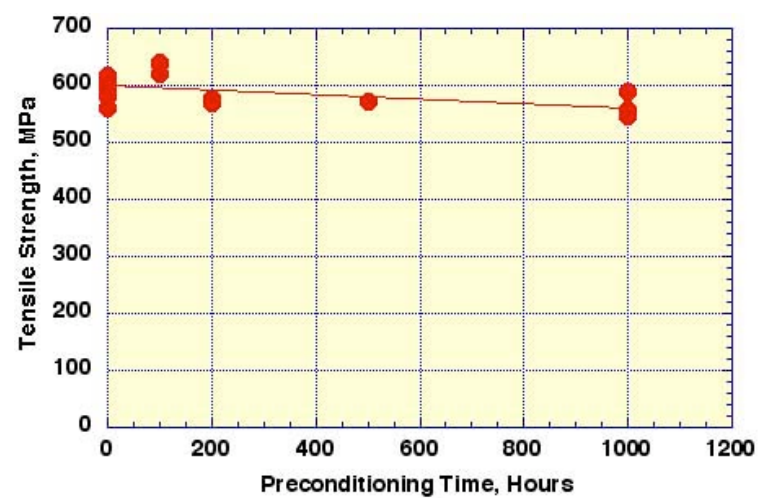

Figure 7.18 Effect of exposure period on ultimate tensile strength: $90^{\circ} \mathrm{C}$.

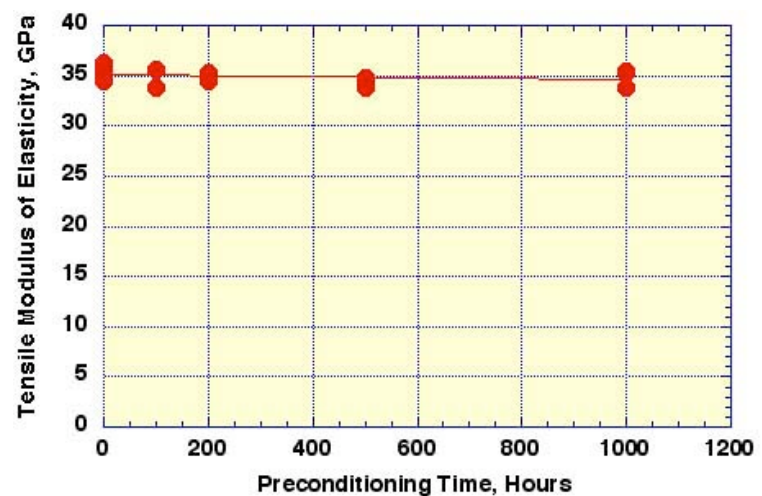

Figure 7.20 Effect of exposure period on tensile modulus of elasticity: $50^{\circ} \mathrm{C}$.

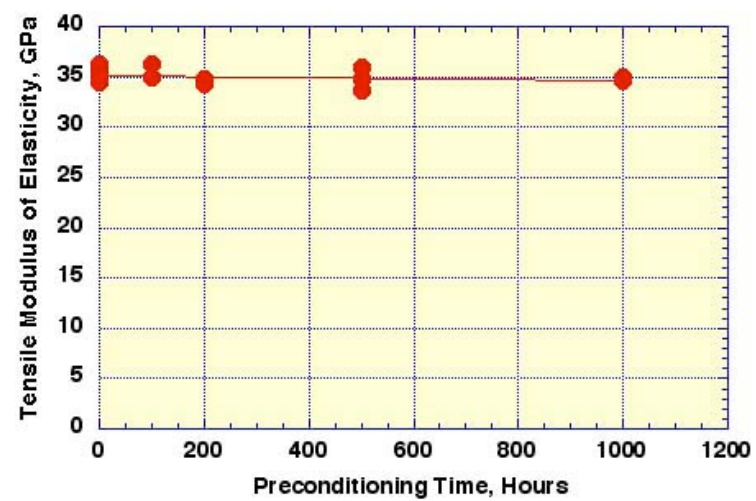

Figure 7.21 Effect of exposure period on tensile modulus of elasticity: $70^{\circ} \mathrm{C}$.

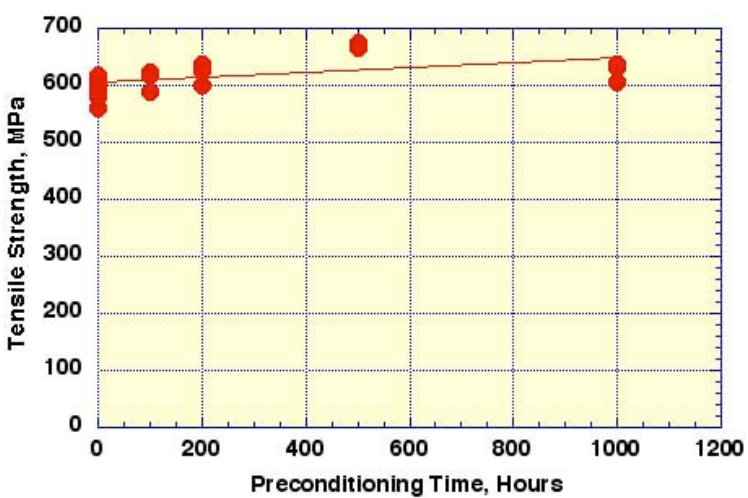

Figure 7.19 Effect of exposure period on ultimate tensile strength: $120^{\circ} \mathrm{C}$.

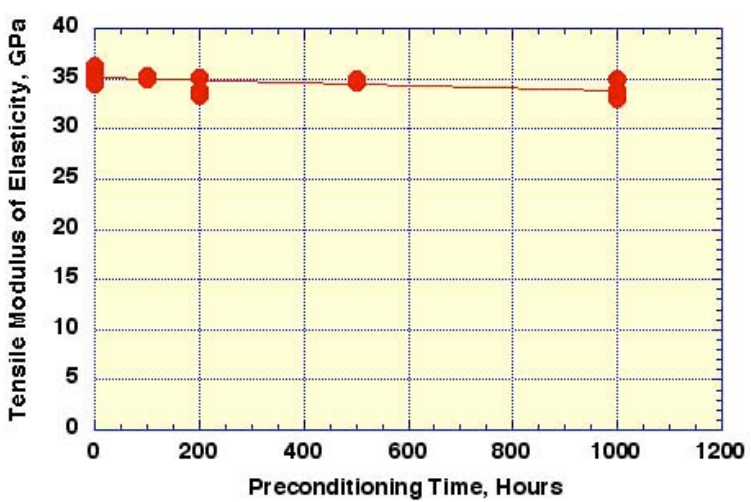

Figure 7.22 Effect of exposure period on tensile modulus of elasticity: $90^{\circ} \mathrm{C}$.

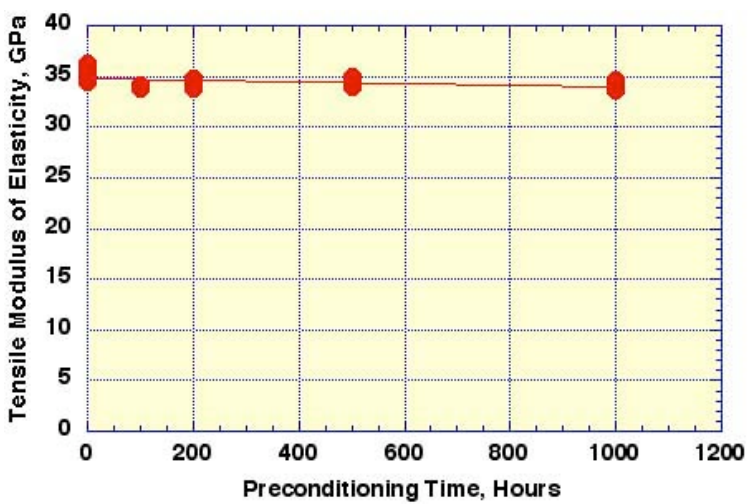

Figure 7.23 Effect of exposure period on tensile modulus of elasticity: $120^{\circ} \mathrm{C}$. 


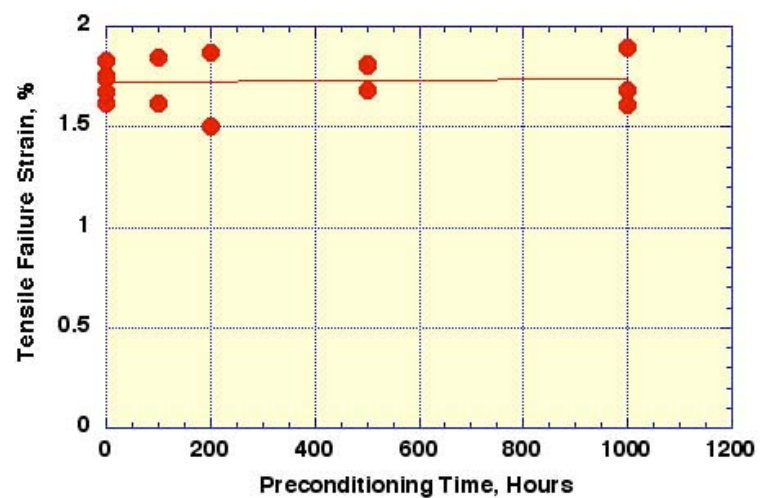

Figure 7.24 Effect of exposure period on tensile failure strain: $50^{\circ} \mathrm{C}$.

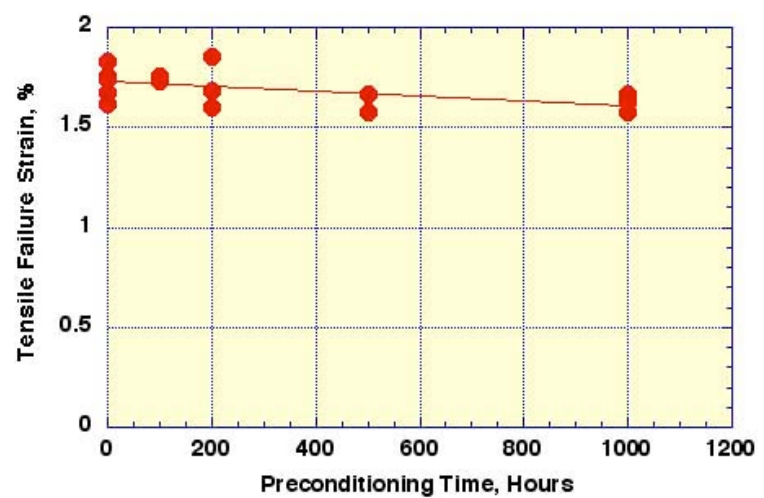

Figure 7.26 Effect of exposure period on tensile failure strain: $90^{\circ} \mathrm{C}$.

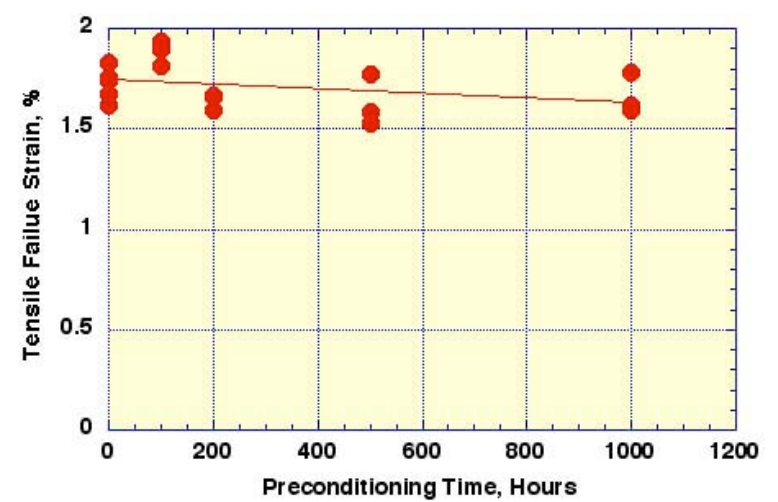

Figure 7.25 Effect of exposure period on tensile failure strain: $70^{\circ}$.

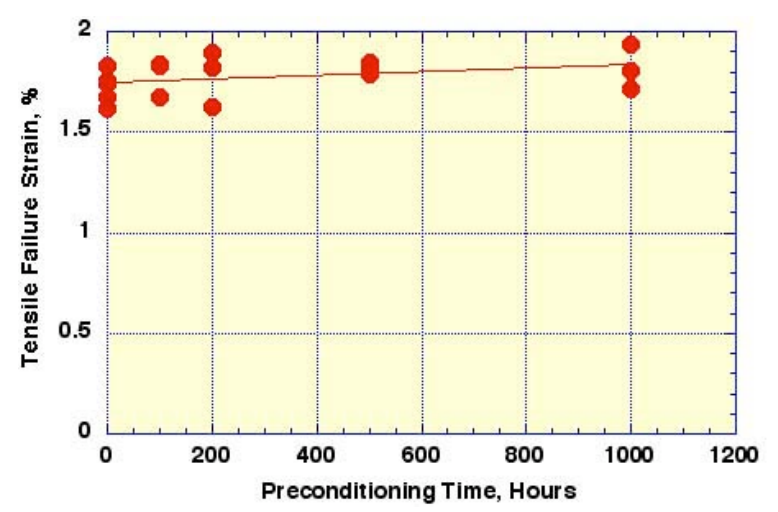

Figure 7.27 Effect of exposure period on tensile failure strain: $120^{\circ} \mathrm{C}$.

increased slightly $(2.7$ to $12.8 \%)$ for the preconditioning temperature $\left(120^{\circ} \mathrm{C}\right)$ above the $\mathrm{T}$ material glass transition temperature. Neither the preconditioning temperature nor the exposure period exhibited an apparent affect on the tensile modulus of elasticity (Figures $7.20-7.23$ ). Tensile failure strains (Figures $7.24-7.27$ ) were affected by the preconditioning temperature and exposure period in a manner similar to that exhibited by the ultimate tensile failure strength.

\subsubsection{COMPRESSION TESTS}

The affect of preconditioning temperature on compressive properties was evaluated using 30 specimens fabricated from Plaque T16. Six specimens were tested at room temperature (i.e., baseline result) and after one-hour exposure at each preconditioning temperature $\left(-40^{\circ}, 70^{\circ}, 90^{\circ}\right.$, and $\left.120^{\circ} \mathrm{C}\right)$. After 60 minutes exposure to each of the preconditioning temperatures, three of the specimens were tested at temperature and three were tested after returning and stabilizing at room temperature. Strain response was obtained by averaging results from strain gages positioned on the front and back faces of each compression specimen. Figures 7.28 and 7.29 present examples of stress versus strain curves at each of 
the preconditioning temperatures for specimens tested after returning to room temperature and at temperature, respectively. Figures $7.30-7.32$ present a comparison of compressive strength,

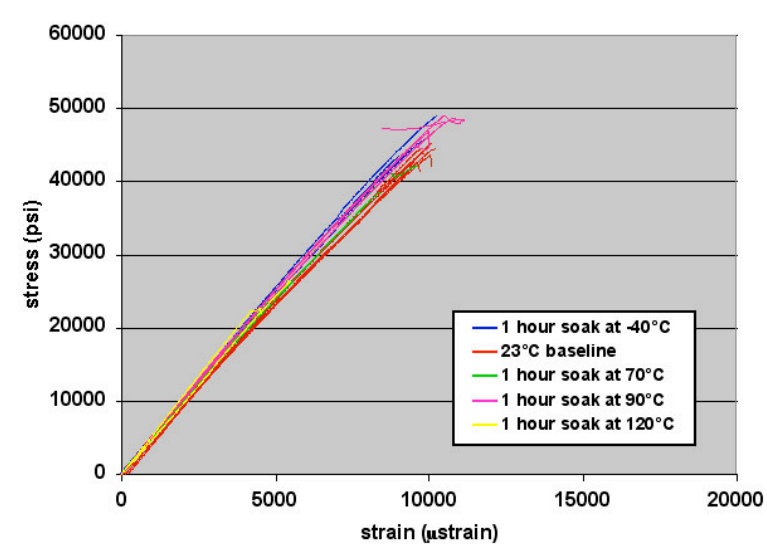

Figure 7.28 Examples of compressive stress vs strain curves: specimens tested at room temperature.

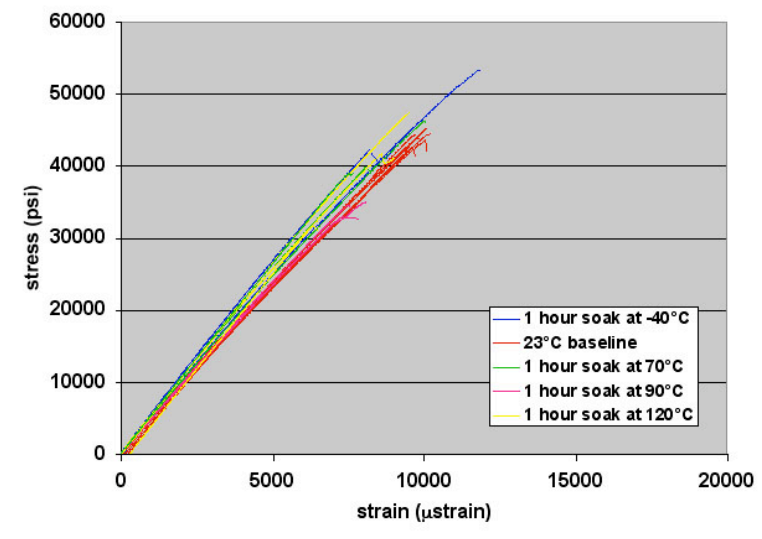

Figure 7.29 Examples of compressive stress vs strain curves: specimens tested at temperature.

compressive modulus of elasticity, and compressive failure strain results, respectively, for specimens tested at temperature and after returning to room temperature prior to testing. As noted in Figure 7.30, the compressive strength of specimens tested after returning to room temperature exhibited little effect of preconditioning temperature whereas the compressive strength of specimens tested at temperature tended to decrease with increasing preconditioning temperature. The decrease in compressive strength was more pronounced for tests conducted at temperatures near or above the material glass transition temperature. Results shown in Figure 7.31 indicate that the preconditioning temperature had little effect on the compressive modulus of elasticity for tests conducted either at temperature or after permitting the specimens to return to room temperature. Compressive failure strain results, Figure 7.32, indicate that the failure strain decreased with increasing preconditioning temperature at temperatures above room temperature with the decrease greatest for specimens tested at temperature.

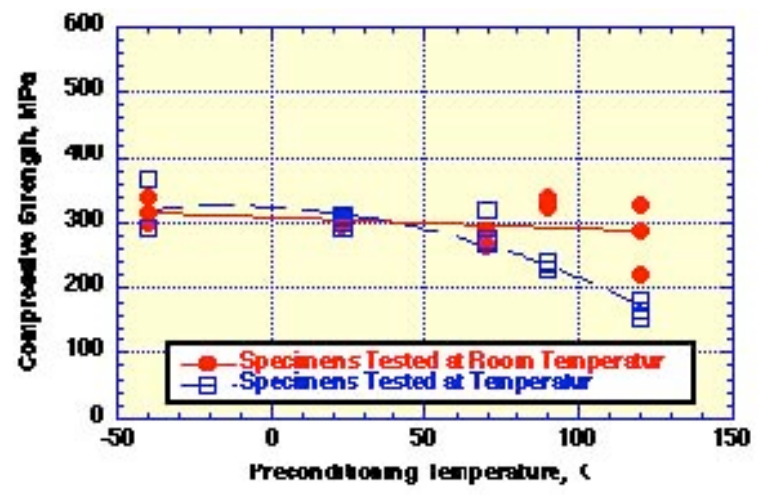

Figure 7.30 Effect of preconditioning temperature on compressive strength.

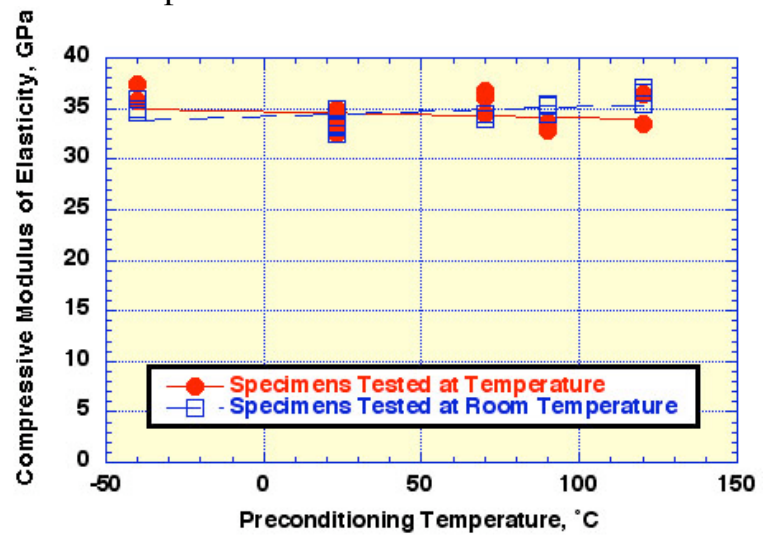

Figure 7.31 Effect of preconditioning temperature on compressive modulus of elasticity. 


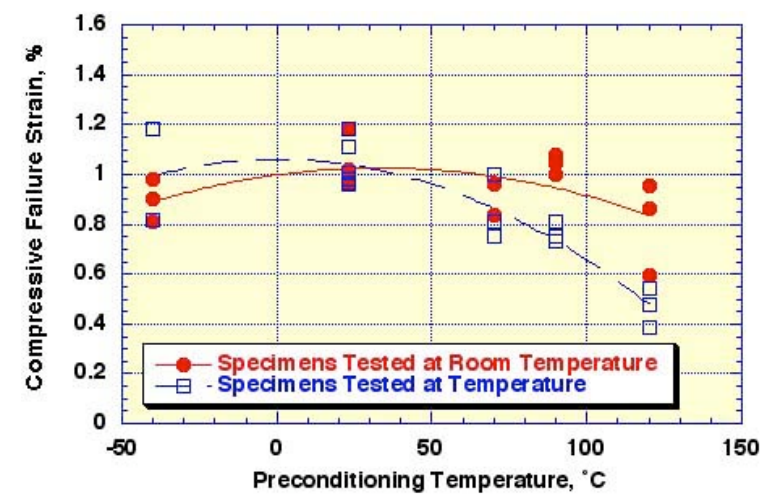

Figure 7.32 Effect of preconditioning temperature on compressive failure strain.

\subsubsection{SHEAR TESTS}

The affect of preconditioning temperature on shear properties was evaluated using 30 specimens fabricated from Plaque T17. The thermal preconditioning (60 minute exposure) and test procedure was the same as described for the compressive tests. Strain response was obtained by averaging results from strain gages positioned on the front and back faces of each shear specimen. Figures $7.33-7.35$ present a comparison of shear strength, shear modulus, and shear failure strain results, respectively, for specimens tested at temperature and after returning to room temperature prior to testing. Shear strength, Figure 7.33, of specimens tested after returning to room temperature were relatively unaffected by preconditioning temperature, however, there was a definite trend for the shear strength to decrease with increasing preconditioning temperature for specimens tested at temperature. Shear modulus, Figure 7.34, exhibited a similar trend to shear strength, however, the modulus of specimens tested at temperature was not as affected by preconditioning temperature as the shear strength of specimens tested at temperature. Shear failure strain, Figure 7.35, exhibited a similar trend to that exhibited by shear strength with the specimens tested at temperature exhibiting a significant decrease in shear failure strain with increasing preconditioning temperature. Except for results at $-40^{\circ} \mathrm{C}$, shear results obtained from specimens tested at temperature were always less than those obtained from specimens tested after returning to room temperature.

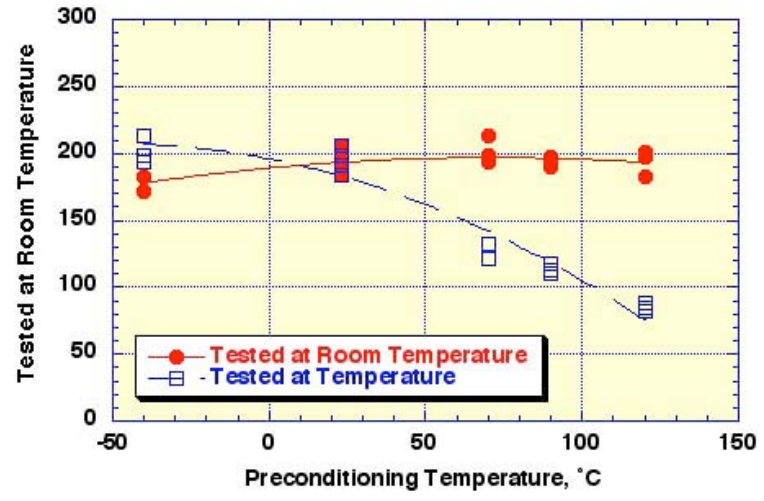

Figure 7.33 Effect of preconditioning temperature on shear strength.

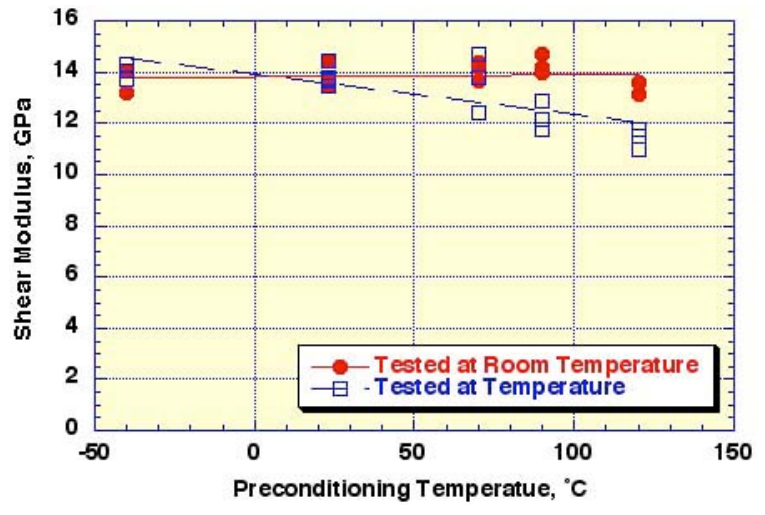

Figure 7.34 Effect of preconditioning temperature on shear modulus. 


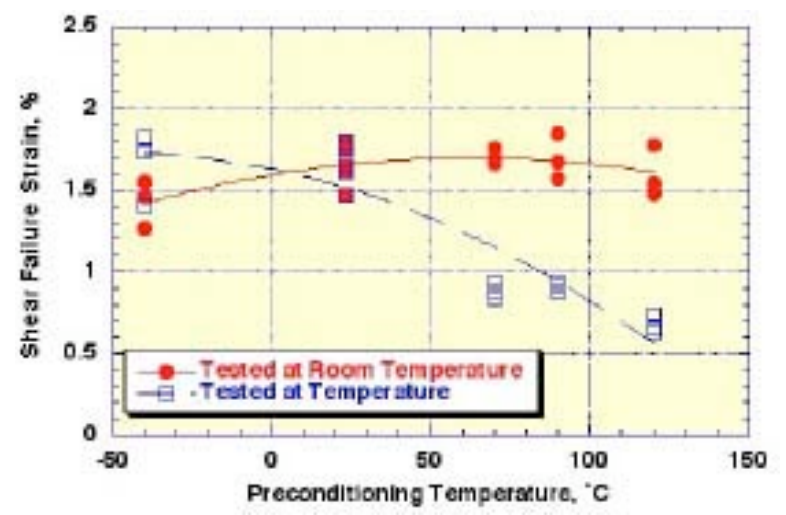

Figure 7.35 Effect of preconditioning temperature on shear failure strain.

\subsubsection{TEMPERATURE MULTIPLICATION FACTORS}

Temperature multiplication factors have been developed from the tension, compression, and shear results presented in Section 7.3 for specimens tested at temperature after a 60 -minute preconditioning period. The stiffness and strength temperature factors are defined as the ratio of the average attemperature value to the average room-temperature value. Average strength and stiffness multiplication factors have been calculated and plotted as functions of temperature. The resulting curves were adjusted to provide factors of 1.00 at room temperature. As a result, correlations between multiplication factors and temperature were developed so that multiplication factors can be established for any temperature in the range from $-40^{\circ}$ to $120^{\circ} \mathrm{C}$.

Average tension, compression, and shear results as a function of preconditioning temperature are presented in Table 7.3. The average stiffness and strength multiplication factors were then calculated and

Table 7.3. Average properties from temperature dependence study

\begin{tabular}{lccccc}
\hline & $\mathbf{- 4 0}^{\circ} \mathbf{C}$ & $\mathbf{2 3}^{\circ} \mathbf{C}$ & $\mathbf{7 0}^{\circ} \mathbf{C}$ & $\mathbf{9 0}^{\circ} \mathbf{C}$ & $\mathbf{1 2 0}^{\circ} \mathbf{C}$ \\
\hline $\begin{array}{l}\text { Tension } \\
\text { Modulus, } \\
\text { GPa }\end{array}$ & 37.25 & 36.84 & 37.31 & 36.36 & 35.48 \\
$\begin{array}{l}\text { Strength, } \\
\text { MPa }\end{array}$ & 545 & 506 & 505 & 506 & 485 \\
$\begin{array}{c}\text { Poisson's } \\
\text { ratio }\end{array}$ & .284 & .289 & .308 & .303 & .301 \\
$\begin{array}{l}\text { Compression } \\
\text { Modulus, } \\
\text { GPa }\end{array}$ & 36.57 & 33.49 & 35.74 & 33.22 & 34.94 \\
$\begin{array}{c}\text { Strength, } \\
\text { MPa }\end{array}$ & 329 & 303 & 287 & 235 & 167 \\
$\begin{array}{l}\text { Shear } \\
\text { Modulus, } \\
\text { GPa }\end{array}$ & 14.03 & 13.80 & 13.64 & 12.25 & 11.40 \\
$\begin{array}{c}\text { Strength, } \\
\text { MPa }\end{array}$ & 202 & 193 & 125 & 113 & 85 \\
\hline
\end{tabular}


plotted as functions of temperature with the resulting curves adjusted to give factors of 1.00 at room temperature. Multiplication factors are presented in Table 7.4 and are used in Part 1 of this report. The stiffness and strength multiplication factors are also plotted in Figures 7.36 and 7.37, respectively. Corresponding plots of stiffness and strength multiplication factors are presented in Figures 7.38 and 7.39, respectively, for the thermoset quasi-isotropic composite ( $\mathrm{Q}$ material). Comparing the stiffness multiplication factors for the two materials indicates that at temperatures greater than room temperature, the tension and compression factors were larger for the T material, but the shear factors were slightly less. Tensile strength multiplication factors were slightly greater for the T material at temperatures greater than the room temperature, the compressive strength multiplication factors for both materials were similar over

Table 7.4. Temperature multiplication factors for determining at-temperature modulus and strength from room-temperature values

\begin{tabular}{lccccc}
\hline & $\mathbf{4 0}^{\circ} \mathbf{C}$ & $\mathbf{2 3}^{\circ} \mathbf{C}$ & $\mathbf{7 0}^{\circ} \mathbf{C}$ & $\mathbf{9 0}^{\circ} \mathbf{C}$ & $\mathbf{1 2 0}^{\circ} \mathbf{C}$ \\
\hline $\begin{array}{l}\text { Tension } \\
\text { Modulus }\end{array}$ & 1.01 & 1.00 & 1.01 & 0.99 & 0.96 \\
Strength & 1.08 & 1.00 & 1.00 & 1.00 & 0.96 \\
& & & & & \\
Compression & & & & & \\
$\quad \begin{array}{l}\text { Modulus } \\
\text { Strength }\end{array}$ & 1.09 & 1.00 & 1.07 & 0.99 & 1.04 \\
& 1.09 & 1.00 & 0.95 & 0.78 & 0.55 \\
Shear & & & & & \\
$\quad \begin{array}{l}\text { Modulus } \\
\text { Strength }\end{array}$ & 1.02 & 1.00 & 0.99 & 0.89 & 0.83 \\
\hline & 1.05 & 1.00 & 0.65 & 0.59 & 0.44 \\
\hline
\end{tabular}

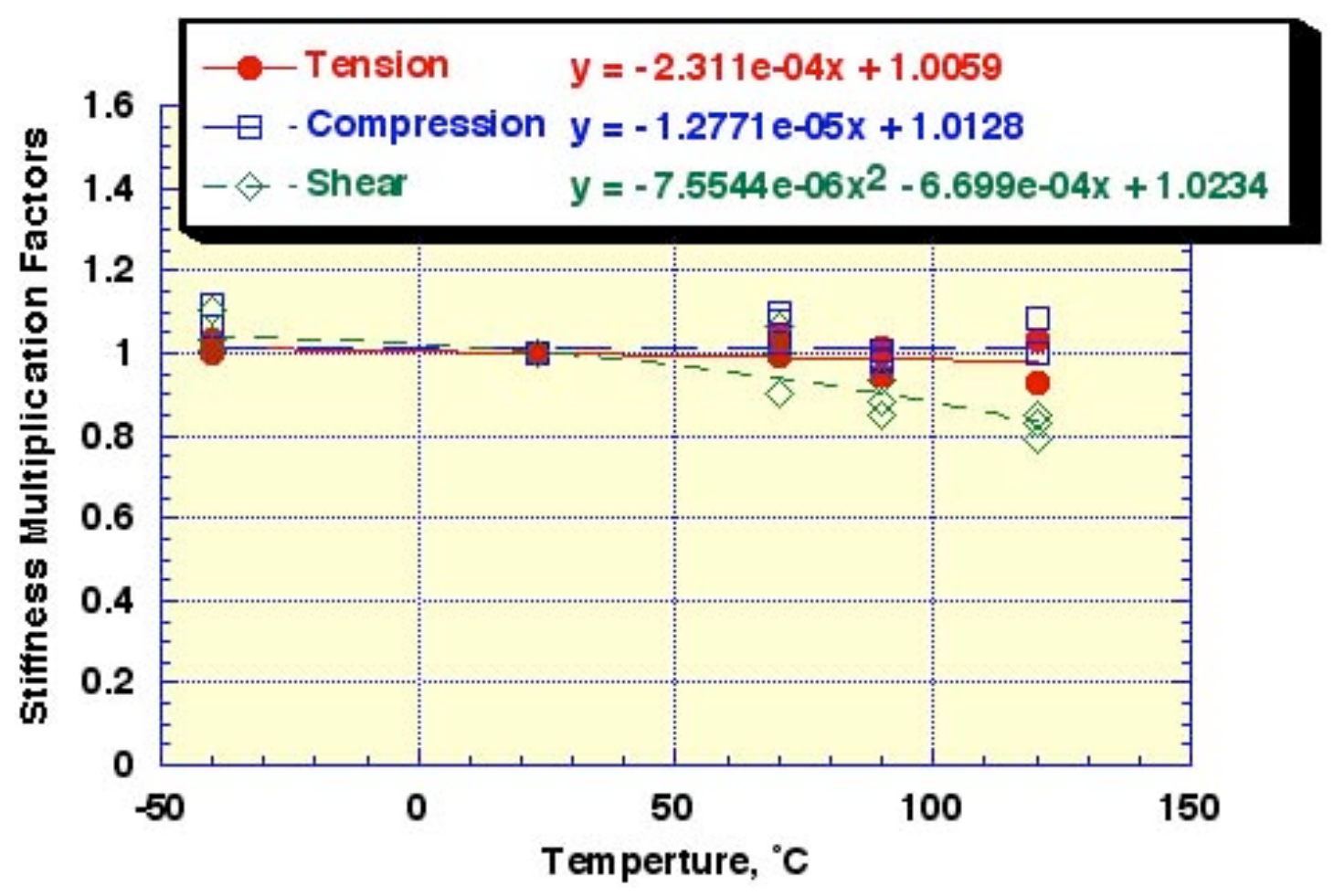

Figure 7.36 Stiffness multiplication factors for PPS quasi-isotropic thermoplastic composite: T material. 


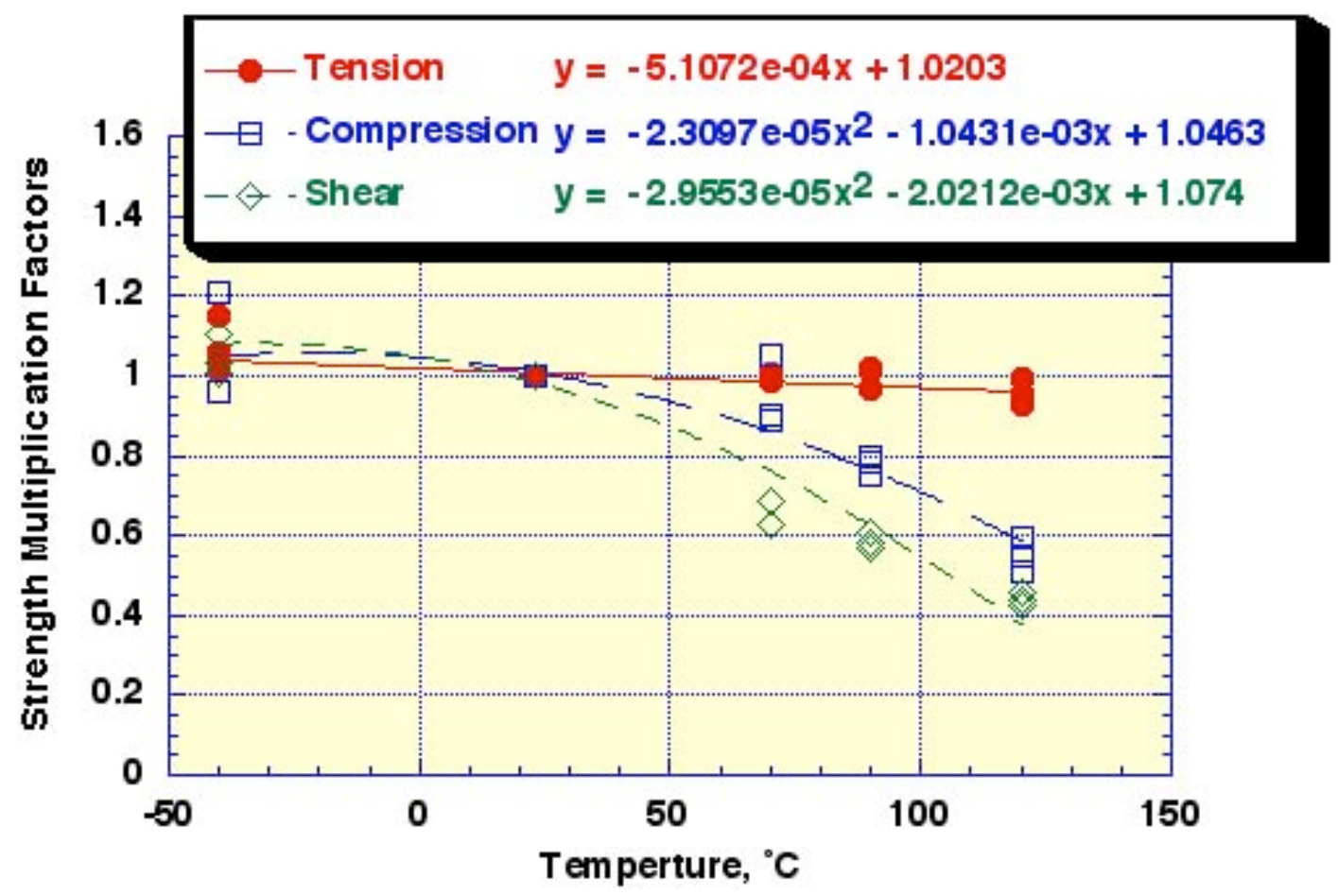

Figure 7.37 Strength multiplication factors for PPS quasi-isotropic thermoplastic composite: T material.

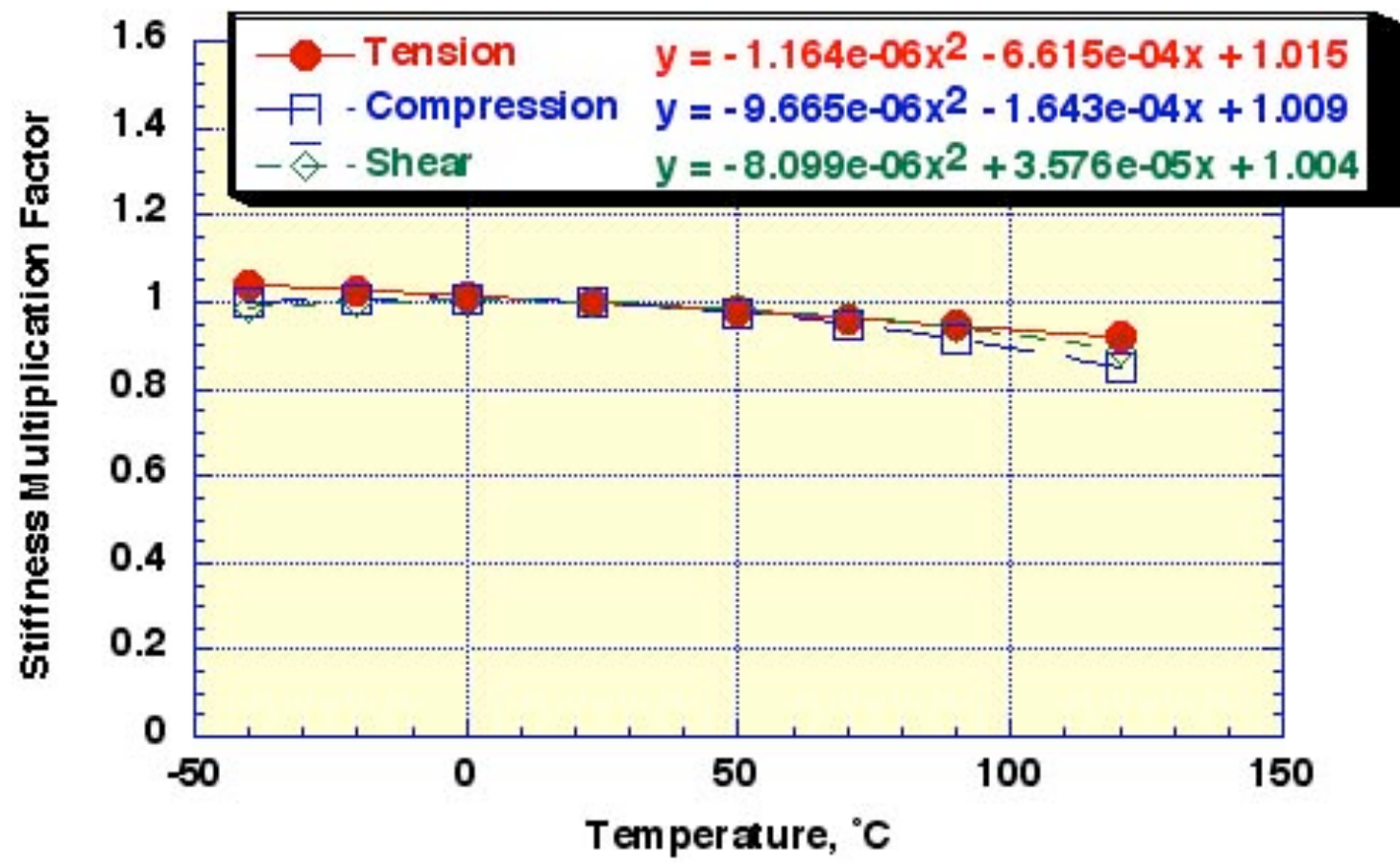

Figure 7.38 Stiffness multiplication factors for the quasi-isotropic thermoset composite: Q material. 


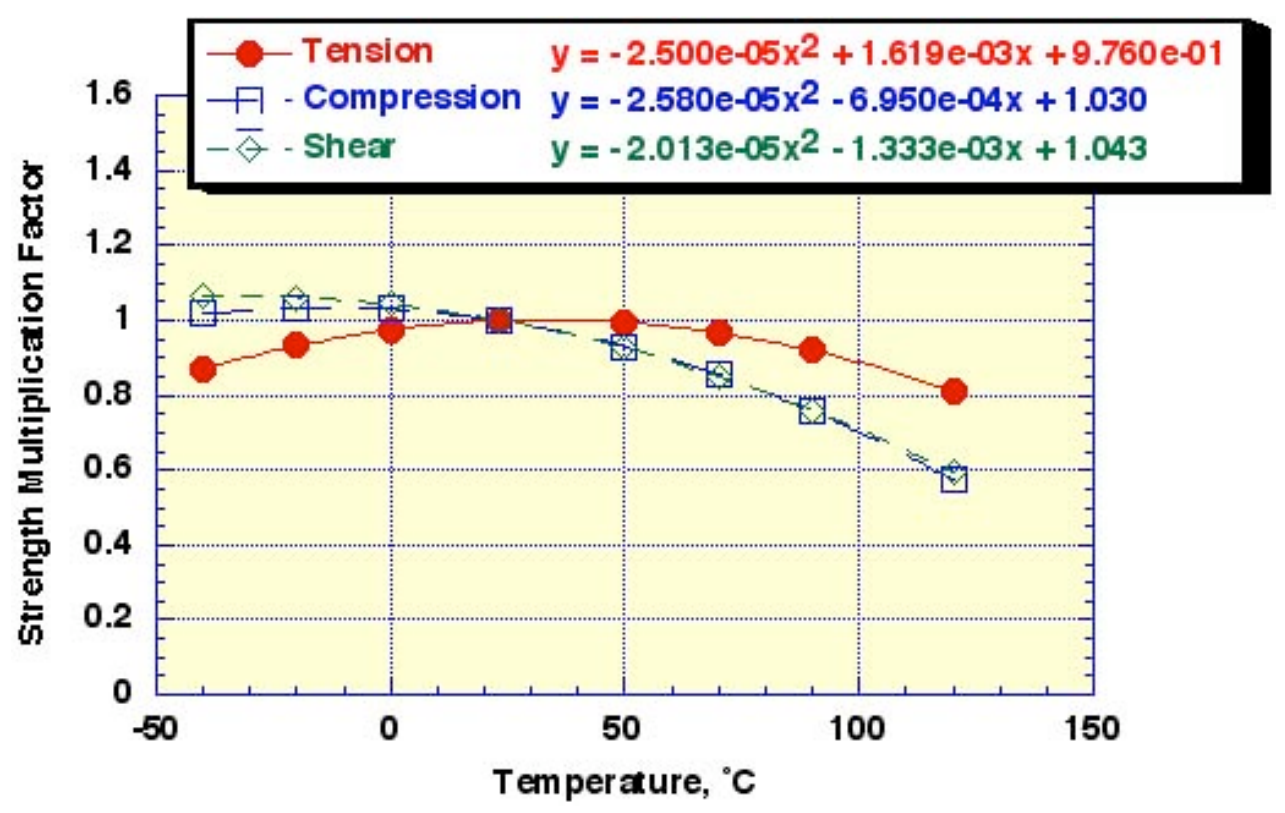

Figure 7.39 Strength multiplication factors for the quasi-isotropic thermoset composite: Q material.

the entire temperature range investigated, and the shear strength multiplication factors for the Q material were slightly greater at temperatures greater than room temperature. Finally, the temperature multiplication factors were applied to the baseline room-temperature properties in Table 7.1 to obtain the at-temperature properties presented in Table 7.5. Poisson's ratio values, which were determined at each preconditioning temperature of interest, represent an exception.

Table 7.5. Calculated baseline properties at different temperatures

\begin{tabular}{lccccc}
\hline & $\mathbf{4 0}^{\circ} \mathbf{C}$ & $\mathbf{2 3}^{\circ} \mathbf{C}$ & $\mathbf{7 0}^{\circ} \mathbf{C}$ & $\mathbf{9 0}^{\circ} \mathbf{C}$ & $\mathbf{1 2 0}^{\circ} \mathbf{C}$ \\
\hline Tensile & & & & & \\
Modulus, GPa & 37.00 & 36.47 & 36.08 & 35.91 & 35.65 \\
Poisson's ratio & 0.284 & 0.289 & 0.308 & 0.303 & 0.301 \\
$\quad$ Strength, MPa & 573 & 556 & 542 & 537 & 528 \\
Compressive & & & & & \\
$\quad$ Modulus, GPa & 34.71 & 34.69 & 34.67 & 34.66 & 34.65 \\
Strength, MPa & 310 & 298 & 254 & 226 & 174 \\
Shear & & & & & \\
$\quad$ Modulus, GPa & 13.91 & 13.45 & 12.59 & 12.09 & 11.18 \\
Strength, MPa & 214 & 195 & 152 & 126 & 78 \\
\hline
\end{tabular}

Poisson's ratio for the $\mathrm{T}$ composite exhibited a similar trend to the $\mathrm{Q}$ composite in that it increased slightly as the preconditioning temperature increased. In the case of the Q composite, Poisson's ratio increased from 0.31 to 0.34 as the temperature increased from -40 to $120^{\circ} \mathrm{C}$.

The tensile modulus, E, shear modulus, G, and Poisson's ratio, $v$, in an isotropic material are related by the expression 


$$
\mathrm{G}=\mathrm{E} / 2(1+v)
$$

Using this expression with the values of $E$ and $v$ in Table 7.5, values of shear modulus, G, were calculated for the different temperatures. Results summarized in Table 7.6 show that calculated values are higher than experimental ones. Furthermore, the percent difference $\Delta \mathrm{G}=100 \%\left(\mathrm{G}_{\text {calc }}-\mathrm{G}_{\exp }\right) / \mathrm{G}_{\exp }$ becomes higher as the temperature increases. Differences between measured and calculated $G$ are larger than results obtained for the Q material.

Table 7.6. Calculated and measured shear moduli at different temperatures

\begin{tabular}{cccc}
\hline Temperature $\left({ }^{\circ} \mathbf{C}\right)$ & $\mathbf{G}_{\text {calc }}(\mathbf{G P a})$ & $\mathbf{G}_{\text {exp }}(\mathbf{G P a})$ & $\boldsymbol{\Delta} \mathbf{G}(\mathbf{\%})$ \\
\hline $\mathbf{- 4 0}$ & 14.41 & 13.91 & 3.59 \\
$\mathbf{2 3}$ & 14.15 & 13.45 & 5.20 \\
$\mathbf{7 0}$ & 13.79 & 12.59 & 9.53 \\
$\mathbf{9 0}$ & 13.78 & 12.09 & 13.98 \\
$\mathbf{1 2 0}$ & 13.70 & 11.18 & 22.54 \\
\hline
\end{tabular}

\subsection{EFFECT OF SEQUENTIAL AND PRIOR LOADING ON STIFFNESS}

Depending on the magnitude of the load, subjecting a specimen to a short-time tensile loading can cause microstructural damage that is subsequently reflected in a loss of residual stiffness.

\subsubsection{SEQUENTIAL LOADING}

To explore the effect of sequential loading on stiffness, 16 tensile specimens were fabricated from Plaque T39. After initial stiffness checks to establish baseline values, four tensile specimens each were subjected to initial loadings of either $20 \%, 40 \%, 60 \%$, or $80 \%$ the plaque average ultimate tensile strength. The specimens were then unloaded and reloaded with the load increased by $20 \%$ the plaque average ultimate tensile strength. This procedure was repeated until the last load cycle in which the specimen was loaded to failure. Modulus of elasticity was determined for each of the specimens for each of the load applications. Table 7.7 presents a summary of the average sequential loading effect test results obtained during the last load cycle to failure (i.e., after sequential loadings).

Table 7.7. Summary of sequential loading test results for final load cycle to failure.

\begin{tabular}{ccccc}
\hline $\begin{array}{c}\text { Initial Load Cycle } \\
\text { (\% UTS) }\end{array}$ & $\begin{array}{c}\text { Number of } \\
\text { Prior Load } \\
\text { Cycles }\end{array}$ & $\begin{array}{c}\text { UTS } \\
\text { (MPa) }\end{array}$ & $\begin{array}{c}\text { E } \\
\text { (GPa) }\end{array}$ & $\begin{array}{c}\text { Failure Strain } \\
\text { (\%) }\end{array}$ \\
\hline 0 to 20 & 4 & 605 & 33.14 & 1.76 \\
0 to 40 & 3 & 610 & 33.15 & 1.78 \\
0 to 60 & 2 & 621 & 34.46 & 1.73 \\
0 to 80 & 1 & 622 & 34.58 & 1.68 \\
0 to 100 (Baseline) & 0 & 600 & 36.13 & 1.67 \\
\hline
\end{tabular}

Figure 7.40 presents average change in stiffness for each of the load applications. Results indicate that the first load increment did not produce a change in stiffness, but succeeding load increments produced increased reductions in the modulus of elasticity relative to baseline values. Examples of stress versus strain results obtained from specimens during their last load increment to failure for specimens subjected to initial loadings ranging from the baseline stiffness to $80 \%$ the plaque average ultimate tensile 
strength are shown in Figure 7.41. Average ultimate tensile strengths and moduli of elasticity obtained from these specimens during their final load cycle to failure are presented in Figures 7.42 and 7.43, respectively. As noted in Figure 7.41, the shape of the stress versus strain curves for the final load cycle

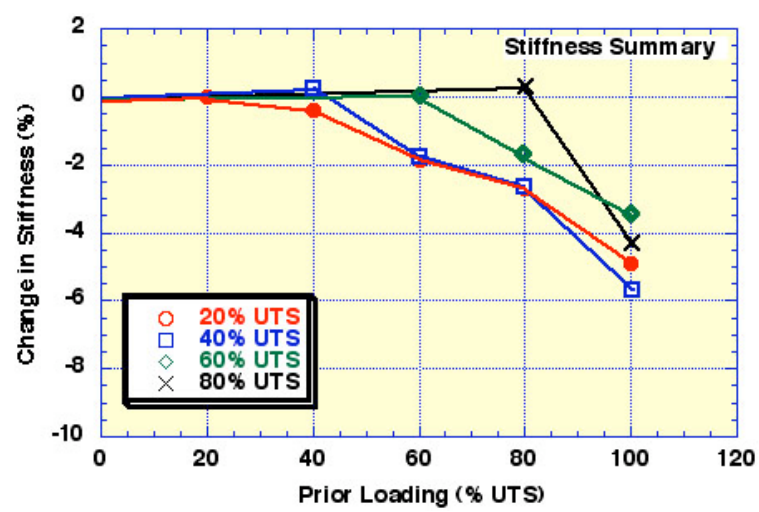

Figure 7.40 Effect of sequential loading on stiffness.

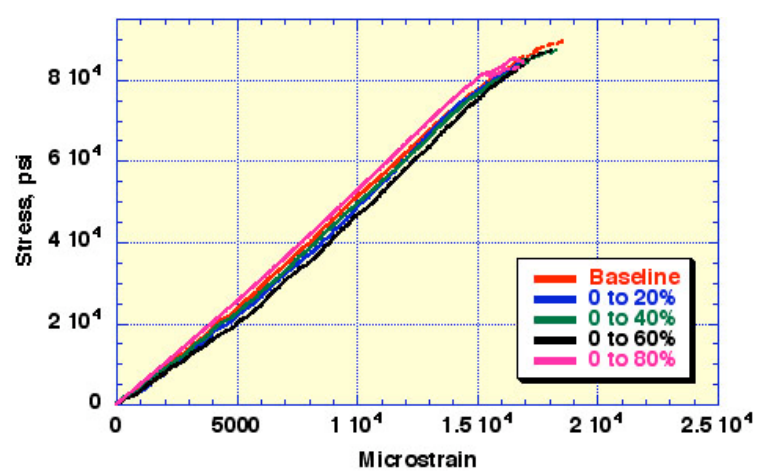

Figure 7.41 Effect of sequential loading on stress versus strain results obtained during final load cycle to failure.

was not significantly changed as a result of prior sequential loading. Relative to the baseline results, the ultimate tensile strength was relatively unaffected by prior loading $(<3.7 \%$ increase relative to baseline), the modulus of elasticity values were reduced $(<8.3 \%)$, and the failure strains increased slightly $(<6.6 \%)$.

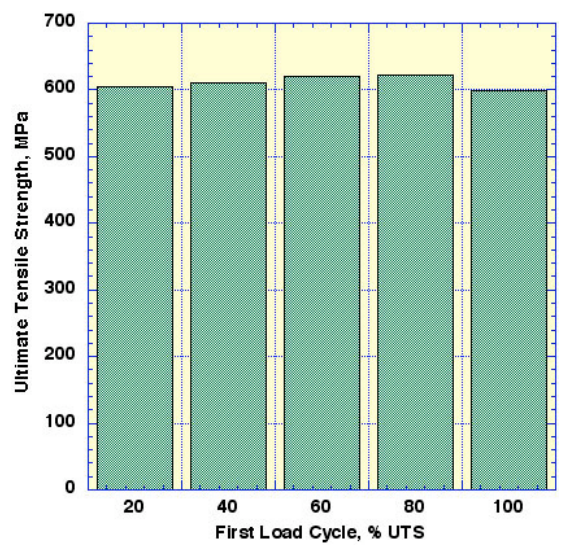

Figure 7.42 Effect of sequential loading on ultimate tensile strength.

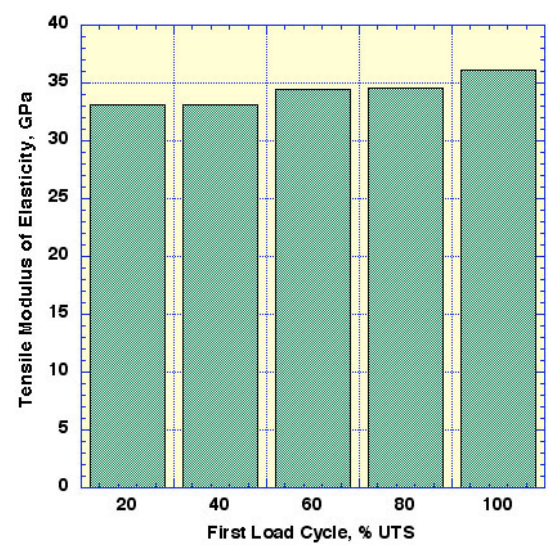

Figure 7.43 Effect of sequential loading on tensile modulus of elasticity.

\subsubsection{PRIOR LOADING}

To investigate the impact of prior loading, 20 tensile specimens were fabricated from Plaque T48. Five specimens each were subjected to sequential loads of $20 \%, 40 \%, 60 \%$ and $80 \%$ UTS with the stiffness checked for each loading. After each target load was reached, the specimen was unloaded and the stiffness rechecked. Finally, each specimen was loaded to failure. Additional groups of five specimens were subjected to load sequences starting either with 40,60 , or $80 \%$ of the UTS. Changes in stiffness were calculated with respect to both the initial load cycle to the particular increment and with respect to the baseline stiffness determined for each specimen. Figures $7.44 \mathrm{a}$ and $7.44 \mathrm{~b}$ present the 
results for stiffness change with respect to prior loading to the same sequential load level and with respect to specimen baseline stiffness, respectively. As noted in these figures, the change in stiffness was

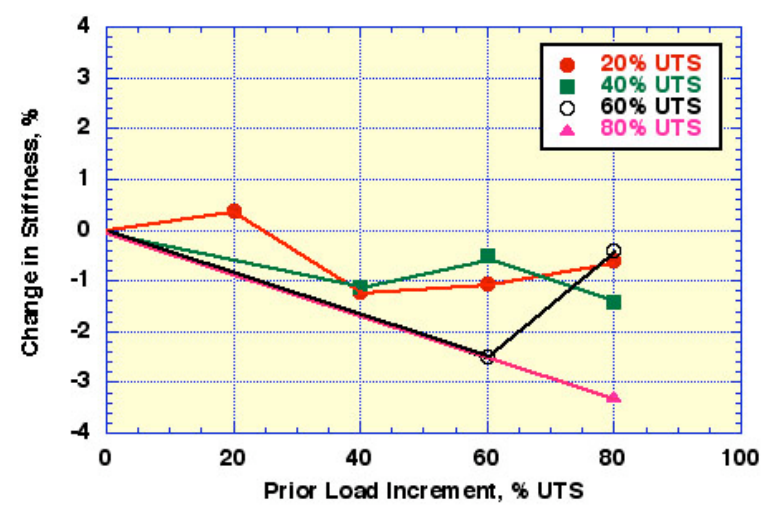

Figure 7.44a Effect of prior load to same level on average stiffness change.

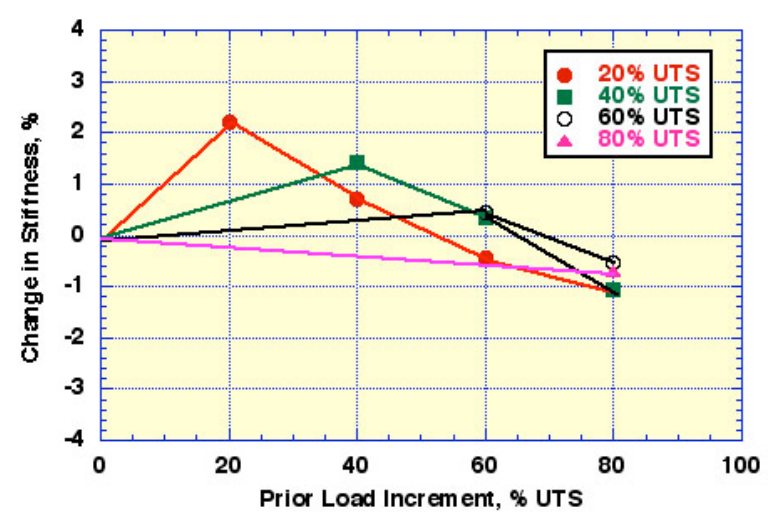

Figure $7.44 \mathrm{~b}$ Stiffness change relative to baseline stiffness due to prior loading.

approximately $3 \%$ or less due to prior loading. Note that stiffness loss at the $\mathrm{S}_{0}$ stress level of $327 \mathrm{MPa}$, which is approximately equal to $60 \%$ of the UTS, was less than $2.5 \%$. ${ }^{*}$ Also the effect of prior loading on stiffness (Figure 7.44) is slightly more than that observed for the $\mathrm{Q}$ composite. In the case of the Q composite, stiffness loss (relative to the baseline stiffness) was less than $1 \%$ in all tests except one, which produced a stiffness loss less than $1.3 \%$.

Comparison of the average tensile property values from prior loading groups with the average values produced by six baseline specimens from the same plaque provides additional insight into the effects of prior short-time loads. The average values are presented in Table 7.8 and indicate that there

Table 7.8. Average tensile properties obtained from groups of specimens subjected to prior short-time static loads

\begin{tabular}{lccc}
\hline $\begin{array}{c}\text { Prior loads (\% } \\
\text { UTS) }\end{array}$ & $\begin{array}{c}\text { Average subsequent } \\
\text { UTS (MPa) }\end{array}$ & $\begin{array}{c}\text { Average subsequent } \\
\text { stiffness (GPa) }\end{array}$ & $\begin{array}{c}\text { Average subsequent } \\
\text { failure strain (\%) }\end{array}$ \\
\hline $\mathbf{0 ( b a s e l i n e )}$ & 566 & 36.90 & 1.530 \\
$\mathbf{2 0 , 4 0 , 6 0 , 8 0}$ & 557 & 36.38 & 1.558 \\
$\mathbf{4 0 , 6 0 , 8 0}$ & 560 & 36.39 & 1.484 \\
$\mathbf{6 0 , 8 0}$ & 546 & 36.39 & 1.512 \\
$\mathbf{8 0}$ & 543 & 35.68 & 1.492 \\
\hline
\end{tabular}

was little effect on the average tensile property values relative to baseline results for the prior loading scenarios investigated $(\leq 4.1 \%)$. For the $\mathrm{Q}$ composite, prior short-time static loads appeared to consistently degrade the strength in that the average UTS values dropped considerably (6.15 to $14.8 \%$ ), with the lowest average UTS produced by the group sequentially loaded to $20,40,60$, and $80 \%$ of the UTS.

\footnotetext{
* Allowable design stress $\mathrm{S}_{0}$ is defined as two thirds of the minimum B-basis ultimate tensile strength (see Chap. 3): $\mathrm{S}_{0}=2 / 3 \mathrm{UTS}_{\min }=327 \mathrm{MPa}$
} 


\subsection{EFFECT OF STRAIN RATE ON TENSILE PROPERTIES}

The effect of strain rate on tensile behavior was investigated by testing 24 specimens fabricated from Plaque T18. The tests were conducted using the test setup presented in Figure 7.45. A slack adapter

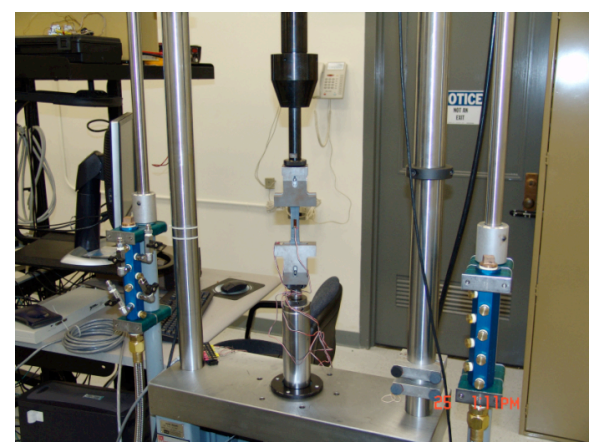

Figure 7.45 Test specimen positioned in slack adapter prior to conduct of strain-rate test.

was included in the load train to permit the actuator to come up to speed prior to loading the specimen. Four specimens each were tested at testing machine nominal stroke rates of $0.0005,0.005,0.05,0.5,5.0$, and $50.0 \mathrm{in} / \mathrm{sec}$. At rates up to $5.0 \mathrm{in} / \mathrm{sec}$, an averaging extensometer was utilized to obtain strain data; however, at the $50.0 \mathrm{in} / \mathrm{sec}$ rate, strain gages had to be utilized due to difficulties in keeping the extensometer attached to the specimen at this high stroke rate. The strain rate for each of the specimens was determined using the text files for the specific test and determining the slope of the strain versus time curve. Strain rates ranged from $4.21 \mathrm{E}-05$ to $5.11 \mathrm{~s}^{-1}$. Figure $7.46-7.48$ present ultimate tensile strength, tensile modulus of elasticity, and failure strain, respectively, as a function of strain rate. As shown by these figures, as the strain rate increased, the ultimate tensile strength increased slightly, the modulus of elasticity was relatively unaffected, and the failure strain decreased. Prior results obtained for the thermoset quasi-isotropic composite (Q material) for strain rates from $1.0 \mathrm{E}-06$ to $10 \mathrm{~s}^{-1}$, indicated small changes in strength and stiffness with strain rate except at the strain rate of $10 \mathrm{~s}^{-1}$, where the stiffness decreased by $26 \%$. Failure strains for the Q material decreased continuously with increasing rate, finally dropping by $14 \%$ at the strain rate of $10 \mathrm{~s}^{-1}$.

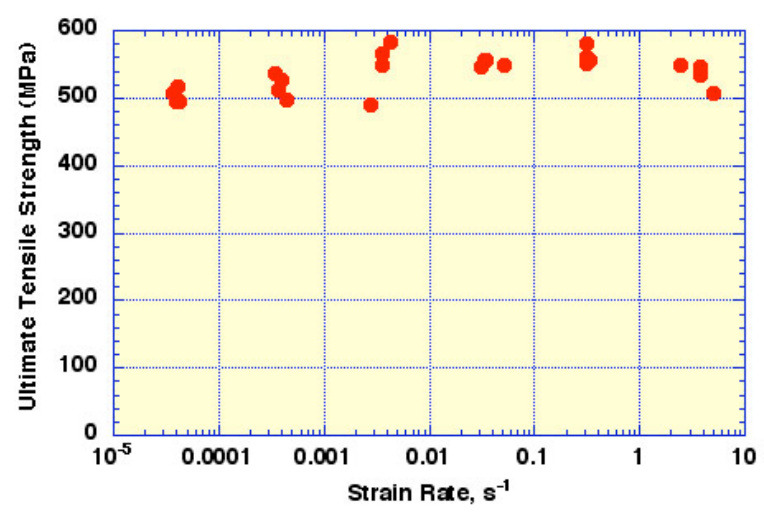

Figure 7.46 Effect of strain rate on ultimate tensile strength.

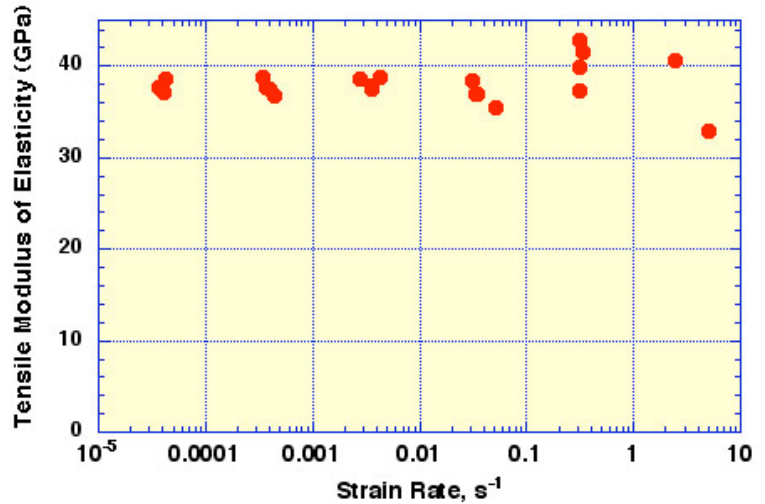

Figure 7.47 Effect of strain rate on tensile modulus of elasticity. 


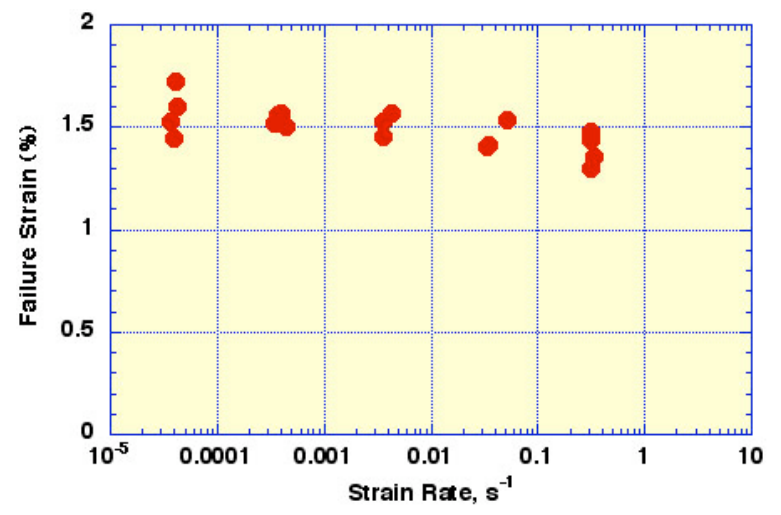

Figure 7.48 Effect of strain rate on tensile failure strain.

\subsection{EFFECTS OF THERMAL CYCLING}

Thermal cycling is a concern because of the significant mismatch between the coefficient of thermal expansion (CTE) of the matrix and that of the fiber. The mismatch could lead to microstructural damage under significant temperature changes. The effects of thermal cycling were investigated through conduct of 12 tensile, 12 compressive, and 12 shear tests. The tensile and shear specimens were fabricated from Plaque T52 and the compression specimens from Plaque T51. Prior to testing, three tensile, compression, or shear specimens each were subjected either to $1,5,10$, or 25 thermal cycles. A thermal cycle between -40 and $120^{\circ} \mathrm{C}$, schematically shown in Figure 7.49 , was chosen to reflect the automotive design temperature range. At both $-40^{\circ} \mathrm{C}$ and $120^{\circ} \mathrm{C}$ the temperature was held for 60 minutes. At conclusion of the designated number of thermal cycles, the specimens were tested. Table 7.9 provides a summary of results. For the temperature range investigated and number of thermal cycles investigated, there was a slight increase in tensile strength $(<9.2 \%)$, decrease in compressive strength $(<8.4 \%)$, and increase in shear strength $(<6.6 \%)$. The tensile, compressive, and shear moduli generally decreased as a

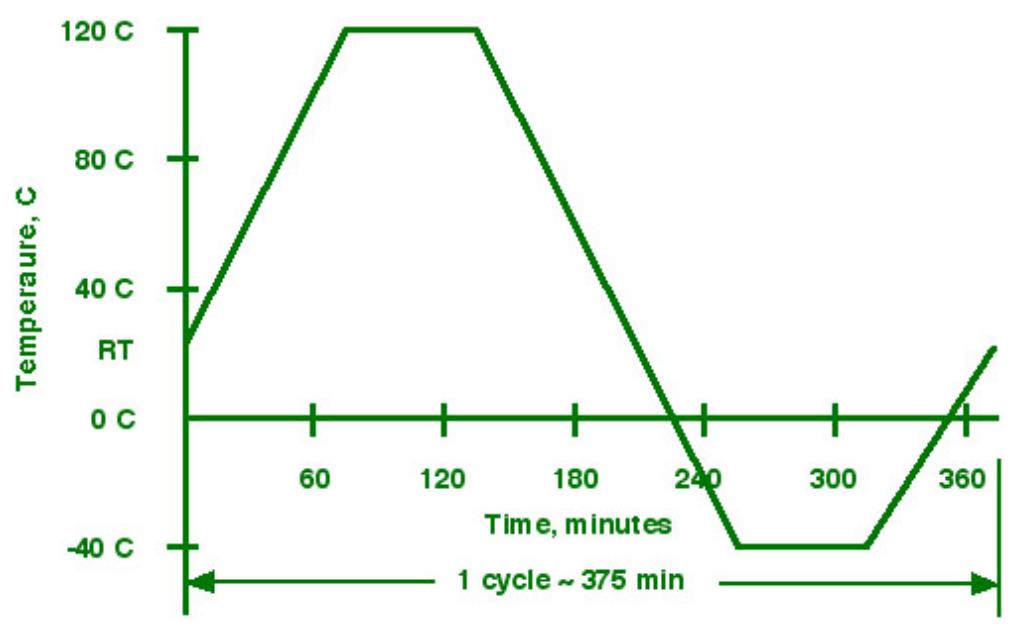

Figure 7.49 Temperature-time relationship for investigating thermal cycling effects. 
Table 7.9 Effect of thermal cycling on tensile, compressive, and shear properties.

\begin{tabular}{|l|c|c|c|c|c|}
\hline \multirow{2}{*}{ Property } & \multicolumn{5}{|c|}{ Number of Thermal Cycles } \\
\cline { 2 - 6 } & $\mathbf{0}$ & $\mathbf{1}$ & $\mathbf{5}$ & $\mathbf{1 0}$ & $\mathbf{2 5}$ \\
\hline Tensile & & & & & \\
\hline Strength (MPa) & 520 & 568 & 551 & 555 & 532 \\
\hline Modulus (GPa) & 36.3 & 35.9 & 36.1 & 35.3 & 35.1 \\
\hline Failure strain (\%) & 1.37 & 1.47 & 1.48 & 1.45 & 1.42 \\
\hline Compressive & & & & & \\
\hline Strength (MPa) & 322 & 295 & 323 & 316 & 312 \\
\hline Modulus (GPa) & 34.6 & 35.3 & 34.4 & 33.4 & 33.7 \\
\hline Failure strain (\%) & 1.05 & 0.83 & 1.04 & 1.03 & 1.02 \\
\hline Shear & & & & & \\
\hline Strength (MPa) & 197 & 197 & 203 & 209 & 210 \\
\hline Modulus (GPa) & 13.27 & 13.11 & 13.11 & 12.8 & 12.71 \\
\hline Failure strain (\%) & 1.66 & 1.76 & 1.68 & 1.79 & 1.83 \\
\hline
\end{tabular}

result of thermal cycles with the largest decrease occurring for the shear modulus $(<4.2 \%)$. Tensile and shear failure strains tended to increase as a result of thermal cycles, whereas, except for results for one thermal cycle, the compressive failure strains were unaffected by number of thermal cycles. For the quasi-isotropic thermoset composite (Q material), tensile and compressive properties were less affected by thermal cycling than were the shear properties. In tension, a stiffness loss of $0.3 \%$ and a strength loss of $6.6 \%$ were observed. In compression, the stiffness loss was $2.9 \%$, but strength improved by $19.7 \%$. However, loss of shear stiffness was considerable (25.1\%), while shear strength dropped only by $3.4 \%$.

\subsection{FLUID EFFECTS}

\subsubsection{Environmental Screening}

From a durability standpoint, it is assumed that structures will be subjected to common automotive fluids and operating atmospheres, therefore design limits must take the resulting property degradation into account. Environmental screening tests were performed using typical automotive fluids in order to determine which (if any) have significant degrading effects on the PPS quasi-isotropic composite. Nine automotive fluids were used in the screening. Details of the fluids are provided in Table 7.10. Parameters investigated in the screening study included weight change, short-beam shear strength, and effects of 1000-h exposure on tensile properties.

Flexural specimens 12.7-mm-wide by 76.2-mm-long were fabricated from Plaques T9, T46, and T49. Twenty flexural specimens were measured, weighed, and submerged in each of the nine automotive fluids investigated (180 specimens). Periodically the specimens were removed from each of the fluids, measured and weighed. A summary of the effect of exposure time to typical automotive fluids on weight change is presented in Figure 7.50. Results presented in Figure 7.50 indicate that windshield washer fluid, gasoline, and brake fluid produced the largest increase in specimen weight after 2000 hours exposure. No significant change in specimen dimensions occurred as a result of fluid exposure $(<1.8 \%)$. 
Table 7.10. Details of automotive fluids used in environmental screening

\begin{tabular}{ll}
\hline \multicolumn{1}{c}{ Common name } & \multicolumn{1}{c}{ Details } \\
\hline Distilled water & Laboratory supply \\
Saltwater & $5 \% \mathrm{NaCl} /$ distilled water \\
Windshield washer fluid & $70 \%$ methanol, 30\% distilled water \\
Antifreeze (coolant) & $90-95 \%$ ethylene glycol, 0-5\% \\
& diethylene glycol \\
Motor oil & Texaco 10W40 \\
Gasoline & Regular, unleaded \\
Brake fluid & Glycols, glycol ethers, glycol ether borate esters \\
& (Castrol GT LMA) \\
Transmission fluid & Exxon Dextron II \\
Battery acid & 34\% sulfuric acid, 66\% water \\
\hline
\end{tabular}
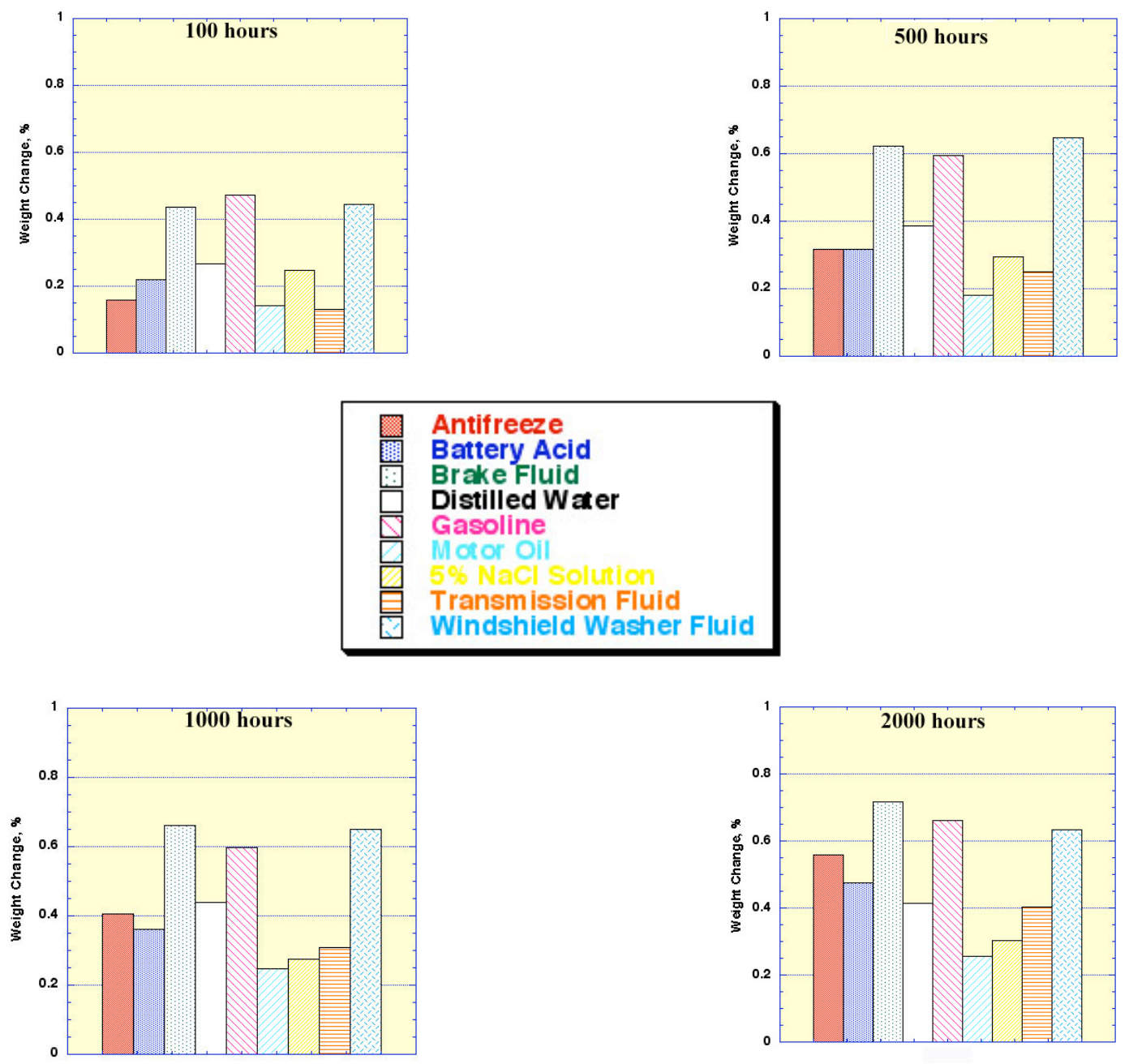

Figure 7.50 Summary of weight change results. 
After exposure periods of 100, 200,500, 1000, and 2000 hours, four specimens were tested to determine the effect of fluid exposure on the short-beam shear strength. Short-beam shear specimens were chosen for this task because they have the highest edge to face area ratio and are therefore most susceptible to environmental damage. All short-beam shear strength specimens were tested using the basic provisions of ASTM Standard D $2344^{3}$, Figure 7.51. A summary of the effect of exposure time to typical automotive fluids on short-beam shear strength is presented in Figure 7.52. Since specimens were

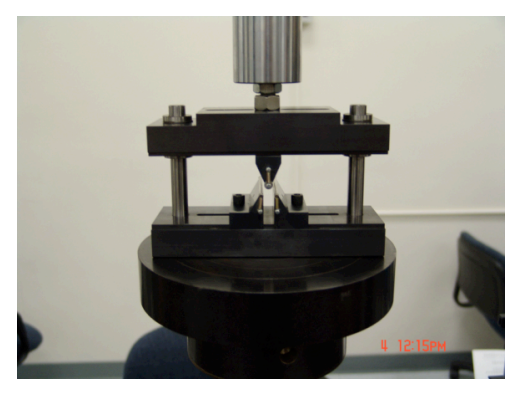

Figure 7.51 Short-beam shear test fixture.
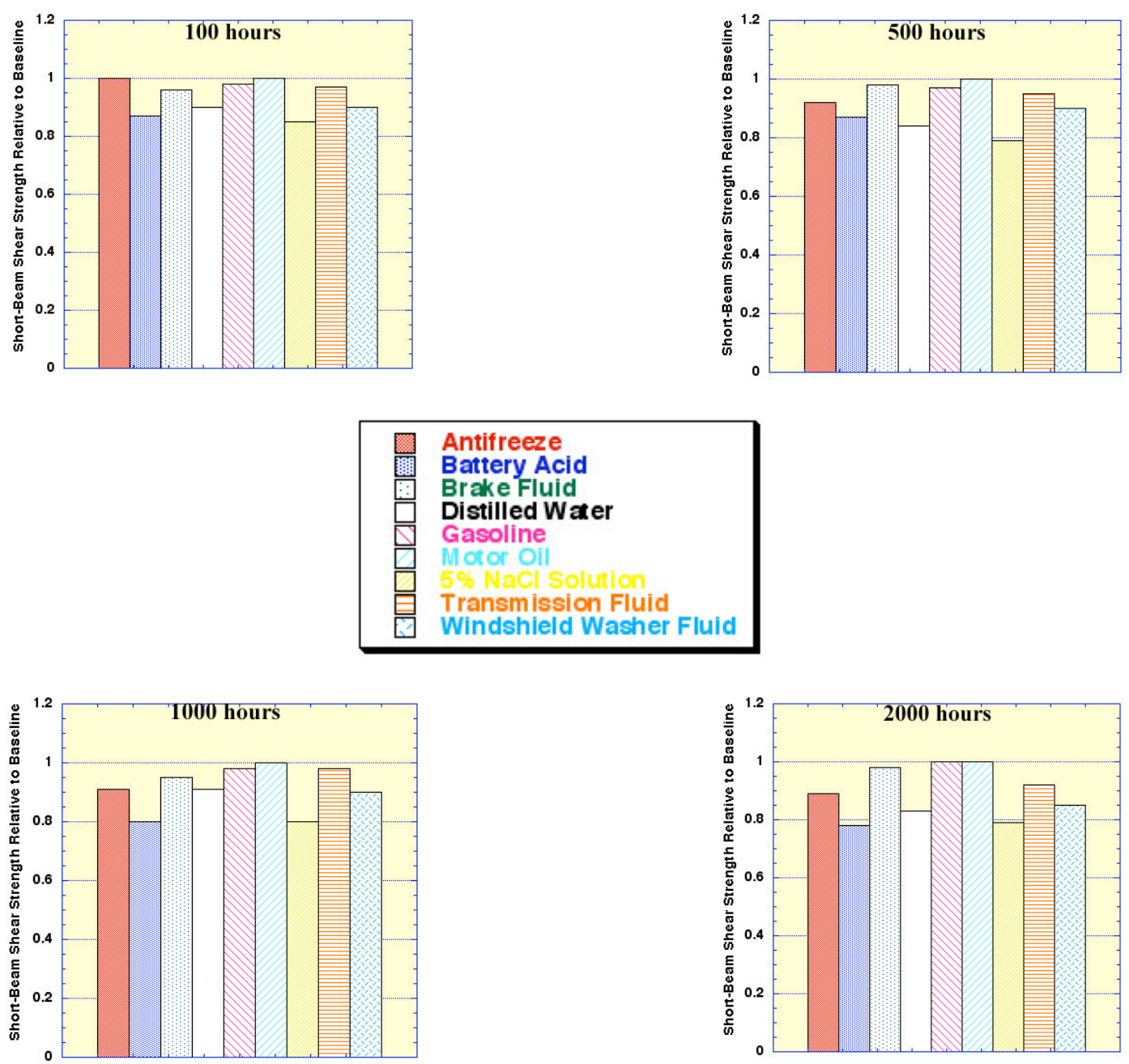

Figure 7.52 Summary of short-beam shear strength results. 
fabricated from more than one plaque, the results have been normalized to the as-received baseline value for each plaque. Results presented in Figure 7.52 indicate that after 2000 hours exposure, battery acid, a $5 \% \mathrm{NaCl}$ solution, and distilled water produced the largest decrease in short-beam shear strength relative to the baseline unexposed value.

Standard tensile specimens fabricated from Plaque T47 were employed to provide data on tensile property degradation due to exposure in typical automotive fluids. Five tensile specimens were exposed in each fluid for $1000 \mathrm{~h}$ prior to testing. In addition, seven tensile specimens were tested in the asreceived condition to establish the baseline. The effects of automotive fluid pre-conditioning on tensile strength, tensile modulus of elasticity, and tensile failure strain are summarized in Figure 7.53. Relative to as-received unexposed baseline results, distilled water (8.03\% reduction) and $5 \% \mathrm{NaCl}$ solution $(6.57 \%$
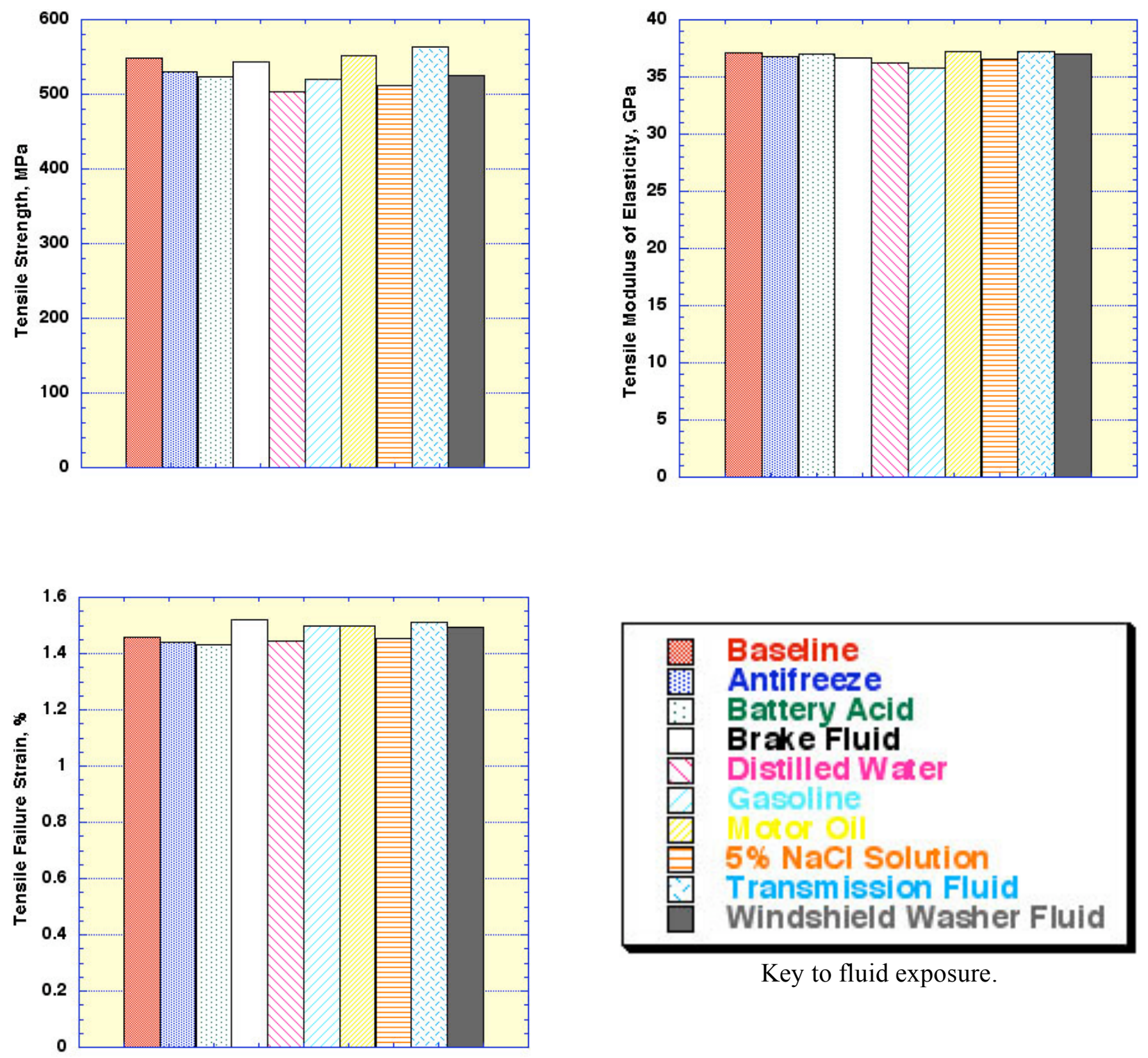

Key to fluid exposure.

Figure 7.53 Effect of 1000 hour exposure time to typical automotive fluids on tensile properties. 
reduction) had the largest affect on tensile strength. The modulus of elasticity was affected most by gasoline (3.75\% reduction), with other fluids having less than a $1.5 \%$ affect. Brake fluid had the largest effect on tensile failure strains $(4.33 \%$ increase) relative to the baseline result.

Based on results presented above and in order to be consistent with prior materials examined as well as to provide a direct comparison to these materials, the fluid exposures most extensively examined were reduced primarily to distilled water and windshield washer fluid. The exposure times of $1000 \mathrm{~h}$ for distilled water and of $100 \mathrm{~h}$ for the windshield washer fluid were judged to be representative of realistic service conditions.

\subsubsection{WINDSHIELD WASHER FLUID AND DISTILLED WATER EFFECTS}

To better define the effects of exposures up to 1000 hours in $23^{\circ} \mathrm{C}$ windshield washer fluid and distilled water (fluids most extensively examined) on tensile, compressive, and shear properties, additional tests were conducted. Tensile, compressive, and shear specimens were fabricated from Plaques T37, T4, and T48, respectively. A minimum of three specimens of each type were tested after exposure periods of 100, 200, 500, and 1000 hours.

\subsubsection{TENSILE PROPERTIES}

The effects of preconditioning periods up to 1000 hours in windshield washer fluid on ultimate tensile strength, tensile modulus of elasticity, and tensile failure strain are summarized in Figure 7.54 7.56 , respectively. Results indicate that the primary effect on average ultimate tensile strength of

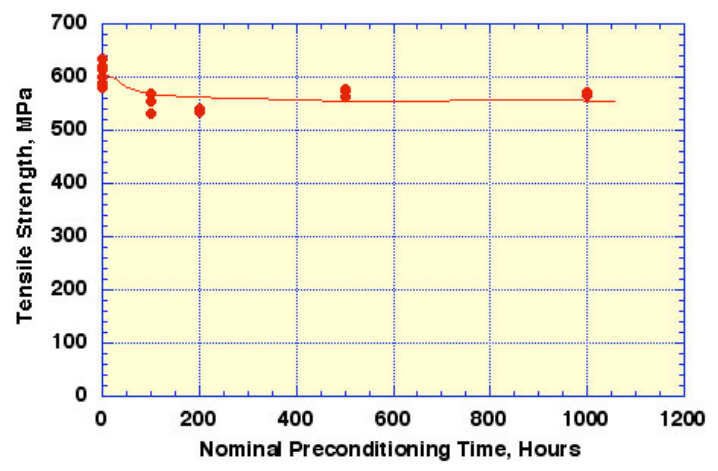

Figure 7.54 Effect of exposure time in windshield washer fluid on UTS.

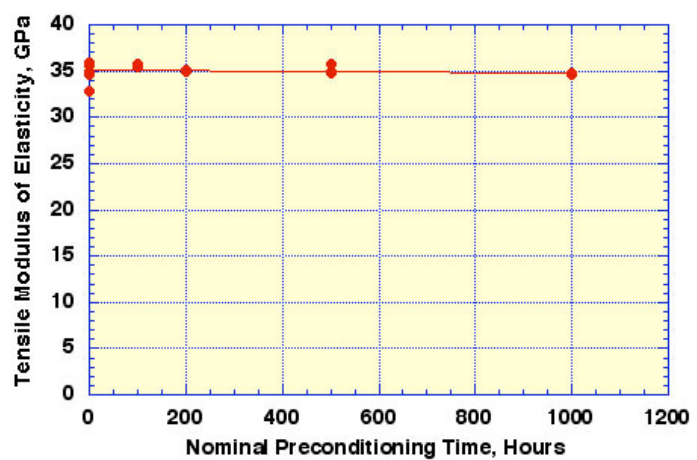

Figure 7.55 Effect of exposure time in windshield washer fluid on tensile stiffness.

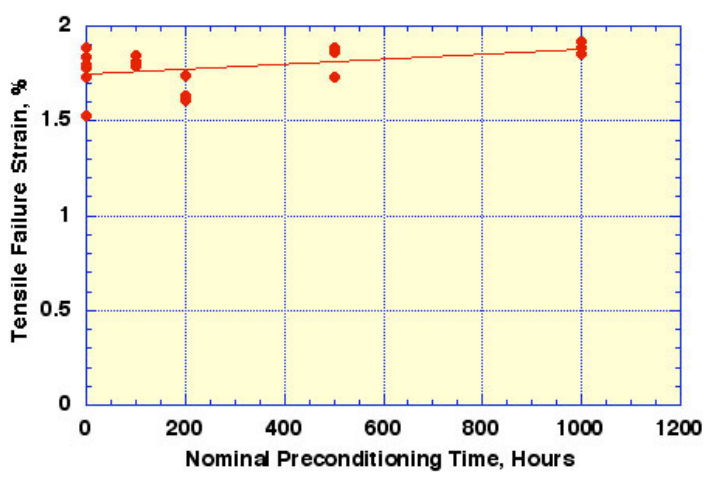

Figure 7.56 Effect of exposure time in windshield washer fluid on tensile failure strain. 
preconditioning in windshield washer fluid occurred during the first 100 hours and resulted in a decrease of about $8.9 \%$ relative to the unexposed baseline average. Longer exposure periods resulted in decreases in average ultimate tensile strength relative to the baseline ranging from 5.6 to $11.1 \%$. Average tensile modulus of elasticity was relatively unaffected by preconditioning in windshield washer fluid for exposure periods investigated with changes ranging from -0.6 to $1.72 \%$ relative to the unexposed baseline average. The average tensile failure strain exhibited a trend to increase slightly with increasing preconditioning period with an increase of $7.39 \%$ after 1000 hours preconditioning relative to the average baseline unexposed value.

The effects of exposure periods up to 1000 hours in distilled water on ultimate tensile strength, tensile modulus of elasticity, and tensile failure strain are summarized in Figure 7.57 - 7.59, respectively. Results obtained for the effect of preconditioning in distilled water on average ultimate tensile strength and modulus of elasticity are similar to those obtained for the effect of preconditioning in windshield washer fluid (i.e., average ultimate tensile strength reduced relative to the baseline result from 3.8 to $9.4 \%$

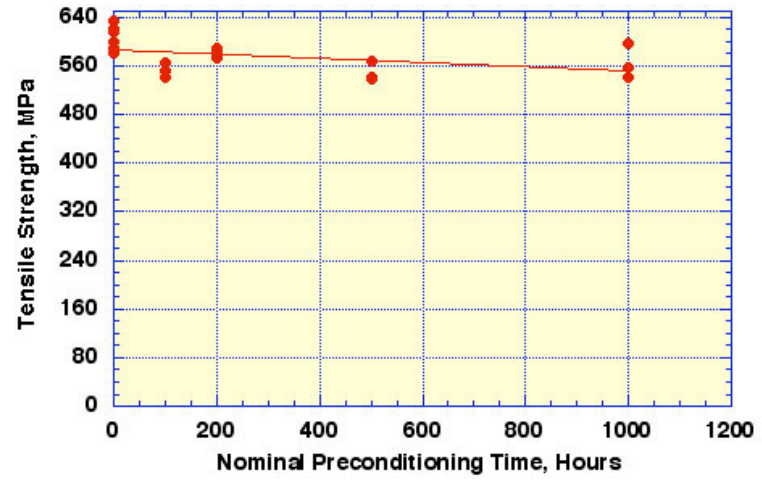

Figure 7.57 Effect of exposure time in distilled water on ultimate tensile strength.

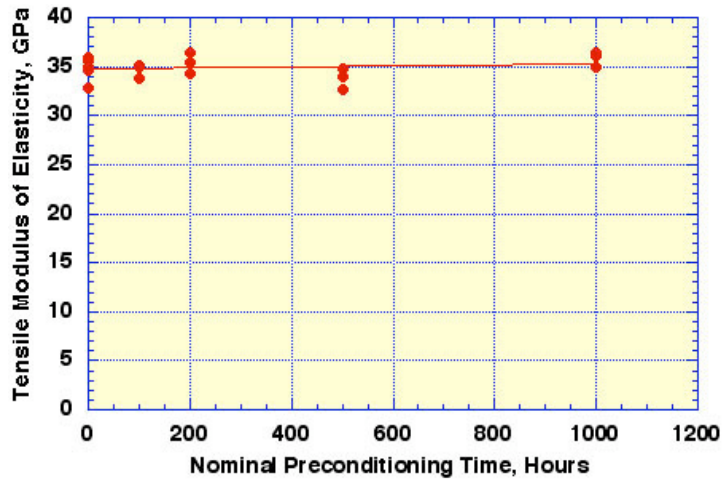

Figure 7.58 Effect of exposure time in distilled water on tensile modulus of elasticity.

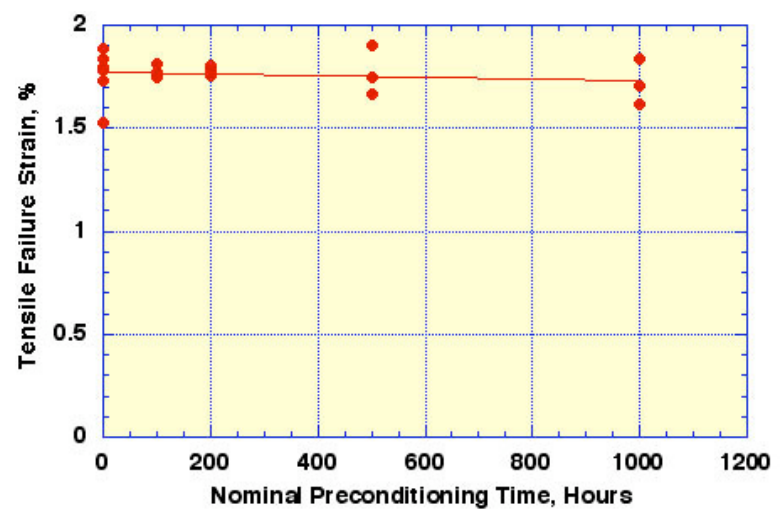

Figure 7.59 Effect of exposure time in distilled water on tensile failure strain.

and average modulus of elasticity changes ranging from a reduction of 3.3\% after 500 hours exposure to an increase of $1.3 \%$ for an exposure period of 200 hours). The average tensile failure strain also was relatively unaffected by the preconditioning period in distilled water with results ranging from an increase 
of $1.1 \%$ after 100 hours to a reduction of $2.3 \%$ after 1000 hours relative to the average baseline unexposed value.

\subsubsection{COMPRESSIVE STRENGTH}

The effects of preconditioning periods up to 1000 hours in windshield washer fluid and distilled water on ultimate compressive strength are summarized in Figures 7.60 and 7.61, respectively. Although results are somewhat limited, they tend to indicate that preconditioning in windshield washer fluid for

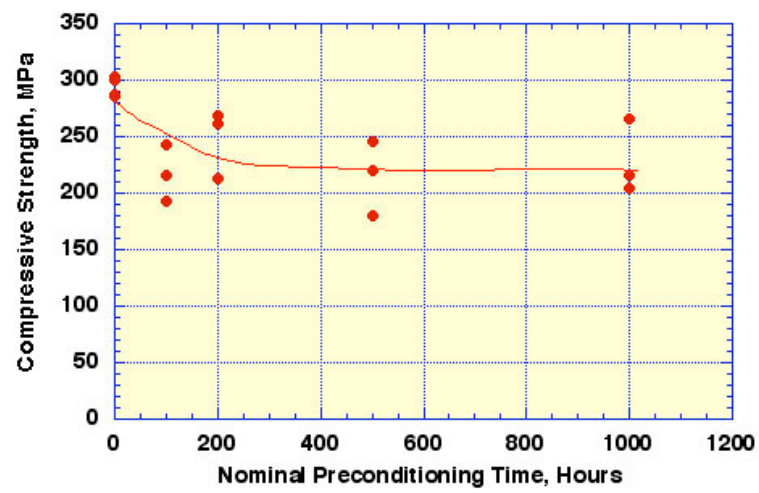

Figure 7.60 Effect of exposure time in windshield washer fluid on compressive strength.

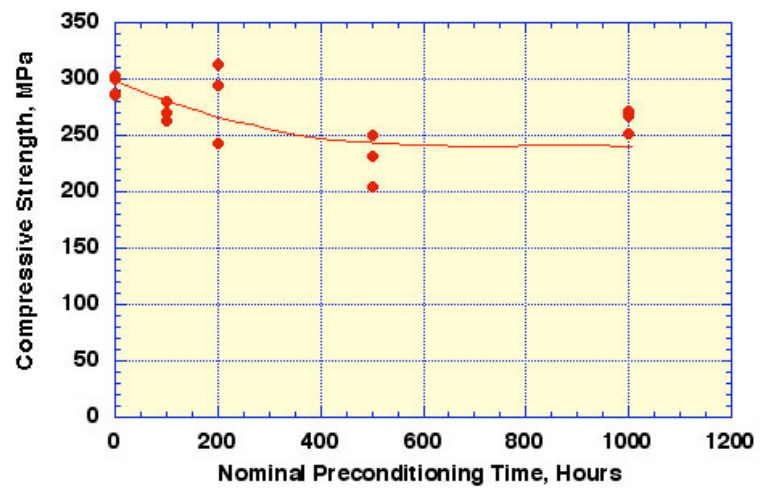

Figure 7.61 Effect of exposure time in distilled water on compressive strength.

periods up to 1000 hours has a greater effect on the average ultimate compressive strength than preconditioning for similar periods in distilled water. Relative to baseline unexposed test results, the reductions in average compressive strength for specimens preconditioned in windshield washer fluid ranged from $16.3 \%$ to $26.8 \%$ while the reductions ranged from $4.1 \%$ to $22.4 \%$ for specimens preconditioned in distilled water, depending on the exposure period. Relative to baseline unexposed results, the percentage reductions in average compressive strength resulting from preconditioning in windshield washer solution and distilled water were greater than the corresponding reductions in average ultimate tensile strength resulting from preconditioning in these fluids.

\subsubsection{SHEAR STRENGTH}

The effects of preconditioning periods up to 1000 hours in windshield washer fluid and distilled water on ultimate shear strength are summarized in Figures 7.62 and 7.63, respectively. These results indicate that preconditioning in windshield washer fluid and distilled water for periods up to 1000 hours resulted in reductions in average ultimate shear strength ranging from $14.1 \%$ to $31.3 \%$ and $28.1 \%$ to $34.9 \%$, respectively, depending on the exposure period. Relative to average unexposed baseline results, the effect of preconditioning in either windshield washer fluid or distilled water was greater on the ultimate shear strength than on either the ultimate tensile or compressive strengths. 


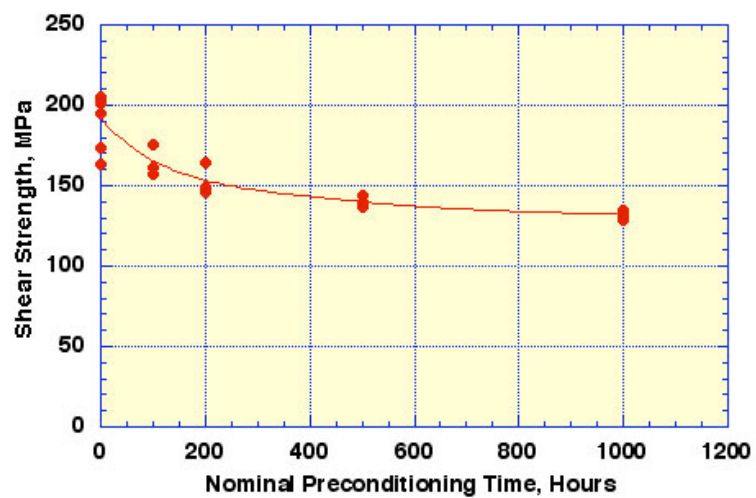

Figure 7.62 Effect of exposure time in windshield washer fluid on shear strength.

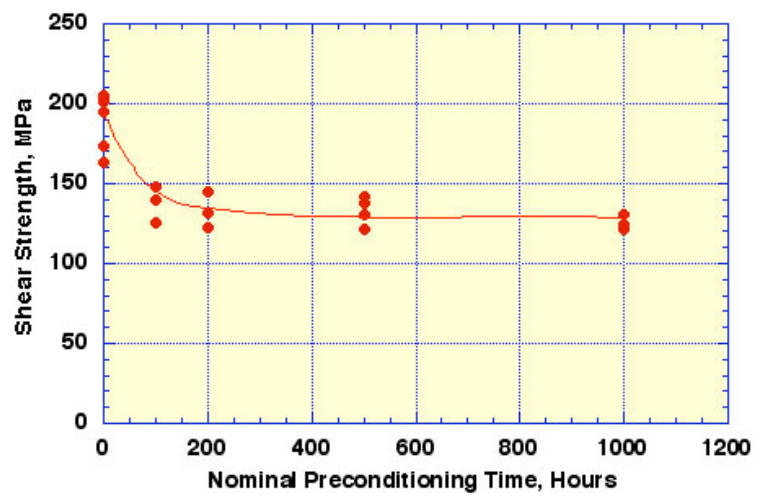

Figure 7.63 Effect of exposure time in distilled water on shear strength.

\subsubsection{FLUID EFFECT MULTIPLICTION FACTORS}

A summary of the effects on strength and stiffness of 100 hour preconditioning in windshield washer fluid and 1000 hour preconditioning in distilled water are presented in Tables 7.11 and 7.12, respectively. Note that in the case of windshield washer fluid and distilled water, compressive and shear stiffness values were not measured. Application of strain gages, required for compression and shear stiffness determinations, would have resulted in excessive loss of the absorbed fluid due to evaporation during gage installation. Also, due to the limited area available on these specimens due to the presence of

Table 7.11. Effects on stiffness and strength of 100-h exposure in windshield washer fluid

\begin{tabular}{lcccc}
\hline & $\begin{array}{c}\text { Change in } \\
\text { stiffness (\%) }\end{array}$ & $\begin{array}{c}\text { Stiffness } \\
\text { multiplication } \\
\text { factor }\end{array}$ & $\begin{array}{c}\text { Change in } \\
\text { strength (\%) }\end{array}$ & $\begin{array}{c}\text { Strength } \\
\text { multiplication } \\
\text { factor }\end{array}$ \\
\hline Tension & 1.72 & 1.02 & -8.91 & 0.91 \\
Compression & - & - & -26.4 & 0.74 \\
Shear & - & - & -14.1 & 0.86 \\
\hline
\end{tabular}

Table 7.12. Effects on stiffness and strength of 1000-h exposure in $23^{\circ} \mathrm{C}$ distilled water

\begin{tabular}{lcccc}
\hline & $\begin{array}{c}\text { Change in } \\
\text { stiffness (\%) }\end{array}$ & $\begin{array}{c}\text { Stiffness } \\
\text { multiplication } \\
\text { factor }\end{array}$ & $\begin{array}{c}\text { Change in } \\
\text { strength (\%) }\end{array}$ & $\begin{array}{c}\text { Strength } \\
\text { multiplication } \\
\text { factor }\end{array}$ \\
\hline Tension & 2.40 & 1.02 & -6.77 & 0.93 \\
Compression & - & - & -10.51 & 0.89 \\
Shear & - & - & -34.9 & 0.65 \\
\hline
\end{tabular}

tabs, it would have been difficult to apply and maintain a fluid-resistant coating prior to exposure that would survive for up to 1000 hours. The multiplication factors in Tables 7.11 and 7.12 are the fluid factors used in Chapters 2 and 3 of Part 1 of this report.

A comparison of standard exposure fluid multiplication factors for the quasi-isotropic PPS thermoplastic ( $\mathrm{T}$ material) and thermoset quasi-isotropic composites ( $\mathrm{Q}$ material) is presented in 
Table 7.13. As noted in the table, tension stiffness multiplication factors are similar for the Q and $\mathrm{T}$ materials for preconditioning in both fluids. Tension, compression, and shear strength multiplication factors are consistently lower for the $\mathrm{T}$ material relative to the $\mathrm{Q}$ material. The reduction in strength multiplication factors is more significant for strengths that tend to be more matrix-dominated (i.e., compression and shear).

Table 7.13. Fluid multiplication factors: comparison of $T$ and $Q$ materials.

\begin{tabular}{|c|c|c|c|c|}
\hline & \multicolumn{2}{|c|}{ Stiffness multiplication factor } & \multicolumn{2}{|c|}{ Strength multiplication factor } \\
\hline & \multicolumn{4}{|c|}{100 hours windshield washer fluid } \\
\hline & T material & Q material & T material & Q material \\
\hline Tension & 1.02 & 1.01 & 0.91 & 1.01 \\
\hline Compression & - & - & 0.74 & 0.98 \\
\hline \multirow[t]{3}{*}{ Shear } & - & - & 0.86 & 1.01 \\
\hline & \multicolumn{4}{|c|}{1000 hours distilled water } \\
\hline & T material & Q material & T material & Q material \\
\hline Tension & 1.02 & 1.01 & 0.93 & 1.00 \\
\hline Compression & - & 0.96 & 0.89 & 0.94 \\
\hline Shear & - & 0.99 & 0.65 & 0.98 \\
\hline
\end{tabular}

\subsection{REFERENCES}

1. J. M. Corum, R L. Battiste, W. Ren, and M. B. Ruggles, Recommended Minimum Test Requirements and Test Methods for Assessing Durability of Random-Glass-Fiber Composites, ORNL6953, Oak Ridge National Laboratory, Oak Ridge, Tenn., 1999.

2. ASTM Standard D3410-87, Standard Test Method for Compressive Properties of Unidirectional or Crossply Fiber-Resin Composites, American Society for Testing and Materials.

3. ASTM Standard D 2344, Test Methods for Apparent Interlaminar Shear Strength of Parallel Fiber Composites by Short Beam Method, American Society for Testing and Materials. 


\section{UNIAXIAL AND BIAXIAL FLEXURAL PROPERTIES}

\subsection{INTRODUCTION}

Since it is nearly impossible to avoid bending in composite sections, there is a need to determine the flexural properties experimentally. This chapter focuses on (1) uniaxial flexural tests of simply supported beams and (2) biaxial flexural tests of simply supported circular plates. These tests produced bending strength data for various temperatures and fluid exposure conditions. They also produced approximate deflection data. A third group of uniaxial flexural tests (three-point bend and cantilever beams) was performed to investigate orientation effects (longitudinal versus transverse) and predictability of bending deformations in the thermoplastic composite material.

\subsection{UNIAXIAL FLEXURAL STRENGTH}

The uniaxial flexural strength tests were performed according to the three-point bend test method specified in ASTM Standard D 790 ${ }^{1}$. Figure 8.1 a presents the flexural strength test setup and Figure 8.1b a flexural specimen at conclusion of testing.
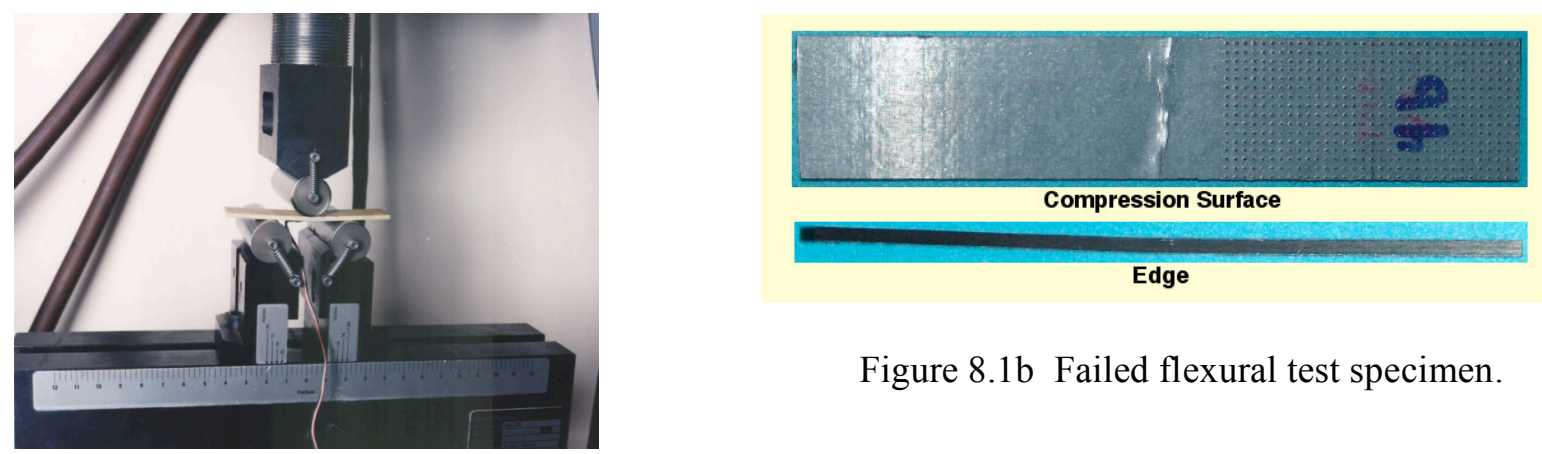

Figure 8.1b Failed flexural test specimen.

Figure 8.1a Flexural strength test setup.

Thirty-one flexural specimens nominally 12.7 -mm-wide by 76.2 -mm-long by 2.9 -mm-thick were fabricated from Plaque T46: seven specimens to establish baseline strength results and twenty-four specimens to investigate the effect of preconditioning temperature.

The average ultimate tensile strength for this plaque was $541 \mathrm{MPa}$ and the average tensile stiffness was $36.85 \mathrm{GPa}$. Uniaxial flexure results are presented in terms of the modulus of rupture (MOR), which is the maximum bending stress at rupture calculated using simple elastic beam theory for an isotropic, homogeneous material. Because the MOR calculations ignore the composite inhomogeneity, results are somewhat qualitative, but nonetheless useful for establishing environmental and temperature multiplication factors as well as providing values for design guidance.

\subsubsection{TEMPERATURE EFFECTS}

Prior to testing, the flexure specimens were subjected to a preconditioning temperature versus time exposure as noted earlier in Figure 7.10. Preconditioning temperatures of $-40^{\circ}, 70^{\circ}, 90$ and $120^{\circ} \mathrm{C}$ were employed to quantify the effects of short-term thermal exposure. Six specimens were tested for each temperature with three of the specimens tested at temperature and three tested after returning and stabilizing at room temperature. Figure 8.2 presents the effect of preconditioning temperature and test temperature on flexural strength. These results indicate that for specimens tested at temperature the 
flexural strength decreases with increasing preconditioning temperature. For specimens permitted to return to room temperature prior to testing, there was a slight trend for the flexural strength to increase as the preconditioning temperature increased.

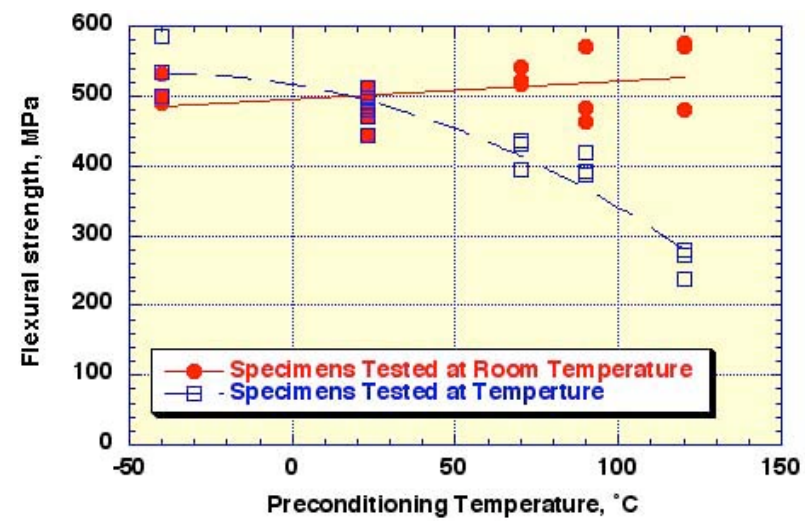

Figure 8.2 Effect of preconditioning and test temperatures on flexural strength.

Table 8.1 presents temperature multiplication factors. The temperature multiplication factors are defined as the ratio of at-temperature MOR to the room-temperature MOR value. Also shown in the table are values of the ratio of the MOR to UTS for the different preconditioning temperatures investigated. The UTS values at temperature were determined by taking the room temperature UTS for Plaque T46 (541 MPa) and multiplying it by the appropriate temperature multiplication factor determined from the information provided in Figure 7.37 for tensile strength. Since it appeared that the flexural specimens failed first at the upper compressive surface (see Figure 8.1b) due to the relatively low compressive strength (relative to tensile strength), the ratio of MOR to ultimate compressive strength (UCS) was also determined and is presented in Table 8.1. This ratio is used in Section 3.4.

Table 8.1 Average uniaxial flexural properties at various temperatures.

\begin{tabular}{|c|c|c|c|c|c|c|}
\hline $\begin{array}{c}\text { Tempera } \\
\text { ture, } \\
{ }^{\circ} \mathrm{C}\end{array}$ & $\begin{array}{c}\text { Modulus } \\
\text { of } \\
\text { Rupture, } \\
\mathrm{MPa}\end{array}$ & $\begin{array}{c}\text { MOR } \\
\text { Multiplication } \\
\text { Factor }\end{array}$ & $\begin{array}{c}\text { UTS at } \\
\text { Temperature, } \\
\mathrm{MPa}\end{array}$ & $\begin{array}{c}\text { Ratio of } \\
\text { MOR to UTS } \\
\text { at temperature }\end{array}$ & $\begin{array}{c}\text { UCS at } \\
\text { Temperature, } \\
\mathrm{MPa}\end{array}$ & $\begin{array}{c}\text { Ratio of } \\
\text { MOR to UCS } \\
\text { at temperature }\end{array}$ \\
\hline-40 & 540 & 1.12 & 558 & 0.97 & 322 & 1.68 \\
\hline 23 & 483 & 1.00 & 541 & 0.89 & 295 & 1.64 \\
\hline 70 & 421 & 0.87 & 528 & 0.80 & 280 & 1.50 \\
\hline 90 & 399 & 0.83 & 523 & 0.76 & 230 & 1.73 \\
\hline 120 & 262 & 0.54 & 514 & 0.51 & 162 & 1.61 \\
\hline
\end{tabular}

At room temperature the ratio of modulus of rupture to ultimate compressive strength is 1.64 . A similar value was obtained at the other temperatures investigated. For the thermoset quasi-isotropic composite (Q material) at $23^{\circ}$ and $120^{\circ} \mathrm{C}$, the ratios of MOR to UTS were 1.80 and 1.71. Modulus of rupture multiplication factors for the thermoplastic $\mathrm{T}$ and thermoset $\mathrm{Q}$ materials as a function of preconditioning temperature are similar for the temperature range investigated. As noted in Chapter 7 (Figure 7.12) and Figure 8.2, the flexural strength of the T composite is affected more significantly by temperature than the ultimate tensile strength because in all likelihood the flexural specimens failed in compression. Also, the ultimate tensile strength of the thermoset $\mathrm{Q}$ composite at preconditioning temperatures above $70^{\circ} \mathrm{C}$ is affected by preconditioning temperature more than the thermoplastic T material composite. 


\subsubsection{FLUID EFFECTS}

The effect of fluids on flexural properties was assessed using the standard exposures of windshield washer fluid $(100 \mathrm{~h}$ preconditioning) and room-temperature distilled water $(1000 \mathrm{~h}$ preconditioning). For each standard exposure, six beam specimens were tested. Flexural specimens were fabricated from Plaque T46. The resulting environmental strength multiplication factors are presented in Table 8.2 together with the corresponding strength multiplication factors for tension, compression, and shear.

Table 8.2. Effects of environment on flexural properties

\begin{tabular}{lccccc}
\hline Environment & MOR & \multicolumn{3}{c}{ Strength multiplication factors } \\
& (MPa) & MOR & Tensile & Compressive & Shear \\
\hline In-air room temperature & 483 & 1.00 & 1.00 & 1.00 & 1.00 \\
$\mathbf{1 0 0 0}$ h in distilled water & 390 & 0.81 & 0.93 & 0.89 & 0.65 \\
$\mathbf{1 0 0}$ h in windshield washer fluid & 408 & 0.84 & 0.91 & 0.74 & 0.86 \\
\hline
\end{tabular}

Results in Table 8.2 indicate that a multiplication factor of 0.81 bounds the effects of $1000 \mathrm{~h}$ in distilled water or $100 \mathrm{~h}$ in windshield washer fluid on uniaxial flexural strength. For the thermoset $\mathrm{Q}$ composite the bounding environmental factor was 0.93 .

\subsection{BIAXIAL FLEXURAL STRENGTH}

The test specimen together with the support and loading arrangement used for biaxial flexural tests is shown in Figure 8.3. The load-ring diameter was $38.1 \mathrm{~mm}$, while the support- ring diameter was $88.9 \mathrm{~mm}$.

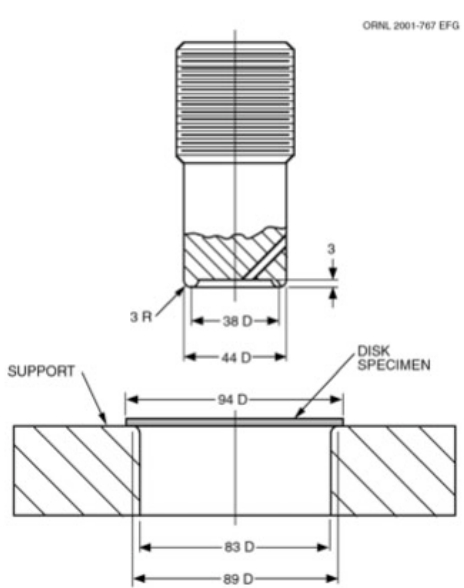

a. Schematic of test fixture.

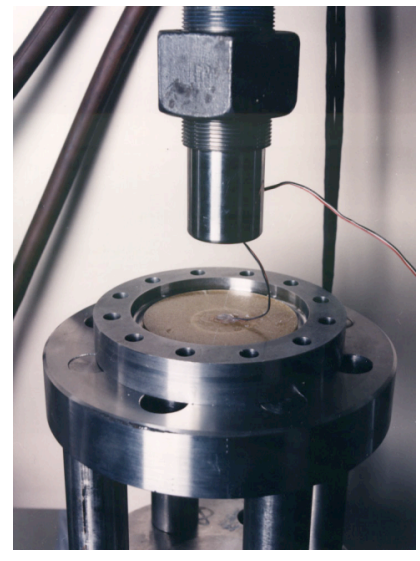

b. Test setup.

Figure 8.3 Biaxial flexure test.

In the case of in-plane isotropy, small-deflection, elastic plate bending theory predicts that the maximum stresses on the bottom surface of the specimen are inside the load ring and are everywhere equibiaxial tension. However, long before failure, deflections become large, so the nonlinear response of the specimen cannot be ignored. At the large deflections, the maximum stresses shift to a location opposite the load ring. A nonlinear, large-deflection finite element analysis is required to predict stresses at failure. 
Biaxial flexure results are presented in terms of the failure load and used in this way to establish environmental and temperature multiplication factors.

Twenty-six 94-mm-diameter test specimens were fabricated from Plaque T43 (UTS = $545 \mathrm{MPa}$ ). Five "as-received" specimens were tested at room temperature, and either three or four specimens each were tested at preconditioning temperatures of $-40^{\circ}, 70^{\circ}, 90^{\circ}$, and $120^{\circ} \mathrm{C}$ after one-hour exposure. To explore fluid effects, four specimens presoaked for $100 \mathrm{~h}$ in windshield washer fluid and four specimens presoaked for $1000 \mathrm{~h}$ in room-temperature distilled water were also tested. All tests were conducted in the laboratory air environment. Results are summarized in Table 8.3.

Multiplication factors presented in Table 8.3 are the ratios of the average failure load, for each set of tests, to the average for the as-received room-temperature (baseline) tests.

Table 8.3. Biaxial flexure strength results

\begin{tabular}{|l|c|c|c|c|}
\hline \multicolumn{1}{|c|}{ Preconditioning Environment } & $\begin{array}{c}\text { Maximum } \\
\text { load, } \mathrm{kN}\end{array}$ & $\begin{array}{c}\text { Coefficient of } \\
\text { variation }\end{array}$ & $\begin{array}{c}\text { Displacement at } \\
\text { Pmax, mm }\end{array}$ & $\begin{array}{c}\text { Multiplication } \\
\text { Factor }\end{array}$ \\
\hline Room temperature & 12.878 & 8.33 & 5.253 & 1.00 \\
\hline $\begin{array}{l}100 \text {-h presoak windshield washer } \\
\text { fluid }\end{array}$ & 10.467 & 4.57 & 4.648 & 0.81 \\
\hline 1000 -h presoak distilled water & 9.697 & 3.68 & 5.011 & 0.75 \\
\hline$-40^{\circ} \mathrm{C}(1 \mathrm{~h})$ & 14.497 & 2.26 & 5.672 & 1.13 \\
\hline $70^{\circ} \mathrm{C}(1 \mathrm{~h})$ & 10.849 & 1.59 & 5.296 & 0.84 \\
\hline $90^{\circ} \mathrm{C}(1 \mathrm{~h})$ & 10.422 & 6.30 & 4.920 & 0.81 \\
\hline $120^{\circ} \mathrm{C}(1 \mathrm{~h})$ & 6.770 & 3.09 & 4.590 & 0.53 \\
\hline
\end{tabular}

The multiplication factors in Table 8.3 follow the same trend as those obtained for the thermoplastic Q composite, with the lowest multiplication factor corresponding to $120^{\circ} \mathrm{C}(0.44$ for the Q composite). The biaxial flexural strength deteriorated faster with increasing temperature in the case of the Q composite than for the thermoplastic T composite, but the multiplication factors for preconditioning in windshield washer fluid and distilled water were lower for the thermoplastic $\mathrm{T}$ material than the thermoset Q material (0.93 and 0.98, respectively). A similar trend was observed relative to the uniaxial flexural strength.

\subsection{COMPARISON OF STRENGTH MULTIPLICATION FACTORS}

Strength multiplication factors obtained in the biaxial flexural tests are further compared with those obtained under various other stress states in Table 8.4. At $120^{\circ} \mathrm{C}$ the biaxial flexural strength multiplication factor (0.53) and the uniaxial flexural strength multiplication factor (0.54) are similar. In the case of the 1000-h distilled water preconditioning, the biaxial flexural strength was reduced by $25 \%$ while uniaxial flexural strength was reduced by $19 \%$. The 100-h exposure in windshield washer fluid produced similar reductions in both biaxial and uniaxial flexural strengths. For the $\mathrm{Q}$ composite, environmental strength multiplication factors ranged from 0.93 (produced in biaxial flexure on specimens presoaked for $1000 \mathrm{~h}$ in distilled water, and in uniaxial flexure L beams subjected to either standard exposure) to 1.01 . 
Table 8.4. Strength multiplication factors relative to in-air room-temperature values

\begin{tabular}{cccc}
\hline Stress state & $\begin{array}{c}\mathbf{1 0 0 0} \mathbf{~} \text { in } \\
\text { distilled water }\end{array}$ & $\begin{array}{c}\mathbf{1 0 0} \mathbf{~} \text { in windshield } \\
\text { washer fluid }\end{array}$ & $\mathbf{1 2 0}^{\circ} \mathbf{C}$ \\
\hline Tension & 0.93 & 0.91 & 0.96 \\
Compression & 0.89 & 0.74 & 0.55 \\
Shear & 0.65 & 0.86 & 0.44 \\
Uniaxial flexure & 0.81 & 0.84 & 0.54 \\
Biaxial flexure & 0.75 & 0.81 & 0.53 \\
\hline
\end{tabular}

Results in Table 8.4 indicates that at $120^{\circ} \mathrm{C}$ the lowest temperature multiplication factor corresponds to shear. For $1000 \mathrm{~h}$ preconditioning in distilled water and $100 \mathrm{~h}$ preconditioning in windshield washer fluid, the lowest multiplication factors were obtained in shear and compression, respectively.

\subsection{PREDICTABILITY OF BENDING DEFORMATIONS}

Eleven beam specimens $254-\mathrm{mm}$-long by 25.4 -mm-wide were fabricated from Plaque T48 to investigate the effect of specimen orientation $\left[0^{\circ}\right.$ versus $90^{\circ}$ (i.e., longitudinal versus transverse) $]$ on flexural strength as well as the predictability of bending deformations. After conduct of initial stiffness checks, each of the 254-mm-long beam specimens was cut into two beam specimens $127-\mathrm{mm}$-long by 25.4-mm-wide. Six each of the beams $\left(0^{\circ}\right.$ orientation, longitudinal $)$ were tested in three-point-bending (76.2-mm span) and as cantilever beams (63.5 mm load span). Five each of the beam specimens $\left(90^{\circ}\right.$, transverse) were also tested in three-point bending and as cantilever beams. Figure 8.1 presents the flexural test setup and Figure 8.4 presents the test setup for the cantilever beam tests.

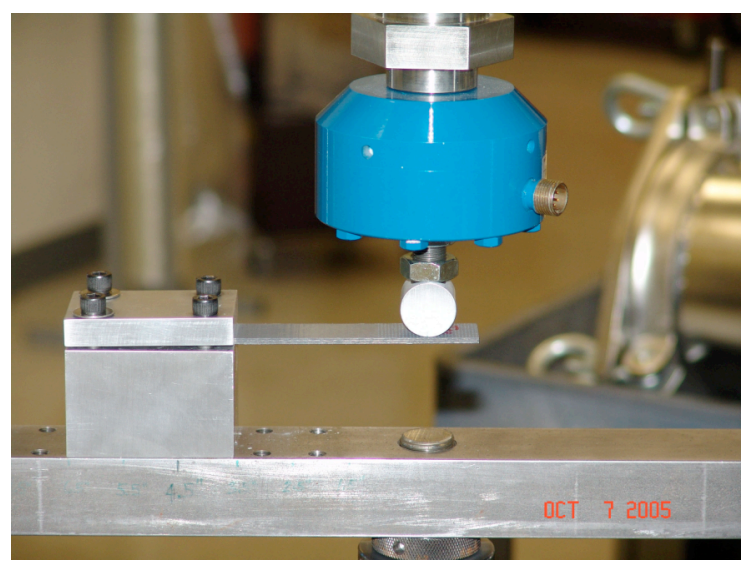

Figure 8.4 Cantilever beam test setup.

In the case of bending deformation, the question arises as to how well the simple isotropic, homogeneous beam-bending theory predicts measured deflections. To answer this question, the deflections of the simply-supported beams tested at $23^{\circ} \mathrm{C}$, as well as of cantilever beams tested at $23^{\circ} \mathrm{C}$, were predicted by two types of analyses, and the results were compared with the measured values.

Two simple linear elastic analyses were performed based on:

- classical isotropic, homogeneous beam-bending theory (without shear), and 
- classical isotropic, homogeneous cylindrical-bending plate theory, which accounts for the fact that the beam is wide by substituting $E /\left(1-v^{2}\right)$ for the stiffness, E, in the beam theory equations ( $v$ is Poisson's ratio)

\subsubsection{Uniaxial Flexure - Three-Point Bending}

Beam deflection was assessed through actuator displacement. The initial uniaxial stiffness of each individual beam was used in the calculations. Beam displacement in three-point bending was determined from:

$$
\begin{aligned}
& \delta_{c}=-\frac{\mathrm{Pl}^{3}}{48 \mathrm{EI}} \text { (beam theory), and } \\
& \delta_{c}=-\frac{\mathrm{Pl}^{3}}{48\left(\frac{\mathrm{E}}{1-v^{2}}\right) \mathrm{I}} \quad \text { (cylindrical-bending theory). }
\end{aligned}
$$

Figures 8.5 and 8.6 present a comparison of measured and predicted load versus deflection for beam specimens oriented in the longitudinal $\left(0^{\circ}\right)$ and transverse $\left(90^{\circ}\right)$ directions, respectively.

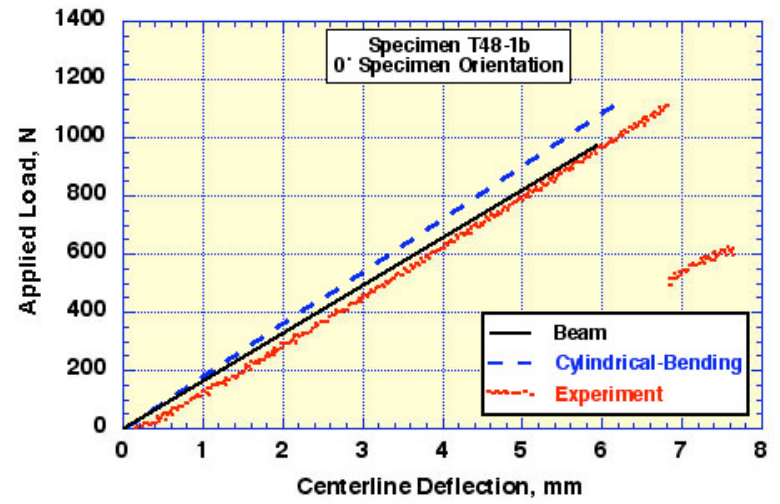

Figure 8.5 Load vs deflection, three-point bend test: $0^{\circ}$ orientation.

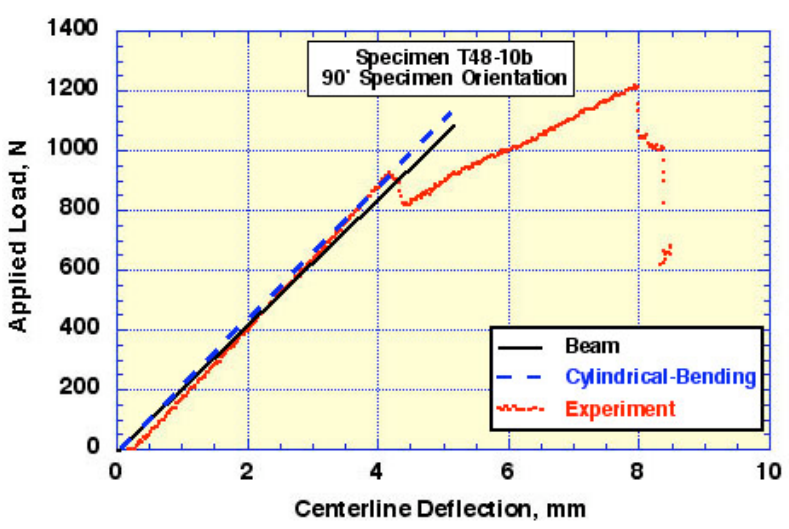

Figure 8.6 Load vs deflection, three-point bend test: $90^{\circ}$ orientation.

Both simple beam and plate theory provide relatively good predictions of the beam deflections for specimens loaded in three-point bending. Comparing Figures 8.5 and 8.6, beam deflections at comparable loads for the transverse beam specimens $\left(90^{\circ}\right.$ orientation) are less than those for the longitudinal beams $\left(0^{\circ}\right.$ orientation). For the transverse beam the outer ply of fibers is aligned along the beam length where it is more effective in resisting applied loads.

\subsubsection{Uniaxial Flexure - Cantilever Beams}

Beam deflection for the cantilever beams also was assessed through actuator displacement. The initial uniaxial stiffness of each individual cantilever beam was used in the calculations. Beam displacement at the point of load application was determined from: 


$$
\begin{aligned}
& \delta_{c}=-\frac{\mathrm{Pl}^{3}}{3 \mathrm{EI}}(\text { beam theory), and } \\
& \delta_{c}=-\frac{\mathrm{Pl}^{3}}{3\left(\frac{\mathrm{E}}{1-v^{2}}\right) \mathrm{I}} \text { (cylindrical-bending theory). }
\end{aligned}
$$

Figures 8.7 and 8.8 present a comparison of measured and predicted load versus deflection for beam specimens oriented in the longitudinal $\left(0^{\circ}\right)$ and transverse $\left(90^{\circ}\right)$ directions, respectively.

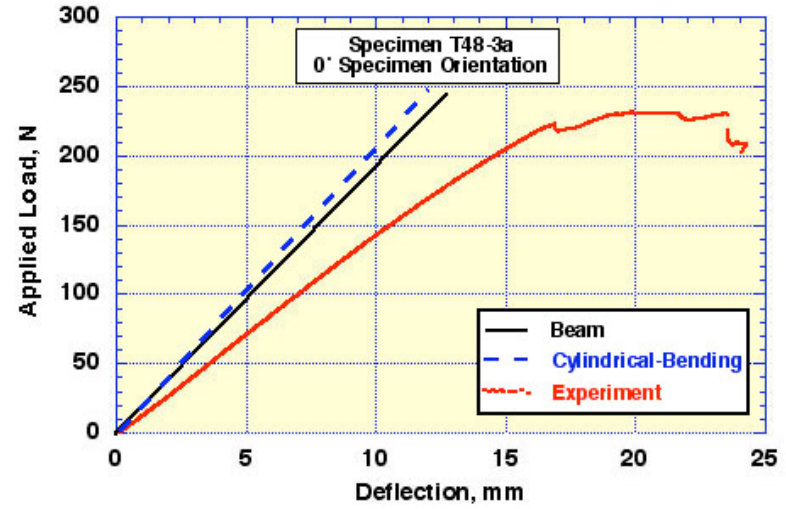

Figure 8.7 Load vs deflection, cantilever beam test: $0^{\circ}$ orientation.

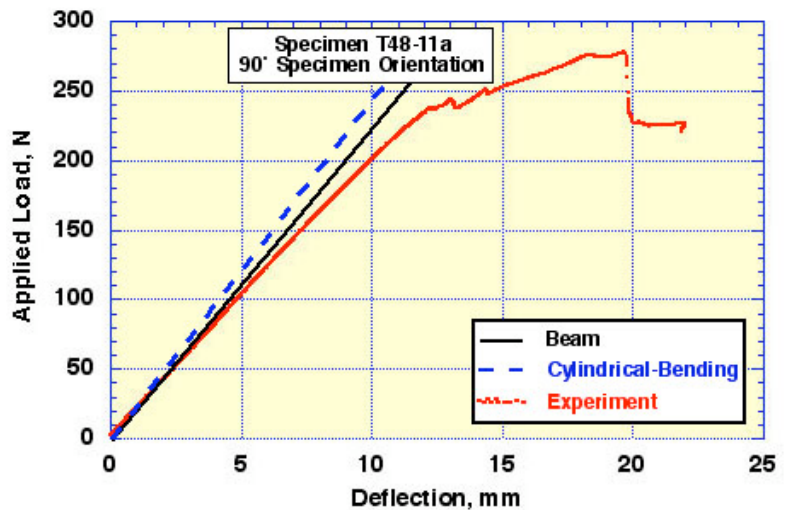

Figure 8.8 Load vs deflection, cantilever beam test: $90^{\circ}$ orientation.

Both simple beam and plate theory generally provided good predictions of the cantilever beam deflections, although somewhat less than actual at a given load. Comparing Figures 8.7 and 8.8, beam deflections at comparable loads for the transverse beam specimens $\left(90^{\circ}\right.$ orientation) are less than those for the longitudinal beams $\left(0^{\circ}\right.$ orientation). As noted previously, the transverse beam outer ply of fibers is aligned along the beam length where it is more effective in resisting applied loads.

\subsection{Reference}

1. ASTM Standard D 790, Test Methods for Flexural Properties of Unreinforced and Reinforced Plastics and Electrical Insulating Materials, American Society for Testing and Materials. 


\section{CYCLIC FATIGUE BEHAVIOR}

\section{$9.1 \quad$ INTRODUCTION}

Three series of cyclic fatigue tests, a total of 141 tests, were performed using specimens fabricated from the quasi-isotropic carbon-fiber-reinforced thermoplastic composite material. The first two series, which were tensile-cycling tests with a ratio, $\mathrm{R}$, of minimum to maximum stress of 0.1 , focused on (1) developing stress vs. cyclic life (S-N) curves at $-40^{\circ}, 23^{\circ}, 70^{\circ}$, and $120^{\circ} \mathrm{C}$, and (2) developing S-N curves for tests in distilled water (1,000 hour preexposure) and windshield washer fluid (100 hour preexposure). The third test series focused on generating S-N curves for characterizing mean stress effects. In addition to tensile cycling tests with $\mathrm{R}=0$, compressive cycling tests with $\mathrm{R}=-\infty$, completelyreversed cycling tests with $\mathrm{R}=-1$, and tensile cycling tests with a mean stress equal to $45 \%$ of the plaque average UTS were performed.* Figure 9.1 presents specimen geometries used for cyclic fatigue tests.

Test specimens for the first test series came from Plaques T24 and T34. Specimens for the second test series came from Plaques T34 and T44. The third test series utilized specimens from Plaque T38. Details of the individual tests and the resulting cyclic lives are tabulated in Tables 9.1, 9.2, and 9.3 for test series 1,2 , and 3, respectively.

The tensile tests tabulated in Tables 9.1 and 9.2 used the standard dogbone-shaped tensile specimen. The central straight-sided portion of these specimens was $20.3 \mathrm{~mm}$ wide and $41.7 \mathrm{~mm}$ long. The radii at each end of the central straight section were $177.8 \mathrm{~mm}$. The mean-stress tests tabulated in Table 9.3 employed the hourglass specimen design depicted in Figure 9.1 to minimize the likelihood of buckling under compressive loads.

In all the tests, the frequency used varied with applied stress in accordance with the following relation, recommended by ACC: ${ }^{1}$

$$
\mathrm{f}=\mathrm{k} \mathrm{S}_{\mathrm{ult}} /\left(\mathrm{S}_{\max }-\mathrm{S}_{\min }\right)
$$

where $\mathrm{k}=3 \mathrm{~Hz}$ was used, $\mathrm{S}_{\mathrm{ult}}$ is the at-temperature UTS of the material, and $\mathrm{S}_{\max }-\mathrm{S}_{\min }$ is the cyclic stress range. The room-temperature UTS for plaques T24, T34, T44, and T38 were 512, 616, 539, and $612 \mathrm{MPa}$, respectively. Corresponding moduli of elasticity values for these plaques were $36.91,36.48$, 37.51, and $35.36 \mathrm{GPa}$, respectively.

Results from each test series are discussed in the following sections. Conclusions and a recommended fatigue design curve are presented in the last section of the chapter.

* See Figure 9.20 for a description of cyclic stress histories used to examine mean-stress effects. 
Table 9.1 Test series 1: tensile fatigue tests of Plaques T24 and T34 specimens at various temperatures

\begin{tabular}{|c|c|c|c|c|c|c|}
\hline Specimen & UTS (\%) & Thickness (in.) & $\begin{array}{l}\text { Width } \\
\text { (in.) }\end{array}$ & $\begin{array}{c}\text { Area } \\
\text { (sq. in.) }\end{array}$ & Failure Cycles & $\begin{array}{c}\text { Failure location } \\
\text { (inches from bottom) }\end{array}$ \\
\hline \multicolumn{7}{|c|}{ Room temperature, lab air } \\
\hline T24-19 & 90.00 & 0.112 & 0.806 & 0.0903 & 552 & 5 \\
\hline $\mathrm{T} 24-6$ & 70.00 & 0.112 & 0.803 & 0.0899 & 111,180 & 3 \\
\hline $\mathrm{T} 24-15$ & 80.00 & 0.112 & 0.805 & 0.0902 & 3,938 & 4.5 \\
\hline $\mathrm{T} 24-17$ & 40.00 & 0.113 & 0.805 & 0.0910 & $3,000,000$ & runout \\
\hline $\mathrm{T} 24-2$ & 90.00 & 0.112 & 0.806 & 0.0903 & 441 & 4.5 \\
\hline $\mathrm{T} 24-3$ & 80.00 & 0.112 & 0.806 & 0.0903 & 5,455 & 5 \\
\hline $\mathrm{T} 24-4$ & 80.00 & 0.112 & 0.804 & 0.0900 & 8,119 & 4 \\
\hline $\mathrm{T} 24-5$ & 70.00 & 0.112 & 0.806 & 0.0903 & 110,646 & 4 \\
\hline $\mathrm{T} 24-7$ & 70.00 & 0.112 & 0.804 & 0.0900 & 209,338 & 3.5 \\
\hline T24-9 & 60.00 & 0.112 & 0.803 & 0.0899 & 958,319 & 4 \\
\hline $\mathrm{T} 24-10$ & 60.00 & 0.112 & 0.806 & 0.0903 & 874,247 & $45 / 8$ \\
\hline $\mathrm{T} 24-11$ & 50.00 & 0.112 & 0.803 & 0.0899 & $5,285,252$ & runout \\
\hline $\mathrm{T} 24-12$ & 50.00 & 0.112 & 0.805 & 0.0902 & $2,918,514$ & runout \\
\hline T24-13 & 55.00 & 0.112 & 0.805 & 0.0902 & $2,182,300$ & runout \\
\hline \multicolumn{7}{|c|}{$-40^{\circ} \mathrm{C}$, liquid nitrogen vapor } \\
\hline $\mathrm{T} 24-30$ & 85.00 & 0.112 & 0.807 & 0.0904 & 4,199 & $41 / 4$ \\
\hline T24-31 & 85.00 & 0.112 & 0.805 & 0.0902 & 3,266 & 4.5 \\
\hline $\mathrm{T} 24-34$ & 80.00 & 0.113 & 0.805 & 0.0910 & 9,821 & 4 \\
\hline $\mathrm{T} 24-35$ & 75.00 & 0.112 & 0.808 & 0.0905 & 43,926 & 3 \\
\hline $\mathrm{T} 24-36$ & 75.00 & 0.112 & 0.807 & 0.0904 & 48,930 & $31 / 2$ \\
\hline $\mathrm{T} 24-37$ & 65.00 & 0.112 & 0.809 & 0.0906 & 265,054 & runout \\
\hline $\mathrm{T} 34-50$ & 55.60 & 0.113 & 0.808 & 0.0913 & $1,102,092$ & 4.25 \\
\hline \multicolumn{7}{|c|}{$70^{\circ} \mathrm{C}$, instrument air } \\
\hline $\mathrm{T} 24-14$ & 80.00 & 0.112 & 0.804 & 0.0900 & 2,743 & 4 \\
\hline $\mathrm{T} 24-16$ & 80.00 & 0.113 & 0.805 & 0.0910 & 2,554 & 4 \\
\hline $\mathrm{T} 24-20$ & 75.00 & 0.112 & 0.803 & 0.0899 & 8,960 & 4.25 \\
\hline $\mathrm{T} 24-21$ & 75.00 & 0.112 & 0.807 & 0.0904 & 3,875 & 4 \\
\hline $\mathrm{T} 24-22$ & 75.00 & 0.112 & 0.806 & 0.0903 & 13,350 & 3.5 \\
\hline $\mathrm{T} 24-23$ & 65.00 & 0.112 & 0.805 & 0.0902 & 369,364 & 4 \\
\hline $\mathrm{T} 24-24$ & 65.00 & 0.111 & 0.806 & 0.0895 & 795,589 & 3.5 \\
\hline $\mathrm{T} 24-26$ & 55.00 & 0.112 & 0.806 & 0.0903 & $2,556,539$ & runout \\
\hline $\mathrm{T} 24-27$ & 55.00 & 0.112 & 0.806 & 0.0903 & $2,376,300$ & runout \\
\hline $\mathrm{T} 24-28$ & 60.00 & 0.112 & 0.803 & 0.0899 & 583,060 & $41 / 4$ \\
\hline $\mathrm{T} 24-29$ & 60.00 & 0.112 & 0.804 & 0.0900 & 533,000 & 4.5 \\
\hline \multicolumn{7}{|c|}{$120^{\circ} \mathrm{C}$, instrument air } \\
\hline T34-36 & 80.00 & 0.1140 & 0.8080 & 0.0921 & 24 & 4.75 \\
\hline $\mathrm{T} 34-42$ & 65.00 & 0.1120 & 0.8080 & 0.0905 & 27,096 & 4.5 \\
\hline T34-43 & 65.00 & 0.1120 & 0.8100 & 0.0907 & 59,806 & 4 \\
\hline T34-44 & 55.00 & 0.1120 & 0.8080 & 0.0905 & $1,871,693$ & 4 \\
\hline T34-45 & 55.00 & 0.1120 & 0.8080 & 0.0905 & 130,513 & 4 \\
\hline T34-46 & 55.00 & 0.1120 & 0.8070 & 0.0904 & 426,891 & 4 \\
\hline T34-47 & 50.00 & 0.1120 & 0.8060 & 0.0903 & 297,167 & 4 \\
\hline T34-48 & 45.00 & 0.1120 & 0.8080 & 0.0905 & $1,094,790$ & 4 \\
\hline T34-49 & 40.00 & 0.112 & 0.81 & 0.0907 & - & runout \\
\hline T34-51 & 50.00 & 0.112 & 0.808 & 0.0905 & 797,107 & 4 \\
\hline T34-52 & 50.00 & 0.115 & 0.809 & 0.0930 & 307,964 & 4 \\
\hline T34-53 & 60.00 & 0.114 & 0.81 & 0.0923 & 2,120 & 5 \\
\hline T34-54 & 60.00 & 0.112 & 0.804 & 0.0900 & 54,275 & 4 \\
\hline
\end{tabular}


Table 9.2 Test series 2: tensile fatigue tests of Plaque T44 in air and fluids

\begin{tabular}{|c|c|c|c|c|c|c|}
\hline Specimen & UTS (\%) & $\begin{array}{c}\text { Thickkness } \\
\text { (in.) }\end{array}$ & Width (in.) & Area (sq. in.) & Failure Cycles & $\begin{array}{c}\text { Failure } \\
\text { Location } \\
\text { (inches from } \\
\text { bottom) } \\
\end{array}$ \\
\hline \multicolumn{7}{|c|}{ Room Temperature, lab air } \\
\hline $\mathrm{T} 44-2$ & 90.00 & 0.114 & 0.804 & 0.0917 & 670 & $41 / 8$ \\
\hline $\mathrm{T} 44-3$ & 90.00 & 0.114 & 0.807 & 0.0920 & 263 & 4.75 \\
\hline $\mathrm{T} 44-4$ & 80.00 & 0.113 & 0.807 & 0.0912 & 7,725 & 4 \\
\hline $\mathrm{T} 44-5$ & 80.00 & 0.114 & 0.806 & 0.0919 & 7,923 & 4.75 \\
\hline T44-6 & 70.00 & 0.113 & 0.805 & 0.0910 & 180,281 & 4 \\
\hline $\mathrm{T} 44-7$ & 70.00 & 0.113 & 0.805 & 0.0910 & 125,203 & 3.5 \\
\hline T44-8 & 70.00 & 0.112 & 0.805 & 0.0902 & 143,964 & 4 \\
\hline T44-9 & 70.00 & 0.113 & 0.804 & 0.0909 & 86,258 & 4 \\
\hline T44-10 & 60.00 & 0.113 & 0.803 & 0.0907 & $1,315,351$ & 4 \\
\hline T44-11 & 60.00 & 0.112 & 0.8 & 0.0896 & $1,704,025$ & $43 / 8$ \\
\hline T44-12 & 55.00 & 0.1130 & 0.8010 & 0.0905 & $2,000,000$ & runout \\
\hline T44-13 & 55.00 & 0.1130 & 0.7990 & 0.0903 & $3,110,126$ & runout \\
\hline \multicolumn{7}{|c|}{ Windshield washer fluid (100 hour presoak) } \\
\hline $\mathrm{T} 44-15$ & 90.00 & 0.1130 & 0.7980 & 0.0902 & 15 & $41 / 4$ \\
\hline T44-16 & 80.00 & 0.1130 & 0.7980 & 0.0902 & 1,132 & $41 / 2$ \\
\hline $\mathrm{T} 44-17$ & 70.00 & 0.1130 & 0.7970 & 0.0901 & 6,113 & 4 \\
\hline T44-18 & 70.00 & 0.1160 & 0.8060 & 0.0935 & 15,702 & 3 \\
\hline T44-19 & 60.00 & 0.1150 & 0.8100 & 0.0933 & 191,600 & $23 / 4$ \\
\hline T44-20 & 60.00 & 0.1140 & 0.8100 & 0.0923 & 442,500 & 5 \\
\hline T44-21 & 60.00 & 0.1140 & 0.8080 & 0.0921 & 229,492 & 4.5 \\
\hline T44-22 & 50.00 & 0.1130 & 0.8070 & 0.0912 & $3,358,084$ & runout \\
\hline T44-24 & 50.00 & 0.1130 & 0.8080 & 0.0913 & $3,782,054$ & runout \\
\hline T44-25 & 50.00 & 0.1130 & 0.8090 & 0.0914 & $1,800,000$ & runout \\
\hline T44-26 & 45.00 & 0.1120 & 0.8070 & 0.0904 & $1,678,760$ & runout \\
\hline T44-27 & 45.00 & 0.1120 & 0.8050 & 0.0902 & $2,052,017$ & runout \\
\hline T44-28 & 45.00 & 0.1120 & 0.8050 & 0.0902 & $2,048,132$ & runout \\
\hline T44-30 & 40.00 & 0.1120 & 0.8050 & 0.0902 & $3,587,567$ & runout \\
\hline T44-31 & 40.00 & 0.1120 & 0.8000 & 0.0896 & $3,462,035$ & runout \\
\hline T44-32 & 40.00 & 0.1120 & 0.8000 & 0.0896 & $6,102,522$ & runout \\
\hline T44-46 & 85.00 & 0.1130 & 0.8080 & 0.0913 & 50 & 3.75 \\
\hline T44-47 & 75.00 & 0.1130 & 0.8080 & 0.0913 & 459 & 4 \\
\hline T44-49 & 65.00 & 0.1130 & 0.8090 & 0.0914 & 25,913 & 4.25 \\
\hline \multicolumn{7}{|c|}{ Distilled Water (1000 hour presoak) } \\
\hline $\mathrm{T} 44-33$ & 45.00 & 0.1120 & 0.8080 & 0.0905 & $2,064,613$ & runout \\
\hline T44-34 & 90.00 & 0.1120 & 0.8010 & 0.0897 & 25 & 4.5 \\
\hline $\mathrm{T} 44-35$ & 80.00 & 0.1160 & 0.8060 & 0.0935 & 1,085 & 4.25 \\
\hline $\mathrm{T} 44-37$ & 70.00 & 0.1160 & 0.8080 & 0.0937 & 14,458 & 4 \\
\hline $\mathrm{T} 44-38$ & 60.00 & 0.1150 & 0.8070 & 0.0928 & 81,948 & \\
\hline T44-39 & 50.00 & 0.1140 & 0.8060 & 0.0919 & $1,137,335$ & \\
\hline T44-41 & 40.00 & 0.1130 & 0.8060 & 0.0911 & $2,728,863$ & runout \\
\hline T44-42 & 90.00 & 0.1130 & 0.8080 & 0.0913 & 112 & 5 \\
\hline T44-43 & 80.00 & 0.1130 & 0.8070 & 0.0912 & 862 & 4.5 \\
\hline T44-44 & 70.00 & 0.1130 & 0.8050 & 0.0910 & 4,083 & 3.75 \\
\hline T44-45 & 60.00 & 0.1130 & 0.8040 & 0.0909 & 57,461 & 4 \\
\hline T44-50 & 45.00 & 0.1130 & 0.8050 & 0.0910 & $2,033,881$ & runout \\
\hline T44-51 & 55.00 & 0.1130 & 0.8080 & 0.0913 & 65,890 & \\
\hline
\end{tabular}


Table 9.3 Test series 3: mean stress fatigue tests of specimens from Plaque T38

\begin{tabular}{|c|c|c|c|c|c|c|}
\hline Specimen & $\begin{array}{c}\text { Actual } \\
\text { Stress } \\
\text { (MPa) }\end{array}$ & UTS (\%) & $\begin{array}{c}\text { Thickness } \\
\text { (in.) }\end{array}$ & Width (in.) & Area (sq. in.) & Failure Cycles \\
\hline \multicolumn{7}{|c|}{ Tensile Cycling, $R=0$} \\
\hline $\mathrm{T} 38-1$ & 490 & 80.00 & 0.115 & 0.8100 & 0.0932 & 10,440 \\
\hline T38-2 & 490 & 80.00 & 0.115 & 0.8090 & 0.0930 & 8,844 \\
\hline $\mathrm{T} 38-3$ & 490 & 80.00 & 0.116 & 0.8090 & 0.0938 & 10,900 \\
\hline $\mathrm{T} 38-4$ & 429 & 70.00 & 0.116 & 0.8090 & 0.0938 & 289,560 \\
\hline $\mathrm{T} 38-5$ & 429 & 70.00 & 0.116 & 0.8100 & 0.0940 & 239,349 \\
\hline $\mathrm{T} 38-7$ & 367 & 60.00 & 0.116 & 0.810 & 0.0929 & 639,398 \\
\hline $\mathrm{T} 38-8$ & 367 & 60.00 & 0.116 & 0.8080 & 0.0937 & 493,831 \\
\hline T38-9 & 367 & 60.00 & 0.115 & 0.7920 & 0.0911 & 812,204 \\
\hline T38-10 & 306 & 50.00 & 0.115 & 0.7900 & 0.0909 & $2,047,390$ \\
\hline T38-11 & 306 & 50.00 & 0.115 & 0.7880 & 0.0906 & $2,077,131$ \\
\hline T38-12 & 306 & 50.00 & 0.115 & 0.8080 & 0.0929 & $3,143,080$ \\
\hline \multicolumn{7}{|c|}{ Tensile Cycling, 45\% UTS mean stress } \\
\hline $\mathrm{T} 38-13$ & 490 & 80.00 & 0.115 & 0.8050 & 0.0926 & 16,593 \\
\hline T38-14 & 490 & 80.00 & 0.116 & 0.8110 & 0.0941 & 7,544 \\
\hline T38-15 & 490 & 80.00 & 0.116 & 0.8110 & 0.0941 & 94,552 \\
\hline T38-16 & 459 & 75.00 & 0.117 & 0.8100 & 0.0948 & 781,230 \\
\hline T38-17 & 459 & 75.00 & 0.116 & 0.8050 & 0.0934 & 514,955 \\
\hline T38-18 & 459 & 75.00 & 0.115 & 0.8100 & 0.0932 & 712,066 \\
\hline T38-19 & 429 & 70.00 & 0.116 & 0.8040 & 0.0933 & $2,195,371$ \\
\hline T38-20 & 429 & 70.00 & 0.115 & 0.8060 & 0.0927 & $2,110,848$ \\
\hline T38-21 & 429 & 70.00 & 0.115 & 0.8090 & 0.0930 & $2,051,812$ \\
\hline \multicolumn{7}{|c|}{ Compressive Cycling, $R=-\infty$} \\
\hline T38-25 & -282 & -46.00 & 0.116 & 0.8060 & 0.0935 & 25 \\
\hline T38-26 & -220 & -36.00 & 0.116 & 0.8070 & 0.0936 & 115,890 \\
\hline T38-27 & -282 & -46.00 & 0.115 & 0.8060 & 0.0927 & 950 \\
\hline T38-28 & -251 & -41.00 & 0.115 & 0.8070 & 0.0928 & 3,313 \\
\hline T38-29 & -251 & -41.00 & 0.115 & 0.8050 & 0.0926 & 2,462 \\
\hline T38-30 & -251 & -41.00 & 0.116 & 0.8100 & 0.0940 & 674 \\
\hline T38-31 & -214 & -35.00 & 0.115 & 0.8080 & 0.0929 & 95,424 \\
\hline T38-32 & -214 & -35.00 & 0.115 & 0.8080 & 0.0927 & 63,046 \\
\hline T38-33 & -214 & -35.00 & 0.116 & 0.8090 & 0.0938 & 51,184 \\
\hline T38-34 & -147 & -24.00 & 0.117 & 0.8080 & 0.0945 & $2,013,076$ \\
\hline T38-35 & -147 & -24.00 & 0.115 & 0.8080 & 0.0929 & $2,194,520$ \\
\hline T38-36 & -147 & -24.00 & 0.115 & 0.8100 & 0.0932 & $2,031,825$ \\
\hline T38-22 & -184 & -30.00 & 0.115 & 0.8070 & 0.0928 & $2,721,298$ \\
\hline T38-23 & -184 & -30.00 & 0.115 & 0.8030 & 0.0923 & $1,775,745$ \\
\hline
\end{tabular}


Table 9.3 (cont.) Test series 3: mean stress fatigue tests of specimens from Plaque T38

\begin{tabular}{|c|c|c|c|c|c|c|}
\hline Specimen & $\begin{array}{l}\text { Actual } \\
\text { Stress } \\
\text { (MPa) }\end{array}$ & UTS (\%) & $\begin{array}{c}\text { Thickness } \\
\text { (in.) }\end{array}$ & Width (in.) & Area (sq. in.) & Failure Cycles \\
\hline \multicolumn{7}{|c|}{ Reversed load cycling, $R=-1$} \\
\hline T38-37 & 282 & 46.00 & 0.115 & 0.8070 & 0.0928 & 2 \\
\hline T38-38 & 282 & 46.00 & 0.116 & 0.8000 & 0.0928 & 15 \\
\hline T38-39 & 282 & 46.00 & 0.116 & 0.8070 & 0.0936 & 17 \\
\hline $\mathrm{T} 38-40$ & 251 & 41.00 & 0.115 & 0.8070 & 0.0928 & 572 \\
\hline T38-41 & 251 & 41.00 & 0.115 & 0.8100 & 0.0932 & 186 \\
\hline T38-42 & 251 & 41.00 & 0.115 & 0.8110 & 0.0933 & 133 \\
\hline $\mathrm{T} 38-43$ & 214 & 35.00 & 0.115 & 0.8100 & 0.0932 & 4,067 \\
\hline T38-44 & 214 & 35.00 & 0.115 & 0.7970 & 0.0917 & 407 \\
\hline T38-45 & 214 & 35.00 & 0.115 & 0.8070 & 0.0928 & 1,788 \\
\hline T38-46 & 184 & 30.00 & 0.115 & 0.8080 & 0.0929 & 31,725 \\
\hline T38-47 & 184 & 30.00 & 0.115 & 0.7970 & 0.0917 & 27,027 \\
\hline T38-48 & 184 & 30.00 & 0.115 & 0.8010 & 0.0921 & 3,470 \\
\hline Т38-49 & 147 & 24.00 & 0.115 & 0.7970 & 0.0917 & 689,038 \\
\hline T38-50 & 147 & 24.00 & 0.115 & 0.8040 & 0.0925 & $2,364,150$ \\
\hline T38-51 & 147 & 24.00 & 0.116 & 0.8030 & 0.0931 & 73,062 \\
\hline T38-52 & 86 & 14.00 & 0.116 & 0.8030 & 0.0931 & $2,671,101$ \\
\hline T38-53 & 86 & 14.00 & 0.117 & 0.8070 & 0.0944 & $4,494,998$ \\
\hline T38-54 & 86 & 14.00 & 0.117 & 0.8110 & 0.0949 & $2,569,295$ \\
\hline
\end{tabular}

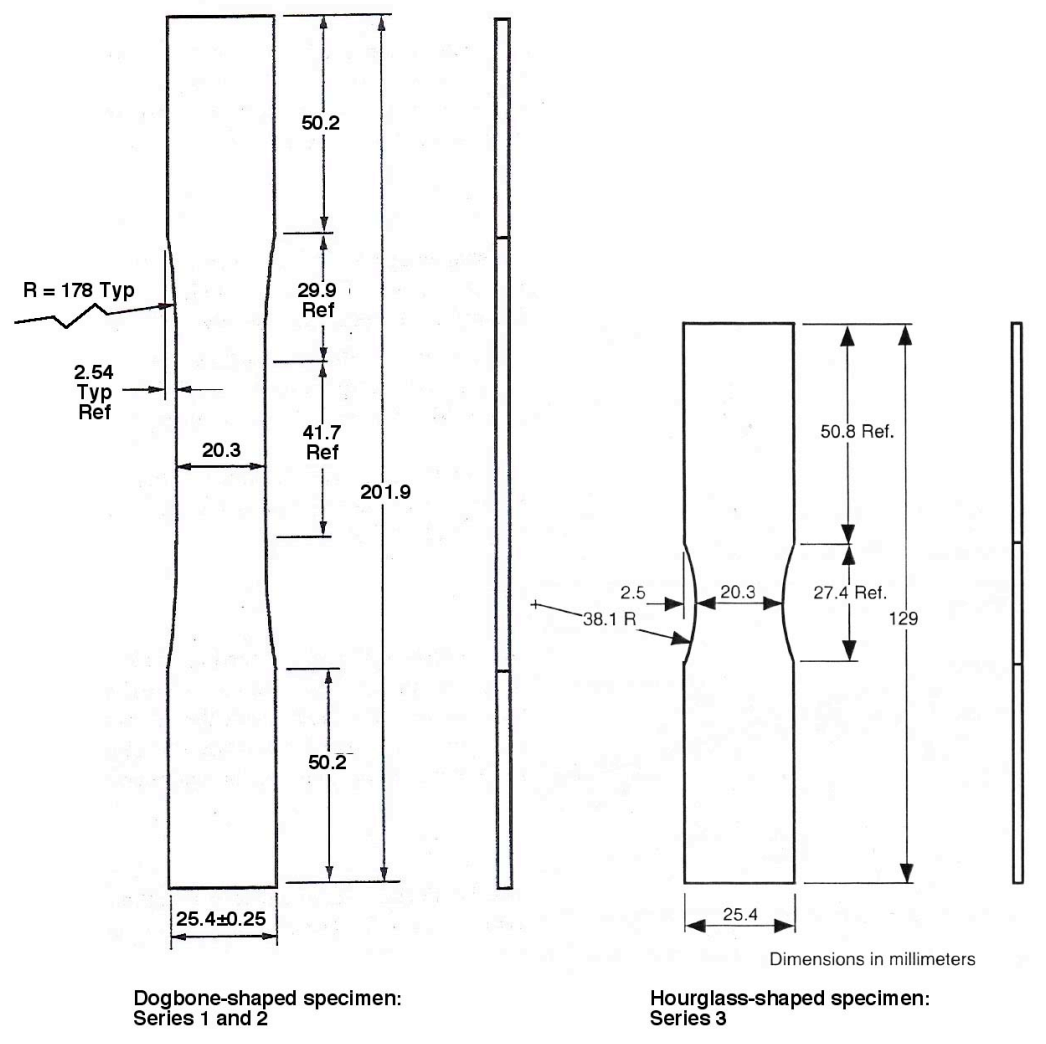

Fig. 9.1. Cyclic fatigue test specimen geometry. 


\subsection{BASLINE TENSILE FATIGUE $(\mathrm{R}=0.1)$}

Baseline in-air, load-controlled tests were performed at a nominal temperature of $23^{\circ} \mathrm{C}$ using specimens from Plaques T24 and T44. The baseline results are plotted in Figure 9.2, which shows cycles to failure as a function of both the maximum cyclic stress and $\%$ of ultimate stress, respectively. A power law curve fit was used that was bounded by the UTS for each plaque. The difference in the fatigue behavior of the two plaques at room temperature, shown in Figure 9.2, can be attributed to the differences in the ultimate strength values of the two plaques.

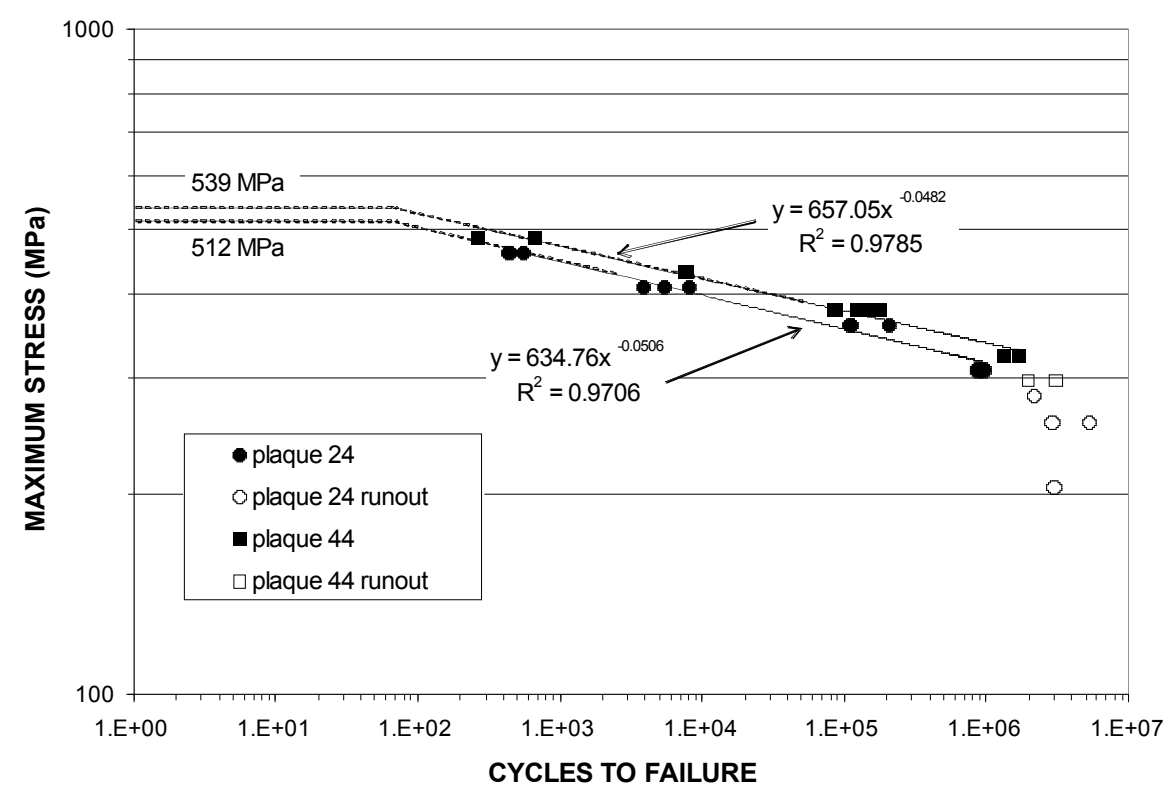

(a) maximum cyclic stress

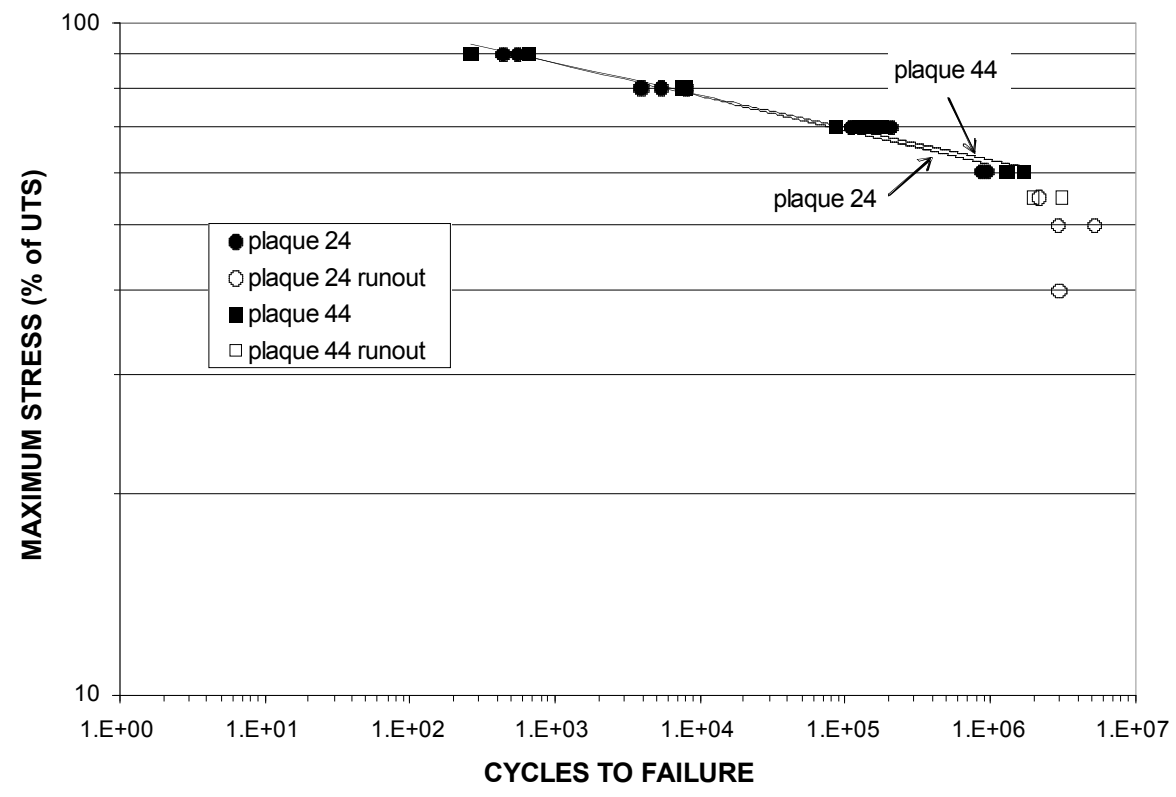

(b) $\%$ of UTS

Figure 9.2. Tensile fatigue $(\mathrm{R}=0.1)$ curves at $23^{\circ} \mathrm{C}$ for specimens from plaques $\mathrm{T} 24$ and $\mathrm{T} 44$. 
Maximum peak cyclic strain and loss of stiffness values are of interest as measures of damage development. These parameters were monitored during each test. An in-house computer control program stopped the normal fatigue cycling at specified cycle intervals and imposed a slow $(1 \mathrm{~Hz})$ reduced load-level cycle to assess stiffness reductions. Data generated at the specified intervals were saved periodically and any time the stiffness changed by $1 \%$ or more. The program checked and recorded the stiffnesses more frequently during the first several hundred cycles. MTS extensometers with a gage length of $25.4 \mathrm{~mm}$ were employed to measure strain. Figure 9.3 shows the maximum strain for room temperature tests for Plaques T24 and T44 as a function of cycle number. The upward turn near the end of the tests is indicative of significant damage development.

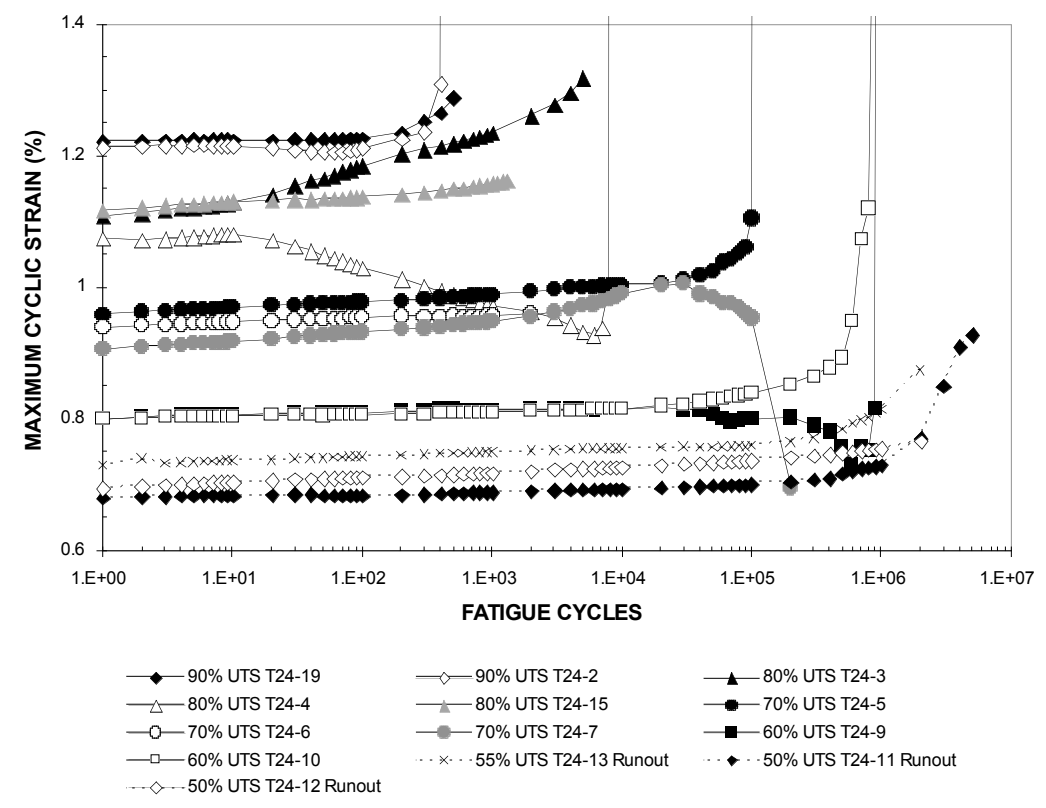

a. Plaque T24.

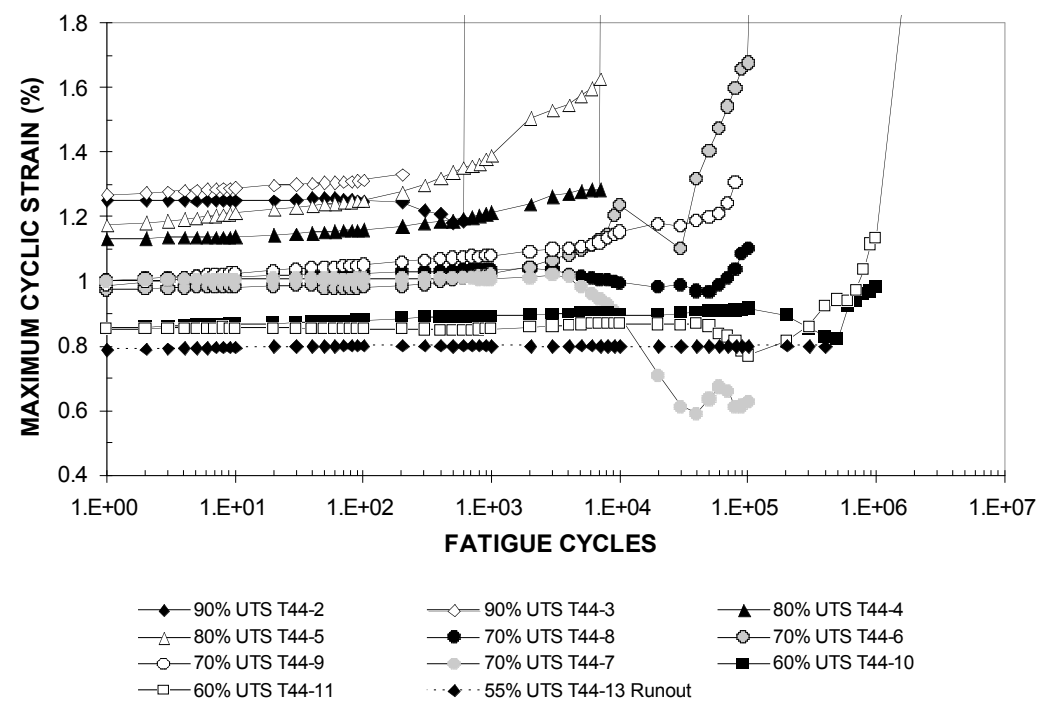

b. Plaque T44.

Figure 9.3. Maximum strain vs. fatigue cycles for specimens at room temperature. 
Of particular importance in cyclic fatigue is the reduction in stiffness, reflecting the accumulation of damage with cycling. Ideally, this loss should not exceed $10 \%$ over the design allowable life. The reduction in stiffness in percent change from the initial stiffness as a function of cyclic life fraction, $\mathrm{n} / \mathrm{N}_{\mathrm{f}}$, is shown in Figure 9.4. With the factor of 20 design margin $\left(\mathrm{n} / \mathrm{N}_{\mathrm{f}}=0.05\right)$ on cyclic life that is

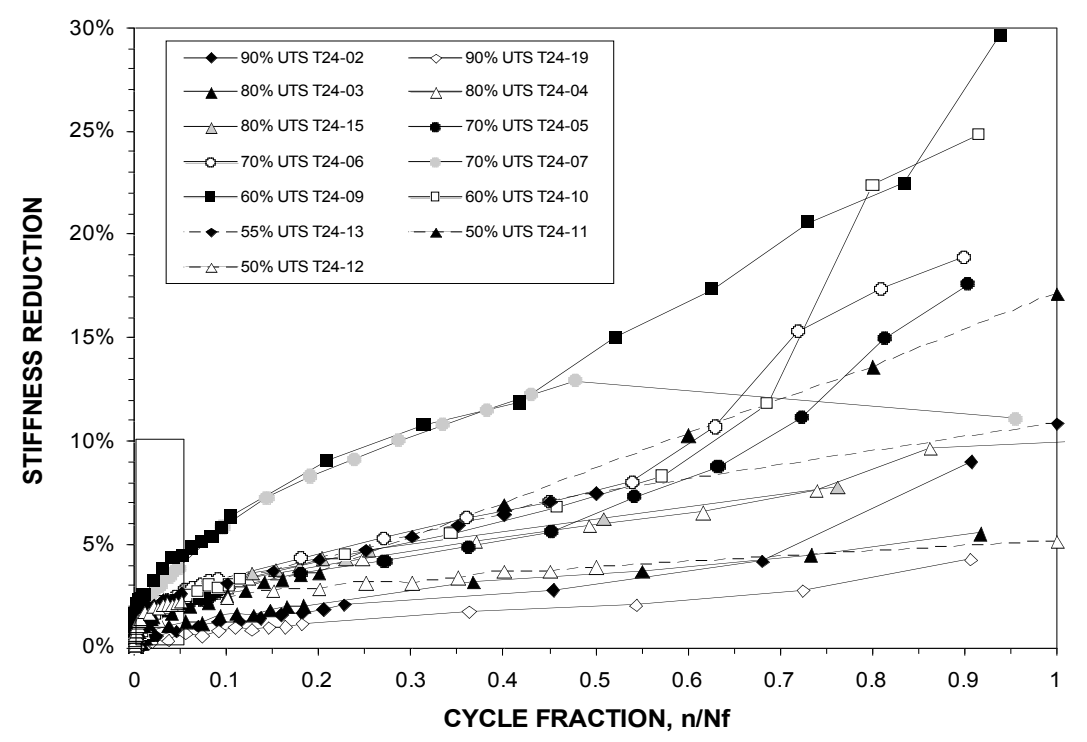

(a) Plaque T24.

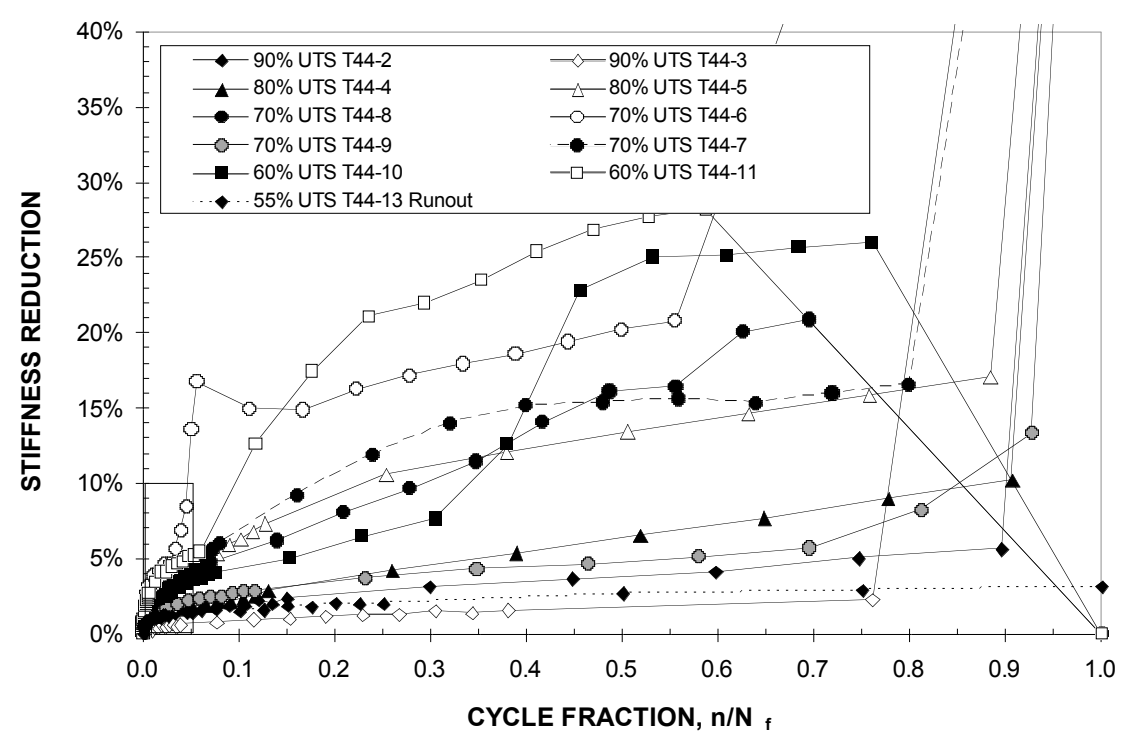

(b) Plaque T44.

Figure 9.4. Stiffness loss vs. cycle fraction, $\mathrm{n} / \mathrm{N}_{\mathrm{f}}$, for specimens tested at room temperature.

recommended later in this chapter, the room temperature stiffness loss is seen to be less than $10 \%$ for each of these tests with the exception of one specimen from Plaque T44. A trend in Figure 9.4 appears to be a decrease in stiffness reduction with increasing stress levels. Of course, the higher stress levels accumulated fewer cycles to failure.

To help validate the room temperature fatigue test results, the specimen temperature was monitored throughout each test using a Type $\mathrm{K}$ thermocouple. Mylar adhesive tape was used to fasten the 
thermocouple at the specimen centerline. Figure 9.5 shows specimen temperature as a function of life fraction. In this case, the specimen temperature is defined as the average of evenly spaced data points recorded during a given fatigue cycle. The curves show temperature changes of up to $20^{\circ} \mathrm{C}$, gradually increasing over the life fraction.

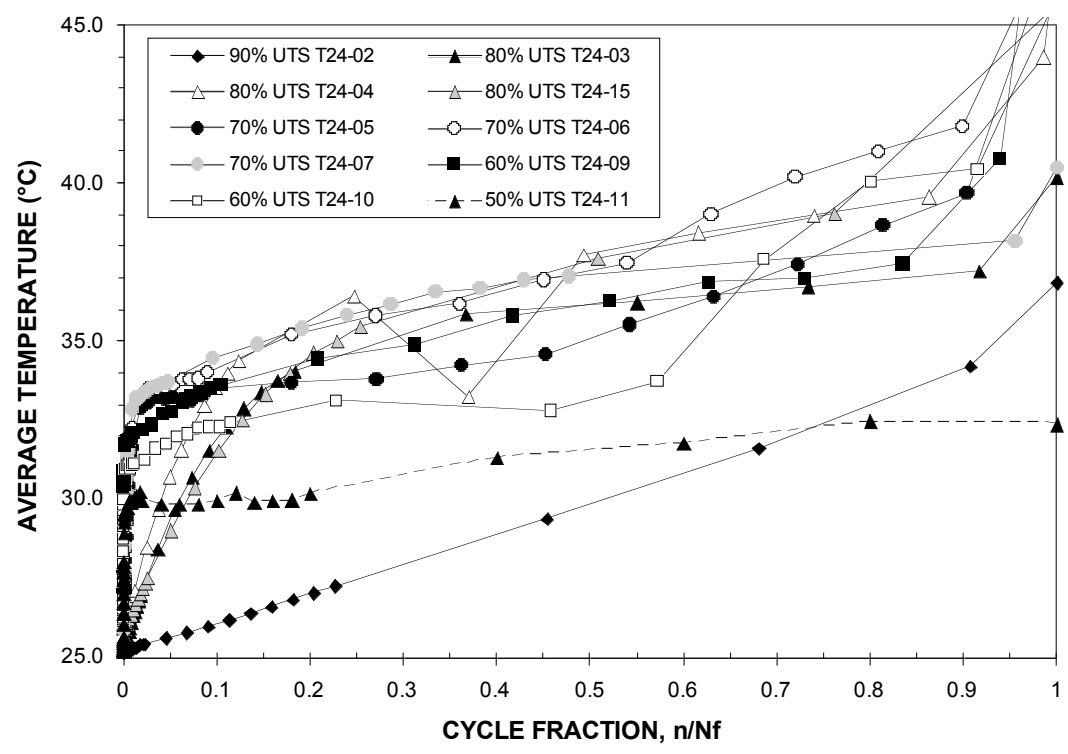

(a) Plaque T24.

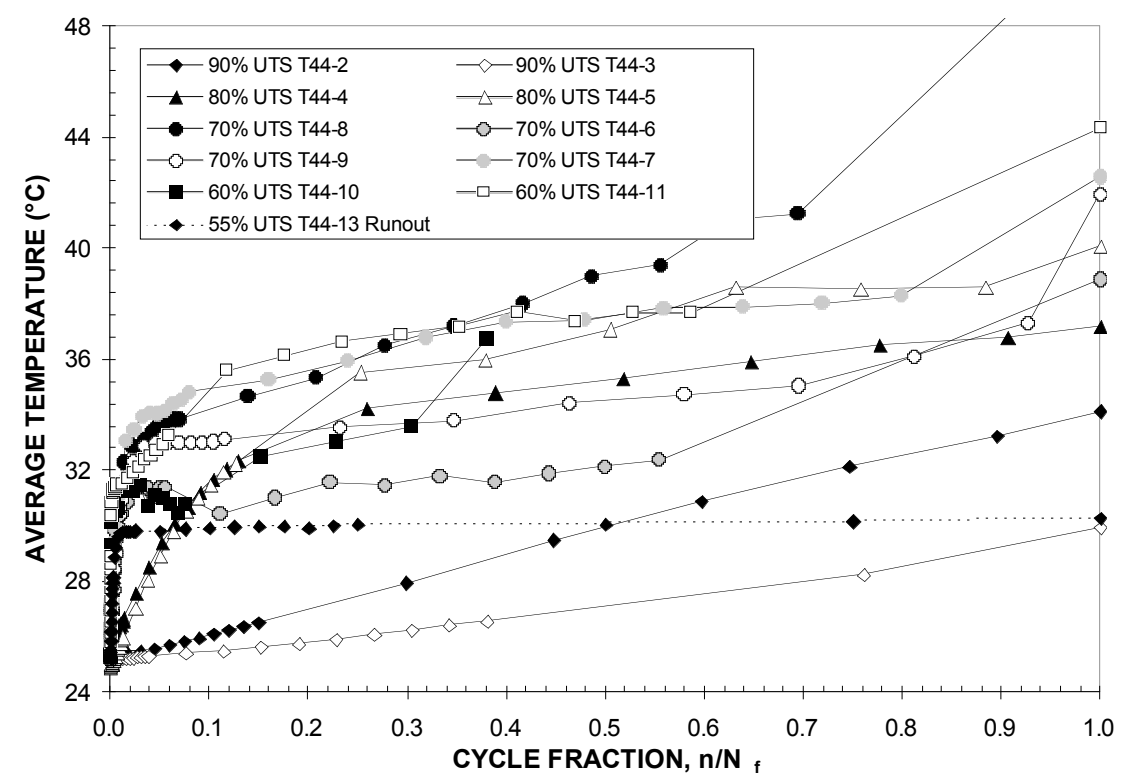

(b) Plaque T44.

Figure 9.5. Temperature vs. cycle fraction, $\mathrm{n} / \mathrm{N}_{\mathrm{f}}$, for room temperature fatigue tests.

Failure locations were recorded for each specimen tested at room temperature and are listed in Tables 9.1 and 9.2. Figure 9.6 shows that failure of these specimens actually occurred over a fairly large section of the composite material, making the identification of the failure location difficult. 


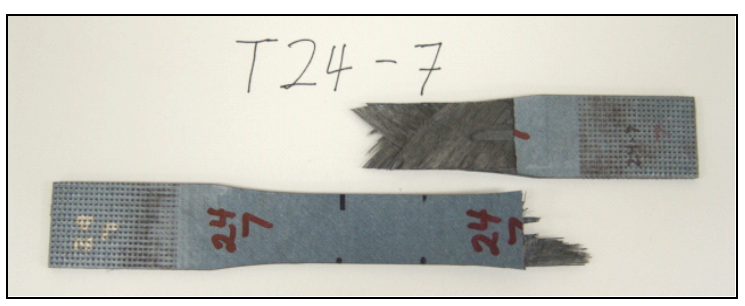

Figure 9.6. Typical failed specimen for room temperature fatigue tests.

\subsection{EFFECTS OF TEMPERATURE}

The following procedure was used to develop a consistent set of fatigue strength values over the $-40^{\circ}$ to $120^{\circ} \mathrm{C}$ temperature range for the quasi-isotropic thermoplastic material. Specimens from Plaques T24 and T34 were used to generate tensile $(\mathrm{R}=0.1) \mathrm{S}-\mathrm{N}$ curves at $-40^{\circ}, 23^{\circ}, 70^{\circ}$ and $120^{\circ} \mathrm{C}$.

Continuous, once through heated air was used to maintain specimen temperature in the $70^{\circ}$ and $120^{\circ} \mathrm{C}$ tests, while liquid nitrogen vapor with on/off control was used for the $-40^{\circ} \mathrm{C}$ tests. For each temperature, factors were developed relating the fatigue strength curve to the corresponding room temperature curve.

Figure 9.7 show the power law curve fits and corresponding data points for the at temperature fatigue tests. The corresponding fatigue strength multiplication factors based on the maximum stress curves are listed in Table 9.4.

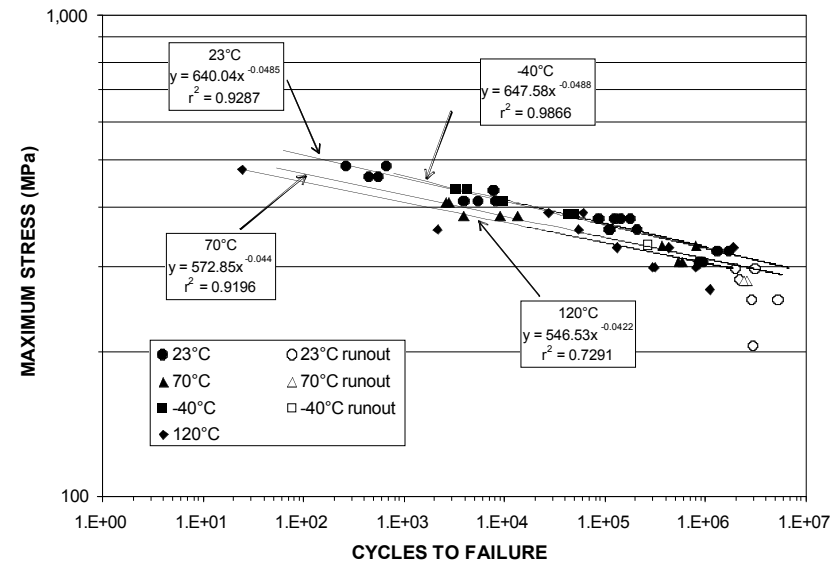

(a)

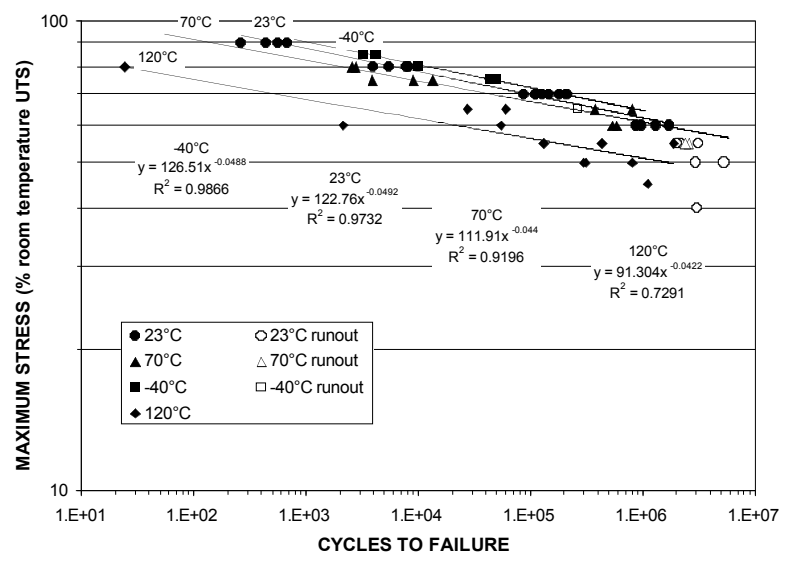

(b)

Figure 9.7. Tensile fatigue curves for Plaques T24 andT 34 specimens at various temperatures:

(a) using maximum stress and (b) using \% of plaque room temperature UTS. 
Table 9.4. Temperature fatigue multiplication factors in terms of maximum stress (MPa)

\begin{tabular}{ccccc}
\hline $\begin{array}{c}\text { Temperature } \\
\left({ }^{\circ} \mathbf{C}\right)\end{array}$ & \multicolumn{4}{c}{ Cycles to failure } \\
\cline { 2 - 5 } & $\mathbf{1 0}^{\mathbf{2}}$ & $\mathbf{1 0}^{\mathbf{4}}$ & $\mathbf{1 0}^{\mathbf{6}}$ & $\mathbf{1 0}^{\mathbf{8}}$ \\
\hline-40 & 1.03 & 1.03 & 1.04 & 1.04 \\
23 & 1.00 & 1.00 & 1.00 & 1.00 \\
70 & 0.93 & 0.96 & 0.98 & 1.00 \\
120 & 0.77 & 0.79 & 0.82 & 0.85 \\
\hline
\end{tabular}

The maximum cyclic strain and stiffness reduction were investigated and displayed to ensure integrity of the fatigue results. The maximum cyclic strain as a function of cycle number for the $-40^{\circ}, 70^{\circ}$ and $120^{\circ} \mathrm{C}$ tests are shown in Figures 9.8-9.10. As in the case of the $23^{\circ} \mathrm{C}$ tests, there is a general trend upward toward the end of the test. The stiffness reduction vs. cycle fraction for the $-40^{\circ}, 70^{\circ}$, and $120^{\circ} \mathrm{C}$ tests are shown in Figures 9.11-9.13. The stiffness losses for all the tests were less that $10 \%$ within the recommended factor of 20 design margin $\left(n / N_{f}=0.05\right)$ on cyclic life.

The average specimen temperatures as a function of cycle fraction for the three test series are shown in Figures 9.14-9.16.

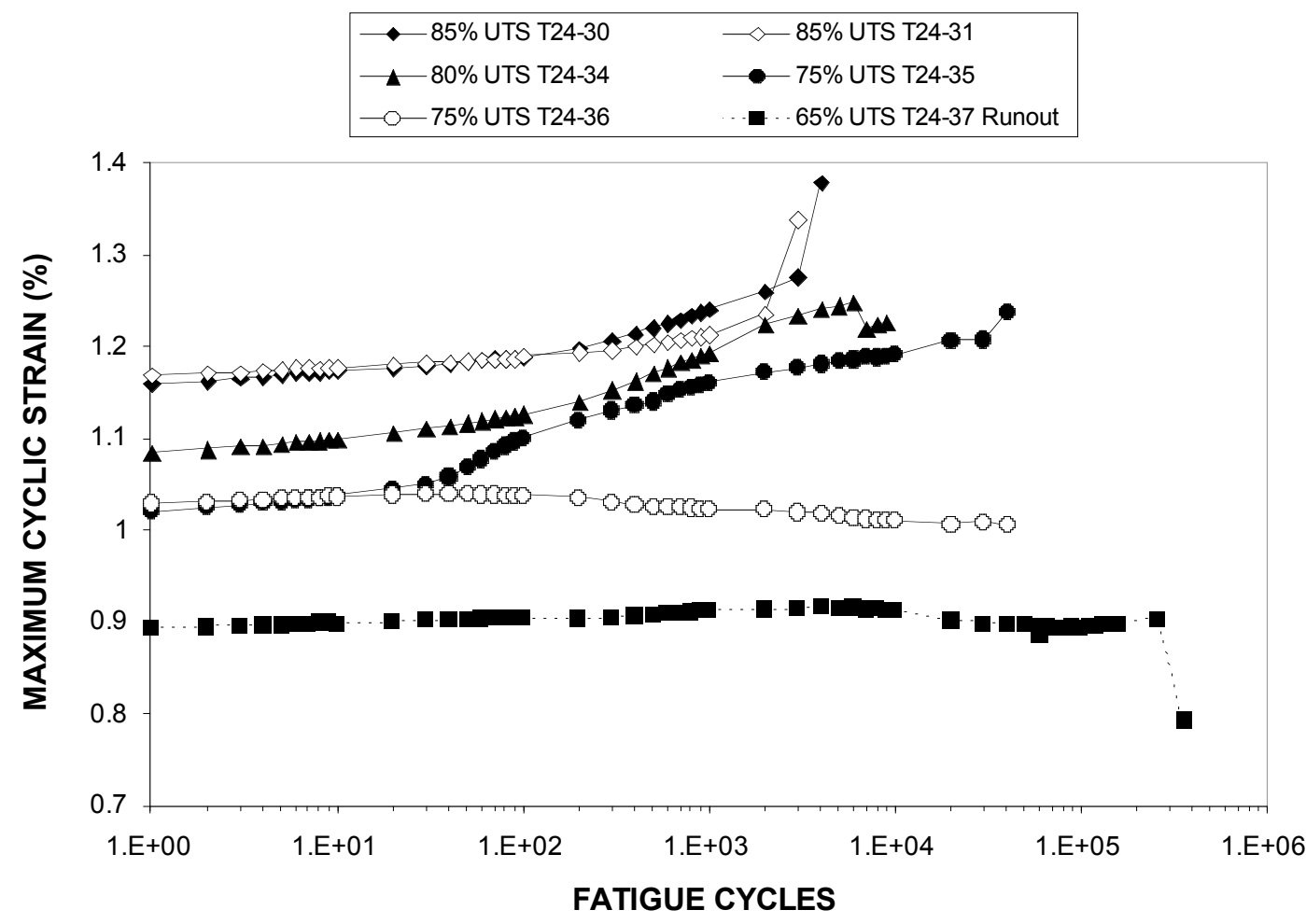

Figure 9.8 Maximum strain behavior at $-40^{\circ} \mathrm{C}$ for specimens from Plaque T24. 


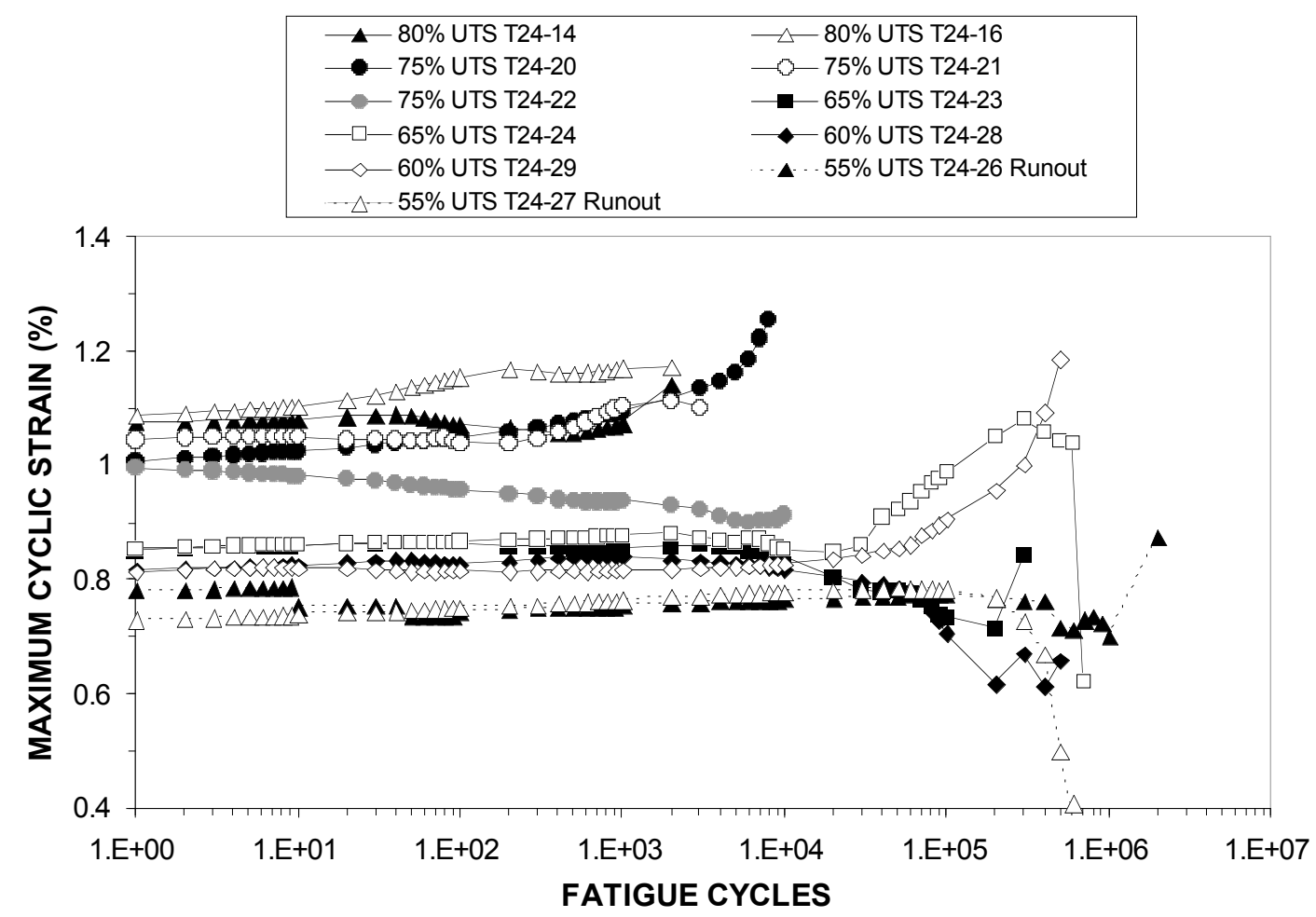

Figure 9.9. Maximum strain behavior at $70^{\circ} \mathrm{C}$ for specimens from Plaque T24.

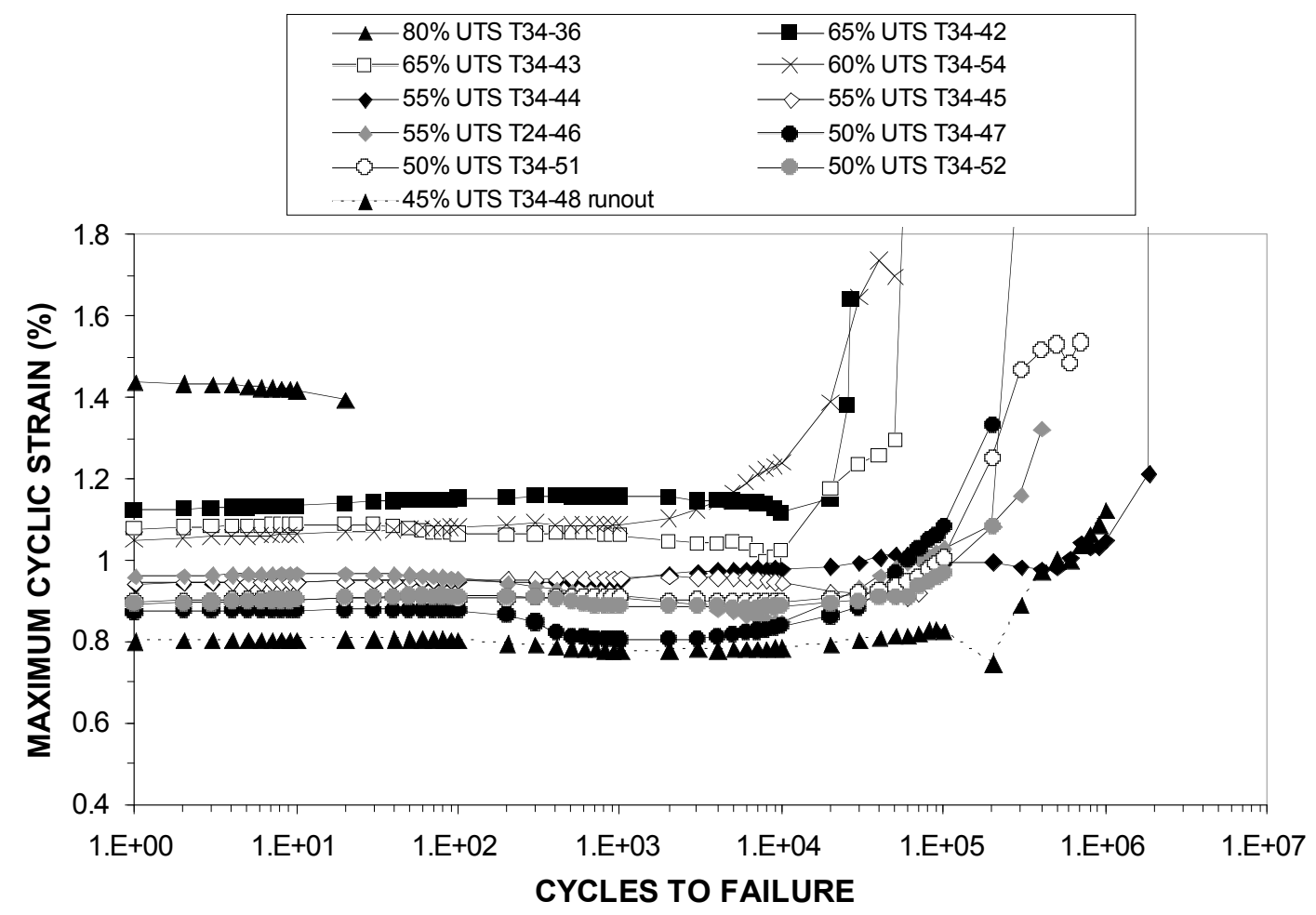

Figure 9.10. Maximum strain behavior at $120^{\circ} \mathrm{C}$ for specimens from Plaque T34. 


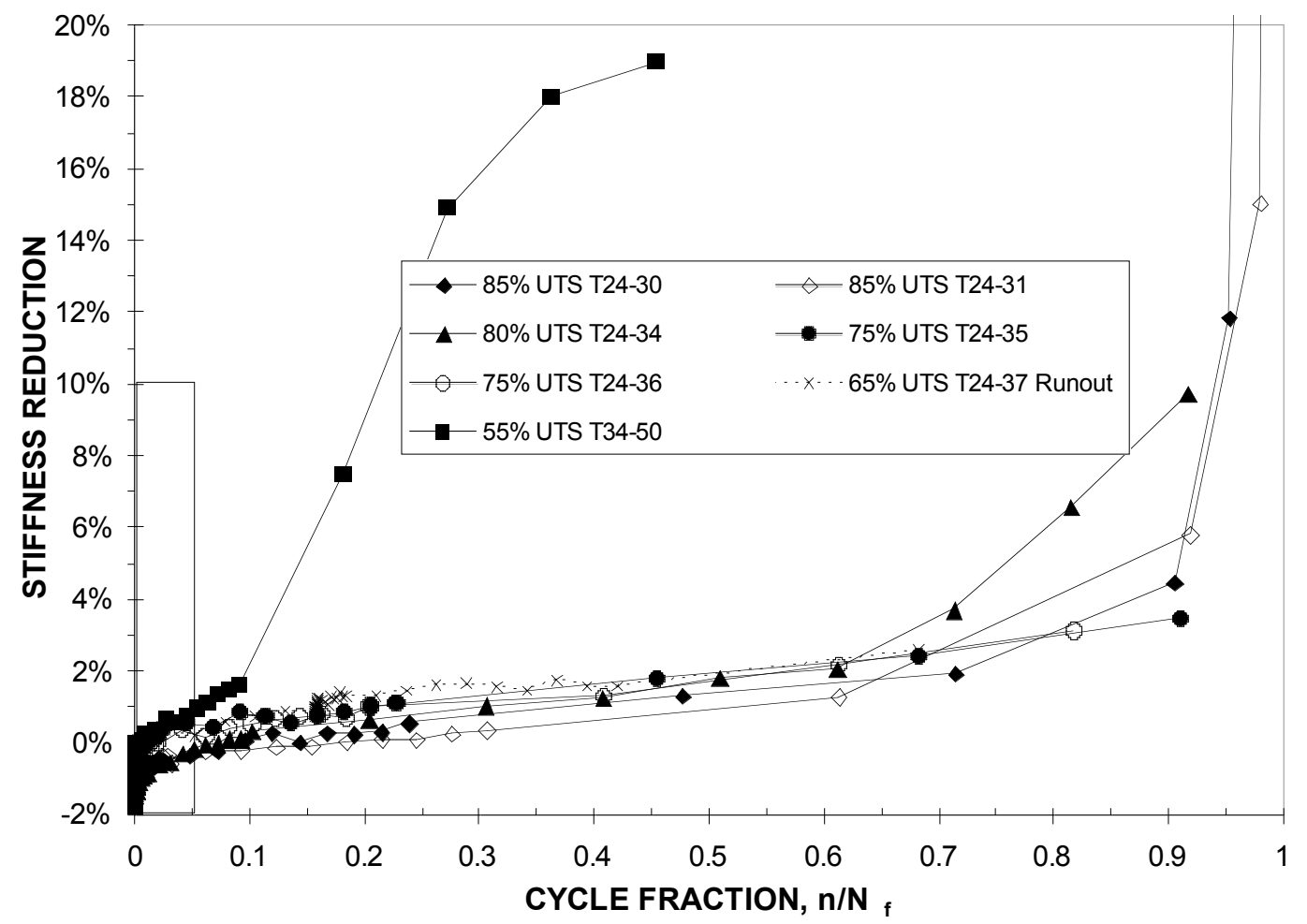

Figure 9.11. Stiffness loss vs. cycle fraction, $\mathrm{n} / \mathrm{N}_{\mathrm{f}}$, for Plaque T24 and T34 specimens tested at $-40^{\circ} \mathrm{C}$.

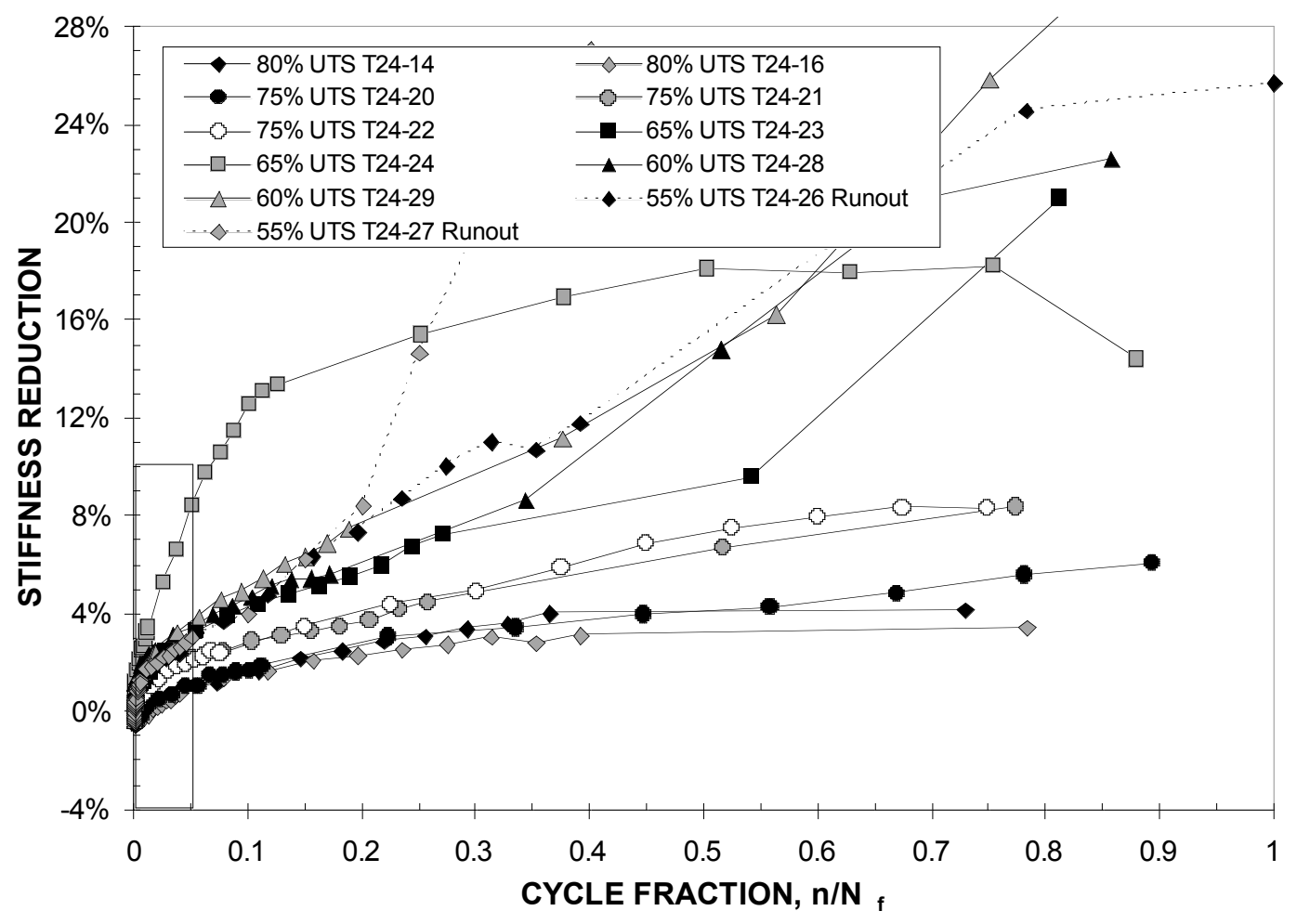

Figure 9.12. Stiffness loss vs. cycle fraction, $\mathrm{n} / \mathrm{N}_{\mathrm{f}}$, for Plaque $\mathrm{T} 24$ specimens tested at $70^{\circ} \mathrm{C}$. 


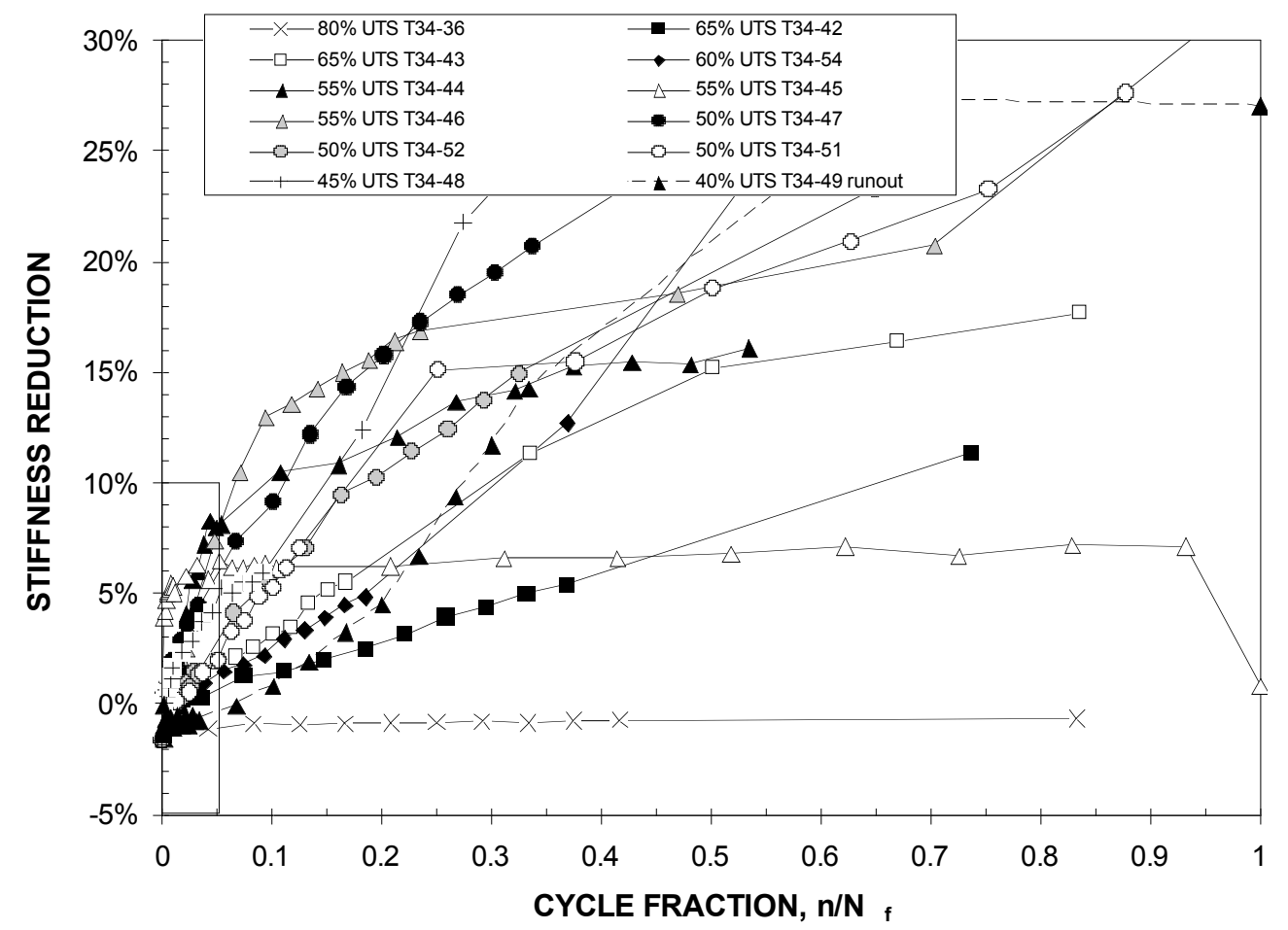

Figure 9.13. Stiffness loss vs. cycle fraction, $\mathrm{n} / \mathrm{N}_{\mathrm{f}}$, for Plaque $\mathrm{T} 34$ specimens tested at $120^{\circ} \mathrm{C}$.

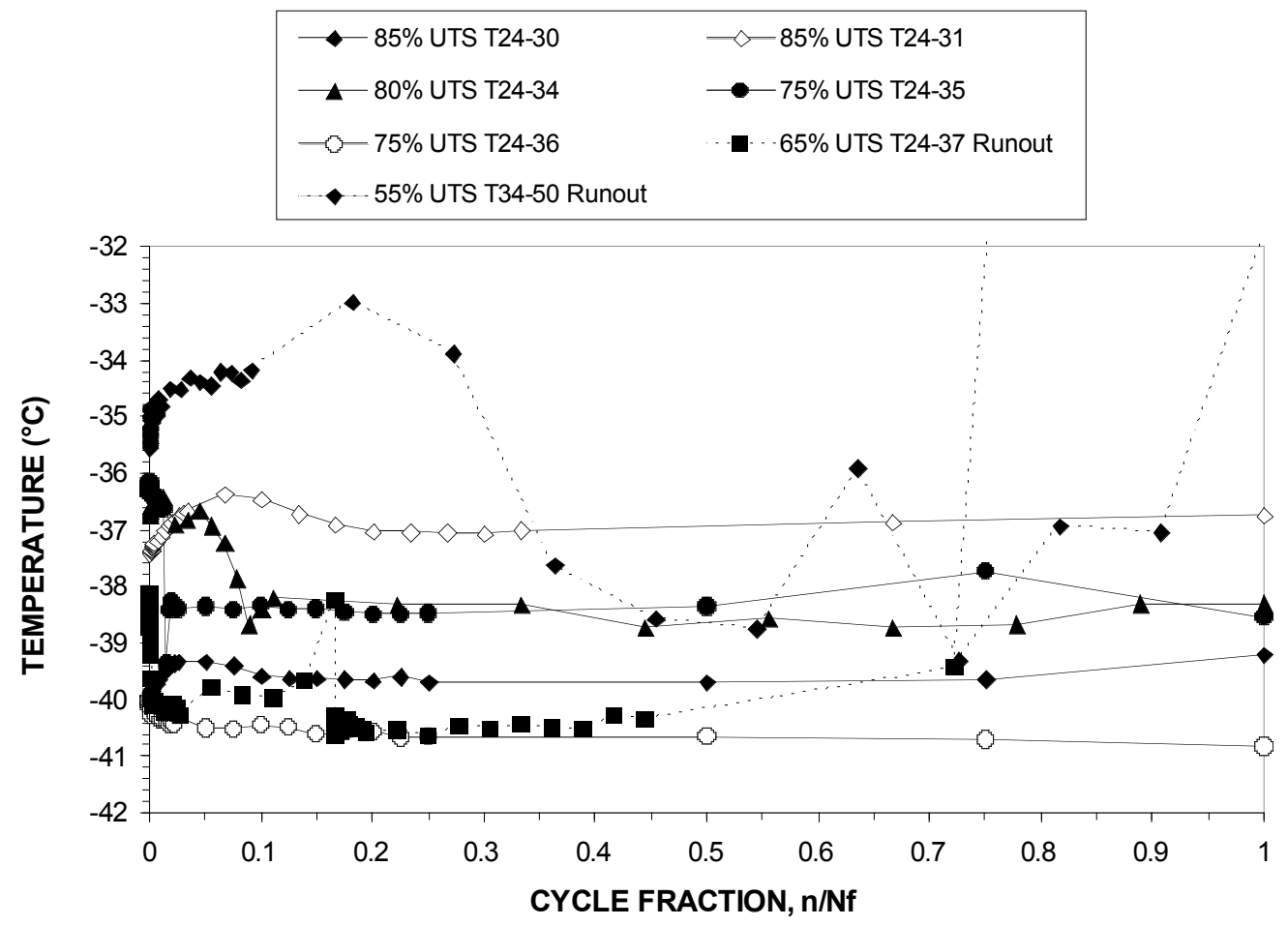

Figure 9.14. Average specimen temperature vs. cycle fraction: Plaque T24 and T34 specimens at $-40^{\circ} \mathrm{C}$. 


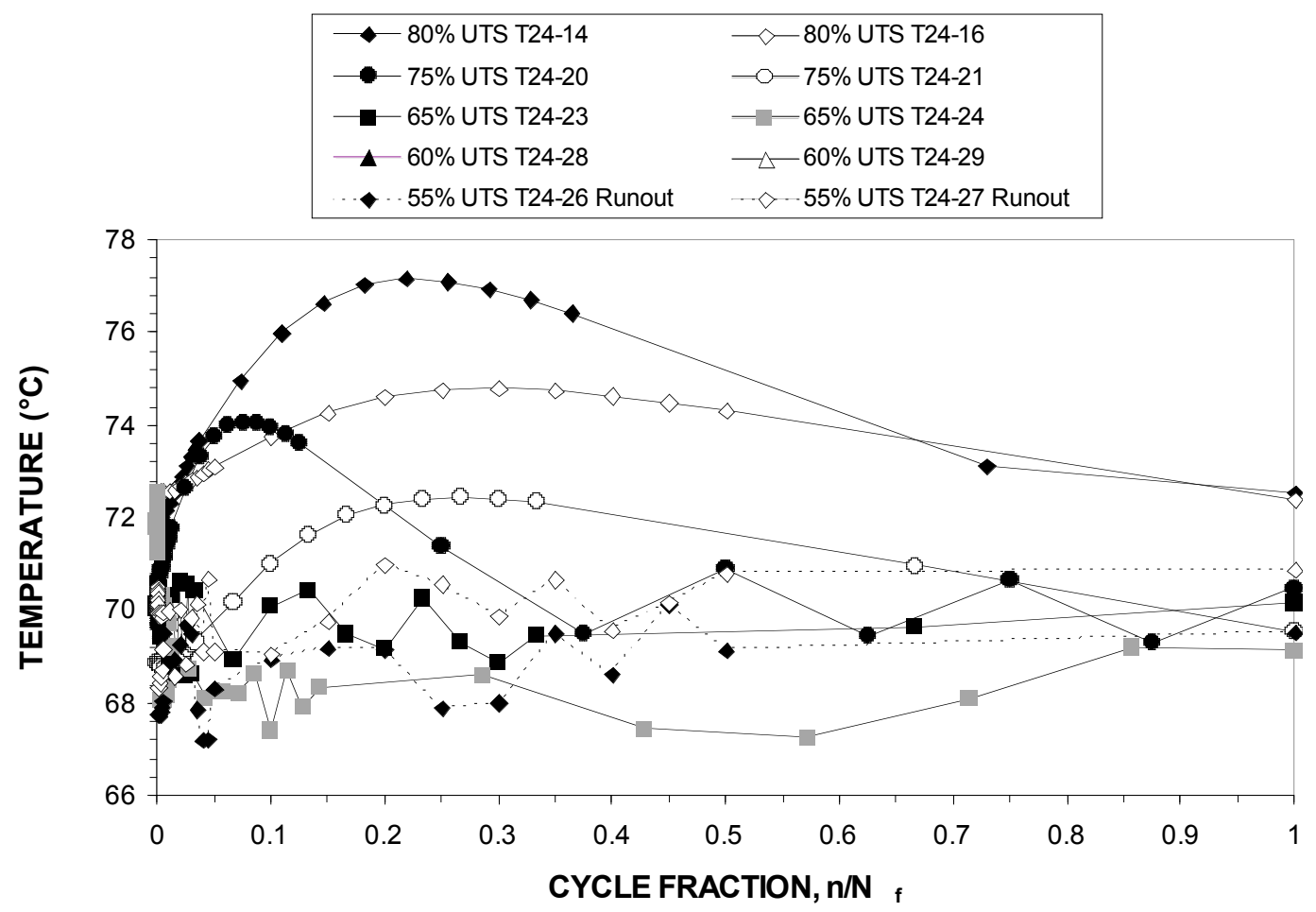

Figure 9.15. Average specimen temperature vs. cycle fraction for Plaque T24 specimens at $70^{\circ} \mathrm{C}$.

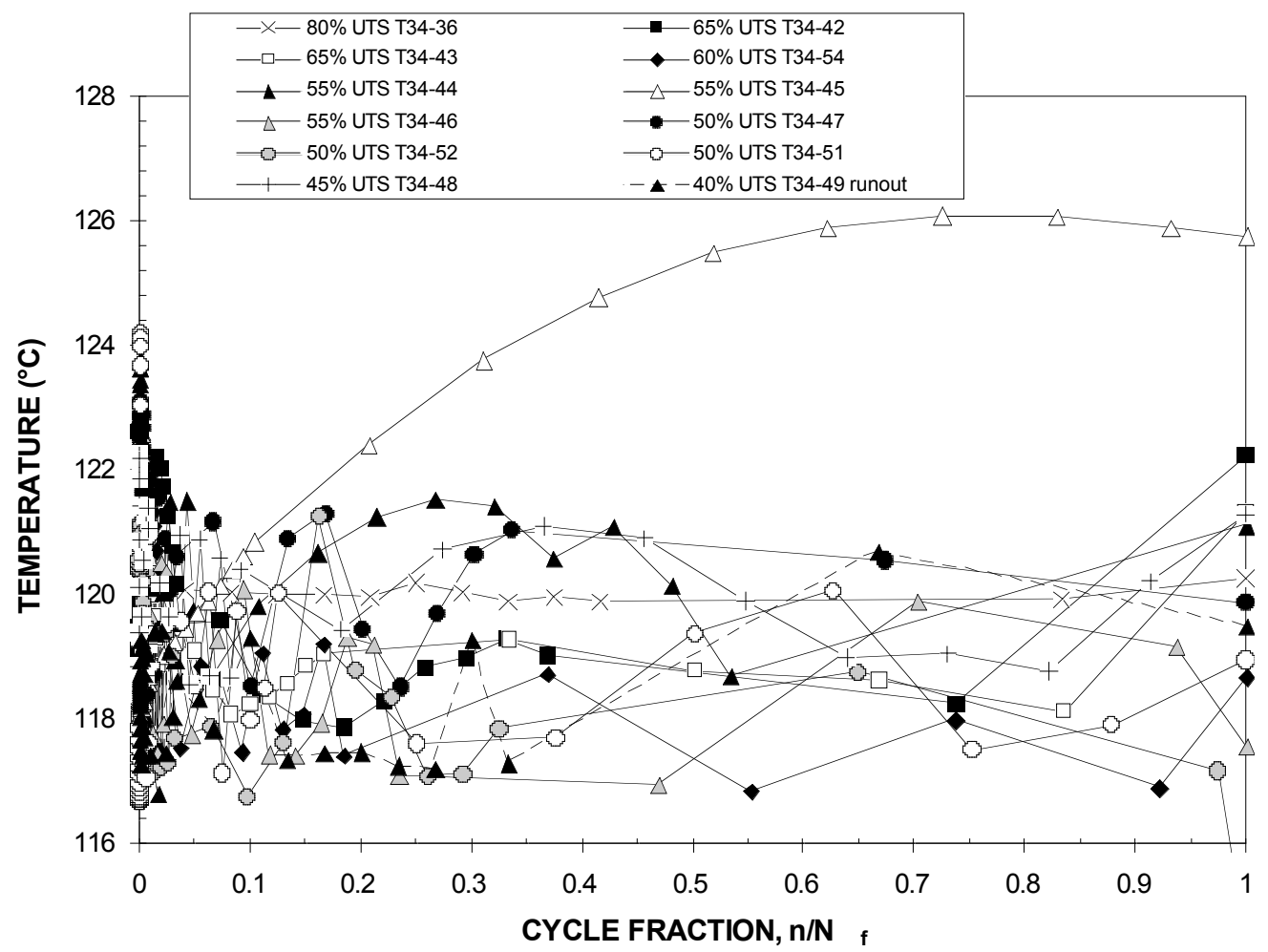

Figure 9.16. Average specimen temperature vs. cycle fraction for Plaque T34 specimens at $120^{\circ} \mathrm{C}$. 


\subsection{FLUID EFFECTS}

Fatigue strength multiplication factors to account for fluid effects were developed in a similar manner to the temperature factors. The following two standard fluid conditions were examined:

- specimens soaked for 1000 hours then tested in distilled water, and

- specimens soaked for 100 hours then tested in windshield washer fluid (70\% methanol, 30\% distilled water by volume).

All of the room temperature tensile fatigue $(\mathrm{R}=0.1)$ tests were carried out on specimens from Plaque T44. In addition to the two fluid exposures, a baseline in-air test series was performed and a resulting fatigue curve was developed (previously discussed in Section 9.2). The ratio of the fatigue strength from a fluid curve to the corresponding strength from the in-air curve provided the fluid reduction factors.

The S-N results from all three fatigue series are plotted in Figure 9.17. The coefficients of determination, $\mathrm{r}^{2}$, for all three data sets are very good. The curve fit equations shown in the figure were used to calculate the fluid multiplication factors. The resulting fluid factors are listed in Table 9.5.

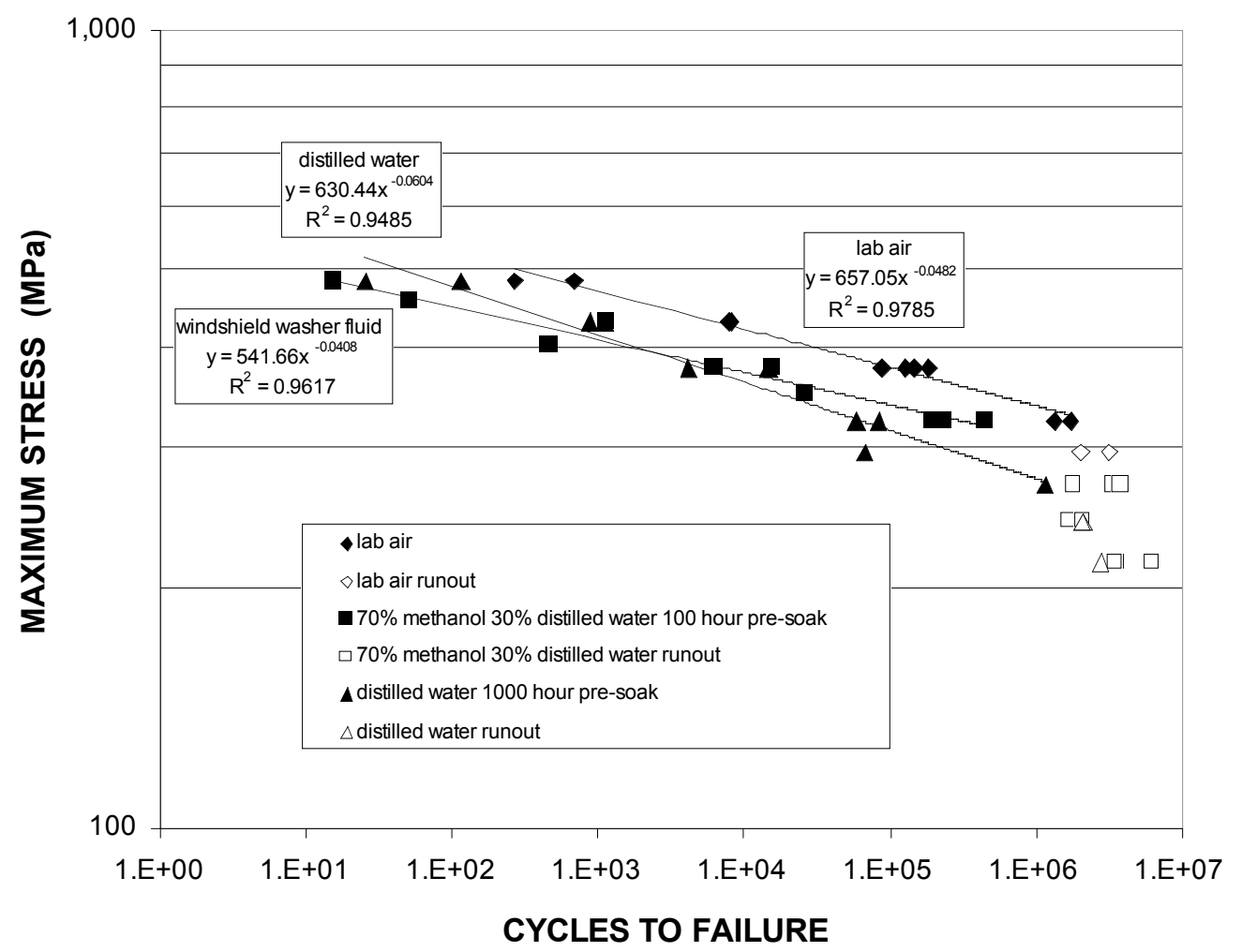

Figure 9.17. Effects of fluids on room temperature fatigue strength for Plaque T44 specimens. 
Table 9.5. Fluid fatigue multiplication factors

\begin{tabular}{lcccc}
\hline \multirow{2}{*}{ Environment } & \multicolumn{4}{c}{ Cycles to failure } \\
\cline { 2 - 5 } & $\mathbf{1 0}^{\mathbf{2}}$ & $\mathbf{1 0}^{\mathbf{4}}$ & $\mathbf{1 0}^{\mathbf{6}}$ & $\mathbf{1 0}^{\mathbf{8}}$ \\
\hline Air & 1.00 & 1.00 & 1.00 & 1.00 \\
Windshield washer fluid & 0.85 & 0.88 & 0.91 & 0.95 \\
Distilled water & 0.91 & 0.86 & 0.81 & 0.77 \\
\hline
\end{tabular}

Figure 9.18 shows the measured stiffness loss for the distilled water and windshield washer fluid specimens. Stiffness losses for the distilled water specimens are all less than $10 \%$ at the recommended factor of 20 design margin $\left(\mathrm{n} / \mathrm{N}_{\mathrm{f}}\right)$ on cyclic life. For the windshield washer tests, three of the specimens had stiffness losses that were approximately $10 \%$ at the recommended factor of 20 design margin.

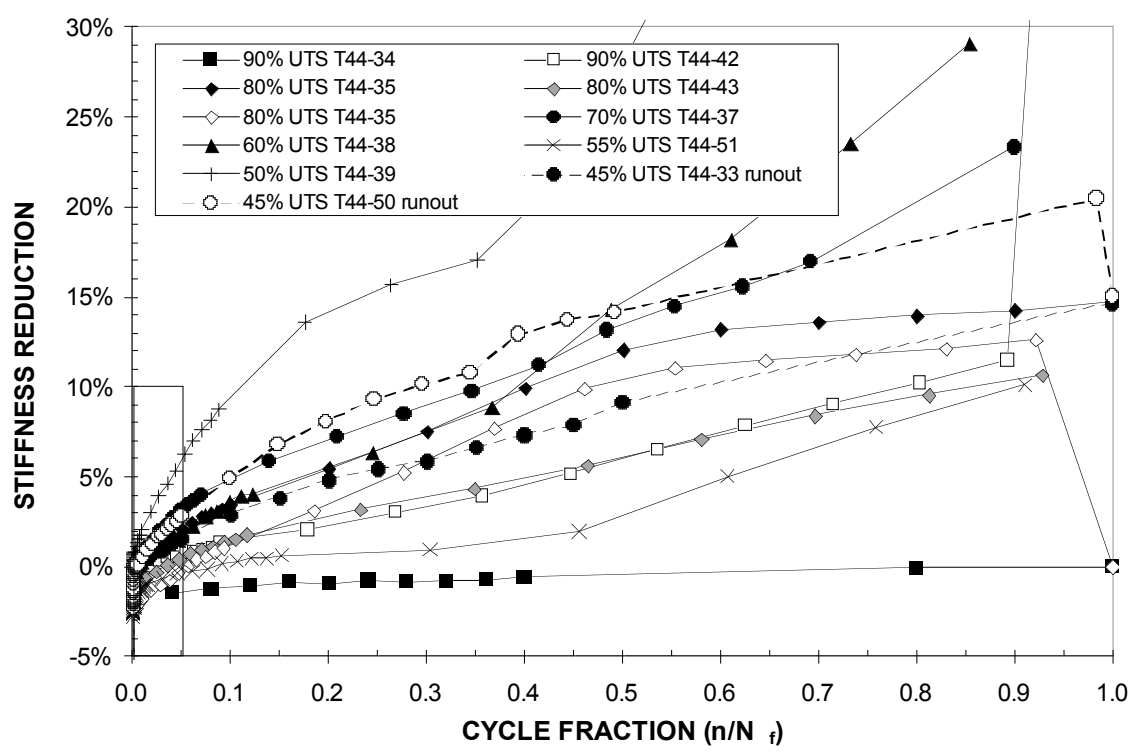

(a) Distilled water.

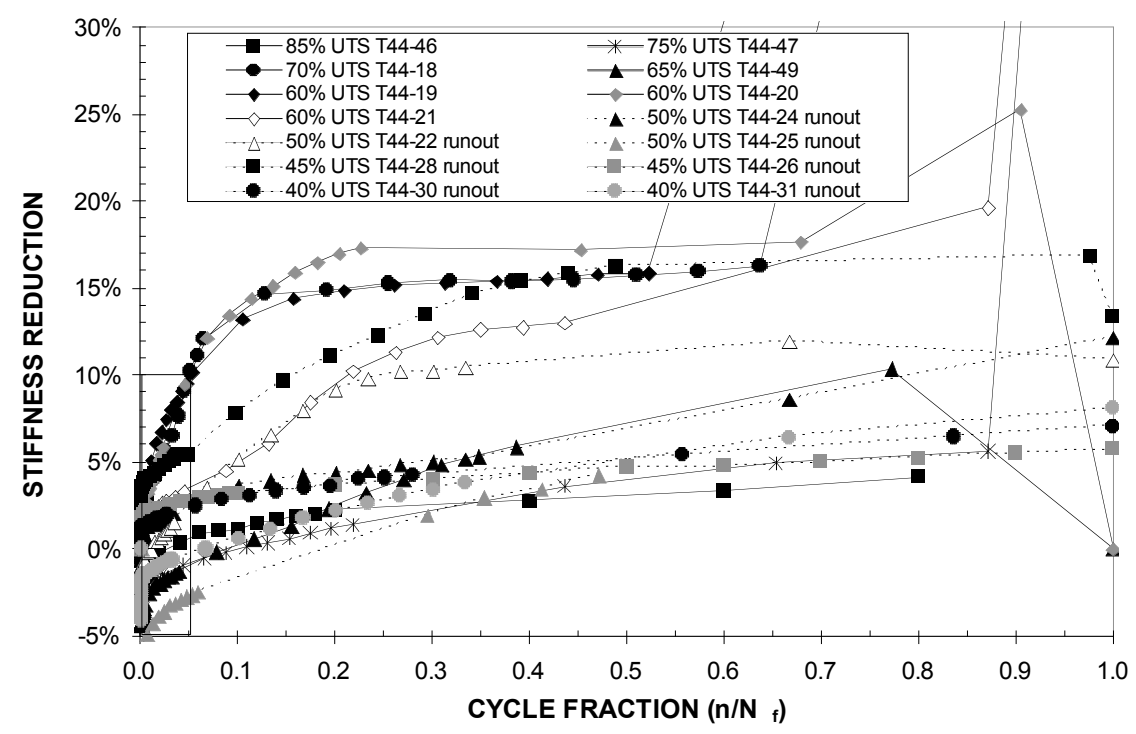

(b) Windshield washer fluid.

Figure 9.18. Stiffness loss vs. cycle fraction, $\mathrm{n} / \mathrm{N}_{\mathrm{f}}$, for Plaque $\mathrm{T} 44$ specimens at room temperature. 
The maximum cyclic strain vs. cycle number for the tests in both fluids is shown in Figure 9.19. The curves appear much the same as the in-air case shown in Figure 9.3b. For the fluid tests, the specimen temperature was not monitored during the fatigue cycling.

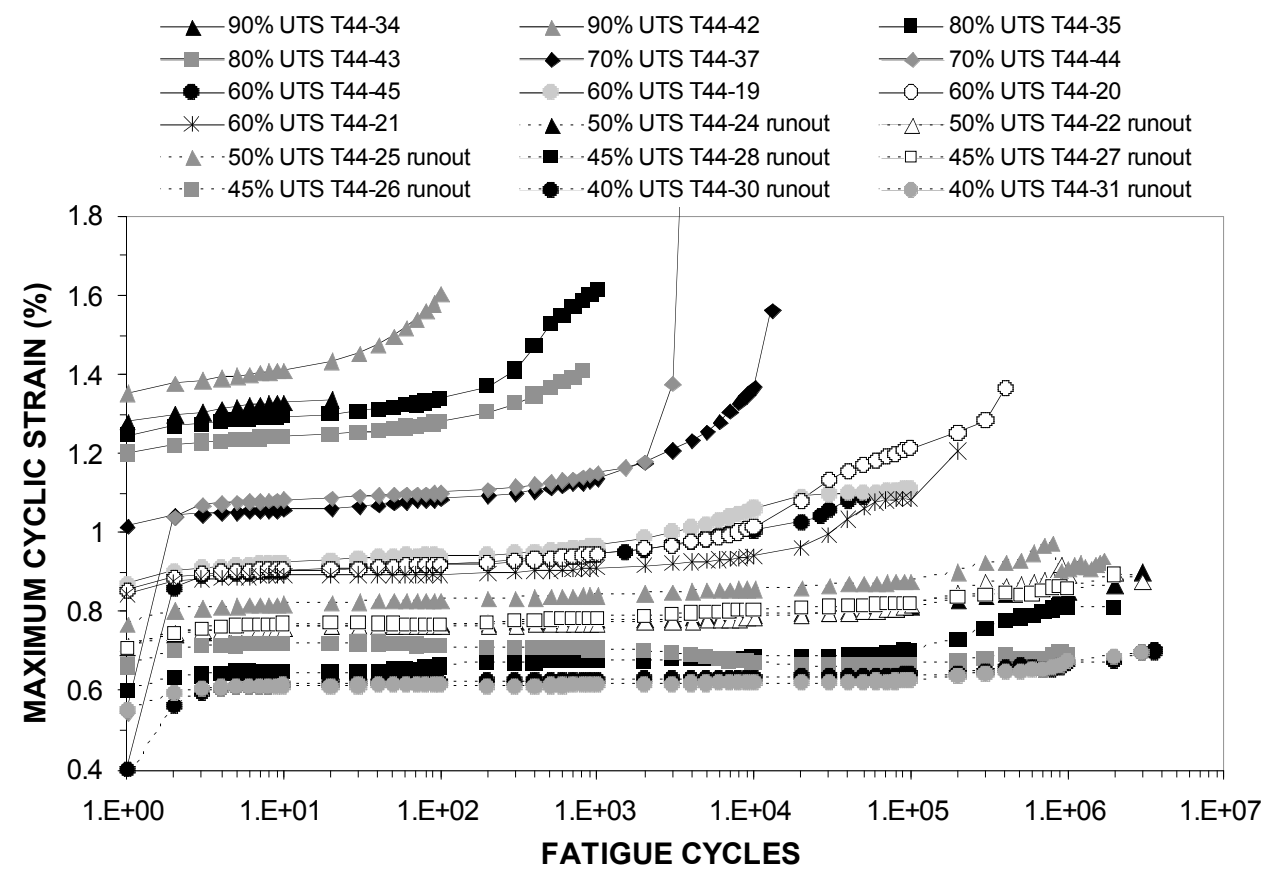

(a) Distilled water.

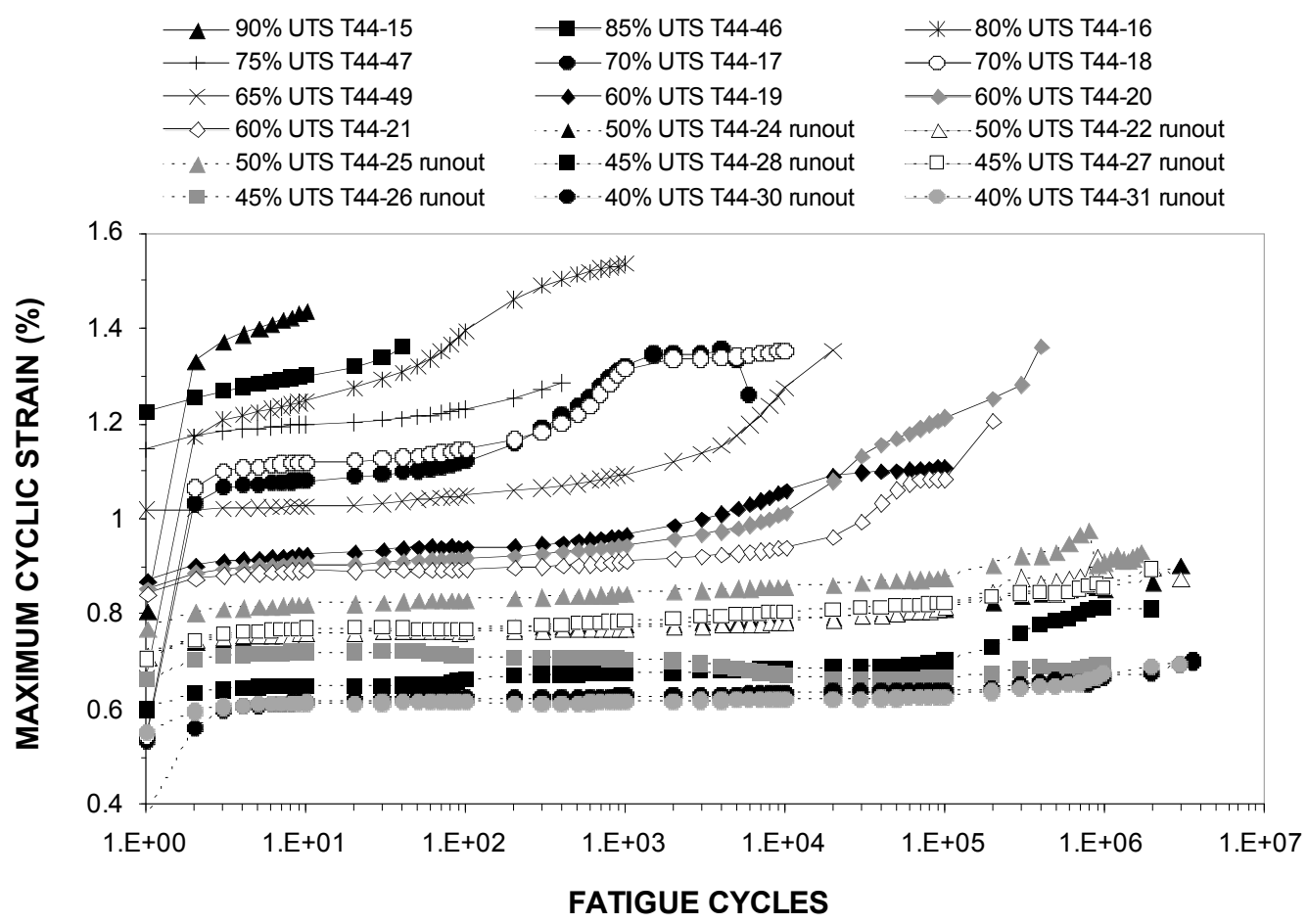

(b) Windshield washer fluid.

Figure 9.19. Maximum strain behavior for Plaque T44 specimens. 


\subsection{EXTENSION TO OTHER TYPES OF CYCLES}

While tensile cycling is expected to commonly occur in automotive structures, other types of cycles, with various mean stresses, are also likely. Consequently, design guidance cannot be limited to tensile cycling only, provisions are needed for assessing other cycle types as well. As was done for the previous composites examined, a limited series of mean-stress fatigue tests was conducted using the hourglass specimen that was shown in Fig. 9.1. Four cycle types, depicted in Figure 9.20, were utilized, and S-N curves were developed for each. Two of the cycle types $-\mathrm{R}=0$ and the cycle with a tensile mean stress of $45 \%$ of the UTS - involved only tensile stresses. The other two cycle types - fullyreversed loading, $\mathrm{R}=-1$, and zero to compressive loading, $\mathrm{R}=-\infty-$ involved compressive stresses. Because compressive loadings, and thus the potential for buckling failure modes, were involved in two of the cycle types, hourglass-shaped specimens were used for all four. All of the mean stress test specimens came from a single plaque (T38) and a minimum of nine specimens was tested for each cycle type.
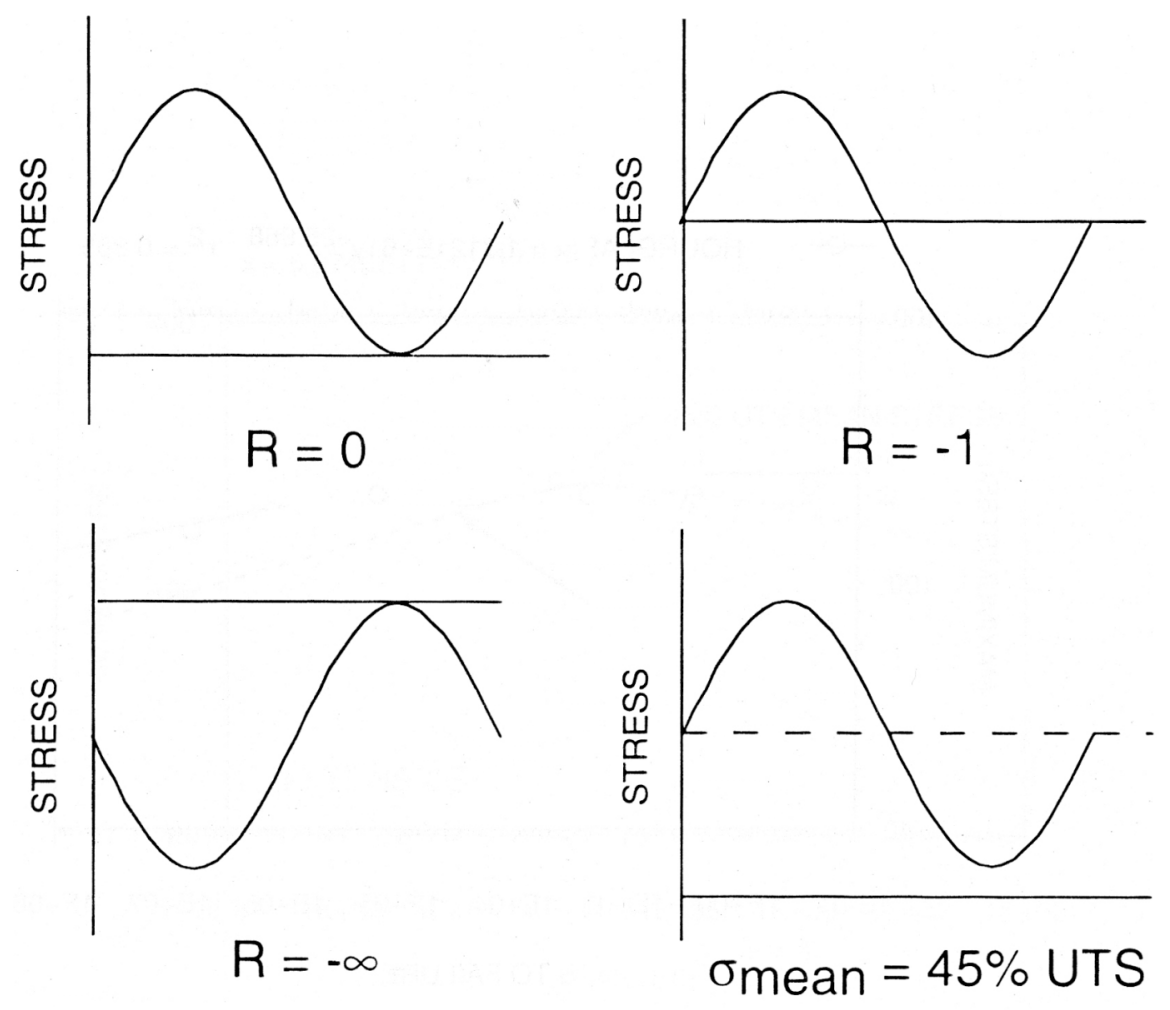

Figure 9.20. Four cyclic stress histories used to examine mean-stress effects.

The first question to be addressed is how well the $\mathrm{R}=0$ tensile fatigue curve obtained from Plaque T38 hourglass specimens matches the $\mathrm{R}=0.1$ curve obtained using dogbone specimens from Plaques T24 andT44. Tensile fatigue $(\mathrm{R}=0)$ results for the hourglass specimens are compared to the results for the dogbone tensile $(\mathrm{R}=0.1)$ fatigue specimens in Figure 9.21. The percentage of ultimate stress was used for the comparison to account for the differences in the UTS of the different plaques. The fatigue curve for the hourglass specimens is similar to the curve for the dogbone specimens. However, the hourglass specimens had a slightly longer fatigue life at $80 \%$ and $70 \%$ UTS and a slightly shorter fatigue life at $60 \%$ UTS. 


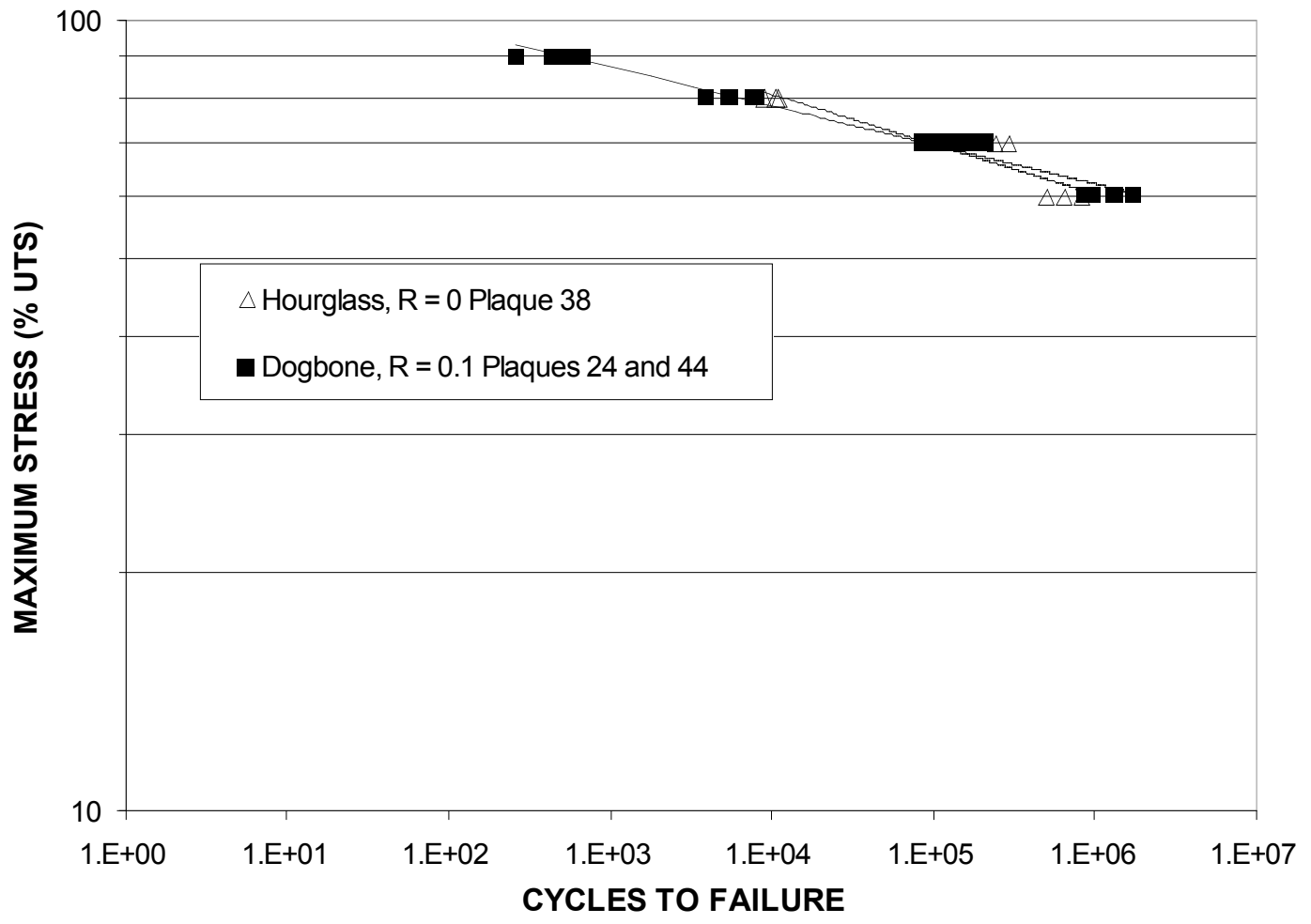

Fig. 9.21. Tensile $\mathrm{S}-\mathrm{N}$ curve for hourglass specimens $(\mathrm{R}=0)$ compared with curve for dogbone specimens $(\mathrm{R}=0.1)$.

The S-N curves on a maximum stress basis (or $\left|S_{\min }\right|$ ) with the corresponding power law curve fits for all four cycle types are shown in Figure 9.22. Figure 9.23 shows the data and resulting curves using the alternating stress component, $\mathrm{S}_{\mathrm{a}}$, rather than the maximum stress as the correlating parameter. Using the alternating stress component brings the slopes of the four curves closer together.

One other stress parameter tried was that suggested by Conle and Ingall. ${ }^{2}$

$$
S=\sqrt{S_{\max } \times S_{a}}
$$

They observed that several sets of data from the literature could be correlated with this parameter, provided that tension and compression were treated separately. This is due to the fact that tension and compression failure modes differed. In this case (Figure 9.24), the correlation is not as good as for the stress amplitude component. 


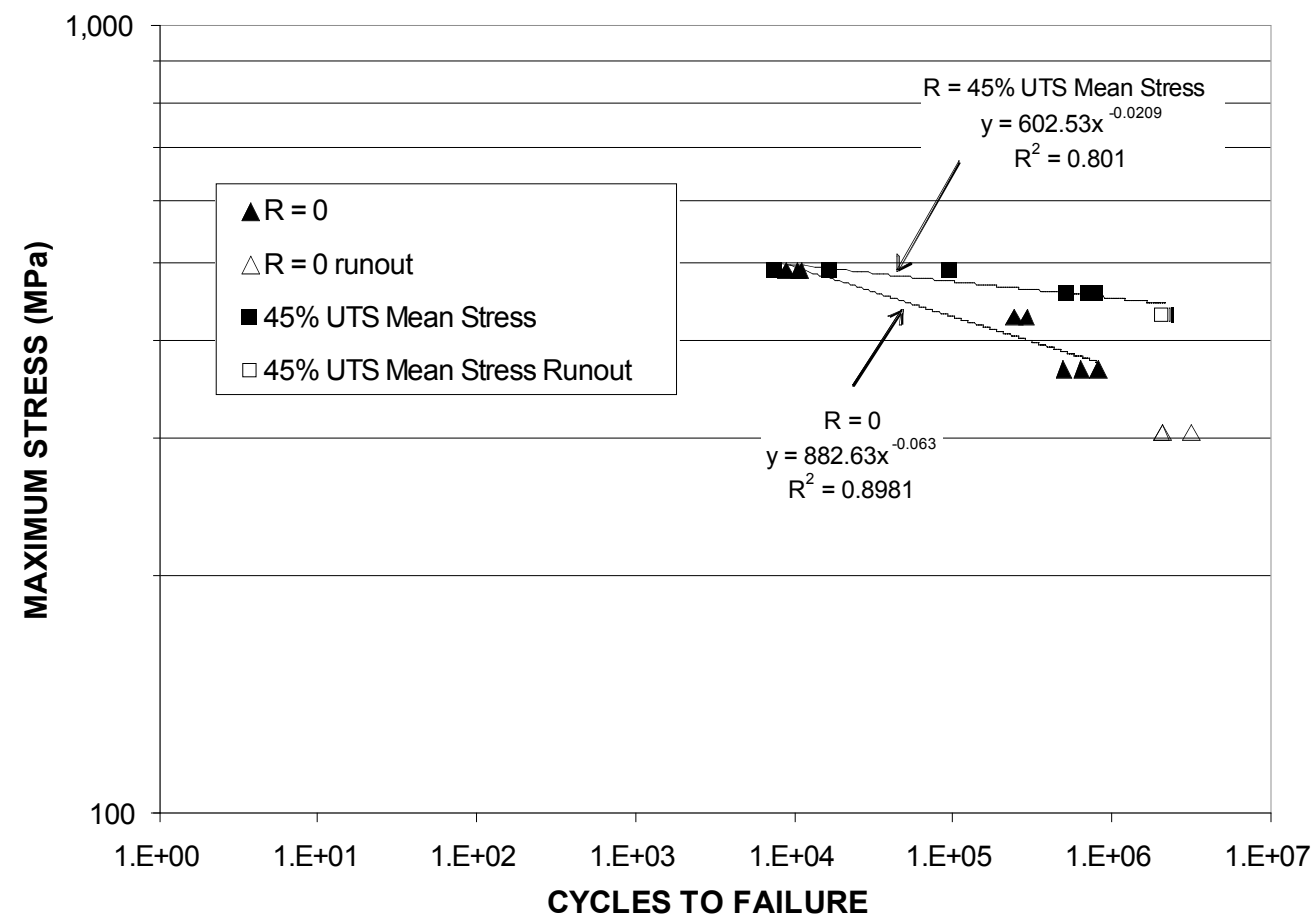

(a) Tensile cycles.

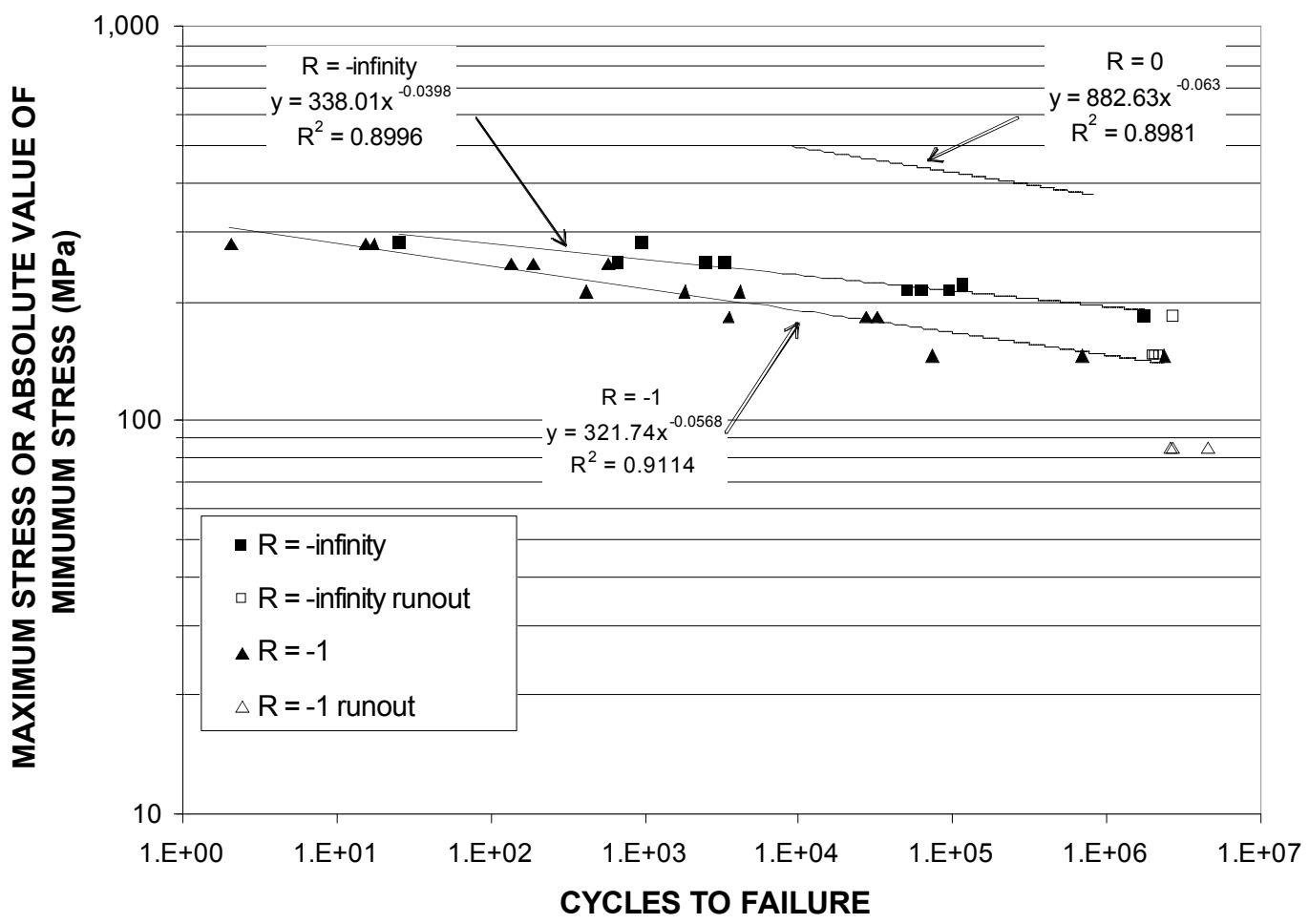

(b) Compressive cycles.

Figure 9.22. Fatigue curves from four different mean-stress cycle types compared on the basis of maximum, or absolute value of minimum stress. 


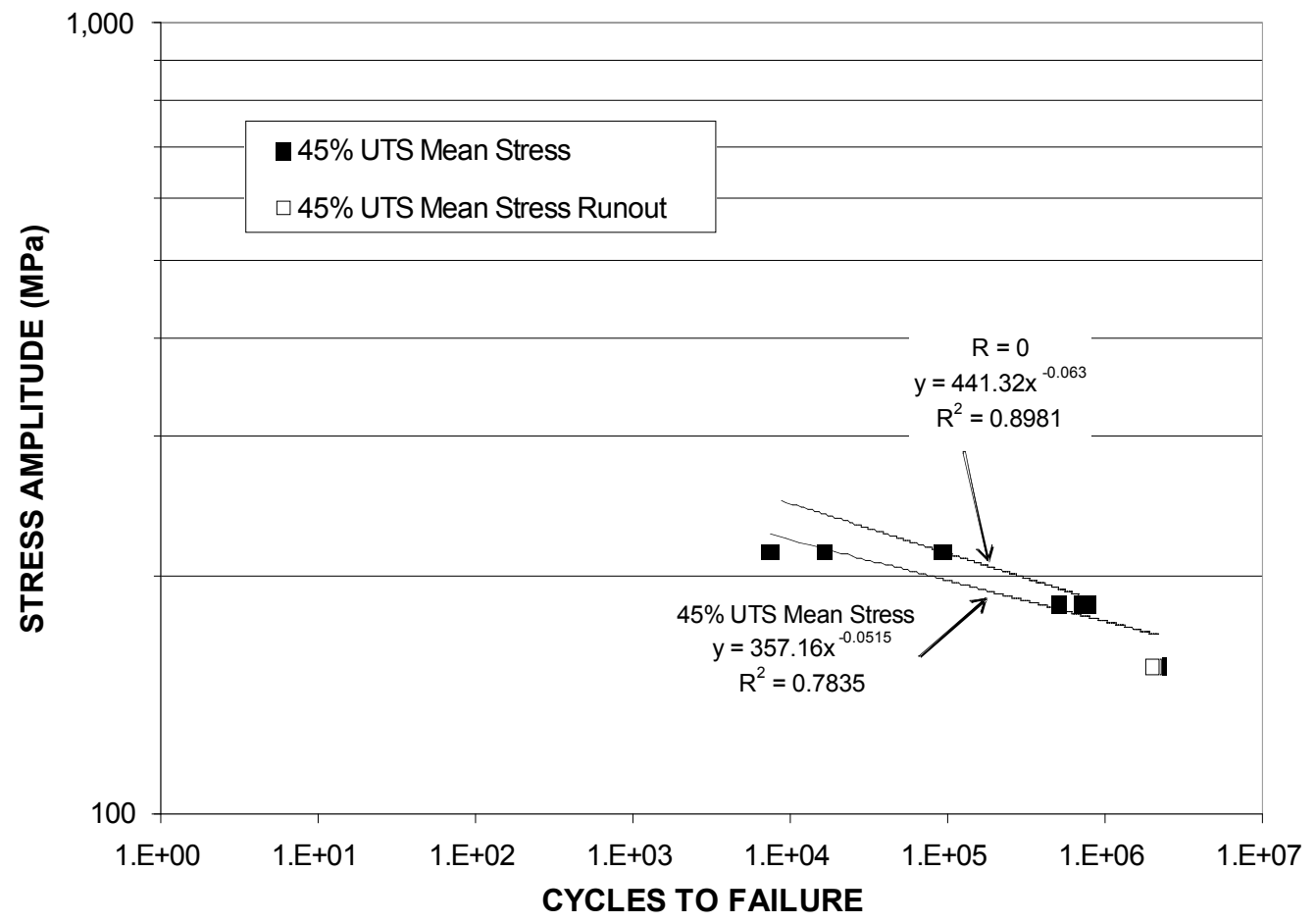

(a) Tensile cycles.

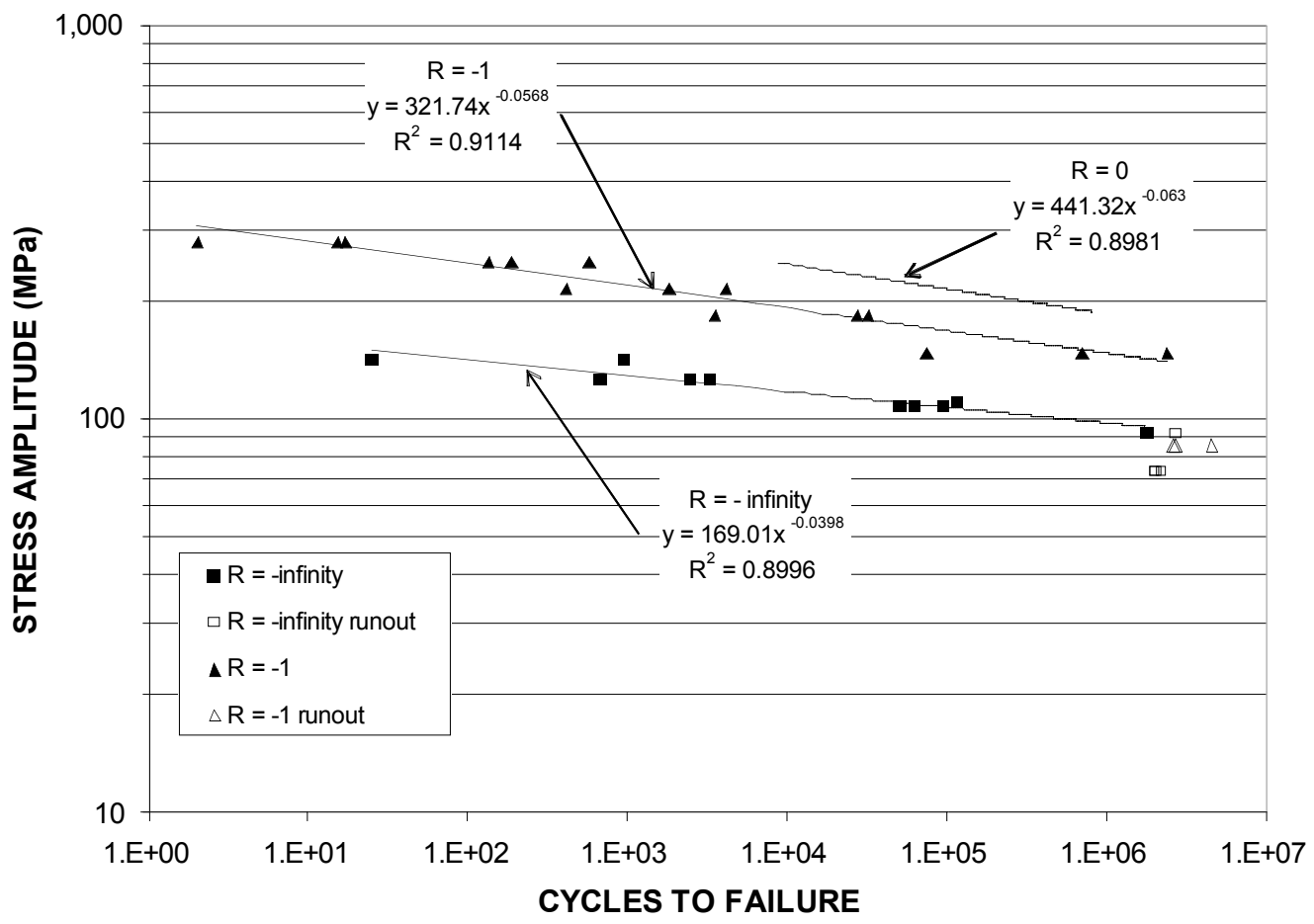

(b) Compressive cycles.

Figure 9.23. Fatigue curves from four different mean-stress cycle types compared on the basis of stress amplitude, $\mathrm{S}_{\mathrm{a}}$. 


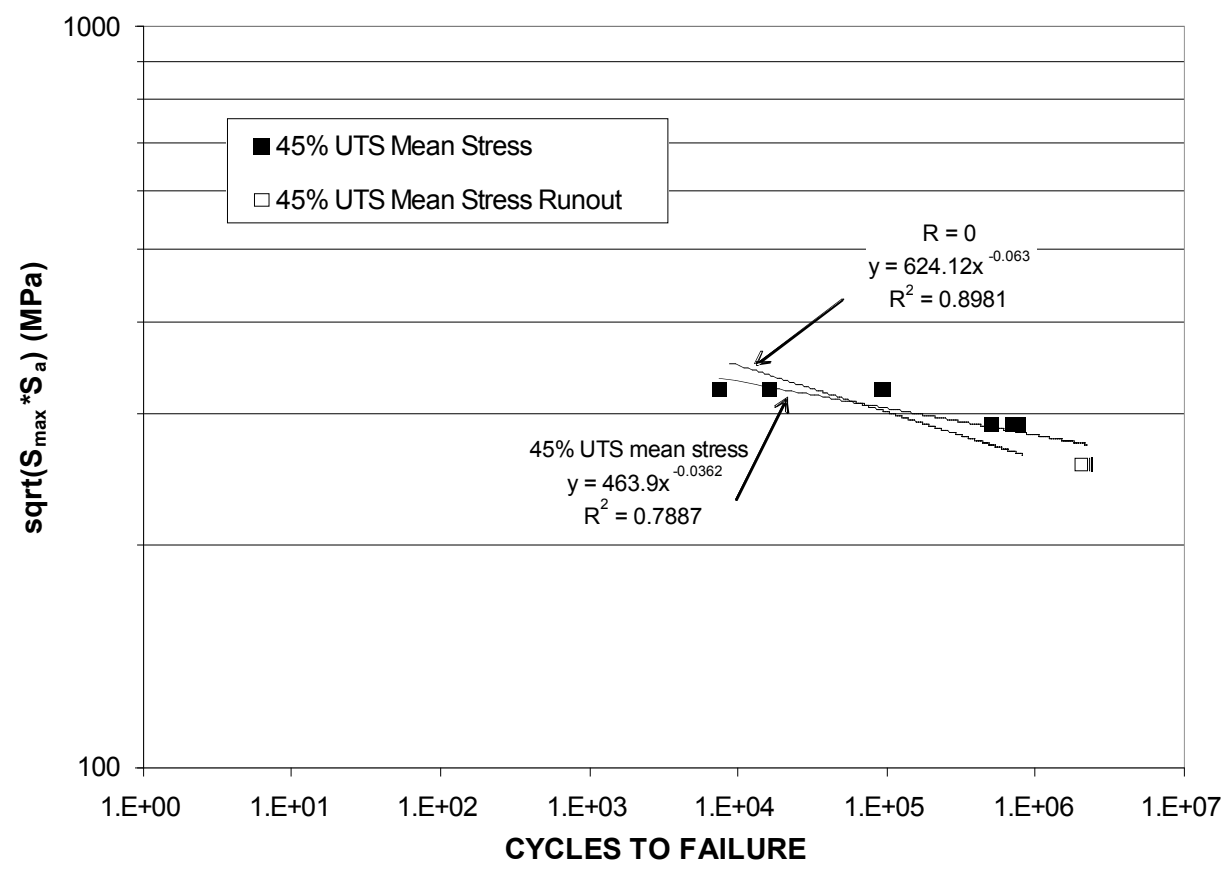

(a) Tensile cycles.

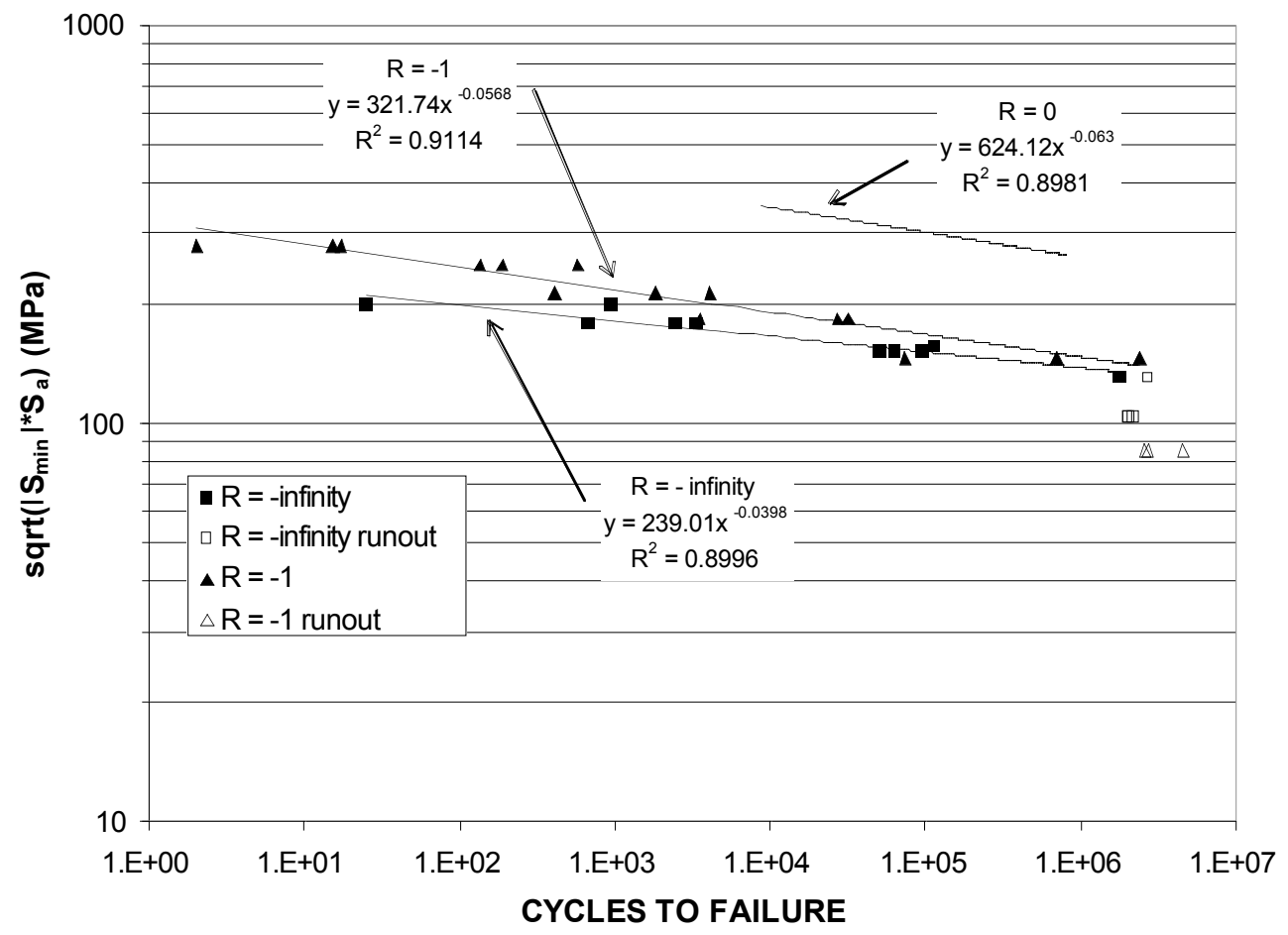

(b) Compressive cycles

Figure 9.24. Fatigue curves from four different mean-stress cycle types compared on the basis of stress parameter $\sqrt{S_{\max } \times S_{a}}$ or $\sqrt{\left|S_{\min }\right| \times S_{a}}$. 
Owen and $\mathrm{Smith}^{3}$ suggested several forms of the Goodman relation for correlating composite fatigue results from tests with various mean stresses. The simplest of these is:

$$
S_{a}=S_{0}\left(1-\frac{\sigma_{m}}{U T S}\right)
$$

where $\mathrm{S}_{\mathrm{a}}$ is the alternating stress in a cycle having mean stress $\sigma_{m}$, and $\mathrm{S}_{0}$ is the alternating stress in a fully reversed cycle $(\mathrm{R}=-1)$ at a given cyclic life.

With the above equation and the expression relating cyclic life to alternating stress component for the $\mathrm{R}=-1$ test series (Figure 9.23b), $\mathrm{S}_{\mathrm{a}}$ for any of the other three test series can be predicted. The resulting predictions are compared with the data in Figures 9.25 and 9.26, for tension and compression respectively.

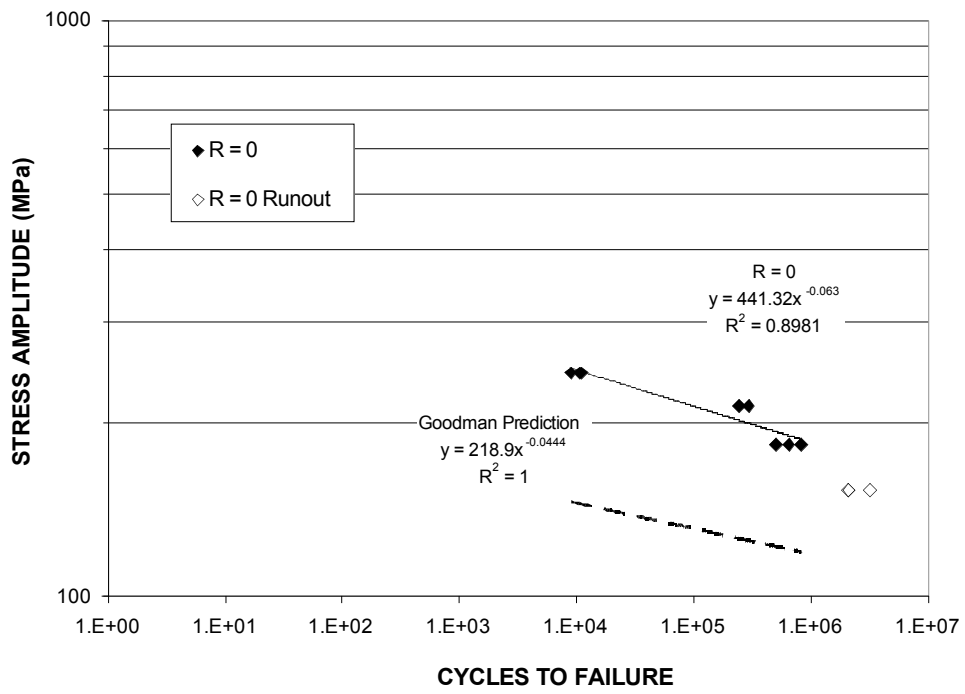

(a) $\mathrm{R}=0$

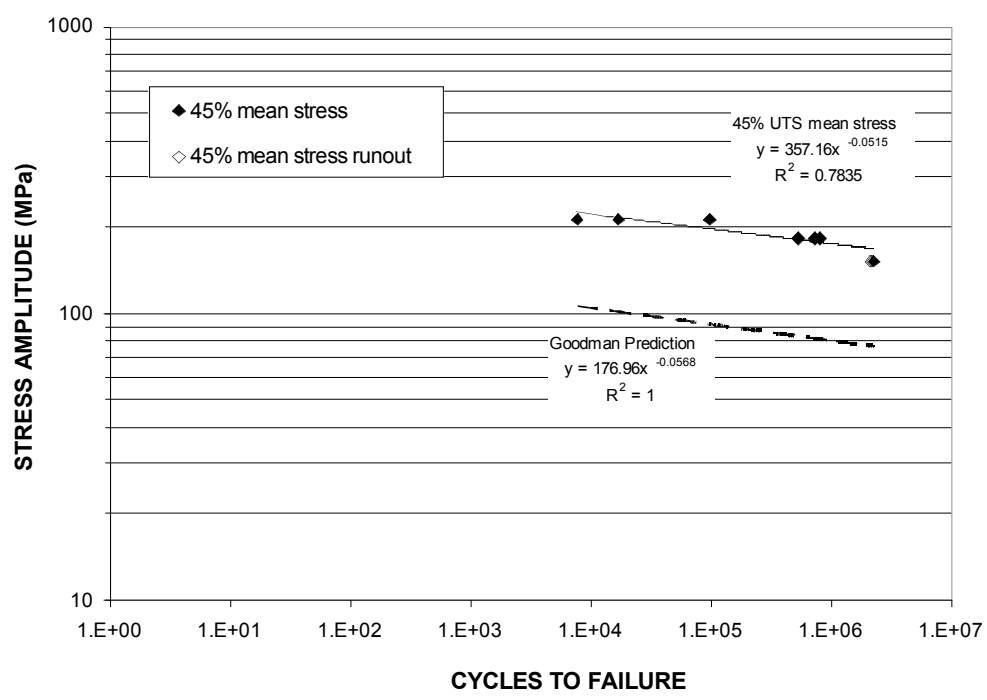

(b) $45 \%$ UTS mean stress

Figure 9.25. Comparison of Goodman predictions (based on $\mathrm{R}=-1$ correlation) with experimental data for tensile mean stress cycle types. 


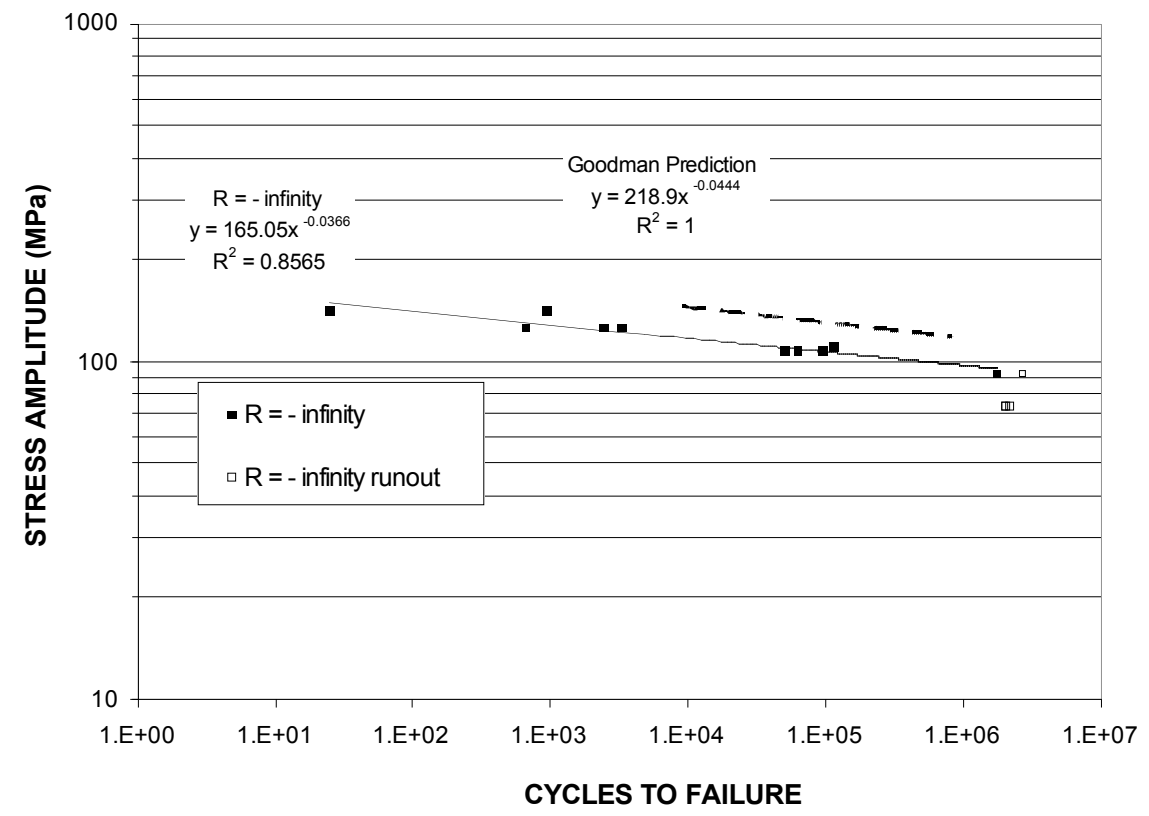

Figure 9.26. Comparison of Goodman prediction (based on $\mathrm{R}=-1$ correlation) with experimental data and curve for compressive mean stress cycle type $(\mathrm{R}=-$ infinity).

Of the stress parameters examined, the Conle and Ingall parameter (Fig. 9.24) appears, from the limited data available, to do the best job of correlating the data for the various cycle types. The recommendations for cyclic design limits provided in the next section provide a single S-N design curve with stress reduction factors given to account for cycles with compressive mean stresses.

\subsection{SUMMARY AND RECOMMENDATIONS}

As shown in Figure 9.27, the S-N curve for the $\mathrm{R}=0.1$ tensile fatigue results, when plotted using the Conle-Ingall parameter, bounds all of the other S-N curves except the compressive curves $\mathrm{R}=-\infty$ and $\mathrm{R}=-1$ curve. The $\mathrm{R}=0.1$ curve is thus proposed as the basis for a single cyclic design curve for the quasi-isotropic carbon-fiber-reinforced thermoplastic composite for all cycles when the mean stress is positive. The steps used to derive the final design curve are illustrated in Figure 9.28. A reduction factor of 20 on cycles was first applied. Because this factor does not quite cover the scatter, an additional multiplication factor of $\mathrm{UTS}_{\mathrm{min}} / \mathrm{UTS}_{\mathrm{avg}}=0.89$ was applied to the cyclic stress. The resulting curve is the final fatigue design curve recommended in Chap. 4 when the mean stress is positive. 


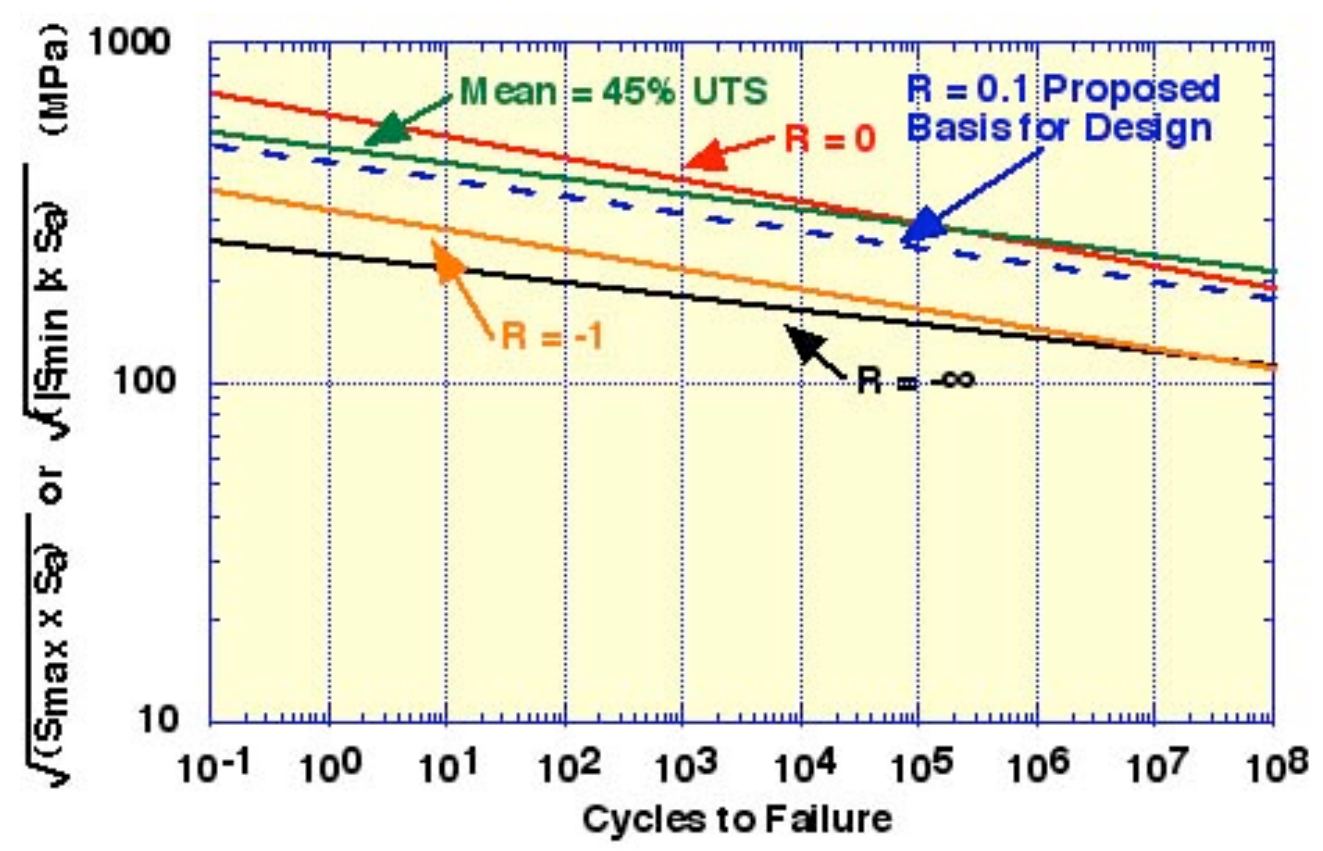

Fig. 9.27. Comparison of room-temperature, in-air S-N curves from mean-stress tests with $\mathrm{R}=0.1 \mathrm{~S}-\mathrm{N}$ curve using $S=\sqrt{S_{\max } \times S_{a}}$ as the cyclic stress parameter.

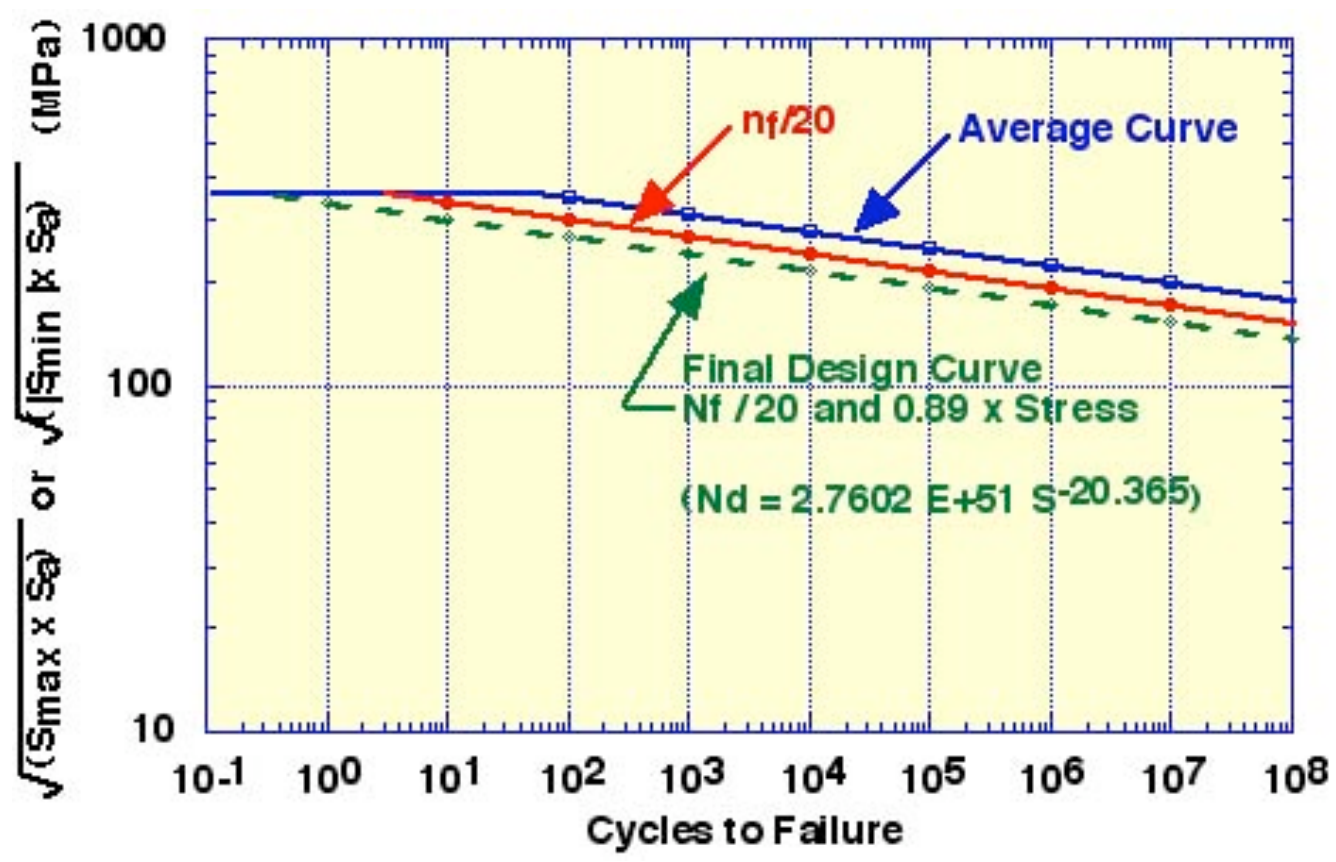

Fig. 9.28. Construction of final recommended design fatigue curve for loads involving a positive mean stress. 
For fatigue that includes a zero or negative mean stress, the following factors should be applied to the fatigue design curve:

\begin{tabular}{ccc}
$\begin{array}{c}\text { Cycles to } \\
\text { failure }\end{array}$ & & $\begin{array}{c}\text { Fatigue strength } \\
\text { multiplication factor }\end{array}$ \\
\cline { 1 - 1 } 10 & 0.40 \\
$10^{2}$ & 0.43 \\
$10^{4}$ & 0.47 \\
$10^{6}$ & 0.53 \\
$10^{8}$ & 0.59
\end{tabular}

These factors were derived by taking the ratio of the stresses given by the equation for the $\mathrm{R}=-\infty$ curve to those given by the equation for the $\mathrm{R}=0$ curve in Figure 9.24 (i.e., the $\mathrm{R}=-\infty$ curve is assumed to apply to all compressive mean stress cycles in the cyclic region where it is below the $\mathrm{R}=0$ curve). Figure 9.29 presents the proposed cyclic design curve for the quasi-isotropic carbon-fiber-reinforced thermoplastic composite for all cycles when the mean stress is zero or negative. To account for temperature and fluid effects in any cycle type, the fatigue strength multiplication factors that were given in Tables 9.4 and 9.5 are recommended.

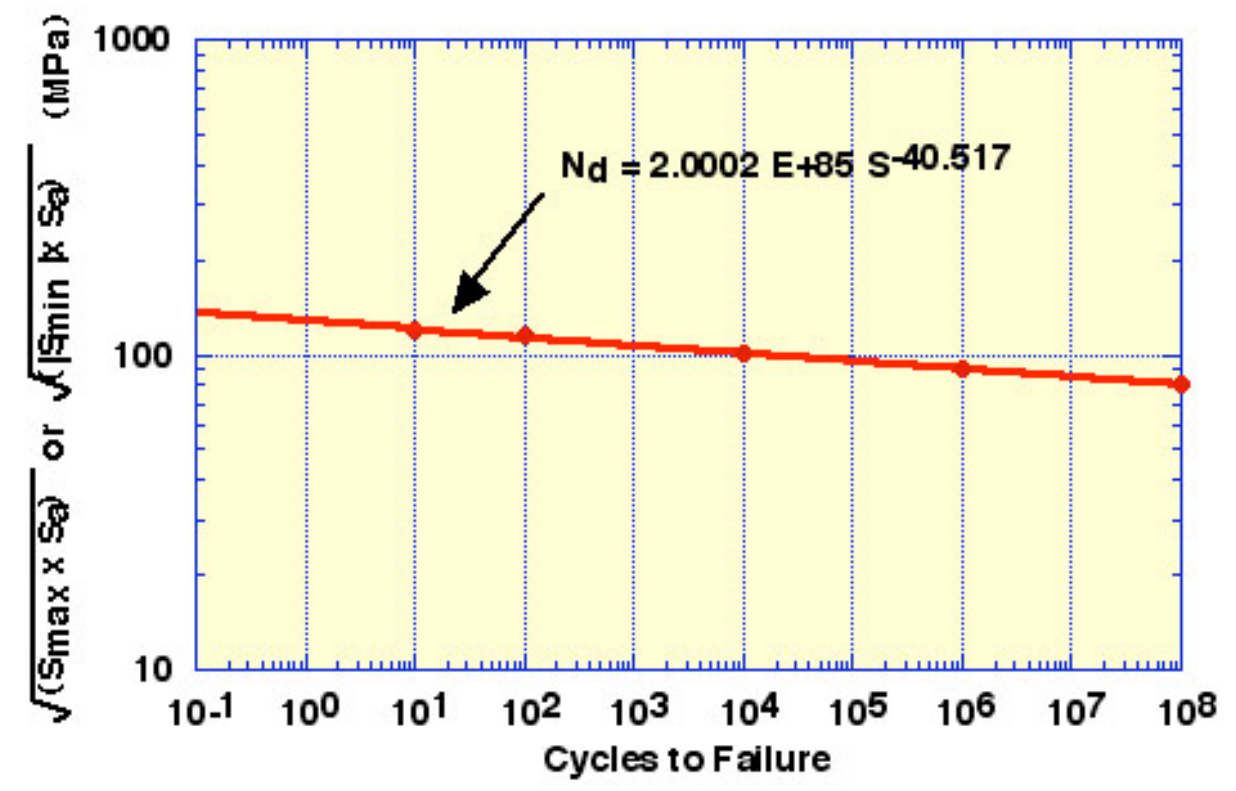

Fig. 9.29. Construction of final recommended design fatigue curve for loads involving a zero or negative mean stress.

\subsection{REFERENCES}

1. J. M. Corum, R. L. Battiste, W. Ren, and M. B. Ruggles, Recommended Minimum Test Requirements and Test Methods for Assessing Durability of Random-Glass-Fiber Composites, ORNL-6953, Oak Ridge National Laboratory, Oak Ridge, Tenn., June 1999.

2. A. Conle and J. P. Ingall, "Effects of Mean Stress on the Fatigue of Composite Materials," Journal of Composite Technology and Research, 7(1), 3-11 (Spring 1985).

3. M. J. Owen and T. R. Smith, "Some fatigue properties of chopped-strand-mat/polyester resin laminates," Plastics and Polymers, 33-44 (February 1968). 


\section{CREEP DEFORMATION}

\subsection{INTRODUCTION}

Constant-load tensile creep deformation tests were performed both in air at room temperature and elevated temperatures and in fluids (distilled water with a nominal presoak of $1000 \mathrm{~h}$ and windshieldwasher fluid with a 100-h presoak). A limited number of compressive creep tests was also performed in air at room temperature and elevated temperature. With the exception of four tensile tests at $70^{\circ} \mathrm{C}$ and three tensile tests at $90^{\circ} \mathrm{C}$, all of the elevated temperature tests were at $120^{\circ} \mathrm{C}$, which is the upper bound of the automotive temperature range of interest. The approach was to develop a room-temperature, in-air, tensile creep equation and to then develop creep multiplication factors to approximately characterize the effects of temperature, fluids, and compressive loadings in terms of the room-temperature, in-air, tensile response.

These steps are described in the subsequent sections of this chapter. First, however, the experimental approach will be briefly summarized.

\subsection{EXPERIMENTAL APPROACH}

All of the tensile creep tests were performed in deadweight test machines that employed lever arms. A total of 18 test machines were utilized in the test program. Figure 10.1 presents eight of the test machines. The tensile specimen used was the standard one used for all of the basic tensile tests (Chap. 7) and tensile fatigue tests (Chap. 9). The center portion of the 25.4-mm-wide, untabbed specimen was dogboned down to a width of $20.3 \mathrm{~mm}$. The specimens were described in Refs. 1 and 2.

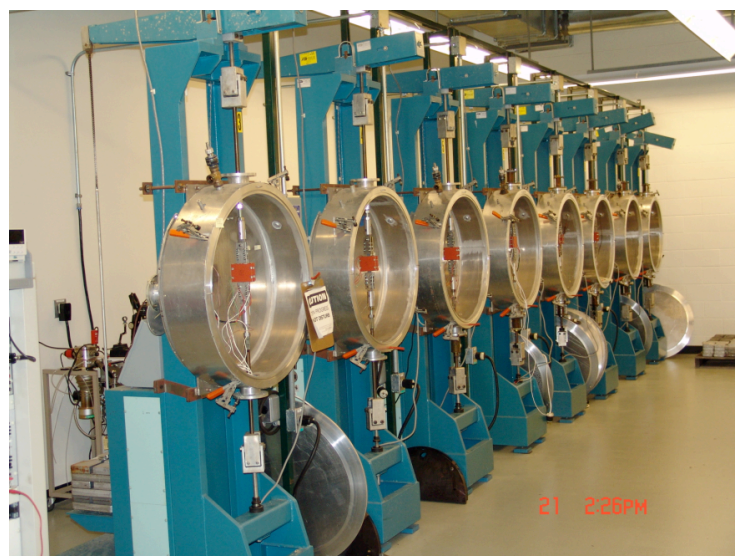

Figure 10.1 Tensile creep tests.

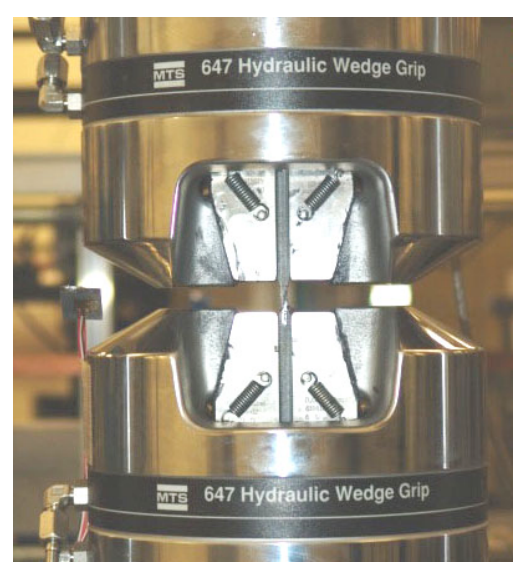

Figure 10.2 Compressive creep tests.

The compressive creep tests were all performed in a hydraulic test machine. The standard tabbed specimen used for basic compressive strength tests (Chap. 7) was used. This 25.4-mm-wide specimen had a gage length of just $12.7 \mathrm{~mm}$ between tabs to minimize buckling problems. The standard IITRI-type compression test fixture ${ }^{2}$ was used for most of the tests. A few compressive creep tests were performed in a well-aligned test machine with hydraulic wedge grips. Figure 10.2 presents a compressive creep test utilizing the well-aligned test machine with hydraulic grips.

The standard loading rates used in the basic tensile and compressive tests were used in the creep tests. Time-dependent creep strain measurements were referenced to the moment the full load was transferred to the specimen. This was determined primarily from strip-chart recordings of strain versus 
time. The strain at which complete load transfer occurred was determined by identifying the strain at which the strip-chart record of strain versus time deviated from linearity. In a few tests the reference strain was determined by voltage readout at the point when the dead load was completely transferred to the specimen (i.e. weight bucket started to swing).

Strain gages were used for the strain measurements. For the tensile tests, gages having a 12.7-mm gage length (Micro-Measurements CEA-13-500UV-350) were used. For compression, the gage length was $6.4 \mathrm{~mm}$ (Micro-Measurements EA-06-250AF-120). To eliminate the sometimes masking effects of thermal- and moisture-expansion strains arising from atmospheric changes, full-bridge compensation was used for each test specimen. Two gages, placed back-to-back on opposite faces, were used on each specimen. These two gages were wired in a full bridge with two gages similarly located on an unstressed piece that was located adjacent to the test specimen during the test and thus experienced the same temperature and humidity variations. This arrangement effectively eliminated bending effects and spurious strain readings that resulted from moisture and temperature changes. Note that although strains caused by moisture-induced expansion/contraction were eliminated, creep compliance itself is still affected by moisture level. This subject was discussed more fully in Chap. 10 of Ref. 1 .

In the elevated-temperature tensile tests, specially designed sandwiched heater assemblies were attached to the center portion of each specimen. As described in Ref. 1, these assemblies also encapsulated the associated unstressed strain-gaged piece. Small heat blankets supplied the heat. Figure 10.3 presents a close-up of an elevated temperature creep test. For the elevated-temperature compressive tests, the entire IITRI fixture was located inside a resistance-heated furnace.

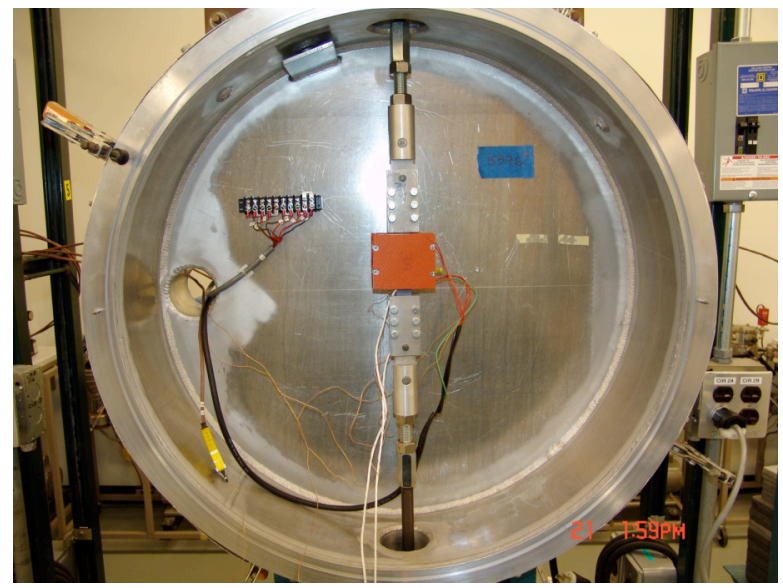

Figure 10.3 Elevated temperature creep test.

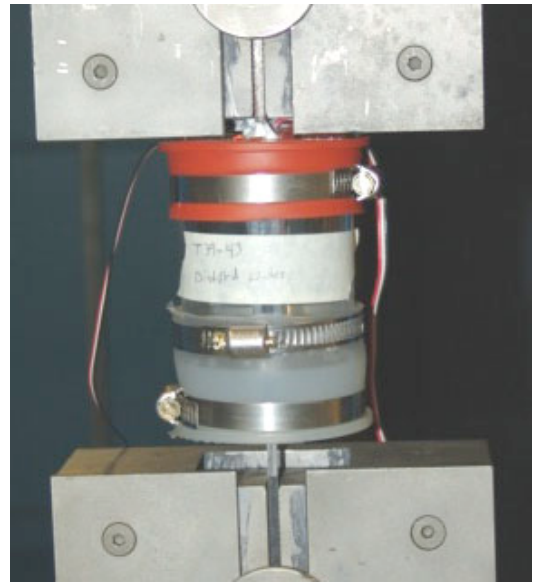

Figure 10.4 Fluid creep test.

For the tests in fluids, an acrylic pipe section with silicon-rubber end plugs was used to contain the fluid over the reduced-width section of the dogbone-shaped tensile specimens. A second container was used for the unstressed piece with dummy strain gages for full-bridge strain-gage compensation. Ref. 1 provides additional information on the fluid creep testing. Figure 10.4 presents a close-up of a fluid creep test.

\subsection{TENSILE TESTS IN AIR}

One hundred sixty-one tensile creep tests were performed in dead-weight machines. This number includes higher-stress tests that were focused on creep rupture and thus did not include creep strain measurements. The 161 tests are summarized in Table 10.1. This chapter addresses the creep behavior as measured in those tests numbered in creep deformation column of Table 10.1. Creep rupture is addressed in Chap. 11. 
Table 10.1. Summary of tensile creep tests

\begin{tabular}{|l|c|c|c|}
\hline \multirow{2}{*}{ Environment } & \multicolumn{2}{|c|}{ Type Test } & \multirow{2}{*}{ Total } \\
\cline { 2 - 3 } & $\begin{array}{c}\text { Creep } \\
\text { Rupture }\end{array}$ & $\begin{array}{c}\text { Creep } \\
\text { Deformation }\end{array}$ & \\
\hline Room-temperature air & 28 & 32 & 60 \\
$70^{\circ} \mathrm{C}$ air & 0 & 4 & 4 \\
$90^{\circ} \mathrm{C}$ air & 0 & 3 & 3 \\
$120^{\circ} \mathrm{C}$ air & 13 & 14 & 27 \\
Distilled water & 17 & 15 & 32 \\
Windshield washer fluid & 18 & 17 & 35 \\
\hline Total Number Tests & 76 & 85 & 161 \\
\hline
\end{tabular}

Table 10.2 lists the applied stress in each test, both in terms of megapascals and as a percentage of the associated average plaque UTS, and it tabulates the key results. Several of the creep test specimens listed in Table 10.2 that did not fail were unloaded and later tested to determine the residual tensile strength, modulus of elasticity, and failure strain. Appendix G provides a summary of the results of these tests. The UTS-adjusted stress values in Table 10.2 are used to develop several of the creep-rupture correlations in Chap. 11.

\subsubsection{Room Temperature}

The room-temperature, in-air specimens were fabricated from six plaques (T10, T23, T31, T39, T41, and T46) (see Appendix B). The short-time loading strains measured in the room-temperature, in-air tests are plotted against applied stress in Fig. 10.5. Figure 10.5a presents the loading strains for all specimens from Plaques T31, T39, T41, and T46 for which loading strain data were obtained. The solid line is a power-law fit to all data points over the data range (a linear line is shown between the origin and the power-law fit at the lowest stress level). The dashed line represents the average virgin stiffness of all tensile specimens. Figure $10.5 \mathrm{~b}$ presents the data in Figure 10.5a with the loading strains normalized by multiplying the strains by the ratio of each specimen's virgin stiffness to the overall stiffness for all specimens. Figure 10.5 implies that loading strains were essentially elastic and that the total strain in the creep tests can be divided, without significant error, into elastic plus time-dependent creep components.

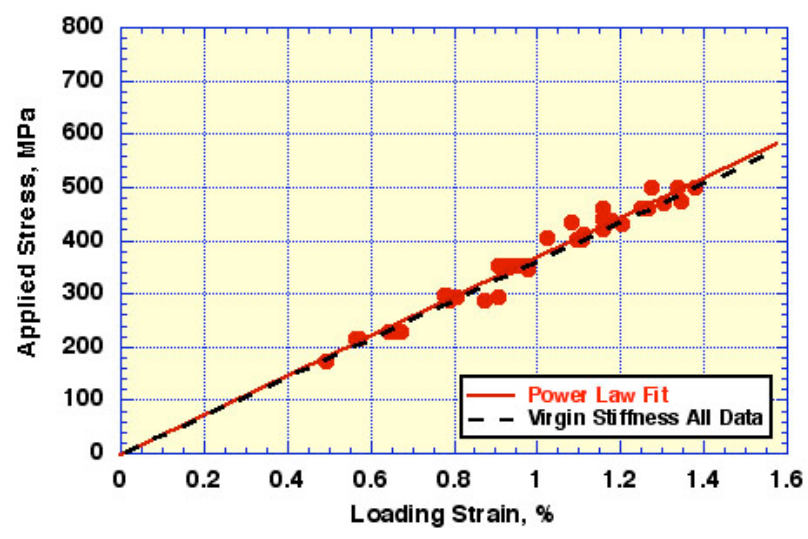

a. Unadjusted loading strains.

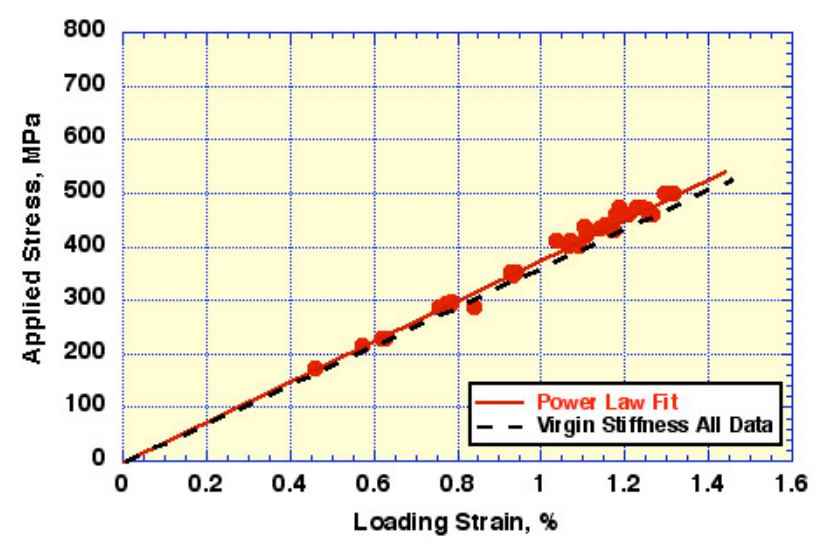

b. Normalized loading strains.

Figure 10.5 Loading strains measured in room-temperature, in-air creep tests. 
Table 10.2. Matrix of tensile creep and creep-rupture tests

\begin{tabular}{|c|c|c|c|c|c|c|c|c|c|}
\hline Specimen & $\begin{array}{l}\text { Area } \\
\left(\text { in. }^{2}\right)\end{array}$ & $\begin{array}{l}\text { Virgin room- } \\
\text { temperature } \\
\text { stiffness }^{a} \\
\text { (GPa) }\end{array}$ & $\begin{array}{c}\text { Plaque } \\
\text { UTS } \\
\text { (MPa) }\end{array}$ & $\begin{array}{l}\text { Applied } \\
\text { Stress } \\
\text { (MPa) }\end{array}$ & 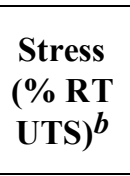 & $\begin{array}{c}\text { Normalized } \\
\text { Applied Stress } \\
\quad(\mathrm{MPa})^{c}\end{array}$ & $\begin{array}{l}\text { Loading } \\
\text { strain } \\
(\%)\end{array}$ & $\begin{array}{c}\text { Rupture } \\
\text { time } \\
\text { (h) }\end{array}$ & Notes \\
\hline \multicolumn{10}{|c|}{ Room temperature } \\
\hline T23-3 & 0.0904 & 36.60 & 515 & 470 & 0.913 & 503 & - & 1.94 & Creep rupture only \\
\hline $\mathrm{T} 23-4$ & 0.0903 & 37.26 & 515 & 471 & 0.914 & 504 & - & 0.03 & Creep rupture only \\
\hline T23-9 & 0.0904 & 37.99 & 515 & 471 & 0.914 & 504 & - & 0.00 & Creep rupture only \\
\hline T23-5 & 0.0905 & 36.69 & 515 & 445 & 0.864 & 476 & - & 2.24 & Creep rupture only \\
\hline T23-6 & 0.0903 & 37.01 & 515 & 445 & 0.864 & 476 & - & 514.04 & Creep rupture only \\
\hline $\mathrm{T} 23-10$ & 0.0903 & 37.58 & 515 & 445 & 0.864 & 476 & - & 1979.00 & Creep rupture only \\
\hline T23-7 & 0.0902 & 38.70 & 515 & 419 & 0.813 & 448 & - & $2490.00 *$ & No failure - unloaded \\
\hline $\mathrm{T} 23-8$ & 0.0902 & 37.81 & 515 & 419 & 0.813 & 448 & - & $2251.00 *$ & No failure - unloaded \\
\hline T23-11 & 0.0902 & 37.67 & 515 & 445 & 0.863 & 476 & - & $1915.00 *$ & No failure - unloaded \\
\hline $\mathrm{T} 23-26$ & 0.0895 & 38.07 & 515 & 490 & 0.951 & 524 & - & 1.65 & Creep rupture only \\
\hline T23-12 & 0.0905 & 36.80 & 515 & 489 & 0.950 & 523 & - & 0.02 & Creep rupture only \\
\hline $\mathrm{T} 23-15$ & 0.0918 & 37.16 & 515 & 479 & 0.930 & 512 & - & 2.64 & Creep rupture only \\
\hline $\mathrm{T} 23-36$ & 0.0911 & 36.47 & 515 & 474 & 0.920 & 507 & - & 16.56 & Creep rupture only \\
\hline T23-14 & 0.0912 & 37.07 & 515 & 459 & 0.890 & 491 & - & $1932.00 *$ & No failure - unloaded \\
\hline $\mathrm{T} 23-16$ & 0.0911 & 37.30 & 515 & 464 & 0.900 & 496 & - & 0.05 & Creep rupture only \\
\hline $\mathrm{T} 23-18$ & 0.0919 & 34.49 & 515 & 453 & 0.880 & 485 & - & 4.07 & Creep rupture only \\
\hline $\mathrm{T} 23-20$ & 0.0903 & 35.99 & 515 & 453 & 0.880 & 485 & - & 89.20 & Creep rupture only \\
\hline $\mathrm{T} 23-21$ & 0.0904 & 36.56 & 515 & 433 & 0.840 & 463 & - & 338.20 & Creep rupture only \\
\hline T23-22 & 0.0902 & 37.18 & 515 & 433 & 0.840 & 463 & - & $3251.96^{*}$ & No failure - unloaded \\
\hline $\mathrm{T} 23-23$ & 0.0902 & 37.78 & 515 & 412 & 0.800 & 441 & - & $2659.39 *$ & No failure - unloaded \\
\hline T10-35 & 0.0874 & 33.20 & 527 & 501 & 0.950 & 524 & - & 0.001 & Creep rupture only \\
\hline $\mathrm{T} 10-4$ & 0.0875 & 35.97 & 527 & 501 & 0.950 & 524 & - & 0.74 & Creep rupture only \\
\hline $\mathrm{T} 10-21$ & 0.0876 & 36.96 & 527 & 490 & 0.930 & 512 & - & 1.11 & Creep rupture only \\
\hline $\mathrm{T} 10-36$ & 0.0876 & 35.63 & 527 & 490 & 0.930 & 512 & - & 0.88 & Creep rupture only \\
\hline T10-14 & 0.0878 & 38.27 & 527 & 480 & 0.910 & 502 & - & 27.12 & Creep rupture only \\
\hline $\mathrm{T} 10-26$ & 0.0878 & 36.68 & 527 & 480 & 0.910 & 502 & - & 0.22 & Creep rupture only \\
\hline $\mathrm{T} 10-11$ & 0.0874 & 37.98 & 527 & 480 & 0.910 & 502 & - & 40.07 & Creep rupture only \\
\hline $\mathrm{T} 23-24$ & 0.0903 & 39.58 & 515 & 453 & 0.880 & 485 & - & $3358.70 *$ & No failure - unloaded \\
\hline
\end{tabular}

*No failure. 
Table 10.2 (cont.) Matrix of tensile creep and creep-rupture tests

\begin{tabular}{|c|c|c|c|c|c|c|c|c|c|}
\hline & $\begin{array}{l}\text { Area } \\
\left.\text { (in. } .^{2}\right)\end{array}$ & $\begin{array}{l}\text { Virgin room- } \\
\text { temperature } \\
\text { stiffness } a \\
\text { (GPa) }\end{array}$ & $\begin{array}{l}\text { Plaque } \\
\text { UTS } \\
\text { (MPa) }\end{array}$ & $\begin{array}{l}\text { Applied } \\
\text { Stress } \\
\text { (MPa) }\end{array}$ & $\begin{array}{c}\text { Stress } \\
\text { (\% RT } \\
\text { UTS) }^{b}\end{array}$ & $\begin{array}{c}\text { Normalized } \\
\text { Applied Stress } \\
\text { (MPa) } c\end{array}$ & $\begin{array}{l}\text { Loading } \\
\text { strain } \\
(\%)\end{array}$ & $\begin{array}{l}\text { Rupture } \\
\text { time } \\
\text { (h) }\end{array}$ & Notes \\
\hline \multicolumn{10}{|c|}{ Room temperature (cont.) } \\
\hline T46-4 & 0.0931 & 37.18 & 541 & 460 & 0.850 & 469 & 1.157 & 0.90 & Failed \\
\hline T46-2 & 0.0902 & 32.15 & 541 & 460 & 0.850 & 469 & 1.370 & 137.47 & Failed \\
\hline T46-11 & 0.0910 & 36.92 & 541 & 473 & 0.874 & 482 & 1.214 & 73.53 & Failed \\
\hline T31-25 & 0.0843 & 37.02 & 589 & 501 & 0.850 & 469 & 1.273 & $1891.16^{*}$ & No failure - unloaded \\
\hline T31-28 & 0.0851 & 35.09 & 589 & 471 & 0.799 & 441 & 1.303 & $1873.23 *$ & No failure - unloaded \\
\hline T31-1 & 0.0828 & 32.16 & 589 & 475 & 0.806 & 444 & 1.344 & $3243.93 *$ & No failure - unloaded \\
\hline T31-24 & 0.0843 & 36.36 & 589 & 441 & 0.749 & 413 & 1.156 & $2686.24 *$ & No failure - unloaded \\
\hline T31-31 & 0.0843 & 34.54 & 589 & 501 & 0.850 & 469 & 1.378 & $2015.01 *$ & No failure - unloaded, \\
\hline T31-19 & 0.0849 & 35.17 & 589 & 438 & 0.744 & 410 & 1.178 & $1559.33 *$ & No failure - unloaded \\
\hline T31-36 & 0.0858 & 35.03 & 589 & 412 & 0.700 & 385 & 1.111 & $1558.78 *$ & No failure - unloaded \\
\hline T31-46 & 0.0842 & 36.51 & 589 & 353 & 0.600 & 330 & 0.936 & $1515.19 *$ & No failure - unloaded \\
\hline T31-47 & $0 . .0843$ & 35.56 & 589 & 353 & 0.600 & 330 & 0.958 & $1173.76^{*}$ & No failure - unloaded \\
\hline T31-48 & 0.0844 & 34.94 & 589 & 295 & 0.500 & 276 & 0.807 & $2065.03 *$ & No failure - unloaded \\
\hline T31-52 & 0.0843 & 31.60 & 589 & 295 & 0.50 & 276 & 0.907 & $1174.80 *$ & No failure - unloaded \\
\hline T31-53 & 0.0842 & 34.75 & 589 & 353 & 0.600 & 330 & 0.974 & $2032.31 *$ & No failure - unloaded \\
\hline $\mathrm{T} 31-50$ & 0.0843 & 35.81 & 589 & 501 & 0.850 & 469 & 1.337 & $2134.78^{*}$ & No failure - unloaded \\
\hline T31-35 & 0.0858 & 35.10 & 589 & 412 & 0.700 & 385 & 1.112 & $1633.43 *$ & No failure - unloaded \\
\hline T46-3 & 0.0934 & 38.33 & 541 & 433 & 0.800 & 441 & 1.084 & $1683.01 *$ & No failure - unloaded \\
\hline T46-7 & 0.0919 & 38.18 & 541 & 406 & 0.750 & 414 & 1.025 & $1539.89 *$ & No failure - unloaded \\
\hline T46-6 & 0.0917 & 37.00 & 541 & 297 & 0.550 & 302 & 0.775 & $1800.02 *$ & No failure - unloaded \\
\hline T46-8 & 0.0919 & 36.70 & 541 & 351 & 0.650 & 357 & 0.930 & $2614.78 *$ & No failure - unloaded \\
\hline T46-14 & 0.0909 & 36.99 & 541 & 216 & 0.400 & 220 & 0.566 & $2855.84 *$ & No failure - unloaded \\
\hline T46-12 & 0.0909 & 37.55 & 541 & 352 & 0.650 & 359 & 0.907 & $2597.97 *$ & No failure - unloaded \\
\hline T46-15 & 0.0905 & 36.44 & 541 & 216 & 0.400 & 220 & 0.574 & $1339.25 *$ & No failure - unloaded \\
\hline T46-17 & 0.0910 & 36.49 & 541 & 297 & 0.550 & 302 & 0.783 & $1340.25 *$ & No failure - unloaded \\
\hline T46-18 & 0.0910 & 36.95 & 541 & 352 & 0.650 & 359 & 0.914 & $1320.45^{*}$ & No failure - unloaded \\
\hline T46-19 & 0.0911 & 34.61 & 541 & 473 & 0.874 & 482 & 1.305 & 0.21 & Failed \\
\hline
\end{tabular}

*No failure. 
Table 10.2 (cont.). Matrix of tensile creep and creep-rupture tests

\begin{tabular}{|c|c|c|c|c|c|c|c|c|c|}
\hline Specimen & $\begin{array}{l}\text { Area } \\
\text { (in. }^{2} \text { ) }\end{array}$ & $\begin{array}{c}\text { Virgin room- } \\
\text { temperature } \\
\text { stiffness } a \\
\text { (GPa) }\end{array}$ & $\begin{array}{l}\text { Plaque } \\
\text { UTS } \\
\text { (MPa) }\end{array}$ & $\begin{array}{l}\text { Applied } \\
\text { Stress } \\
\text { (MPa) }\end{array}$ & 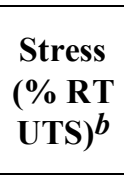 & $\begin{array}{c}\text { Normalized } \\
\text { Applied Stress } \\
(\mathrm{MPa})\end{array}$ & $\begin{array}{l}\text { Loading } \\
\text { strain } \\
(\%)\end{array}$ & $\begin{array}{l}\text { Rupture } \\
\text { time } \\
\text { (h) }\end{array}$ & Notes \\
\hline \multicolumn{10}{|c|}{ Room temperature (cont.) } \\
\hline T41-30 & 0.0914 & 35.44 & 575 & 403 & 0.700 & 386 & 1.096 & $1613.75^{*}$ & No failure - unloaded \\
\hline T41-41 & 0.0909 & 35.83 & 575 & 403 & 0.700 & 386 & 1.108 & $1515.99^{*}$ & No failure - unloaded \\
\hline T39-42 & 0.0915 & 34.82 & 600 & 420 & 0.699 & 386 & 1.159 & $1516.35^{*}$ & No failure - unloaded \\
\hline $\mathrm{T} 41-31$ & 0.0915 & 35.14 & 575 & 230 & 0.400 & 220 & 0.642 & $1515.68^{*}$ & No failure - unloaded \\
\hline T41-29 & 0.0914 & 34.82 & 575 & 230 & 0.400 & 220 & 0.657 & $1999.74 *$ & No failure - unloaded \\
\hline \multicolumn{10}{|c|}{$70^{\circ} \mathrm{C}$} \\
\hline $\mathrm{T} 41-21$ & 0.0920 & 35.85 & 575 & 460 & 0.800 & 441 & 1.266 & $2162.43^{*}$ & No failure - unloaded \\
\hline T41-14 & 0.0919 & 35.83 & 575 & 345 & 0.600 & 331 & 0.962 & $1992.91^{*}$ & No failure - unloaded \\
\hline T41-12 & 0.0921 & 35.42 & 575 & 402 & 0.700 & 385 & 1.125 & $2209.18^{*}$ & No failure - unloaded \\
\hline T41-51 & 0.0918 & 36.80 & 575 & 287 & 0.498 & 275 & 0.775 & $4435.94 * \#$ & No failure - unloaded \\
\hline \multicolumn{10}{|c|}{$90^{\circ} \mathrm{C}$} \\
\hline T41-19 & 0.0918 & 34.32 & 575 & 460 & 0.800 & 441 & 1.360 & $2039.51 *$ & No failure - unloaded \\
\hline T41-13 & 0.0921 & 35.28 & 575 & 403 & 0.700 & 386 & 1.144 & $1969.27 *$ & No failure - unloaded \\
\hline T41-20 & 0.0917 & 34.94 & 575 & 403 & 0.700 & 386 & 1.176 & $1988.64 *$ & No failure - unloaded \\
\hline \multicolumn{10}{|c|}{$120^{\circ} \mathrm{C}$} \\
\hline T23-49 & 0.0910 & 37.94 & 515 & 399 & 0.774 & 427 & 1.127 & 16.99 & Failed \\
\hline $\mathrm{T} 23-50$ & 0.0912 & 37.46 & 515 & 384 & 0.746 & 411 & 1.088 & 4.93 & Failed \\
\hline T31-10 & 0.0836 & 36.10 & 589 & 504 & 0.856 & 471 & - & 106.30 & Failed \\
\hline T31-38 & 0.0851 & 36.72 & 589 & 501 & 0.850 & 469 & 1.438 & 1.29 & Failed \\
\hline T31-40 & 0.0834 & 36.54 & 589 & 471 & 0.800 & 441 & 1.336 & 101.02 & Failed \\
\hline T31-39 & 0.0843 & 37.50 & 589 & 505 & 0.858 & 472 & 1.417 & 55.82 & Failed \\
\hline T31-44 & 0.0842 & 36.14 & 589 & 442 & 0.750 & 413 & 1.314 & 87.90 & Failed \\
\hline T41-1 & 0.0913 & 35.41 & 575 & 521 & 0.905 & 499 & 1.579 & 0.005 & Failed \\
\hline $\mathrm{T} 41-2$ & 0.0919 & 35.40 & 575 & 518 & 0.900 & 496 & 1.582 & 0.001 & Failed \\
\hline $\mathrm{T} 41-8$ & 0.0920 & 34.83 & 575 & 431 & 0.750 & 413 & 1.354 & 271.38 & Failed \\
\hline T10-27 & 0.0876 & 37.61 & 527 & 411 & 0.781 & 427 & - & $3757.93^{*, \#}$ & No failure - unloaded \\
\hline
\end{tabular}

*No failure.

\#Updated result after preparation of creep rupture section of report. 
Table 10.2 (cont.) Matrix of tensile creep and creep-rupture tests

\begin{tabular}{|c|c|c|c|c|c|c|c|c|c|}
\hline Specimen & $\begin{array}{l}\text { Area } \\
\left.\text { (in. }{ }^{2}\right)\end{array}$ & $\begin{array}{c}\text { Virgin room- } \\
\text { temperature } \\
\text { stiffness } a \\
\text { (GPa) }\end{array}$ & $\begin{array}{l}\text { Plaque } \\
\text { UTS } \\
\text { (MPa) }\end{array}$ & $\begin{array}{l}\text { Applied } \\
\text { Stress } \\
\text { (MPa) }\end{array}$ & $\begin{array}{l}\text { Stress } \\
(\% \text { RT } \\
\text { UTS })^{b}\end{array}$ & $\begin{array}{c}\text { Normalized } \\
\text { Applied Stress } \\
\text { (MPa) }^{c}\end{array}$ & $\begin{array}{c}\text { Loading } \\
\text { strain } \\
(\%)\end{array}$ & $\begin{array}{c}\text { Rupture } \\
\text { time } \\
\text { (h) }\end{array}$ & Notes \\
\hline \multicolumn{10}{|c|}{$120^{\circ} \mathrm{C}$ (cont.) } \\
\hline T31-2 & 0.0827 & 34.55 & 589 & 424 & 0.720 & 397 & 1.327 & $2833.65^{*}$ & No failure - unloaded \\
\hline T31-4 & 0.0828 & 35.80 & 589 & 424 & 0.720 & 397 & 1.215 & $1065.24 *$ & No failure - unloaded \\
\hline T31-11 & 0.0836 & 37.57 & 589 & 475 & 0.806 & 444 & - & $2615.29^{*}$ & No failure - unloaded \\
\hline T31-5 & 0.0836 & 35.10 & 589 & 445 & 0.756 & 416 & - & $3308.00 *$ & No failure - unloaded \\
\hline T31-22 & 0.0851 & 36.51 & 589 & 412 & 0.699 & 385 & 1.196 & $1970.44 *$ & No failure - unloaded \\
\hline T31-33 & 0.0833 & 36.06 & 589 & 475 & 0.806 & 444 & 1.400 & $2183.18^{*}$ & No failure - unloaded \\
\hline T31-43 & 0.842 & 36.22 & 589 & 442 & 0.750 & 413 & 1.263 & $2115.75^{*}$ & No failure - unloaded \\
\hline T31-42 & 0.0843 & 36.03 & 589 & 471 & 0.800 & 441 & 1.351 & $2116.00 *$ & No failure - unloaded \\
\hline $\mathrm{T} 41-4$ & 0.0914 & 36.59 & 575 & 403 & 0.700 & 386 & 1.140 & 1997.06* & No failure - unloaded \\
\hline T41-5 & 0.0919 & 34.04 & 575 & 345 & 0.600 & 331 & 1.071 & $1996.49 *$ & No failure - unloaded \\
\hline T41-6 & 0.0897 & 34.91 & 575 & 345 & 0.600 & 331 & 1.038 & $2011.92 *$ & No failure - unloaded \\
\hline T41-7 & 0.0897 & 35.14 & 575 & 288 & 0.500 & 276 & 0.862 & $1948.81 *$ & No failure - unloaded \\
\hline T41-9 & 0.0915 & 34.65 & 575 & 403 & 0.700 & 386 & 1.215 & 1993.73* & No failure - unloaded \\
\hline T41-15 & 0.0927 & 35.42 & 575 & 230 & 0.400 & 220 & 0.678 & 1945.07* & No failure - unloaded \\
\hline T41-23 & 0.0915 & 34.61 & 575 & 287 & 0.500 & 275 & 0.880 & $2548.66^{*}$ & No failure - unloaded \\
\hline T41-16 & 0.0926 & 35.32 & 575 & 230 & 0.400 & 220 & 0.704 & $1610.50 *$ & No failure - unloaded \\
\hline \multicolumn{10}{|c|}{ Distilled Water } \\
\hline T39-9 & 0.0915 & 35.18 & 600 & 480 & 0.800 & 441 & 1.388 & 0.222 & Failed \\
\hline T10-43 & 0.0870 & 37.30 & 527 & 469 & 0.890 & 490 & - & 0.003 & Failed \\
\hline T10-32 & 0.0875 & 36.76 & 527 & 458 & 0.870 & 479 & - & 225.06 & Failed \\
\hline T10-15 & 0.0886 & 36.82 & 527 & 458 & 0.870 & 479 & - & 2.27 & Failed \\
\hline T10-37 & 0.0874 & 36.77 & 527 & 448 & 0.850 & 468 & - & 250.21 & Failed \\
\hline T10-16 & 0.0884 & 36.26 & 527 & 453 & 0.860 & 474 & - & 9.14 & Failed \\
\hline $\mathrm{T} 10-2$ & 0.0875 & 35.47 & 527 & 464 & 0.880 & 485 & - & 0.05 & Failed \\
\hline $\mathrm{T} 10-3$ & 0.0874 & 36.59 & 527 & 443 & 0.840 & 463 & - & 66.55 & Failed \\
\hline $\mathrm{T} 10-8$ & 0.0875 & 38.00 & 527 & 448 & 0.850 & 468 & - & $3189.32^{*, \#}$ & No failure - unloaded \\
\hline T10-34 & 0.0886 & 37.00 & 527 & 432 & 0.820 & 452 & - & 192.24 & Failed \\
\hline
\end{tabular}

*No failure.

\#Updated result after preparation of creep rupture section of report. 
Table 10.2 (cont.) Matrix of tensile creep and creep-rupture tests

\begin{tabular}{|c|c|c|c|c|c|c|c|c|c|}
\hline Specimen & $\begin{array}{l}\text { Area } \\
\left.\text { (in. } .^{2}\right)\end{array}$ & $\begin{array}{c}\text { Virgin room- } \\
\text { temperature } \\
\text { stiffness }^{a} \\
(\mathrm{GPa})\end{array}$ & $\begin{array}{l}\text { Plaque } \\
\text { UTS } \\
\text { (MPa) }\end{array}$ & $\begin{array}{l}\text { Applied } \\
\text { Stress } \\
\text { (MPa) }\end{array}$ & $\begin{array}{l}\text { Stress } \\
\text { (\% RT } \\
\text { UTS })^{b}\end{array}$ & $\begin{array}{c}\text { Normalized } \\
\text { Applied Stress } \\
(\mathrm{MPa})\end{array}$ & $\begin{array}{l}\text { Loading } \\
\text { strain } \\
(\%)\end{array}$ & $\begin{array}{c}\text { Rupture } \\
\text { time } \\
\text { (h) }\end{array}$ & Notes \\
\hline \multicolumn{10}{|c|}{ Distilled Water (cont.) } \\
\hline T10-49 & 0.0874 & 36.76 & 527 & 437 & 0.830 & 457 & - & 829.98 & Failed \\
\hline T10-29 & 0.0877 & 36.60 & 527 & 453 & 0.860 & 474 & - & 2.87 & Failed \\
\hline T10-45 & 0.0872 & 37.03 & 527 & 464 & 0.880 & 485 & - & 1.90 & Failed \\
\hline T10-51 & 0.0885 & 37.20 & 527 & 474 & 0.900 & 496 & - & 0.03 & Failed \\
\hline T10-42 & 0.0875 & 36.94 & 527 & 480 & 0.910 & 502 & - & 0.28 & Failed \\
\hline T39-45 & 0.0918 & 35.63 & 600 & 480 & 0.799 & 441 & 1.414 & 0.08 & Failed \\
\hline T41-24 & 0.0914 & 35.49 & 575 & 512 & 0.890 & 491 & - & 0.002 & Failed \\
\hline T39-10 & 0.0916 & 34.75 & 600 & 420 & 0.700 & 386 & 1.217 & $1848.07^{*}$ & No failure - unloaded \\
\hline T39-11 & 0.0914 & 35.51 & 600 & 360 & 0.600 & 331 & 1.021 & $1827.95^{*}$ & No failure - unloaded \\
\hline T39-12 & 0.0923 & 35.85 & 600 & 300 & 0.500 & 276 & 0.839 & $1850.48^{*}$ & No failure - unloaded \\
\hline T39-38 & 0.0920 & 35.05 & 600 & 360 & 0.600 & 331 & 1.016 & $2715.22 *$ & No failure - unloaded \\
\hline T39-39 & 0.0920 & 36.08 & 600 & 480 & 0.799 & 441 & 1.359 & $1842.42 *$ & No failure - unloaded \\
\hline T39-40 & 0.0922 & 35.23 & 600 & 450 & 0.750 & 413 & 1.274 & $1842.70^{*}$ & No failure - unloaded \\
\hline T39-50 & 0.0922 & 34.89 & 600 & 240 & 0.400 & 220 & 0.681 & $1877.50^{*}$ & No failure - unloaded \\
\hline T39-41 & 0.0911 & 34.13 & 600 & 420 & 0.699 & 386 & 1.207 & $6360.03^{*, \#}$ & No failure - unloaded \\
\hline T39-44 & 0.0925 & 35.25 & 600 & 300 & 0.500 & 276 & 0.878 & $6355.76^{*, \#}$ & No failure - unloaded \\
\hline T39-43 & 0.0925 & 34.77 & 600 & 240 & 0.400 & 220 & 0.676 & $2161.33^{*}$ & No failure - unloaded \\
\hline T41-36 & 0.0902 & 35.14 & 575 & 440 & 0.765 & 422 & 1.215 & $4511.51^{*, \#}$ & No failure - unloaded \\
\hline T41-35 & 0.0902 & 35.09 & 575 & 403 & 0.700 & 386 & 1.127 & $1343.11 *$ & No failure - unloaded \\
\hline T41-37 & 0.0912 & 35.49 & 575 & 345 & 0.600 & 331 & 0.945 & $1292.11^{*}$ & No failure - unloaded \\
\hline T41-28 & 0.0910 & 34.11 & 575 & 172 & 0.300 & 165 & 0.502 & $4175.80^{*, \#}$ & No failure - unloaded \\
\hline $\mathrm{T} 41-48$ & 0.0911 & 35.90 & 575 & 172 & 0.300 & 165 & 0.480 & $1178.21 *$ & No failure - unloaded \\
\hline \multicolumn{10}{|c|}{ Windshield Washer Fluid } \\
\hline T39-7 & 0.0914 & 35.11 & 600 & 480 & 0.799 & 441 & 1.405 & 0.81 & Failed \\
\hline T10-48 & 0.0875 & 37.98 & 527 & 501 & 0.950 & 524 & - & 0.02 & Failed \\
\hline T10-19 & 0.0869 & 35.96 & 527 & 500 & 0.950 & 523 & - & 0.03 & Failed \\
\hline T10-6 & 0.0877 & 36.66 & 527 & 490 & 0.930 & 512 & - & 3.27 & Failed \\
\hline
\end{tabular}

*No failure.

\#Updated result after preparation of creep rupture section of report. 
Table 10.2 (cont.) Matrix of tensile creep and creep-rupture tests

\begin{tabular}{|c|c|c|c|c|c|c|c|c|c|}
\hline Specimen & $\begin{array}{l}\text { Area } \\
\left(\text { in. }^{2}\right)\end{array}$ & $\begin{array}{l}\text { Virgin room- } \\
\text { temperature } \\
\text { stiffness } a \\
\text { (GPa) }\end{array}$ & $\begin{array}{c}\text { Plaque } \\
\text { UTS } \\
\text { (MPa) }\end{array}$ & $\begin{array}{l}\text { Applied } \\
\text { Stress } \\
\text { (MPa) }\end{array}$ & 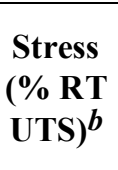 & $\begin{array}{c}\text { Normalized } \\
\text { Applied Stress } \\
\quad(\mathrm{MPa})^{c}\end{array}$ & $\begin{array}{l}\text { Loading } \\
\text { strain } \\
(\%)\end{array}$ & $\begin{array}{l}\text { Rupture } \\
\text { time } \\
\text { (h) }\end{array}$ & Notes \\
\hline \multicolumn{10}{|c|}{ Windshield Washer Fluid (cont.) } \\
\hline T10-17 & 0.0855 & 36.60 & 527 & 490 & 0.930 & 512 & - & 0.005 & Failed \\
\hline T10-18 & 0.0878 & 37.93 & 527 & 448 & 0.850 & 468 & - & $3764.85^{*, \#}$ & No failure - unloaded \\
\hline T10-22 & 0.0877 & 37.45 & 527 & 448 & 0.850 & 468 & - & $3763.95 *, \#$ & No failure - unloaded \\
\hline T10-7 & 0.0875 & 37.91 & 527 & 458 & 0.870 & 479 & - & $3767.24 * \#$ & No failure - unloaded \\
\hline $\mathrm{T} 10-31$ & 0.0877 & 36.54 & 527 & 458 & 0.870 & 479 & - & $3154.39 *, \#$ & Failed \\
\hline T10-5 & 0.0877 & 37.11 & 527 & 469 & 0.890 & 490 & - & 880.12 & Failed \\
\hline T10-13 & 0.0878 & 37.63 & 527 & 480 & 0.910 & 502 & - & 144.00 & Failed \\
\hline T10-41 & 0.0874 & 36.85 & 527 & 471 & 0.893 & 492 & - & 239.79 & Failed \\
\hline T10-33 & 0.0881 & 36.76 & 527 & 485 & 0.920 & 507 & - & 28.60 & Failed \\
\hline T10-44 & 0.0876 & 37.27 & 527 & 474 & 0.900 & 496 & - & 0.38 & Failed \\
\hline $\mathrm{T} 10-24$ & 0.0885 & 37.40 & 527 & 469 & 0.890 & 490 & - & $2153.11^{*, \#}$ & No failure - unloaded \\
\hline $\mathrm{T} 10-38$ & 0.0875 & 35.89 & 527 & 437 & 0.830 & 457 & - & $2153.12 *, \#$ & No failure - unloaded \\
\hline T10-23 & 0.0877 & 37.56 & 527 & 459 & 0.870 & 480 & - & $2153.09 *, \#$ & No failure - unloaded \\
\hline T10-9 & 0.0875 & 37.76 & 527 & 448 & 0.850 & 468 & - & $2014.58^{*, \#}$ & No failure - unloaded \\
\hline T39-24 & 0.0920 & 35.05 & 600 & 240 & 0.400 & 220 & 0.680 & $717.26^{*}$ & No failure - unloaded \\
\hline T39-23 & 0.0919 & 35.18 & 600 & 300 & 0.500 & 276 & 0.853 & $530.29 *$ & No failure - unloaded \\
\hline T39-51 & 0.0919 & 34.77 & 600 & 240 & 0.400 & 220 & 0.678 & $1991.21 *$ & No failure - unloaded \\
\hline T39-47 & 0.0918 & 36.43 & 600 & 240 & 0.400 & 220 & 0.664 & $1847.45 *$ & No failure - unloaded \\
\hline T39-49 & 0.0922 & 35.51 & 600 & 420 & 0.699 & 386 & 1.176 & $2614.33 *$ & No failure - unloaded \\
\hline T39-8 & 0.0914 & 35.37 & 600 & 422 & 0.703 & 388 & 1.196 & $1875.12 *$ & No failure - unloaded \\
\hline T39-36 & 0.0927 & 35.09 & 600 & 360 & 0.600 & 331 & 1.008 & $2352.52 *$ & No failure - unloaded \\
\hline T39-35 & 0.0927 & 34.63 & 600 & 300 & 0.500 & 276 & 0.867 & $2357.32 *$ & No failure - unloaded \\
\hline T41-32 & 0.0919 & 34.89 & 575 & 287 & 0.500 & 275 & 0.790 & $1687.30 *$ & No failure - unloaded \\
\hline T41-43 & 0.0907 & 34.70 & 575 & 345 & 0.600 & 331 & 0.979 & $2061.67 *$ & No failure - unloaded \\
\hline T41-45 & 0.0911 & 34.06 & 575 & 230 & 0.400 & 220 & 0.671 & $1326.07 *$ & No failure - unloaded \\
\hline $\mathrm{T} 41-46$ & 0.0909 & 35.07 & 575 & 287 & 0.500 & 275 & 0.873 & $2346.83 *$ & No failure - unloaded \\
\hline
\end{tabular}

*No failure.

\#Updated result after preparation of creep rupture section of report. 
Table 10.2 (cont.) Matrix of tensile creep and creep-rupture tests

\begin{tabular}{|c|c|c|c|c|c|c|c|c|c|}
\hline Specimen & $\begin{array}{l}\text { Area } \\
\left(\text { (in. }^{2}\right)\end{array}$ & $\begin{array}{c}\text { Virgin room- } \\
\text { temperature } \\
\text { stiffness } a \\
(\mathrm{GPa}) \\
\end{array}$ & $\begin{array}{c}\text { Plaque } \\
\text { UTS } \\
\text { (MPa) }\end{array}$ & $\begin{array}{l}\text { Applied } \\
\text { Stress } \\
\text { (MPa) }\end{array}$ & $\begin{array}{c}\text { Stress } \\
(\% \text { RT } \\
\text { UTS })^{b}\end{array}$ & $\begin{array}{c}\text { Normalized } \\
\text { Applied Stress } \\
\quad(\mathrm{MPa})^{c}\end{array}$ & $\begin{array}{c}\text { Loading } \\
\text { strain } \\
(\%)\end{array}$ & $\begin{array}{c}\text { Rupture } \\
\text { time } \\
\text { (h) }\end{array}$ & Notes \\
\hline \multicolumn{10}{|c|}{ Windshield Washer Fluid (cont.) } \\
\hline $\mathrm{T} 41-50$ & 0.0915 & 36.52 & 575 & 431 & 0.750 & 413 & 1.167 & $1699.13^{*}$ & No failure - unloaded \\
\hline T41-38 & 0.0909 & 36.59 & 575 & 460 & 0.800 & 441 & 1.251 & $2257.98^{*}$ & No failure - unloaded \\
\hline T41-39 & 0.0909 & 36.47 & 575 & 460 & 0.800 & 441 & 1.264 & $2086.93 *$ & No failure - unloaded \\
\hline T41-49 & 0.0910 & 35.56 & 575 & 431 & 0.750 & 413 & 1.203 & $2086.19 *$ & No failure - unloaded \\
\hline T41-25 & 0.0918 & 34.06 & 575 & 174 & 0.303 & 167 & 0.492 & $698.21 *$ & No failure - unloaded \\
\hline
\end{tabular}

${ }^{a}$ Virgin stiffness measured on each specimen.

${ }^{\mathrm{b}}$ Percentage of room-temperature plaque UTS.

${ }^{\mathrm{c}}$ Applied stress multiplied by overall average UTS all plaques/plaque average UTS. Overall average UTS all plaques $=551 \mathrm{MPa}$

*No failure. 
Examples of total strain versus time and time-dependent, room temperature creep strain are presented in Figures 10.6 and 10.7, respectively (additional room-temperature, in-air creep deformation results are presented in Appendix F). Log-log plots of the time-dependent, room temperature creep strain curves in Figure 10.7 are presented in Figure 10.8. Each of the log-log plots of time-dependent, room temperature creep strain was fit with a power-law curve (data $\leq 1 \mathrm{~h}$ were not utilized) having the form

$$
\varepsilon_{\mathrm{c}}=\mathrm{At}^{\mathrm{n}},
$$

where $t$ is the creep time, and the coefficient $\mathrm{A}$ and exponent $\mathrm{n}$ are functions of stress. The power-law fits produced coefficients $\mathrm{A}$ and exponents $\mathrm{n}$.

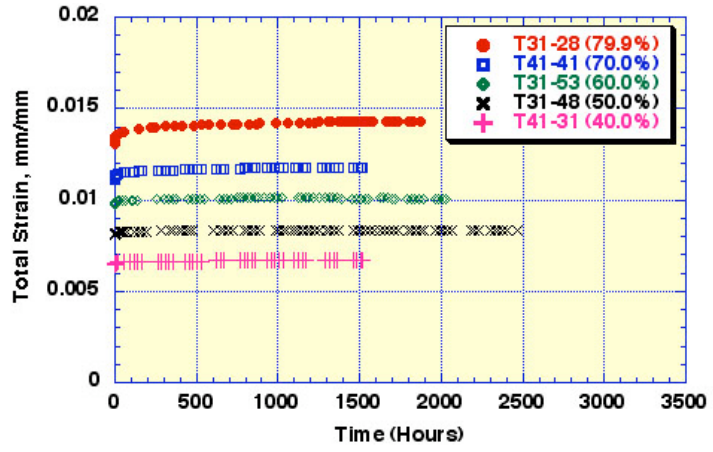

Figure 10.6 Examples of room temperature total strain versus time results.

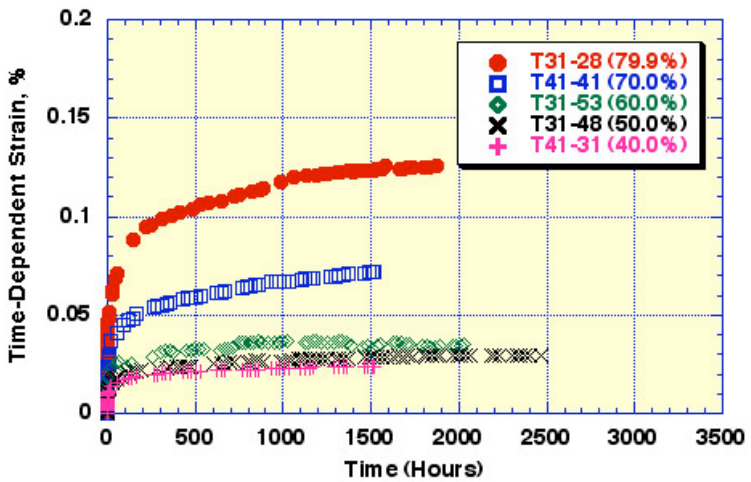

Figure 10.7 Examples of room temperature time-dependent strain versus time results.

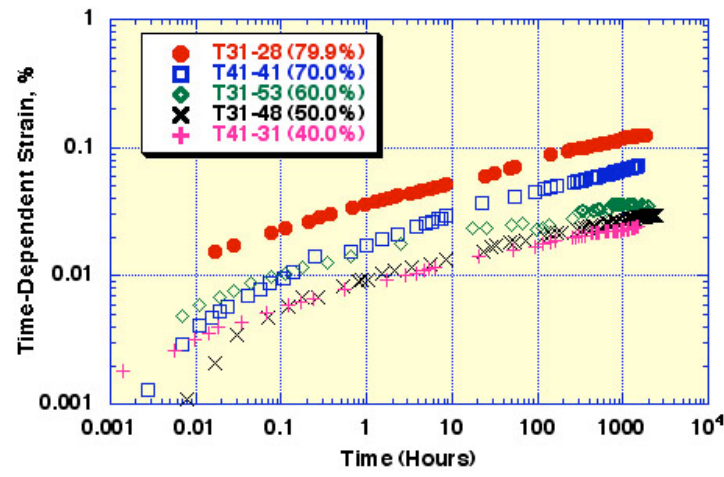

Figure 10.8 Time-dependent, room temperature creep data.

Values of $\mathrm{A}$ and $\mathrm{n}$ from the power-law curve fits of data such as shown in Figure 10.8 are plotted in Fig. 10.9 vs stress. The best reasonably simple expression was chosen in each case- a power law for A and a binomial for $\mathrm{n}$. The resulting curve-fit expressions for $\mathrm{A}$ and $\mathrm{n}$ in Eq. (10.1) are

$$
\left.\begin{array}{c}
\mathrm{A}=1.056 \times 10^{-7} \sigma^{2.0614} \\
\mathrm{n}=-4.1316 \times 10^{-7} \sigma^{2}+3.4953 \times 10^{-4} \sigma \\
+0.062324
\end{array}\right\}
$$

where $\sigma$ is stress in megapascals, $\varepsilon_{\mathrm{c}}$ in Eq. (10.1) is in percent, and time, $\mathrm{t}$, is in hours. 


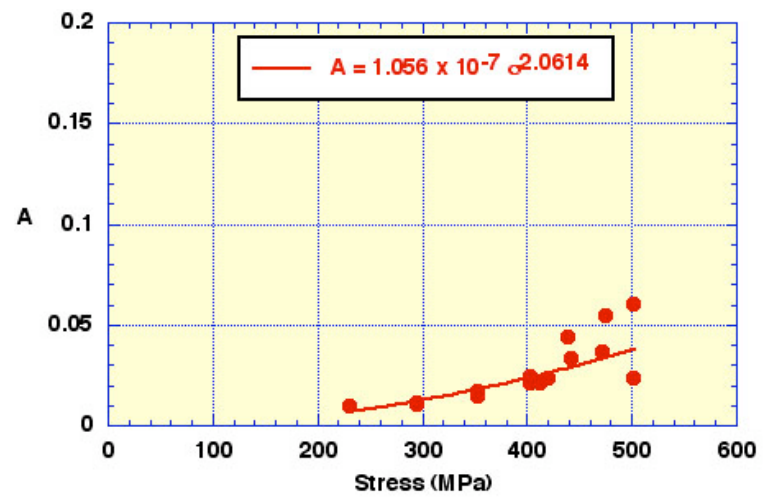

a. Determination of A, room temperature, in-air.

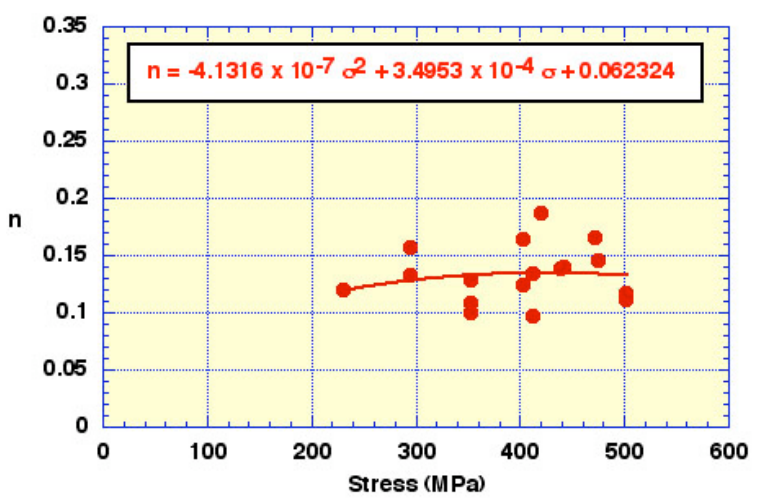

b. Determination of $\mathrm{n}$, room temperature, in-air.

Figure 10.9 Power-law coefficient A and exponent $\mathrm{n}$ as functions of applied stress at room temperature.

A comparison of the creep equation (Eqn. 10.1) predicted results with the original experimental data presented in Fig. 10.7 is provided in Figure 10.10a. The predictions of time-dependent strain at relatively high stress levels $(\geq 70.0 \%)$ tend to be greater than those measured, whereas at stress levels below this the predicted strains are slightly less than those measured. Figure $10.10 \mathrm{~b}$ presents the same results except the predicted strains were determined using a normalized stress in which the actual applied stress was adjusted by multiplying it by the ratio of the overall plaque UTS (551 MPa) to the individual plaque UTS. As shown in Figure 10.10b, this reduced the difference between measured and predicted values at the lower stress values, but increased the difference at the highest stresses. Predicted creep curves over the stress range from 50 to $400 \mathrm{MPa}$ are shown in Fig. 10.11 .

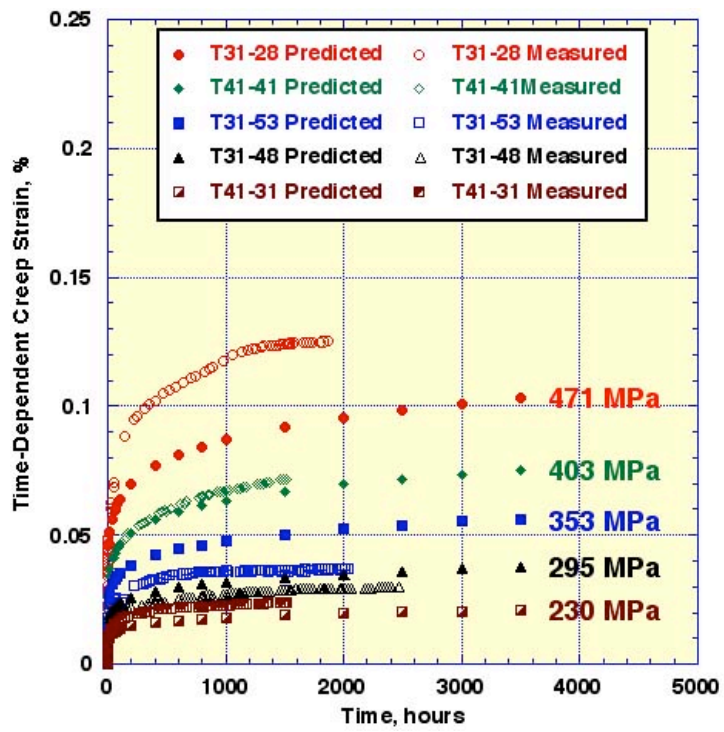

a. Actual applied stress.

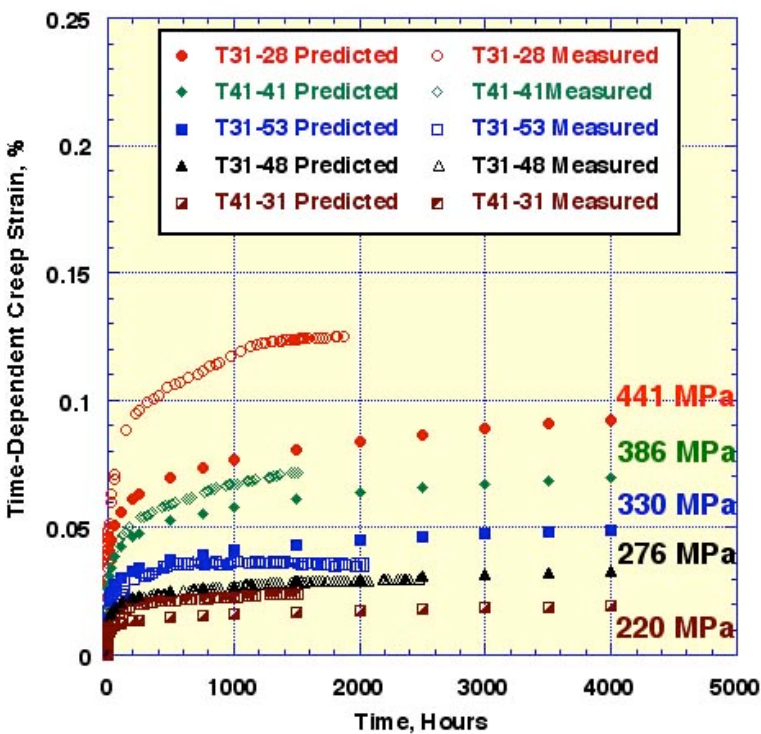

b. Normalized applied stress.

Fig. 10.10. Comparison of measured and predicted in-air room-temperature creep strains. 


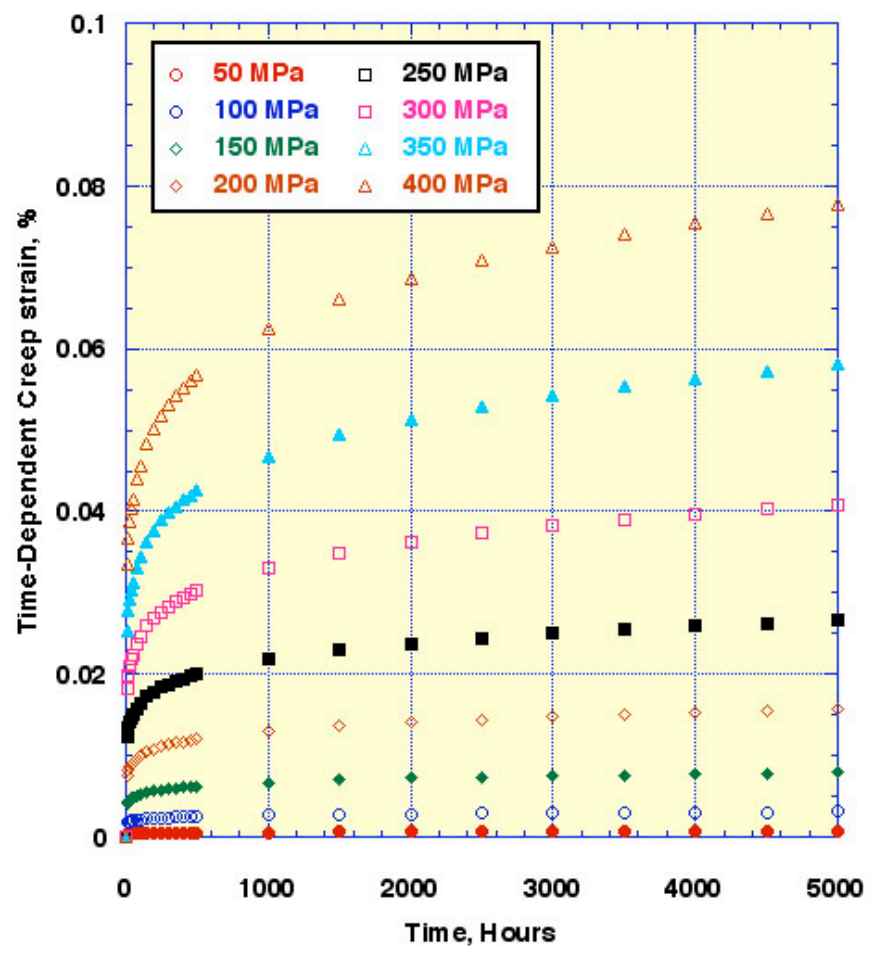

Fig. 10.11. Time-dependent room-temperature creep strains predicted by power-law creep equation.

Predicted room-temperature isochronous stress-strain curves are presented in Figure 10.12.

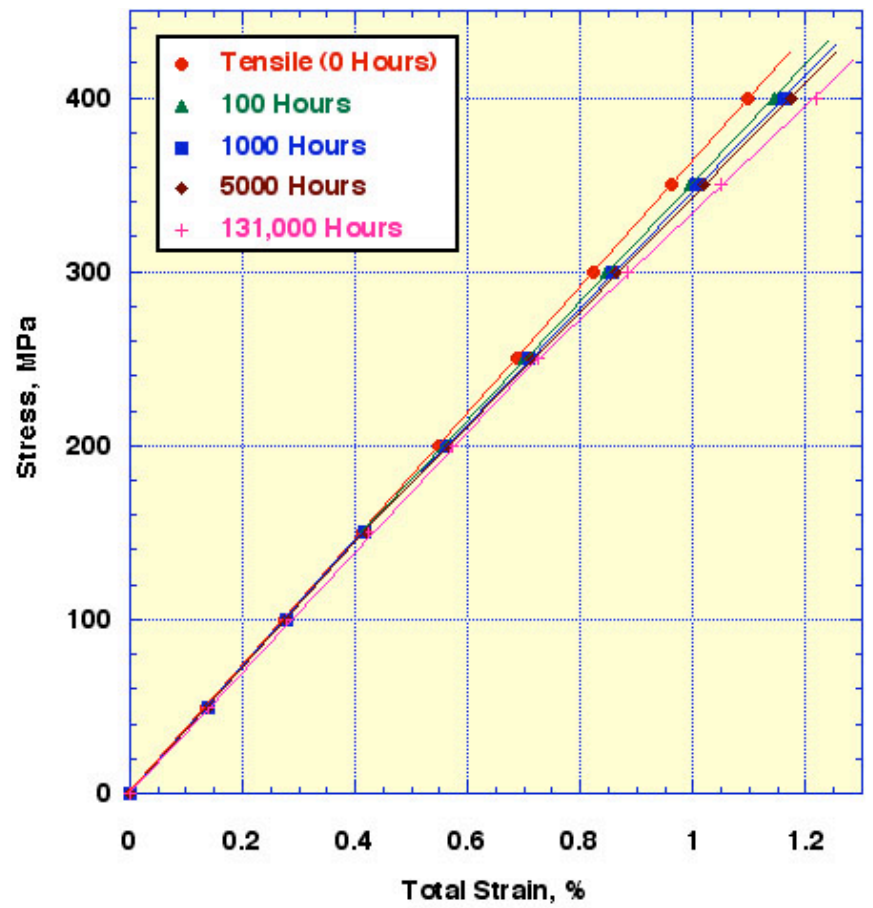

Fig. 10.12. Predicted room-temperature isochronous stress-strain curves. 
A comparison of predicted creep response for the quasi-isotropic carbon-fiber reinforced thermoplastic T material and the quasi-isotropic carbon-fiber reinforced thermoset Q material is provided in Figure 10.13. At stress levels corresponding to about $60 \%$ UTS and less the Q material predicted strains are greater than those predicted for the T material. However, at higher stress levels the T material predicted creep strains are greater than those predicted for the Q material. As noted previously, at high stress levels the predicted creep strains for the $\mathrm{T}$ material were greater than those determined experimentally.

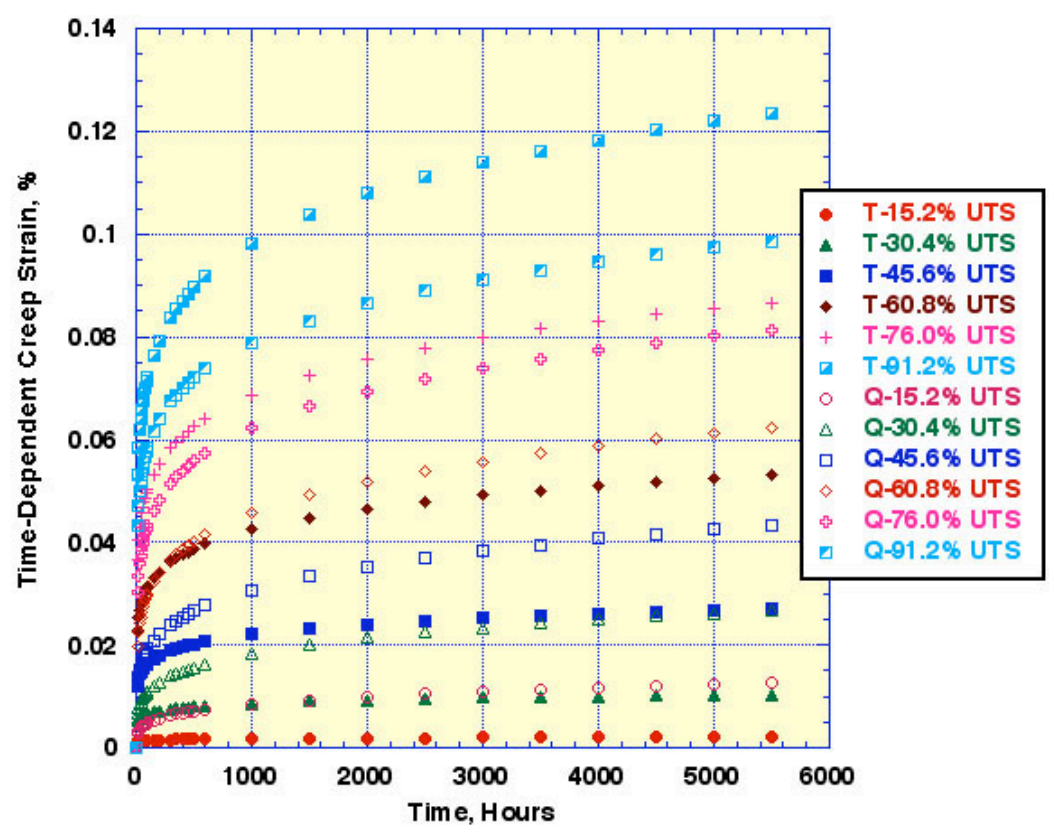

Fig. 10.13. Comparison of predicted creep response of quasi-isotropic carbon-fiber reinforced thermoplastic ( $\mathrm{T}$ material) and quasi-isotropic carbon-fiber reinforced thermoset ( $\mathrm{Q}$ material) composites.

\subsubsection{Elevated Temperature}

The $120^{\circ} \mathrm{C}$, in-air creep specimens were fabricated from four plaques (T10, T23, T31, and T41) (see Appendix B). The short-time loading strains measured in the $120^{\circ} \mathrm{C}$, in-air tests are plotted against applied stress in Figure 10.14. Figure 10.14a presents the loading strains for all specimens from Plaques T23, T31, and T41 for which loading strain data were obtained. The solid line is a power-law fit to all data points over the data range (a linear line is shown between the origin and the power-law fit at the lowest stress level). The dashed line represents the average virgin stiffness of all tensile specimens. The dashed line has been adjusted for the effect of $120^{\circ} \mathrm{C}$ on the tensile modulus (see Table 7.4). Figure $10.14 \mathrm{~b}$ presents the data in Figure $10.14 \mathrm{a}$ with the loading strains normalized by multiplying the strains by the ratio of each specimen's virgin stiffness to the overall stiffness for all specimens. Figure 10.14 implies that loading strains were essentially elastic. 


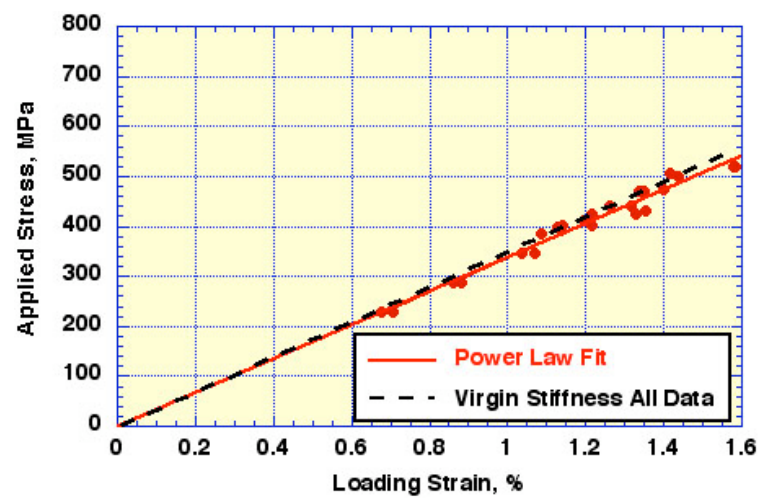

a. Unadjusted loading strains.

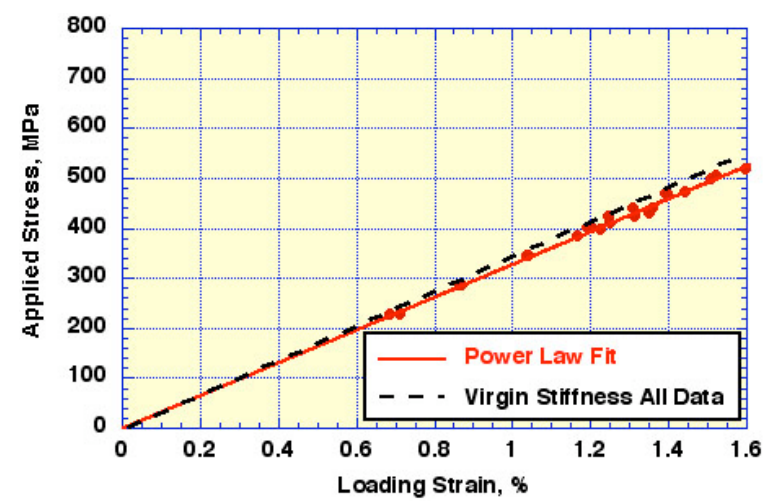

b. Normalized loading strains.

Figure 10.14 Loading strains measured in $120^{\circ} \mathrm{C}$, in-air creep tests.

Examples of elevated temperature $\left(120^{\circ} \mathrm{C}\right)$ total strain versus time and time-dependent, elevated temperature creep strain are presented in Figures 10.15 and 10.16 , respectively (additional $120^{\circ} \mathrm{C}$ in-air creep deformation results are presented in Appendix F). Log-log plots of the time-dependent, elevated temperature creep strain curves in Figure 10.16 are presented in Figure 10.17. Each of the log-log plots of time-dependent, elevated temperature creep strain such as shown in Figure 10.17 was fit with a powerlaw curve (data less than $1 \mathrm{~h}$ was not utilized) having the form

$$
\varepsilon_{\mathrm{c}}=\mathrm{At}^{\mathrm{n}},
$$

where $t$ is the creep time, and the coefficient $\mathrm{A}$ and exponent $\mathrm{n}$ are functions of stress. The power-law fits produced coefficients $\mathrm{A}$ and exponents $\mathrm{n}$.

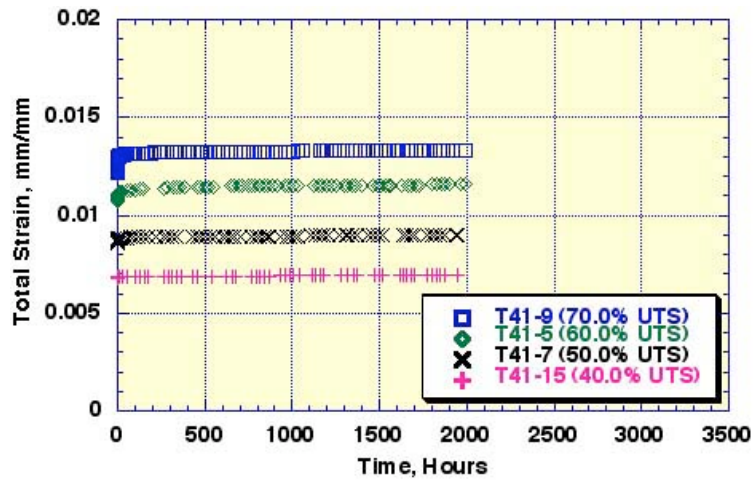

Figure 10.15 Examples of elevated temperature total strain versus time results.

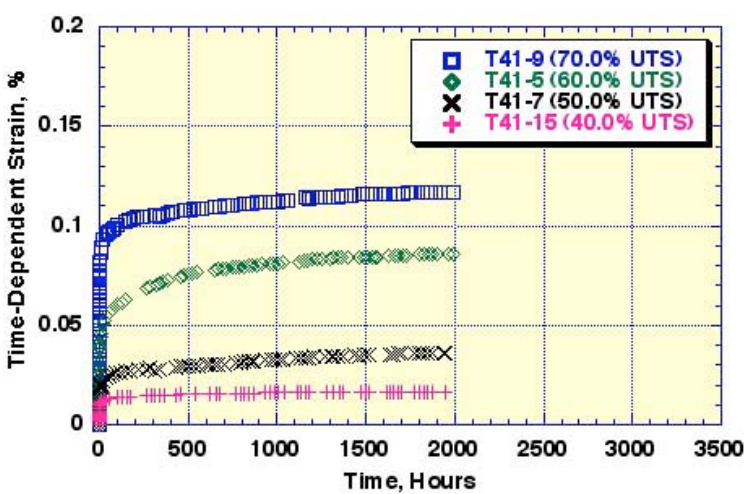

Figure 10.16 Examples of elevated temperature time-dependent strain versus time results. 


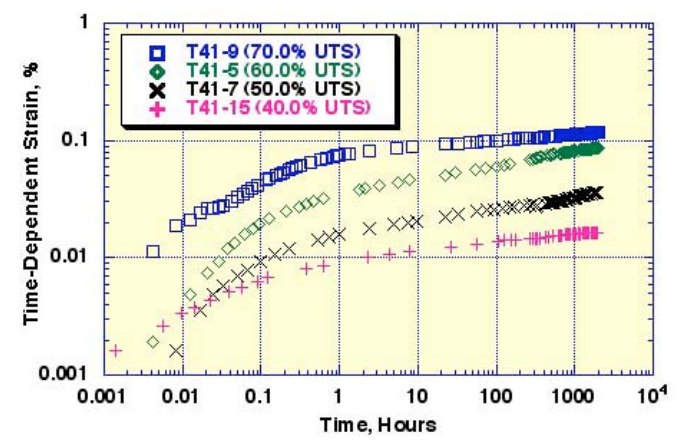

Figure 10.17 Time-dependent, elevated temperature creep data.

Values of $\mathrm{A}$ and $\mathrm{n}$ from the curve fits of the data such as shown in Figure 10.17 are plotted in Figure 10.18 vs stress. The best reasonably simple expression was chosen in each case - a power law for $\mathrm{A}$ and $\mathrm{a}$ binomial for $\mathrm{n}$. The resulting curve-fit expressions for $\mathrm{A}$ and $\mathrm{n}$ in Eq. (10.3) are

$$
\left.\begin{array}{c}
\mathrm{A}=8.366 \times 10^{-9} \sigma^{2.5834} \\
\mathrm{n}=-2.0172 \times 10^{-6} \sigma^{2}+1.5173 \times 10^{-3} \sigma \\
-0.16349
\end{array}\right\}
$$

where $\sigma$ is stress in megapascals, $\varepsilon_{\mathrm{c}}$ in Eq. (10.3) is in percent, and time, $\mathrm{t}$, is in hours.
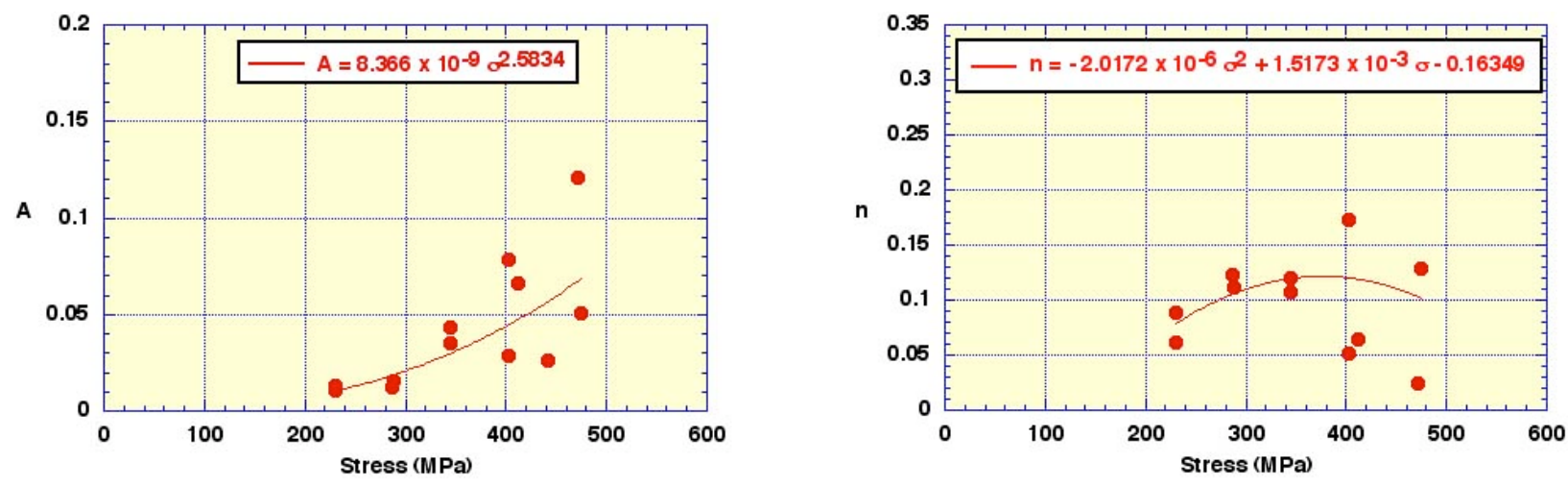

a. Determination of A, elevated temperature, in-air.

b. Determination of $n$, elevated temperature, in-air

Fig. 10.18 Power-law coefficient A and exponent $\mathrm{n}$ as functions of applied stress at elevated temperature.

Predicted creep strains from Eqs. (10.3) and (10.4) are compared with the original $120^{\circ} \mathrm{C}$ experimental data in Figure 10.19. The predicted curves appear to provide reasonable and consistent predictions for the stress range considered (e.g., 230 to $403 \mathrm{MPa}$, or 40 to $70 \%$ UTS). At stress levels greater than about $60 \%$ UTS the measured values are slightly greater than the predicted results. Measured and predicted results at stress levels of 40 and 50\% UTS show very good agreement. Figure 10.19b presents the same results except the predicted strains were determined using a normalized stress in which the actual applied stress was adjusted by multiplying it by the ratio of the overall plaque UTS (551 MPa) to the individual plaque UTS. As shown in Figure 10.19b, this reduced the difference between measured 
and predicted values at the lower stress values, but increased the difference at the highest stresses. Figure 10.20 provides predicted creep curves covering the stress range from 50 to $400 \mathrm{MPa}$.

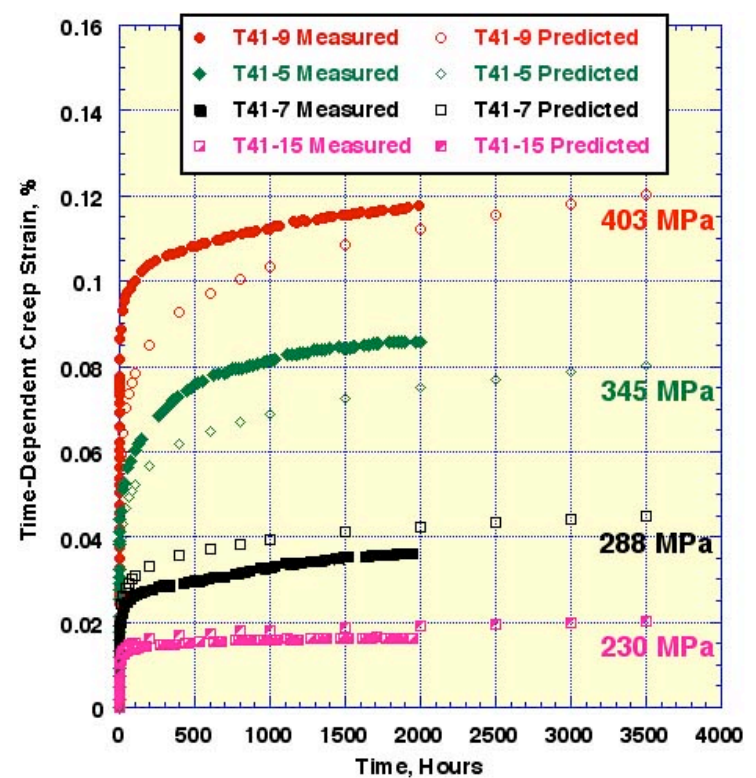

a. . Actual applied stress.

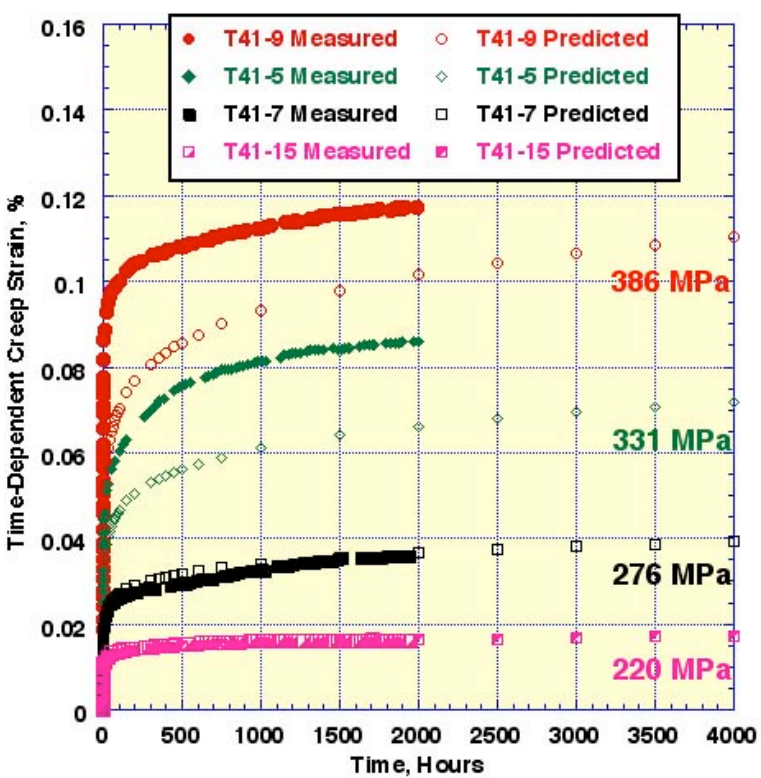

b. Normalized applied stress.

Fig. 10.19. Comparison of measured and predicted $120^{\circ} \mathrm{C}$ creep strain.

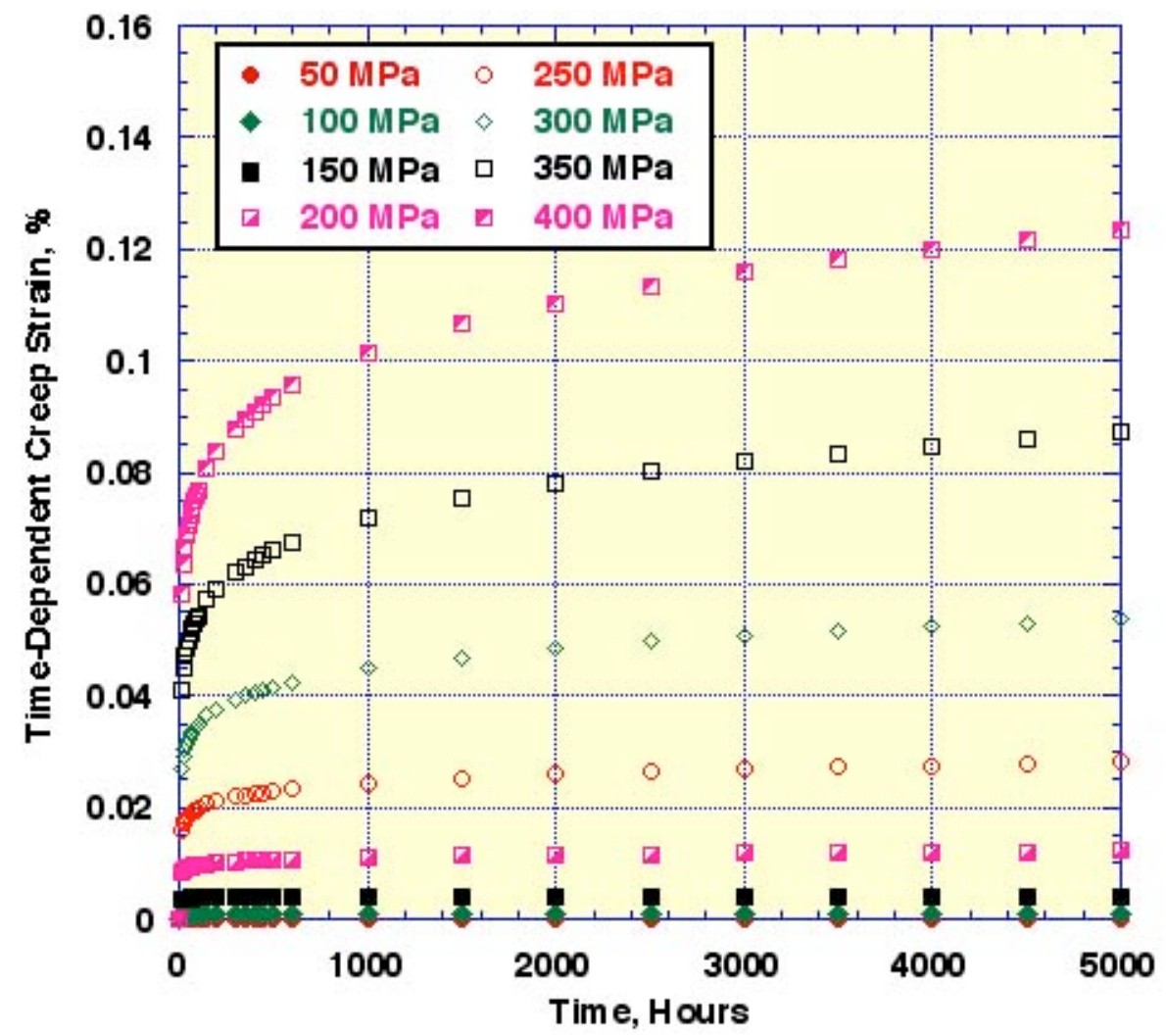

Fig. 10.20. Time-dependent, $120^{\circ} \mathrm{C}$ creep strains predicted by creep equation. 
The corresponding isochronous stress-strain curves are shown in Figure 10.21.

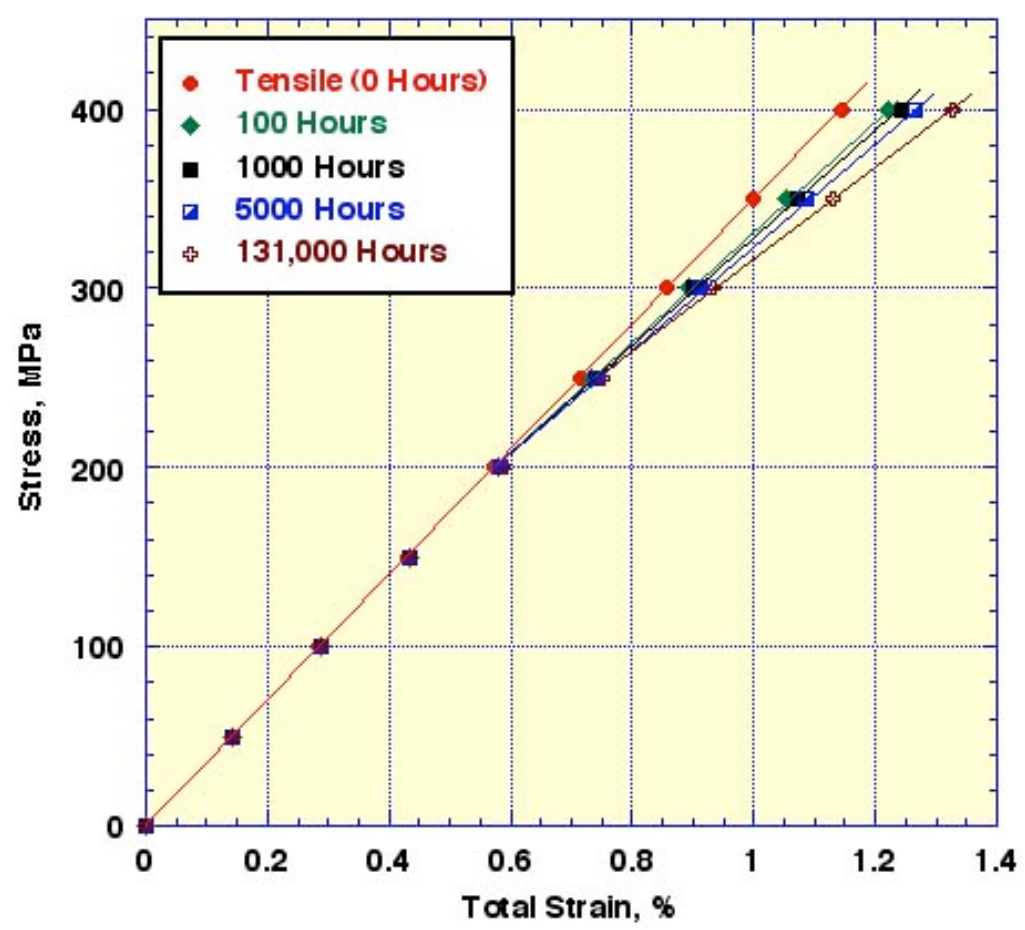

Fig. 10.21. Predicted $120^{\circ} \mathrm{C}$ isochronous stress-strain curves.

By ratioing predicted strains at $120^{\circ} \mathrm{C}$ [Eqs. (10.3) and (10.4)] to the corresponding roomtemperature predictions [Eqs. (10.1) and (10.2)], the following table of creep strain multiplication factors was obtained (Table 10.3). The factor increased slightly with stress level and did not vary significantly with time.

Table 10.3. Factors for predicting tensile creep strains at $120^{\circ} \mathrm{C}$ from room-temperature predictions

\begin{tabular}{rcccccccc}
\cline { 2 - 9 } Time, $\mathbf{h}$ & \multicolumn{8}{c}{ Stress, MPa } \\
\cline { 2 - 9 } & $\mathbf{5 0}$ & $\mathbf{1 0 0}$ & $\mathbf{1 5 0}$ & $\mathbf{2 0 0}$ & $\mathbf{2 5 0}$ & $\mathbf{3 0 0}$ & $\mathbf{3 5 0}$ & $\mathbf{4 0 0}$ \\
\hline 50 & 0.31 & 0.54 & 0.77 & 1.01 & 1.24 & 1.44 & 1.60 & 1.70 \\
100 & 0.28 & 0.49 & 0.73 & 0.97 & 1.21 & 1.42 & 1.58 & 1.68 \\
200 & 0.25 & 0.45 & 0.68 & 0.93 & 1.18 & 1.40 & 1.57 & 1.67 \\
500 & 0.21 & 0.40 & 0.63 & 0.89 & 1.14 & 1.38 & 1.55 & 1.64 \\
1000 & 0.19 & 0.37 & 0.60 & 0.85 & 1.12 & 1.36 & 1.53 & 1.63 \\
3000 & 0.15 & 0.32 & 0.54 & 0.80 & 1.08 & 1.33 & 1.51 & 1.60 \\
5000 & 0.14 & 0.30 & 0.52 & 0.78 & 1.06 & 1.31 & 1.50 & 1.59 \\
\hline
\end{tabular}

As noted in the table, the $120^{\circ} \mathrm{C}$ creep strain multiplier was much less than that obtained from previous materials investigated. The $120^{\circ} \mathrm{C}$ creep strain multiplier for the quasi-isotropic thermoset composite (Q material) varied from 3.9 at $25 \mathrm{MPa}$ to 2.9 at $100 \mathrm{MPa}$. The factor also did not appear to vary significantly with time. An exposure temperature of $120^{\circ} \mathrm{C}$ had a greater effect on the tensile properties of the Q material (i.e., tensile strength reduced approximately $20 \%$ relative to room temperature) than it did for the quasi-isotropic thermoplastic composite ( $\mathrm{T}$ material) that experienced about a $4 \%$ reduction.

Four and three creep-deformation tests, respectively, were performed at the intermediate temperatures of $70^{\circ}$ and $90^{\circ} \mathrm{C}$. The stress levels ranged from 49.8 to $89.0 \%$ UTS for the $70^{\circ} \mathrm{C}$ tests and 
70.0 to $80.0 \%$ for the $90^{\circ} \mathrm{C}$ tests. Figure 10.22 presents a comparison of total strain results at a stress level of $70.0 \%$ UTS for test temperatures of $23^{\circ}, 70^{\circ}, 90^{\circ}$, and $120^{\circ} \mathrm{C}$. Figures 10.23 and 10.24 present time-dependent creep strain results indicating the effect of temperature. Comparing time-dependent strains at 1500 hours based on experimental results provides creep strain multipliers ranging from 1.54 at $70^{\circ} \mathrm{C}$ to 1.67 at $120^{\circ} \mathrm{C}$. As a result of the somewhat inconsistent results presented in Table 10.3, a creep multiplication factor of 1.7 at $120^{\circ} \mathrm{C}$ was used in developing the analysis guidance in Chap. 2 of Part 1 . All specimens were fabricated from Plaque T41.

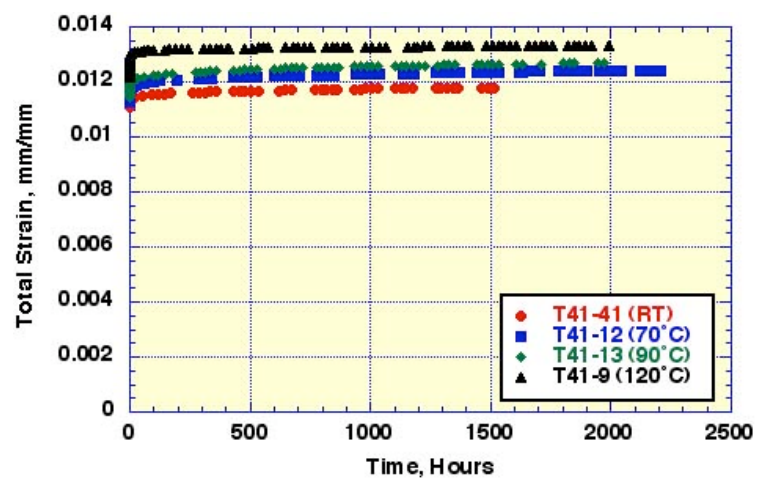

Figure 10.22 Examples of temperature effect on total strain versus time results: $70 \%$ UTS.

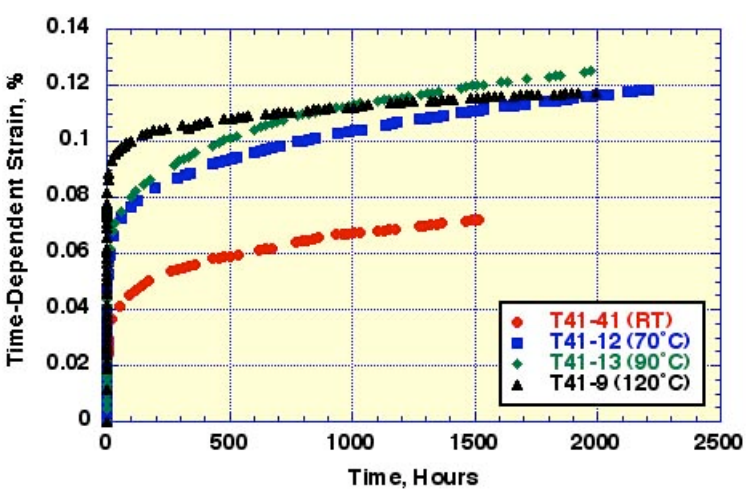

Figure 10.23 Examples of temperature effect on time-dependent strain versus time results: $70 \%$ UTS.

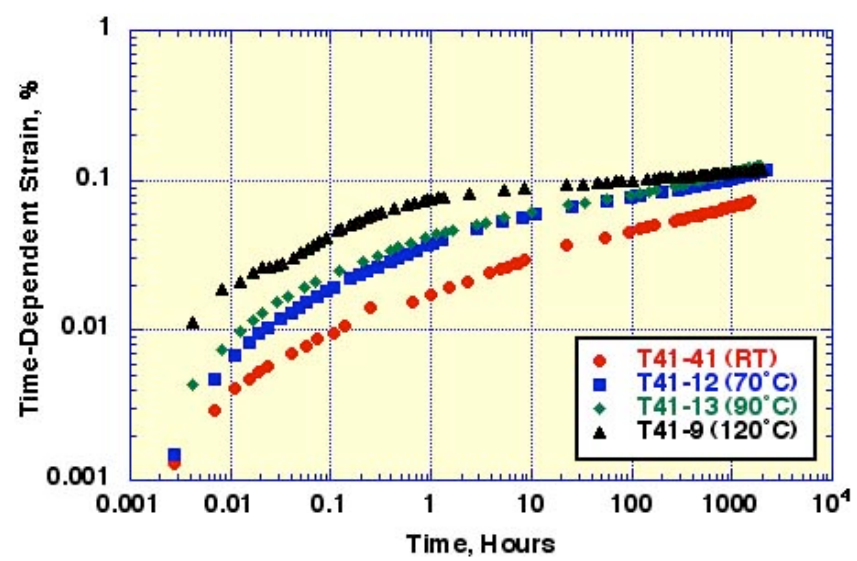

Figure 10.24 Examples of temperature effect on time-dependent creep data: $70 \%$ UTS.

Comparisons of measured time-dependent creep strains with the predicted room-temperature curves are presented in Figures 10.25 and 10.26 for temperatures of $70^{\circ}$ and $90^{\circ} \mathrm{C}$, respectively. The predicted room-temperature creep curves for $70^{\circ}$ and $90^{\circ} \mathrm{C}$ tend to be less than the measured curves at all stress levels shown for both temperatures. A much more thorough investigation of creep at $70^{\circ}$ and $90^{\circ} \mathrm{C}$ would be required to explain or understand the reasons for the differences between measured and predicted creep strains. Based on the data at hand, a constant multiplication factor of 1.3, corresponding, somewhat arbitrarily, to a time of $1000 \mathrm{~h}$, was chosen to approximate the $70^{\circ} \mathrm{C}$ behavior in terms of roomtemperature behavior. This factor was obtained for the stress level of $287 \mathrm{MPa}$ in Figure 10.25 and is used in Chap. 2 of Part 1. The value, which compares to a corresponding factor of 1.2 for the quasiisotropic thermoset composite (Q material), should be more than adequately conservative over longer time periods. 


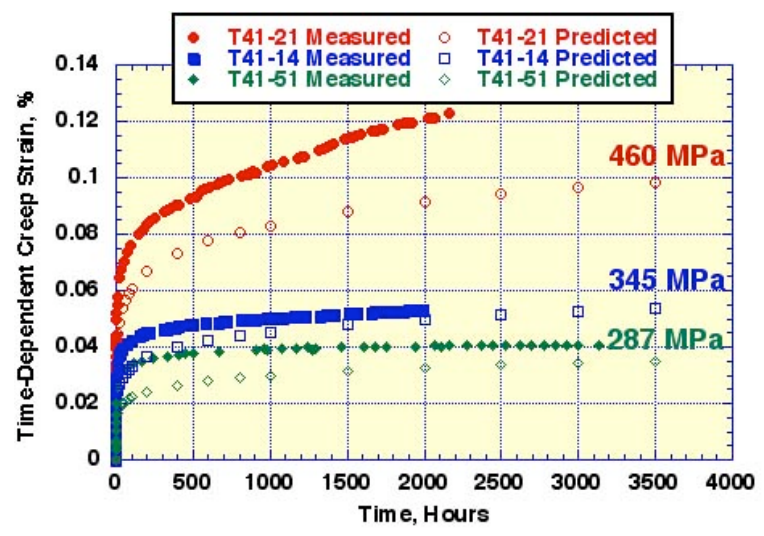

Figure 10.25 Comparison of measured and predicted time-dependent creep strains : $70^{\circ} \mathrm{C}$.

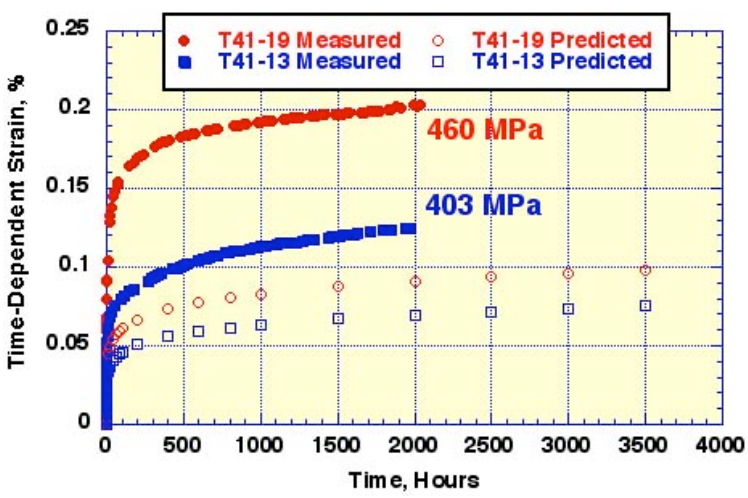

Figure 10.26 Comparison of measured and predicted time-dependent creep strains : $90^{\circ} \mathrm{C}$.

\subsection{TENSILE TESTS IN FLUIDS}

\subsubsection{Distilled Water}

As shown in Tables 10.1 and 10.2, 15 creep deformation tests were performed on specimens fabricated from Plaques T39 and T41 that were submerged in distilled water. Prior to loading, the specimens were presoaked in distilled water for a nominal period of $1000 \mathrm{~h}$.

Examples of total strain versus time and time-dependent, room temperature creep strain are presented in Figures 10.27 and 10.28, respectively. Results in Figure 10.28 at loading levels representing 60.0, 50.0, and 40.0\% UTS are compared with predicted creep curves in air in Figure 10.29. The results are presented in terms of actual applied stress and normalized stress such as was done in Figure 10.10. As noted in the Figure 10.29a, the predicted creep strains are greater than the measured results except at the lowest stress level (i.e., 40\% UTS). Normalizing the applied stress reduced the difference between measured and predicted creep strain, except at lowest stress level. Comparing the distilled water results in Figure 10.28 with room temperature, in-air results in Figure 10.7 at comparable loadings (i.e., \% UTS) at a time of 1500 hours provides creep multiplication factors that range from 1.16 at $40 \%$ UTS to 1.35 at $60 \%$ UTS. Thus, to account for the effect of distilled water on creep, a multiplication factor of 1.4 is recommended in Chap. 2 of Part 1. The corresponding distilled-water multiplication factor recommended for the quasi-isotropic thermoset composite (Q material) was 1.5.

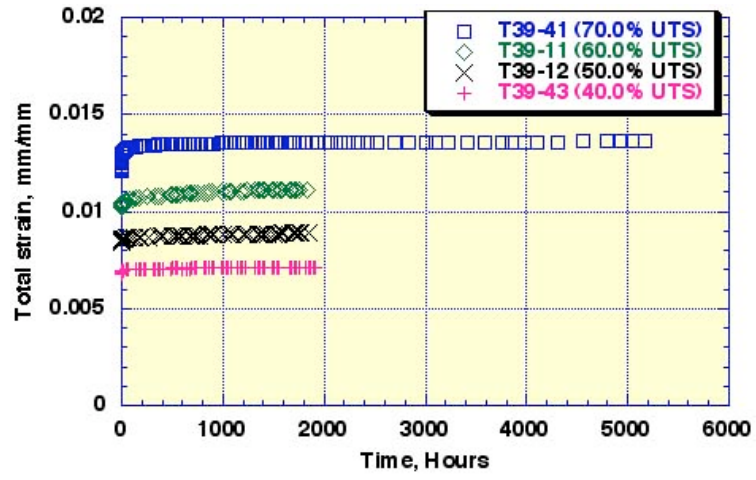

Figure 10.27 Examples of room temperature total strain versus time results: distilled water exposure.

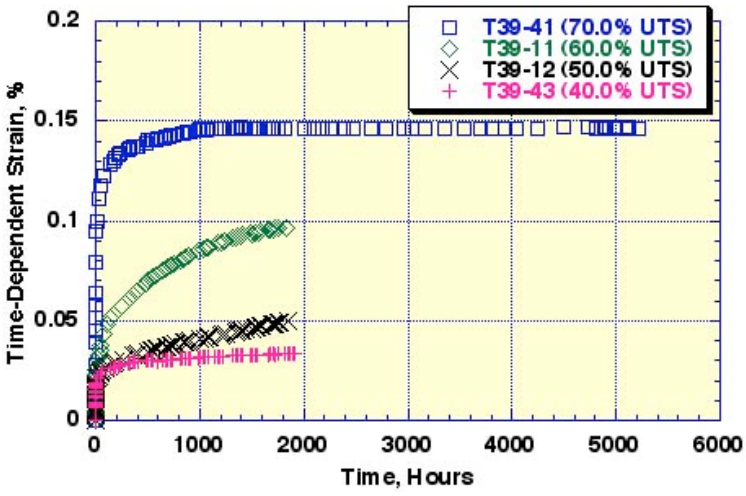

Figure 10.28 Examples of room temperature time-dependent strain versus time results: distilled water exposure. 


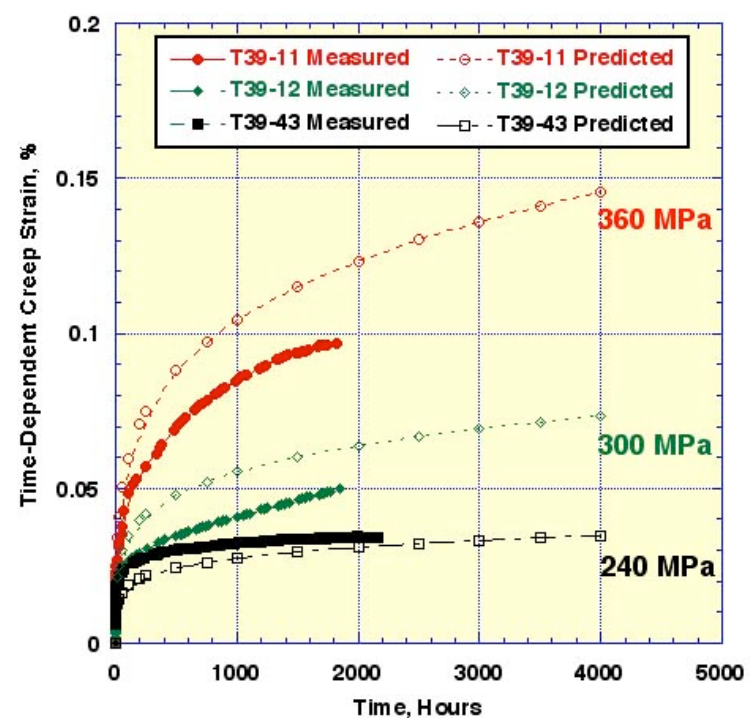

a. Actual applied stress.

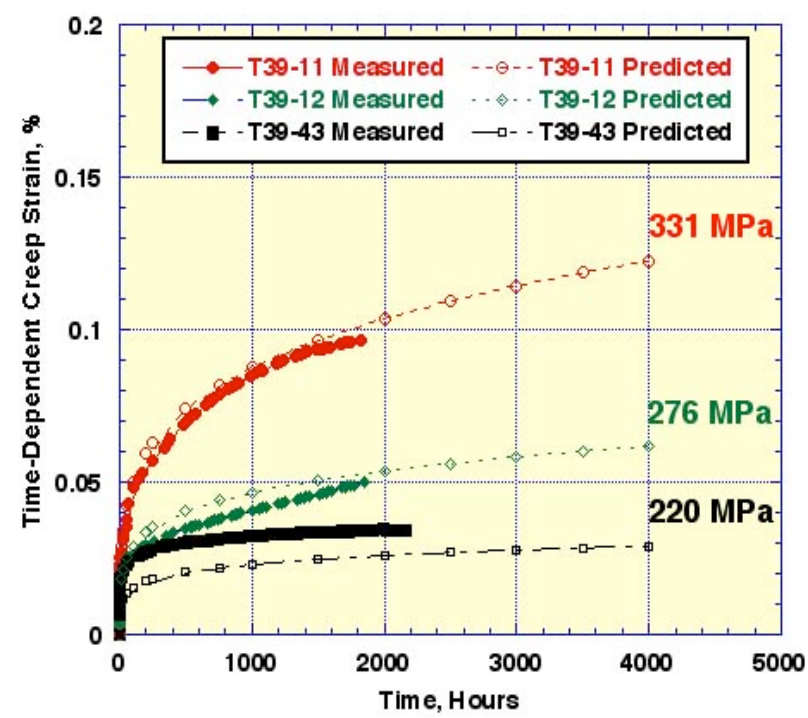

b. Normalized applied stress.

Fig. 10.29. Time-dependent creep response of specimens tested in distilled water compared to predicted response in air.

\subsubsection{Windshield Washer Fluid}

As shown in Tables 10.1 and 10.2, seventeen creep deformation tests were performed on specimens submerged in windshield washer fluid. Prior to loading, the specimens were presoaked in windshield washer fluid for a nominal period of $100 \mathrm{~h}$. Windshield washer fluid tensile creep deformation specimens were fabricated from Plaques T39 and T41.

Examples of total strain versus time and time-dependent, room temperature creep strain are presented in Figures 10.30 and 10.31, respectively. Results in Figure 10.31 at loading levels representing 70.0, 60.0, 50.0, and 40.0 \% UTS are compared with predicted creep curves in air in Figure 10.32. The results are presented in terms of actual applied stress and normalized stress such as was done in Figure 10.10. As noted in the Figure 10.32a, the predicted creep strains are greater than the measured results. Normalizing the applied stress tended to increase the difference between measured and predicted creep strains. Comparing the measured and predicted creep strains at a time of 1500 hours provides creep multiplication factors that range from 1.77 at $40 \%$ UTS to 2.19 at $50 \%$ UTS. Thus, to account for the effect of windshield washer fluid on creep, a multiplication factor of 2.2 is recommended in Chap. 2 of Part 1. The corresponding distilled-water multiplication factor recommended for the quasi-isotropic thermoset composite (Q material) was 1.7. 


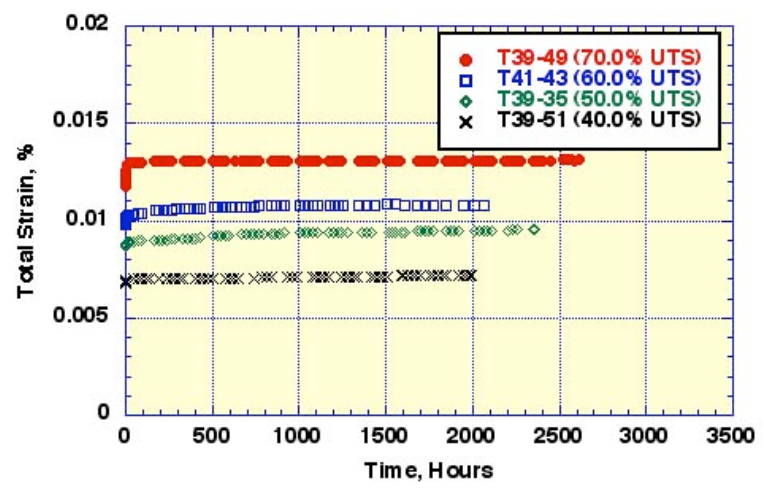

Figure 10.30 Examples of room temperature total strain versus time results: windshield washer fluid exposure.

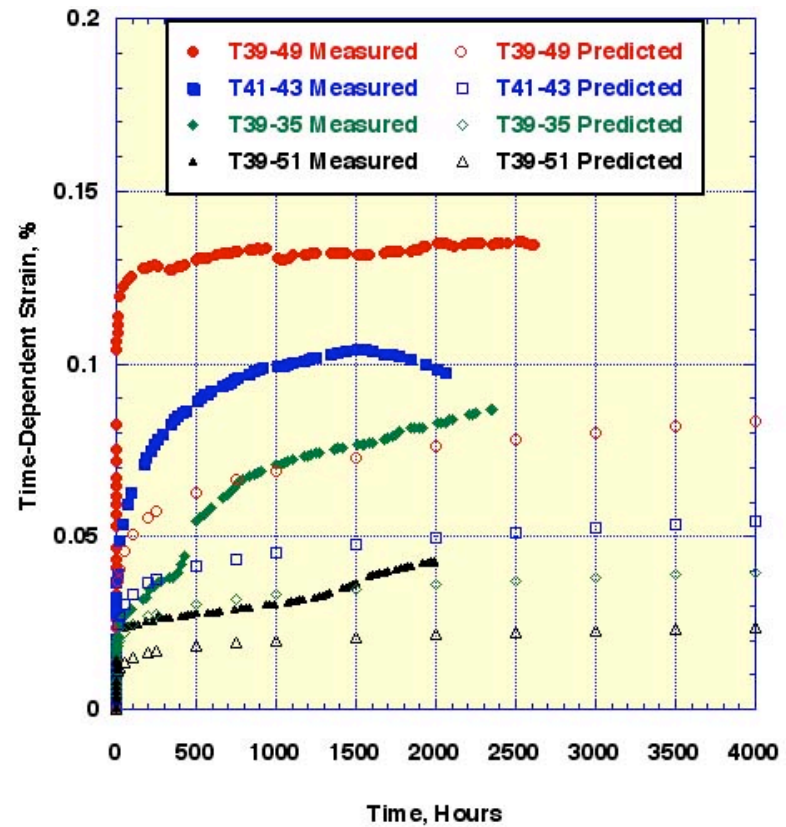

a. Actual applied stress.

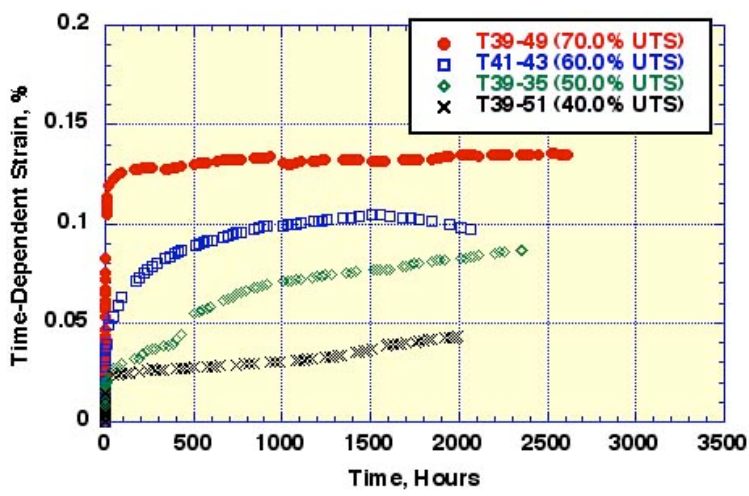

Figure 10.31 Examples of room temperature time-dependent strain versus time results: windshield washer fluid exposure.

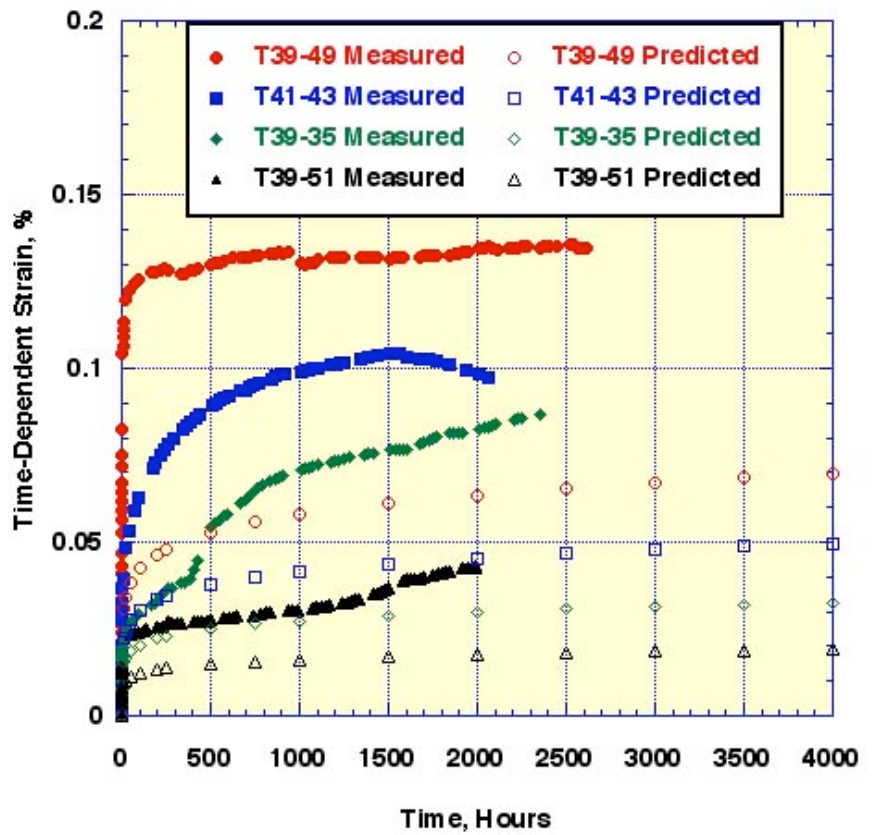

b. Normalized applied stress.

Fig. 10.32. Time-dependent creep response of specimens tested in windshield washer fluid compared to predicted response in air. 


\subsection{COMPRESSIVE TESTS}

The 14 compressive creep tests that were performed are tabulated in Table 10.4. Two tests at room temperature and three at $120^{\circ} \mathrm{C}$ were of reasonably long durations to provide useful creep data for this section. Specimens were fabricated from Plaque T37 (UTS $=606 \mathrm{MPa}, \mathrm{UCS}=301 \mathrm{MPa}$ ). Based on results presented in Chapter 7 , the UCS at $120^{\circ} \mathrm{C}$ is $55.0 \%$ the room temperature UCS. Typical failed compressive creep sprecimens for the room and $120^{\circ} \mathrm{C}$ compressive creep tests are presented in Figure 10.33 .

Table 10.4. Matrix of compressive creep and creep-rupture tests.

\begin{tabular}{|c|c|c|c|c|c|c|c|}
\hline Specimen & $\begin{array}{c}\text { Thickness } \\
\text { (mm) }\end{array}$ & $\begin{array}{c}\text { Area } \\
\left(\mathrm{mm}^{2}\right)\end{array}$ & $\begin{array}{l}\text { Stress } \\
\text { (MPa) }\end{array}$ & $\begin{array}{c}\text { Stress } \\
\text { (\% UCS) }\end{array}$ & $\begin{array}{c}\text { Loading } \\
\text { strain } \\
(\%)\end{array}$ & $\begin{array}{c}\text { Rupture } \\
\text { time } \\
\text { (h) }\end{array}$ & Notes \\
\hline \multicolumn{8}{|c|}{ Room temperature } \\
\hline T37-32 & 2.921 & 2.921 & 256 & 85.0 & 0.7969 & 0.259 & IITRI Fixture \\
\hline T37-33 & 2.896 & 2.896 & 256 & 85.0 & 0.8261 & 0.015 & 647 Grips \\
\hline T37-34 & 2.896 & 2.896 & 241 & 80.0 & 0.8154 & 1.105 & Wyoming Fixture \\
\hline T37-36 & 2.870 & 2.870 & 226 & 75.0 & 0.7266 & 5.977 & IITRI Fixture \\
\hline T37-39 & 2.896 & 2.896 & 211 & 70.0 & 0.6637 & runout & IITRI Fixture, quit at $550 \mathrm{~h}$ \\
\hline $\mathrm{T} 37-42$ & 2.870 & 2.870 & 211 & 70.0 & 0.6409 & runout & 647 Grips, quit at $550 \mathrm{~h}$ \\
\hline \multicolumn{8}{|c|}{$120^{\circ} \mathrm{C}$} \\
\hline T37-56 & 2.870 & 2.870 & 151 & 50.0 & 0.5258 & 0.003 & IITRI Fixture \\
\hline T37-61 & 2.921 & 2.921 & 135 & 45.0 & 0.4431 & 0.124 & IITRI Fixture \\
\hline $\mathrm{T} 37-50$ & 2.896 & 2.896 & 135 & 45.0 & 0.4630 & 0.049 & IITRI Fixture \\
\hline T37-55 & 2.896 & 2.896 & 120 & 40.0 & 0.4120 & 0.131 & IITRI Fixture \\
\hline $\mathrm{T} 37-59$ & 2.896 & 2.896 & 120 & 40.0 & 0.3914 & runout & IITRI Fixture, quit at $160 \mathrm{~h}$ \\
\hline T37-60 & 2.896 & 2.896 & 90 & 30.0 & 0.3030 & runout & IITRI Fixture, quit at $340 \mathrm{~h}$ \\
\hline T37-40 & 2.921 & 2.921 & 120 & 40.0 & 0.4171 & 1.583 & 647 Grips \\
\hline T37-31 & 2.896 & 2.896 & 90 & 30.0 & 0.2957 & runout & 647 Grips, quit at $120 \mathrm{~h}$ \\
\hline
\end{tabular}
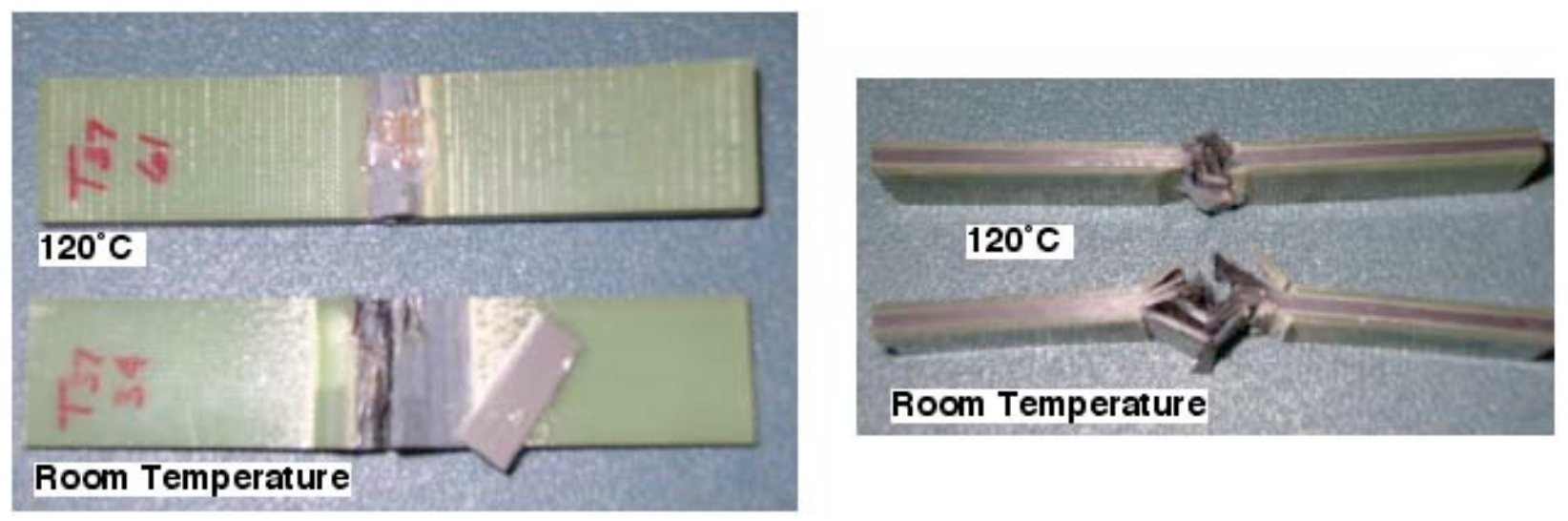

Figure 10.33 Typical failed compressive creep specimens.

Figure 10.34 presents compressive creep test results (total creep strain versus log time) for specimens tested at room temperature. Also included in the figure are the higher stress, short-time results, but these results were too close to the ultimate compressive stress level to provide applicable creep data. Time-dependent compressive creep strain results are presented in Figure 10.35. Figure 10.35a presents 
results for the short-time tests and Figure $10.35 \mathrm{~b}$ for the longer duration tests. Although the room temperature tests were conducted using temperature-compensating dummy gages, changes in the laboratory temperature and humidity may have contributed to the data scatter observed for the two longer duration tests shown in Figure 10.35b. Figure 10.36 provides a comparison of compressive creep strain results and laboratory high and low temperatures over a 22-day period for Specimen T37-39. These data were obtained during a period when the laboratory environmental-control system was being modified.

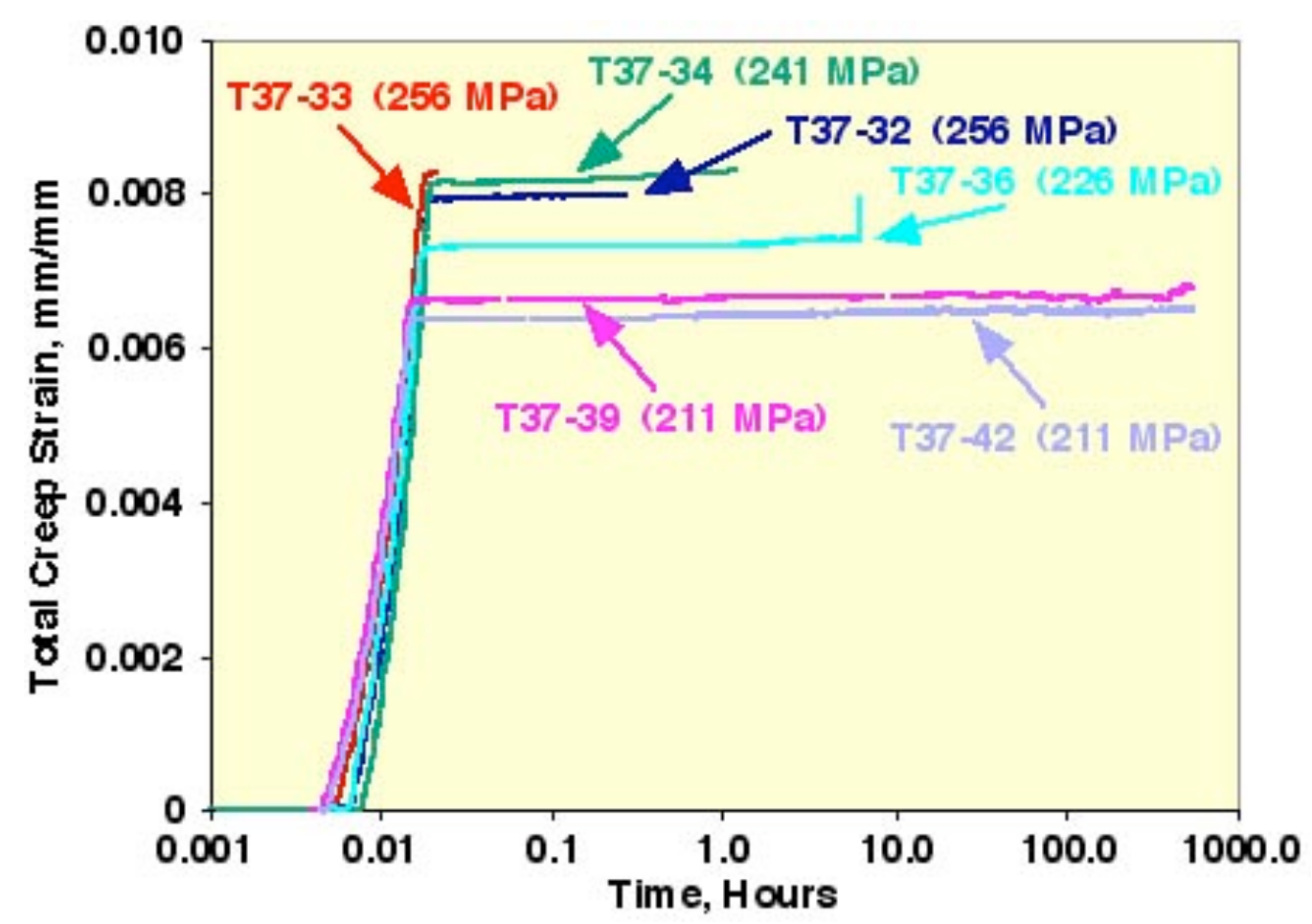

Figure 10.34 Room Temperature total creep strain versus log time results.
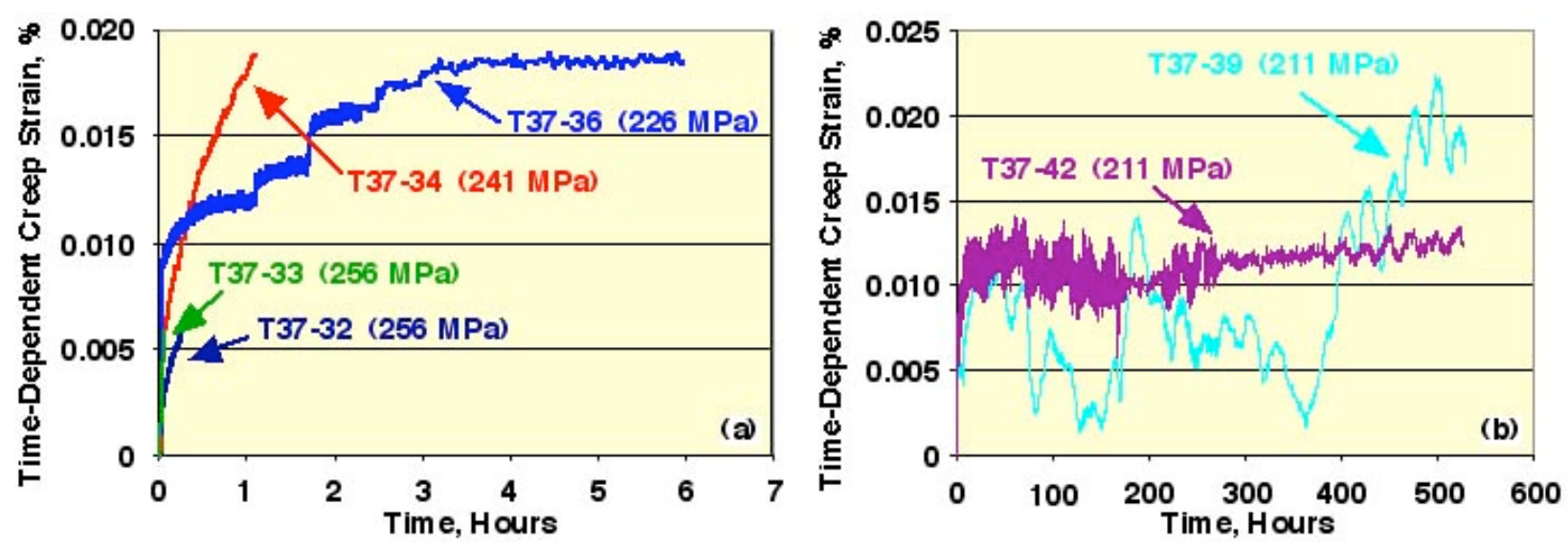

Figure 10.35 Time-dependent creep strain versus time:

(a) short-time test results, (b) longer duration test results. 

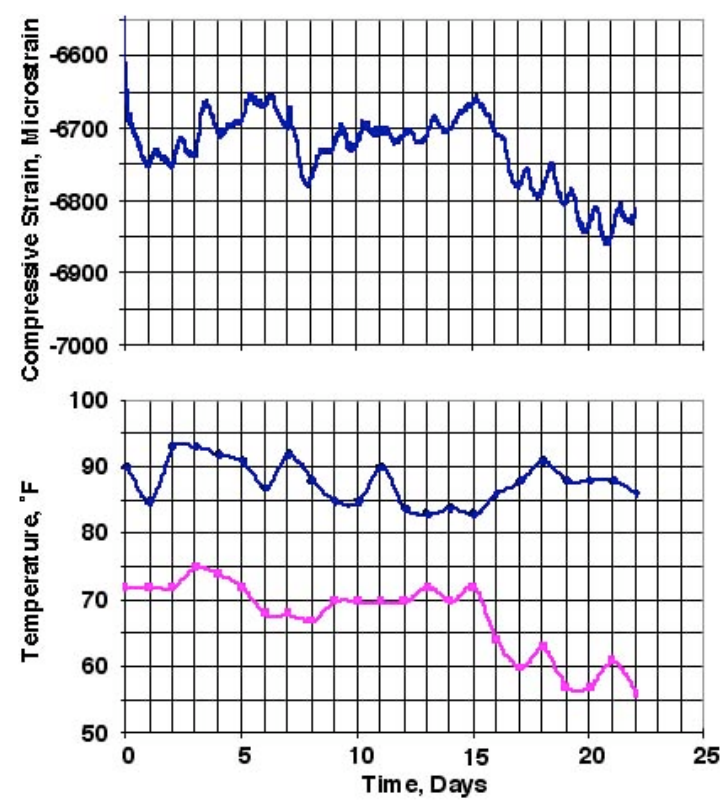

Figure 10.36 Comparison of compressive creep strain with laboratory daily temperature fluctuations.

The time-dependent creep strains measured in one of the room-temperature tests are plotted in Figure 10.37. Also shown in the figure is the predicted tensile creep response using Eqns. 10.1 and 10.2. Only the response for specimen T37-42 is presented because of the problem with data scatter (see Figure 10.35b). Although the results are extremely limited, the comparison between measured and predicted time-dependent creep strains is good. At later times predicted creep response is slightly greater than measured (e.g., $\sim 7 \%$ at 500 hours). This result, although quite limited, indicates that compressive creep at room temperature is essentially the same as tensile creep. This same observation was made for the quasi-isotropic carbon-fiber thermoset composite.

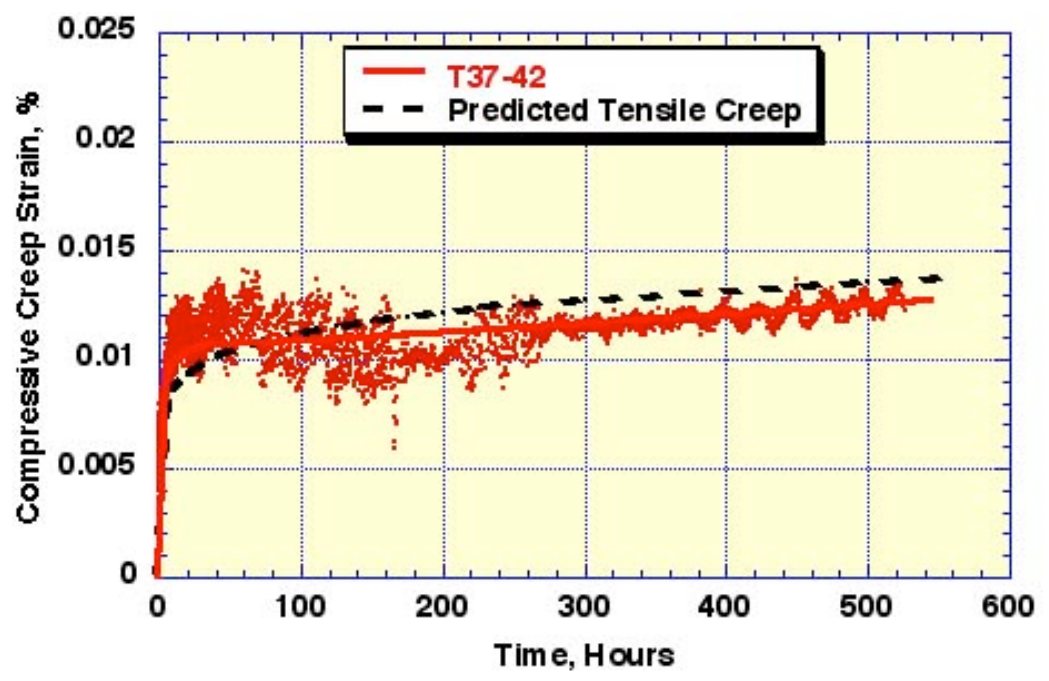

Figure 10.37 Time-dependent compressive creep response compared to predicted tensile creep at room temperature (dashed curve). 
For the $120^{\circ} \mathrm{C}$ compressive creep tests, thermal strains during heat up were monitored to establish a minimum heat up period prior to application of load. Since the tests were conducted in an environmental chamber, temperature-compensating dummy strain gages were not used for the $120^{\circ} \mathrm{C}$ tests. Figure 10.38 presents thermal strain versus time results obtained during heat up for five of the $120^{\circ} \mathrm{C}$ creep tests. These results indicate that at least a two-hour heat up period should be utilized. Figure 10.39 presents

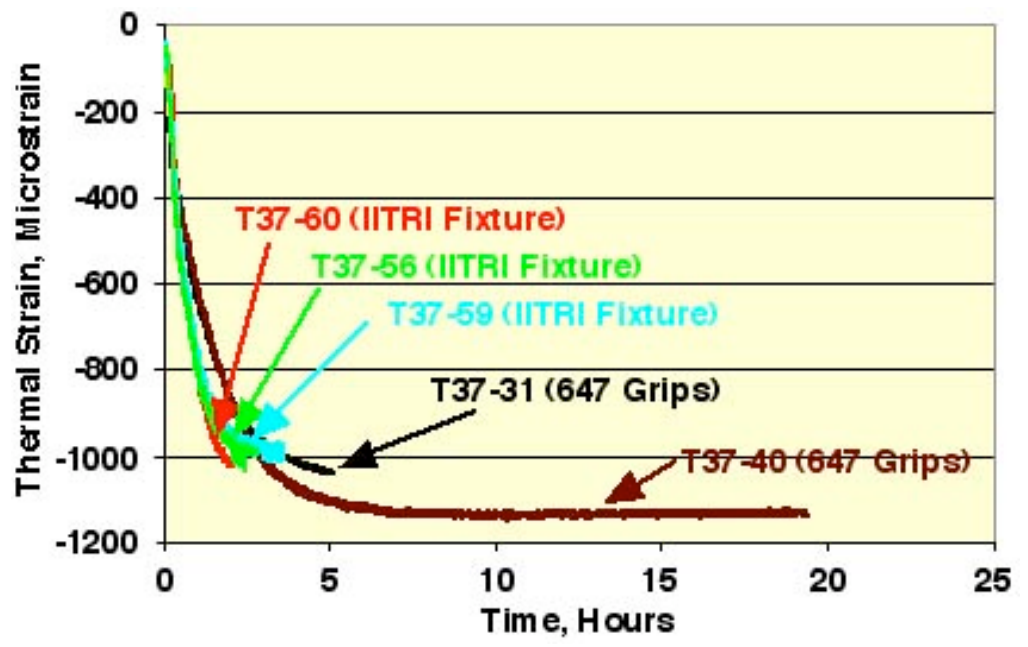

Figure 10.38 Thermal strain during heat up of $120^{\circ} \mathrm{C}$ compressive creep specimens.

compressive creep test results (total creep strain versus log time) for specimens tested at $120^{\circ} \mathrm{C}$. Also included in the figure are the higher stress, short-time results, but these results were too close to the ultimate compressive stress level to provide applicable creep data. Time-dependent compressive creep strain results are presented in Figure 10.40. Figure 10.40a presents results for the short-time tests and Figure $10.40 \mathrm{~b}$ for the longer duration tests.

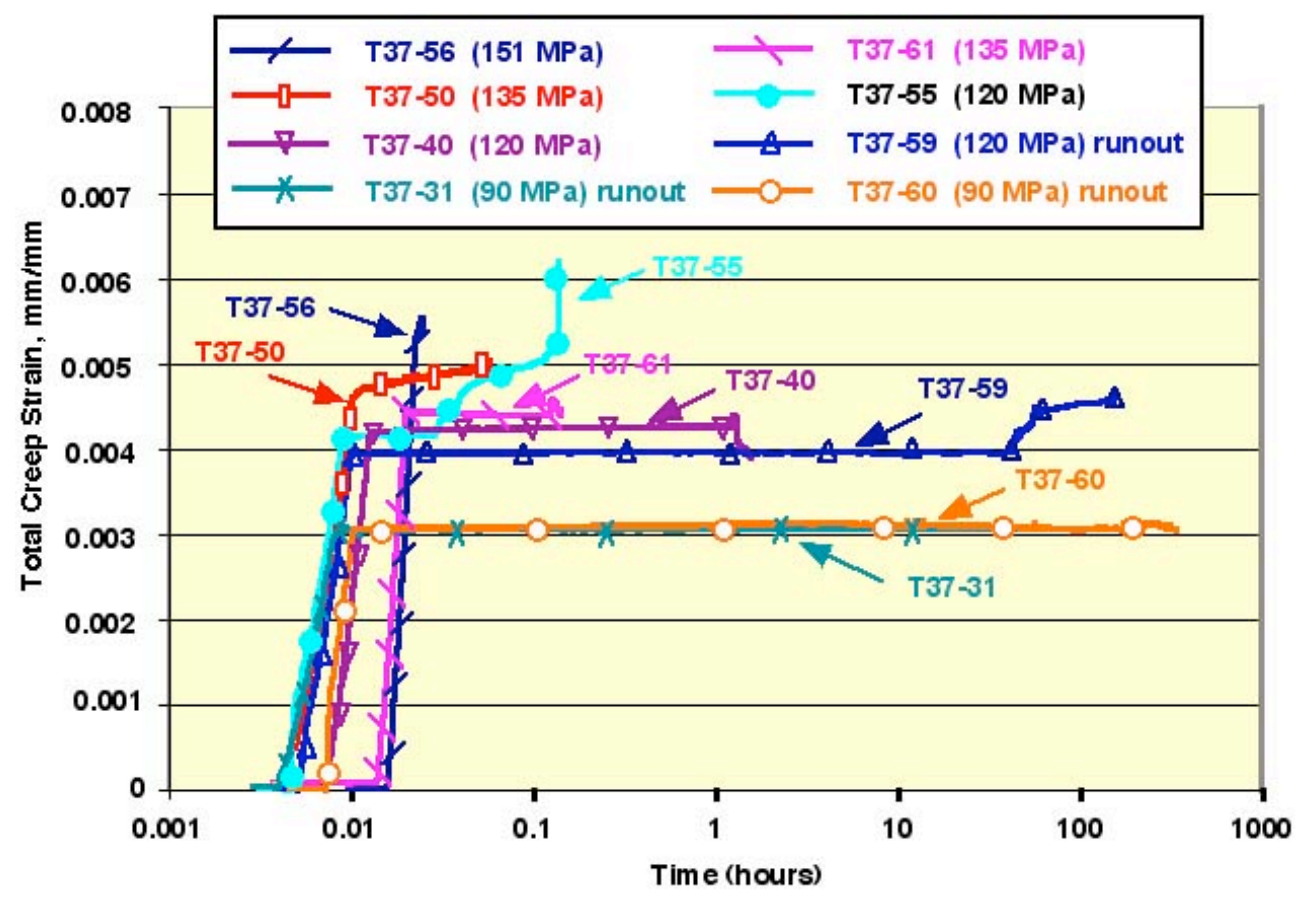

Figure $10.39120^{\circ} \mathrm{C}$ total creep strain versus $\log$ time results. 

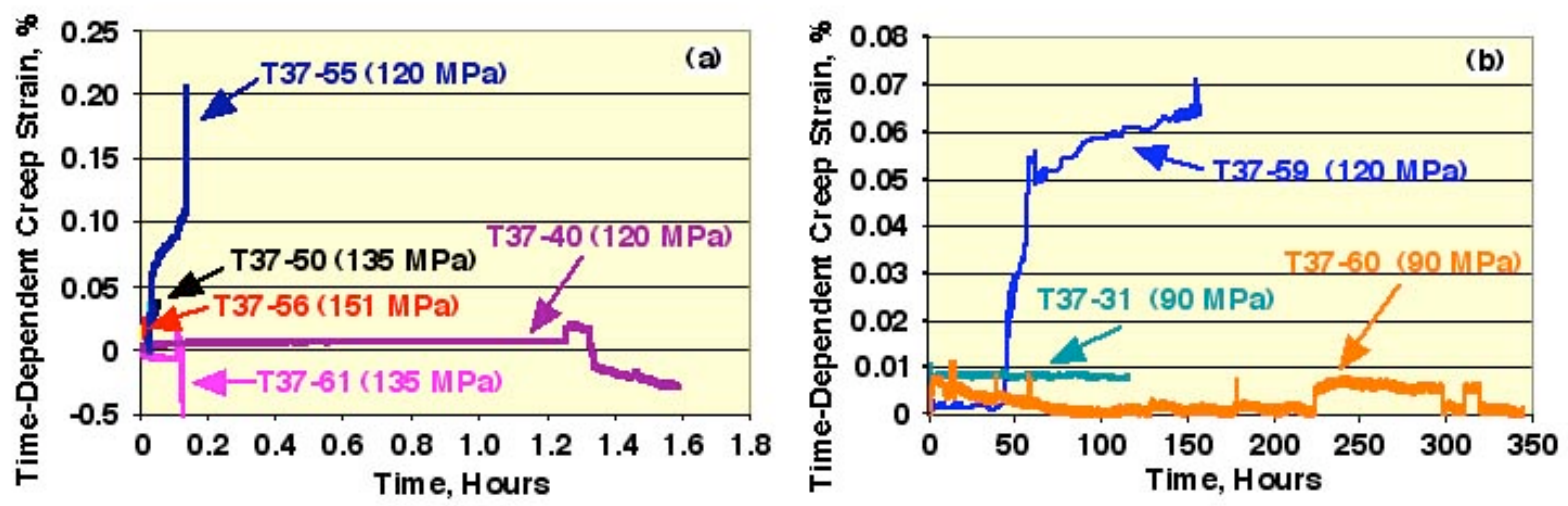

Figure $10.40120^{\circ} \mathrm{C}$ time-dependent creep strain versus time:

(a) short-time test results, (b) longer duration test results.

The time-dependent creep strains measured in one of the $120^{\circ} \mathrm{C}$ tests are plotted in Figure 10.41. Also shown in the figure is the predicted tensile creep response using Eqns. 10.1 and 10.2 (room temperature) and Eqns. 10.3 and $10.4\left(120^{\circ} \mathrm{C}\right)$. Only the response for specimen T37-31 is presented because of the scatter in data exhibited by the other three long-duration tests (see Figure 10.40b). Although the results are extremely limited, the compressive creep measured is about six times the predicted room temperature and $120^{\circ} \mathrm{C}$ tensile creep. The latter factor may vary with time and perhaps stress. Compressive creep loadings should be carefully considered in design.

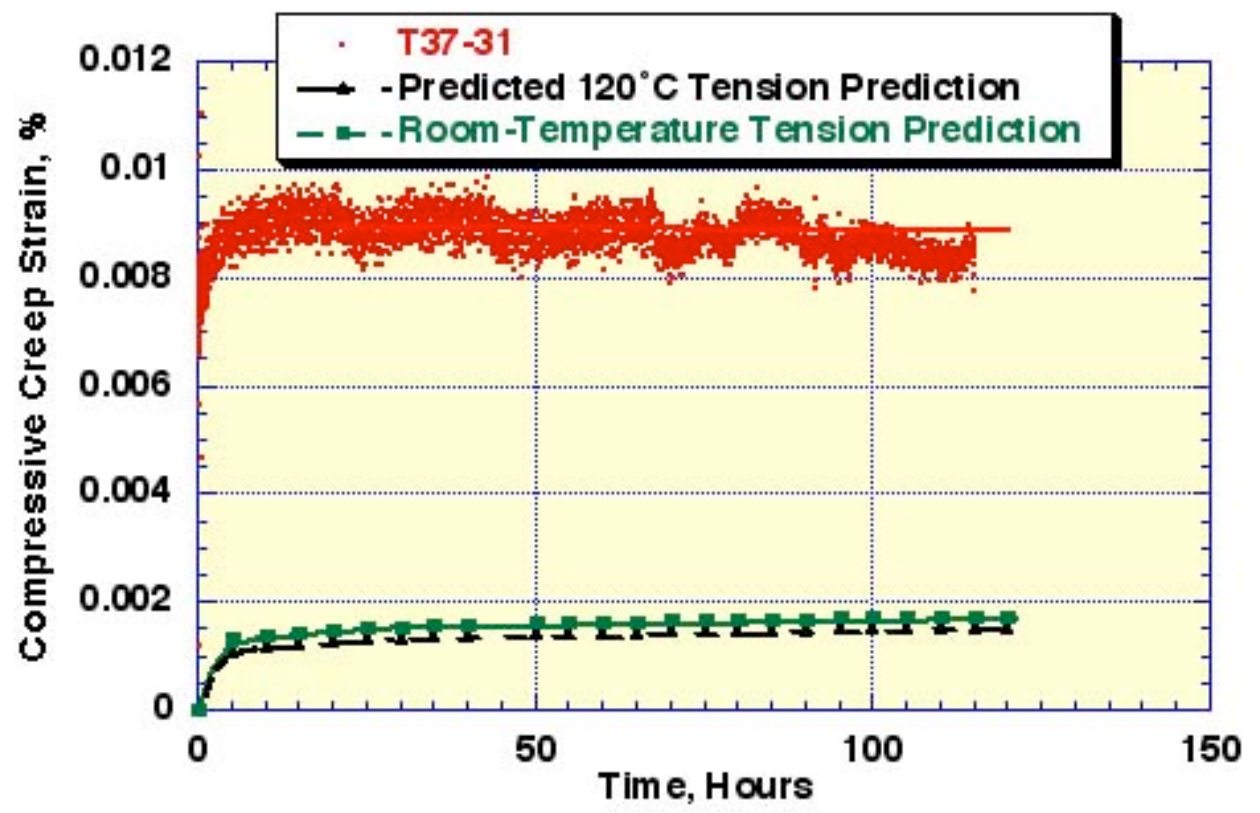

Figure 10.41 Time-dependent compressive creep response at $120^{\circ} \mathrm{C}$ compared to predicted tensile creep at room temperature (solid curve) and at $120^{\circ} \mathrm{C}$ (dashed curve). 


\subsection{SUMMARY}

The overall approach was to develop a well-based equation that describes time-dependent creep response at room temperature. Multiplication factors were to then be developed to account for the effects of temperature, fluids, and compressive loadings. In total, some 85 creep tests yielding time-dependent strain data were performed.

At room and elevated temperature, long-term creep can be adequately described by a power law of the form $\dot{\varepsilon}_{\mathrm{c}}=\mathrm{At}^{\mathrm{n}}$, where $\mathrm{A}$ and $\mathrm{n}$ are functions of stress. At room temperature, long-term timedependent creep strains are fairly small compared to elastic strains: at 15 years, they represent only about $11 \%$ the elastic loading strains (see Fig. 10.12). In the case of the quasi-isotropic laminate, they were slightly greater - about $16 \%$ of the elastic loading strain. At $120^{\circ} \mathrm{C}$, the time-dependent creep strains for the thermoplastic composite were also fairly small compared to elastic strains: at 15 years, they represent only about $16 \%$ the elastic loading strains (see Fig. 10.21). Equation (10.1), with the constants A and $\mathrm{n}$ given by Eq. (10.2), is the master equation for predicting room-temperature in-air tensile creep strains. To estimate creep strains for other conditions, the strains predicted by Eqs. (10.1) and (10.2) should be multiplied by the factors tabulated below.

\begin{tabular}{lcc}
\multicolumn{1}{c}{ Conditions } & Creep multiplication factor \\
\hline $70^{\circ} \mathrm{C}$ in air & & 1.3 \\
$120^{\circ} \mathrm{C}$ in air & & 1.7 \\
Distilled water & 1.4 \\
Windshield washer fluid & 2.2 \\
Compression at room temperature & & 1.0 \\
Compression at $120^{\circ} \mathrm{C}$ & $6^{a}$ \\
\cline { 1 - 1 }${ }^{a}$ Factor depends on time and perhaps stress. &
\end{tabular}

The $70^{\circ} \mathrm{C}$ tensile creep factor listed above is slightly larger than the corresponding factor for the quasi-isotropic thermoset composite $(1.3$ vs 1.2$)$, while the $120^{\circ} \mathrm{C}$ tensile creep factor is smaller $(1.7$ vs 4.3). The fluid factor for distilled water is a little less than for the quasi-isotropic thermoset material (1.4 vs 1.7) but slightly larger for the windshield washer fluid (2.2 vs 1.5$)$. Finally, the room-temperature compressive creep factors of 1.0 are the same, and the $120^{\circ} \mathrm{C}$ compressive creep factor is less (6), but in about the same range as that for the thermoset composite (7.8 to 18).

\subsection{REFERENCES}

1. J. M. Corum et al., Durability-Based Design Criteria for a Quasi-Isotropic Carbon-Fiber Automotive Composite, ORNL/TM-2002/39, Oak Ridge National Laboratory, Oak Ridge, Tenn., March 2002.

2. J. M. Corum, R. L. Battiste, W. Ren, and M. B. Ruggles, Recommended Minimum Test Requirements and Test Methods for Assessing Durability of Random-Glass-Fiber Composites, ORNL-6953, Oak Ridge National Laboratory, Oak Ridge, Tenn., June 1999. 


\section{CREEP RUPTURE}

\subsection{INTRODUCTION}

The goal of this chapter is to develop creep-rupture curves for tensile and compressive stresses over the temperature range from $-40^{\circ} \mathrm{C}$ to $120^{\circ} \mathrm{C}$. Also, room-temperature tensile creep-rupture curves are developed from test results of specimens tested either in distilled water or in windshield-washer fluid. In either case, the specimens were first subjected to the standard presoak: (1) 1000-h in distilled water or (2) 100-h in windshield-washer fluid. The creep-rupture curves presented in this chapter, together with the basic short-time strength properties presented in Chap. 7, are the bases for the time-dependent allowable design stresses given in Chap. 3.

The creep-rupture tests carried out were listed in the creep test summary tables in Chap. 10. In the case of tensile tests, rupture times less than $0.5 \mathrm{~h}$ were not used in this chapter. In the case of compression, because of the dearth of failure points, they were used. Tests above a certain stress level that were stopped before failure were considered runouts. They are shown in the creep-rupture plots, but they were not used in developing creep-ruptured correlations. The number of tests of each kind that were used in this chapter are summarized below.

Tensile
Room temperature
$120^{\circ} \mathrm{C}$
Compressive
Room temperature
$120^{\circ} \mathrm{C}$
Tensile, 1000 -h presoak in distilled water
Tensile, 100 -h presoak in windshield-washer fluid

\section{Rupture Runout}

$\begin{array}{cc}19 & 7 \\ 8 & 0 \\ & \\ 4 & 2 \\ 5 & 3 \\ 10 & 4 \\ 9 & 14\end{array}$

The strategy followed in this chapter is to first develop average creep-rupture curves (stress vs rupture time) at room temperature and $120^{\circ} \mathrm{C}$ for both tension and compression. Design allowable stress curves are derived for these four conditions by reducing the stress to two-thirds of the average stress to rupture. A time-temperature parameter approach is then employed, first in tension and then in compression, to develop design allowable stress curves at temperatures of $-40^{\circ} \mathrm{C}$ and $70^{\circ} \mathrm{C}$. The design allowable stresses are the basis for the stress allowables in Chap. 3.

For the fluid effects tests, average creep-rupture curves are derived for each of the two standard fluid exposures. The resulting average stresses are ratioed to the corresponding average stresses from the roomtemperature in-air, creep-rupture curve, to derive strength reduction factors for various times. These are employed in Chap. 3 to account for fluid effects.

\subsection{TESTS IN AIR}

\subsubsection{Tensile Failures at Room Temperature and $120^{\circ} \mathrm{C}$}

In Chap. 3, the time-independent allowable tensile stress, $\mathrm{S}_{0}$, is based on UTS values from 207 tensile tests on specimens from 36 different plaques. In an attempt to render the creep-rupture results more

consistent with $\mathrm{S}_{0}$ and representative of overall average behavior, an adjusted stress was used for all of the tensile creep-rupture tests.

$$
\sigma_{a d j}=\frac{551}{U T S_{\text {plaque }}} \times \sigma .
$$


Here, $551 \mathrm{MPa}$ is the average UTS from all of the tests on specimens from 36 plaques; $\mathrm{UTS}_{\text {plaque }}$ is the average UTS of the plaque from which the specimen came; $\sigma$ is the actual applied stress; and $\sigma_{\text {adj }}$ is the adjusted stress. Intuitively, use of the adjusted stress should reduce the scatter where specimens from several plaques were used. While it did not lead to a reduction in scatter in this case, it was still used to provide consistency with $\mathrm{S}_{0}$, as described above.

The room-temperature data points are plotted in Fig. 11.1, where they are fitted by a power law representing average creep-rupture behavior. The corresponding curve for the quasi-isotropic carbon-fiber thermoset composite is also shown for comparison. ${ }^{1}$

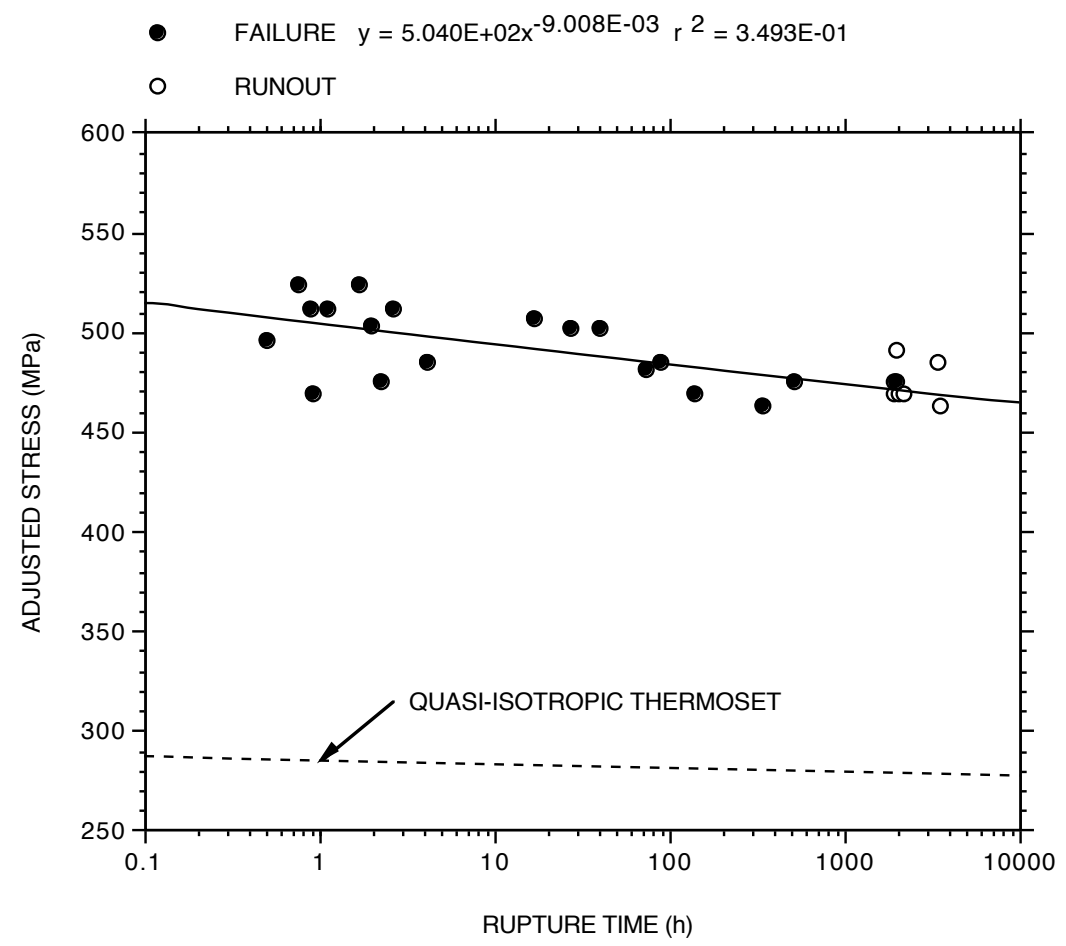

Fig. 11.1. Tensile creep-rupture data and average curve at room temperature in air.

Figure 11.2 shows the construction of a design allowable stress curve based on the lesser of the following two criteria:

- $80 \%$ of the minimum creep-rupture stress

- two-thirds of the average creep-rupture stress.

The first criterion alone was used for developing time-dependent allowable stresses for all of the previous composite materials investigated in the ORNL Durability project. However, in the case of the choppedcarbon-fiber thermoset composite, it was pointed out that the second criterion, based on two-thirds of the average stress, would be a better choice. ${ }^{2}$ It is used here, and it meshes reasonably well with the $\mathrm{S}_{0}$ value, as shown in Fig. 11.2.

Figure 11.3 shows the failure points and the average creep-rupture curve for $120^{\circ} \mathrm{C}$. The average roomtemperature curve from the previous figures is shown, as is the $120^{\circ} \mathrm{C}$ design allowable stress curve. 


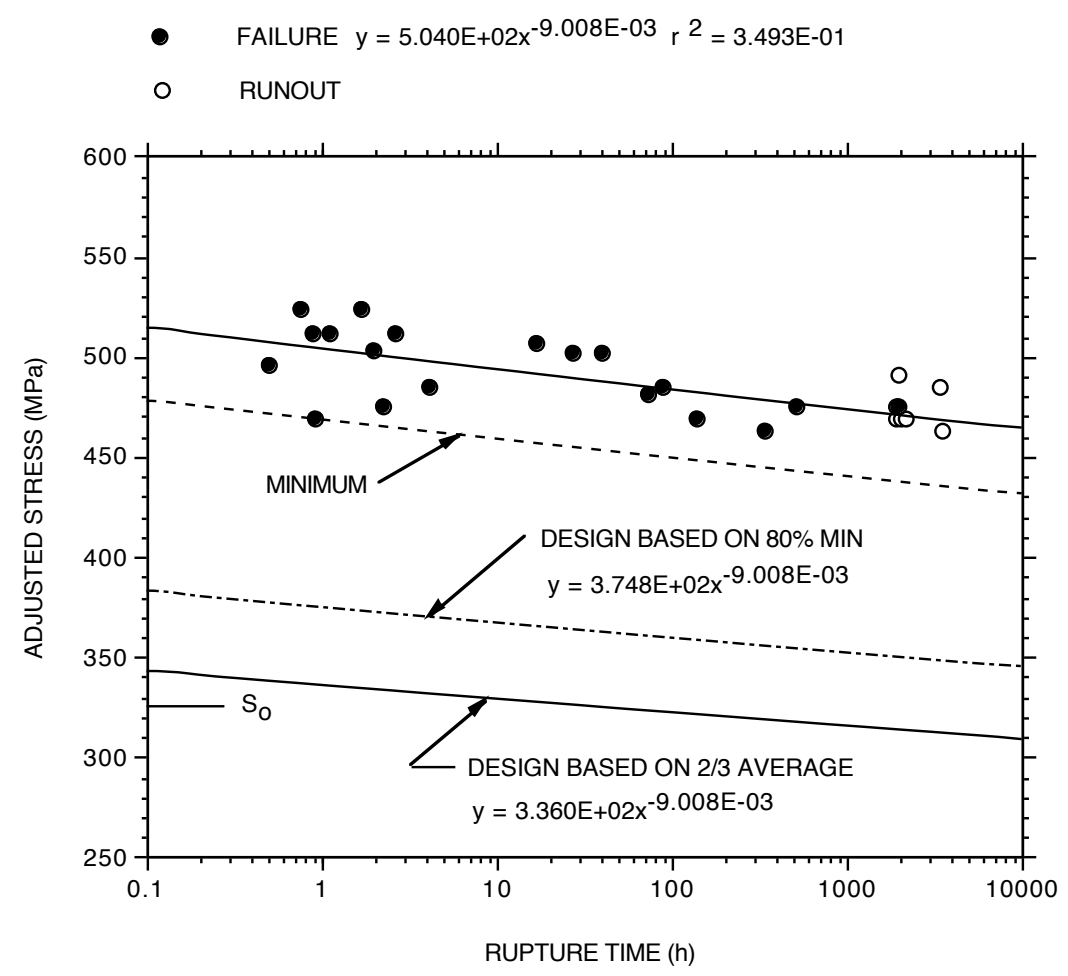

Fig. 11.2. Development of design curve for tensile creep-rupture at room temperature in air.

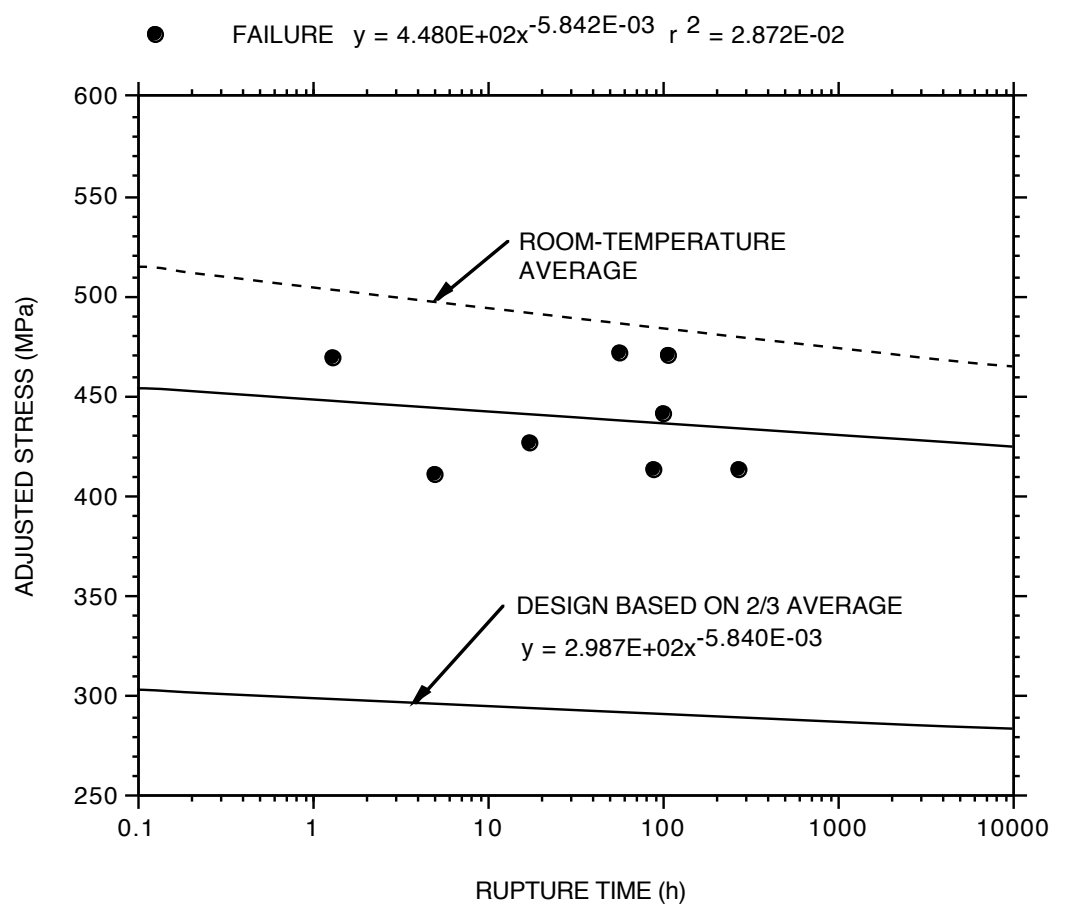

Fig. 11.3. Tensile creep-rupture data, average curve, and design curve at temperature of $120^{\circ} \mathrm{C}$ in air. 


\subsubsection{Compressive Failures at Room Temperature and $120^{\circ} \mathrm{C}$}

In contrast to the tensile tests, which involved specimens from several plaques, all of the compressive specimens came from a single plaque, T37. That plaque had an ultimate compressive strength of $301 \mathrm{MPa}$ compared to the overall average compressive strength of $295 \mathrm{MPa}$ (from 10 plaques). Because of this small difference, adjusted stresses were not used for the compressive data points.

Average compressive creep-rupture results for room temperature and $120^{\circ} \mathrm{C}$ are shown in Fig. 11.4, where they are compared with the corresponding average tensile curves. The compressive rupture stresses are less than half the tensile stresses, which is reasonably consistent with ratio of short-time ultimate compressive strength to ultimate tensile strength. Compressive creep-rupture design curves are obtained by taking two-thirds of the average curves.

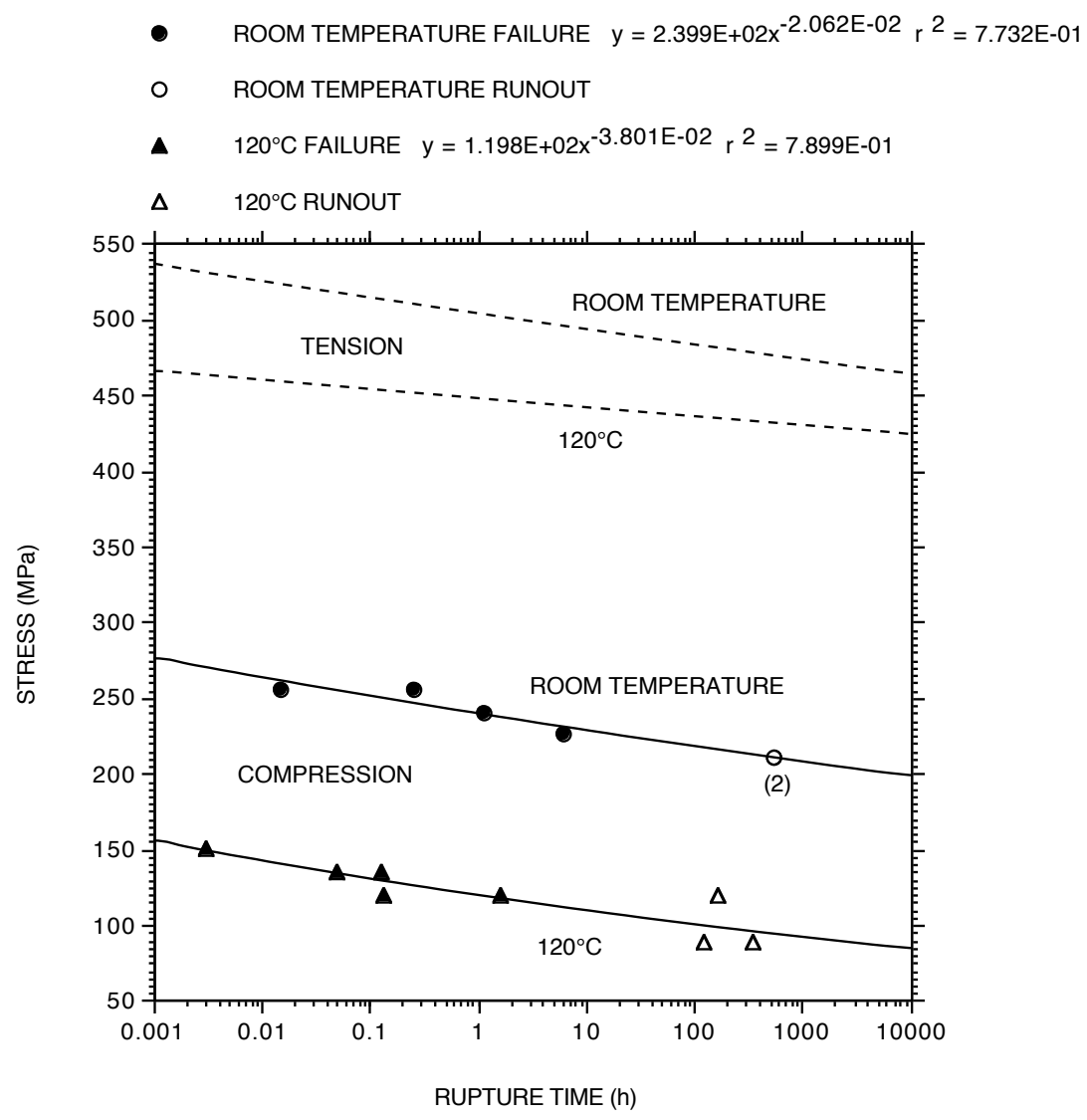

Fig. 11.4. Compressive creep-rupture data and average curves at room temperature and $120^{\circ} \mathrm{C}$.

\subsubsection{Time-Temperature Creep-Rupture Parameter}

In the previous subsections, tensile and compressive creep-rupture curves were developed for just two temperatures-room temperature and $120^{\circ} \mathrm{C}$. However, allowable stresses are required over the full $-40^{\circ} \mathrm{C}$ to $120^{\circ} \mathrm{C}$ temperature range. In particular, allowables are tabulated in Chap. 3 at $-40^{\circ}$ and $70^{\circ} \mathrm{C}$, in addition to room temperature and $120^{\circ} \mathrm{C}$. To develop creep-rupture data at temperatures other than room temperature and $120^{\circ} \mathrm{C}$, a time-temperature parameter was employed. The job of the time-temperature parameter is to merge creep-rupture curves at different temperatures into a single curve by using a temperature-compensated abscissa (i.e., while the ordinate remains rupture stress, the abscissa is a function of both temperature and time). 
The Manson-Haferd time-temperature parameter was used, as it was for the quasi-isotropic and chopped carbon-fiber thermoset composites. ${ }^{1,2}$ The parameter, which has two constants, is expressed as

$$
P_{M H}=\frac{T-T_{a}}{\log _{10} t_{r}-\log _{10} t_{a}}
$$

where $T$ is absolute temperature, usually expressed in degrees Rankin, and $t_{r}$ is rupture time in hours. The constants $T_{a}$ and $t_{a}$ are found by plotting lines of $T$ vs $\log t_{r}$ for constant stress levels. The constants $T_{a}$ and $t_{a}$ correspond to the intersection point of these lines. ${ }^{3}$

If pairs of $\left(\sigma, t_{r}\right)$ data points are determined from the power-law expressions for the design curves at room temperature and $120^{\circ} \mathrm{C}$, they can be used to construct the plots of $\mathrm{T} v \operatorname{vog}_{10} \mathrm{t}_{\mathrm{r}}$ in Figs. 11.5 and 11.6, for tension and compression, respectively. The resulting Manson-Haferd parameters are

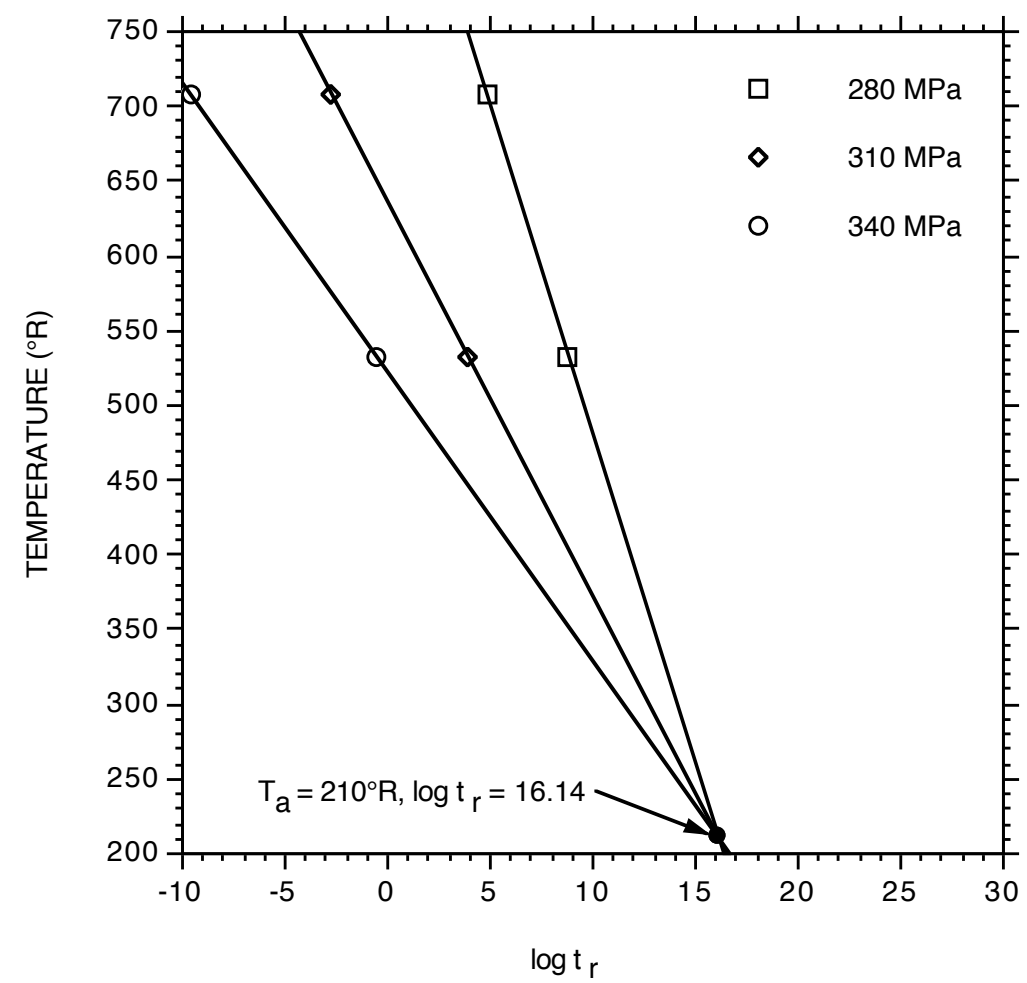

Fig. 11.5. Manson-Haferd construction for tensile creep rupture. Data points are calculated from roomtemperature and $120^{\circ} \mathrm{C}$ design curve equations (see Figs. 11.2 and 11.3).

$$
P_{M H}=\frac{1.8 T+282}{\log _{10} t_{r}-16.14}
$$

for tension, and

$$
P_{M H}=\frac{1.8 T-455}{\log _{10} t_{r}+17.34}
$$




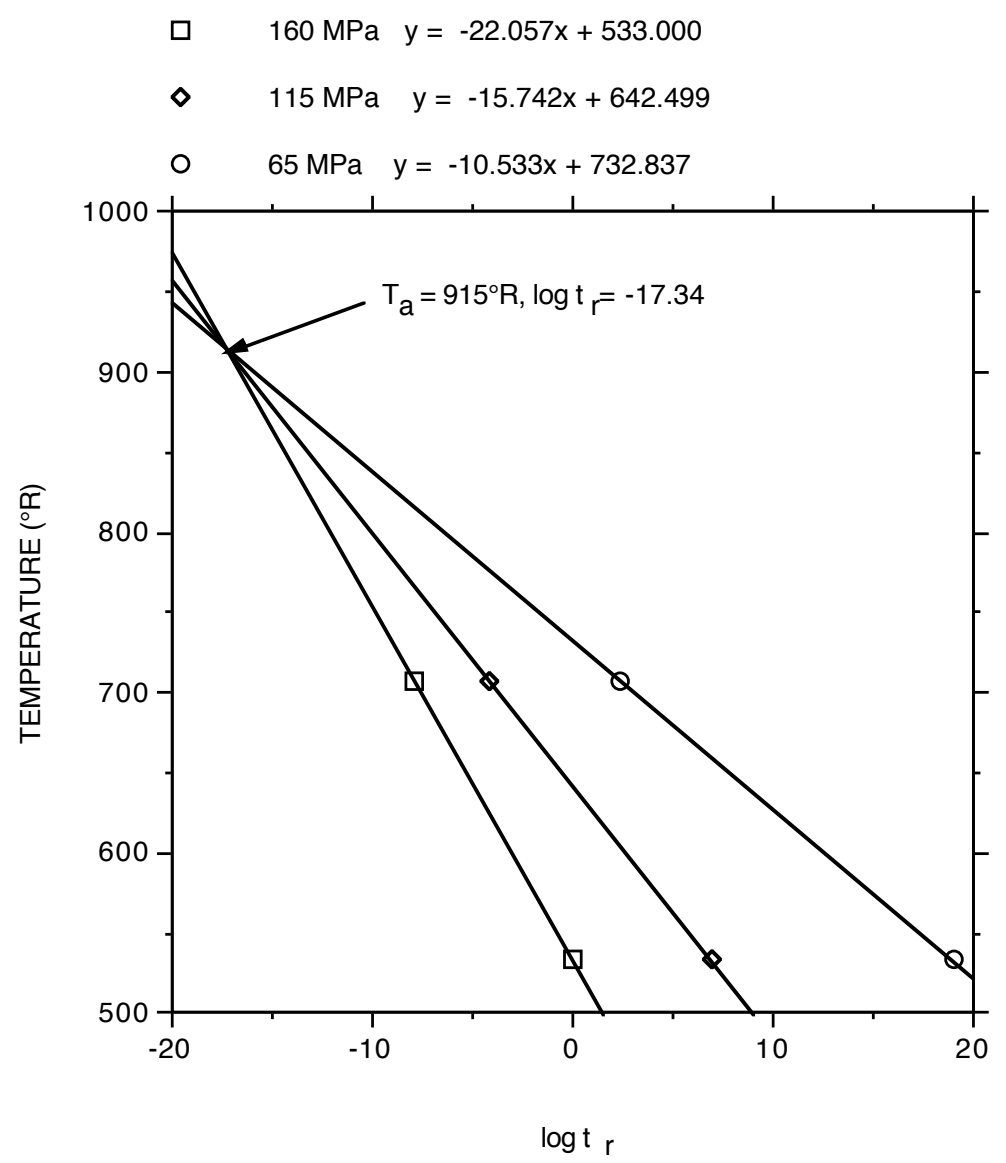

Fig. 11.6. Manson-Haferd construction for compressive creep rupture. Data points are calculated from average curve equations multiplied by two-thirds factor.

for compression. The temperature $\mathrm{T}$ in these latter expressions has been converted to degrees Celsius.

Now we can plot design allowable stress vs the Manson-Haferd parameter for tension and for compression using stress-time points from the room-temperature and $120^{\circ} \mathrm{C}$ design allowable stress correlations that we have. The resulting curves are shown in Figs. 11.7 and 11.8, for tension and compression, respectively."

Using Figs. 11.7 and 11.8 , the missing design allowable stress curves at $-40^{\circ} \mathrm{C}$ and $70^{\circ} \mathrm{C}$ can be constructed. The complete set of allowable creep-rupture stress curves for tension and for compression is shown in Fig. 11.9. These curves are the bases for the reduction factors that are given in the summary section at the end of this chapter.

\subsection{TESTS IN FLUIDS}

The fluid tensile creep-rupture tests were performed in one of two fluids:

- distilled water, including a nominal pretest exposure of $1000 \mathrm{~h}$, and

\footnotetext{
${ }^{*}$ The difference in the slope of these two curves results from the fact that for tension the slope of the $120^{\circ} \mathrm{C}$ curve is less than that of the room-temperature curve. This is unusual and is not the case for the compressive curves.
} 


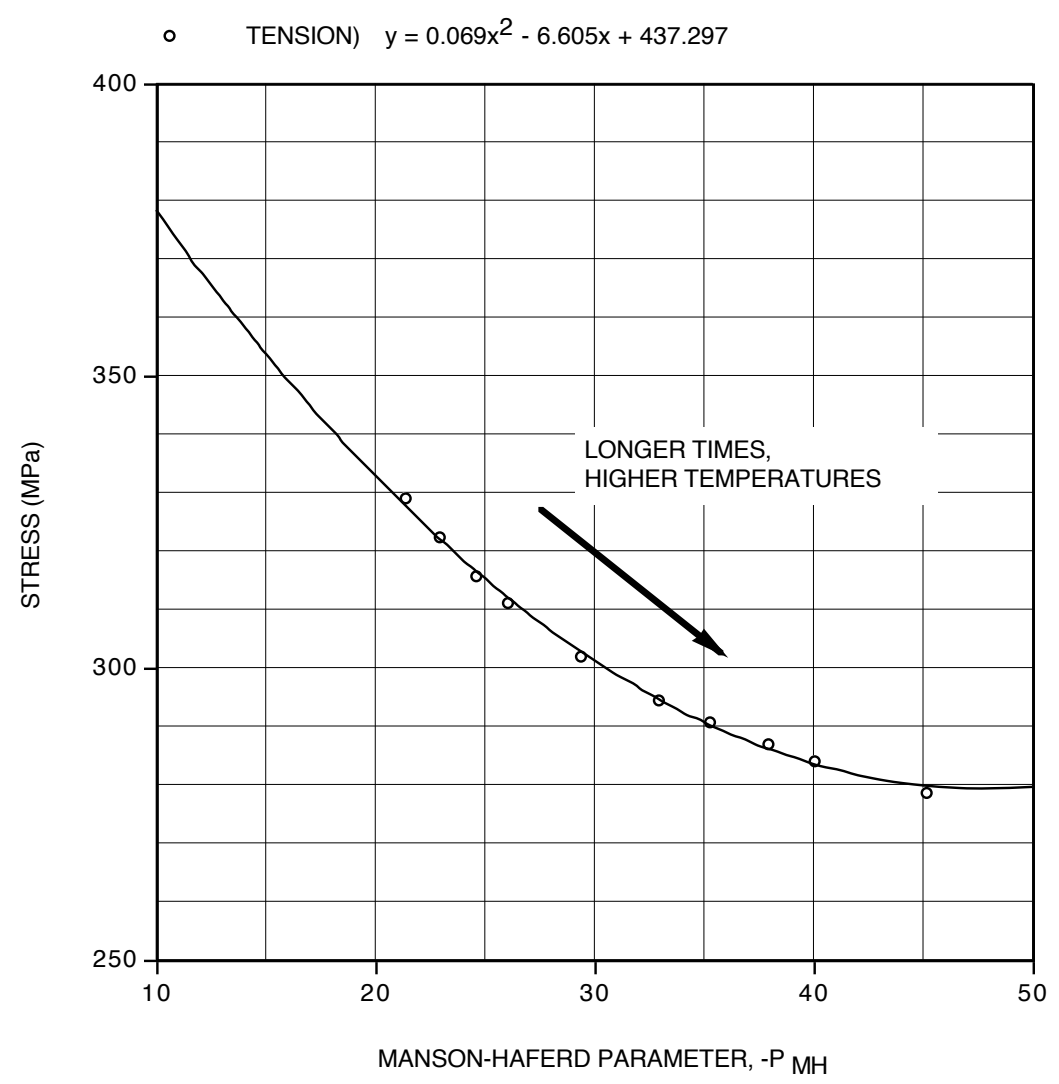

Fig. 11.7. Manson-Haferd curve for tensile creep-rupture design stresses.

- windshield-washer fluid (70\% methanol/30\% distilled water) including a nominal pretest exposure of $100 \mathrm{~h}$.

Data scatter in the windshield-washer fluid tests was fairly large, but using adjusted stress made the scatter significantly worse. Hence, adjusted stress was not used in either of the creep-rupture correlations.

\subsubsection{Distilled Water}

The distilled water rupture points and runouts are plotted in Fig. 11.10, and the resulting average rupture curve is compared to the average in-air rupture curve from Fig. 11.1. For distilled water, stress or adjusted stress plots exhibit about the same scatter, but the stress plot is a little lower, and thus more conservative. The ratio of the fluid curve stress to the in-air curve stress provides the fluid stress reduction factor for a given time.

\subsubsection{Windshield-washer fluid}

The windshield-washer-fluid rupture points and runouts are plotted in Fig. 11.11, where the average rupture curve is again compared to the in-air-average curve. The scatter is large, as reflected by the low coefficient of determination, $r^{2}$. However, the reduction due to the windshield-washer fluid is not as great as for distilled water. Consequently, reduction factors from the latter are used in Chap. 3 to bound both fluid effects.

Note that both the distilled-water creep-rupture curve (Fig. 11.10) and the windshield-washer-fluid curve (Fig. 11.11) have a smaller slope than the in-air-curve-i.e., the effect of the fluids becomes smaller 
with time. This same trend was observed, for both fluids, in the case of the previously-examined chopped-

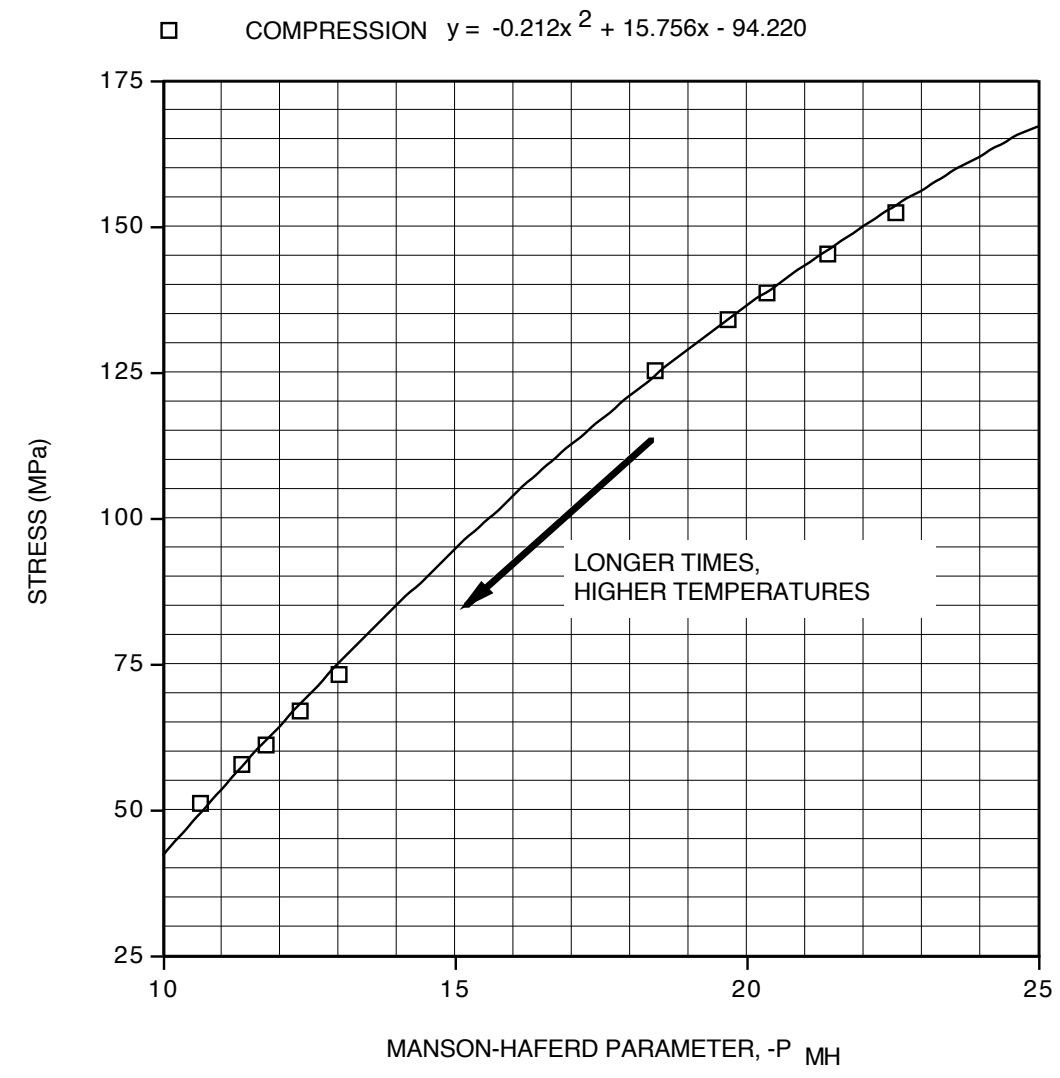

Fig. 11.8. Manson-Haferd curve for compressive creep-rupture design stresses. Note that compressive stress is plotted without the negative sign.

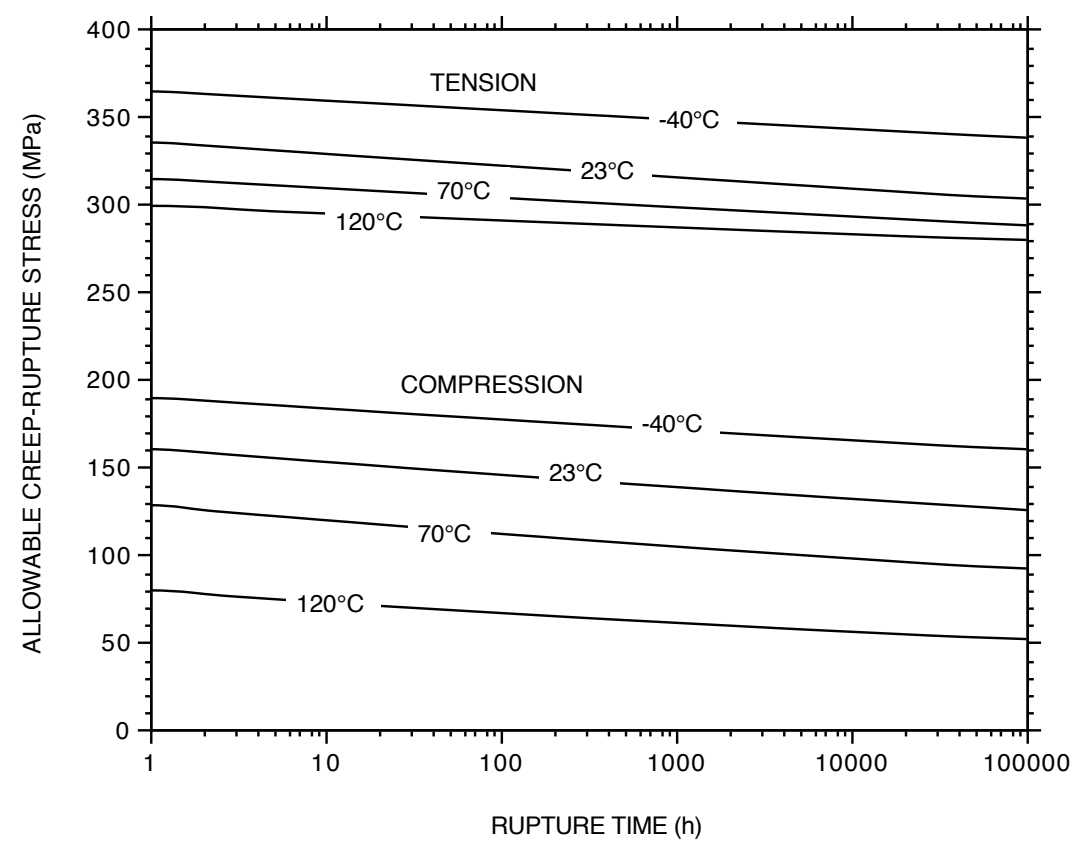

Fig. 11.9. Final tensile and compressive creep-rupture design curves. 
carbon-fiber composite. ${ }^{2}$ And, it was observed for distilled water in the case of the quasi-isotropic carbonfiber thermoset composite. ${ }^{1}$

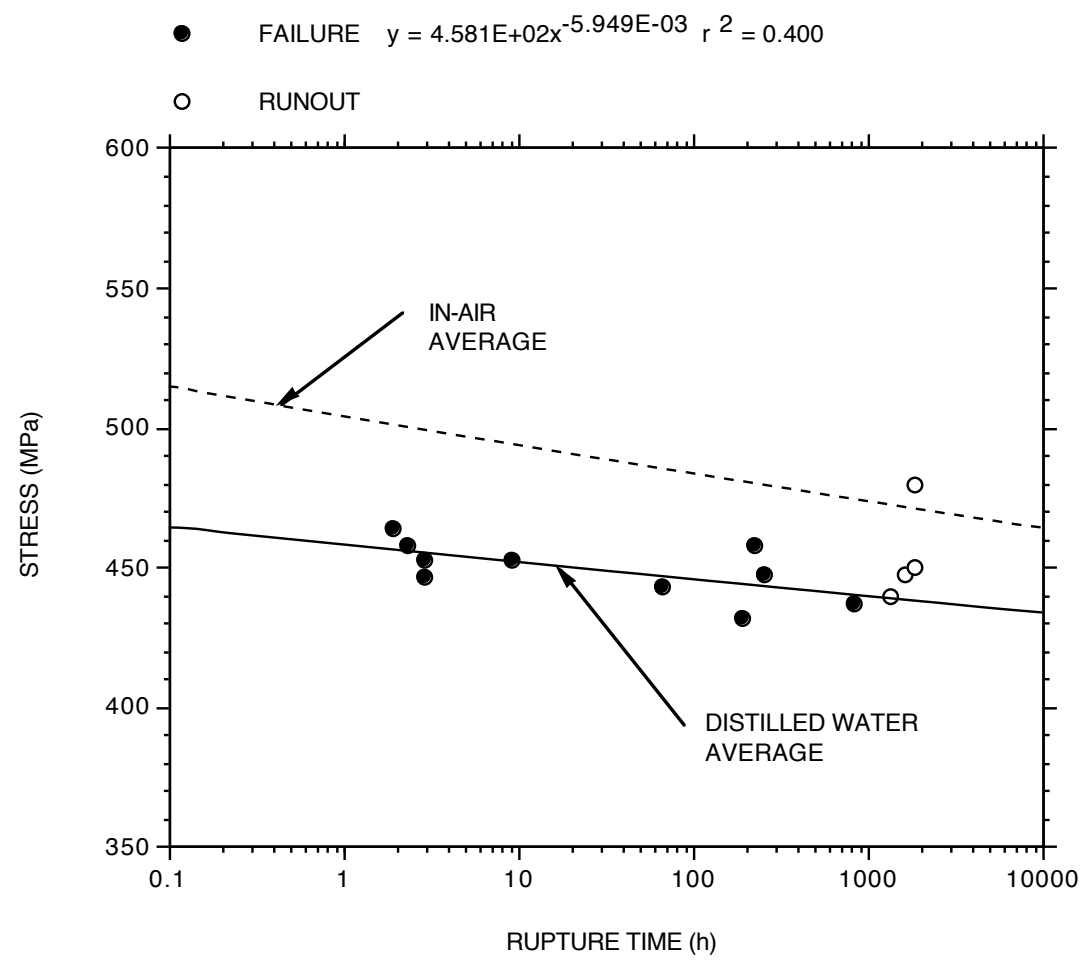

Fig. 11.10. Creep-rupture data and average curve for specimens tested in distilled water compared to in-air curve.

\subsection{SUMMARY}

Both tensile and compressive creep-rupture data were generated in air at room temperature and at $120^{\circ} \mathrm{C}$. From these data, design allowable creep-rupture curves were developed based on two-thirds of the average stress to produce rupture. Using these latter curves in combination with the Manson-Haferd timetemperature parameter, design allowable creep-rupture curves were developed for the two other temperatures of interest: $-40^{\circ} \mathrm{C}$ and $70^{\circ} \mathrm{C}$. The resulting eight curves were presented in Fig. 11.9.

Tensile creep-rupture data were also generated for the two standard fluid exposure conditionsdistilled water and windshield-washer fluid.

All of the results of this chapter are summarized in Tables 11.1 and 11.2. The first table lists the allowable in-air tensile stresses at room temperature. The time-dependent allowables in Table 11.1 were calculated from the equation in Fig.11.2 for the design curve based on two-thirds the average rupture stress. The zero-time values are the $S_{0}$ allowable stresses from Chap. 3 . The corresponding values for the quasiisotropic carbon-fiber thermoset composite are shown in parentheses for comparison. ${ }^{1}$ 
Table 11.1. Allowable tensile stresses at room temperature in air

\begin{tabular}{lcccccc}
\hline & \multicolumn{7}{c}{ Time (h) } \\
\cline { 2 - 7 } & $\mathbf{0}$ & $\mathbf{1 0}$ & $\mathbf{1 0 0}$ & $\mathbf{1 0 0 0}$ & $\mathbf{5 0 0 0}$ & $\mathbf{1 3 1 , 0 0 0}$ \\
\hline Stress, MPa & $327^{\mathrm{a}}$ & 329 & 322 & 316 & 311 & 302 \\
& $(194)^{\mathrm{b}}$ & $(213)$ & $(212)$ & $(210)$ & $(209)$ & $(207)$ \\
\hline
\end{tabular}

${ }^{\mathrm{a}} \mathrm{S}_{0}$ value from Chap. 3 .

${ }^{\mathrm{b}}$ Stresses in parentheses are the corresponding allowables for the quasi-isotropic Carbon-fiber thermoset composite.

Table 11.2 summarizes the time-independent and time-dependent allowable stresses as multiplication factors to be applied to the corresponding room-temperature, in-air allowable stress in Table 11.1. Factors greater than 1.00 have been tabulated as 1.00. Again, the factors in parentheses are those for the quasiisotropic carbon fiber thermoset composite. The factors shown in Table 11.2 allow the effects of loading, temperature, and fluids to be readily compared, and they provide a basis for comparing these effects for the two quasi-isotropic composites.

The room-temperature in-air, tensile allowable stress for the thermoplastic composite varies from $69 \%$ larger than that for the thermoset at zero time to $46 \%$ larger at $131,000 \mathrm{~h}$ (15 years). However, compressive stresses are significantly more damaging for the thermoplastic, and the same is probably true for shear, if the short-time allowables are an indication. This is true except at $120^{\circ} \mathrm{C}$, where the effects of temperature and time are greater for the thermoset composite. For tensile stresses, the effect of distilled water is slightly more damaging in the thermoplastic composite than in the thermoset. The opposite is true for windshieldwasher fluid at the longer times.

No data exists for the time-dependent effects of fluids on compressive and shear creep rupture. However, if the short-time values are an indication, the effects would be expected to be large in the thermoplastic composite. The assumption is made in Chap. 3 that the time-independent factors in Table 11.2 can be conservatively applied for all times for those conditions where data do not exist in Table 11.2. 


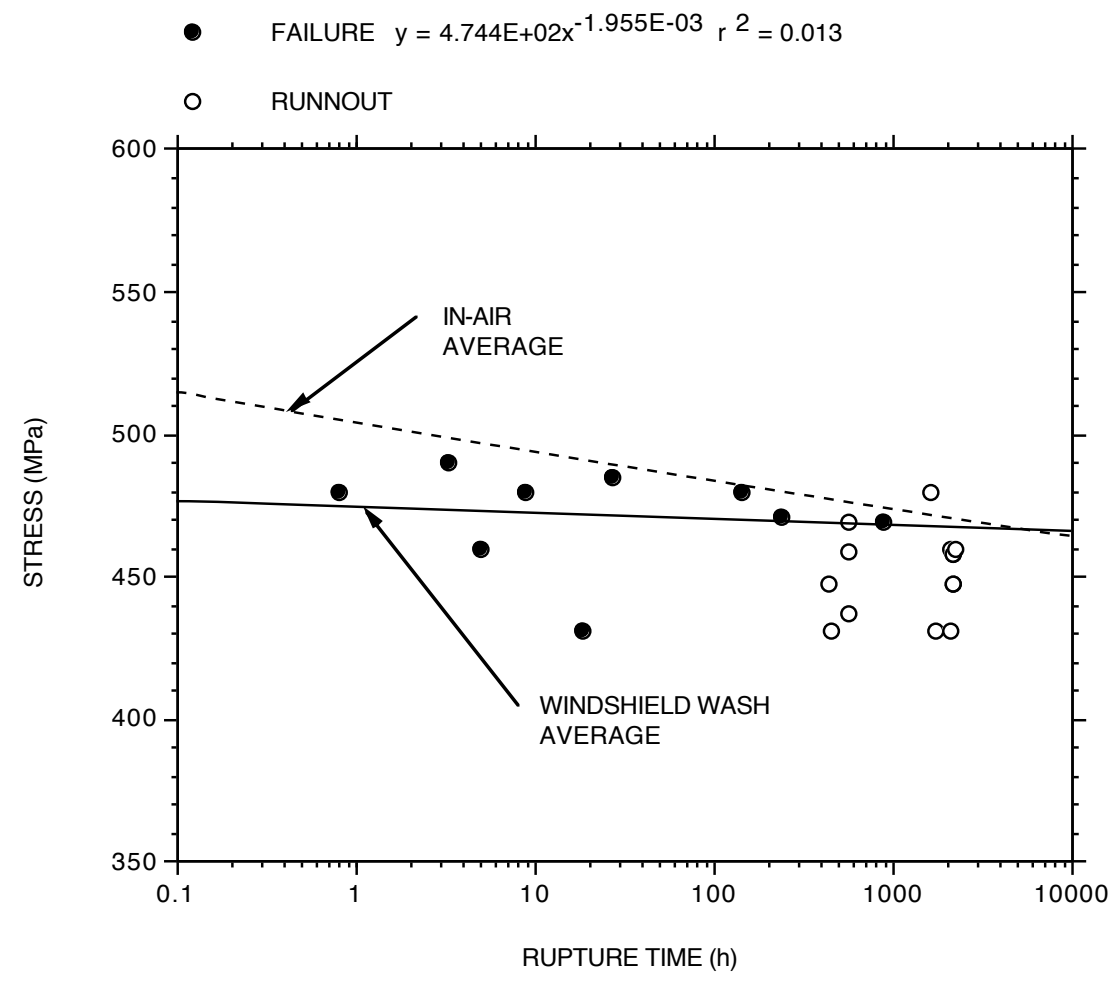

Fig. 11.11. Creep-rupture data and average curve for specimens tested in windshield-washer fluid compared to in-air curve 
Table 11.2. Creep-rupture strength multiplication factors (relative to in-air, room-temperature, tensile values)

\begin{tabular}{|c|c|c|c|c|c|c|}
\hline \multirow[t]{2}{*}{ Condition } & \multicolumn{6}{|c|}{ Time (h) } \\
\hline & $0^{b}$ & 10 & 100 & 1000 & 5000 & 131,000 \\
\hline \multicolumn{7}{|l|}{ In-air tension } \\
\hline$-40^{\circ} \mathrm{C}^{\mathrm{a}}$ & $1.00(0.87)^{\mathrm{c}}$ & $1.00(1.00)$ & $1.00(1.00)$ & $1.00(1.00)$ & $1.00(1.00)$ & $1.00(1.00)$ \\
\hline $23^{\circ} \mathrm{C}$ & $1.00(1.00)$ & $1.00(1.00)$ & $1.001 .00)$ & $1.00(1.00)$ & $1.00(1.00)$ & $1.00(1.00)$ \\
\hline $70^{\circ} \mathrm{C}^{\mathrm{a}}$ & $1.00(0.96)$ & $0.94(0.96)$ & $0.94(0.96)$ & $0.95(0.96)$ & $0.95(0.95)$ & $0.95(0.95)$ \\
\hline $120^{\circ} \mathrm{C}$ & $0.96(0.81)$ & $0.90(0.77)$ & $0.90(0.74)$ & $0.91(0.70)$ & $0.91(0.68)$ & $0.92(0.63)$ \\
\hline \multicolumn{7}{|l|}{ In-air compression } \\
\hline$-40^{\circ} \mathrm{C}^{\mathrm{a}}$ & $0.58(0.68)$ & $0.56(0.77)$ & $0.55(0.77)$ & $0.54(0.77)$ & $0.54(0.77)$ & $0.53(0.76)$ \\
\hline $23^{\circ} \mathrm{C}$ & $0.54(0.67)$ & $0.46(0.73)$ & $0.45(0.72)$ & $0.44(0.71)$ & $0.43(0.70)$ & $0.42(0.68)$ \\
\hline $70^{\circ} \mathrm{C}^{\mathrm{a}}$ & $0.51(0.58)$ & $0.37(0.65)$ & $0.35(0.62)$ & $0.33(0.61)$ & $0.32(0.59)$ & $0.30(0.55)$ \\
\hline $120^{\circ} \mathrm{C}$ & $0.29(0.39)$ & $0.22(0.17)$ & $0.21(0.13)$ & $0.19(0.09)$ & $0.19(0.08)$ & $0.17(0.05)$ \\
\hline \multicolumn{7}{|l|}{ In-air shear } \\
\hline$-40^{\circ} \mathrm{C}$ & $0.37(0.71)$ & & & & & \\
\hline $23^{\circ} \mathrm{C}$ & $0.35(0.67)$ & & & & & \\
\hline $70^{\circ} \mathrm{C}$ & $0.23(0.57)$ & & & & & \\
\hline $120^{\circ} \mathrm{C}$ & $0.15(0.40)$ & & & & & \\
\hline \multicolumn{7}{|c|}{ Distilled water (1000-h presoak) } \\
\hline Tension & $0.93(1.00)$ & $0.92(0.97)$ & $0.92(0.97)$ & $0.93(0.98)$ & $0.93(0.98)$ & $0.94(0.99)$ \\
\hline Compression & $0.48(0.63)$ & & & & & \\
\hline Shear & $0.23(0.66)$ & & & & & \\
\hline \multicolumn{7}{|c|}{ Windshield-washer fluid (100-h presoak) } \\
\hline Tension & $0.91(1.00)$ & $0.96(0.97)$ & $0.97(0.96)$ & $0.99(0.96)$ & $1.00(0.95)$ & $1.00(0.94)$ \\
\hline Compression & $0.40(0.66)$ & & & & & \\
\hline Shear & $0.30(0.67)$ & & & & & \\
\hline
\end{tabular}

${ }^{\mathrm{a}}$ From Manson-Haferd correlation.

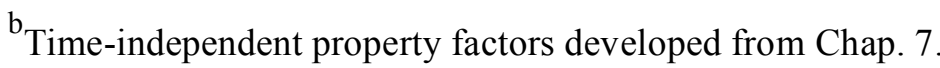

${ }^{c}$ Corresponding factors for quasi-isotropic thermoset composite shown in parenthesis.

\subsection{REFERENCES}

1. J. M. Corum et al., Durability-Based Design Criteria for a Quasi-Isotropic Carbon-Fiber Automotive Composite, ORNL/TM-2002/39, Oak Ridge National Laboratory, Oak Ridge, Tenn., March 2002.

2. J. M. Corum et al., Durability-Based Design Criteria for a Chopped-Carbon-Fiber Automotive Composite, ORNL/TM-2003/86, Oak Ridge National Laboratory, Oak Ridge, Tenn., May 2003.

3. H. Kraus, Creep Analysis, John Wiley and Sons, New York, 1980. 


\section{DAMAGE TOLERANCE - IMPACT DAMAGE}

\subsection{INTRODUCTION}

Damage tolerance is the ability of a material or structure to continue to perform its function in the presence of damage, which might occur in the form of initial flaws or as service-induced damage, such as that due to incidental low-energy impacts. Damage tolerance is an important consideration in assessing the durability of a composite for automotive structural applications. This chapter and its companion, Chap. 13, address the effects of impact damage and of holes and cracks, respectively. They provide the bases for the damage tolerance assessment guidance given in Chap. 5 of Part 1.

This chapter addresses two aspects of impact damage. The first is resistance to the formation of impact damage, which is covered in Sect. 12.2. The impact tests performed on the PPS/carbon-fiber composite are summarized, and correlations between damage area and impactor mass and velocity are developed. Section 12.3 then focuses on the second aspect of impact damage-damage tolerance. Specifically, damage-induced reductions in compressive and tensile strengths are given as functions of impact damage area.

\subsection{IMPACT TESTS}

Baseline impact damage area correlations were based on the results of tests in a pendulum impact facility and an air-gun facility, representing events such as tool drops and kickups of roadway debris respectively. Specimens were the same in both cases-nominally $2.8-\mathrm{mm}$-thick by 229 -mm-square plates clamped on a 203-mm-diam circle and impacted at the center. A 12.7-mm-diam hardened-steel hemispherical impactor point was used in both facilities. The facilities are the same as were used in impact tests of each of the five composites previously characterized in the ORNL Automotive Composite Durability project. They are described in Refs. 1 and 2.

In addition to baseline tests on specimens in the as-received condition, a small series of pendulum and air-gun tests was performed on annealed specimens. Also, a small series of tests was performed on as-received specimens to assess the effects of impacts at a low temperature $\left(-40^{\circ} \mathrm{C}\right)$. The low temperature tests were conducted by flowing vapor from liquid nitrogen through a chamber enclosing the back face of the specimen (the front face was insulated until just prior to the impact). As in the baseline and annealed material test series, both pendulum and air-gun tests were performed at $-40^{\circ} \mathrm{C}$. Finally, a series of brickdrop tests was performed on as-received material to determine the ability of the baseline tests to cover more realistic events involving irregular impactor shapes. Brick drops are, in fact, one of the design loadings for pickup boxes. The specimen and support conditions used for the brick drops were identical to those used for the pendulum and air-gun tests.

Forty-two impact tests were performed, as follows:

- Pendulum

- 10 baseline tests of as-received specimens

- 4 tests of annealed specimens

- 4 tests at $-40^{\circ} \mathrm{C}$

- Air-gun

- 10 baseline tests of as-received specimens

- 4 tests of annealed specimens

- 4 tests at $-40^{\circ} \mathrm{C}$

- 6 brick drop tests. 
The details of these tests, including the resulting measured damage areas, are provided in Table 12.1. In the pendulum and air-gun tests, impactor velocity was measured just prior to impact using laser-based devices. In the brick-drop case, the tabulated velocities at impact were calculated from the drop height. The measured peak force listed for the pendulum tests came from a miniature dynamic load cell located behind the impactor point of the pendulum weight. The tabulated damage areas in Table 12.1 were determined from ultrasonic C-scans performed after the plates were impacted. The procedure for obtaining the C-scans, as well as the measurement of the indicated damage areas were the same as used for each of the previous five composites tested.

The second column in Table 12.1 indicates the final disposition of each impact specimen. Five baseline pendulum impact specimens and five baseline air-gun impact specimens were cut into specimens destined for compressive strength testing. Four baseline pendulum and four baseline air-gun specimens were used for tensile strength testing. With the exception of one pendulum and one air-gun specimen that were sectioned for microscopy studies, all the other impact specimens were used for compressive strength testing.

\subsubsection{Baseline Results}

The visible impact damage in the PPS/carbon-fiber composite baseline impacted specimens was generally similar to that observed in the quasi-isotropic urethane/carbon fiber composite tested earlier in the ORNL project. ${ }^{3}$ The front (impacted) face of the specimens exhibited either a faint circular dent, in the case of the lower energy level tests, or a deeper dent, often accompanied by circumferential cracking around the edge and/or cracks within the crater of the dent, in the case of the higher energy level tests. In no case did complete penetration occur. On the backside of the specimens, where damage is more extensive, the appearance ranged from short faint cracks, to raised pyramids or relatively long surface fiber delaminations in the case of higher energy level tests. While the long delaminations were more prevalent in the air-gun specimens, they did occur to a lesser extent in a few pendulum specimens.

The back sides of two specimens-one subjected to the most server pendulum impact and the other to the most severe air-gun impact-are shown in Figs. 12.1 and 12.2. The pendulum specimen in Fig. 12.1 exhibits the typical pyramidal bulge, while the air-gun specimen in Fig. 12.2 exhibits cracks and delaminations along the surface fiber direction (horizontal in both specimens). To provide some understanding of the so-called impact damage state, or internal cracking pattern, the two specimens depicted in Figs. 12.1 and 12.2 were sent to Delsen Testing 
Table 12.1. List of impact tests

\begin{tabular}{|c|c|c|c|c|c|}
\hline Specimen number & Property tests & Velocity $(\mathrm{m} / \mathrm{s})$ & Energy (J) & Maximum force (N) & Damage area $\left(\mathrm{mm}^{2}\right)$ \\
\hline \multicolumn{6}{|c|}{ Pendulum baseline (12.7-mm diam, $11.52 \mathrm{~kg}$ ) } \\
\hline T6-40 & $\mathrm{CAI}^{\mathrm{a}}$ & 1.02 & 6.00 & 2798 & 161 \\
\hline T16-35 & Tensile & 1.00 & 5.71 & 2699 & 252 \\
\hline T53-1 & CAI & 1.42 & 11.60 & 4159 & 271 \\
\hline T53-2 & Tensile & 1.43 & 11.71 & 4196 & 348 \\
\hline T49-72 & CAI & 1.81 & 18.89 & 5959 & 568 \\
\hline T49-73 & Tensile & 1.84 & 19.59 & 6085 & 516 \\
\hline $\mathrm{T} 22-40$ & CAI & 2.11 & 25.55 & 5413 & 974 \\
\hline $\mathrm{T} 52-46$ & Tensile & 2.08 & 24.85 & 5875 & 806 \\
\hline $\mathrm{T} 51-20$ & CAI & 2.30 & 30.51 & 5623 & 942 \\
\hline T51-21 & Microscopy & 2.49 & 35.69 & 5539 & 1090 \\
\hline \multicolumn{6}{|c|}{ Pendulum, annealed material (12.7-mm diam, $11.52 \mathrm{~kg})$} \\
\hline $\mathrm{T} 28-25$ & $\mathrm{CAI}$ & 1.40 & 11.27 & 4238 & 381 \\
\hline T28-28 & CAI & 1.54 & 13.66 & 4700 & 381 \\
\hline T28-26 & CAI & 1.68 & 16.18 & 5119 & 548 \\
\hline T28-27 & CAI & 1.95 & 21.82 & 5329 & 761 \\
\hline \multicolumn{6}{|c|}{ Pendulum, $-40^{\circ} \mathrm{C}(12.7-\mathrm{mm}$ diam, $11.52 \mathrm{~kg})$} \\
\hline $\mathrm{T} 2-25^{\mathrm{b}}$ & CAI & 1.42 & 11.61 & 4028 & 329 \\
\hline $\mathrm{T} 2-28$ & CAI & 1.60 & 14.81 & 5161 & 497 \\
\hline $\mathrm{T} 2-26$ & $\mathrm{CAI}$ & 1.68 & 16.17 & 5539 & 510 \\
\hline $\mathrm{T} 2-27$ & CAI & 1.99 & 22.84 & 7050 & 716 \\
\hline \multicolumn{6}{|c|}{ Air gun baseline (12.7-mm diam, $0.02244 \mathrm{~kg})$} \\
\hline T53-3 & $\mathrm{CAI}$ & 33.91 & 12.90 & & 510 \\
\hline T53-4 & Tensile & 34.84 & 13.62 & & 406 \\
\hline T51-22 & CAI & 44.00 & 21.72 & & 1052 \\
\hline T51-23 & Tensile & 44.34 & 22.06 & & 987 \\
\hline T42-41 & CAI & 52.32 & 30.71 & & 1716 \\
\hline T52-47 & Tensile & 52.29 & 30.67 & & 1677 \\
\hline T6-41 & CAI & 58.98 & 39.03 & & 2729 \\
\hline T16-36 & Tensile & 59.23 & 39.36 & & 3542 \\
\hline $\mathrm{T} 22-41$ & CAI & 67.28 & 50.79 & & 5994 \\
\hline T49-74 & Microscopy & 74.08 & 61.57 & & 4206 \\
\hline \multicolumn{6}{|c|}{ Air gun, annealed (12.7-mm diam, $0.02244 \mathrm{~kg})$} \\
\hline T26-29 & CAI & 43.45 & 21.19 & & 981 \\
\hline T26-30 & CAI & 52.64 & 31.10 & & 2884 \\
\hline $\mathrm{T} 27-25$ & CAI & 58.82 & 38.82 & & 3935 \\
\hline $\mathrm{T} 27-26$ & CAI & 58.88 & 38.90 & & 4613 \\
\hline \multicolumn{6}{|c|}{ Air gun, $-40^{\circ} \mathrm{C}(12.7-\mathrm{mm}$ diam, $0.02244 \mathrm{~kg})$} \\
\hline $\mathrm{T} 7-25$ & CAI & 43.79 & 21.52 & & 1729 \\
\hline T7-26 & CAI & 54.48 & 33.30 & & 3600 \\
\hline T7-27 & CAI & 61.59 & 42.57 & & 5903 \\
\hline T7-28 & CAI & 62.56 & 43.91 & & 5884 \\
\hline \multicolumn{6}{|c|}{ Brick drop $(1.73 \mathrm{~kg})$} \\
\hline T1-25 & CAI & 4.89 & 20.68 & & 161 \\
\hline T14-29 & CAI & 5.99 & 31.01 & & 529 \\
\hline T14-30 & CAI & 6.47 & 36.18 & & 400 \\
\hline T1-26 & CAI & 5.99 & 31.01 & & 587 \\
\hline T1-27 & CAI & 6.91 & 41.35 & & 632 \\
\hline T1-28 & CAI & 6.91 & 41.35 & & 768 \\
\hline
\end{tabular}

Compression after impact

Velocity not measured. Average from three other tests at same drop height used. 


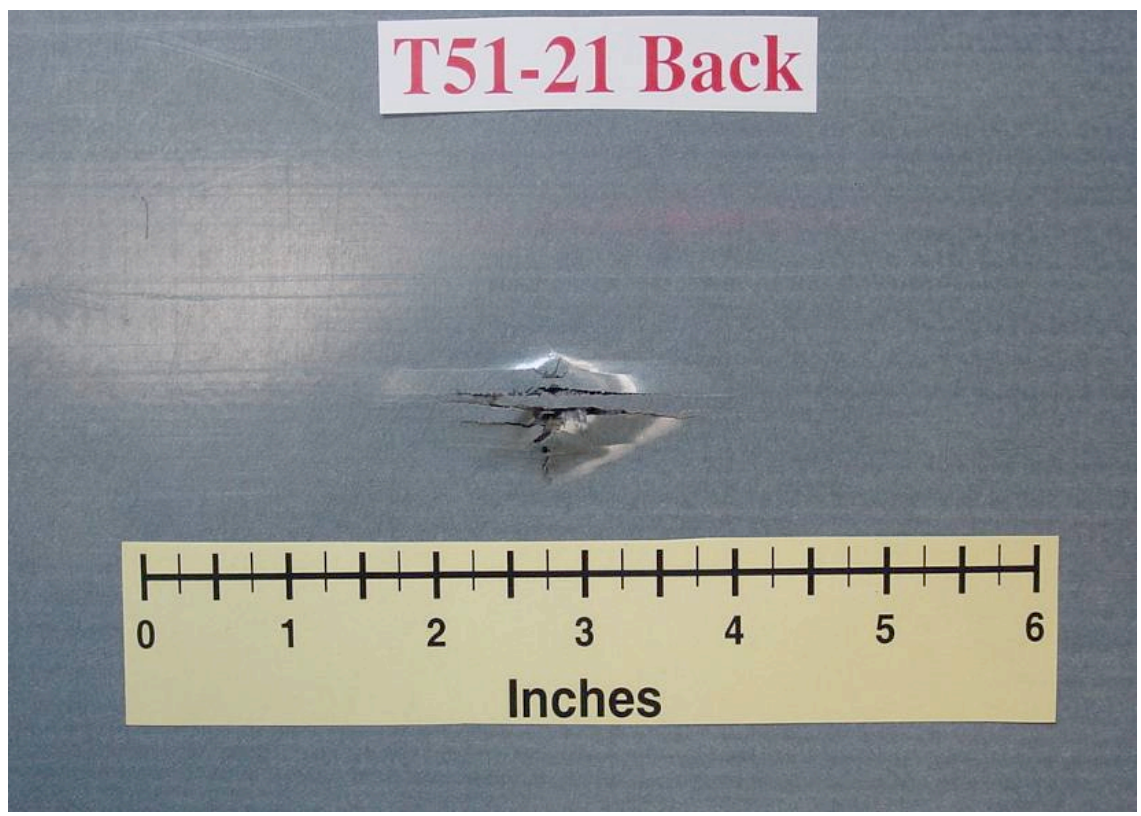

Fig. 12.1. Visible damage on back face of impact specimen T51-21, which was subjected to a pendulum impact that produced significant damage. Refer to Fig. 12.4 for photomicrographs of cross sections of this specimen.

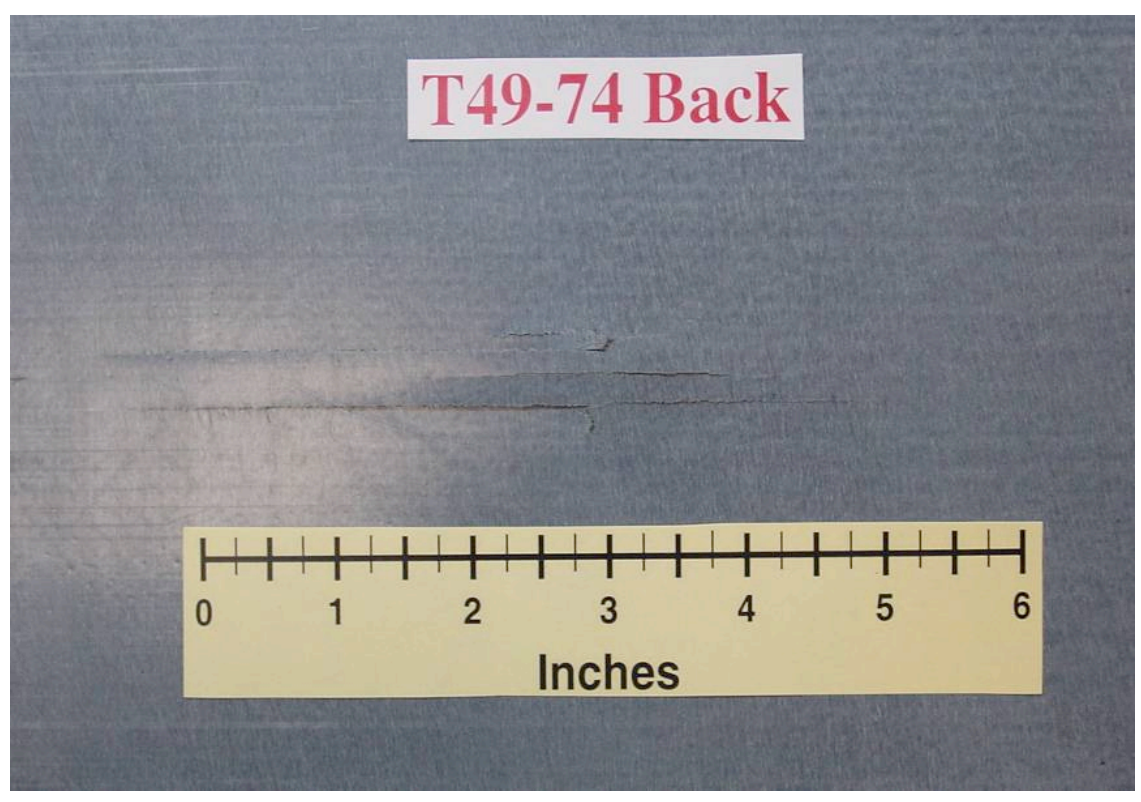

Fig. 12.2. Visible damage on back face of impact specimen T49-74, which was subjected to an airgun impact that produced significant damage. Refer to Fig. 12.5 for photomicrographs of cross sections of this specimen. 
Laboratories, where photomicroscopy specimens were cut from them. Several specimens were taken along horizontal and vertical lines through the center of the impact damage area. The specimens were metallographically prepared so that their polished faces were perpendicular to the lines-i.e., the specimens along a horizontal line had their faces oriented perpendicular to the horizontal line, and likewise for specimens along the vertical line. A series of photomicrographs was taken of each specimen face at various magnifications.

Before examining the results, a brief discussion of the typical impact damage state in layered composites will be helpful. Figure 12.3 illustrates that state. In the center of the impact damage area both matrix and fiber damage occur, and the area becomes larger on the back face. Beyond the central area were both matrix and fiber damage occur is an area of only matrix damage (both interlaminar and transverse cracks). The shape of the damage area depends on the layup and can vary through the thickness.
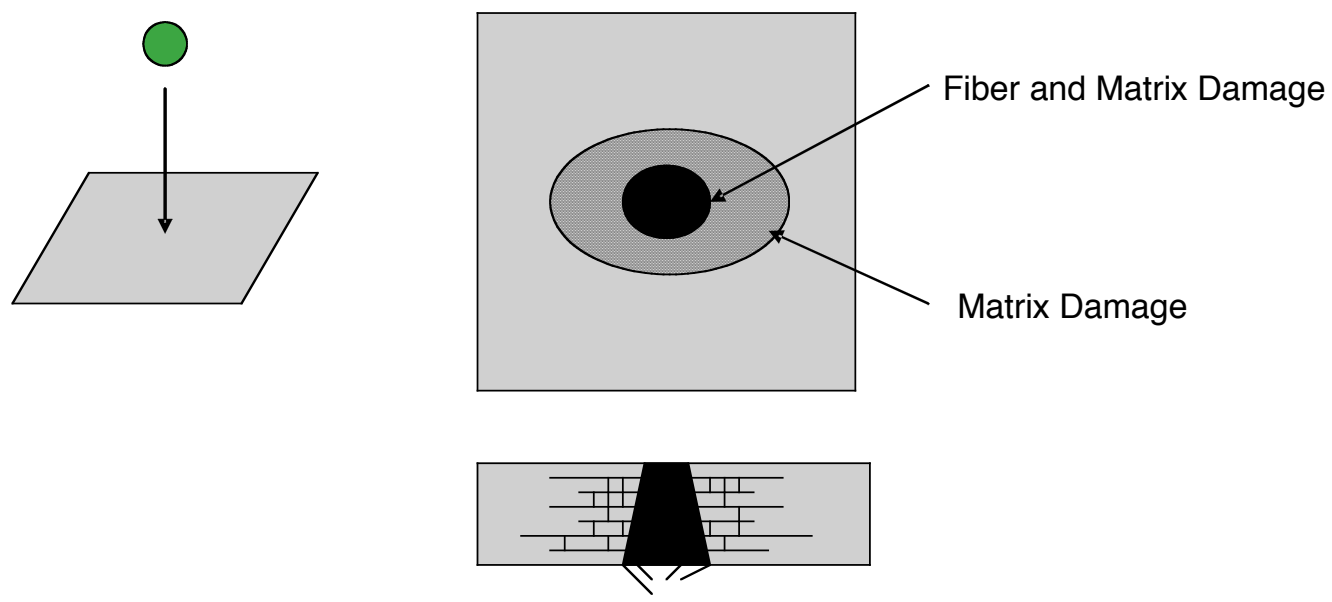

Fig. 12.3. Schematic of impact damage state.

Typical photomicrographs for the specimens in Figs. 12.1 and 12.2 are shown in Figs. 12.4 and 12.5, respectively. These are low-magnification pictures in order to show the full thickness of the composite (16 plys plus surface coatings). The left-hand views in each figure, which depict sections near the center of the damage area, exhibit extensive matrix cracking, delaminations, and fiber breakage. The right-hand views depict sections near the edge of the damage area and exhibit mostly matrix cracking. Note the delamination of the back-surface outer ply in both figures. Also, there is an interior delamination in Fig. 12.5.

Examination of the ultrasonic C-scans for specimens impacted at increasing energy levels (see Fig. 12.6) reveals a basic difference in the characteristic damage states for pendulum- and air-gunimpacted specimens at the higher energy levels. At low to moderate energy levels, the damage areas for both types of impacts appear as circles. At the highest energy levels, the pendulum-impacted specimens consistently exhibit a central circle of severe damage, with two lobes extending in the direction of the back-face surface fibers (typified by the upper right-hand scan in Fig. 12.6). This indicates that matrix cracking and delaminations outside the central circle are largely confined to these lobes. In contrast, the lower right-hand scan typifies the appearance of C-scans for the higher energy level tests of specimens impacted by the air gun. Here, there is again a central circle of severe damage, but rather than two lobes, there are multiple ones, 


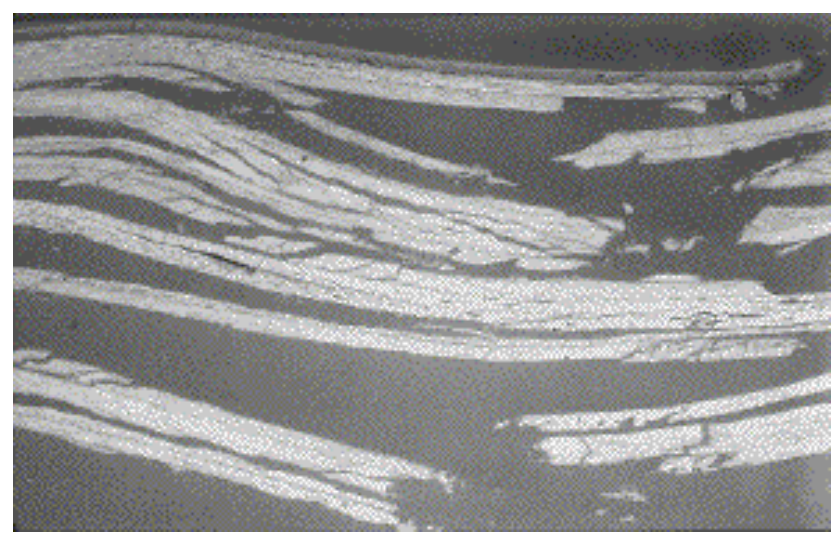

V1, Near Center

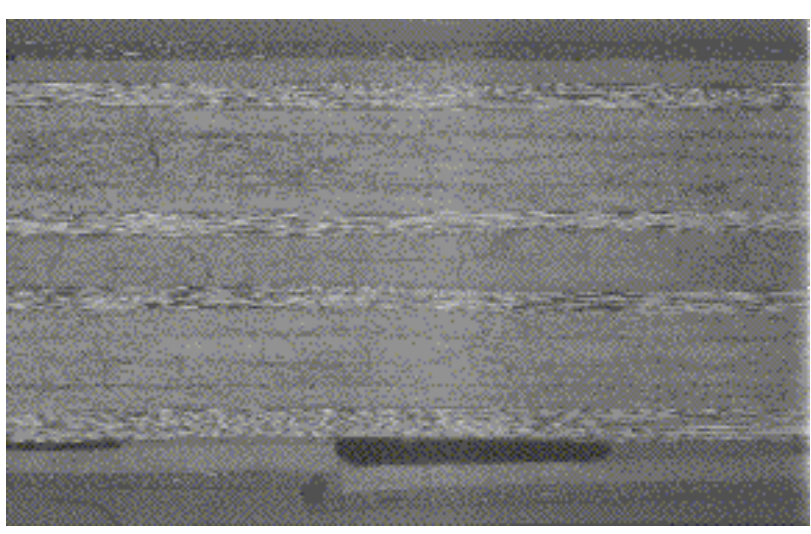

H3, Near Edge

Fig. 12.4. Low-magnification photomicrographs of full thickness of specimen T51-21, which was subjected to a pendulum impact. The photomicrograph on the left is of a vertical cross section (perpendicular to vertical axis) near the center of the damage area, while the right-hand image is of a horizontal cross section (perpendicular to horizontal axis) at the outer right edge of the damage area (refer to Fig. 12.1).

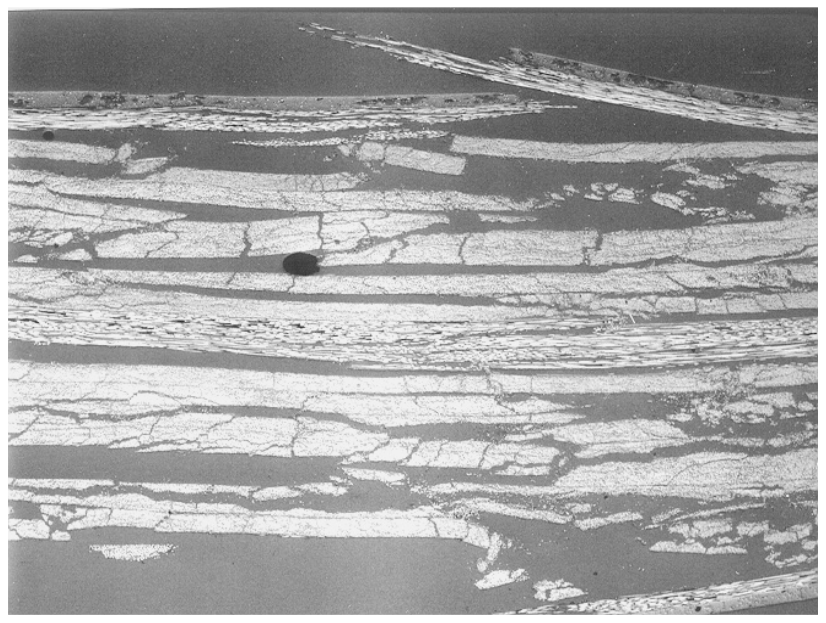

V1, Near Center

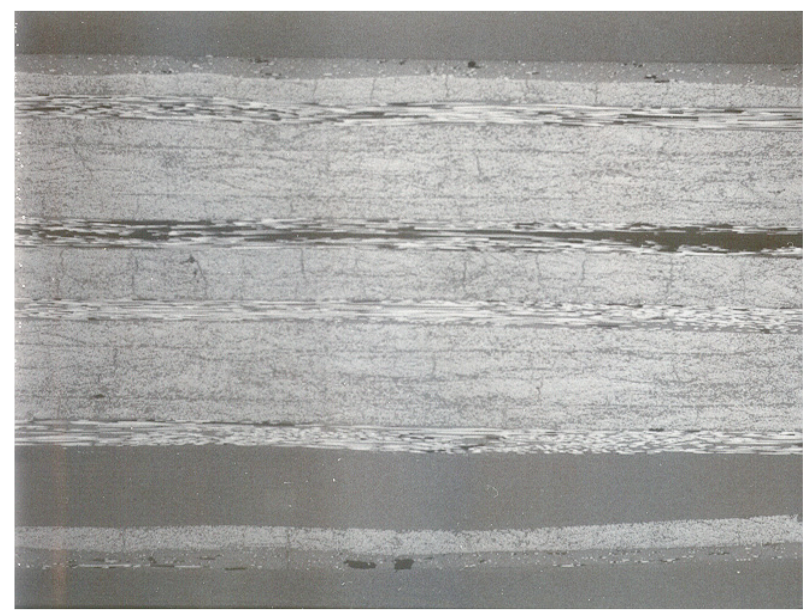

H3, Near Edge

Fig.12.5. Low magnification photomicrographs of full thickness of specimen T49-74, which was subjected to an air-gun impact. The photomicrograph on the left is of a vertical cross section (perpendicular to vertical axis) near the center of the damage area, while the right-hand image is of a horizontal cross section (perpendicular to horizontal axis) at the outer right edge of the damage area (refer to Fig. 12.2).

corresponding to each fiber direction. This indicates that, at least near the back face, there are delaminations in multiple layers. Consequently, for a given energy level, the projected air-gun damage areas are significantly larger than those produced by pendulum impacts. 


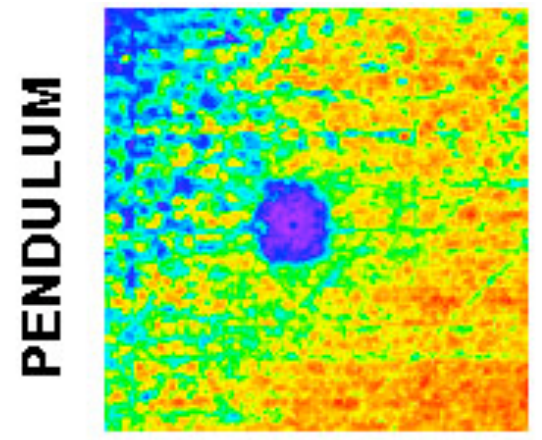

$11.6 \mathrm{~J}$

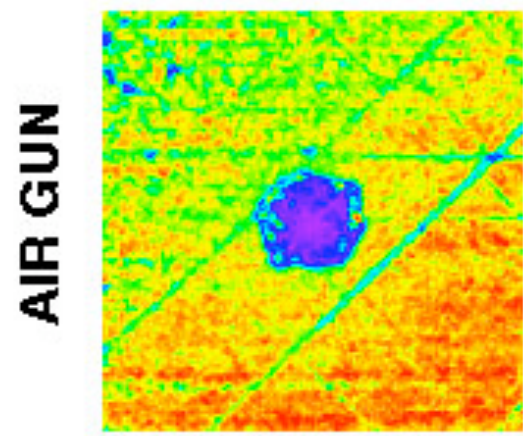

$12.9 \mathrm{~J}$

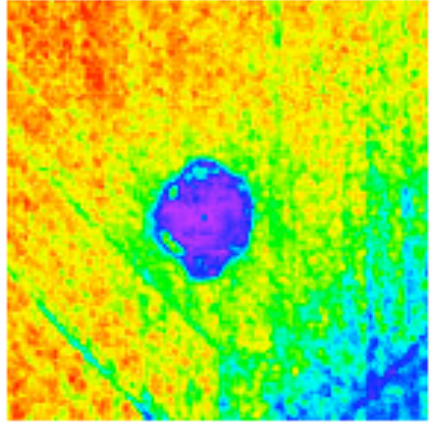

$19.6 \mathrm{~J}$

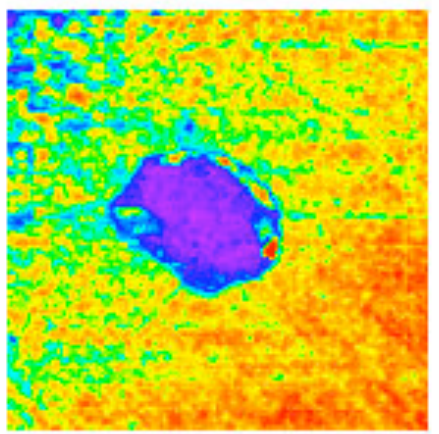

$21.8 \mathrm{~J}$

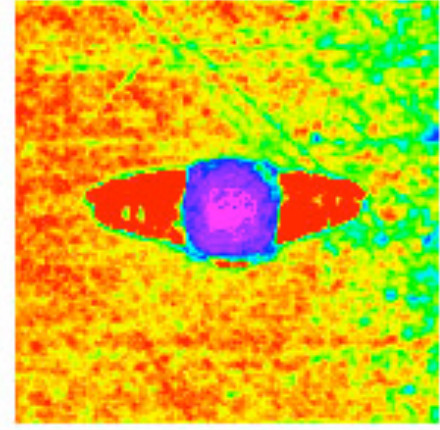

$35.7 \mathrm{~J}$

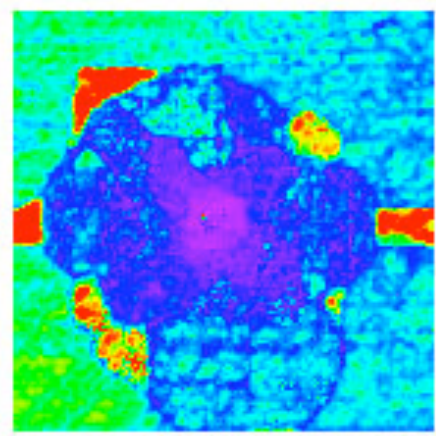

$61.6 \mathrm{~J}$

Fig. 12.6. Typical C-scan images of specimens impacted at increasing energy levels. The top row is of pendulum specimens and the bottom row is of air gun specimens. The right-hand images in each case are of the specimens depicted in the previous figures. Each image depicts a 101.6- $\mathrm{x}$ 101.6-mm area.

The damage areas measured in the base-line tests are plotted in Fig. 12.7 as functions of impactor kinetic energy. As was the case for each of the three urethane/carbon-fiber composites previously characterized, kinetic energy does not adequately correlate the results. However, whereas pendulum impacts produced the largest damage areas in each of the urethane composites, the air-gun impacts produced significantly larger damage areas for the PPS composite. This was noted above and is attributed to the greater propensity to delaminate in the case of the PPS composite.

It is difficult to compare impact damage resistance of the various carbon-fiber composites that have been tested because of their different thicknesses and fiber volume contents. The curves for the quasi-isotropic urethane composite are shown dashed in Fig. 12.7. ${ }^{3}$ The PPS material shows better resistance. However, it is $2.8-\mathrm{mm}$ thick, whereas the urethane composite was just 2.2-mm thick. Also, the PPS material has a higher fiber volume ( $53 \%$ vs $40 \%$ for the urethane composite). The urethane/choppedcarbon-fiber composite, which was $3-\mathrm{mm}$ thick and had a $42 \%$ fiber volume fraction, exhibited considerably better impact resistance than the PPS composite, particularly in the case of air-gun impacts. 


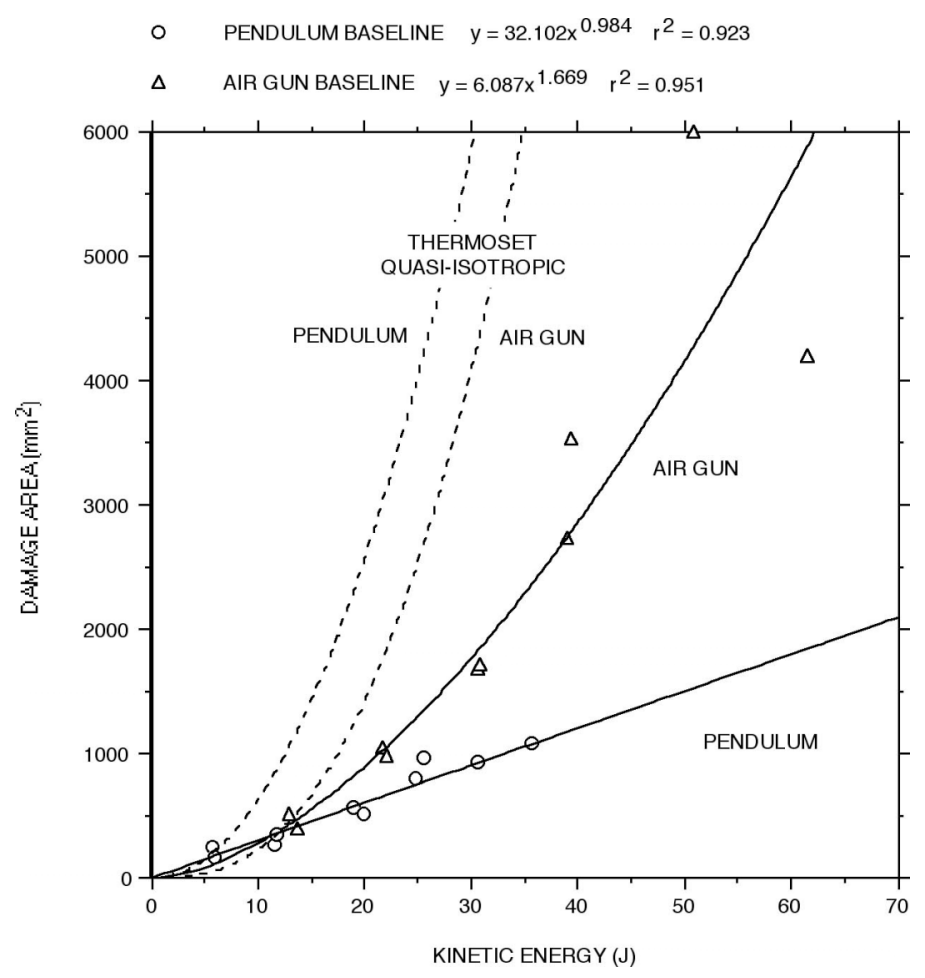

Fig. 12.7. Baseline impact damage areas vs kinetic energy. Quasi-isotropic thermoset composite results (dashed) are shown for comparison. Note that the urethane composite was 2.2-mm thick while the current PPS composite is $2.8-\mathrm{mm}$ thick.

An improved correlating parameter is used in Fig. 12.8, where the damage is expressed as a power-law function of the parameter (mass ${ }^{0.465} \mathrm{x}$ velocity). Only the baseline data tabulated in Table 12.1 were used in Fig. 12.8. The baseline correlation, which will be used in subsequent comparisons, is invalid at the lower and upper ends. At the lower end, some threshold exists below which no damage occurs; at the upper end, damage is bounded by the ballistic limit, above which complete penetration occurs.

The maximum force measured during the pendulum impacts is plotted in Fig. 12.9 as a function of pendulum velocity. The curve fit is based only on the baseline tests of as received specimens. The data from the tests at $-40^{\circ} \mathrm{C}$ indicate forces somewhat larger than those reached in the room-temperature tests. The dashed curves in Fig. 12.9 show the maximum force measured in baseline tests of the quasi-isotropic and crossply urethane composites. ${ }^{3,4}$ The curve for the chopped-fiber urethane composite lies in between these two. ${ }^{5}$ The higher force in the current PPS composite likely reflects its higher stiffness, volume content, and in the case of the quasi-isotropic urethane composite, thickness. 


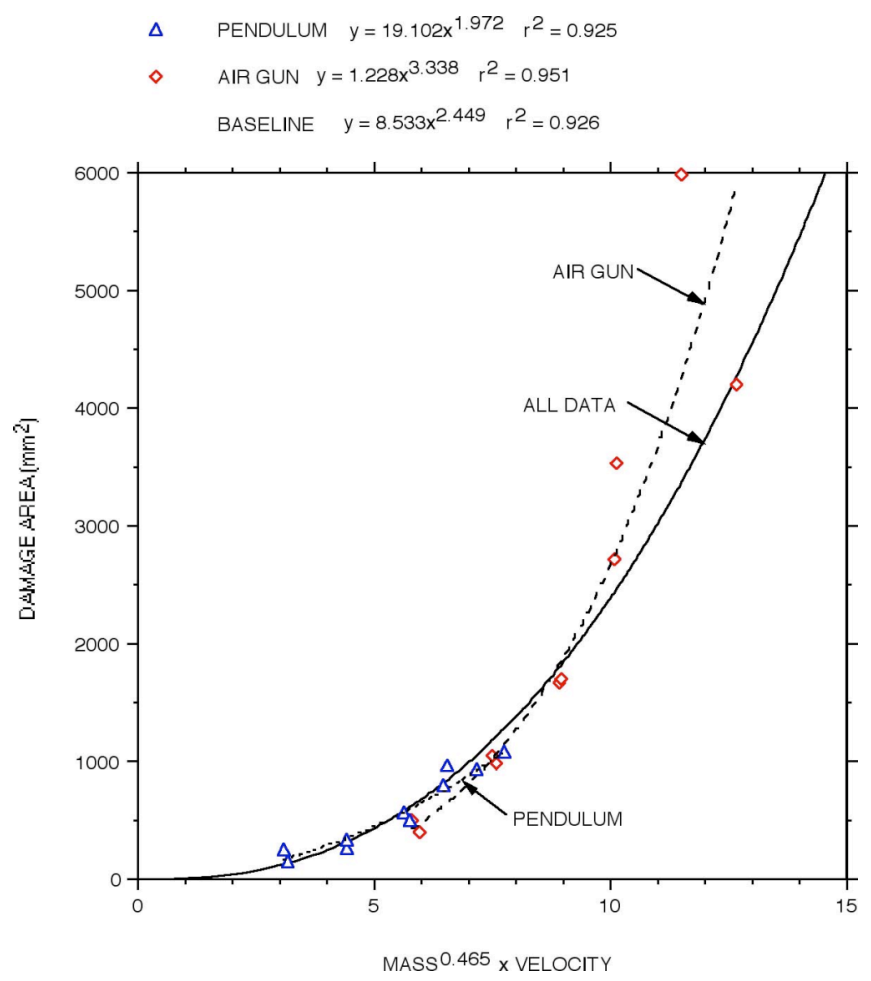

Fig. 12.8. Baseline impact damage area vs mass ${ }^{0.465} \mathrm{x}$ velocity (mass in $\mathrm{kg}$ and velocity in $\mathrm{m} / \mathrm{s}$ ). The dashed lines are correlations for the pendulum results alone and the air gun results alone. The solid line is based on both sets of data from tests of as-received specimens.

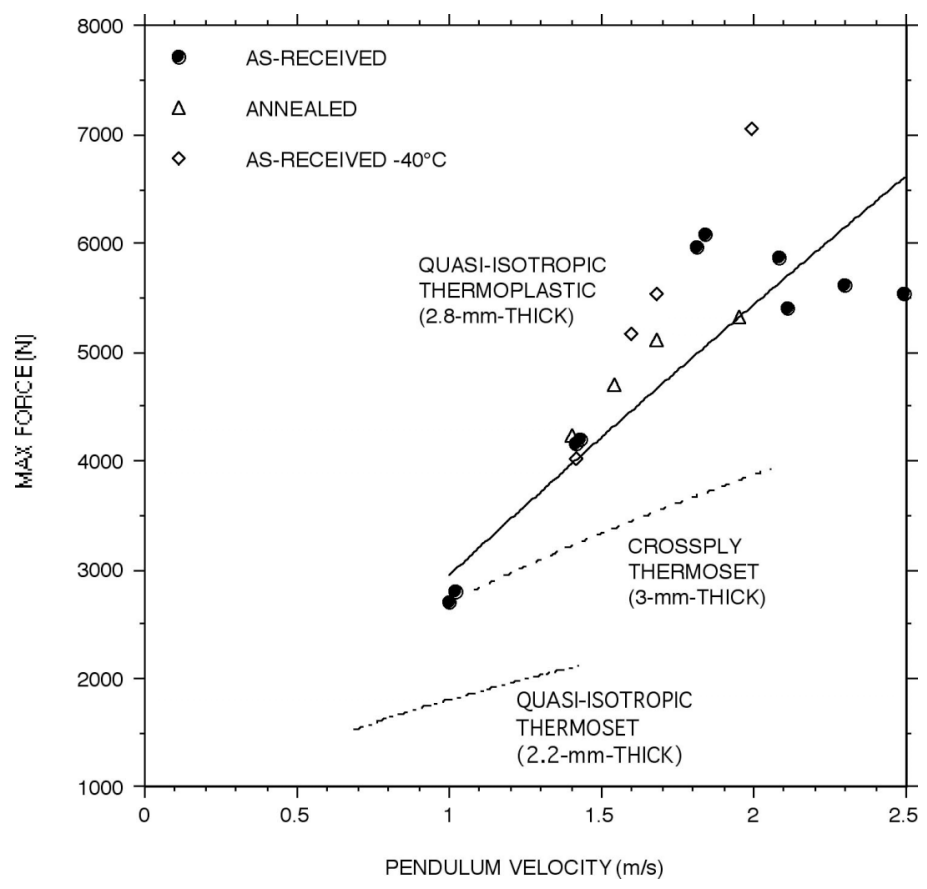

Fig. 12.9. Comparison of peak impact forces measured in pendulum tests of three candidate carbon-fiber composites. 


\subsubsection{Effects of Annealing and Low-Temperature}

Figures 12.10 and 12.11 compare the impact damage areas measured in the tests of annealed specimens and the tests of as-received specimens at $-40^{\circ} \mathrm{C}$, respectively, with the baseline correlation for as-received specimens. Figure 12.10 indicates that annealed material may be somewhat more prone to delaminations at the higher air-gun energy levels. Likewise, Fig. 12.11 indicates that testing at $-40^{\circ} \mathrm{C}$ also has a degrading effect at higher energy levels. This is probably due to some embrittlement of the thermoplastic matrix and the resulting increased propensity for matrix cracking and delamination.

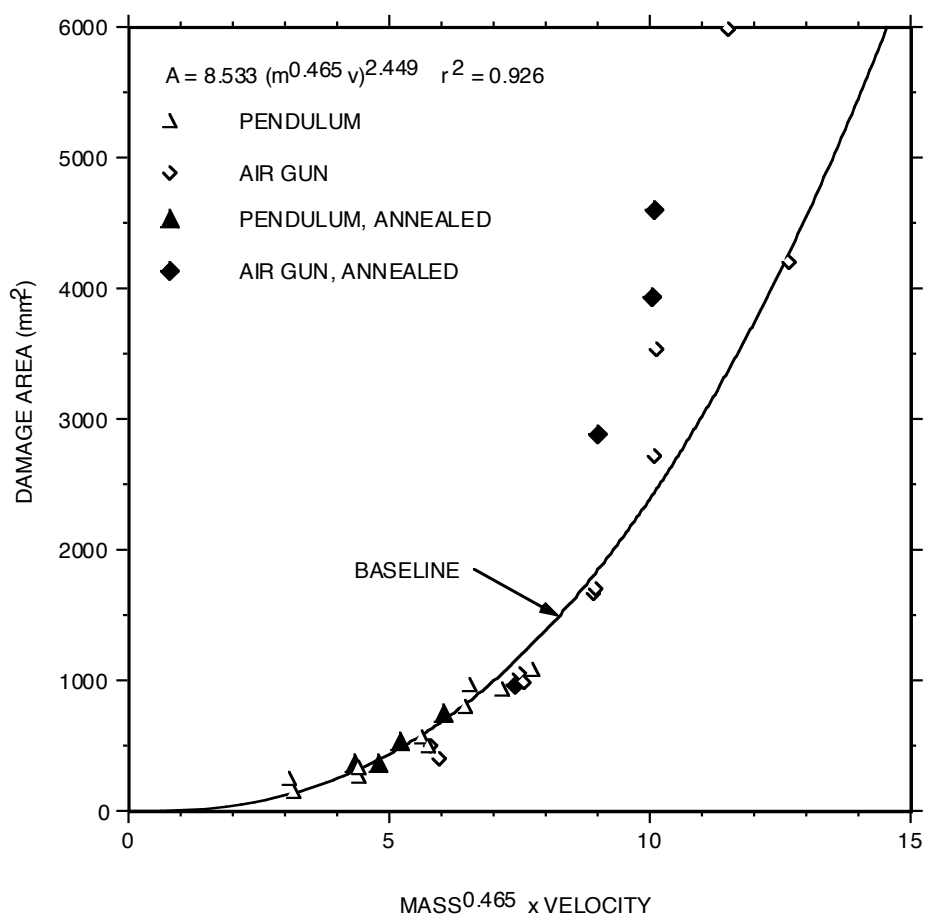

Fig. 12.10. Impact damage in annealed specimens compared to results for baseline, as-received specimens.

\subsubsection{Brick-Drop Tests}

The test results presented in the previous sections were all produced by smooth hemispherical steel impactor points. Brick drops, which are one of the loadings specified for composite pickup boxes, provide an opportunity to determine if the results can be used to predict damage areas due to impacts from more irregular objects.

Six brick-drop tests were performed, as tabulated in Table 12.1. The bricks were ordinary redface bricks with reasonably sharp corners. The average mass of the bricks was $1.73 \mathrm{~kg}$; and they were dropped from heights ranging from 1.22 to $2.44 \mathrm{~m}$ ( 4 to $8 \mathrm{ft}$ ). The bricks were dropped so that they hit on a sharp corner with the center of gravity in line with the impact point.

Figure 12.12 compares damage areas produced by the bricks, with the baseline correlation and data from the pendulum and air-gun tests. All six of the brick-drop data points are well below the baseline correlations. 


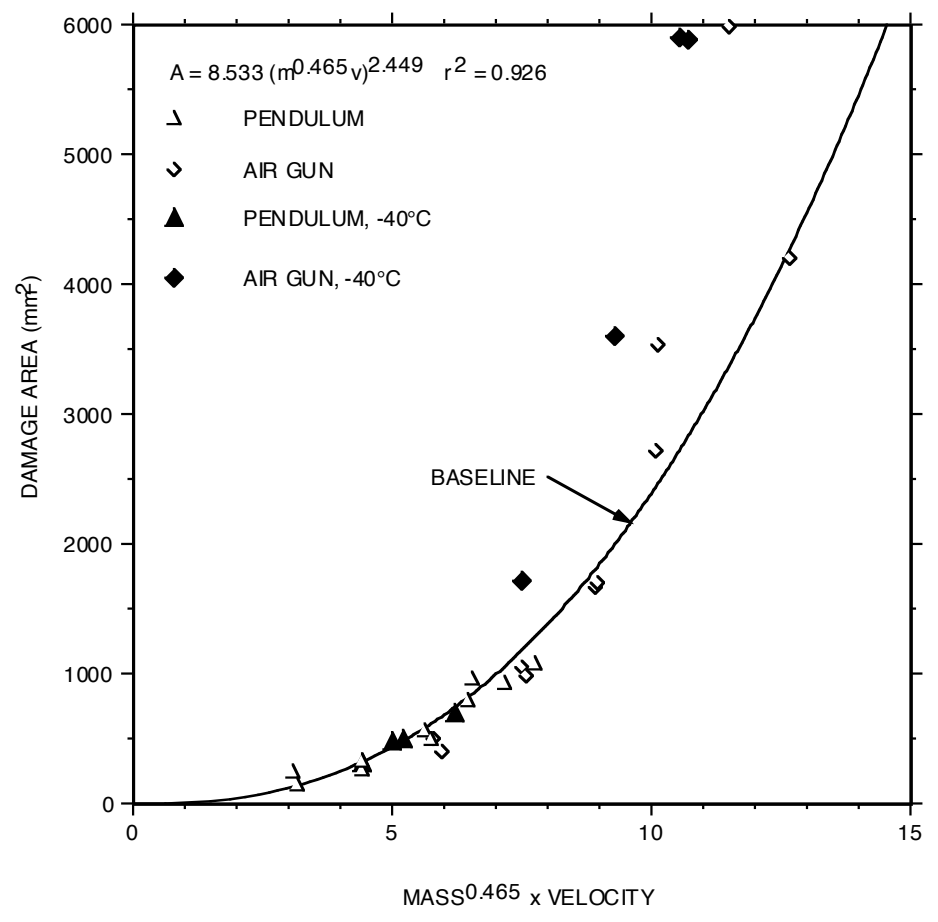

Fig. 12.11. Impact damage in specimens tested at $-40^{\circ} \mathrm{C}$ compared to room-temperature baseline results.

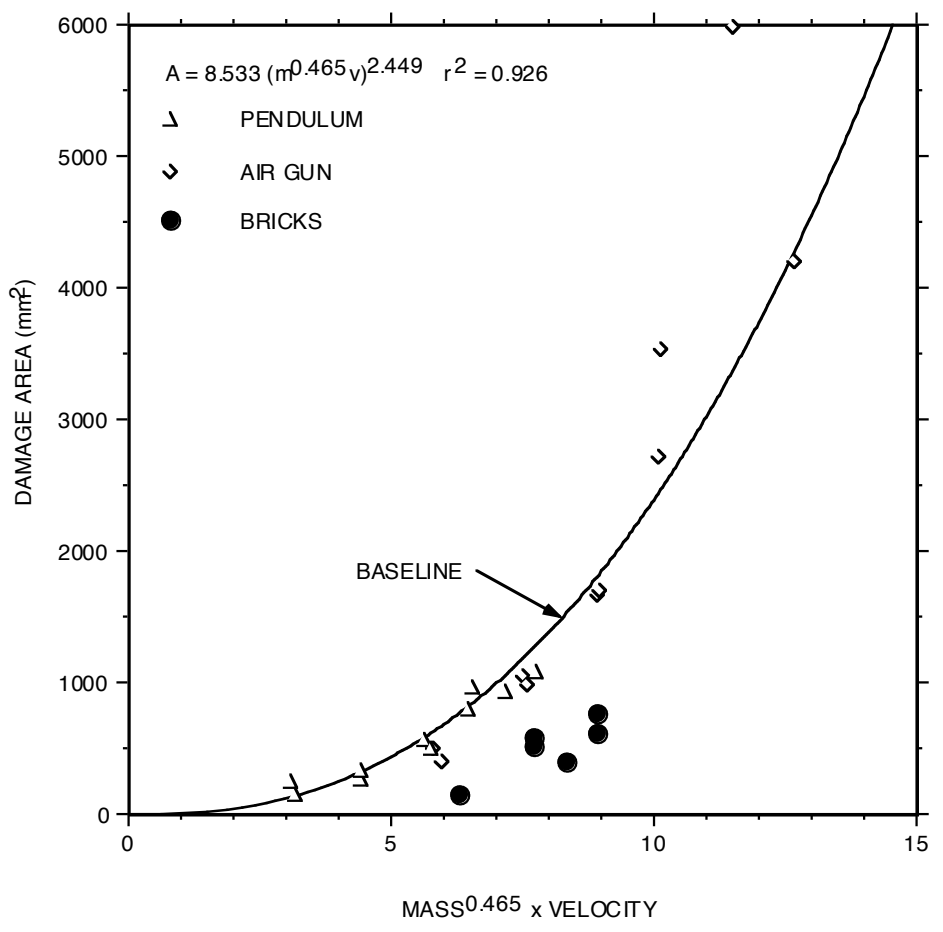

Fig. 12.12. Impact damage in specimens subjected to brick drops compared to baseline correlation. 


\subsection{DEGRADATION OF STRENGTH PROPERTIES}

\subsubsection{Introduction}

All but two of the 42 impacted test specimens were subsequently cut into specimens to be used for compressive or tensile strength tests. The layout used for cutting these strength specimens is shown in Fig. 12.13. The center specimen contained the impact damage; the left-hand specimen contained no damage; and the right-hand specimen contained a circular hole. The holes ranged in diameter from 6.4- to 38.1-mm, as follows.

\begin{tabular}{ccc}
$\begin{array}{c}\text { Hole diam } \\
(\mathbf{m m})\end{array}$ & & $\begin{array}{c}\text { Number of } \\
\text { Specimens }\end{array}$ \\
\cline { 1 - 1 } 6.4 & 8 \\
12.7 & 8 \\
19.1 & 8 \\
25.4 & 8 \\
31.8 & 1 \\
38.1 & 1
\end{tabular}

Circular-hole specimens were not cut from the brick-drop impacted specimens because the impact damage was usually somewhat off-center, leaving room for only two full-width specimens.

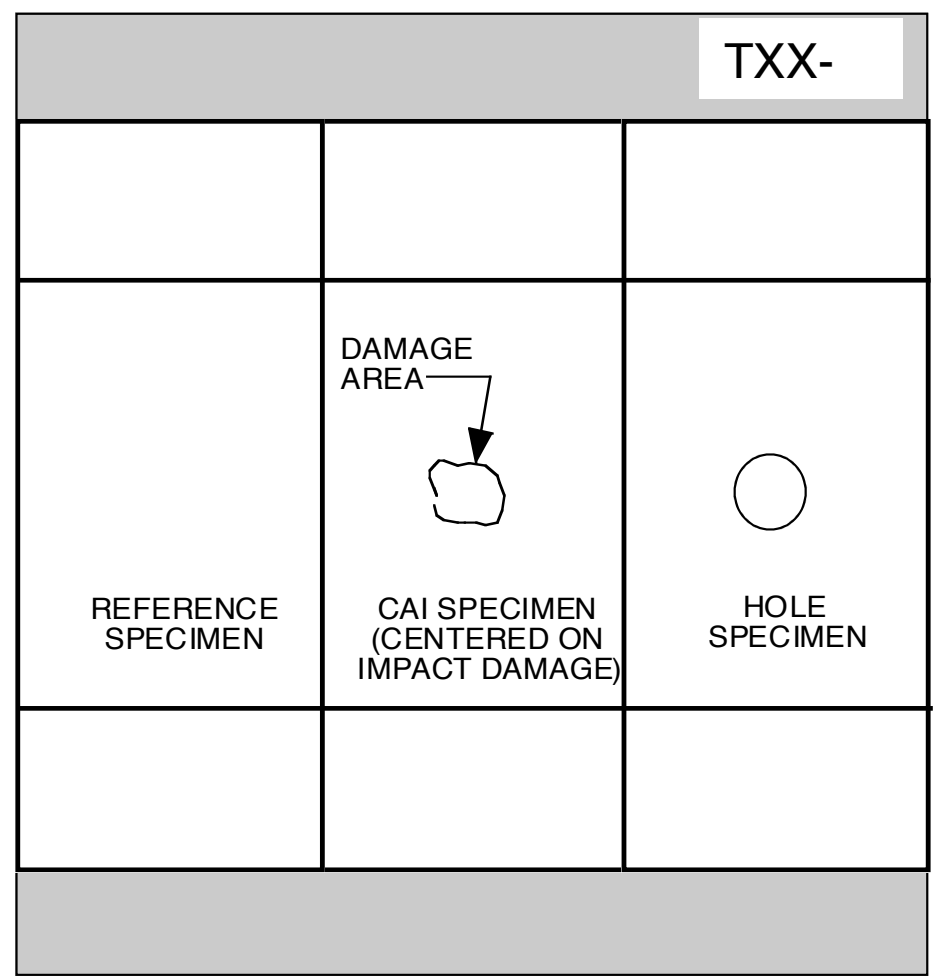

Fig. 12.13. Layout used for cutting CAI-type specimens from impacted plate specimens.

As designated in the second column of Table 12.1, ten of the baseline impact specimens were cut into specimens that were tested in compression; specimens from the other eight were tested in tension. All 
of the strength specimens from the annealed impact specimens, the specimens impacted at $-40^{\circ} \mathrm{C}$ and the brick-drop tests were tested in compression.

The strength specimens were identical, whether tested in compression or tension. The specimen design shown in Fig. 12.14, was originally intended for compression-after-impact (CAI) tests. ${ }^{6}$ Hence the specimens are referred to here as CAI-type specimens, whether used for compressive or tensile tests. The specimen is $76.2-\mathrm{mm}$ wide by $177.8-\mathrm{mm}$ long, with $38.1-\mathrm{mm}$-long tabs at each end." Steel antibuckling plates with a 38.1-mm-diam circular hole at the center are used to restrain the specimen against lateral deflections when tested in compression. Bolts holding the plates were secured just finger tight. The specimens were tested in a hydraulic test machine. For tensile tests, the antibuckling plates were omitted.

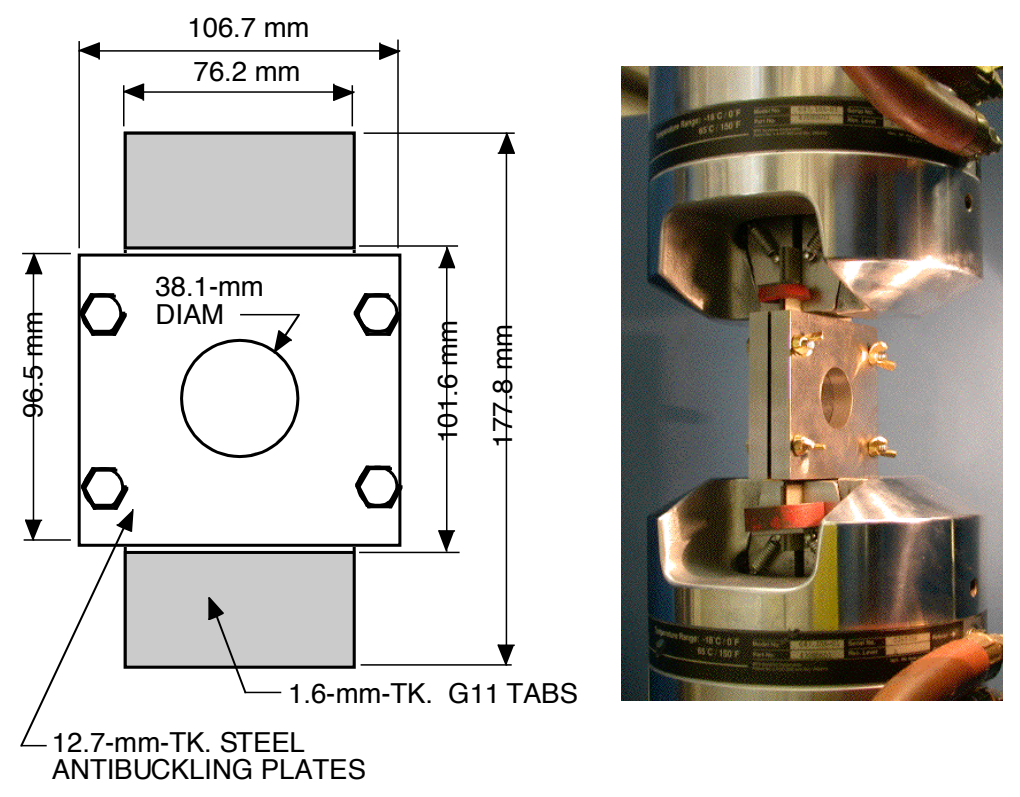

Fig. 12.14. "CAI-type" specimen used for both tension-and compression-after-impact strength tests.

The compressive test results are discussed in Sect. 12.3.2, while the tensile results are discussed in Sect. 12.3.3.

\subsubsection{Compression-After-Impact}

To determine the strength reduction caused by the impact damage in a specific impacted plate specimen, the strength of the center specimen was ratioed to the average strength of all of the undamaged specimens of as-received or, as appropriate, of annealed material.

Figure 12.15 shows the compressive strength reduction determined for the five baseline pendulum and five baseline air-gun impacted specimens. The fact that air-gun specimens exhibit more damage tolerance than pendulum specimens under compressive loads is probably related to the measured damage areas of the air-gun specimens being inflated by the different delamination orientations across the thickness. In the case of the urethane quasi-isotropic composite tested earlier, the air gun specimens exhibited slightly greater damage tolerance than pendulum specimens, but the two curves were sufficiently close that, for comparison purposes, the data were represented by a single curve. ${ }^{3}$ That curve

\footnotetext{
* The undamaged specimens and circular hole specimens were slightly less than 76.2-mm wide, to allow for the width of the saw kerf.
} 
is shown dashed in Fig. 12.15 for comparison. It matches the PPS quasi-isotropic composite pendulum curve fairly closely.

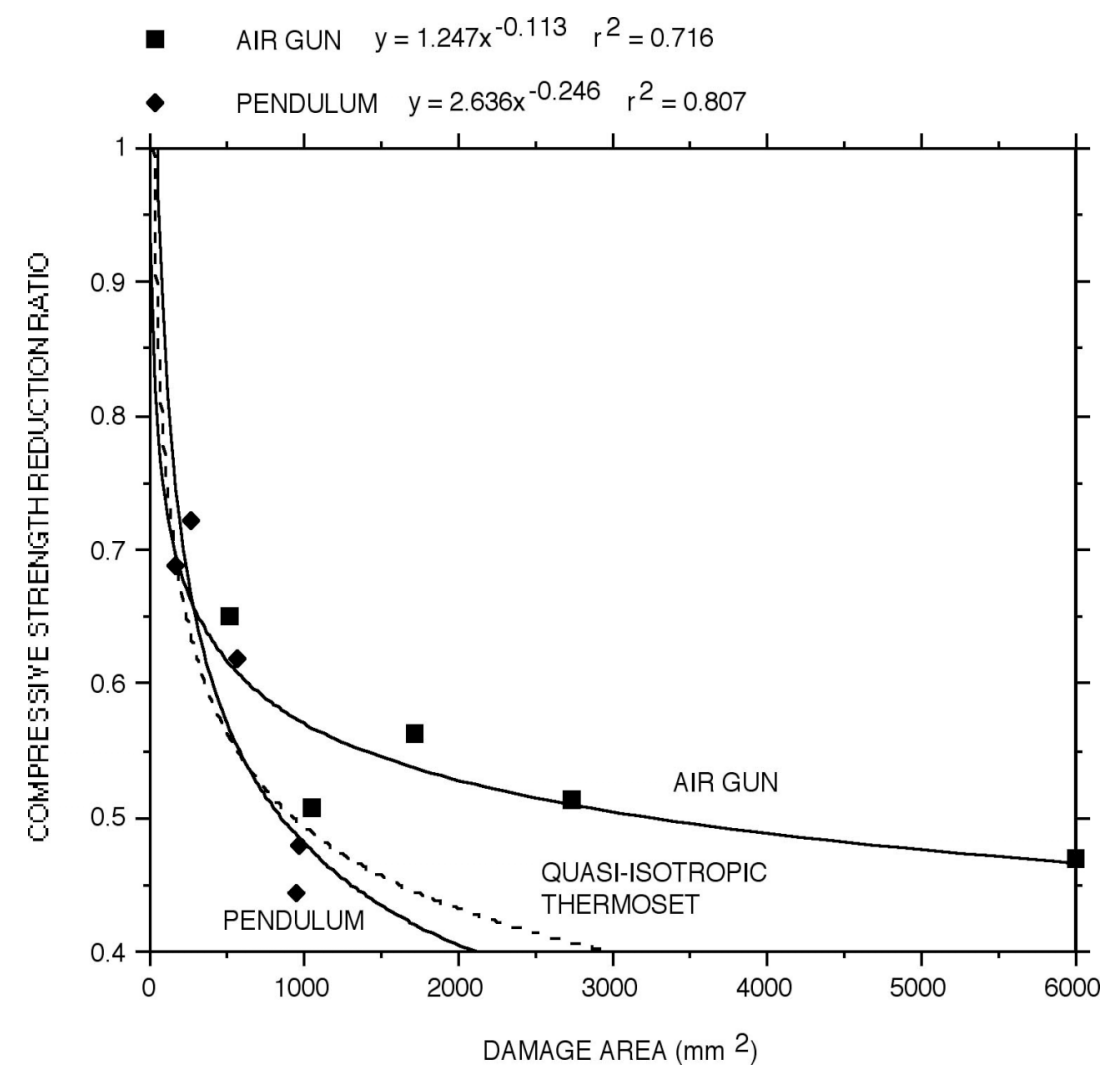

Fig. 12.15. Relative retained CAI strength vs damage area for as-received specimens. Quasi-isotropic thermoset composite correlation (based on both pendulum and air gun data) shown for comparison.

Compressive strength reduction data for the annealed specimens are compared in Fig. 12.16 with baseline curves for as-received specimens. There is little perceived difference. A similar comparison of the baseline curves with data from specimens impacted at $-40^{\circ} \mathrm{C}$ is shown in Fig. 12.17. Here, specimens impacted at the lower temperature do appear to be slightly more damage tolerant.

The compressive strength reductions for the six brick-drop specimens are compared in Fig. 12.18 with the baseline curves. They, too, show more damage tolerance than do the baseline specimens. 


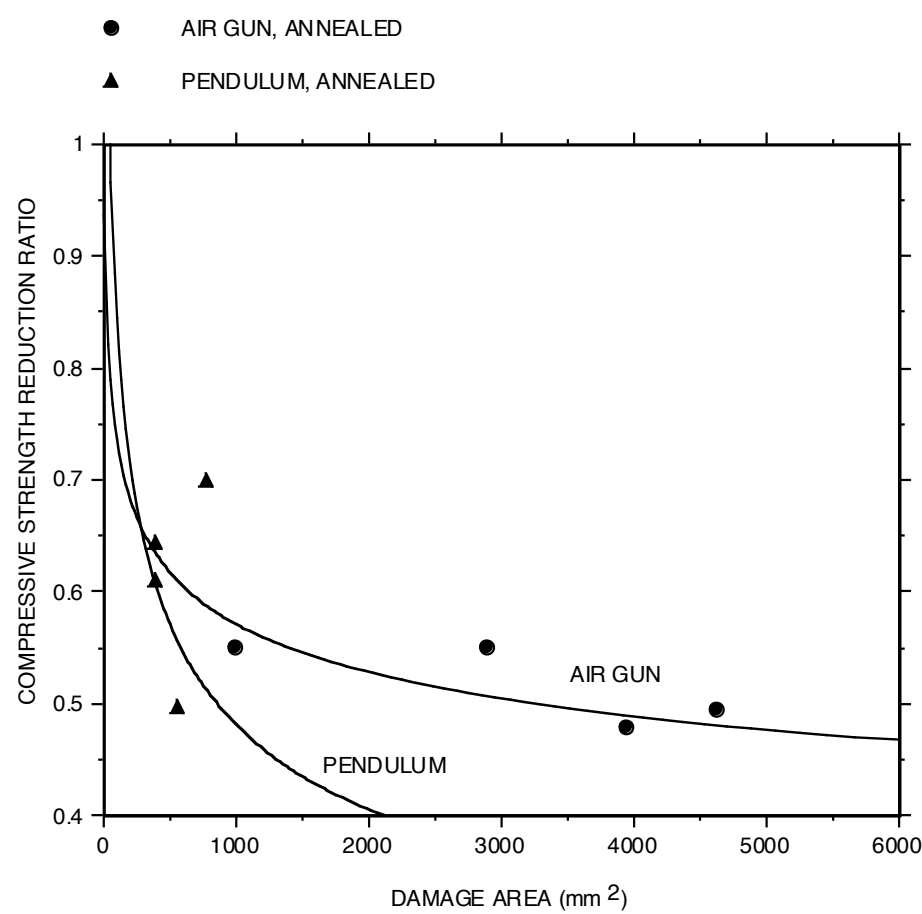

Fig. 12.16. Relative retained CAI strength in annealed specimens compared with results for as received specimens (curves).

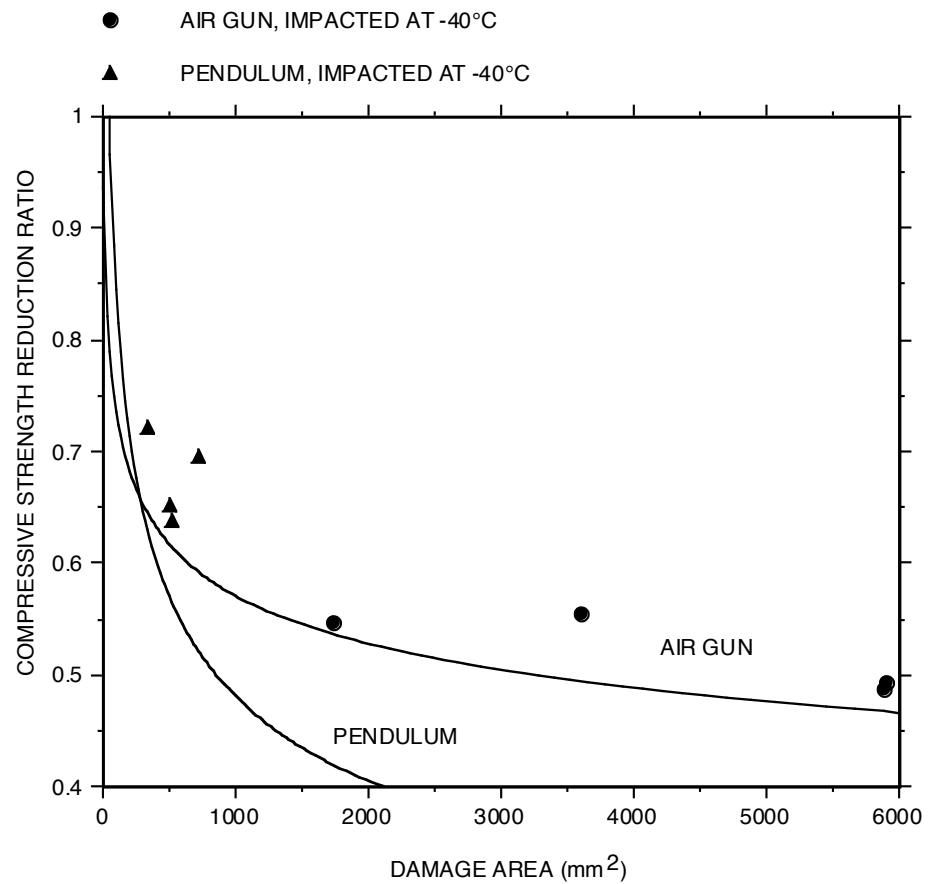

Fig. 12.17. Relative retained CAI strength in specimens impacted at $-40^{\circ} \mathrm{C}$ compared with results for as-received specimens impacted at room temperature (curves). 


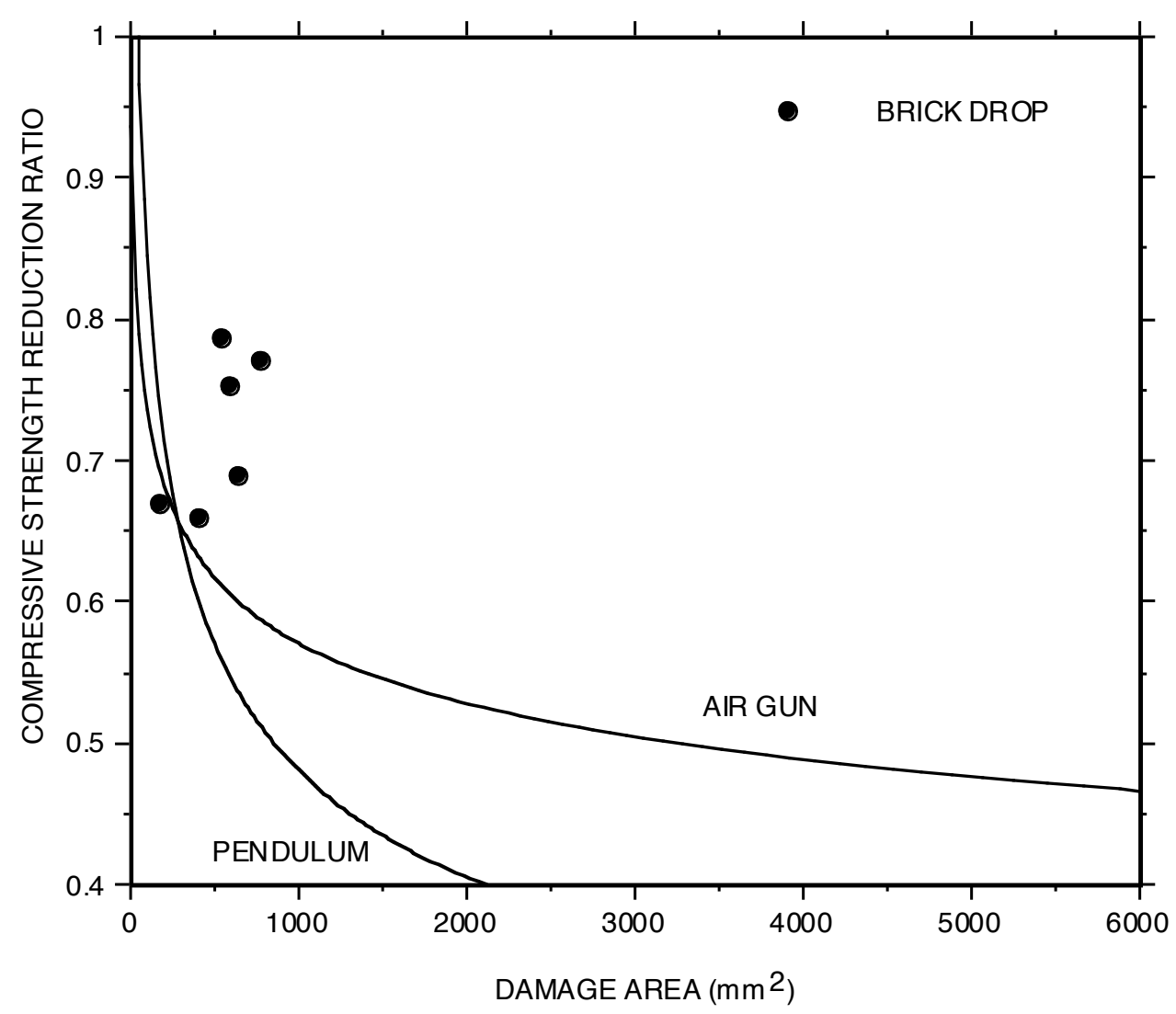

Fig. 12.18. Relative retained CAI strength in specimens impacted by bricks compared with baseline results (curves).

\subsubsection{Tension-After Impact}

As shown in Fig. 12.19, tensile strength reductions, which are due primarily to fiber damage, are less than the previously presented compressive strength reductions, which are due also to matrix cracking and delaminations. In tension, as in compression, the air-gun specimens exhibit more damage tolerance than do the pendulum-impacted specimens.

\subsubsection{Similarity to Hole Effects}

The effects of damage in the form of holes or cracks in the PPS/carbon-fiber composite are addressed in Chap.13. In this section correlations based on the compressive and tensile tests of the circular-hole specimens cut from the impacted plates are compared with the results of the tests of impactdamaged specimens. It is generally assumed that for an equivalent area, hole results provide a lower bound for impact damage results. 


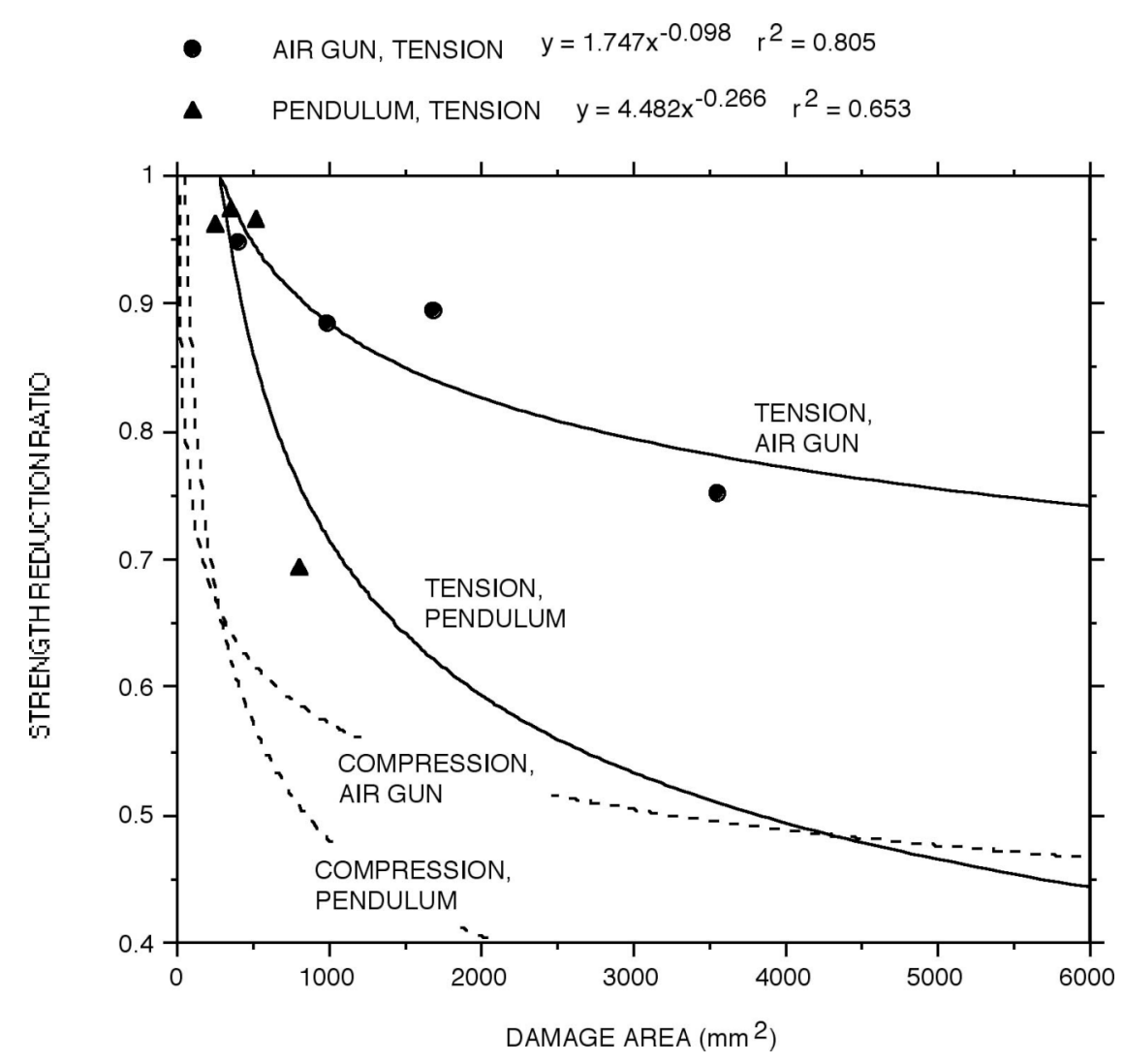

Fig. 12.19. Relative retained tensile strength after impact (solid curves) compared to CAI results (dashed curves). Based on baseline impact tests of as-received specimens.

The comparisons are shown in Figs. 12.20(a) and 12.20(b) for compression and tension respectively. The differences are significant, particularly in the case of tension, where a large portion of the damage areas consists only of matrix damage which has little effect on tensile strength. In the case of the previously tested urethane quasi-isotropic composite, only compressive strength results were obtained. $^{3}$ The strength reduction due to holes was also less than that due to impact damage, but the difference was much less than exhibited in Fig. 12.20(a).

\subsection{SUMMARY AND CONCLUSIONS}

Eighteen pendulum impact tests, simulating quasi-static events such as tool drops, and eighteen air-gun impact tests, simulating kickups of roadway debris, were performed. These included baseline tests of as-received material as well as tests of annealed material and tests of as-received material at a temperature of $-40^{\circ} \mathrm{C}$. Six brick-drop tests were also performed. The impact damage area was correlated with the quantity $\mathrm{m}^{0.465} \mathrm{v}$, where $\mathrm{m}$ is impactor mass in $\mathrm{kg}$ and $\mathrm{v}$ is impactor velocity in $\mathrm{m} / \mathrm{s}$.

Compared with the thermoset urethane/carbon-fiber composite tested previously, the thermoplastic PPS/carbon-fiber composite was more resistant to impact damage. However, it should be remembered that the latter was 2.8 - $\mathrm{mm}$ thick, whereas the former was only 2.2 - $\mathrm{mm}$ thick. 


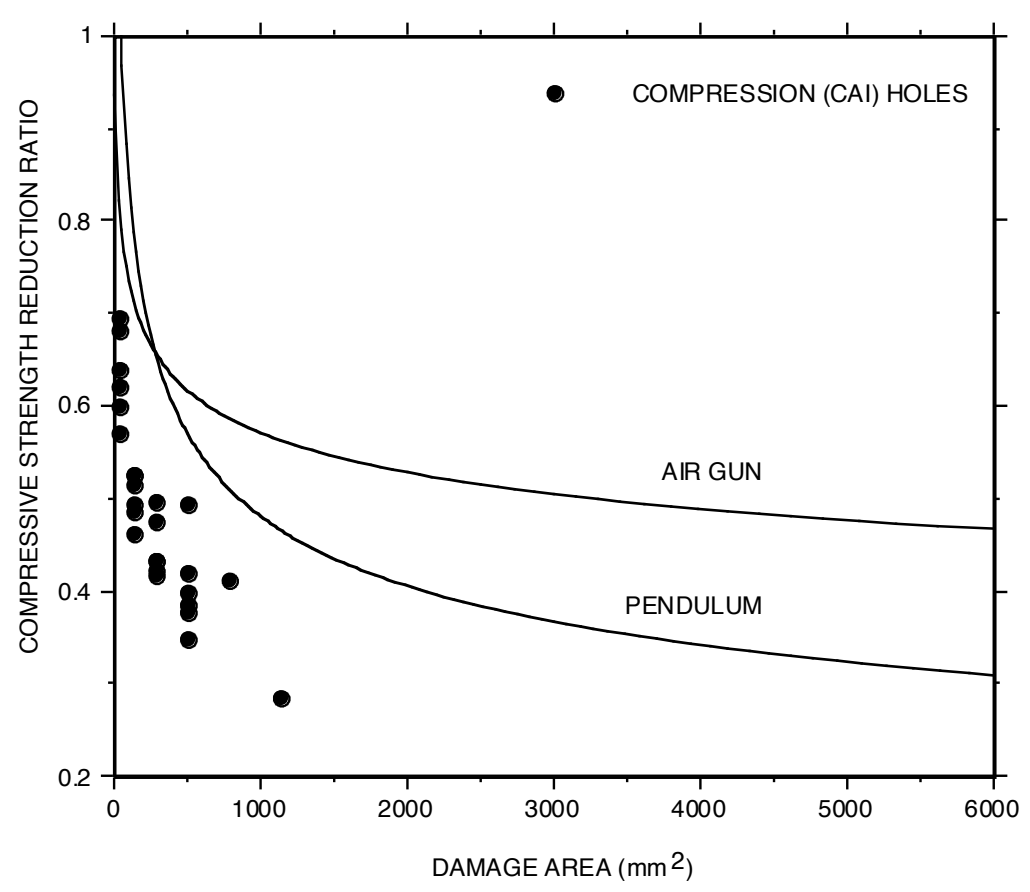

(a) Compressive CAI strength

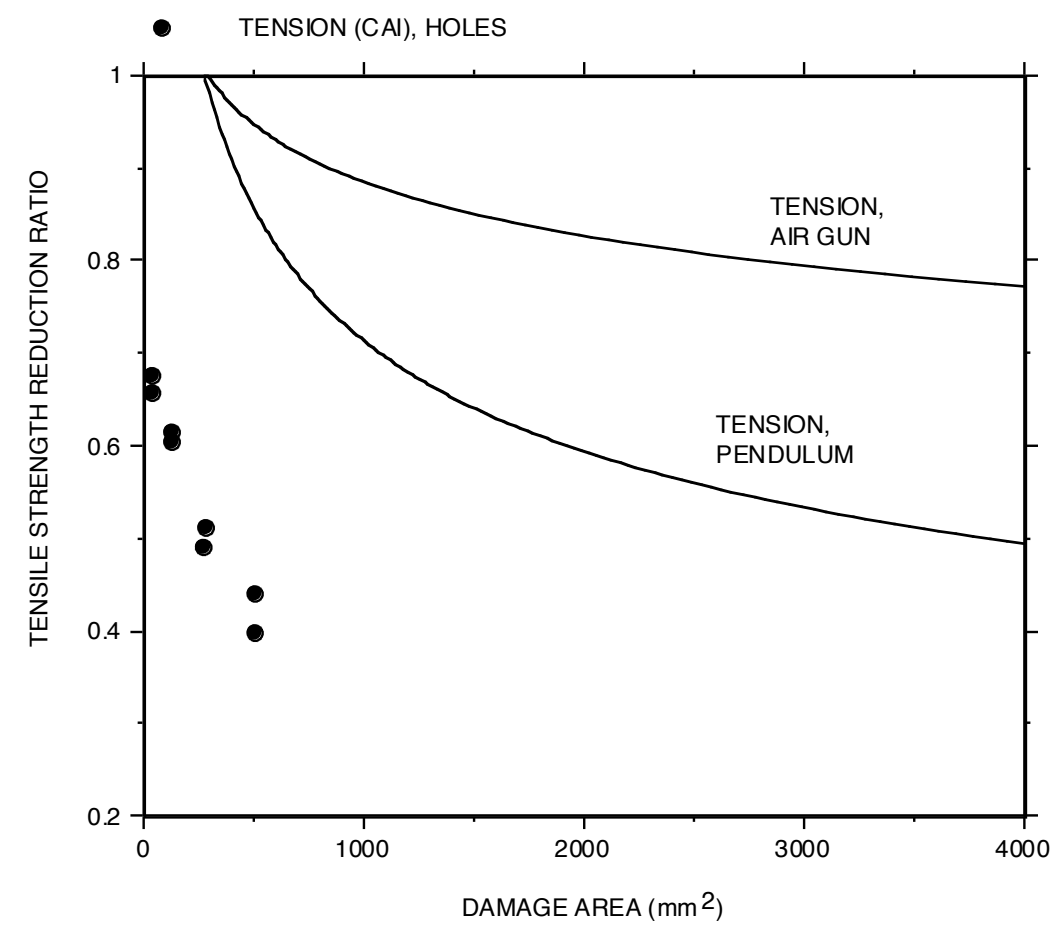

(b) Tensile CAI-type strength

Fig. 12.20. Comparison of relative retained strength for specimens with holes compared to results for specimens with impact damage. All hole data, including those from annealed specimens, are included. 
All of the impact damage data are plotted in Fig. 12.21, where a single upperbound "design" curve is plotted. This is the curve used in Chap. 5 of Part 1 for conservatively estimating damage area. As can be seen from Fig. 12.21, both annealed materials and as-received material testes at $-40^{\circ} \mathrm{C}$ appear to be somewhat less damage resistant than as-received material tested at room temperature. The "design" curve, however, bounds all of the data, including those resulting from brick drops.

Residual strength-after-impact measurements were made to determine damage tolerance. All but two of the impacted plates were cut into strength test specimens. Most were used for compression-afterimpact tests, but some specimens from baseline impact specimens were used for tension-after-impact testing. Undamaged specimens and specimens with circular holes of various sizes were also cut from the impacted plates and tested. The undamaged specimen results were used as references for determining strength reduction ratios.

All of the strength-after-impact data are plotted in Fig. 12.22. In this case, a lower bound "design" curve is shown. This curve was used in Chap. 5 of Part 1 for degradation due to impacts. The strength reductions from air-gun impacts in Fig. 12.22 are generally less than for pendulum impacts. The pronounced difference is thought to be due to the fact that damage areas from the air-gun impacts reflect delaminations having different orientations through the composite thickness. Pendulum impacted specimens did not exhibit this kind of damage. The propensity to delaminate, which affects compressive strength much more than tensile strength, is also believed to be responsible for the fact that compressive strength reduction is significantly greater than tensile strength reduction.

Strength reduction due to holes (both compressive and tensile) is significantly greater than that due to impact damage. This is unlike the differences exhibited by the previous composites tested. Again this is believed to be related to the greater propensity for delaminations to occur in the PPS/carbon-fiber composite.

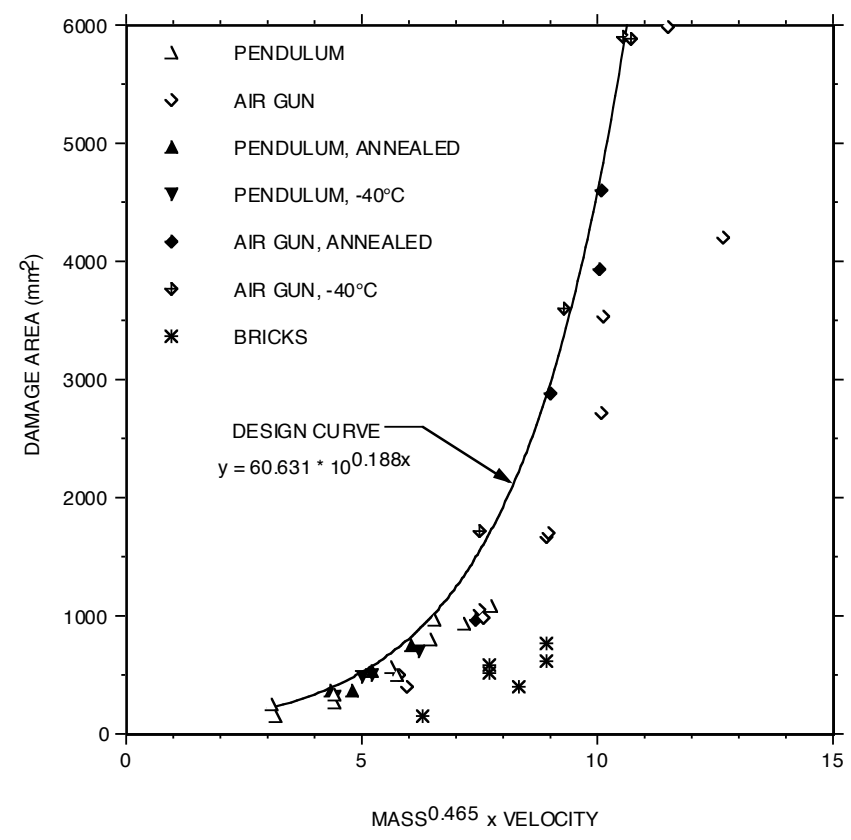

Fig. 12.21. Construction of design curve for conservatively estimating damage from impactor mass and velocity. 


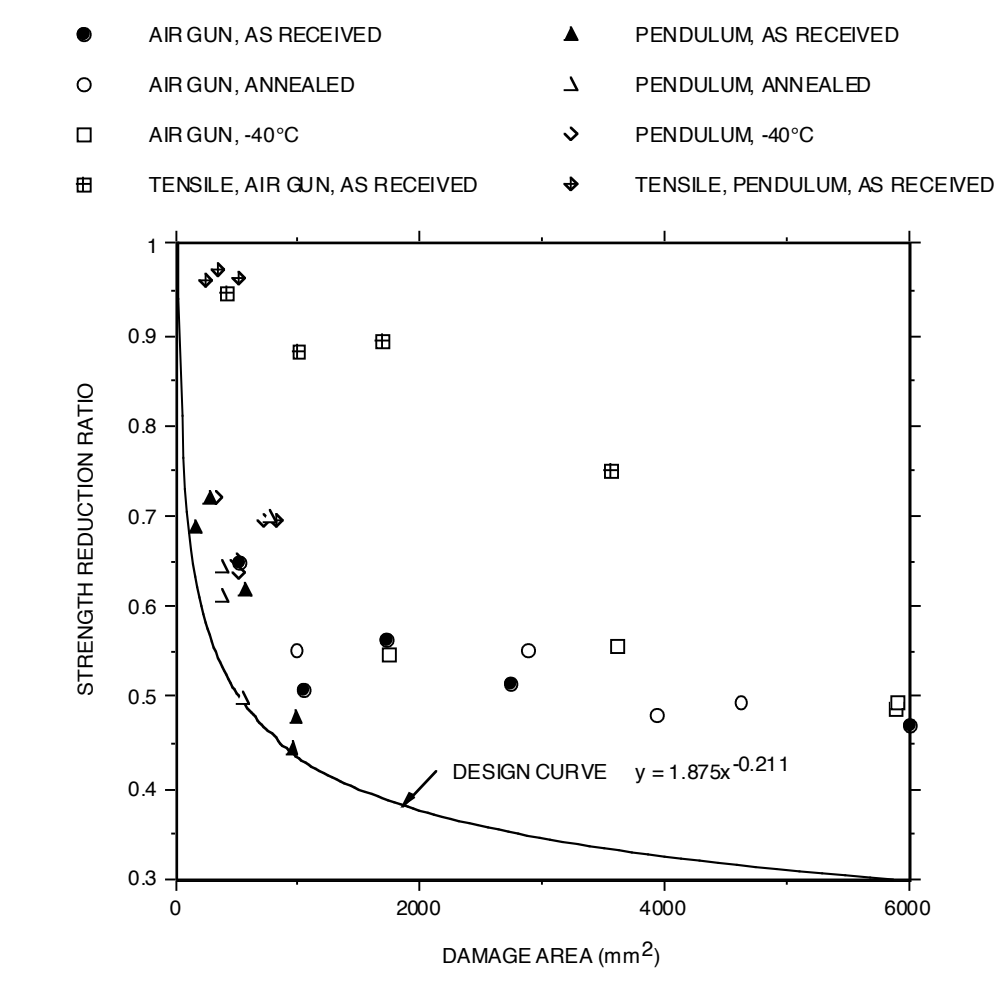

Fig. 12.22. Construction of lower-bound curve for estimating strength degradation due to impact damage.

\subsection{REFERENCES}

1. J. M. Corum, R. L. Battiste, W. Ren, and M. B. Ruggles, Recommended Minimum Test Requirements and Test Methods for Assessing Durability of Random-Glass-Fiber Composites, ORNL6953, Oak Ridge National Laboratory, Oak Ridge, Tenn., June 1999.

2. J. M. Corum, R. L. Battiste, and M. B. Ruggles-Wrenn, "Low-Energy Impact Effects on Candidate Automotive Structural Composites," Composite Science and Technology, 63 (6), 755-769, 2003.

3. J. M. Corum et al., Durability-Based Design Criteria for a Quasi-Isotropic Carbon-Fiber Automotive Composite, ORNL/TM-2002/39, Oak Ridge National Laboratory, Oak Ridge, Tenn., March 2002.

4. J. M. Corum et al., Durability-Based Design Criteria for a Chopped-Carbon-Fiber Automotive Composite, ORNL/TM-2003/86, Oak Ridge National Laboratory, Oak Ridge, Tenn., May 2003.

5. J. M. Corum et al., Durability-Based Design Properties of Reference Crossply Carbon-Fiber Composite, ORNL/TM-2000/322, Oak Ridge National Laboratory, Oak Ridge, Tenn., April 2001.

6. P. Sjöblom and B. Hwang, "Compression-After-Impact: The \$5000 Data Point," 34th International SAMPE Symposium, 1411-1421 (May 1989). 


\section{DAMAGE TOLERANCE - CIRCULAR HOLES AND CRACKS}

\subsection{INTRODUCTION}

Circular holes typify stress concentrations in composites, and they have consequently received wide attention. Several investigators have shown that the length of the discontinuity perpendicular to a stress field, not its shape, is the governing parameter, at least in fiber-dominated lay-ups. ${ }^{1-3}$ Consequently, holes are used to characterize the effects of other discontinuities and flaws in composites. Thus, circular holes play a significant role in the recommended damage tolerance evaluation procedures recommended in Chap. 5 of Part 1.

The study of circular hole effects reported here was motivated by the above and by the fact that automotive structures typically have a multitude of holes. Their effect on structural strength and stiffness must be assessed.

\subsection{BACKGROUND}

Before describing the test program and results, it will be helpful to briefly review the effect of circular holes in composites. Unlike the case for homogeneous materials, the effective stress concentration, and hence gross failure stress, in a composite depends on hole size. The larger the hole, the larger the effective stress concentration; very small holes produce practically no apparent stress concentration. This effect has been described by Whitney and Nuismer ${ }^{1,4}$ with two closely related criteria that are based on the nature of the predicted stress distributions adjacent to large and small holes, as illustrated in Fig. 13.1. In the first approach, it is assumed that failure occurs when the predicted stress over some distance, $d_{o}$, away from the hole is equal to or greater than the UTS. This is referred to as the "point criterion". The second criterion assumes that failure occurs when the average stress over some distance, $a_{0}$, equals the UTS. This is referred to as the "average criterion". The Whitney-Nuismer criteria were successfully used to correlate hole strength reduction results for the quasi-isotropic urethane composite. $^{5}$

Using a fracture mechanics model, where fracture stress depends on flaw size to a power, Mar and $\mathrm{Lin}^{4}$ proposed the following equation for the fracture stress of notched fiber-dominated composites:

$$
\bar{\sigma}_{\infty}=H(2 R)^{-m},
$$

where $\bar{\sigma}_{\infty}$ is the gross stress in an infinitely-wide uniaxially-loaded plate, and $2 \mathrm{R}$ is the notch length or hole diameter. A power-law formulation was found to provide a good correlation for hole strengthreduction results for all of the thermoset/carbon-fiber composites characterized previously in the ORNL Composite Durability project. Consequently, it is used in this chapter, as well as in the previous chapter. 


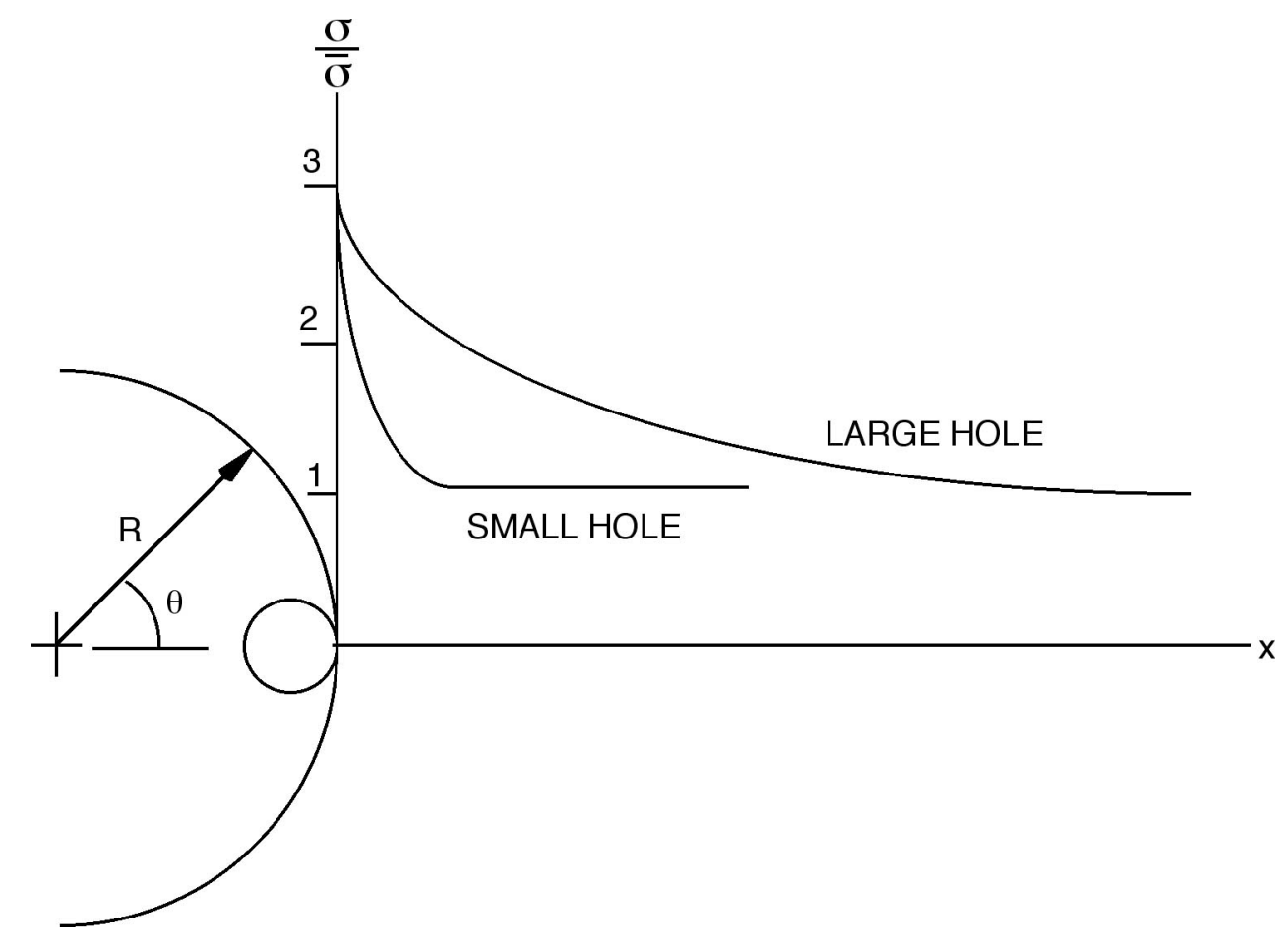

Fig. 13.1. Schematic representation of predicted axial stress distributions at large and small holes in a uniaxially loaded, infinitely wide plate.

\subsection{TEST PROGRAM AND DATA ANALYSIS}

In addition to the tensile and compressive tests of the CAI-type specimens with holes presented in Chap. 12, tensile tests were performed on a second set of hole specimens and on a set of center-cracked specimens.

These various data sets are described below.

- CAI-type hole specimens from impacted plates (Chap. 12)

- 8 tensile (6.4-, 12.7-, 19.1-, and 25.4-mm-diam holes)

- 26 compressive* (6.4-, 12.7-, 19.1-, 25.4-, 31.8-, and 38.1-mm-diam holes)

- 40 unflawed reference specimens from impacted plates

- Tensile study of holes and cracks

- 16 with holes (3.2-, 6.4-, 12.7-, and 19.1-mm-diam holes)

- 16 with cracks (crack lengths same as above hole diameters)

- 16 unflawed reference specimens

The CAI specimens with holes, as well as the corresponding unflawed reference specimens were each slightly less than 76.2-mm wide, and they came from several different plaques. The hole and crack specimens in the tensile study, on the other hand, had various widths, and they came from just two plaques - T32 for the hole specimens and T33 for the crack specimens. The layouts for the specimens are

\footnotetext{
* Total includes tests of specimens from annealed impacted plates and plates impacted at $-40^{\circ} \mathrm{C}$, since no discernible difference was observed between results from these specimens and baseline tests.
} 
shown in Fig. 13.2. From left to right, the nominal specimen widths in each group of specimens were 25.4-, 50.8- 25.4-, 25.4-, 76.2-, and 25.4- $\mathrm{mm}$. While the two unflawed end specimens in each group were nominally $25.4-\mathrm{mm}$ wide, they were dogboned in the test section to a width of $20.3 \mathrm{~mm}$. All of the specimens were 254-mm long.

The smaller holes in the specimens depicted in Fig. 13.2(a) were drilled with carbide bits. The larger holes were cut with titanium-nitrate (TIN) coated carbide burrs. The slits in the specimens depicted in Fig. 13.2(b) were cut using a jeweler's saw having a thickness of just $50-75$ microns. Tiny holes, just large enough to thread the saw blade through, were first drilled at each end of the slit.

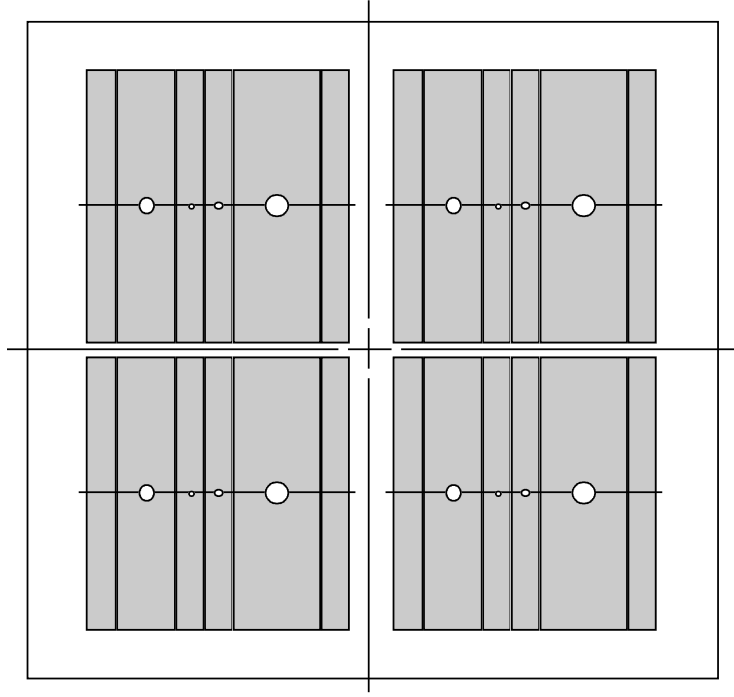

(a)

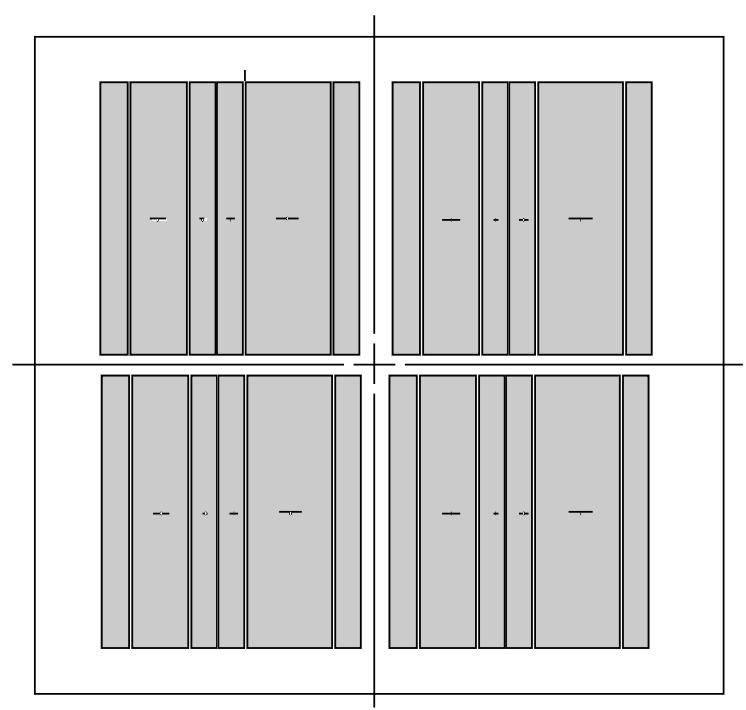

(b)

Fig. 13.2. Layout of tensile specimens for hole and crack studies: (a) holes (plaque T32) and (b) cracks (plaque T33).

To render the results from the various test series more comparable and useful, two adjustments were made to the data. First, the experimentally-obtained gross failure stress (the average stress away from the hole or crack) were converted to an equivalent stress in an infinitely-wide plate. Second, in the case of the tensile holes and cracks, the reference UTS value used as the baseline to determine strength degradation was adjusted to the width of each particular hole specimen. This latter adjustment was made using the width-effect curve, which was presented in Chap. 7 and is repeated here in Fig. 13.3.

While the second of the above adjustments is meant to account for the specimen width effect in this specific PPS/carbon-fiber composite, the first adjustment is strictly a geometric effect determined for a homogeneous, isotropic material. The relations used to determine the gross failure stress in an equivalent infinitely-wide plate are given below. ${ }^{4}$

Holes:

$$
\bar{\sigma}_{\infty}=\frac{1}{3}\left[2+\left(1-\frac{a}{w}\right)^{3}\right] \bar{\sigma} /\left(1-\frac{a}{w}\right) .
$$


Cracks:

$$
\bar{\sigma}_{\infty}=\left[\frac{2 w}{\pi a} \tan \left(1-\frac{\pi a}{2 w}\right)\right]^{1 / 2} \bar{\sigma}
$$

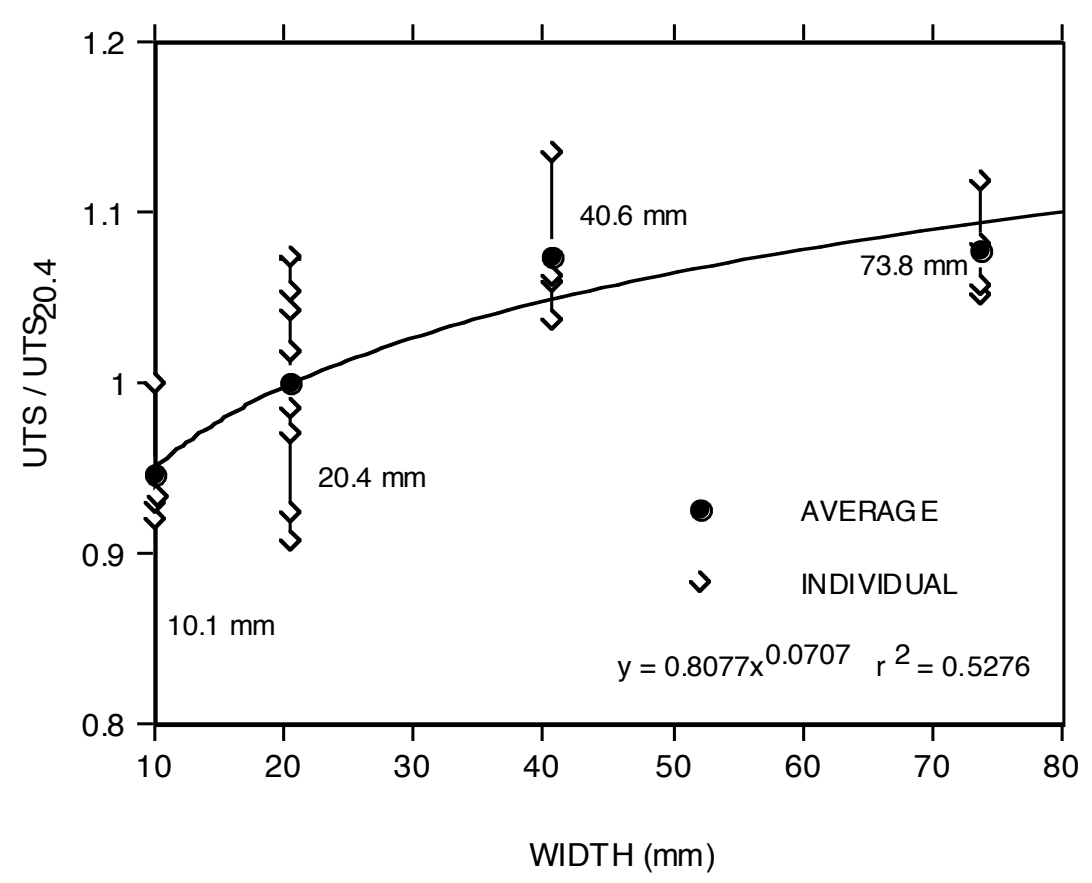

Fig. 13.3. Experimentally determined factor for adjusting UTS to account for specimen width.

In these relations, $\bar{\sigma}$ is the gross stress away from the hole or crack, in the actual finite-width specimen, $\bar{\sigma}_{\infty}$ is the gross stress in an equivalent infinitely-wide plate, $a$ is the hole diameter or crack length, and $w$ is the width of the finite-width specimen. These equations are based on formulas for the stress concentration factor in an elastic, isotropic, homogeneous plate of arbitrary width. Equations (13.1) and (13.2) follow by equating the maximum stress in an infinitely-wide plate to that in the finite-width plate.

\subsection{TEST RESULTS AND CORRELATIONS}

The adjusted results from tensile tests of both the CAI-type hole specimens and the hole specimens from the tensile study described in this chapter are shown in Fig. 13.4, where they are compared with tensile hole test results for the quasi-isotropic urethane/carbon-fiber composite. ${ }^{5}$ The notch strength that is plotted is the gross failure stress in an infinitely-wide plate away from the hole. The results compare well to those from the previously-tested urethane composites. 


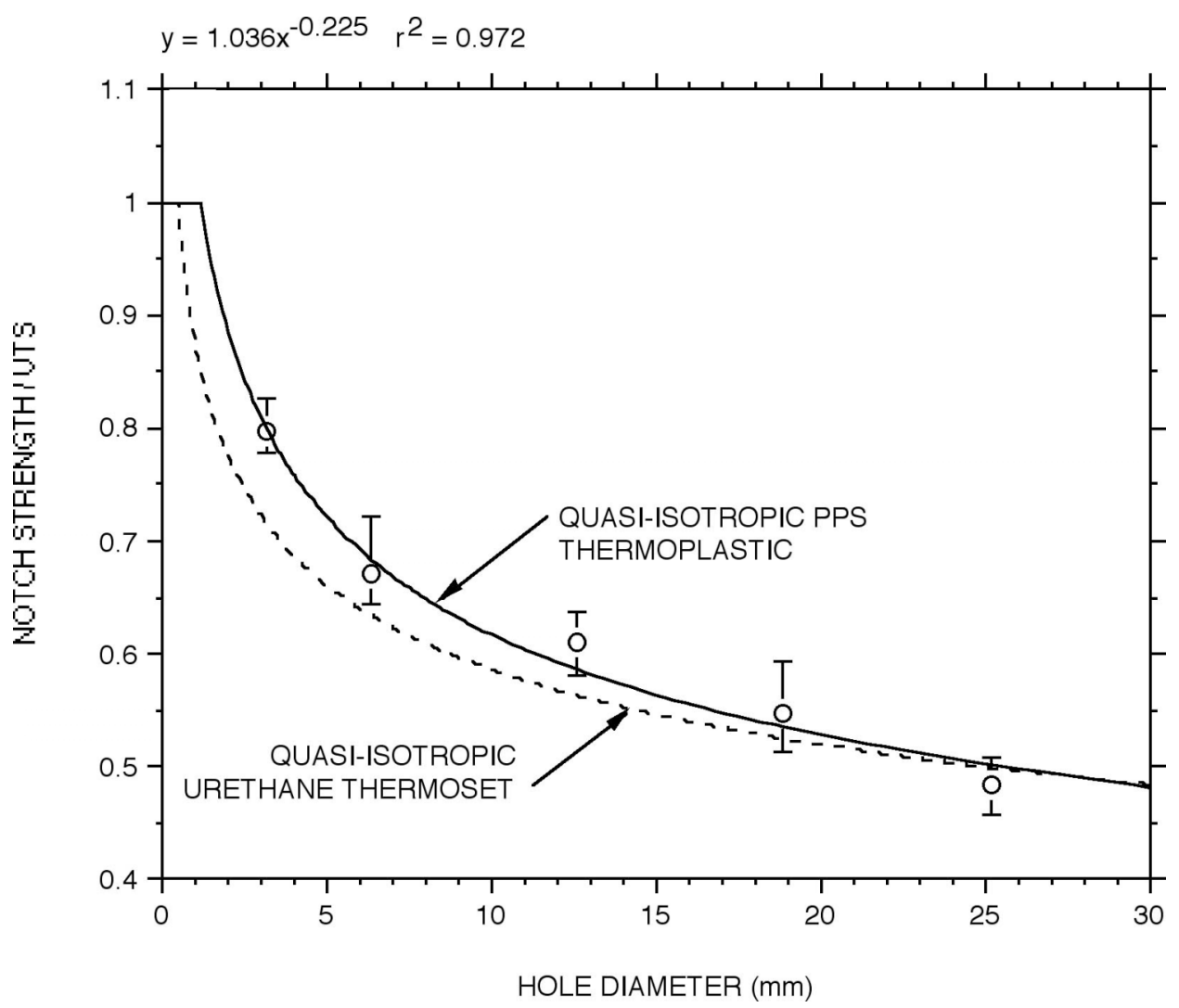

Fig. 13.4. Results of tensile hole study compared to results of similar study on quasi-isotropic urethane composite. Vertical bars represent the range of data points (at least six points for each diameter). Results have been converted to an infinitely-wide plate in both cases.

Strength results from the tensile tests of cracked specimens are compared in Fig. 13.5 with the correlation for the hole specimens from Fig. 13.4. The effect of cracks is very similar to that of holes, which is in agreement with the usual assumption, discussed earlier. These results, and the power-law correlations, tend to confirm the adequacy of the fracture-mechanics-type relation proposed by Mar and Lin [Eq. (13.1)].

Finally, the compressive results from tests of the CAI-type hole specimens are compared in Fig. 13.6 with the tensile hole correlation from Fig. 13.4. Holes appear to be only slightly more damaging in compression than in tension. This is in marked contrast to the tensile and compressive strength reductions presented in Chap. 12 for impact-damaged specimens. There, because of the nature of the damage-central area of both matrix damage and fiber breakage and surrounding area of only matrix damage-the compressive results show a significantly greater strength loss than do the tensile results. This is because only the central portion of the measured damage area affects tensile strength while the full area affects compressive strength. In the case of holes, this difference in the nature of the damage does not exist. 


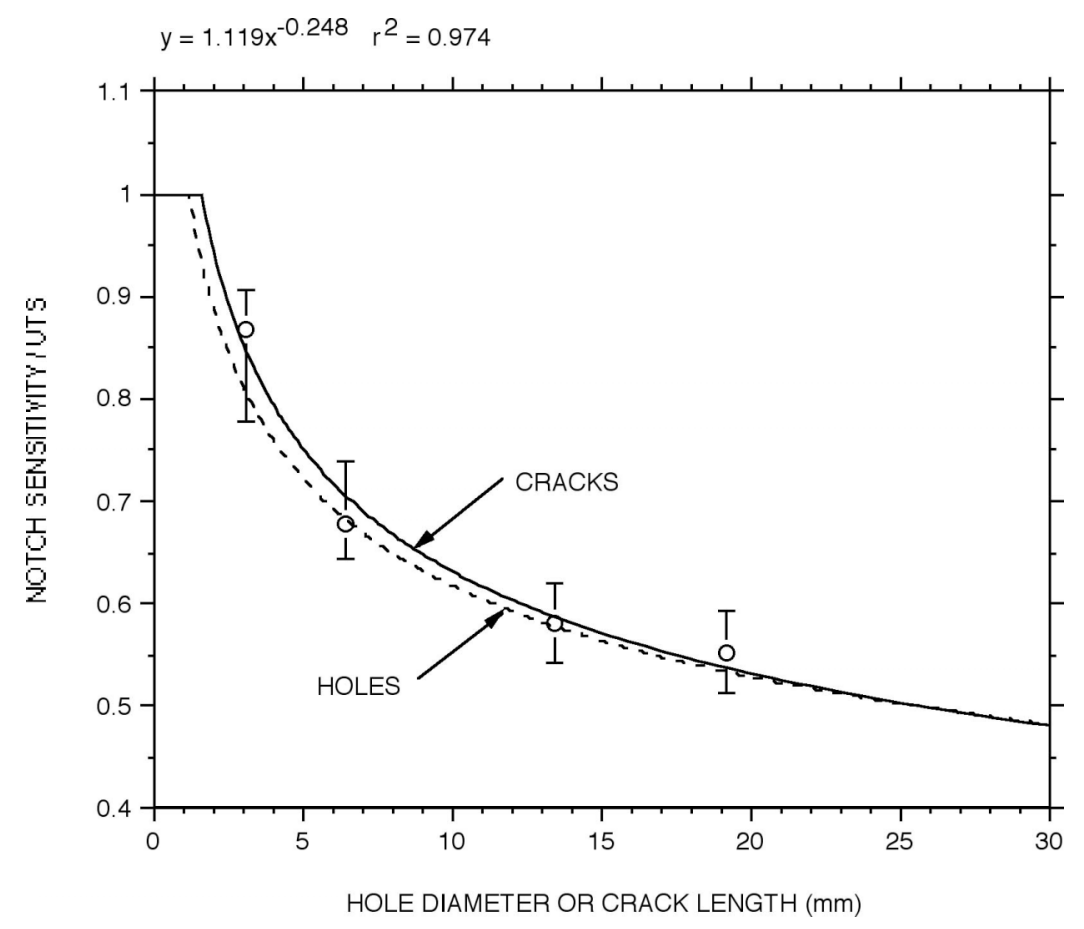

Fig. 13.5. Comparison of the effect of cracks on tensile strength degradation to that of holes.

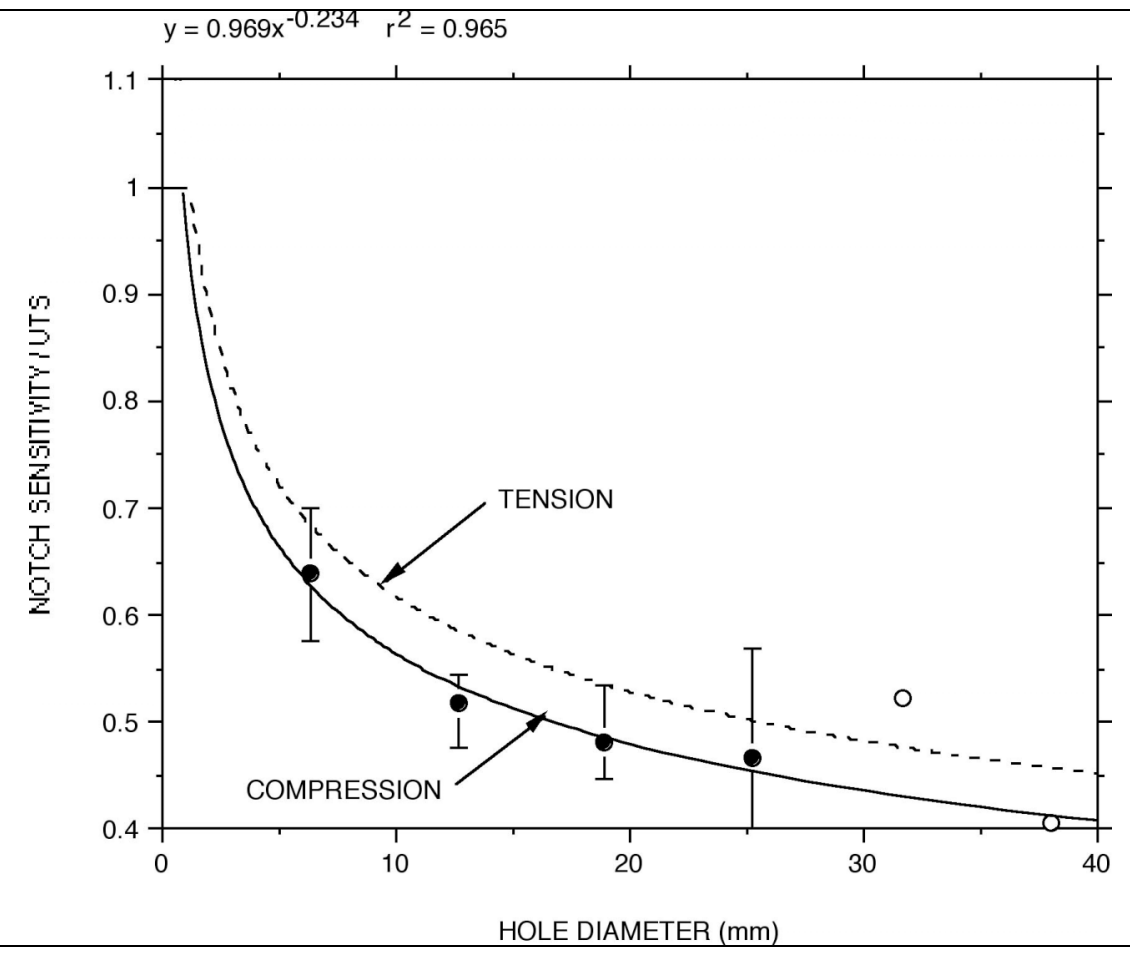

Fig. 13.6. Comparison of tensile hole results (from Fig. 13.4) with CAI-type compressive hole results (from Chap. 12). There are six CAI-type compressive data points for each diameter except the two largest ones, where there is just one data point each. These latter two data points were not used in developing the compressive correlation. 


\subsection{SUMMARY AND CONCLUSIONS}

A total of 66 tensile and compressive strength tests (plus 56 associated reference tests of unflawed specimens) was performed to study the effects of defects in the quasi-isotropic PPS/carbon-fiber composite. Tensile and compressive tests specimens with holes and tensile tests of specimens with lateral cracks were included.

The data from these tests were well behaved and were consistent with the usual assumptions made for continuous-fiber composites and with the fracture-mechanics-type relationship proposed by Mar and Lin.

- The CAI-type tensile hole results presented in Chap. 12 and the tensile hole study results presented in this chapter form a relatively tight band and resulted in a good correlation.

- The tensile hole results compared well to those of a similar study on a quasi-isotropic urethane thermoset composite.

- The tensile strength reduction correlations for holes and lateral cracks agree closely, confirming that it is the length of a discontinuity perpendicular to the stress field and not its shape, that governs the failure stress.

- For a given hole size, compressive strength reduction was slightly greater than tensile strength reduction.

As a consequence of these conclusions, the compressive strength reduction curve is used in Chap 5 of Part 1 as a lower-bound curve for assessing flaws in the quasi-isotropic PPS/carbon-fiber composite.

\subsection{REFERENCES}

1. J. M. Whitney and R. J. Nuismer, "Stress Fracture Criteria for Laminated Composites Containing Stress Concentrations," J. Composite Materials, 8, 253-265 (1974).

2. J. W. Mar and K. Y. Lin, "Fracture of Boron/Aluminum Composites with Discontinuities," J. Composite Materials, 11, 405-421 (1977).

3. G. Caprino, "On the Prediction of Residual Strength of Notched Laminates," J. Materials Science, 18, 2269-2273 (1983).

4. R. J. Nuismer and J. M. Whitney, "Uniaxial Failure of Composite Laminates Containing Stress Concentrations," Fracture Mechanics of Composites," ASTM STP 593, ed. J. M. Whitney, American Society for Testing and Materials, 1975, pp. 117-142.

5. J. M. Corum et al., Durability-Based Design Criteria for a Quasi-Isotropic Carbon-Fiber Automotive Composite, ORNL/TM-2002/39, Oak Ridge National Laboratory, Oak Ridge, Tenn., March 2002. 
13-8 
Appendix A

Summary of Plaque Specimen Distribution 

Appendix A: Summary of Plaque Specimen Distribution

\begin{tabular}{|c|c|c|c|c|c|c|c|c|c|c|c|c|c|c|c|c|c|c|c|c|c|c|c|c|c|c|c|}
\hline \multirow{4}{*}{$\begin{array}{c}\text { Plaque } \\
\text { Designation }\end{array}$} & \multicolumn{27}{|c|}{ Specimen Type and Number } \\
\hline & \multicolumn{4}{|c|}{ Tension } & \multicolumn{4}{|c|}{ Compression } & \multicolumn{4}{|c|}{ Shear } & \multicolumn{2}{|c|}{ Flexure } & \multicolumn{2}{|c|}{ Beam } & \multicolumn{9}{|c|}{ Width } & \multirow[t]{2}{*}{ Impact } & \multirow[t]{2}{*}{ Biaxial } \\
\hline & & Orien & tion & & & Orien & ation & & & Orien & ation & & & & & & & & & & & & 22 & & & & \\
\hline & $0^{\circ}$ & $22.5^{\circ}$ & $45^{\circ}$ & $90^{\circ}$ & $0^{\circ}$ & $22.5^{\circ}$ & $45^{\circ}$ & $90^{\circ}$ & $0^{\circ}$ & $22.5^{\circ}$ & $45^{\circ}$ & $90^{\circ}$ & $0^{\circ}$ & $90^{\circ}$ & $0^{\circ}$ & $90^{\circ}$ & 10.2 & 20.3 & 40.6 & 73. & & 10.2 & 20.3 & 40.6 & 73.7 & & \\
\hline $\mathrm{T} 1$ & 3 & & & & & & & & 6 & 6 & 6 & 6 & & & & & & & & & & & & & & 4 & \\
\hline $\mathrm{T} 2$ & 3 & & & & & & & & 6 & 6 & 6 & 6 & & & & & & & & & & & & & & 4 & \\
\hline $\mathrm{T} 3$ & 6 & & & & & & & & & & & & & & 12 & 11 & & & & & & 4 & 4 & 4 & 4 & & \\
\hline $\mathrm{T} 4$ & 6 & & & & 29 & & & & & & & & & & & & 4 & 4 & 4 & 4 & & & & & & & \\
\hline T6 & 7 & & & 7 & 6 & & & 7 & 6 & & & 6 & & & & & & & & & & & & & & 2 & \\
\hline $\mathrm{T} 7$ & 3 & & & & & & & & 6 & 6 & 6 & 6 & & & & & & & & & & & & & & 4 & \\
\hline $\mathrm{T} 8$ & 4 & & & & 32 & 30 & & & & & & & & & & & & & & & & & & & & & \\
\hline T9 & 6 & 30 & & & & & & & & & & & 45 & & & & & & & & & & & & & & \\
\hline T10 & 52 & & & & & & & & & & & & & & & & & & & & & & & & & & \\
\hline T11 & 7 & 6 & 6 & 6 & 7 & 6 & 6 & 8 & & & & & & & & & & & & & & & & & & & \\
\hline T14 & 7 & & & & 7 & 7 & 7 & 7 & & & & & & & & & & & & & & & & & & 2 & \\
\hline T16 & 4 & & & & 30 & & & & 6 & & & & & & & & & & & & & & & & & 2 & \\
\hline T17 & 30 & & & & & & & & 30 & & & & & & & & & & & & & & & & & & \\
\hline T18 & 51 & & & & & & & & & & & & & & & & & & & & & & & & & & \\
\hline T19 (Annealed) & 30 & & & & & & & & 30 & 32 & & & & & & & & & & & & & & & & & \\
\hline T21 (Annealed) & 10 & 30 & & 7 & & & & & & & & & & & & & & & & & & & & & & & \\
\hline $\mathrm{T} 22$ & 7 & & & 7 & 6 & & & 7 & 6 & & & 6 & & & & & & & & & & & & & & 2 & \\
\hline $\mathrm{T} 23$ & 51 & & & & & & & & & & & & & & & & & & & & & & & & & & \\
\hline $\mathrm{T} 24$ & 51 & & & & & & & & & & & & & & & & & & & & & & & & & & \\
\hline T26 (Annealed) & 7 & & & & 7 & 7 & 7 & 7 & & & & & & & & & & & & & & & & & & 2 & \\
\hline T27 (Annealed) & 7 & 6 & 6 & 5 & & & & & & & & & & & & & & & & & & & & & & 2 & \\
\hline T28 (Annealed) & 3 & & & & & & & & 6 & 6 & 6 & 6 & & & & & & & & & & & & & & 4 & \\
\hline T29 (Annealed) & 4 & & & & 31 & 30 & & & & & & & & & & & & & & & & & & & & & \\
\hline T31 & 51 & & & & & & & & & & & & & & & & & & & & & & & & & & \\
\hline
\end{tabular}


Appendix A: Summary of Plaque Specimen Distribution (Concl'd)

\begin{tabular}{|c|c|c|c|c|c|c|c|c|c|c|c|c|c|c|c|c|c|c|c|c|c|c|c|c|c|c|}
\hline \multirow{4}{*}{$\begin{array}{c}\text { Plaque } \\
\text { Designation }\end{array}$} & \multicolumn{26}{|c|}{ Specimen Type and Number } \\
\hline & \multicolumn{4}{|c|}{ Tension } & \multicolumn{4}{|c|}{ Compression } & \multicolumn{4}{|c|}{ Shear } & \multicolumn{2}{|c|}{ Flexure } & \multicolumn{2}{|c|}{ Beam } & \multicolumn{8}{|c|}{ Width } & \multirow[t]{2}{*}{ Impact } & \multirow[t]{2}{*}{ Biaxial } \\
\hline & & Orienta & & & & Orient & & & & Orien & ation & & & & & & & & & & & & & & & \\
\hline & $0^{\circ}$ & $22.5^{\circ}$ & $45^{\circ}$ & $90^{\circ}$ & $0^{\circ}$ & $22.5^{\circ}$ & $45^{\circ}$ & $90^{\circ}$ & $0^{\circ}$ & 22.5 & $45^{\circ}$ & $90^{\circ}$ & $0^{\circ}$ & $90^{\circ}$ & $0^{\circ}$ & $90^{\circ}$ & 10.2 & 20.3 & 40.6 & 73.7 & 10.2 & 20.3 & 40.6 & 73.7 & & \\
\hline T32 & $24^{*}$ & & & & & & & & & & & & & & & & & & & & & & & & & \\
\hline T33 & $24 * *$ & & & & & & & & & & & & & & & & & & & & & & & & & \\
\hline $\mathrm{T} 34$ & 51 & & & & & & & & & & & & & & & & & & & & & & & & & \\
\hline T36 & 51 & & & & & & & & & & & & & & & & & & & & & & & & & \\
\hline T37 & 30 & & & & 33 & & & & & & & & & & & & & & & & & & & & & \\
\hline T38 & 17 & & & & $51 * * *$ & & & & & & & & & & & & & & & & & & & & & \\
\hline T39 & 51 & & & & & & & & & & & & & & & & & & & & & & & & & \\
\hline T41 & 51 & & & & & & & & & & & & & & & & & & & & & & & & & \\
\hline T42 & 7 & & & 7 & 6 & & & 7 & 6 & & & 6 & & & & & & & & & & & & & 2 & \\
\hline T43 & 7 & & & & & & & & & & & & & & & & & & & & & & & & & 26 \\
\hline T44 & 51 & & & & & & & & & & & & & & & & & & & & & & & & & \\
\hline T46 & 19 & & & & & & & & & & & & 150 & & & & & & & & & & & & & \\
\hline T47 & 51 & & & & & & & & & & & & & & & & & & & & & & & & & \\
\hline T48 & 26 & & & & & & & & 35 & & & & & & 6 & 5 & & & & & & & & & & \\
\hline T49 & 3 & & & 3 & & & & & & & & & 48 & 10 & 4 & 3 & & & & & & & & & 3 & \\
\hline T51 & 3 & & & & 16 & & & & & & & & & & & & & & & & & & & & 4 & \\
\hline T52 & 15 & & & & 15 & & & & 15 & & & & & & & & & & & & & & & & 2 & \\
\hline T53 & 3 & & & & & & & & & & & & & & & & & & & & & & & & 4 & \\
\hline $\begin{array}{c}\text { Total } \\
\text { Number } \\
\text { Specimens }\end{array}$ & 894 & 72 & 12 & 42 & 276 & 80 & 20 & 43 & 158 & 56 & 24 & 42 & 243 & 10 & 22 & 19 & 4 & 4 & 4 & 4 & 4 & 4 & 4 & 4 & 43 & 26 \\
\hline
\end{tabular}

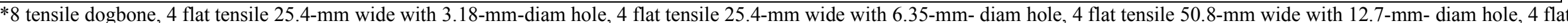
tensile 76.2-mm wide with 19.1-mm- diam hole.

**8 tensile dogbone, 4 flat tensile 25.4 -mm wide with 3.18-mm-long slit, 4 flat tensile 25.4 -mm wide with 6.35 -mm-long slit, 4 flat tensile 50.8 -mm wide with 12.7 -mm-long slit, 4 flat tensile 76.2-mm wide with 19.1-mm-long slit.

***Hourglass specimens for fatigue tests to investigate mean-stress effects. 


\section{Appendix B}

Summary of Baseline Test Results: As-Received Material 



\section{Appendix B： Summary of Baseline Tensile Test Results: As-Received Material}

\begin{tabular}{|c|c|c|c|c|c|c|c|c|}
\hline $\begin{array}{l}\text { Plaque } \\
\text { Number }\end{array}$ & $\begin{array}{c}\text { Number } \\
\text { Tests }\end{array}$ & $\begin{array}{c}\text { UTSavg } \\
(\mathrm{MPa})\end{array}$ & $\begin{array}{c}\text { UTSmin } \\
(\mathrm{MPa})\end{array}$ & $\begin{array}{c}\text { UTSmax } \\
(\mathrm{MPa})\end{array}$ & $\begin{array}{l}\text { Eavg } \\
(\mathrm{MPa})\end{array}$ & $\begin{array}{l}\text { Emin } \\
(\mathrm{GPa})\end{array}$ & $\begin{array}{l}\text { Emax } \\
(\mathrm{GPa})\end{array}$ & $\begin{array}{c}\text { Failure } \\
\text { Strain, } \\
\%\end{array}$ \\
\hline T1 & 3 & 534 & 525 & 541 & 37.52 & 37.17 & 37.85 & 1.424 \\
\hline $\mathrm{T} 2$ & 3 & 522 & 497 & 543 & 37.88 & 37.85 & 37.93 & 1.370 \\
\hline $\mathrm{T} 3$ & 6 & 504 & 479 & 546 & 35.13 & 32.85 & 36.80 & 1.447 \\
\hline $\mathrm{T} 4$ & 6 & 516 & 473 & 559 & 36.29 & 32.34 & 37.95 & 1.400 \\
\hline T6 & 6 & 537 & 517 & 550 & 37.53 & 37.09 & 38.68 & 1.432 \\
\hline $\mathrm{T} 7$ & 3 & 533 & 516 & 548 & 37.87 & 37.82 & 37.95 & 1.426 \\
\hline $\mathrm{T} 8$ & 4 & 538 & 503 & 558 & 35.47 & 32.47 & 37.25 & 1.486 \\
\hline T9 & 6 & 537 & 500 & 554 & 36.55 & 32.97 & 38.14 & 1.462 \\
\hline T10 & 8 & 527 & 488 & 553 & 36.42 & 31.54 & 38.45 & 1.450 \\
\hline T11 & 7 & 546 & 521 & 571 & 37.31 & 34.08 & 38.36 & 1.460 \\
\hline T14 & 7 & 546 & 483 & 586 & 38.66 & 37.72 & 39.78 & 1.420 \\
\hline T16 & 4 & 497 & 481 & 509 & 37.77 & 36.89 & 38.80 & 1.332 \\
\hline T17 & 6 & 506 & 495 & 519 & 36.84 & 36.60 & 37.16 & 1.401 \\
\hline T18 & 4 & 504 & 496 & 516 & 37.76 & 37.05 & 38.58 & 1.575 \\
\hline T22 & 6 & 511 & 498 & 527 & 36.74 & 35.34 & 37.52 & 1.436 \\
\hline $\mathrm{T} 23$ & 6 & 515 & 500 & 528 & 37.54 & 36.23 & 38.62 & 1.376 \\
\hline $\mathrm{T} 24$ & 6 & 512 & 481 & 540 & 36.91 & 34.69 & 38.58 & 1.421 \\
\hline T31 & 10 & 589 & 538 & 606 & 35.13 & 32.20 & 36.61 & 1.751 \\
\hline T32 & 8 & 595 & 558 & 624 & 34.59 & 31.23 & 36.27 & 1.746 \\
\hline $\mathrm{T} 33$ & 8 & 606 & 556 & 645 & 34.76 & 30.69 & 36.62 & 1.798 \\
\hline T34 & 11 & 616 & 565 & 654 & 36.48 & 35.44 & 37.37 & 1.670 \\
\hline T36 & 6 & 594 & 559 & 616 & 35.30 & 34.40 & 35.51 & 1.727 \\
\hline T37 & 6 & 606 & 581 & 634 & 34.97 & 32.78 & 35.98 & 1.760 \\
\hline T38 & 5 & 612 & 591 & 638 & 35.36 & 34.13 & 36.68 & 1.771 \\
\hline T39 & 6 & 600 & 566 & 633 & 36.13 & 35.36 & 37.07 & 1.666 \\
\hline T41 & 6 & 575 & 535 & 599 & 34.93 & 34.39 & 35.58 & 1.714 \\
\hline T42 & 6 & 523 & 486 & 549 & 36.78 & 34.77 & 37.79 & 1.419 \\
\hline T43 & 7 & 545 & 520 & 565 & 37.34 & 35.67 & 38.33 & 1.423 \\
\hline T44 & 6 & 539 & 513 & 571 & 37.51 & 36.47 & 39.23 & 1.435 \\
\hline T46 & 5 & 541 & 506 & 571 & 36.85 & 36.12 & 37.78 & 1.434 \\
\hline T47 & 8 & 549 & 526 & 558 & 37.12 & 36.28 & 38.50 & 1.456 \\
\hline $\mathrm{T} 48$ & 6 & 566 & 525 & 598 & 36.90 & 36.10 & 38.02 & 1.530 \\
\hline T49 & 3 & 526 & 499 & 547 & 36.02 & 35.47 & 36.87 & 1.453 \\
\hline T51 & 3 & 503 & 501 & 504 & 36.73 & 36.62 & 36.92 & 1.499 \\
\hline T52 & 3 & 520 & 501 & 535 & 36.34 & 35.86 & 36.76 & 1.418 \\
\hline T53 & 3 & 510 & 496 & 527 & 36.29 & 36.20 & 36.35 & 1.471 \\
\hline Tot. Tests & 207 & & & & & & & \\
\hline Overall Avg. & & 551 & & & 36.45 & & & 1.531 \\
\hline Std. Dev. & & 42.10 & & & 1.54 & & & 0.160 \\
\hline $\mathrm{COV}, \%$ & & 7.64 & & & 4.22 & & & 10.45 \\
\hline Overall Min. & & 473 & & & 30.69 & & & 1.276 \\
\hline Overall Max. & & 654 & & & 39.78 & & & 1.943 \\
\hline
\end{tabular}





\section{Appendix B: Summary of Baseline Compressive Test Results: As-Received Material}

\begin{tabular}{|c|c|c|c|c|c|c|c|c|}
\hline $\begin{array}{c}\text { Plaque } \\
\text { Number }\end{array}$ & $\begin{array}{c}\text { Number } \\
\text { Tests* }\end{array}$ & $\begin{array}{c}\text { UCSavg } \\
(\mathrm{MPa})\end{array}$ & $\begin{array}{c}\text { UCSmin } \\
(\mathrm{MPa})\end{array}$ & $\begin{array}{c}\text { UCSmax } \\
(\mathrm{MPa})\end{array}$ & $\begin{array}{c}\text { Eavg } \\
(\mathrm{MPa})\end{array}$ & $\begin{array}{c}\text { Emin } \\
(\mathrm{GPa})\end{array}$ & $\begin{array}{c}\text { Emax } \\
(\mathrm{GPa})\end{array}$ & $\begin{array}{c}\text { Failure } \\
\text { Strain, } \\
\%\end{array}$ \\
\hline T4 & 5 & 295 & 286 & 303 & 34.21 & 31.22 & 35.56 & 0.947 \\
\hline T6 & 6 & 320 & 292 & 349 & 35.57 & 33.98 & 36.91 & 0.990 \\
\hline T8 & 5 & 254 & 233 & 304 & 34.94 & 33.03 & 36.75 & 0.804 \\
\hline T11 & 6 & 254 & 197 & 338 & 33.82 & 31.88 & 35.32 & 0.828 \\
\hline T16 & 6 & 303 & 294 & 312 & 33.49 & 32.48 & 35.04 & 1.0201 \\
\hline T22 & 6 & 301 & 271 & 334 & 35.65 & 32.91 & 37.19 & 0.928 \\
\hline T37 & 6 & 301 & 249 & 350 & 33.23 & 32.05 & 34.25 & 1.008 \\
\hline T42 & 6 & 321 & 288 & 336 & 34.73 & 33.76 & 34.91 & 1.016 \\
\hline T51 & 4 & 323 & 287 & 351 & 34.64 & 33.83 & 35.64 & 1.050 \\
\hline T52 & 6 & 287 & 266 & 304 & 32.65 & 30.98 & 33.97 & 0.940 \\
\hline Tot. Tests & 56 & & & & & & & \\
\hline Overall Avg. & & 295 & & & 34.26 & & & 0.950 \\
\hline Std. Dev. & & 37.27 & & & 1.50 & & & 0.13 \\
\hline COV, \% & & 12.63 & & & 4.38 & & & 13.47 \\
\hline Overall Min. & & 197 & & & 32.65 & & & 0.712 \\
\hline Overall Max. & & 350 & & & 33.98 & & & 1.223 \\
\hline
\end{tabular}





\section{Appendix B: Summary of Baseline Shear Test Results: As-Received Material}

\begin{tabular}{|c|c|c|c|c|c|c|c|c|}
\hline $\begin{array}{c}\text { Plaque } \\
\text { Number }\end{array}$ & $\begin{array}{c}\text { Number } \\
\text { Tests }\end{array}$ & $\begin{array}{c}\text { USSavg } \\
(\mathrm{MPa})\end{array}$ & $\begin{array}{c}\text { USSmin } \\
(\mathrm{MPa})\end{array}$ & $\begin{array}{c}\text { USSmax } \\
(\mathrm{MPa})\end{array}$ & $\begin{array}{c}\text { Gavg } \\
(\mathrm{MPa})\end{array}$ & $\begin{array}{c}\text { Gmin } \\
(\mathrm{GPa})\end{array}$ & $\begin{array}{c}\text { Gmax } \\
(\mathrm{GPa})\end{array}$ & $\begin{array}{c}\text { Failure } \\
\text { Strain, } \\
\%\end{array}$ \\
\hline $\mathrm{T} 1$ & 6 & 185 & 176 & 207 & 13.50 & 13.02 & 14.19 & 1.490 \\
\hline T2 & 6 & 202 & 194 & 205 & 13.04 & 12.39 & 13.68 & 1.662 \\
\hline T7 & 6 & 192 & 184 & 206 & 12.94 & 12.08 & 13.92 & 1.531 \\
\hline T17 & 6 & 193 & 184 & 206 & 13.80 & 13.48 & 14.43 & 1.650 \\
\hline T48 & 7 & 192 & 174 & 205 & 13.50 & 13.12 & 15.53 & 1.517 \\
\hline T52 & 3 & 197 & 191 & 201 & 13.27 & 13.07 & 13.42 & 1.661 \\
\hline Tot. Tests & 34 & & & & & & & \\
\hline Overall Avg. & & 193 & & & 13.40 & & & 1.63 \\
\hline Std. Dev. & & 11.05 & & & 0.70 & & & 0.12 \\
\hline COV, \% & & 5.73 & & & 5.22 & & & 7.30 \\
\hline Overall Min. & & 174 & & & 12.08 & & & 1.324 \\
\hline Overall Max. & & 207 & & & 15.53 & & & 1.805 \\
\hline
\end{tabular}



Appendix C

Summary of Baseline Test Results: Annealed Material 


$$
\text { C-2 }
$$




\section{Appendix C Summary of Baseline Tensile Test Results: Annealed Material}

\begin{tabular}{|c|c|c|c|c|c|c|c|c|}
\hline $\begin{array}{c}\text { Plaque } \\
\text { Number }\end{array}$ & $\begin{array}{c}\text { Number } \\
\text { Tests }\end{array}$ & $\begin{array}{c}\text { UTSavg } \\
(\mathrm{MPa})\end{array}$ & $\begin{array}{c}\text { UTSmin } \\
(\mathrm{MPa})\end{array}$ & $\begin{array}{c}\text { UTSmax } \\
(\mathrm{MPa})\end{array}$ & $\begin{array}{c}\text { Eavg } \\
(\mathrm{MPa})\end{array}$ & $\begin{array}{c}\text { Emin } \\
(\mathrm{GPa})\end{array}$ & $\begin{array}{c}\text { Emax } \\
(\mathrm{GPa})\end{array}$ & $\begin{array}{c}\text { Failure } \\
\text { Strain, } \\
\%\end{array}$ \\
\hline T19 & 6 & 514 & 488 & 539 & 36.85 & 36.06 & 38.13 & 1.385 \\
\hline T21 & 4 & 523 & 510 & 545 & 37.07 & 36.52 & 38.04 & 1.366 \\
\hline T26 & 7 & 554 & 512 & 605 & 38.41 & 37.41 & 39.07 & 1.401 \\
\hline T27 & 7 & 545 & 523 & 617 & 37.14 & 35.66 & 39.19 & 1.449 \\
\hline T28 & 3 & 528 & 521 & 533 & 38.51 & 38.25 & 38.62 & 1.340 \\
\hline T29 & 4 & 568 & 521 & 597 & 36.24 & 34.11 & 37.11 & 1.532 \\
\hline Tot. Tests & 31 & & & & & & & \\
\hline Overall Avg. & & 539 & & & 37.38 & & & 1.415 \\
\hline Std. Dev. & & 30.92 & & & 1.15 & & & 0.088 \\
\hline COV, \% & & 5.74 & & & 3.08 & & & 6.22 \\
\hline Overall Min. & & 488 & & & 34.11 & & & 1.237 \\
\hline Overall Max. & & 617 & & & 39.19 & & & 1.585 \\
\hline
\end{tabular}




\section{Appendix C Summary of Baseline Compression Test Results: Annealed Material}

\begin{tabular}{|c|c|c|c|c|c|c|c|c|}
\hline $\begin{array}{c}\text { Plaque } \\
\text { Number }\end{array}$ & $\begin{array}{c}\text { Number } \\
\text { Tests }\end{array}$ & $\begin{array}{c}\text { UCSavg } \\
(\mathrm{MPa})\end{array}$ & $\begin{array}{c}\text { UCSmin } \\
(\mathrm{MPa})\end{array}$ & $\begin{array}{c}\text { UCSmax } \\
(\mathrm{MPa})\end{array}$ & $\begin{array}{c}\text { Eavg } \\
(\mathrm{MPa})\end{array}$ & $\begin{array}{c}\text { Emin } \\
(\mathrm{GPa})\end{array}$ & $\begin{array}{c}\text { Emax } \\
(\mathrm{GPa})\end{array}$ & $\begin{array}{c}\text { Failure } \\
\text { Strain, } \\
\%\end{array}$ \\
\hline T26 & 7 & 305 & 265 & 337 & 34.89 & 33.09 & 36.33 & 0.958 \\
\hline T29 & 6 & 278 & 205 & 341 & 35.33 & 34.61 & 36.47 & 0.871 \\
\hline Tot. Tests & 13 & & & & & & & \\
\hline Overall Avg. & & 292 & & & 35.09 & & & 0.918 \\
\hline Std. Dev. & & 38.32 & & & 0.94 & & & 0.13 \\
\hline COV, \% & & 13.12 & & & 2.68 & & & 14.35 \\
\hline Overall Min. & & 265 & & & 33.09 & & & 0.623 \\
\hline Overall Max. & & 341 & & & 36.47 & & & 1.138 \\
\hline
\end{tabular}




\section{Appendix C Summary of Baseline Shear Test Results: Annealed Material}

\begin{tabular}{|c|c|c|c|c|c|c|c|c|}
\hline $\begin{array}{c}\text { Plaque } \\
\text { Number }\end{array}$ & $\begin{array}{c}\text { Number } \\
\text { Tests }\end{array}$ & $\begin{array}{c}\text { USSavg } \\
(\mathrm{MPa})\end{array}$ & $\begin{array}{c}\text { USSmin } \\
(\mathrm{MPa})\end{array}$ & $\begin{array}{c}\text { USSmax } \\
(\mathrm{MPa})\end{array}$ & $\begin{array}{c}\text { Eavg } \\
(\mathrm{MPa})\end{array}$ & $\begin{array}{c}\text { Emin } \\
(\mathrm{GPa})\end{array}$ & $\begin{array}{c}\text { Emax } \\
(\mathrm{GPa})\end{array}$ & $\begin{array}{c}\text { Failure } \\
\text { Strain, } \\
\%\end{array}$ \\
\hline T19 & 6 & 191 & 180 & 202 & 13.39 & 12.89 & 13.96 & 1.625 \\
\hline T28 & 6 & 201 & 190 & 209 & 13.92 & 13.57 & 14.23 & 1.541 \\
\hline Tot. Tests & 12 & & & & & & & \\
\hline Overall Avg. & & 196 & & & 13.60 & & & 1.590 \\
\hline Std. Dev. & & 9.56 & & & 0.46 & & & 0.18 \\
\hline COV, \% & & 4.88 & & & 3.44 & & & 11.38 \\
\hline Overall Min. & & 180 & & & 12.89 & & & 1.375 \\
\hline Overall Max. & & 209 & & & 14.23 & & & 2.033 \\
\hline
\end{tabular}




\section{Appendix D}

Summary and Comparison of Results for As-Received and Annealed Materials on the Effect of Specimen Orientation on Tensile, Compressive, and Shear Properties*

- Figure 1.3 identifies specimen orientation designation. Annealed material was heated at $230^{\circ} \mathrm{C}$ for two hours in an attempt to increase material crystallinity prior to specimen fabrication. 



\section{Effect of Specimen Orientation on Tensile Properties: As-Received Material}
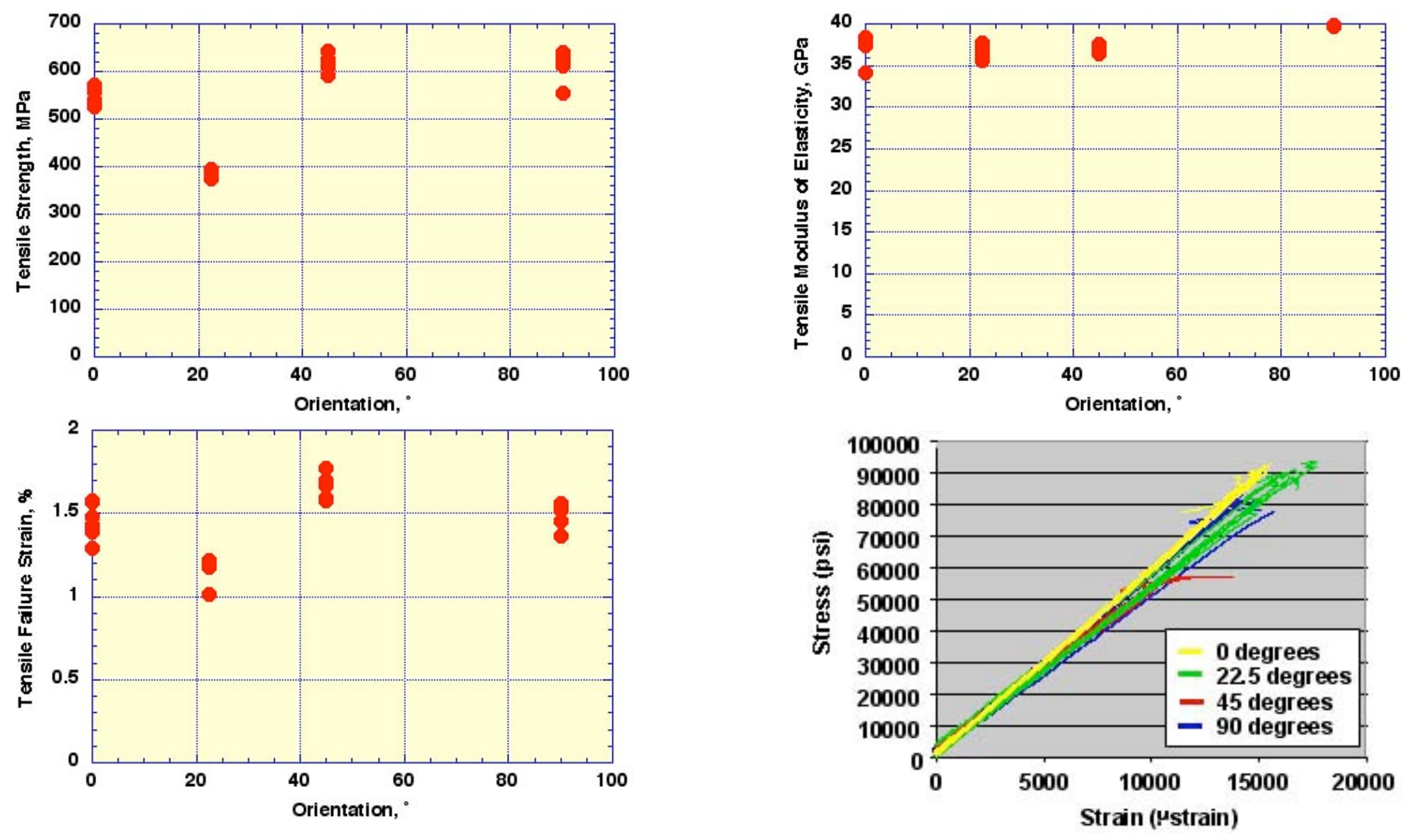


\section{Effect of Specimen Orientation on Tensile Properties: Annealed Material}
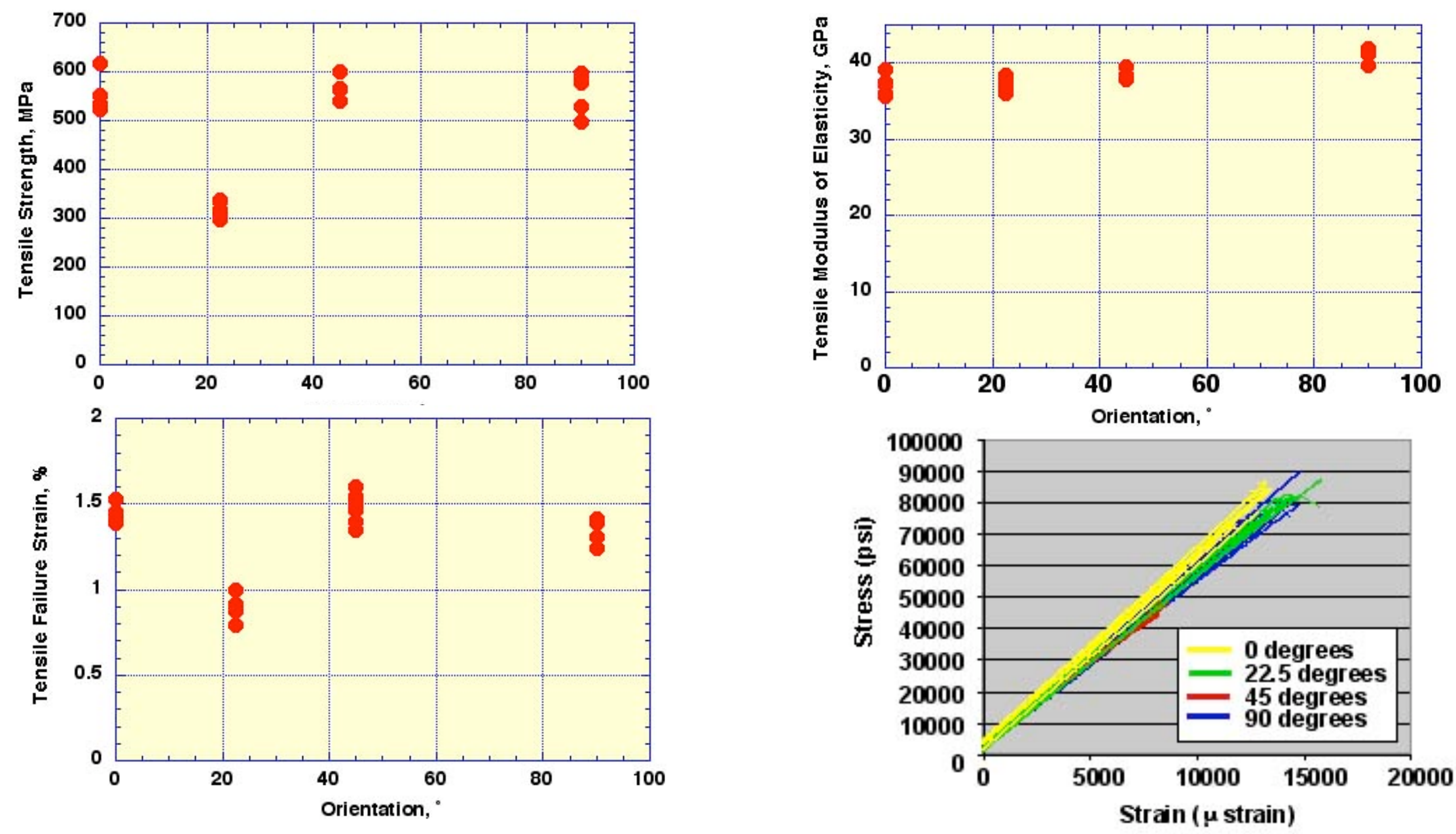


\section{Effect of Specimen Orientation on Tensile Properties: As-Received vs Annealed Material}
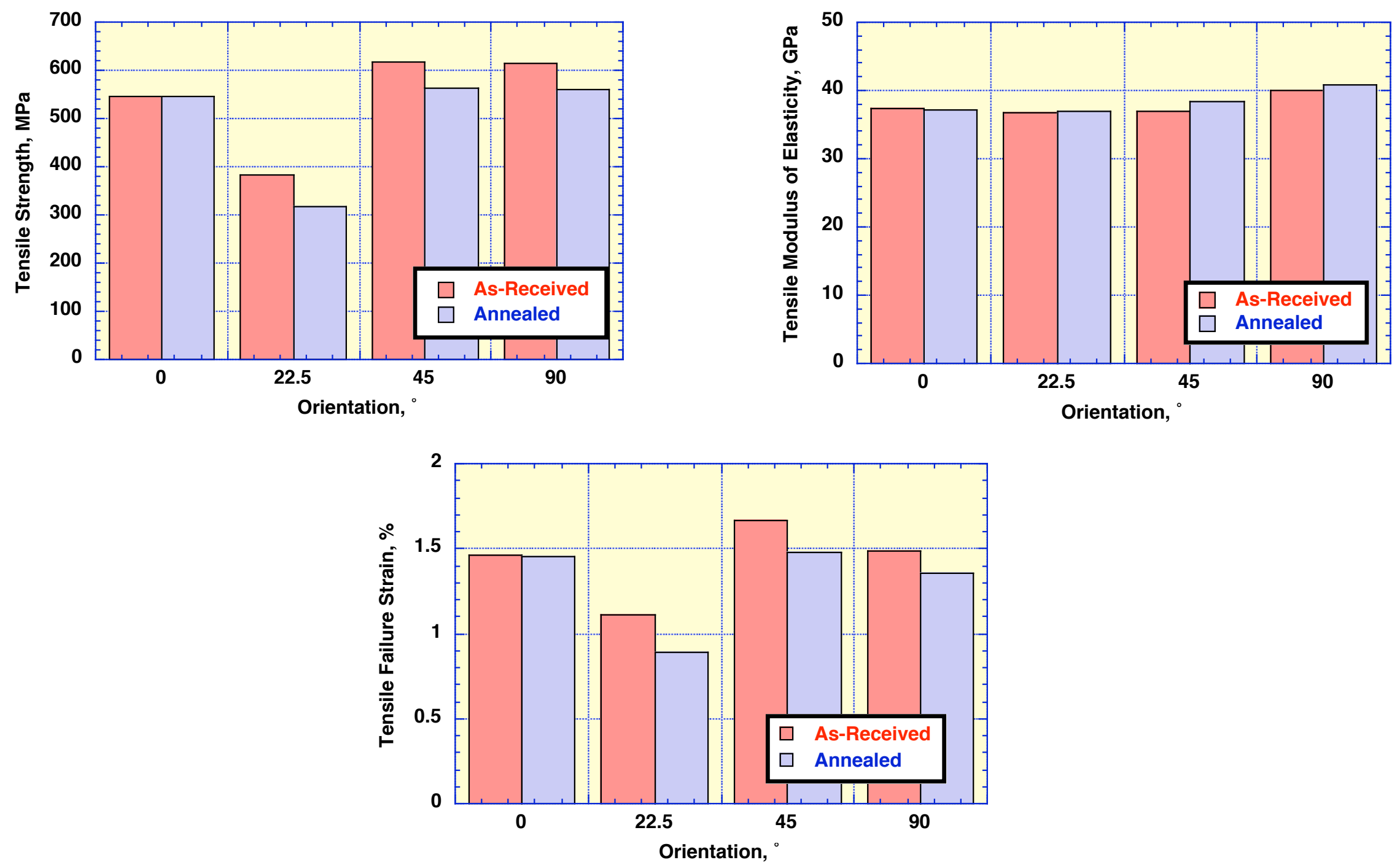


\section{Commentary: Specimen Orientation - Tension Results}

- As-received material

- Tensile strength at $22.5^{\circ}$ orientation was about $30 \%$ less than that at $0^{\circ}$

- Tensile modulus relatively unaffected by orientation

- Tensile failure strain results exhibited similar trend to tensile strength

- Annealed material

- Tensile strength at $22.5^{\circ}$ orientation was about $40 \%$ less than that at $0^{\circ}$

- Tensile modulus relatively unaffected by orientation

- Tensile failure strain results exhibited similar trend to tensile strength

- As-received versus annealed material

- Annealed material tensile strengths were slightly less than as-received material results at orientations other than $0^{\circ}$

- Tensile modulus results similar for as-received and annealed materials and unaffected by specimen orientation

- Tensile failure strains slightly less for annealed material compared to as-received material strains 


\section{Effect of Specimen Orientation on Compressive Properties: As-Received Material}
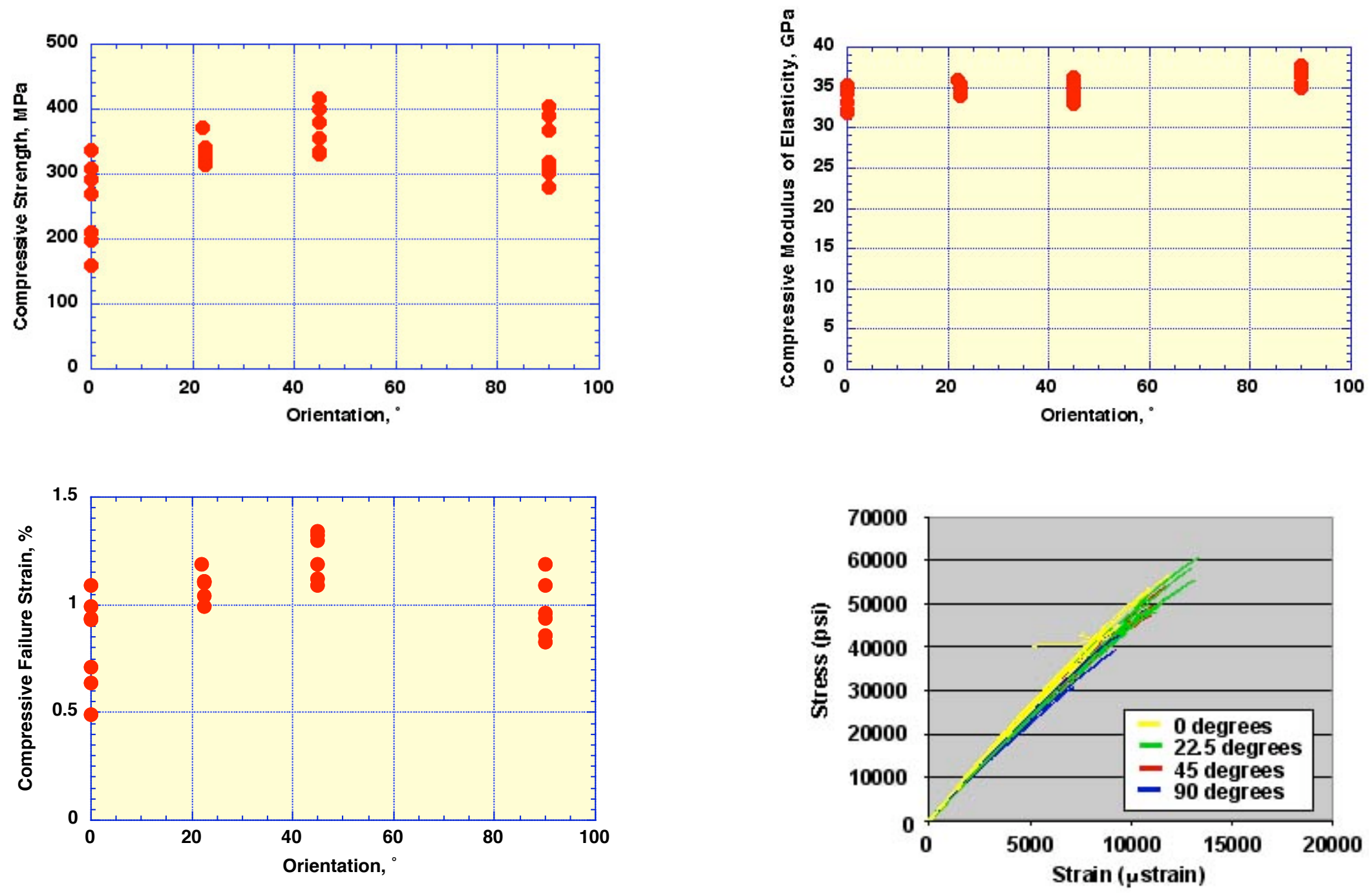


\section{Effect of Specimen Orientation on Compressive Properties: Annealed Material}
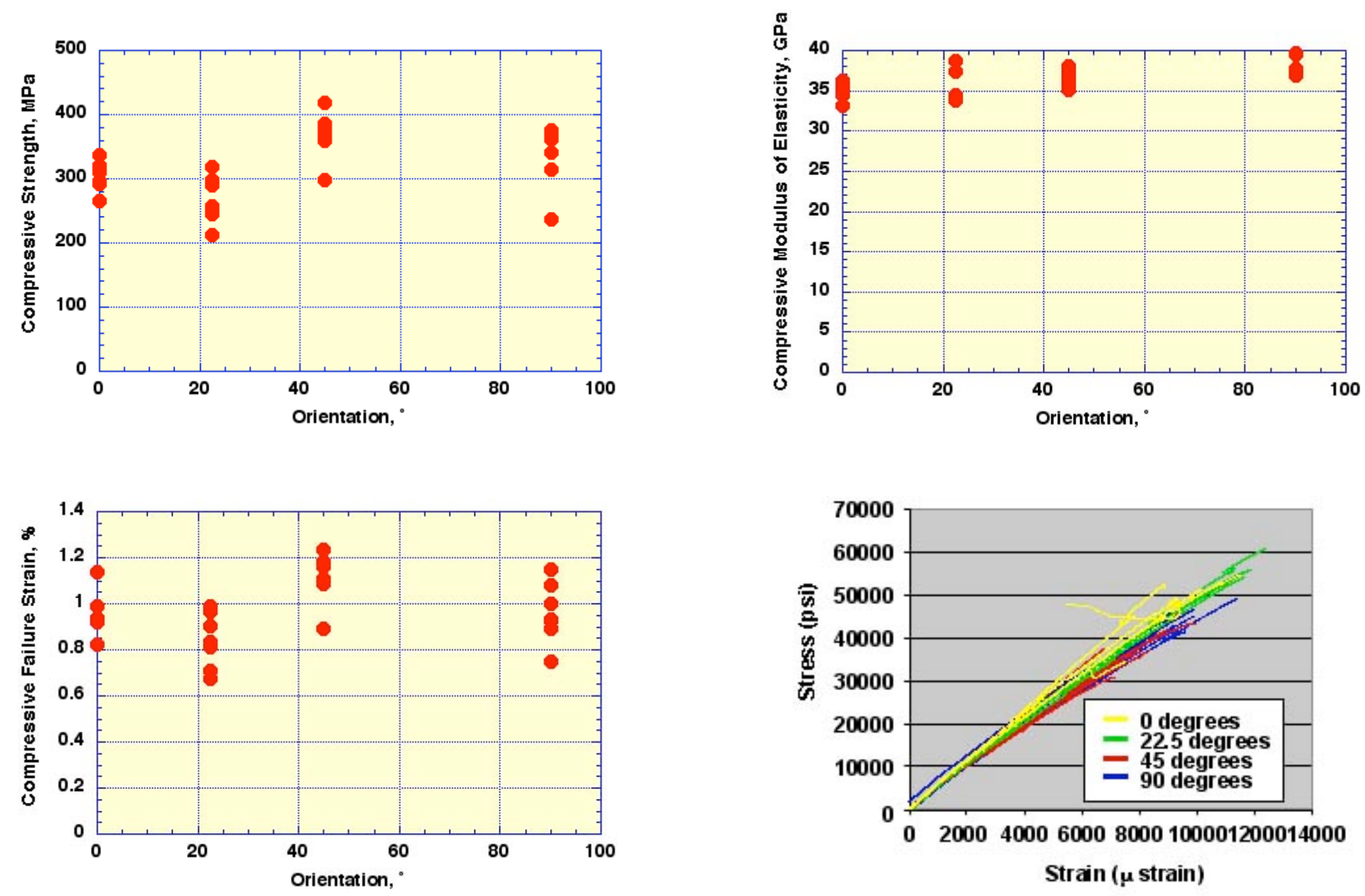


\section{Effect of Specimen Orientation on Compressive Properties: As-Received vs Annealed Material}
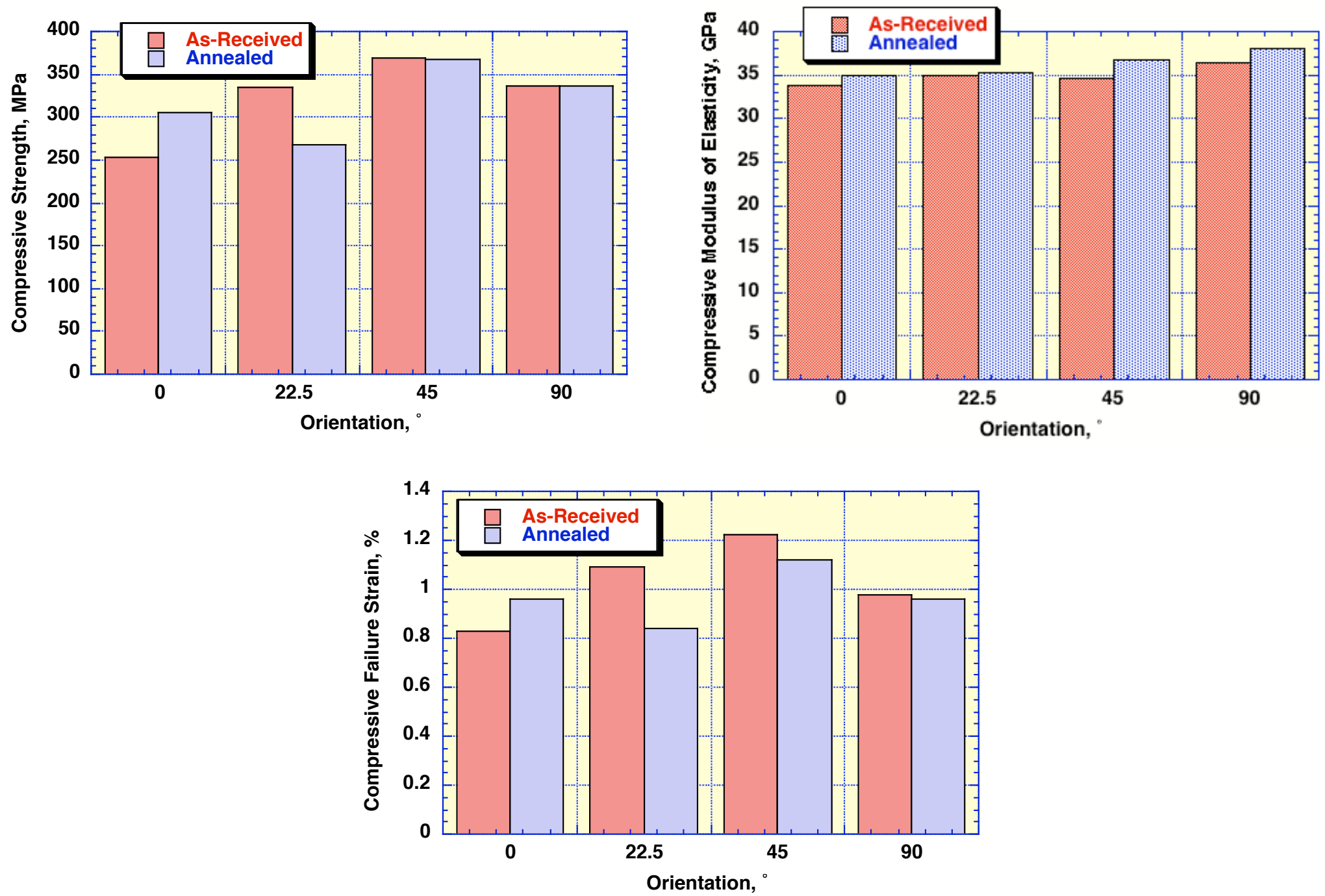


\section{Commentary: \\ Specimen Orientation - Compression Results}

- As-received material

- Compressive strength was maximum at $45^{\circ}$ specimen orientation

- Compressive modulus was relatively unaffected by specimen orientation

- Compressive failure strain results exhibited a similar trend to compressive strength results

- Annealed material

- Compressive strength was maximum at $45^{\circ}$ specimen orientation

- Compressive modulus was relatively unaffected by specimen orientation

- Compressive failure strain results exhibited a similar trend to compressive strength results

- As-received versus annealed material

- Compressive strength for both as-received and annealed materials was maximum at $45^{\circ}$ specimen orientation

- Compressive moduli similar for both materials and relatively unaffected by specimen orientation

- Compressive failure strains exhibited similar trend to compressive strength with maximum at $45^{\circ}$ orientation 


\section{Effect of Specimen Orientation on Shear Properties: As-Received Material}
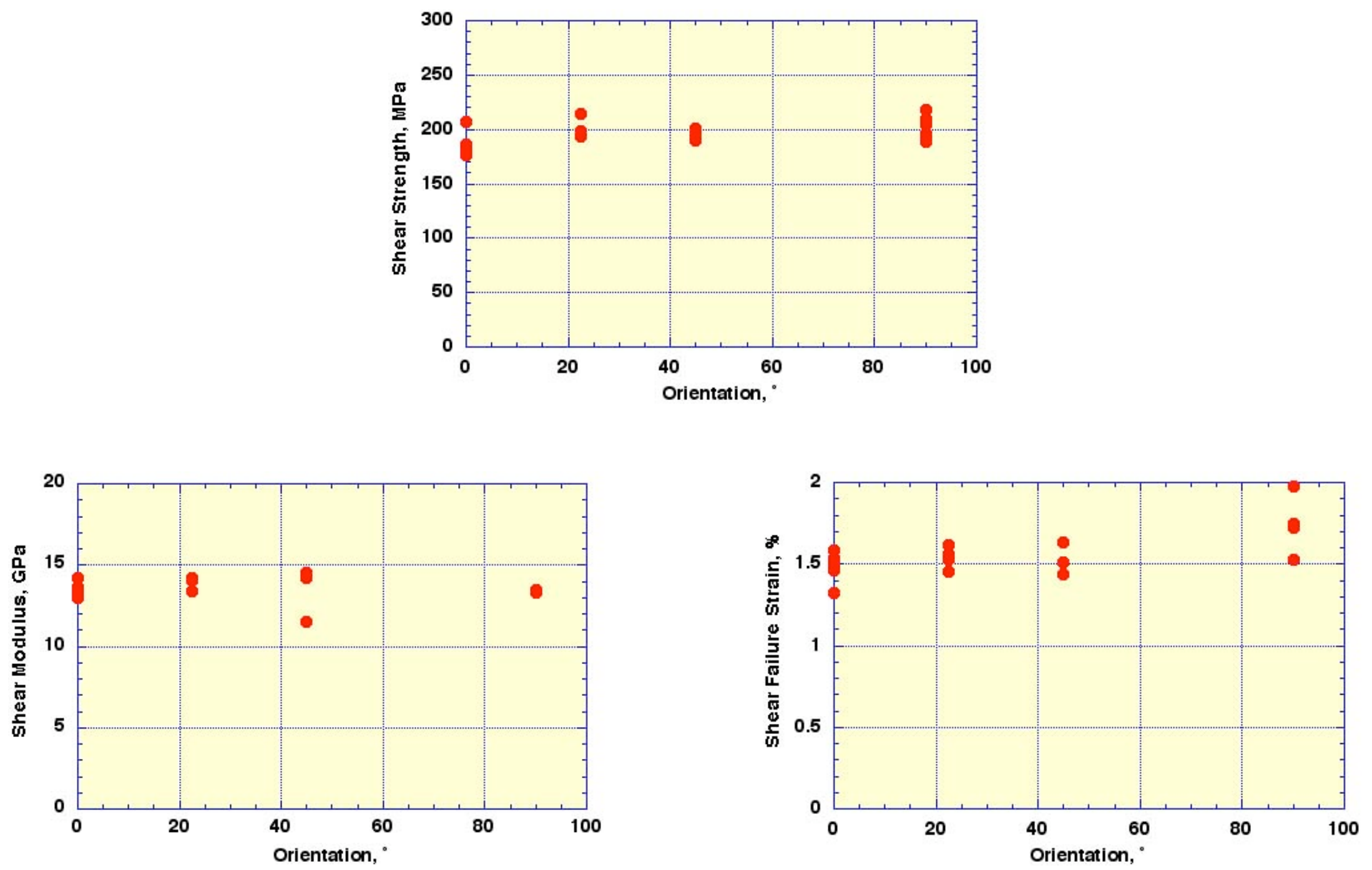


\section{Effect of Specimen Orientation on Shear Properties: Annealed Material}
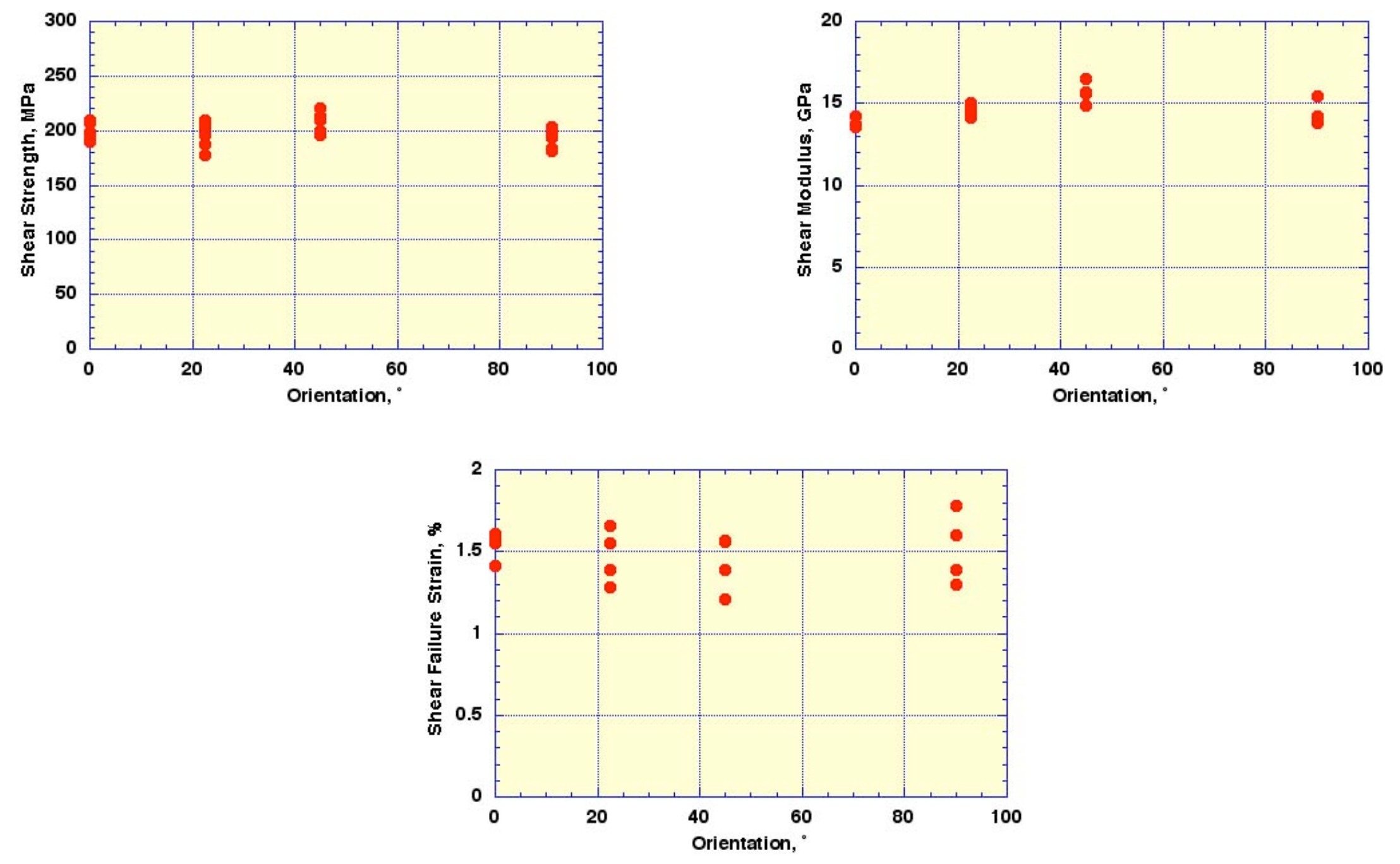


\section{Effect of Specimen Orientation on Shear Properties: As-Received vs Annealed Material}
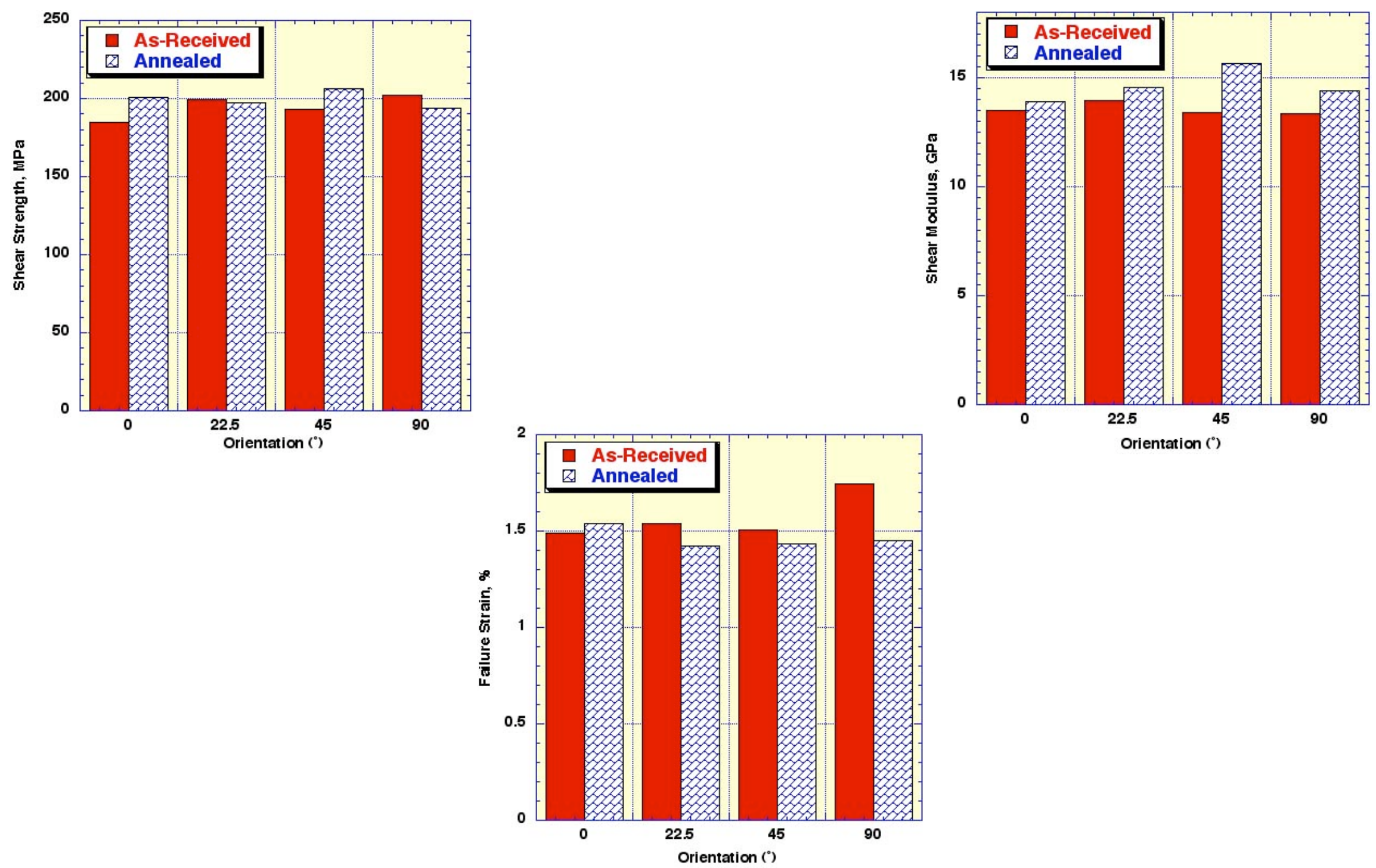


\section{Commentary: Specimen Orientation - Shear Results}

- As-received material

- Shear strength unaffected by specimen orientation

- Shear modulus unaffected by specimen orientation

- Shear failure strains were maximum at $90^{\circ}$ specimen orientation

- Annealed Material

- Shear strength unaffected by specimen orientation

- Shear modulus maximum at $45^{\circ}$ specimen orientation

- Shear failure strains minimum at $45^{\circ}$ specimen orientation

- As-received versus annealed material

- Shear strength for both as-received and annealed materials relatively unaffected by specimen orientation

- Shear modulus of annealed material greater than shear modulus of asreceived material at each specimen orientation

- Shear failure strains of as-received material greater than that of annealed material except at $0^{\circ}$ specimen orientation 


\section{Appendix E}

Summary and Comparison of Results for As-Received and Annealed Materials on the Effect of Elevated Temperature and Specimen Orientation $\left(0^{\circ}\right.$ and $\left.22.5^{\circ}\right)$ on Tensile, Compressive, and Shear Properties

- $\quad$ Figure 1.3 identifies specimen orientation designation. Annealed material was heated at $230^{\circ} \mathrm{C}$ for two hours in an attempt to increase material crystallinity prior to specimen fabrication. Orientation of $22.5^{\circ}$ selected for additional evaluation because it represented weakest direction in tensile tests. Shear specimens were not investigated having $22.5^{\circ}$ orientation. 



\section{Summary of Orientation and Temperature Effects on Tensile Properties: As-Received Material Tested at Room Temperature}
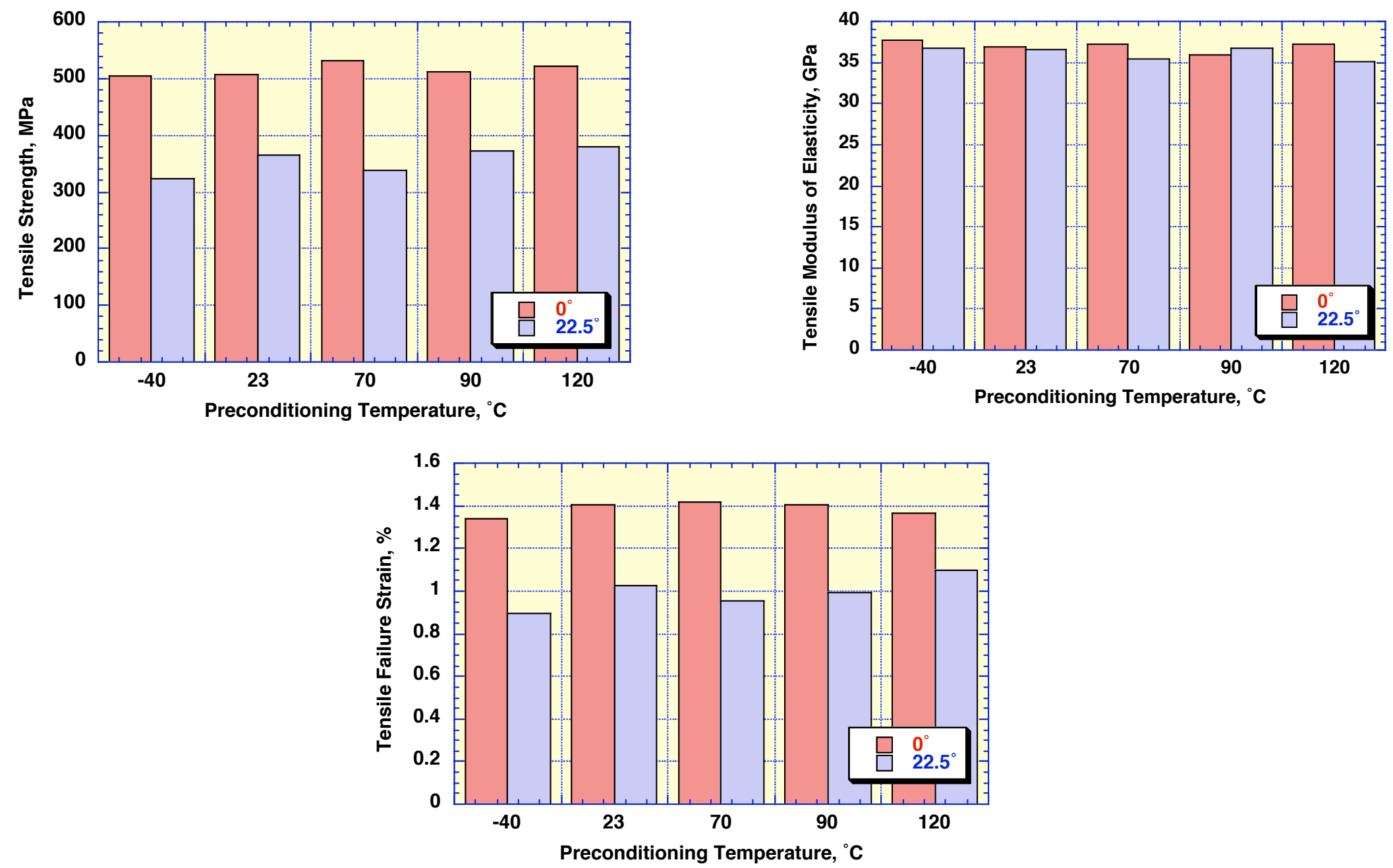


\section{Summary of Orientation and Temperature Effects on Tensile Properties: As-Received Material Tested at Temperature}
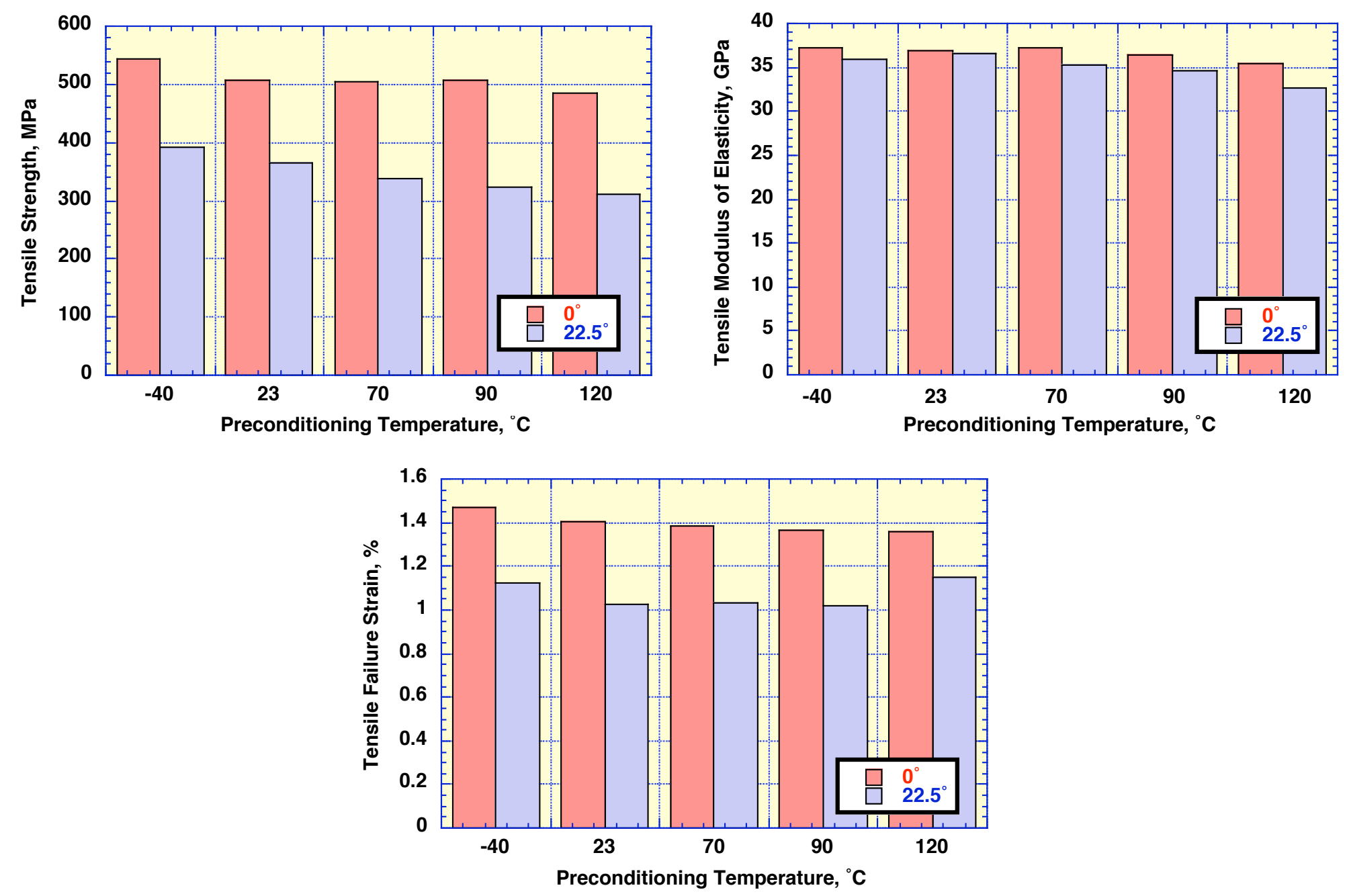


\section{Commentary: Temperature Effects - Tensile Results As-Received Material}

- As-received material $0^{\circ}$ specimen orientation

- Tensile strengths of specimens tested at temperature decreased slightly with increasing preconditioning temperature, while specimens tested at RT tended to increase slightly $(\leq 10 \%)$

- Tensile modulus showed a very slight trend to decrease with increasing preconditioning temperature for tests both at $\mathrm{RT}$ and temperature

- Tensile strains exhibited a similar trend to strength results

- Poisson's ratio similar for specimens tested either at room temperature or at temperature and exhibited a trend to increase slightly with increasing preconditioning temperature

- As-received material $22.5^{\circ}$ specimen orientation

- Tensile strengths of specimens tested at temperature decreased with increasing preconditioning temperature, while specimens tested at RT tended to increase, with changes greater than obtained for $0^{\circ}$ specimen orientation

- Tensile modulus tended to decrease slightly with increasing preconditioning temperature, with little difference between specimens tested either at temperature or at RT

- Tensile strains exhibited a similar trend to strength results 


\section{Commentary: Temperature Effects - Tensile Results As-Received Material}

- As-received $0^{\circ}$ versus $22.5^{\circ}$ specimen orientation at RT

- $0^{\circ}$ specimen tensile strengths were consistently greater than $22.5^{\circ}$ specimen results with difference greatest at $70^{\circ} \mathrm{C}(\sim 35 \%)$

- Tensile modulus results were similar for both specimen orientations, with little difference between preconditioning temperature results

- Tensile failure strains exhibited a trend similar to strength results

- When normalized, results for $0^{\circ}$ and $22.5^{\circ}$ specimen orientations exhibited similar trends with little difference between preconditioning temperature results

- As-received $0^{\circ}$ versus $22.5^{\circ}$ specimen orientation at temperature

- Tensile strength, moduli of elasticity, and failure strains exhibited trends similar to RT test results

- When normalized, tensile strength and modulus results tended to decrease at $\mathrm{T}>70^{\circ} \mathrm{C}$ with the decrease more for the $22.5^{\circ}$ material 


\section{Summary of Orientation and Temperature Effects on Tensile Properties: Annealed Material Tested at Room Temperature}
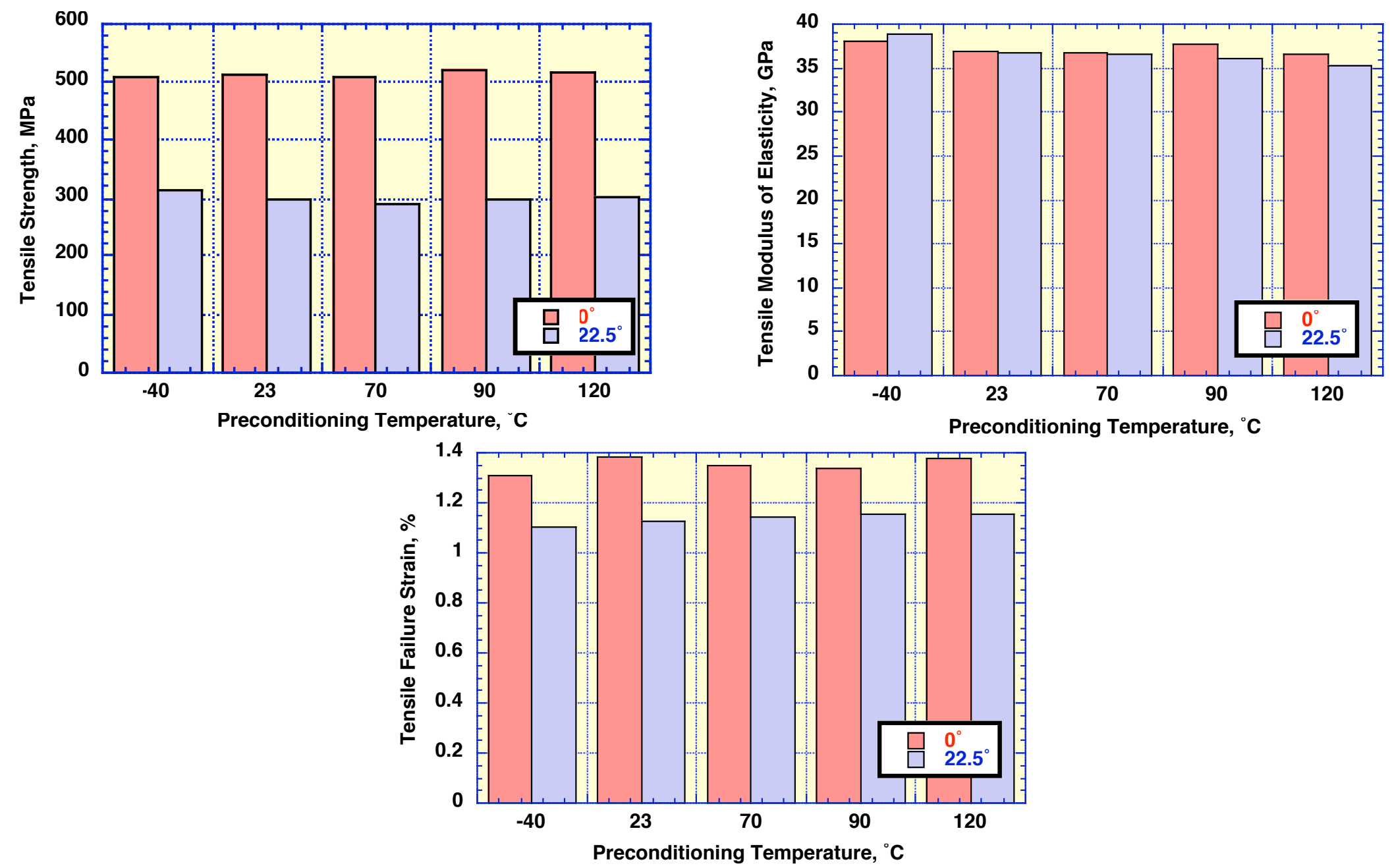


\section{Summary of Orientation and Temperature Effects on Tensile Properties: Annealed Material Tested at Temperature}
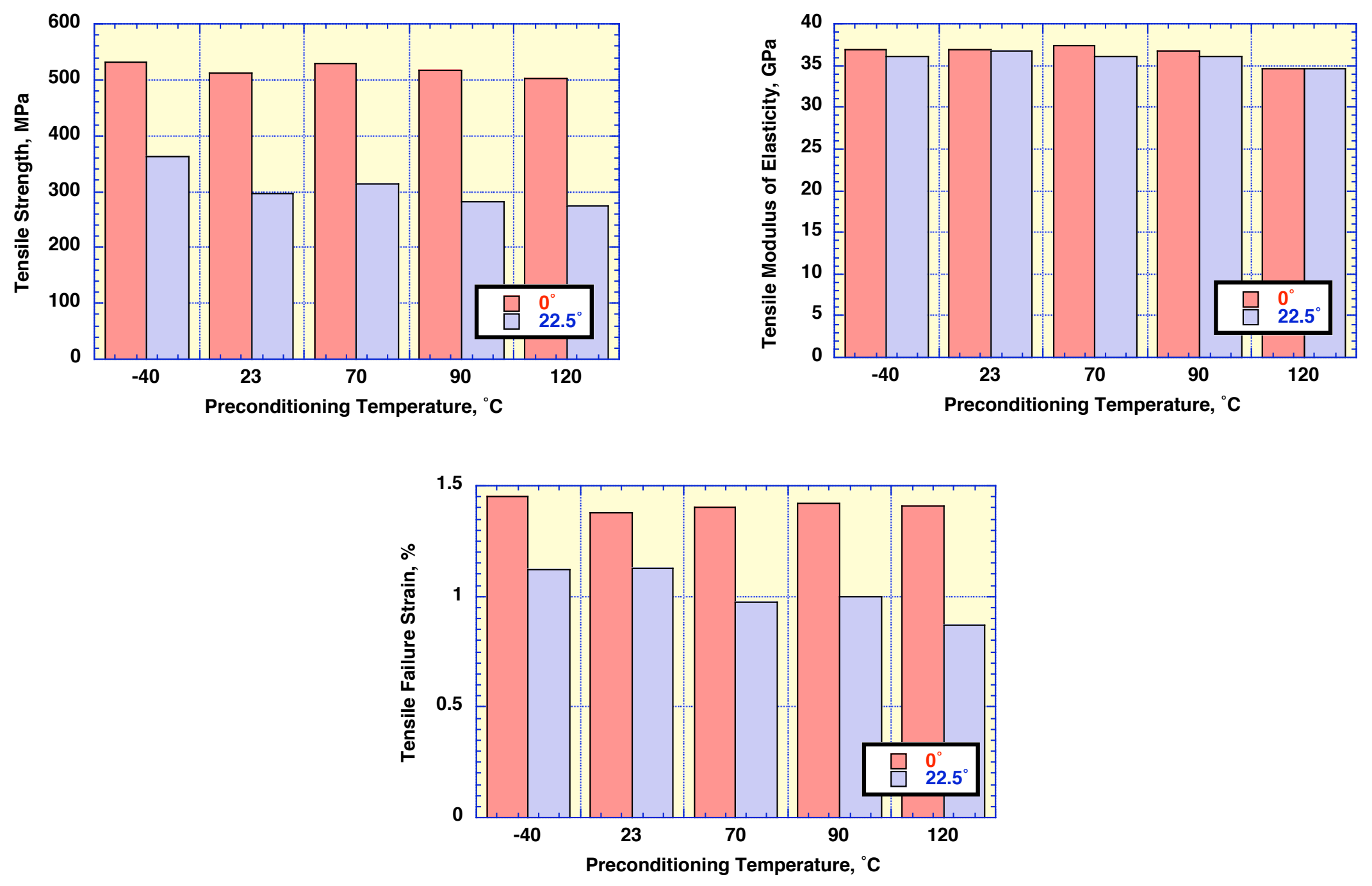


\section{Commentary: \\ Temperature Effect - Tensile Results Annealed Material}

- Annealed material $0^{\circ}$ specimen orientation

- Tensile strength, modulus of elasticity, and tensile failure strain were relatively unaffected by preconditioning temperature and whether tested at temperature or RT

- Annealed material $22.5^{\circ}$ specimen orientation

- Tensile strength of specimens tested at temperature tended to decrease with increasing preconditioning temperature, while strength of specimens tested at RT was unaffected

- Tensile modulus of specimens tested at temperature and those tested at $\mathrm{RT}$ both decreased slightly with increasing preconditioning temperature

- Tensile strains of specimens tested at temperature tended to decrease with increasing preconditioning temperature, while results for specimens tested at RT tended to increase slightly 


\section{Commentary: Temperature Effect - Tensile Results Annealed Material (cont.)}

- Annealed $0^{\circ}$ versus $22.5^{\circ}$ specimen orientation at RT

- Tensile strengths and failure strains for $0^{\circ}$ specimen orientation were consistently greater than values obtained from $22.5^{\circ}$ specimens at the same preconditioning temperature

- Tensile modulus was relatively unaffected by either specimen orientation or preconditioning temperature

- When normalized, results for $0^{\circ}$ and $22.5^{\circ}$ specimen orientations were consistent

- Annealed $0^{\circ}$ versus $22.5^{\circ}$ specimen orientation at temperature

- Tensile strengths and failure strains were consistently greater for $0^{\circ}$ specimen orientation than $22.5^{\circ}$ specimen orientation

- Tensile modulus was relatively unaffected by either specimen orientation or preconditioning temperature

- When normalized, results for $0^{\circ}$ and $22.5^{\circ}$ specimen orientations were consistent 


\section{Effect of Temperature on Tensile Strength: As-Received vs Annealed Material, $0^{\circ}$ Specimen Orientation}
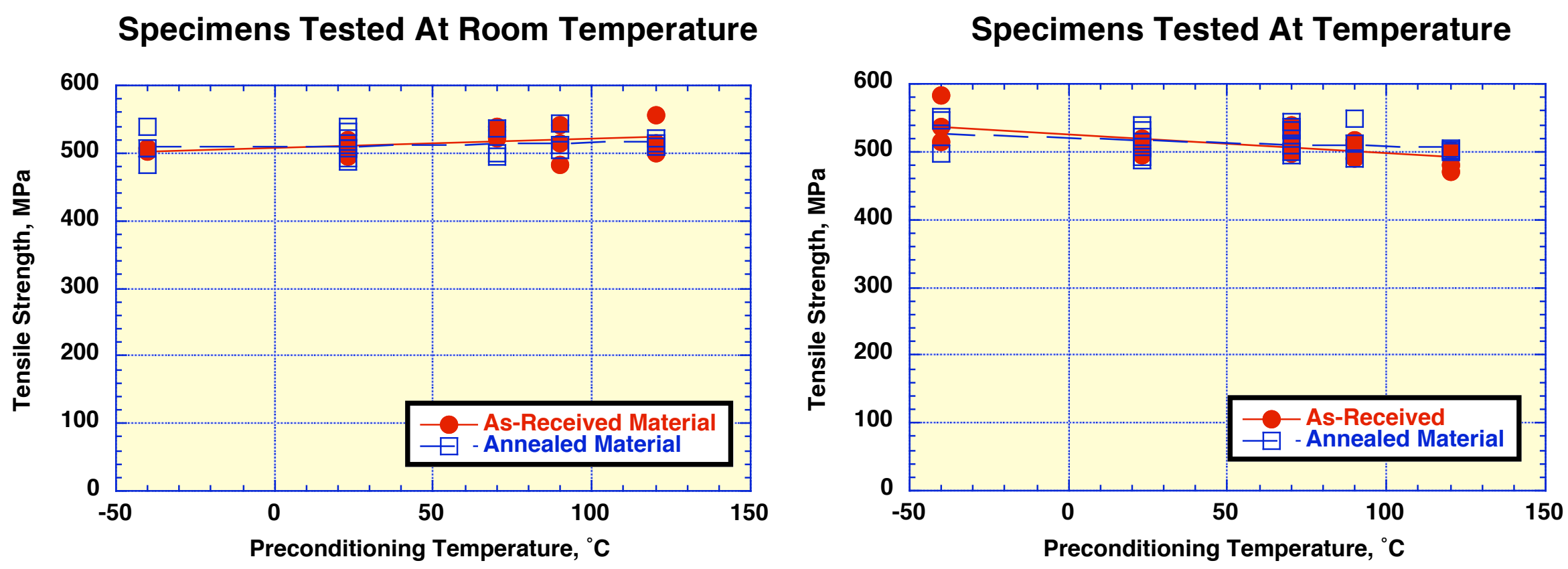


\section{Effect of Temperature on Tensile Modulus: As-Received vs Annealed Material, $0^{\circ}$ Specimen Orientation}
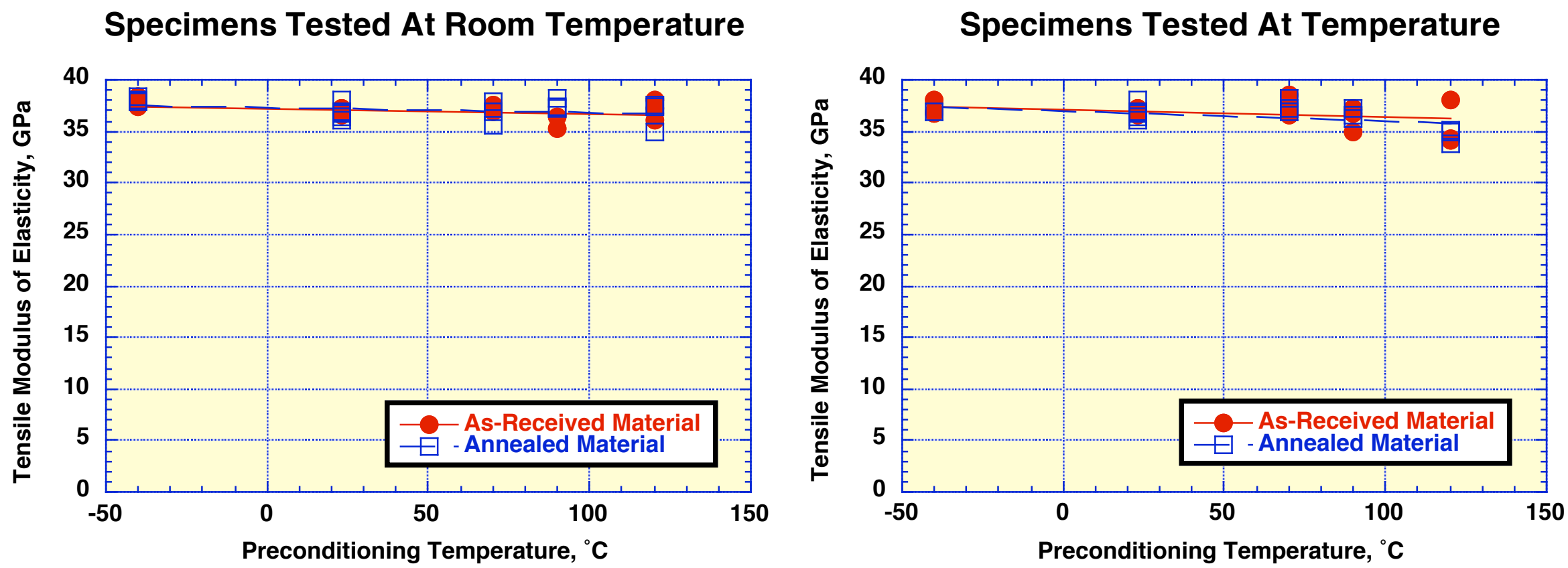


\section{Effect of Temperature on Tensile Failure Strain: As-Received vs Annealed Material, $0^{\circ}$ Specimen Orientation}
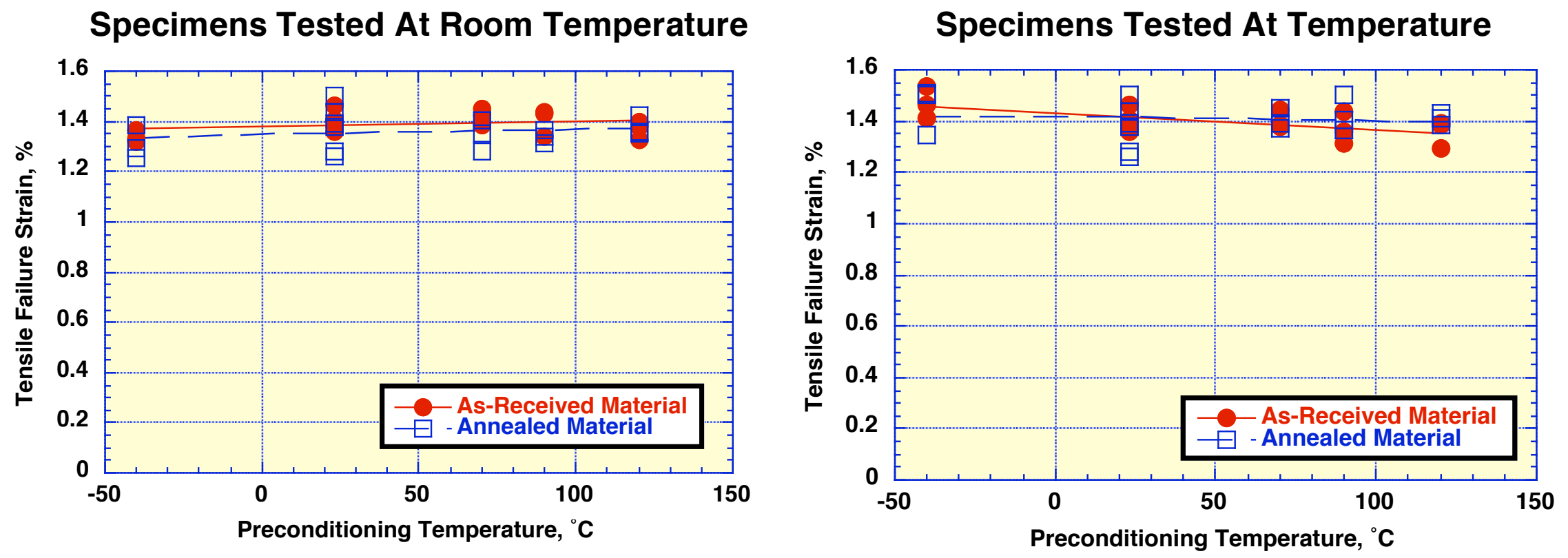


\section{Effect of Temperature on Tensile Strength: As-Received vs Annealed Material, $22.5^{\circ}$ Specimen Orientation}

Specimens Tested At Room Temperature

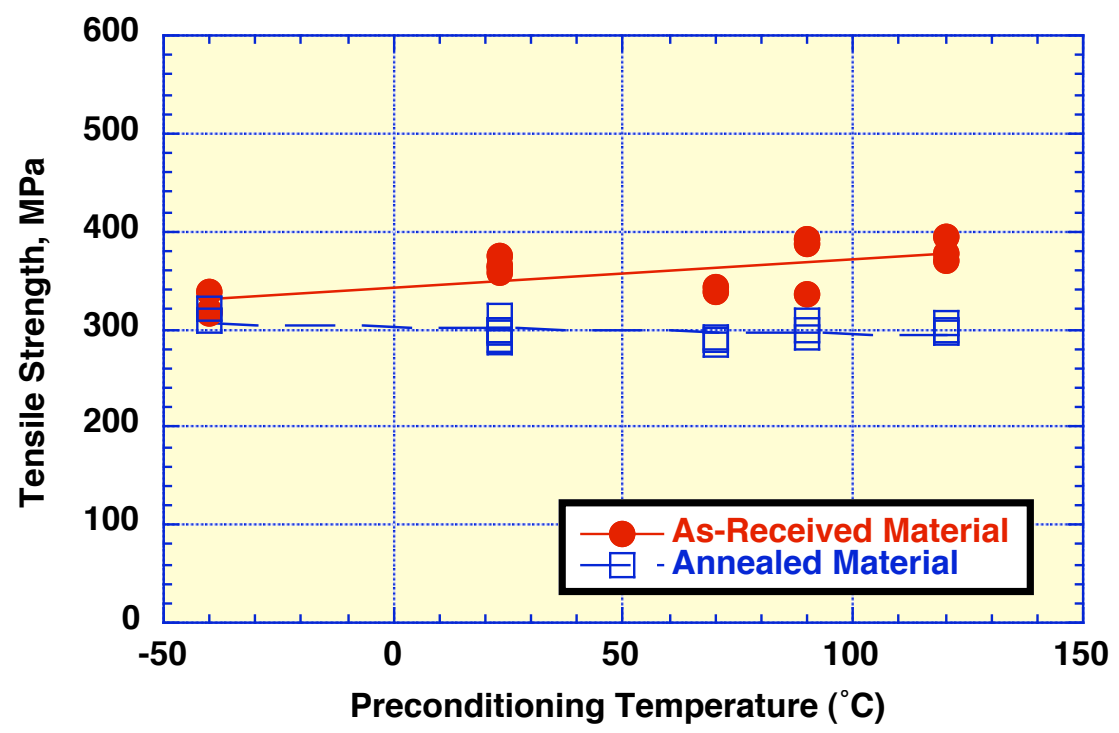

Specimens Tested At Temperature

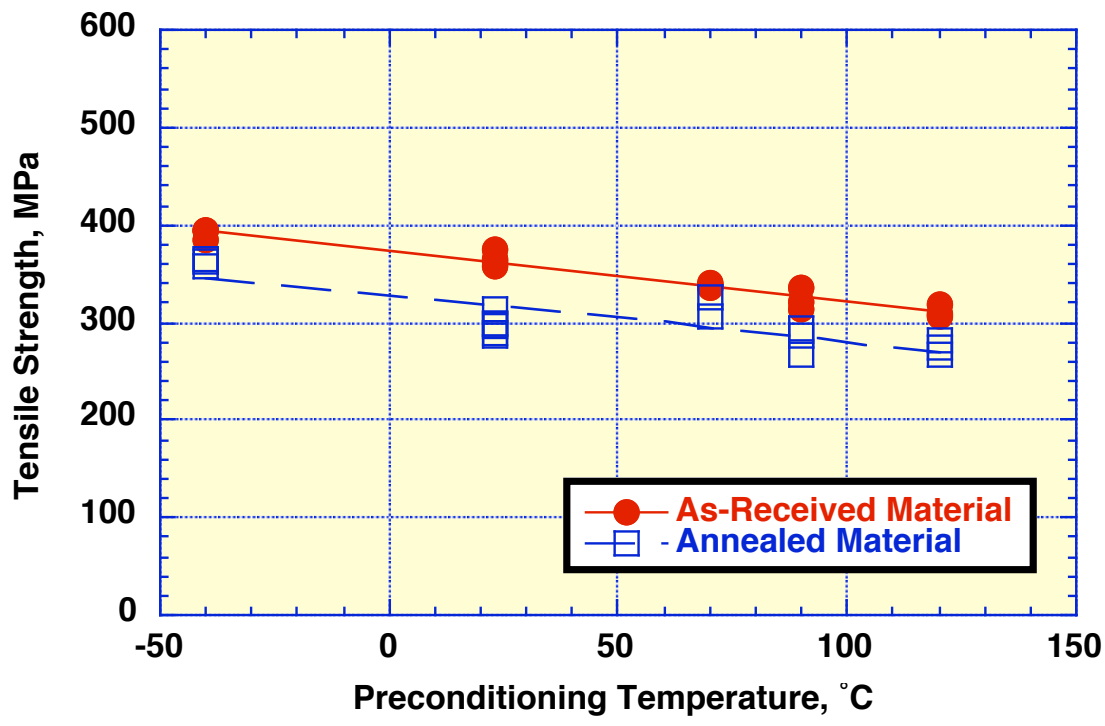




\section{Effect of Temperature on Tensile Modulus: As-Received vs Annealed Material, $22.5^{\circ}$ Specimen Orientation}

Specimens Tested At Room Temperature

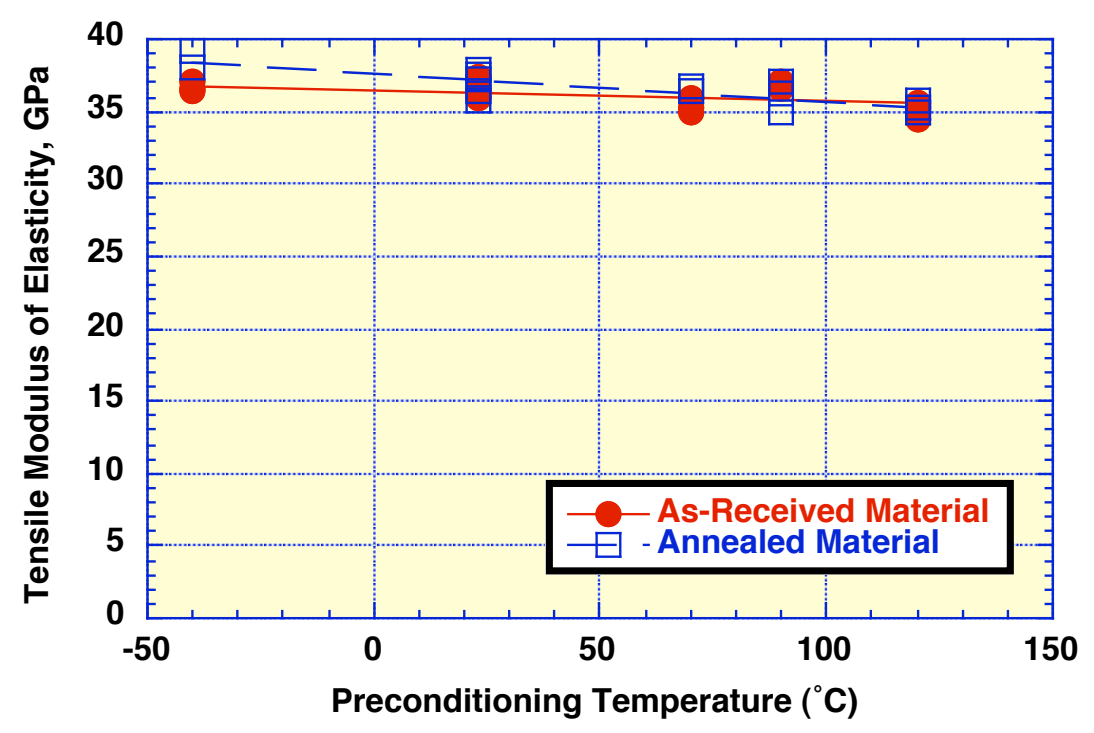

Specimens Tested At Temperature

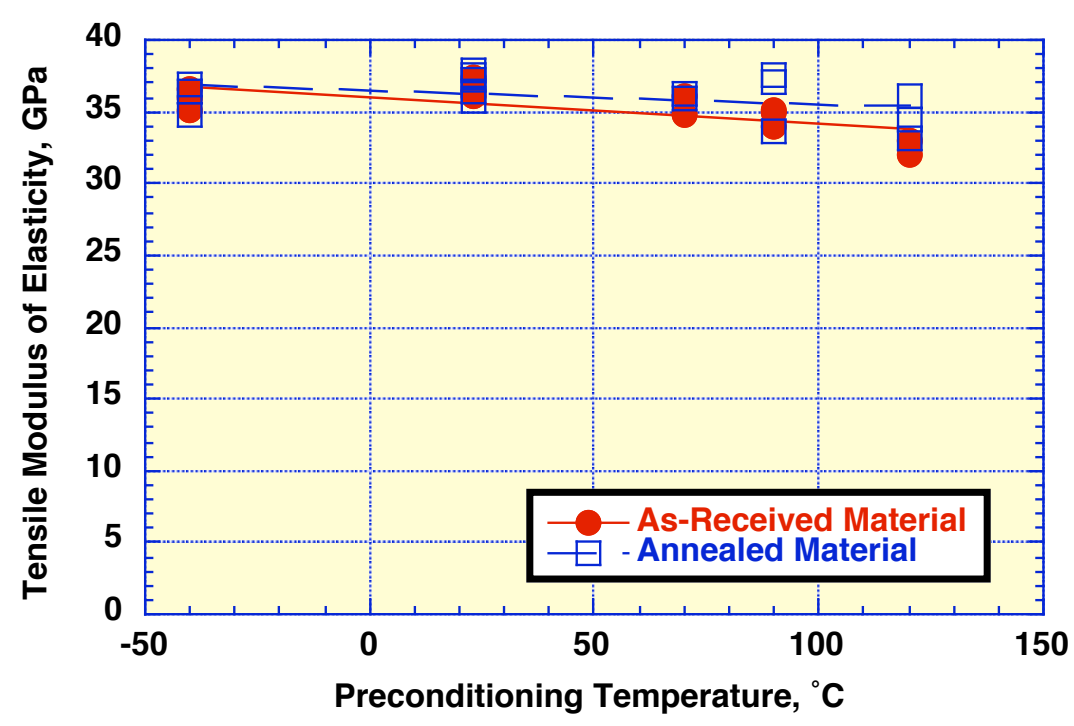




\section{Effect of Temperature on Tensile Failure Strain: As-Received vs Annealed Material, $22.5^{\circ}$ Specimen Orientation}

Specimens Tested At Room Temperature

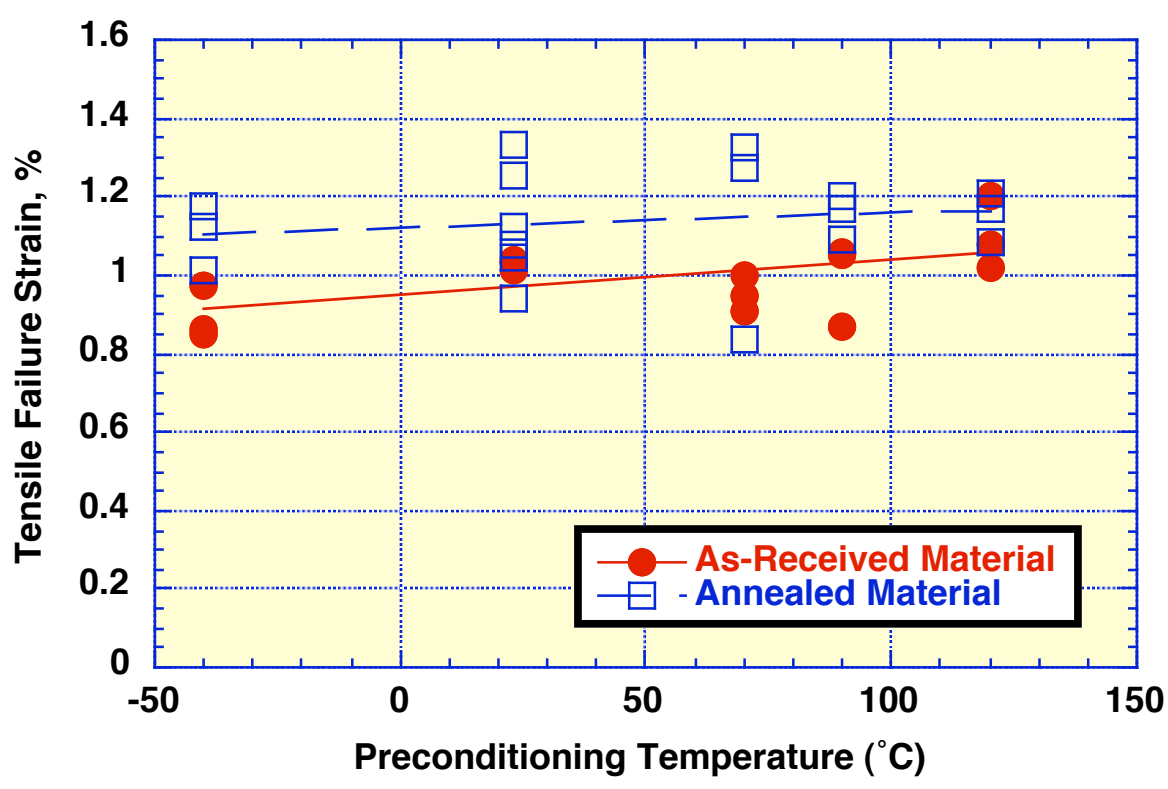

Specimens Tested At Temperature

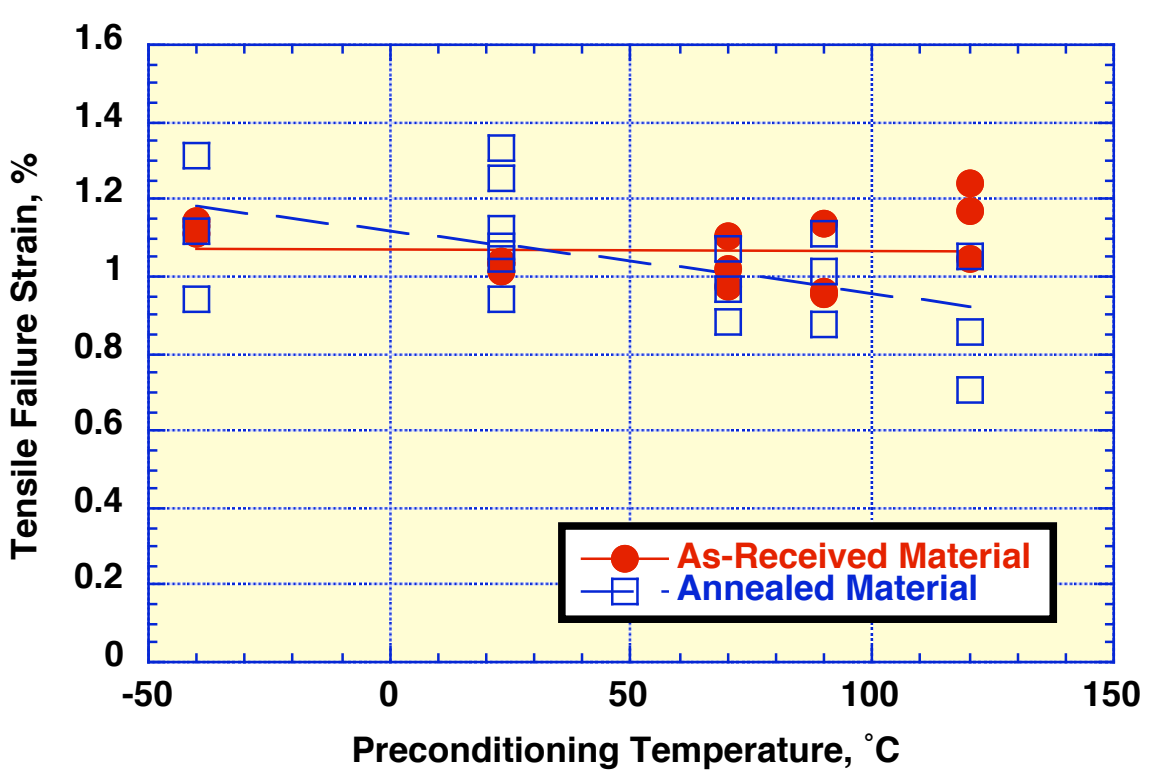




\section{Commentary: \\ Temperature Effect - Tensile Results As-Received versus Annealed Material}

- As-received versus annealed material $0^{\circ}$ specimen orientation

- Tensile strengths for both as-received and annealed specimens tested at RT tended to increase slightly with increasing preconditioning temperature and decrease slightly for specimens tested at temperature

- Tensile modulus for both as-received and annealed specimens tended to be relatively unaffected by preconditioning temperature for specimens tested either at temperature or RT

- Tensile failure strains were relatively unaffected by preconditioning temperature for either as-received or annealed specimens tested either at temperature or $\mathrm{RT}$ 


\section{Commentary: \\ Temperature Effect - Tensile Results (cont.) As-Received versus Annealed Material}

- As-received versus annealed material $22.5^{\circ}$ specimen orientation

- Tensile strengths of as-received specimens tested at RT tended to increase with increasing preconditioning temperature while annealed specimens showed little change

- Tensile strengths of as-received and annealed specimens tested at temperature both tended to decrease at similar rates with increasing preconditioning temperature

- Tensile modulus of as-received and annealed specimens tested either at temperature or RT exhibited a slight trend to decrease with increasing preconditioning temperature

- Tensile failure strains of both as-received and annealed specimens tested at RT tended to increase with increasing preconditioning temperature

- Tensile failure strains of annealed specimens tested at temperature tended to decrease with increasing preconditioning temperature, but as-received specimens were relatively unaffected 


\section{Summary of Orientation and Temperature Effects on Compressive Properties: As-}

\section{Received Material Tested at Room Temperature}
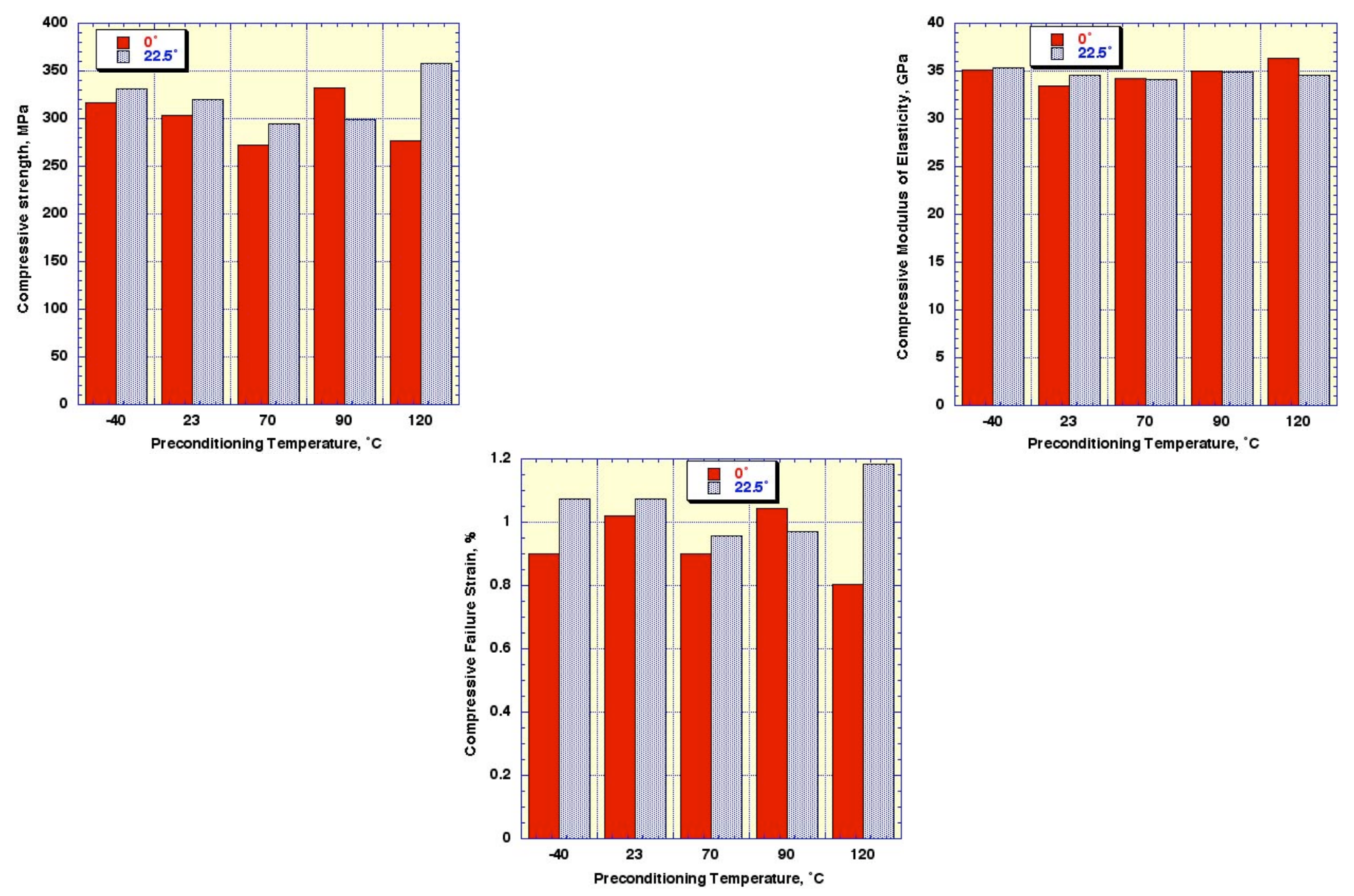


\section{Summary of Orientation and Temperature Effects on Compressive Properties: As- Received Material Tested at Temperature}
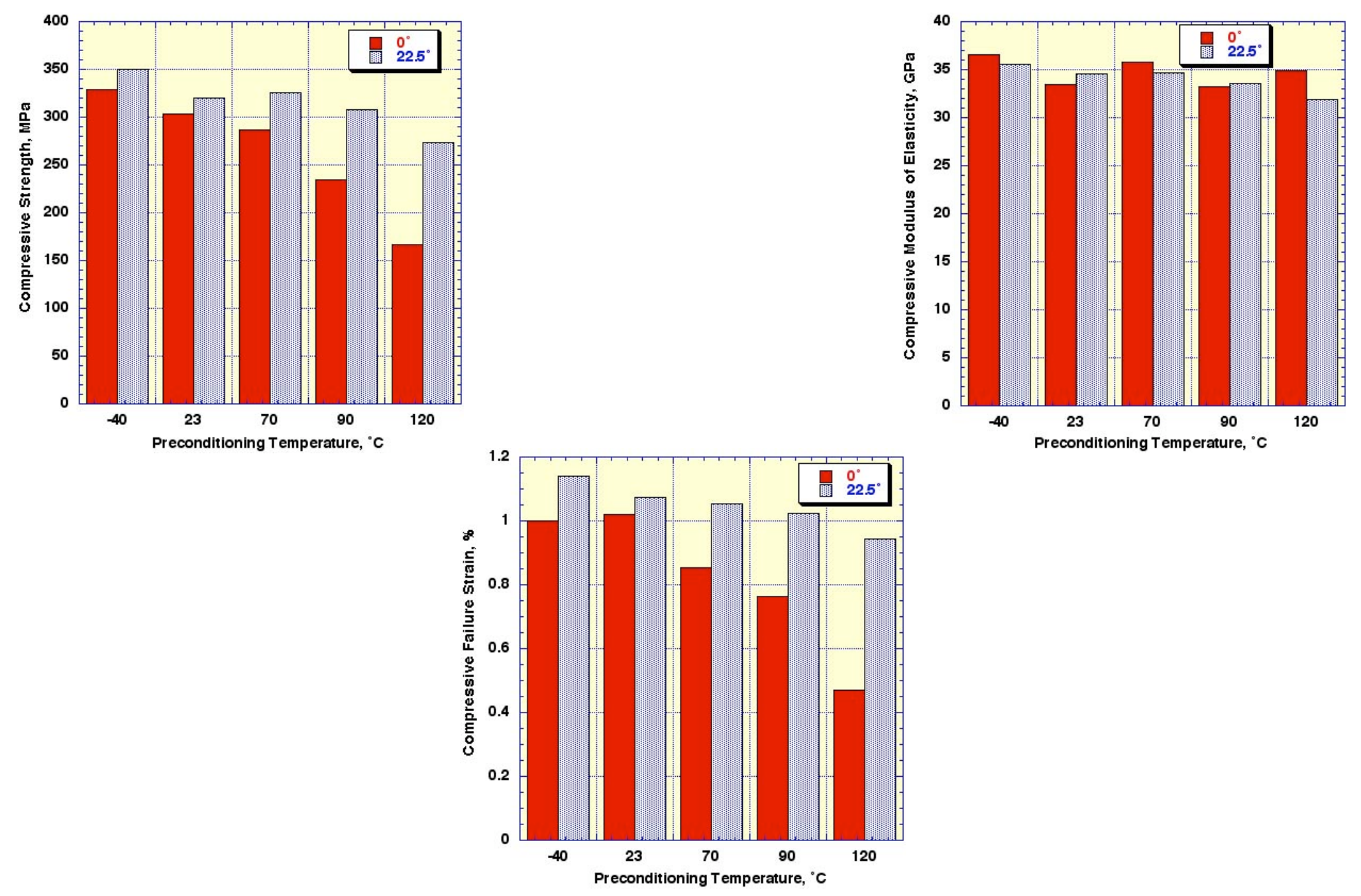


\section{Commentary: \\ Temperature Effects - Compressive Results As-Received Material}

- As-received material $0^{\circ}$ specimen orientation

- Compressive strengths and failure strains exhibited a trend to decrease with increasing preconditioning temperature for specimens tested at temperature, but compressive strength of specimens tested at RT was relatively unaffected by preconditioning temperature

- Modulus results were unaffected by preconditioning temperature and similar for specimens tested either at temperature or RT

- As-received material $0^{\circ}$ versus $22.5^{\circ}$ specimen orientation

- Compressive strengths of specimens having a $22.5^{\circ}$ orientation were consistently greater than those from specimens having a $0^{\circ}$ orientation when tested at either temperature or room temperature

- Modulus results for $0^{\circ}$ and $22.5^{\circ}$ orientations were similar and unaffected by preconditioning temperature

- Compressive failure strains exhibited a similar trend to compressive strength results 


\section{Effect of Temperature on Compressive Properties: Annealed Material $0^{\circ}$ Specimen Orientation}
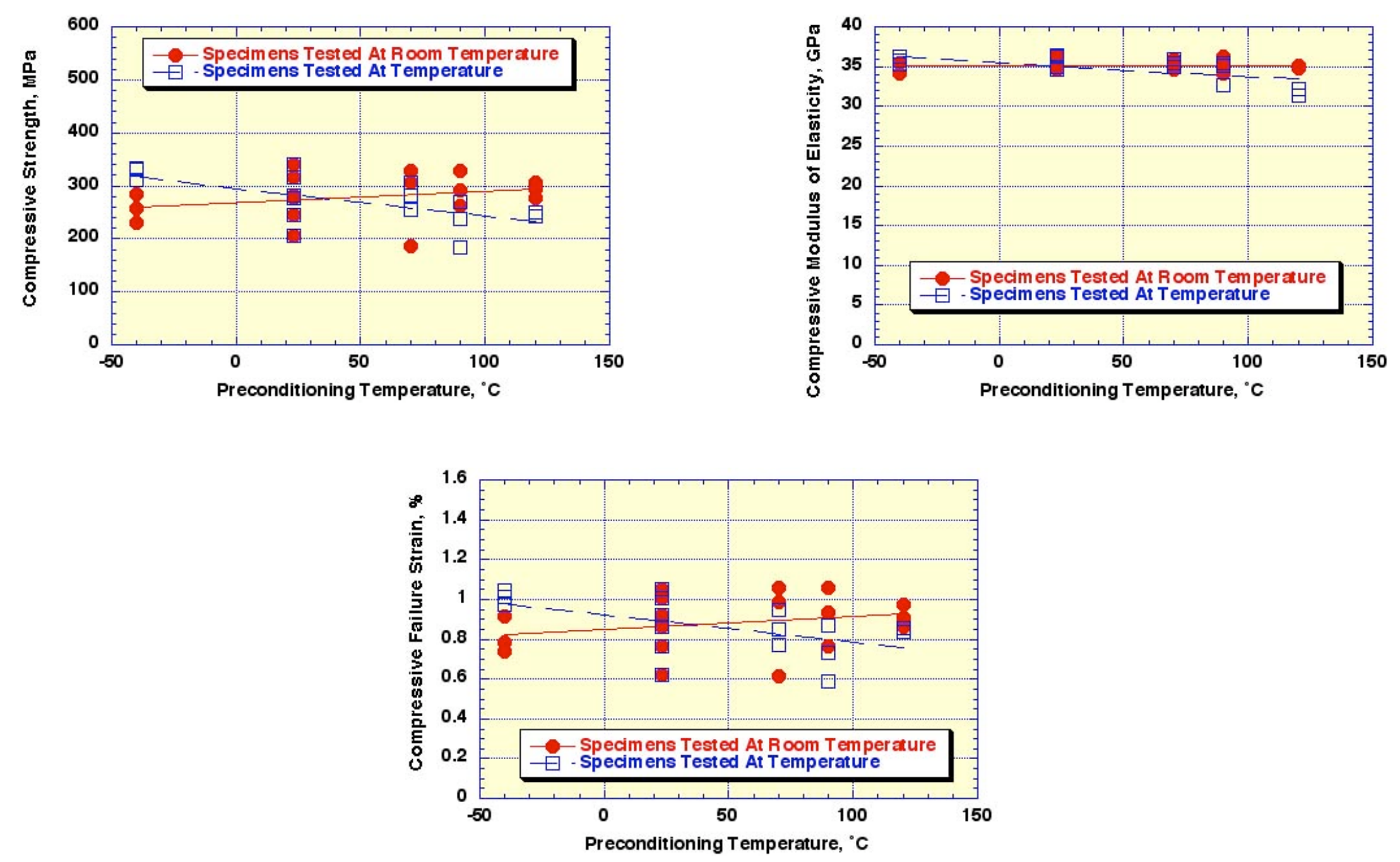


\section{Summary of Orientation and Temperature Effects on Compressive Properties: Annealed Material Tested at Room Temperature}
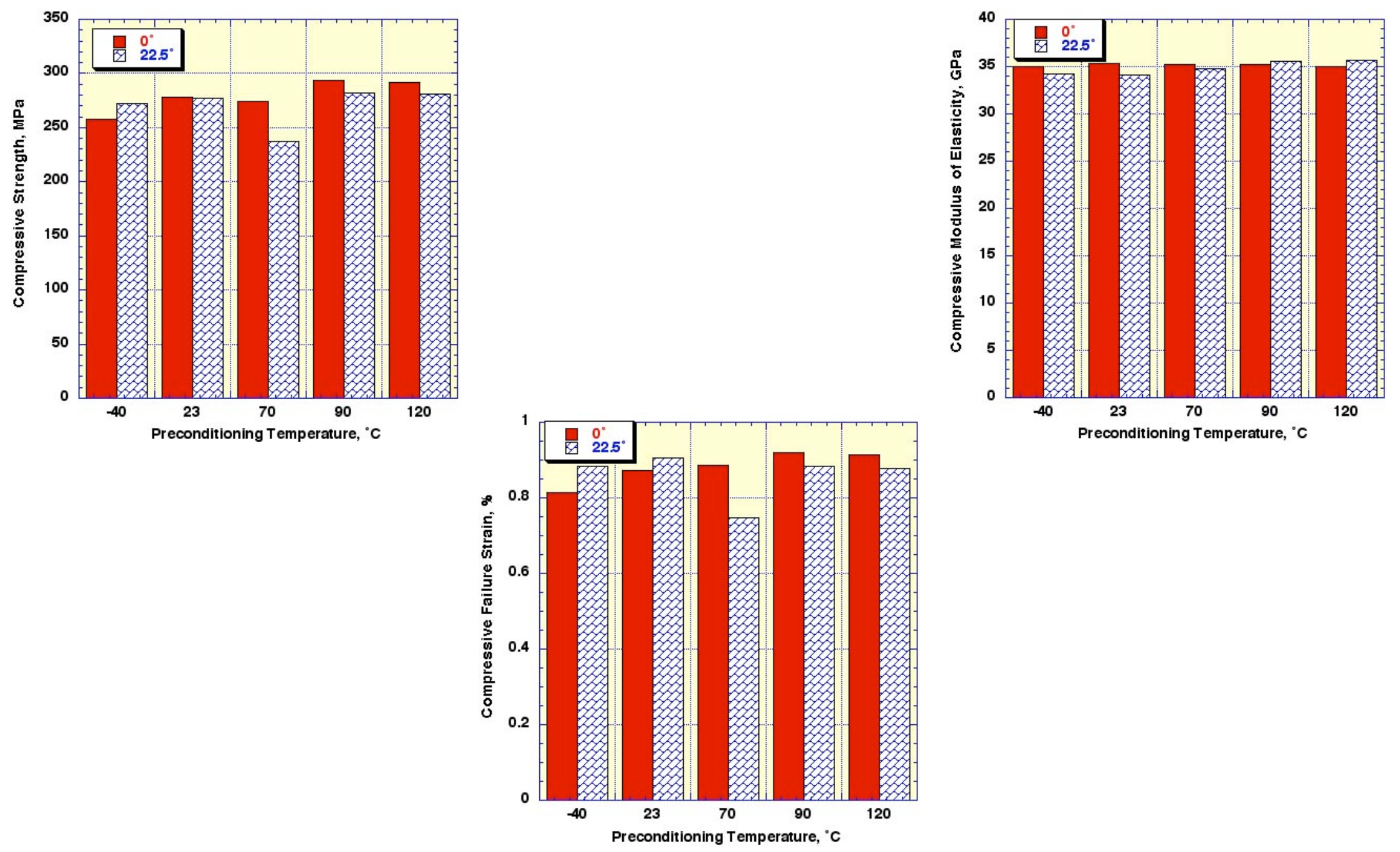


\section{Summary of Orientation and Temperature Effects on Compressive Properties: Annealed Material Tested at Temperature}
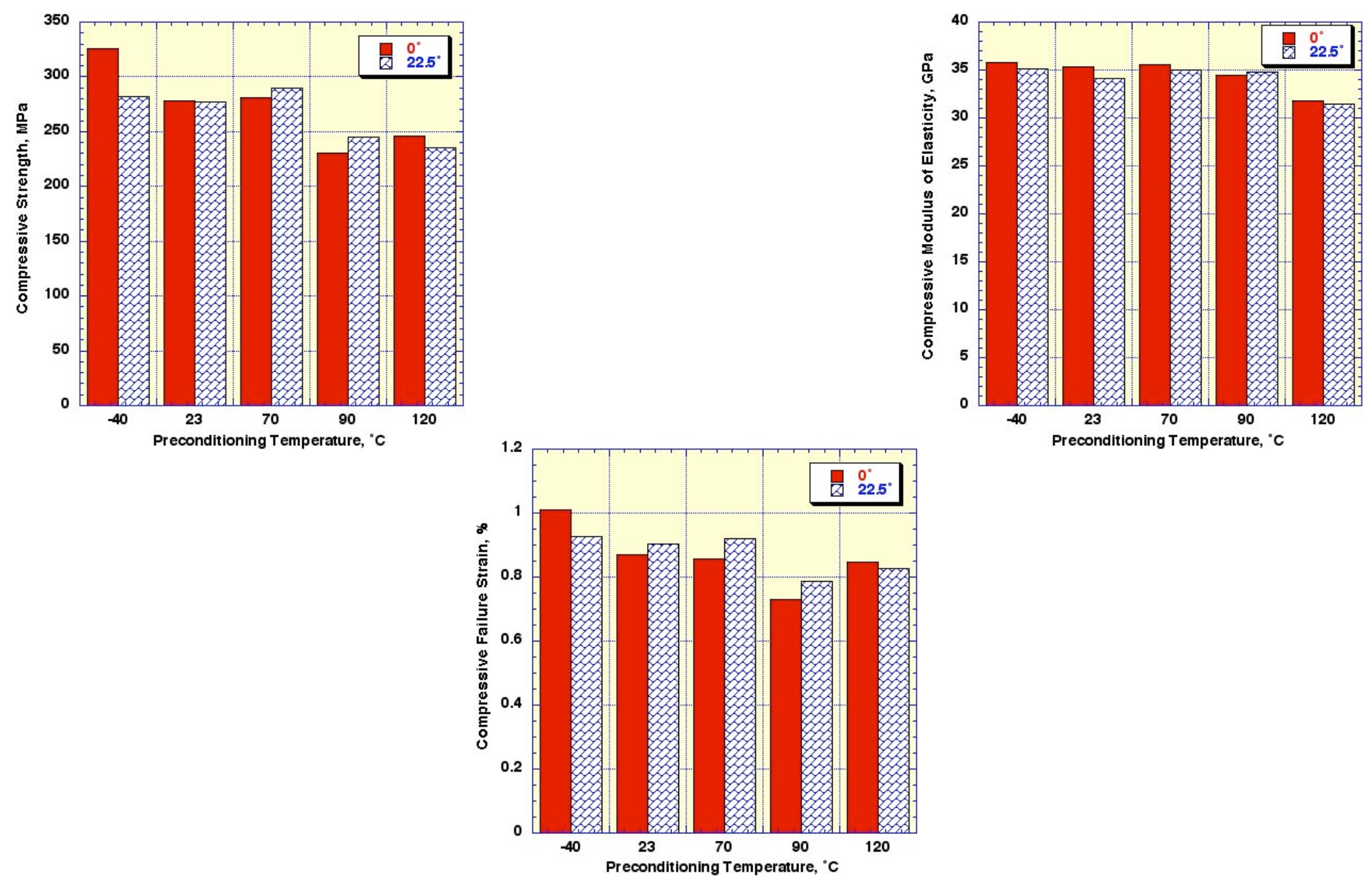


\section{Commentary: \\ Temperature Effects - Compressive Results Annealed Material}

- $\quad 0^{\circ}$ Specimen Orientation

- Compressive strengths and failure strains exhibited a trend to decrease slightly when tested at temperature and increase slightly when tested at room temperature

- Modulus results exhibited a slight trend to decrease with increasing preconditioning temperature when tested at temperature, but were unaffected by preconditioning temperature when tested at room temperature

- $\quad 0^{\circ}$ versus $22.5^{\circ}$ Specimen Orientation

- Compressive strengths of specimens having $0^{\circ}$ orientation were consistently greater than those having $22.5^{\circ}$ orientation when tested at room temperature, with compressive strength increasing slightly with increasing preconditioning temperature; both $0^{\circ}$ and $22.5^{\circ}$ specimens exhibited a trend for compressive strength to decrease with increasing preconditioning temperature when tested at temperature

- Modulus results for $0^{\circ}$ and $22.5^{\circ}$ orientations were similar and unaffected by preconditioning temperature for specimens tested either at temperature or room temperature (except at $120^{\circ} \mathrm{C}$ ) 


\section{Effect of Temperature on Compressive Strength: As-Received vs Annealed Material, $0^{\circ}$ Specimen Orientation}

Specimens Tested at Room Temperature

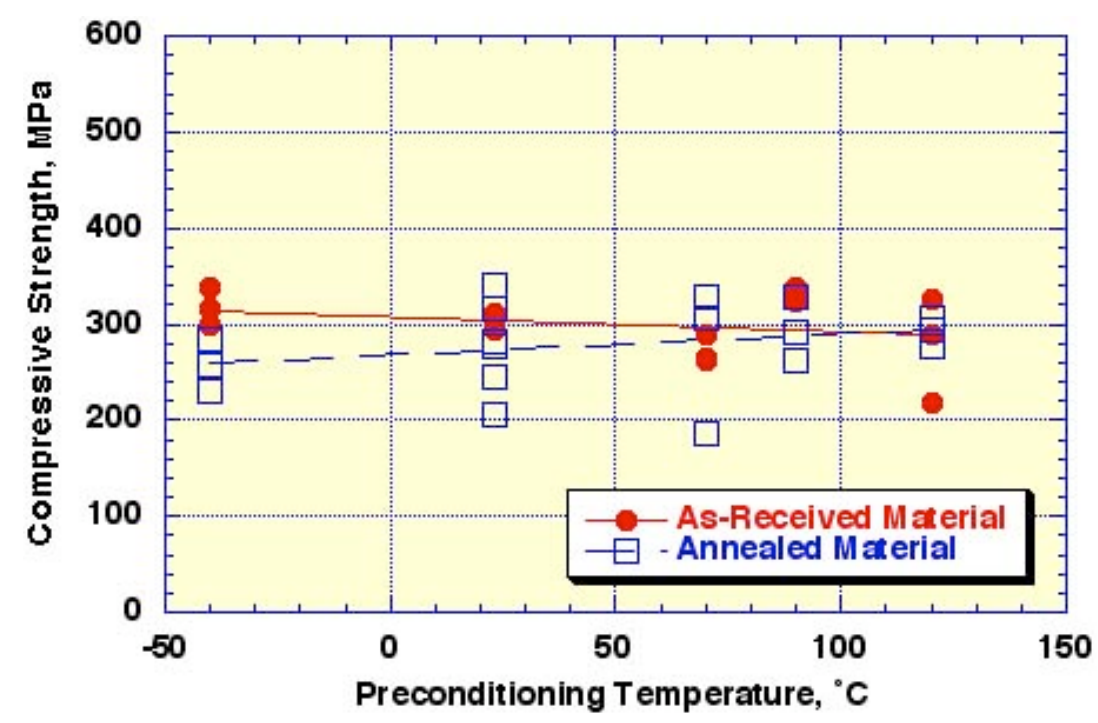

Specimens Tested at Temperature

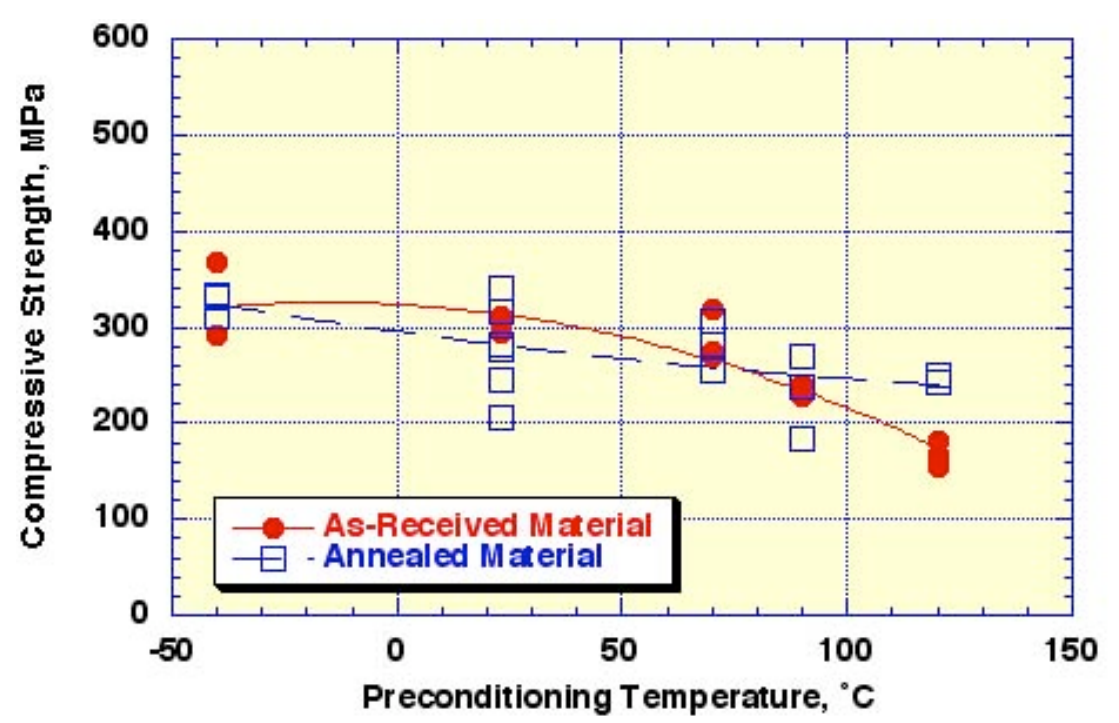




\section{Effect of Temperature on Compressive Modulus: As-Received vs Annealed Material, $0^{\circ}$ Specimen Orientation}
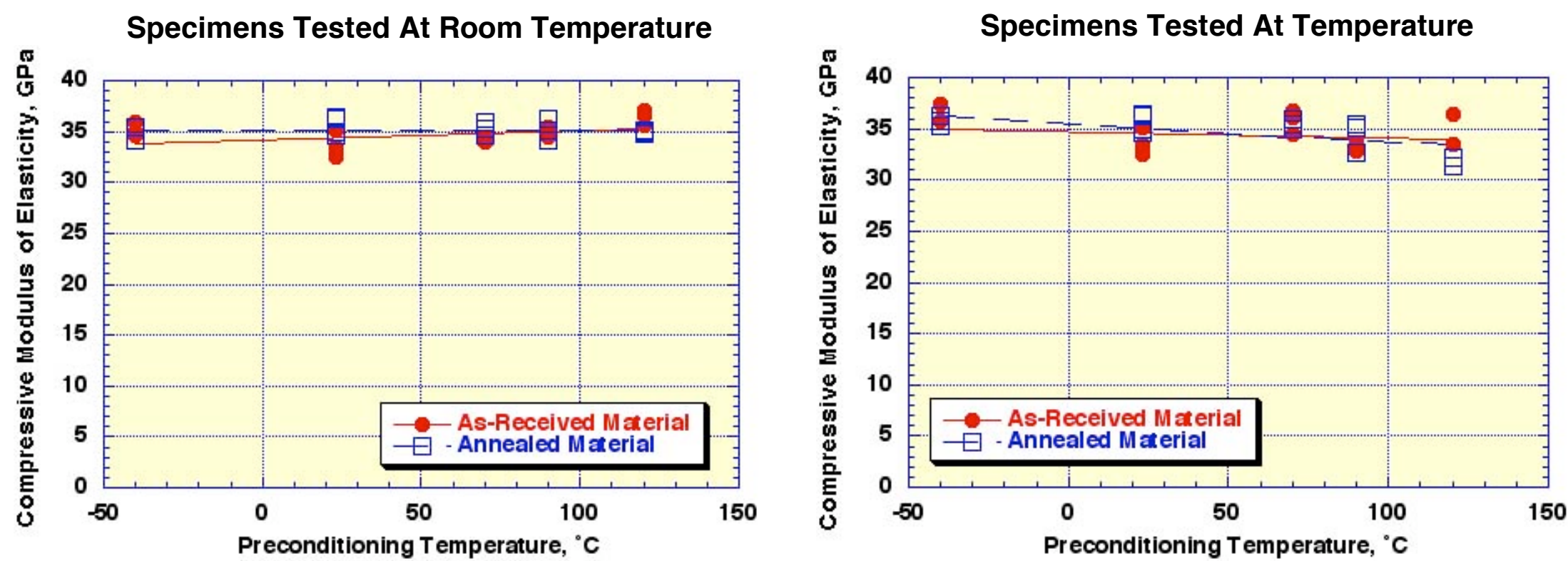


\section{Effect of Temperature on Compressive Failure Strain: As-Received vs Annealed Material, $0^{\circ}$ Specimen Orientation}

Specimens Tested At Room Temperature

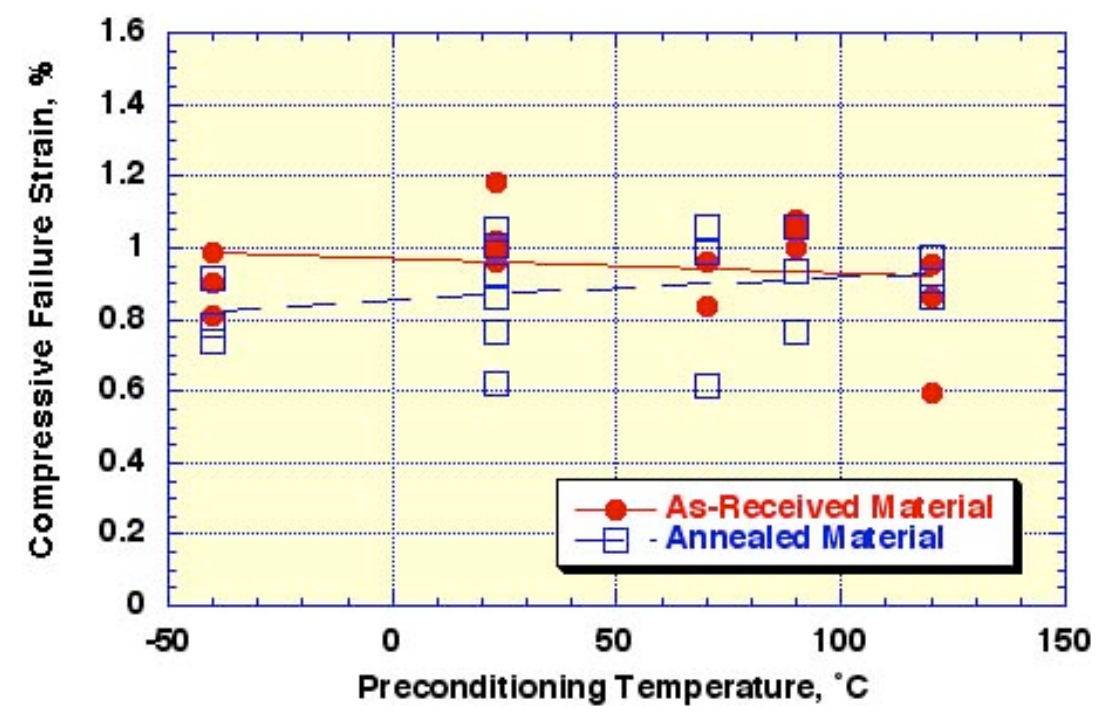

Specimens Tested At Temperature

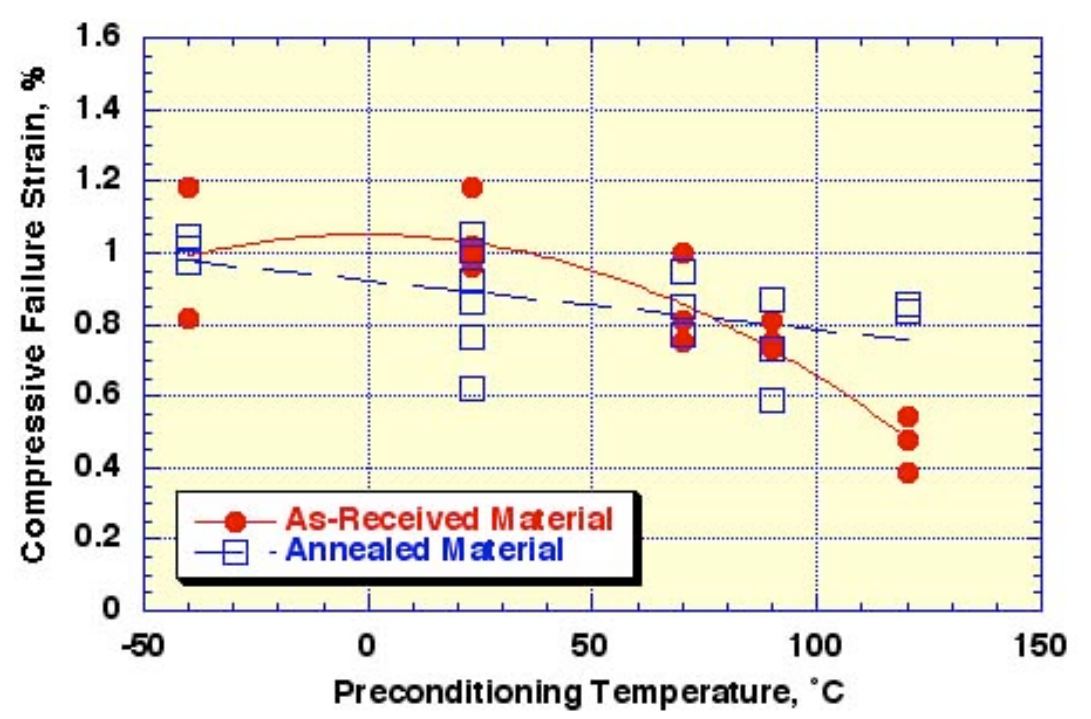




\section{Commentary: \\ Temperature Effects - Compressive Results As-Received versus Annealed Material}

- Compressive strengths of as-received and annealed materials tended to decrease slightly with increasing preconditioning temperature when tested at temperature, but preconditioning temperature had little effect on asreceived material tested at room temperature while annealed material compressive strength tended to increase slightly with preconditioning temperature when tested at room temperature

- Modulus of as-received and annealed materials exhibited a slight trend to decrease with preconditioning temperature when tested at temperature, but preconditioning temperature had little effect on modulus of either material when tested at room temperature

- Failure strain of as-received and annealed materials tended to decrease with increasing preconditioning temperature when tested at temperature, but when tested at room temperature the as-received material exhibited a slight trend to decrease with increasing preconditioning temperature while the annealed material increased slightly with increasing preconditioning temperature 


\section{Effect of Temperature on Shear Properties: As-Received Material $0^{\circ}$ Specimen Orientation}
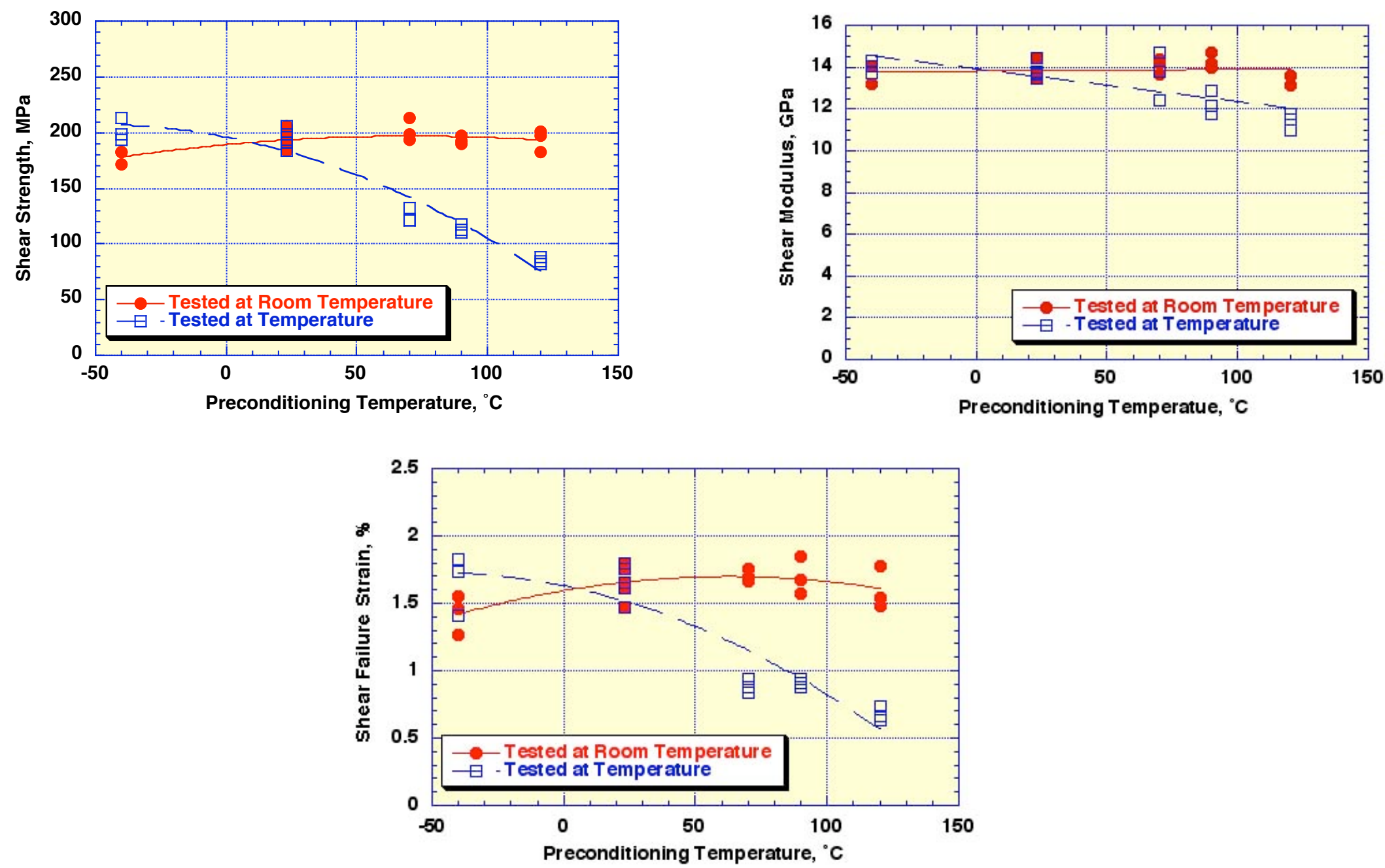


\section{Commentary: \\ Temperature Effects - Shear Results As-Received Material $0^{\circ}$ Specimen Orientation}

- Shear strength of specimens tested at temperature tended to decrease with increasing preconditioning temperature, but was relatively unaffected by preconditioning temperature for specimens tested at room temperature

- Modulus of specimens tested at temperature tended to decrease with increasing preconditioning temperature when tested at temperature, but showed little effect of preconditioning temperature when tested at room temperature

- Failure strains for specimens tested at temperature decreased with increasing preconditioning temperature when tested at temperature, but were relatively unaffected by preconditioning temperature $\left(T>23^{\circ} \mathrm{C}\right)$ when tested at room temnerature 


\section{Effect of Temperature on Shear Properties: Annealed Material $0^{\circ}$ Specimen Orientation}
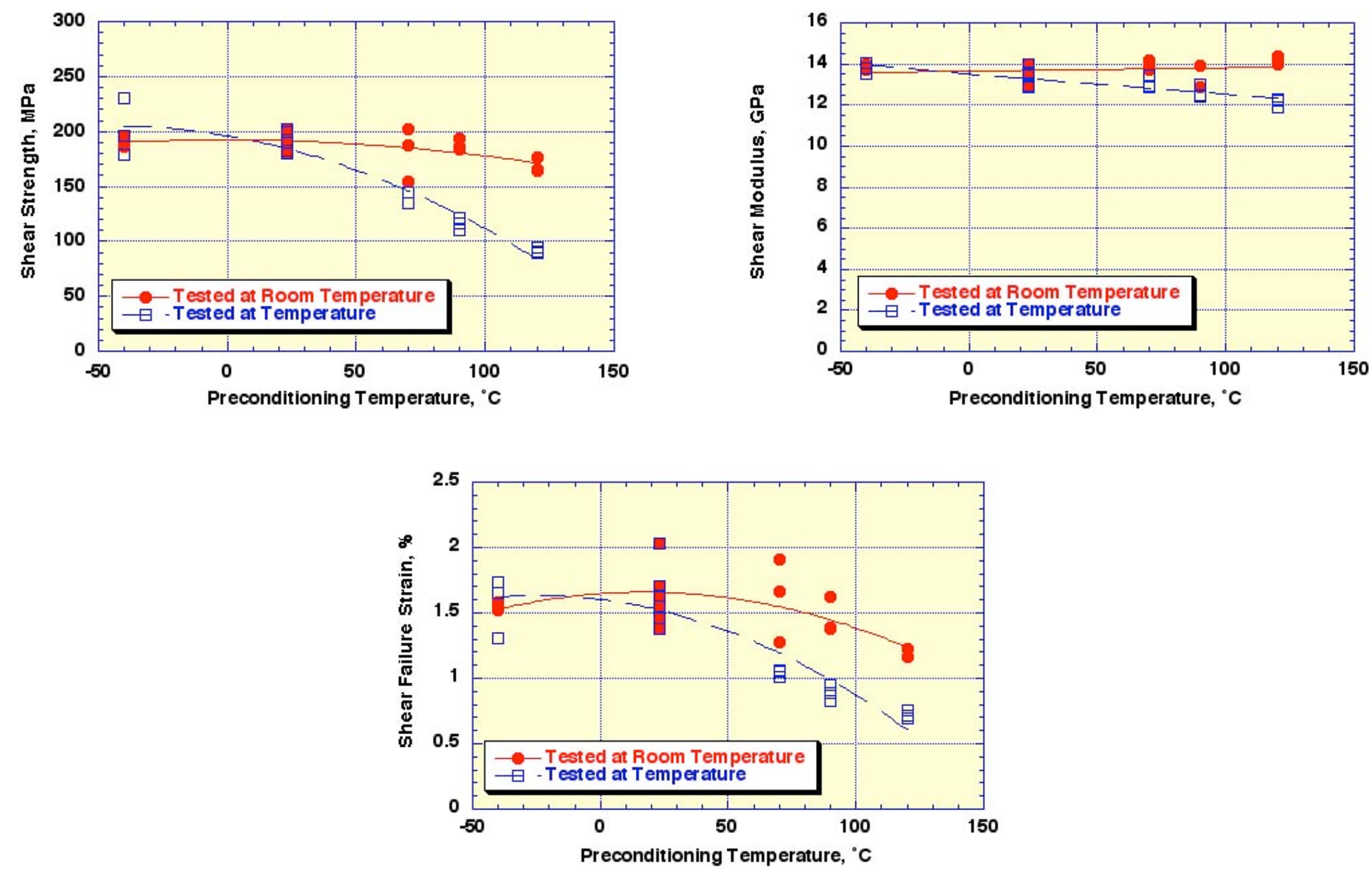


\section{Commentary: \\ Temperature Effects - Shear Results Annealed Material $0^{\circ}$ Specimen Orientation}

- Shear strength tended to decrease with increasing preconditioning temperature for specimens tested either at temperature or room temperature with decrease greatest for specimens tested at temperature

- Modulus of specimens tested at temperature tended to decrease with increasing preconditioning temperature, but showed little effect of preconditioning temperature when tested at room temperature

- Failure strains decreased with increasing preconditioning temperature for specimens tested at either temperature or room temperature with decrease greatest for specimens tested at temperature 


\section{Effect of Temperature on Shear Strength: As-Received vs Annealed Material, $0^{\circ}$ Specimen Orientation}
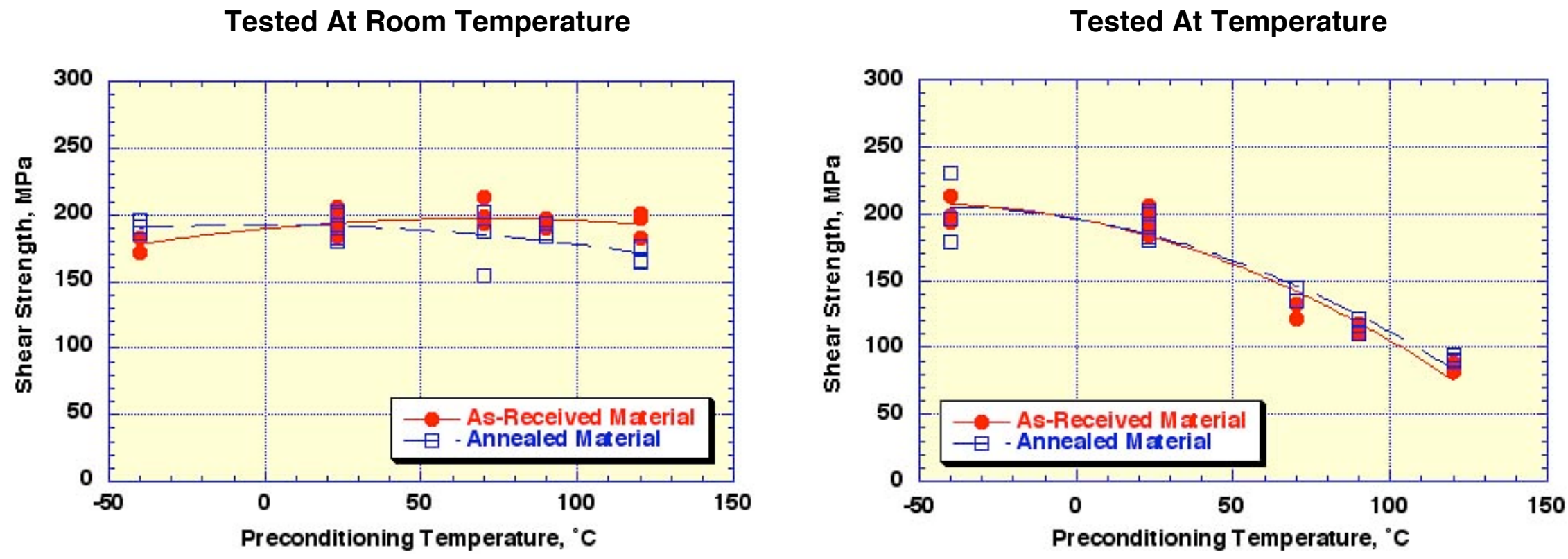


\section{Effect of Temperature on Shear Modulus: As-Received vs Annealed Material, $0^{\circ}$ Specimen Orientation}
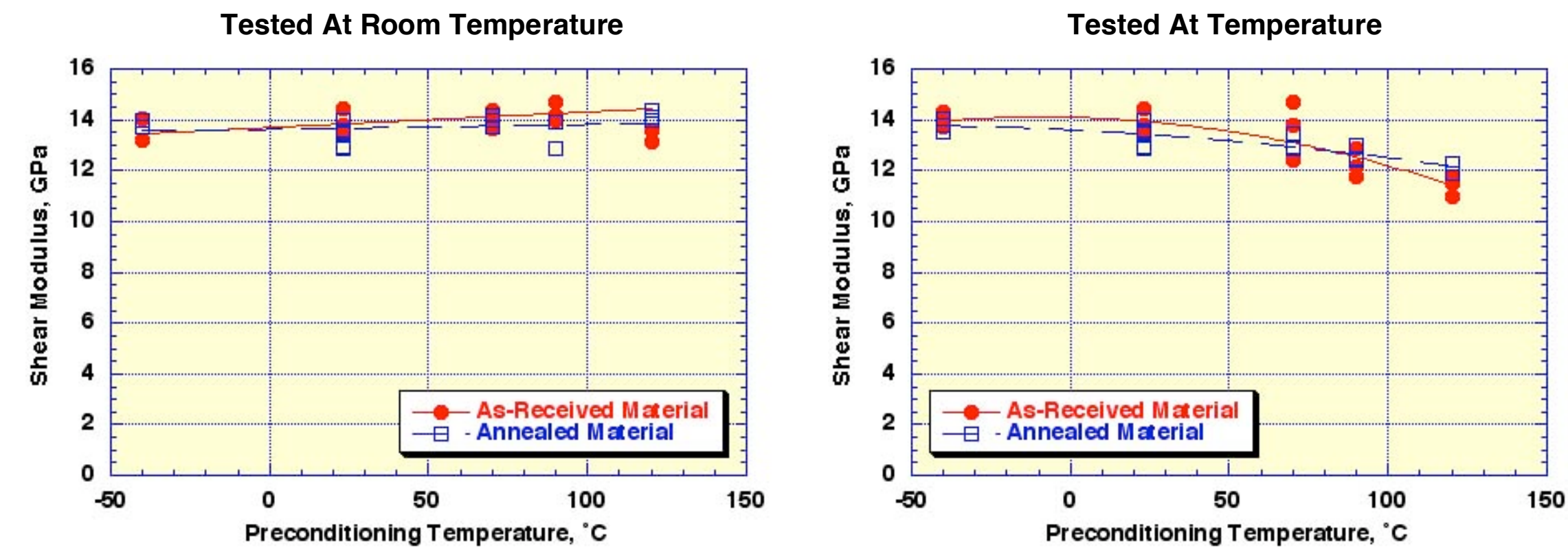


\section{Effect of Temperature on Shear Failure Strain: As-Received vs Annealed Material, $0^{\circ}$ Specimen Orientation}
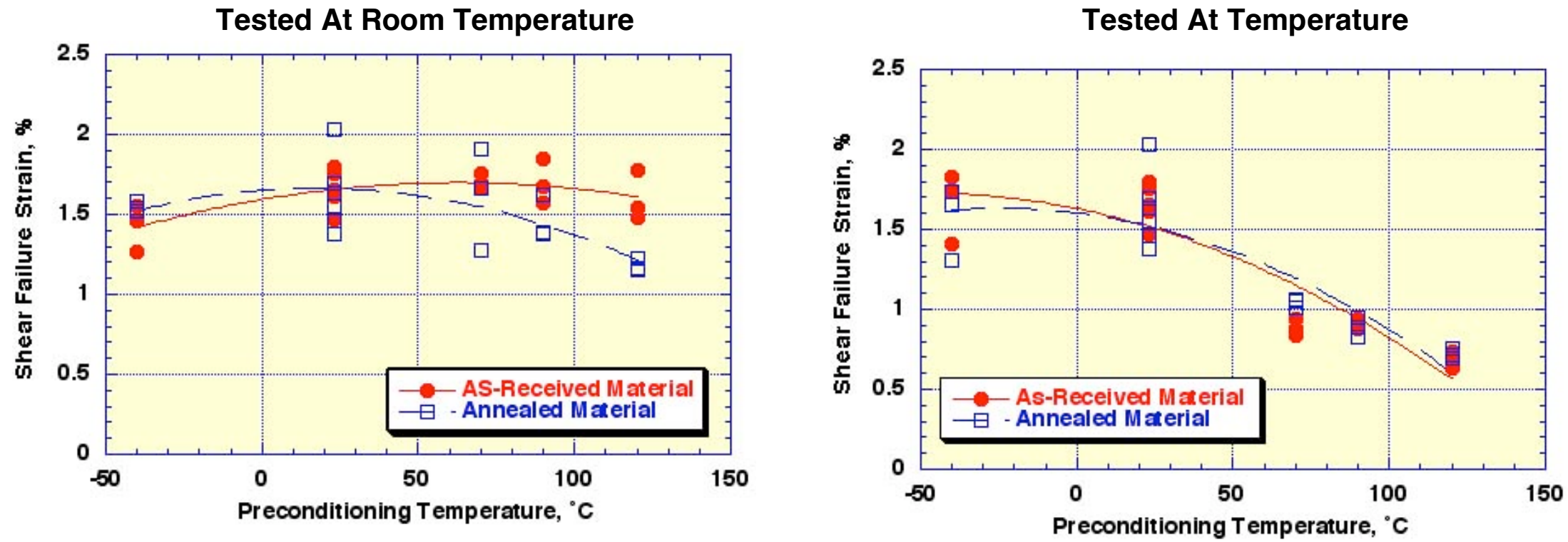


\section{Commentary: \\ Temperature Effects - Shear Results As-Received versus Annealed Material}

- Shear strengths of both as-received and annealed materials decreased with increasing preconditioning temperature when tested at temperature and were relatively unaffected by preconditioning temperature when tested at room temperature

- Modulus of both as-received and annealed materials tended to decrease slightly with increasing preconditioning temperature when tested at temperature and increase slightly when tested at room temperature

- Failure strains of both as-received and annealed materials tended to decrease with increasing preconditioning temperature when tested at temperature 

Appendix F

Tensile Creep Test Result Summary 

Specimen Number: T31-25

Load Level: $85.0 \%$ UTS

Environment: In-Air Room Temperature

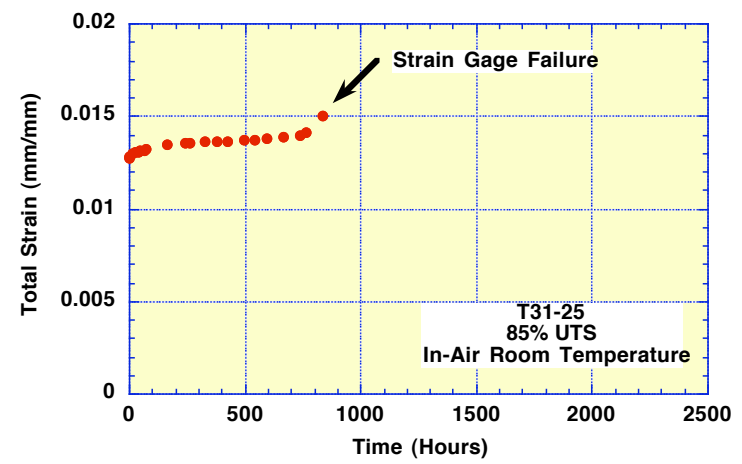

Total Strain vs Time

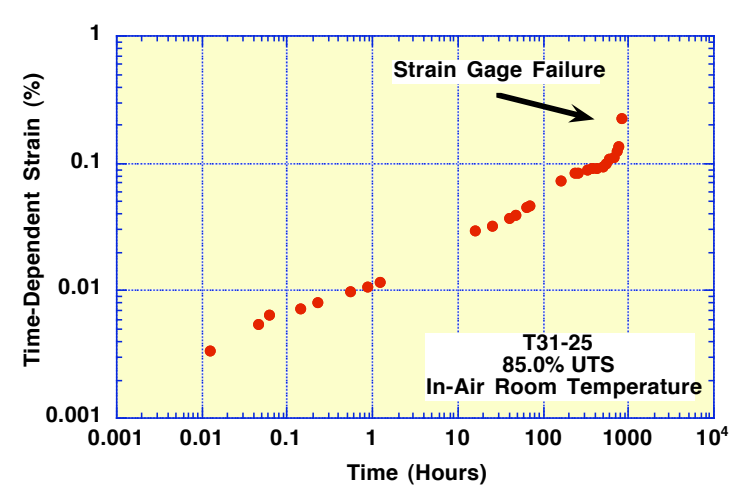

Time-Dependent Strain (Log Plot)

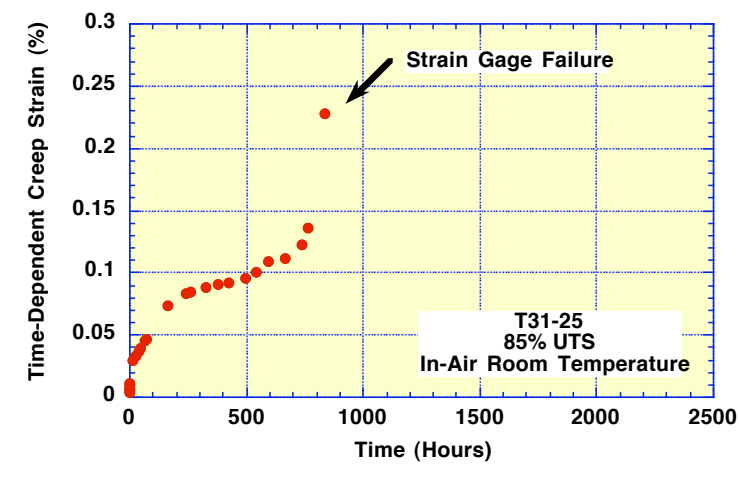

Time-Dependent Strain (Linear Plot)

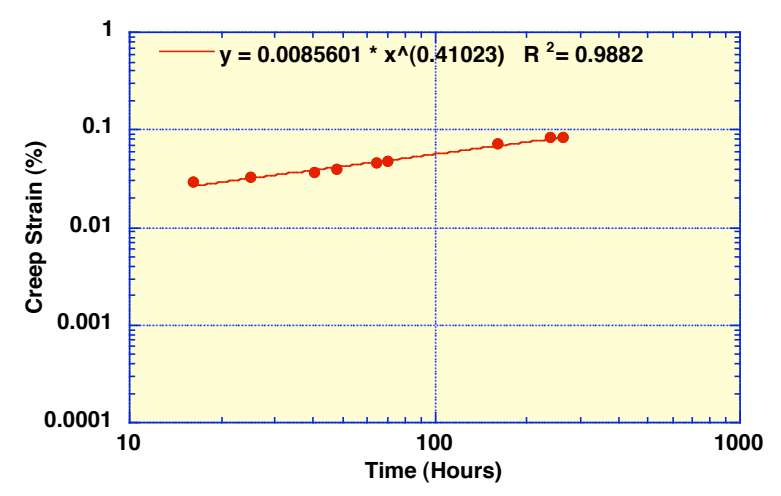

curves. Power Law Fit 
Specimen Number: T31-28

Load Level: $79.9 \%$ UTS

Environment: In-Air Room Temperature

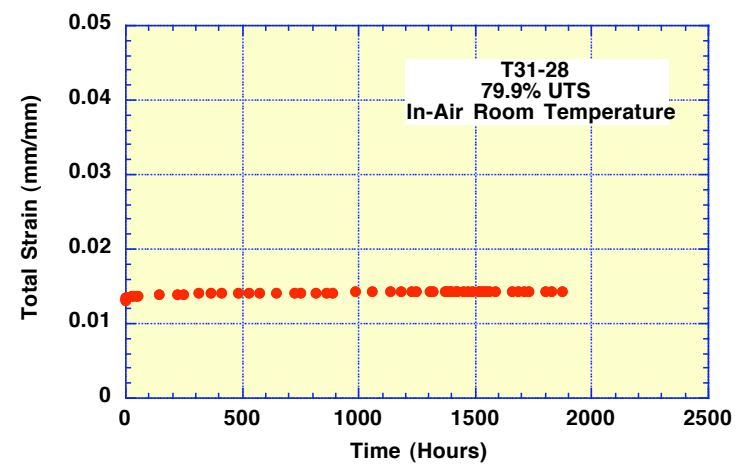

Total Strain vs Time

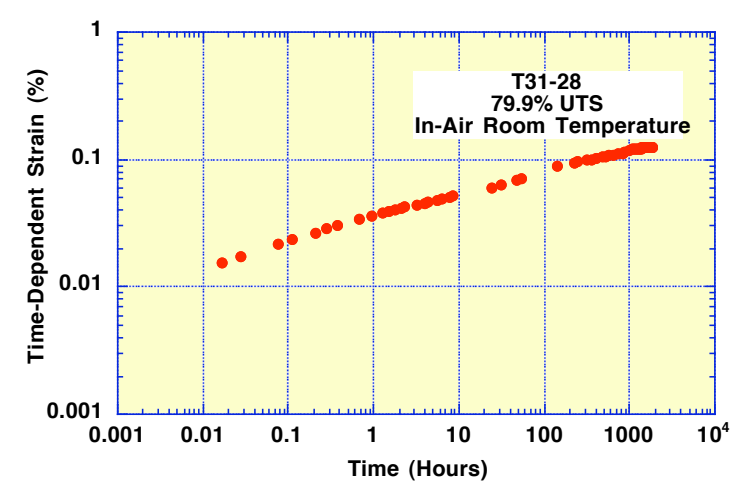

Time-Dependent Strain (Log Plot)

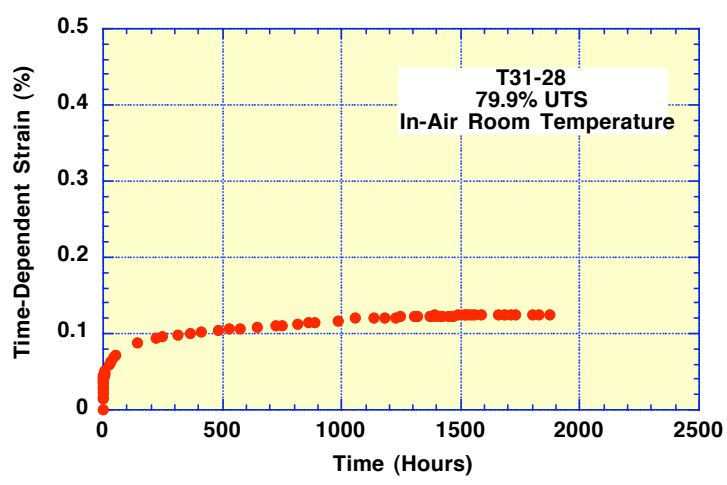

Time-Dependent Strain (Linear Plot)

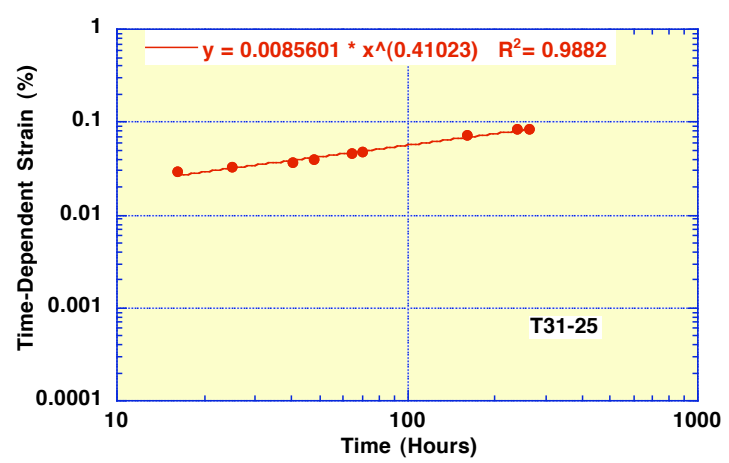

Power Law Fit. 
Specimen Number: T31-1

Load Level: $80.6 \%$ UTS

Environment: In-Air Room Temperature

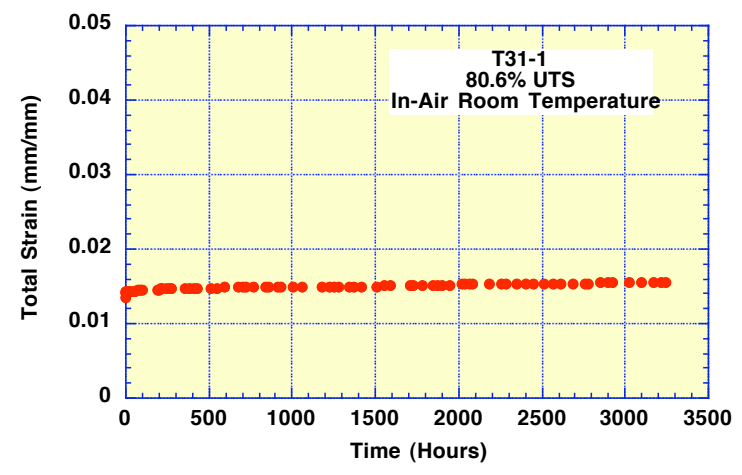

Total Strain vs Time

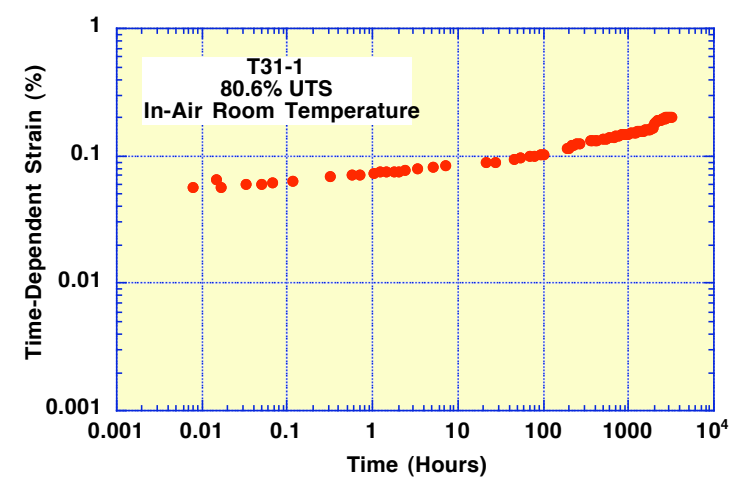

Time-Dependent Strain (Log Plot)

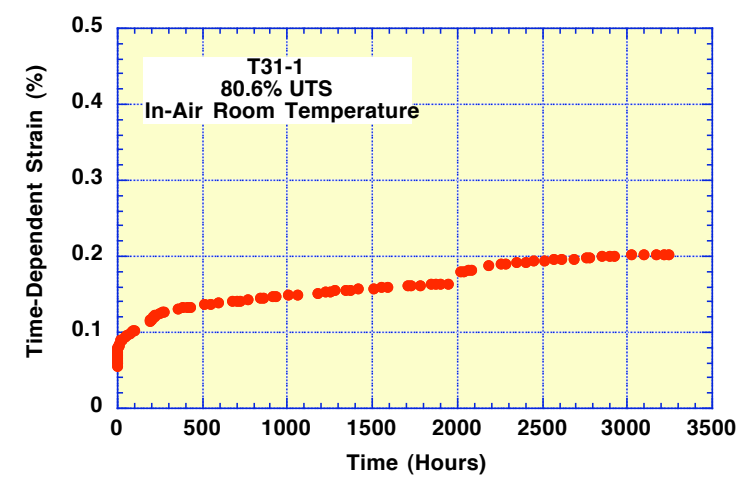

Time-Dependent Strain (Linear Plot)

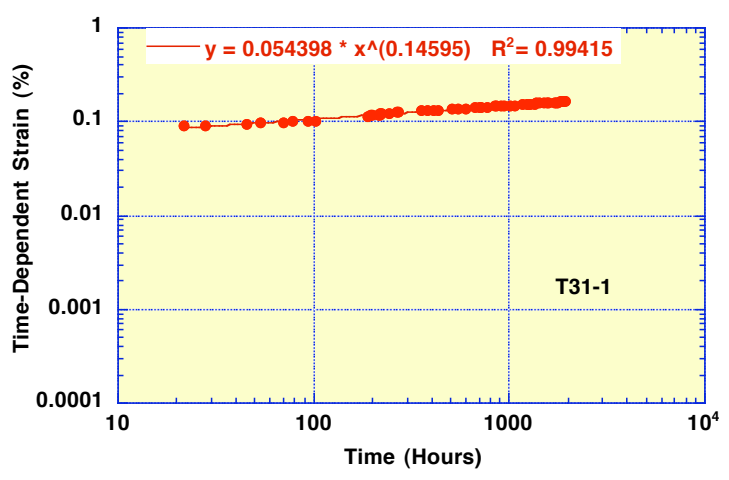

Power Law Fit 
Specimen Number: T31-24

Load Level: $74.9 \%$ UTS

Environment: In-Air Room Temperature

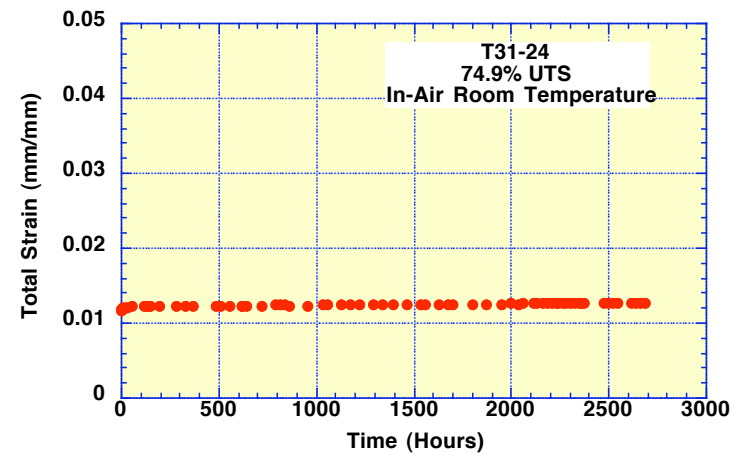

Total Strain vs Time

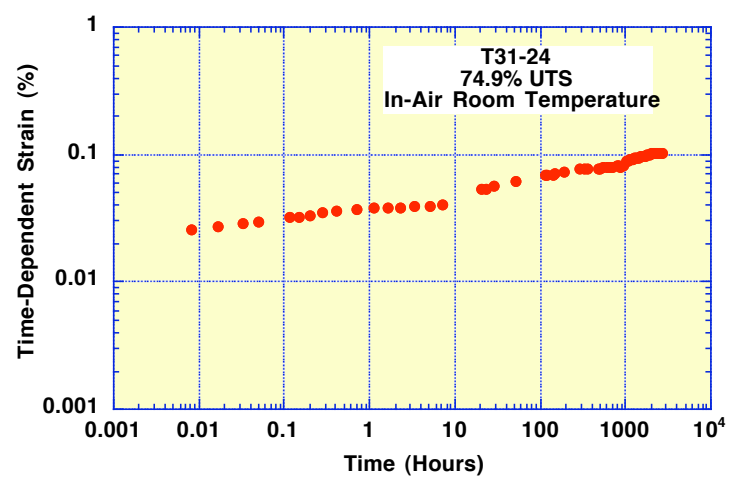

Time-Dependent Strain (Log Plot)

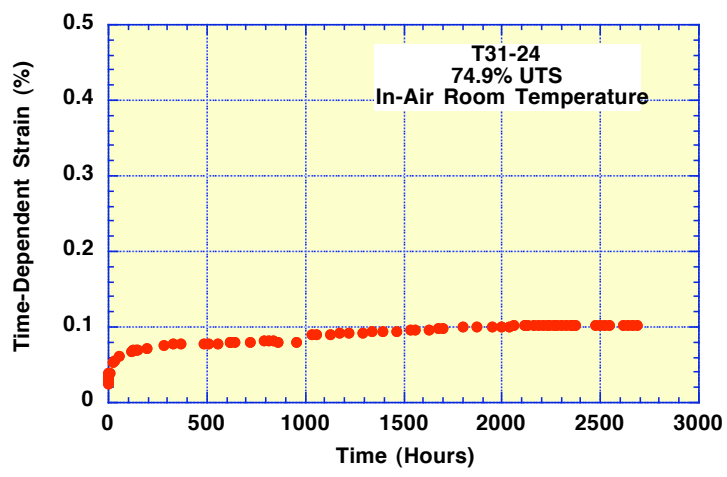

Time-Dependent Strain (Linear Plot)

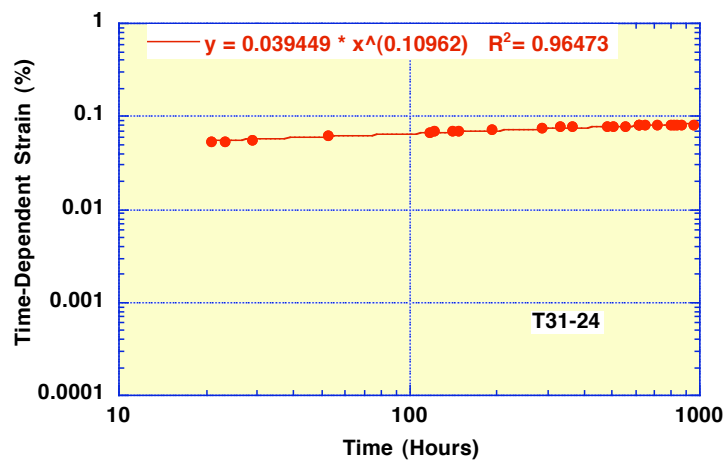

Power Law Fit. 


\section{Specimen Number: T31-31}

Load Level: $85.0 \%$ UTS

Environment: In-Air Room Temperature

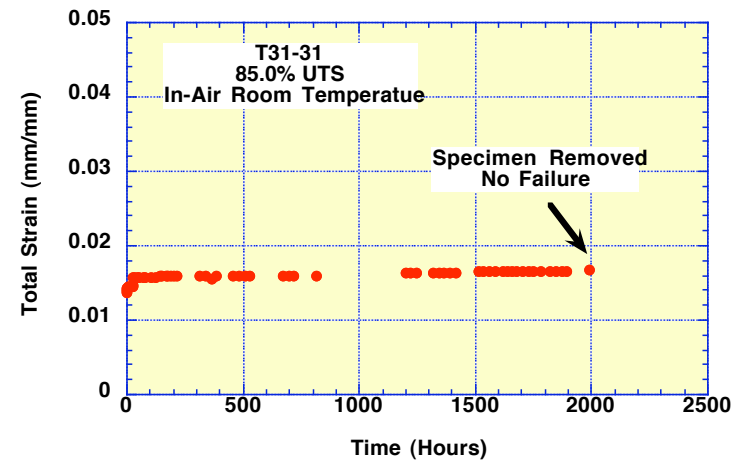

Total Strain vs Time

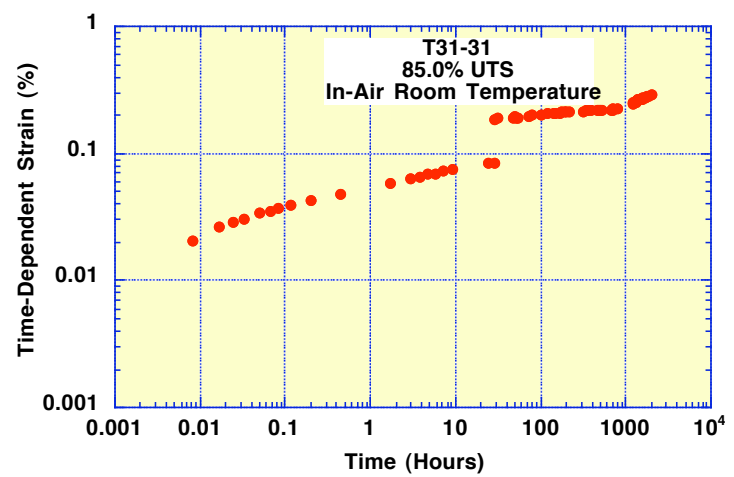

Time-Dependent Strain (Log Plot)

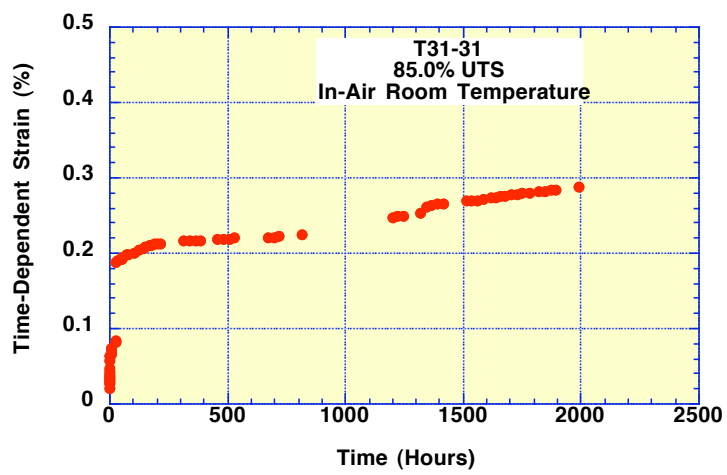

Time-Dependent Strain (Linear Plot)

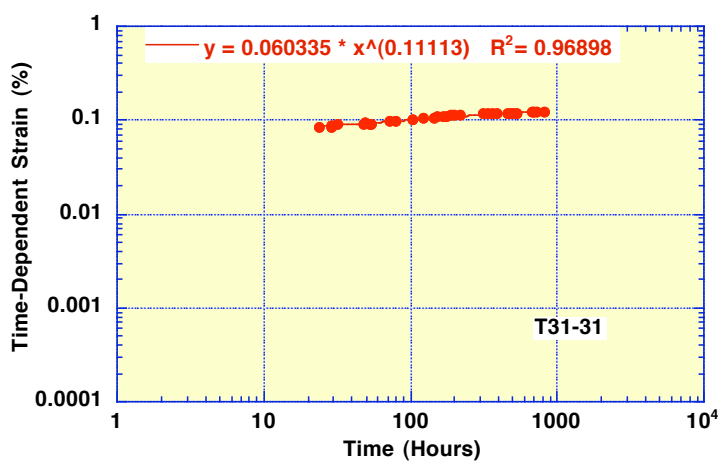

Power Law Fit. 
Specimen Number: T31-19

Load Level: $74.4 \%$ UTS

Environment: In-Air Room Temperature

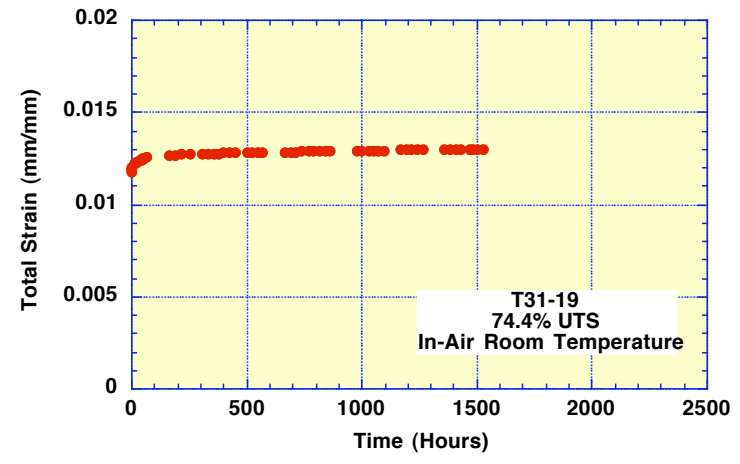

Total Strain vs Time

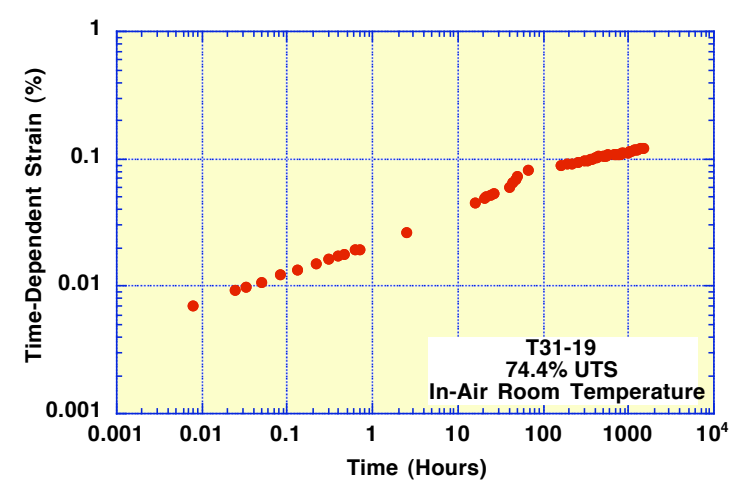

Time-Dependent Strain (Log Plot)

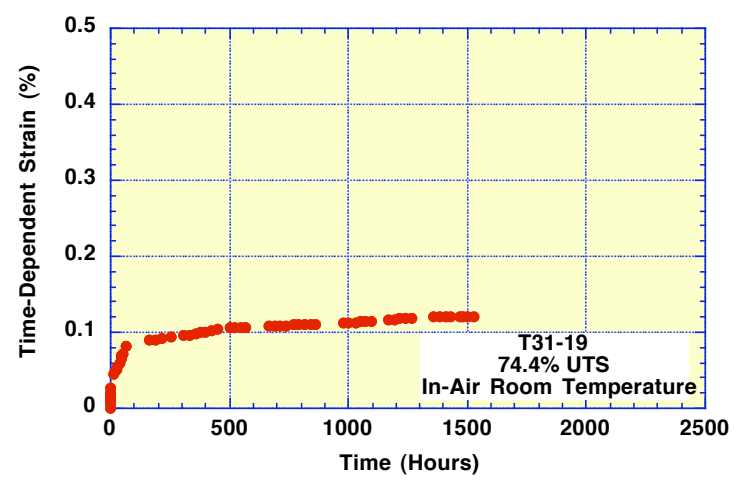

Time-Dependent Strain (Linear Plot)

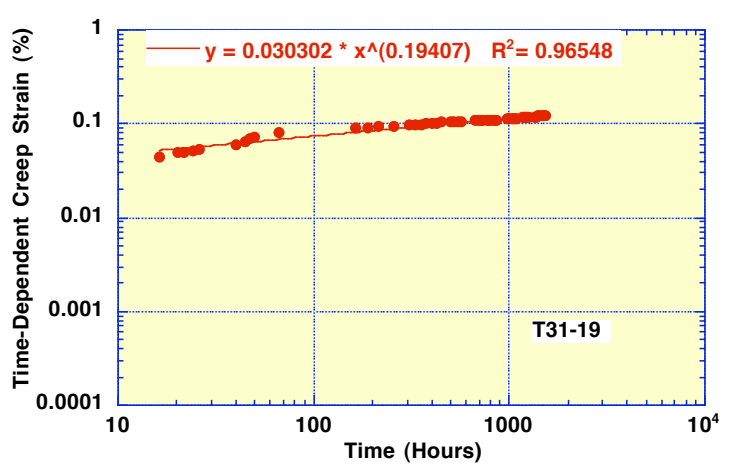

Power Law Fit. 
Specimen Number: T31-36

Load Level: $70.0 \%$ UTS

Environment: In-Air Room Temperature

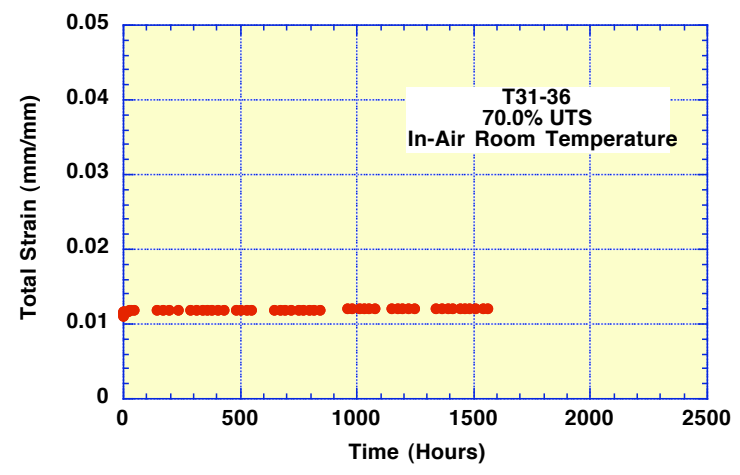

Total Strain vs Time

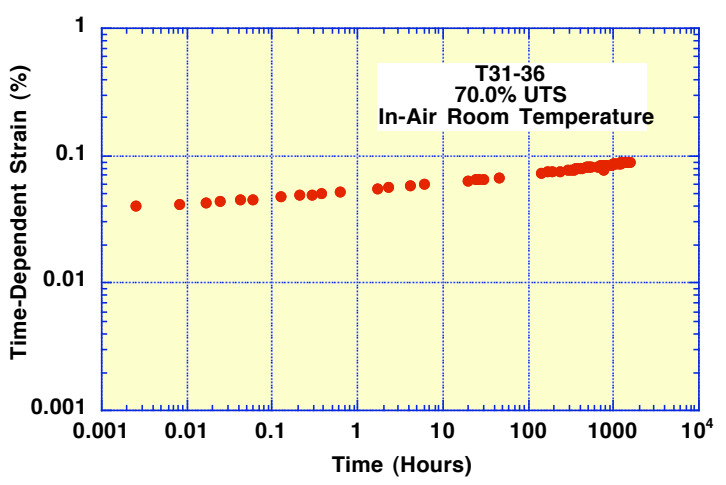

Time-Dependent Strain (Log Plot)

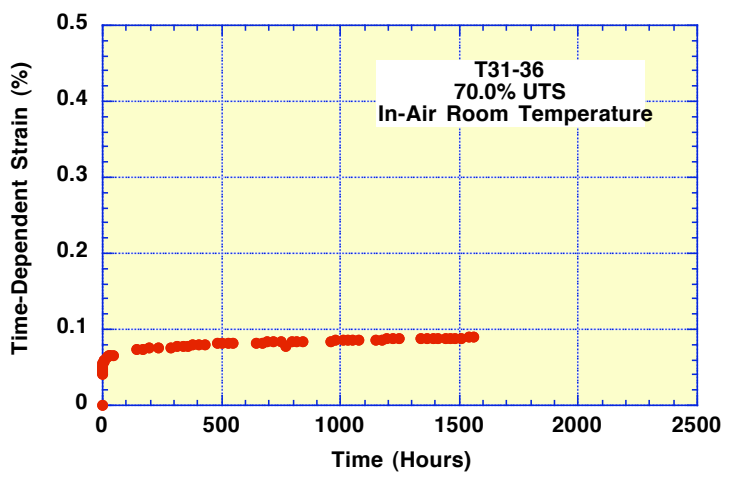

Time-Dependent Strain (Linear Plot)

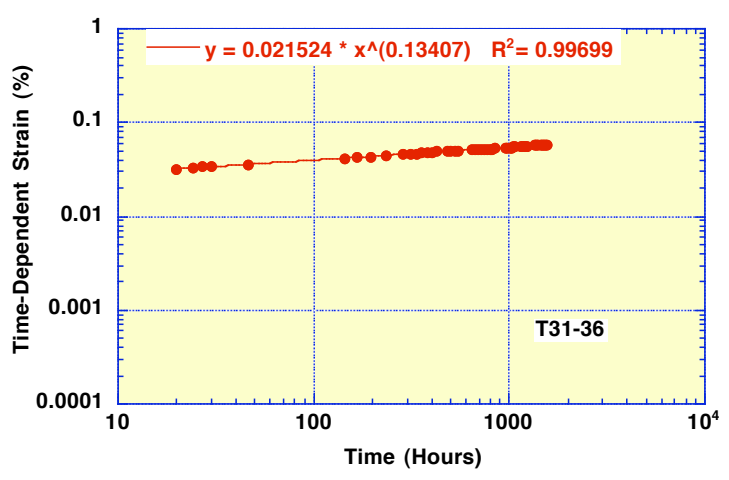

Power Law Fit. 
Specimen Number: T31-46

Load Level: $60.0 \%$ UTS

Environment: In-Air Room Temperature

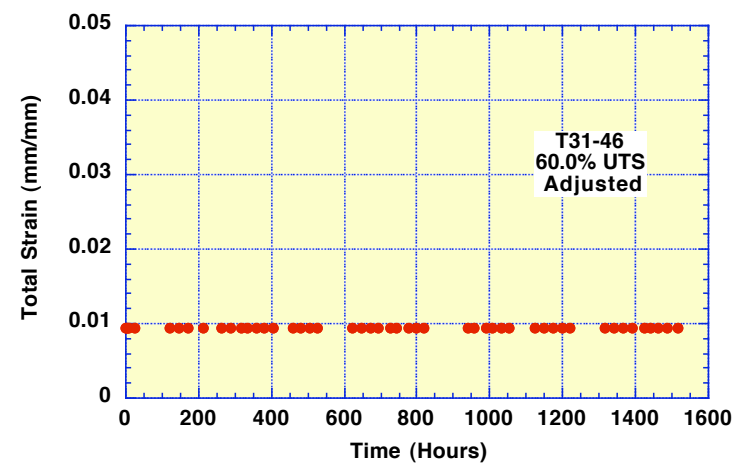

Total Strain vs Time

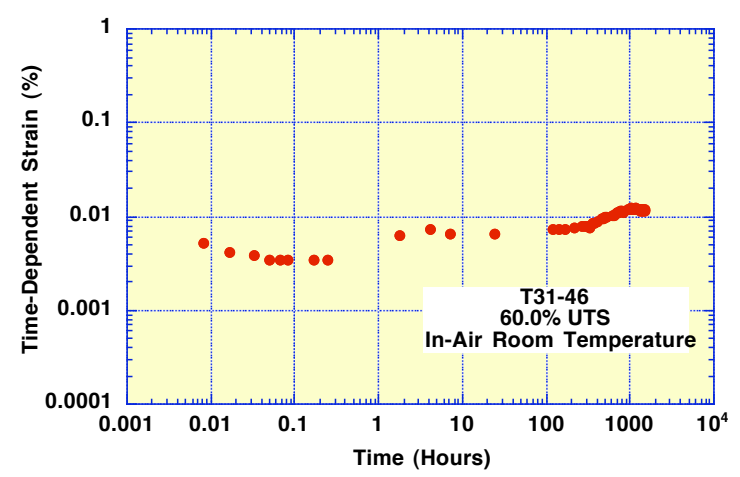

Time-Dependent Strain (Log Plot)

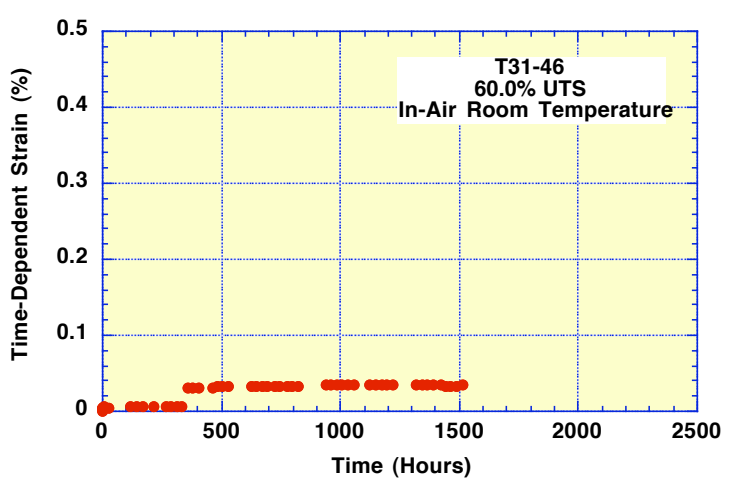

Time-Dependent Strain (Linear Plot)

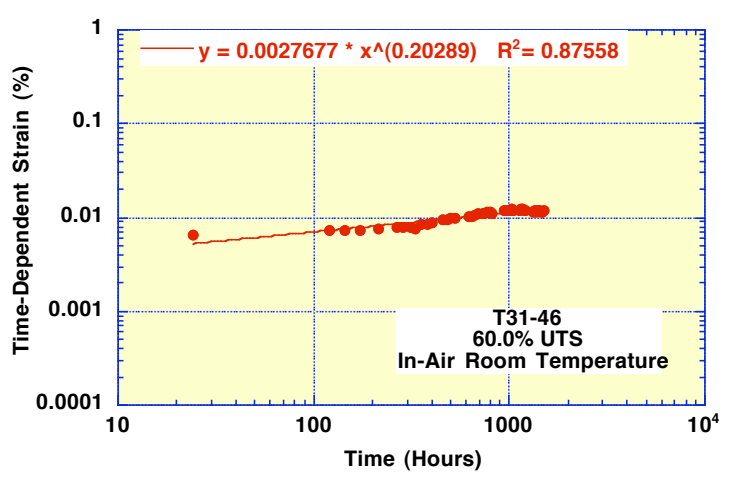

Power Law Fit. 
Specimen Number: T31-47

Load Level: $60.0 \%$ UTS

Environment: In-Air Room Temperature

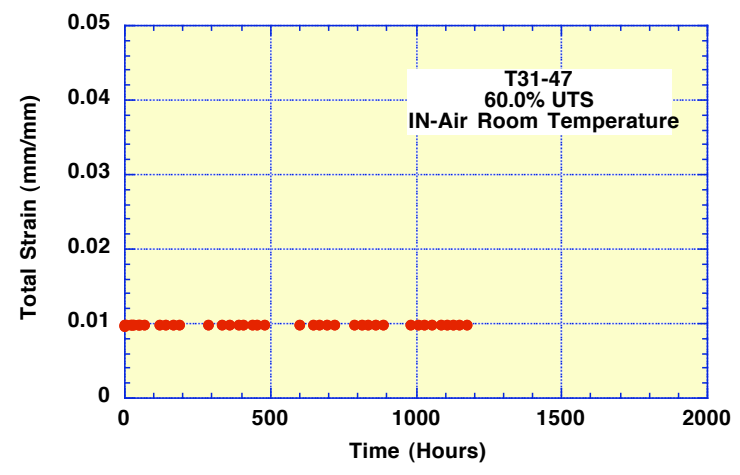

Total Strain vs Time

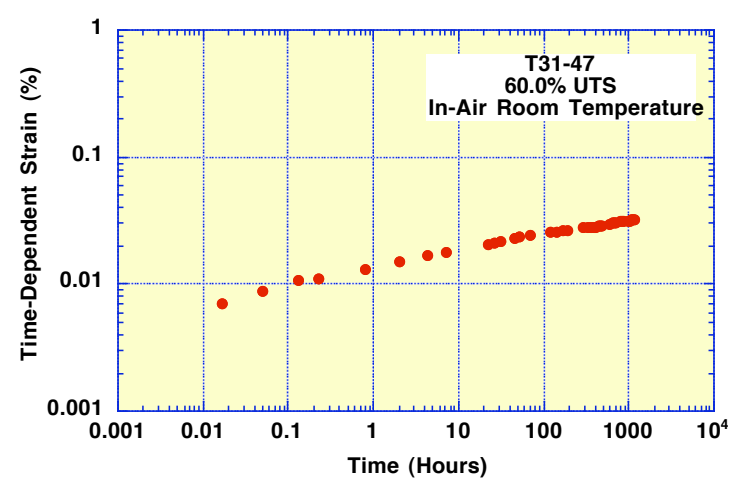

Time-Dependent Strain (Log Plot)

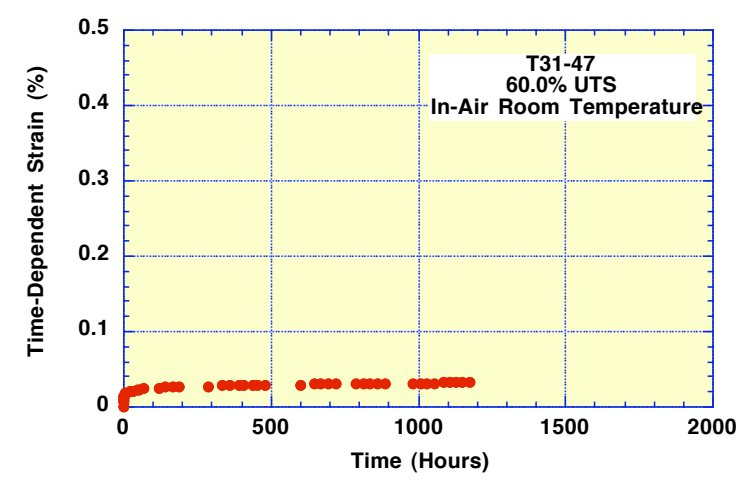

Time-Dependent Strain (Linear Plot)

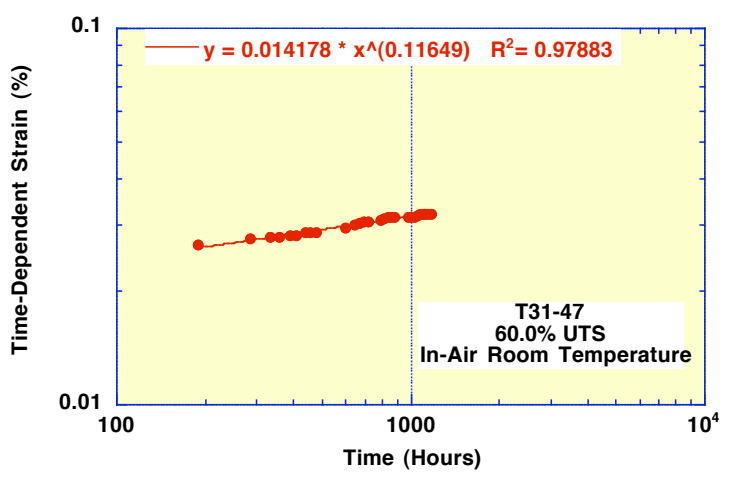

Power Law Fit. 
Specimen Number: T31-48

Load Level: $\mathbf{5 0 . 0 \%}$ UTS

Environment: In-Air Room Temperature

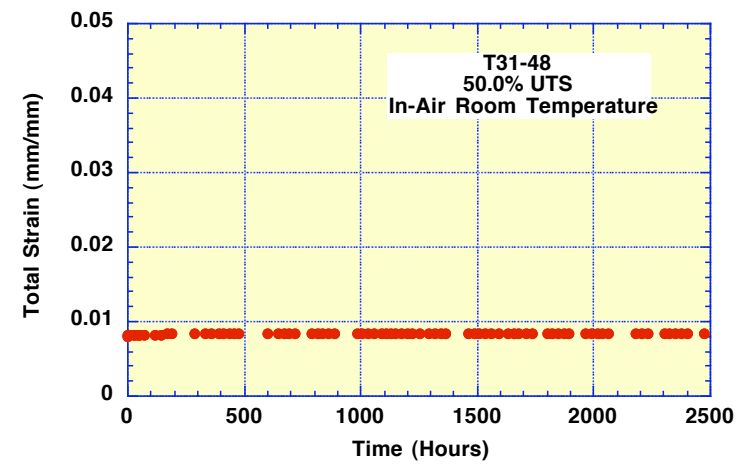

Total Strain vs Time

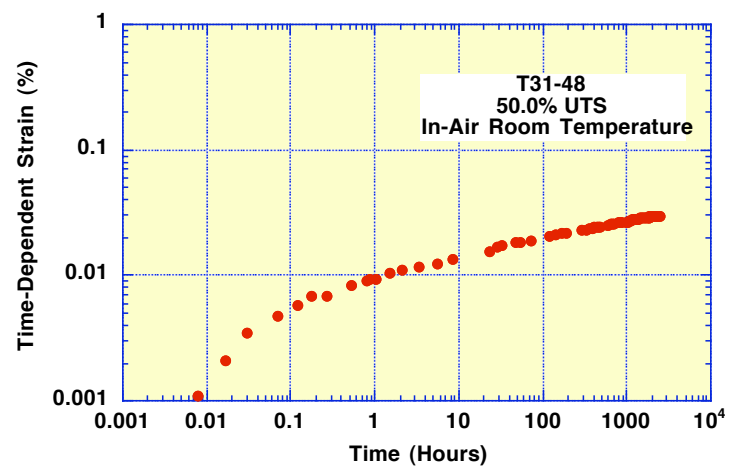

Time-Dependent Strain (Log Plot)

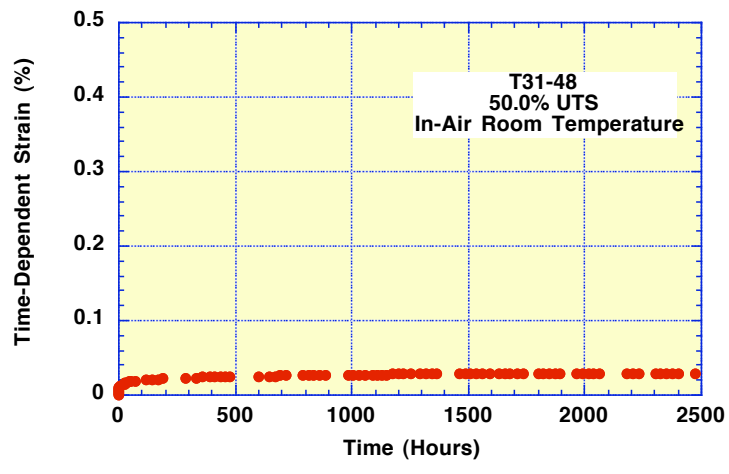

Time-Dependent Strain (Linear Plot)

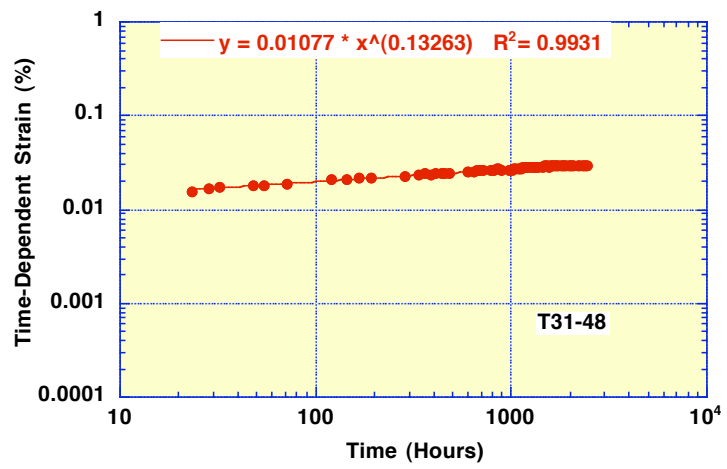

Power Law Fit. 
Specimen Number: T31-52

Load Level: $50.0 \%$ UTS

Environment: In-Air Room Temperature

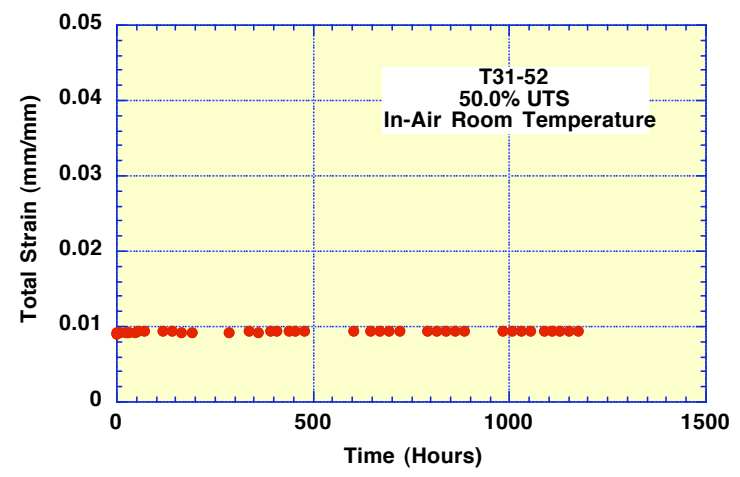

Total Strain vs Time

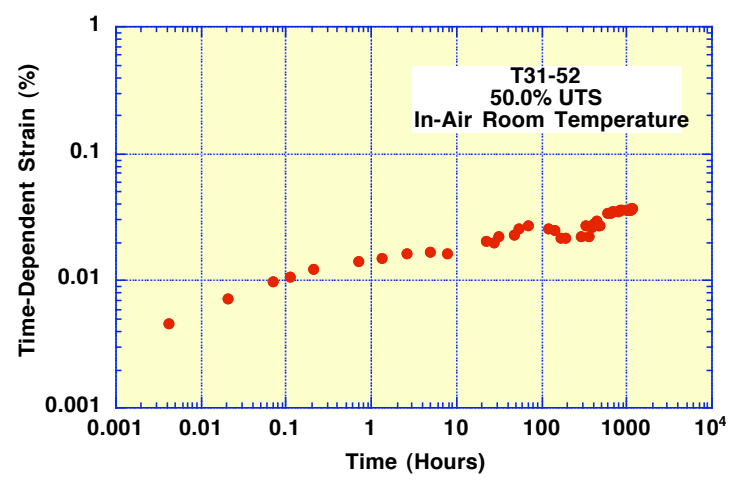

Time-Dependent Strain (Log Plot)

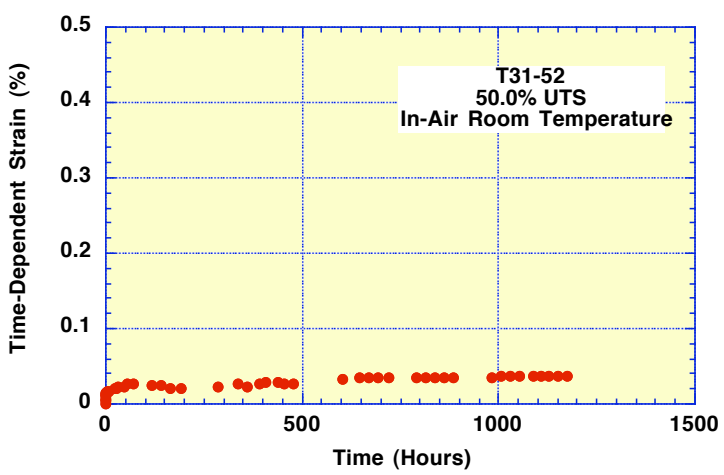

Time-Dependent Strain (Linear Plot)

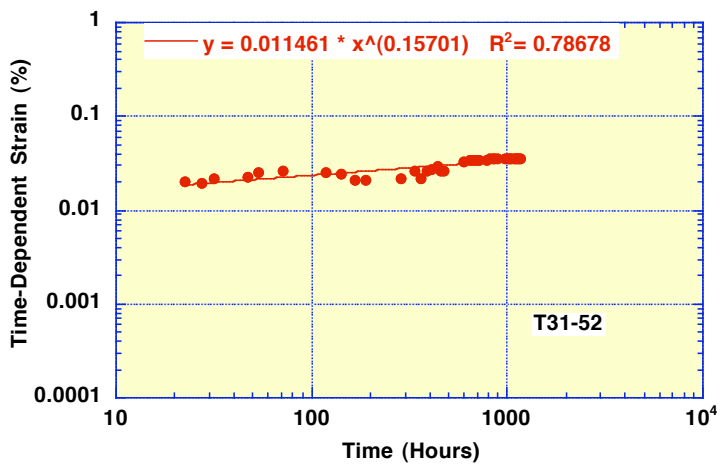

Power Law Fit. 
Specimen Number: T31-53

Load Level: $50.0 \%$ UTS

Environment: In-Air Room Temperature

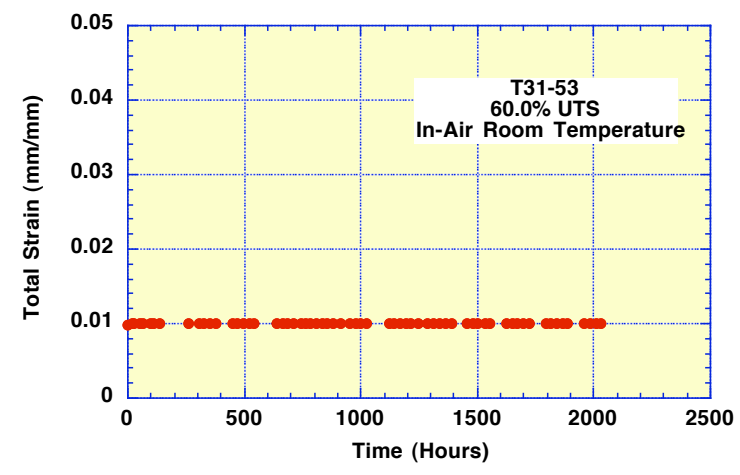

Total Strain vs Time

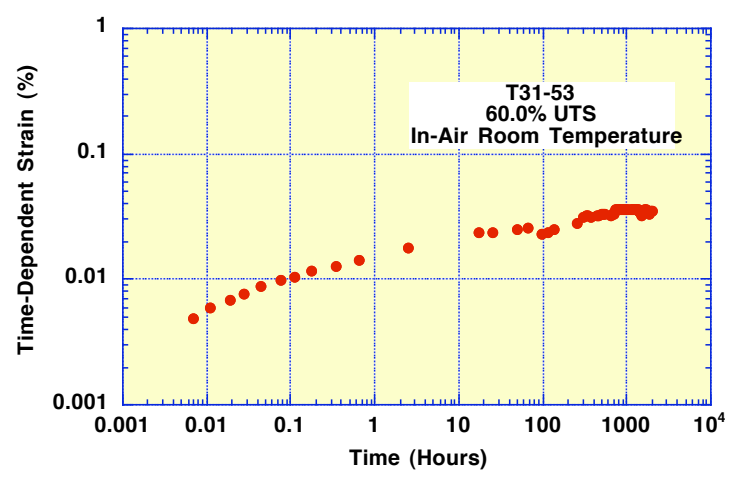

Time-Dependent Strain (Log Plot)

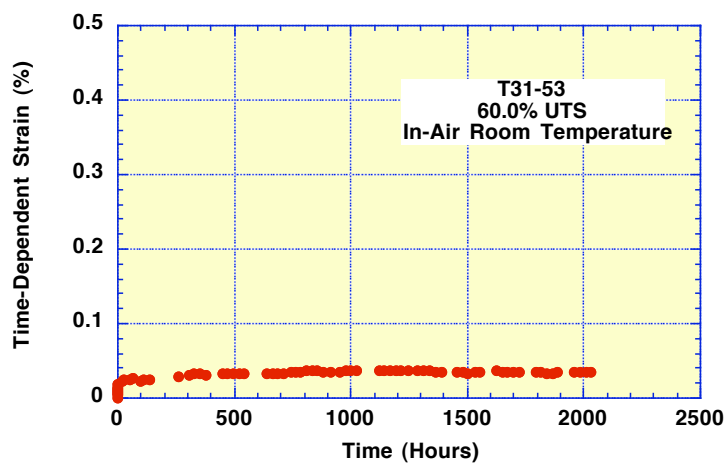

Time-Dependent Strain (Linear Plot)

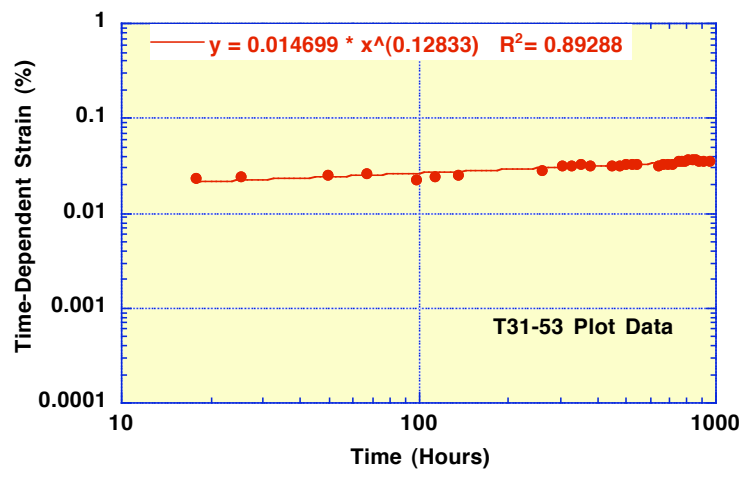

Power Law Fit. 
Specimen Number: T31-50

Load Level: $85.0 \%$ UTS

Environment: In-Air Room Temperature

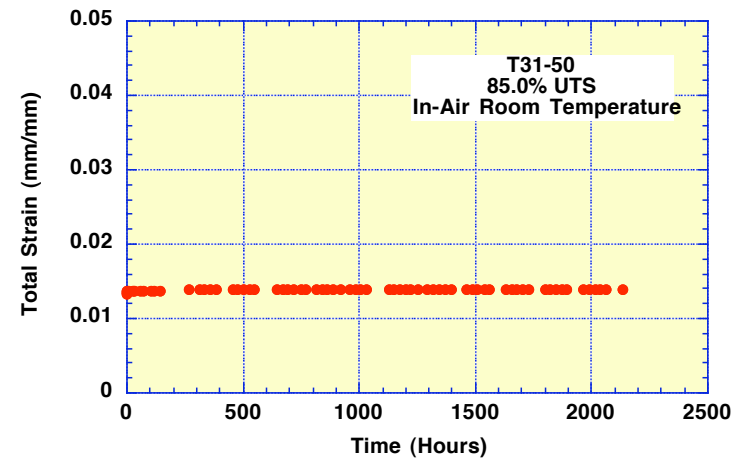

Total Strain vs Time

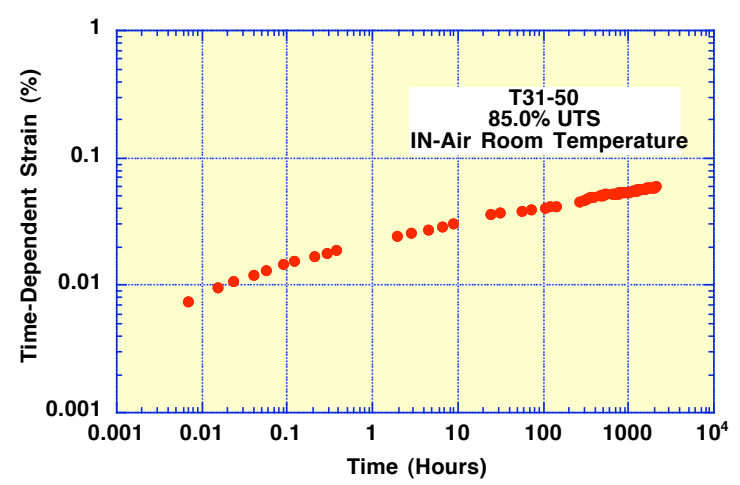

Time-Dependent Strain (Log Plot)

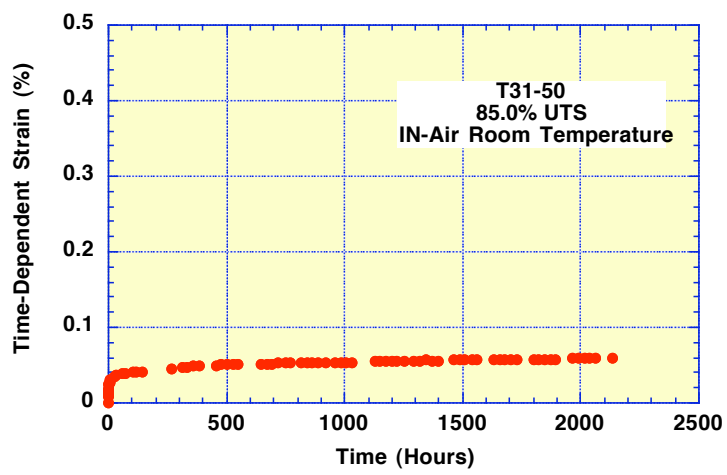

Time-Dependent Strain (Linear Plot)

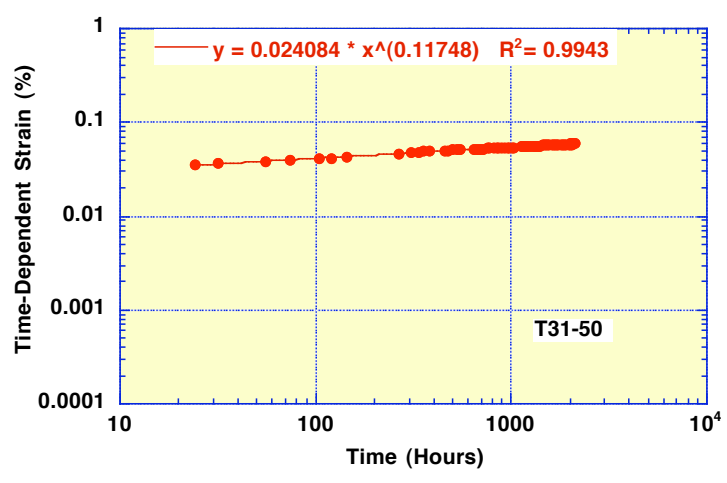

Power Law Fit. 
Specimen Number: T31-35

Load Level: $70.0 \%$ UTS

Environment: In-Air Room Temperature

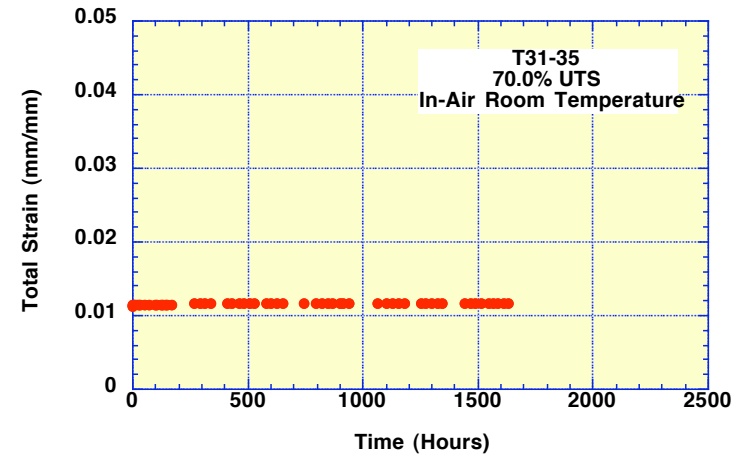

Total Strain vs Time

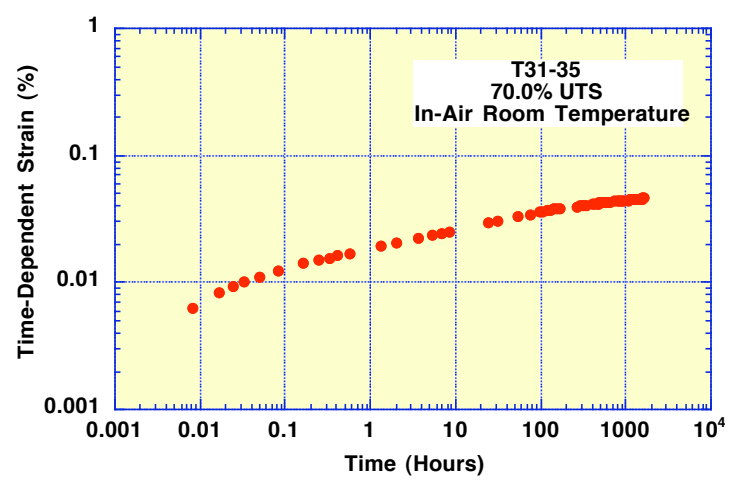

Time-Dependent Strain (Log Plot)

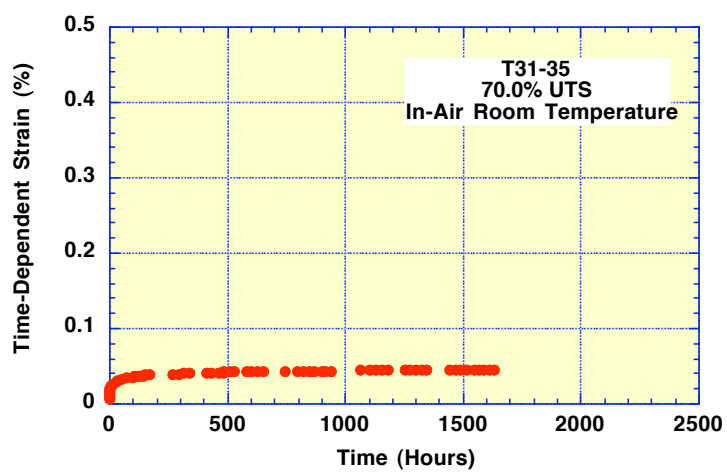

Time-Dependent Strain (Linear Plot)

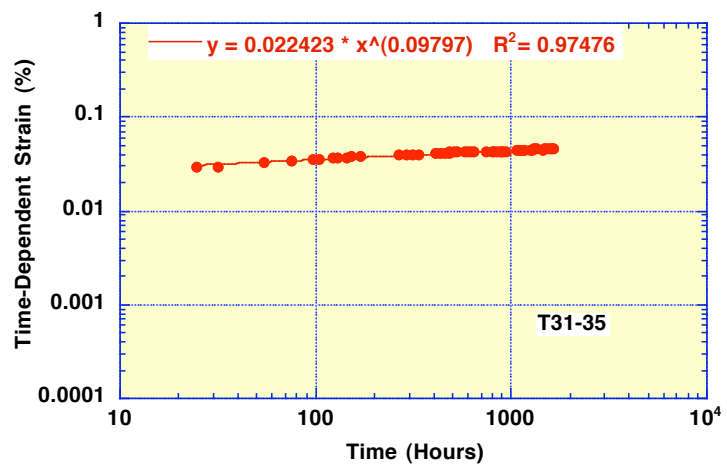

Power Law Fit. 
Specimen Number: T46-3

Load Level: $55.0 \%$ UTS

Environment: In-Air Room Temperature

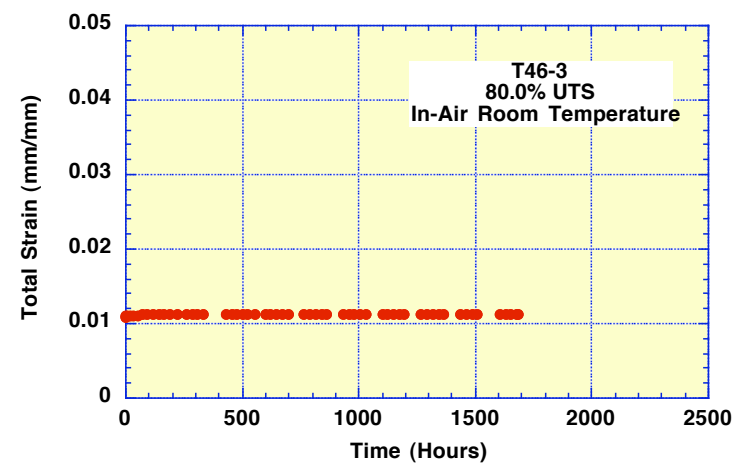

Total Strain vs Time

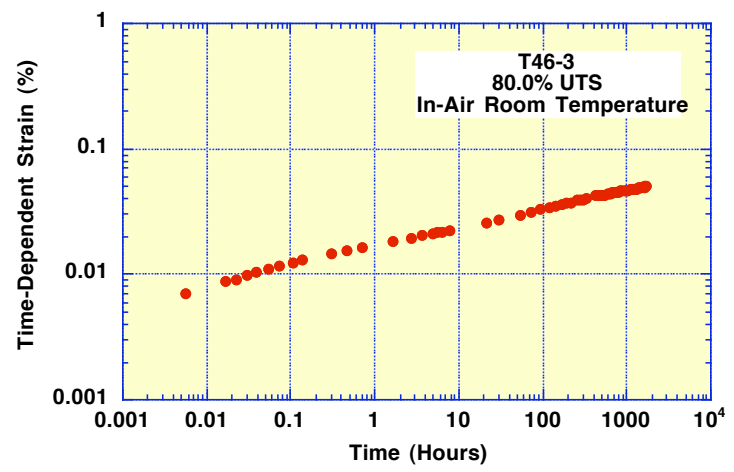

Time-Dependent Strain (Log Plot)

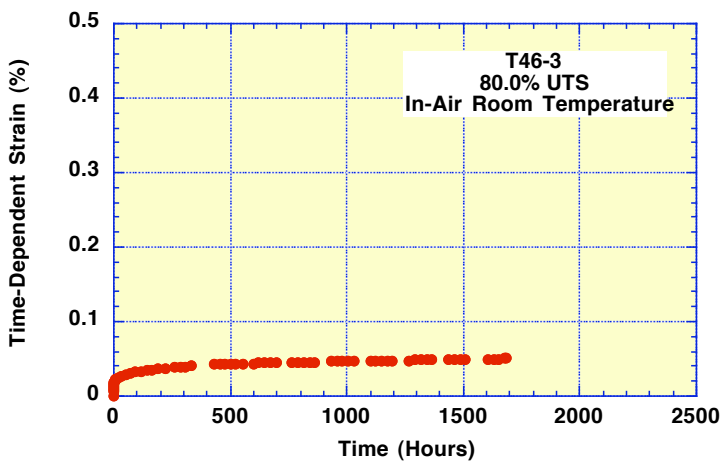

Time-Dependent Strain (Linear Plot)

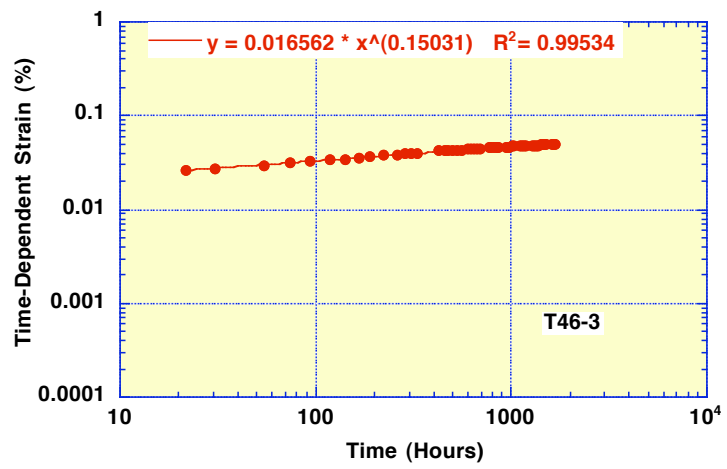

Power Law Fit. 
Specimen Number: T46-7

Load Level: $75.0 \%$ UTS

Environment: In-Air Room Temperature

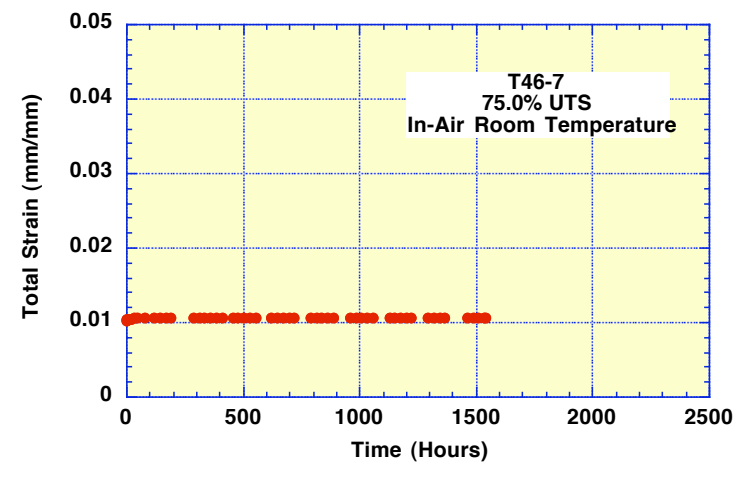

Total Strain vs Time

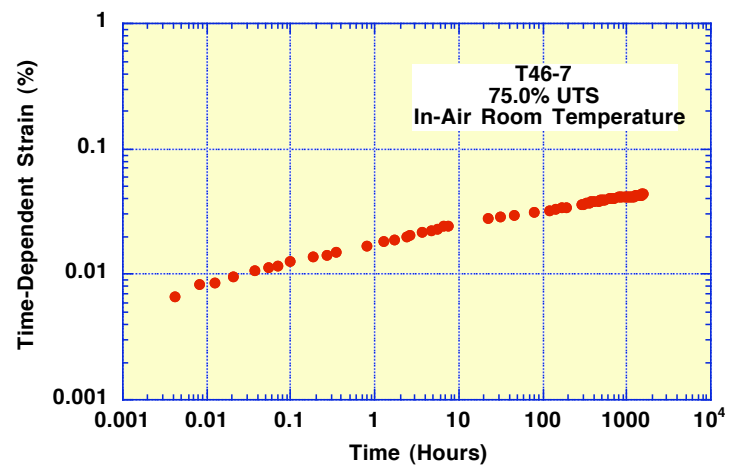

Time-Dependent Strain (Log Plot)

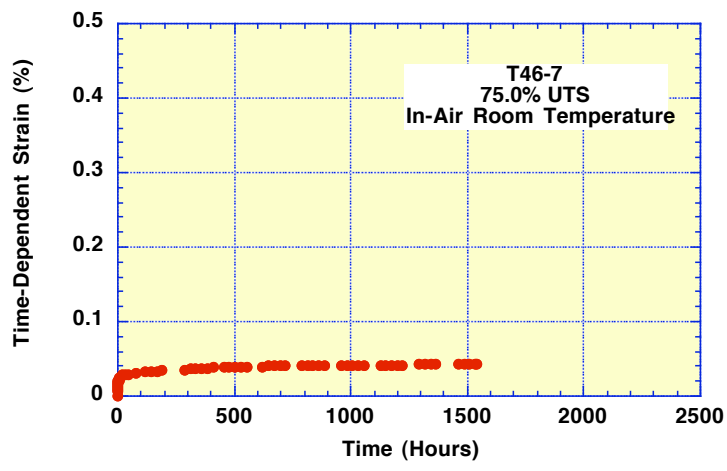

Time-Dependent Strain (Linear Plot)

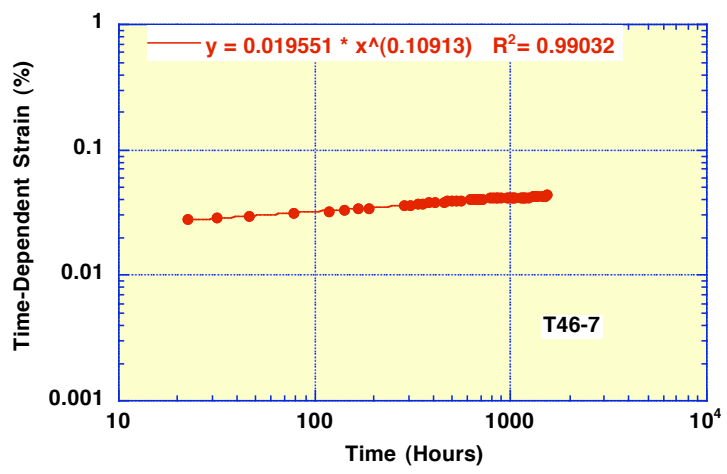

Power Law Fit. 
Specimen Number: T46-6

Load Level: $75.0 \%$ UTS

Environment: In-Air Room Temperature

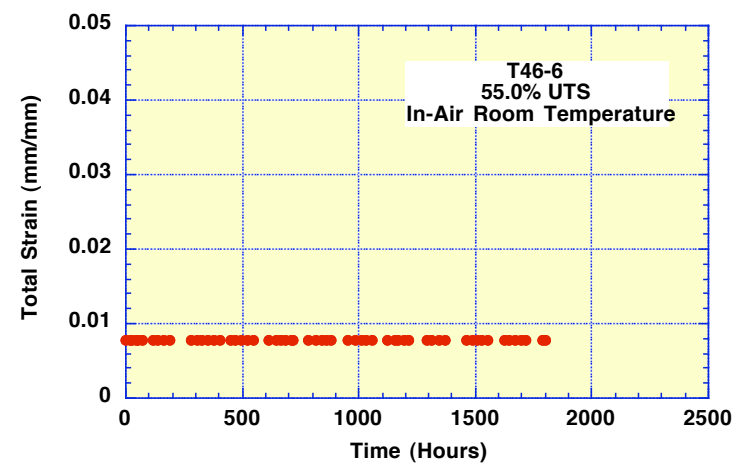

Total Strain vs Time

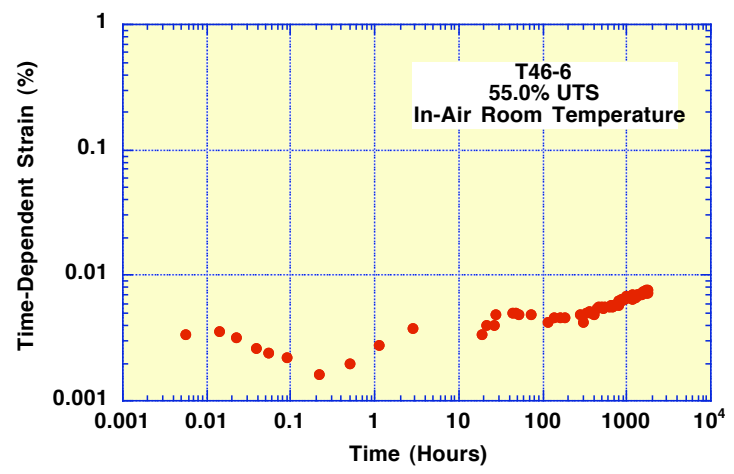

Time-Dependent Strain (Log Plot)

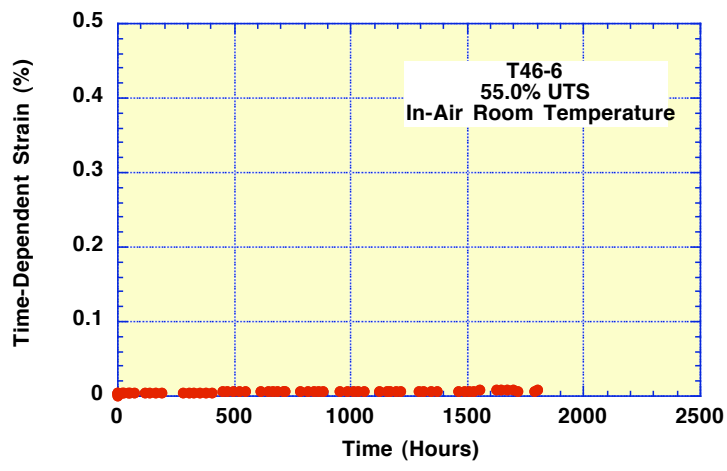

Time-Dependent Strain (Linear Plot)

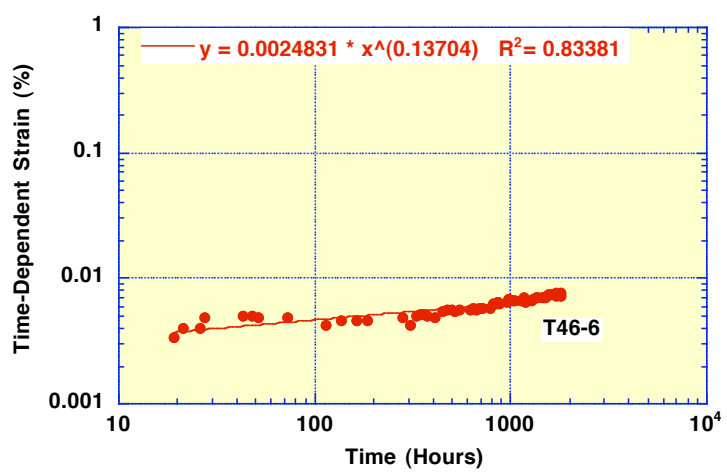

Power Law Fit. 
Specimen Number: T46-8

Load Level: $65.0 \%$ UTS

Environment: In-Air Room Temperature

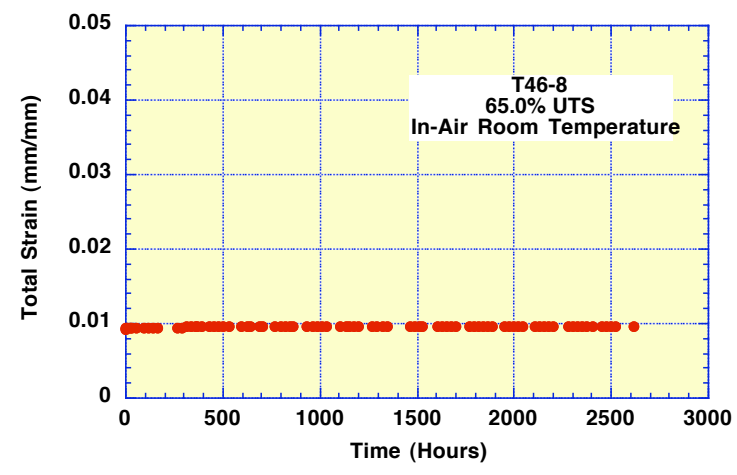

Total Strain vs Time

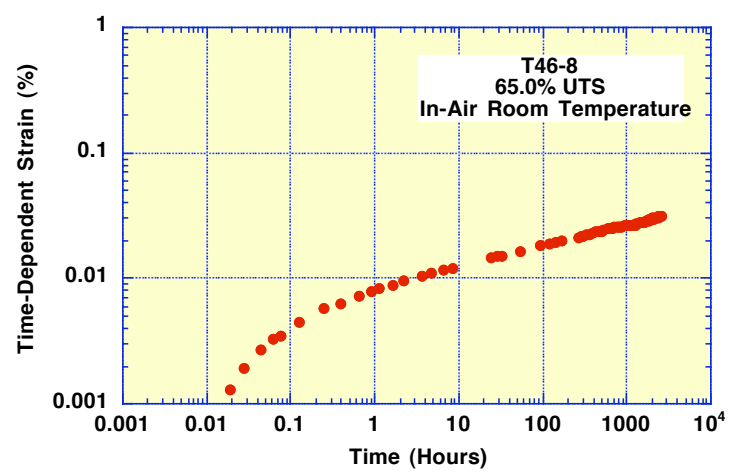

Time-Dependent Strain (Log Plot)

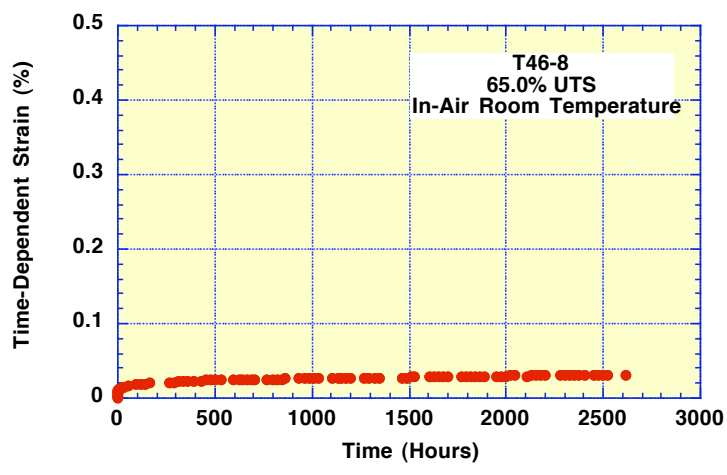

Time-Dependent Strain (Linear Plot)

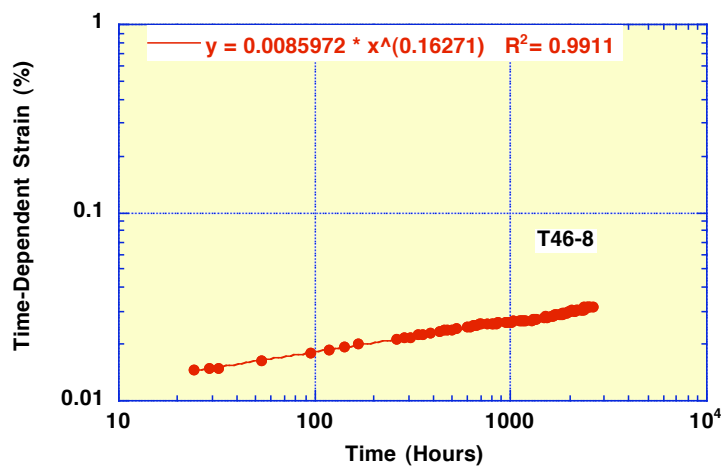

Power Law Fit. 
Specimen Number: T46-14

Load Level: $85.0 \%$ UTS

Environment: In-Air Room Temperature

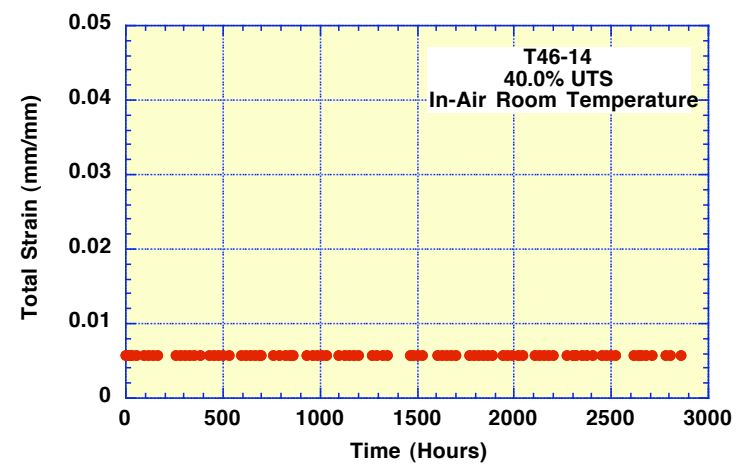

Total Strain vs Time

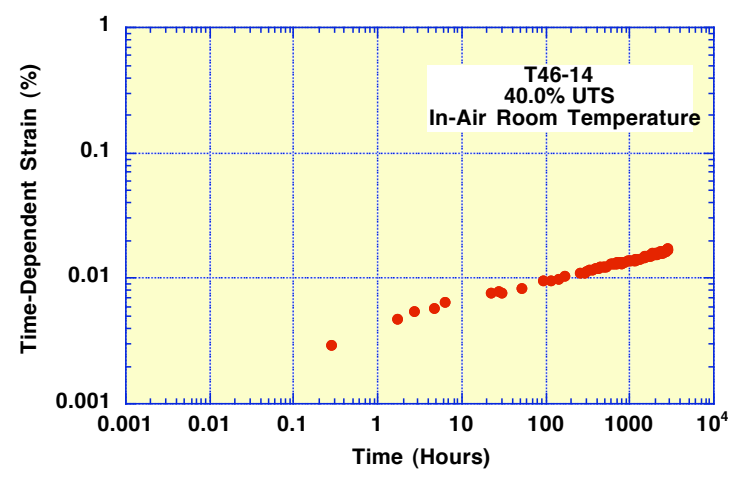

Time-Dependent Strain (Log Plot)

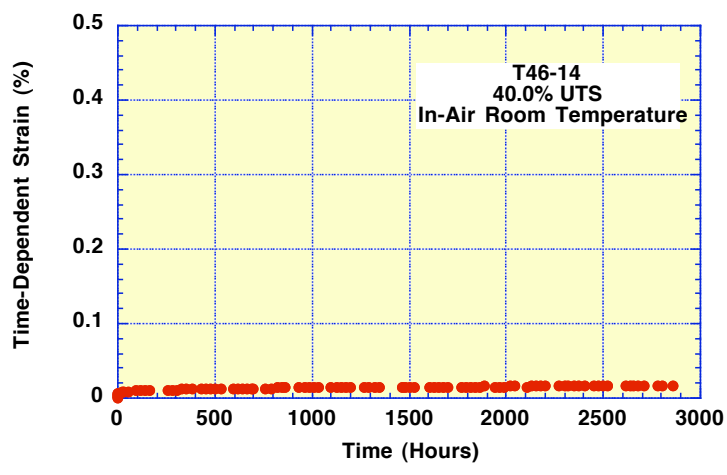

Time-Dependent Strain (Linear Plot)

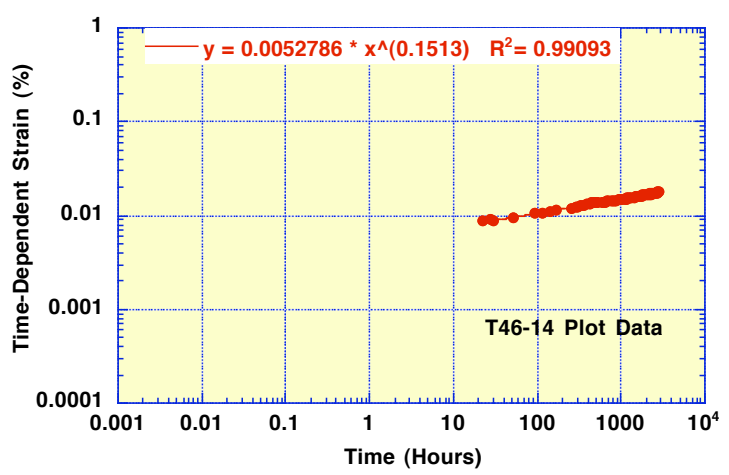

Power Law Fit. 
Specimen Number: T46-12

Load Level: $65.0 \%$ UTS

Environment: In-Air Room Temperature

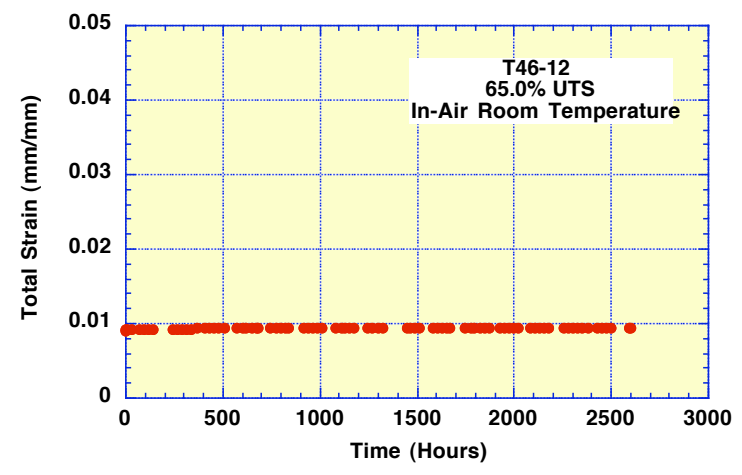

Total Strain vs Time

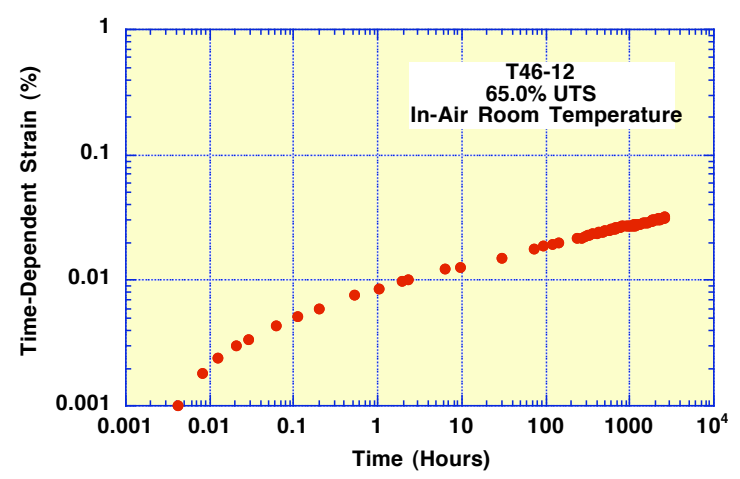

Time-Dependent Strain (Log Plot)

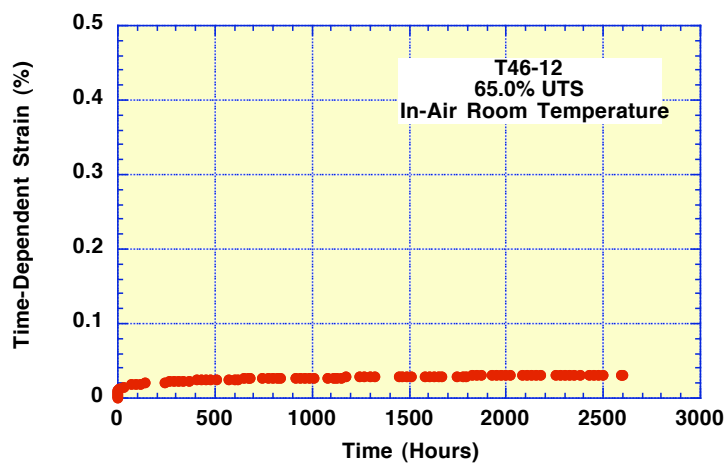

Time-Dependent Strain (Linear Plot)

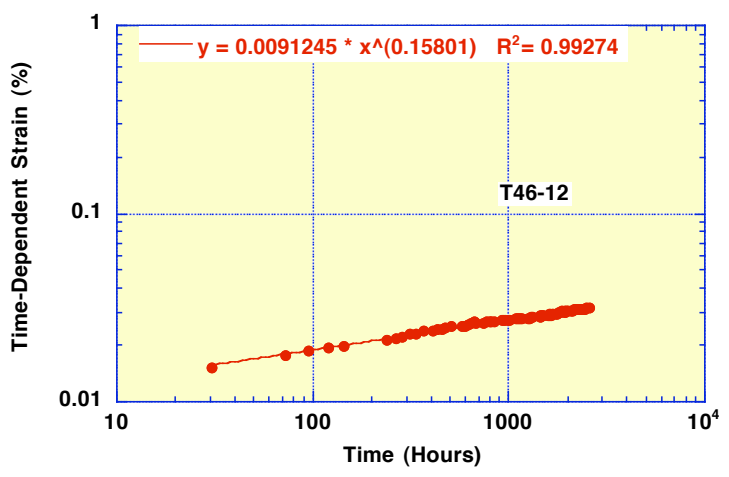

Power Law Fit. 
Specimen Number: T46-15

Load Level: $40.0 \%$ UTS

Environment: In-Air Room Temperature

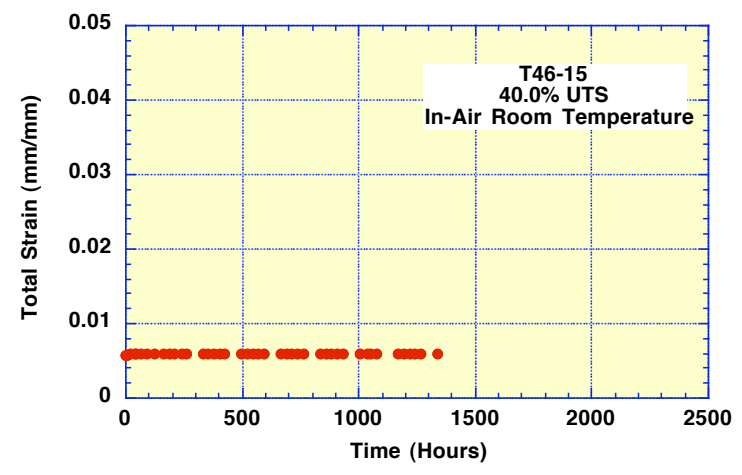

Total Strain vs Time

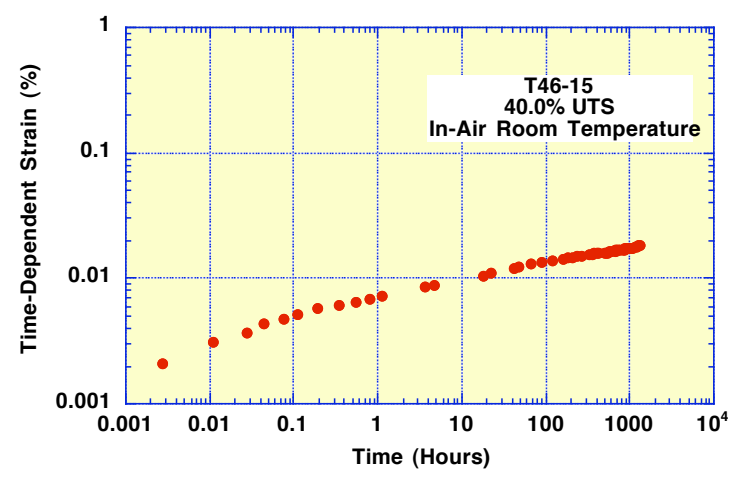

Time-Dependent Strain (Log Plot)

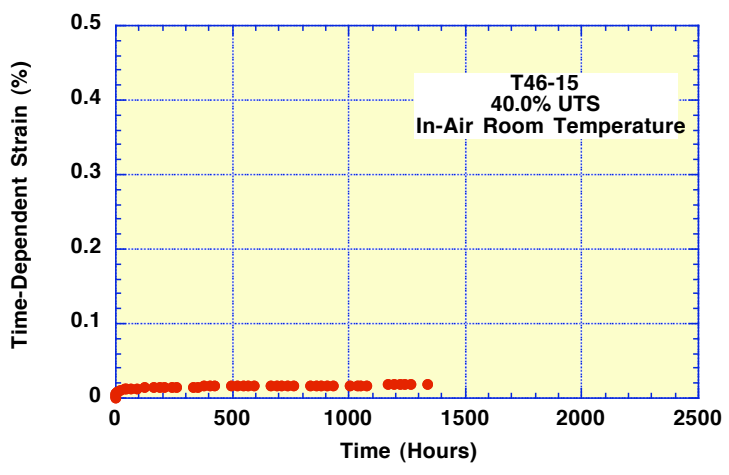

Time-Dependent Strain (Linear Plot)

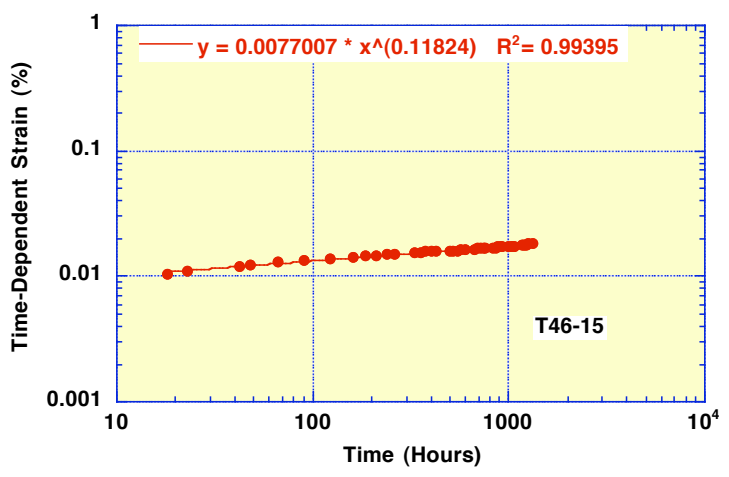

Power Law Fit. 
Specimen Number: T46-17

Load Level: $55.0 \%$ UTS

Environment: In-Air Room Temperature

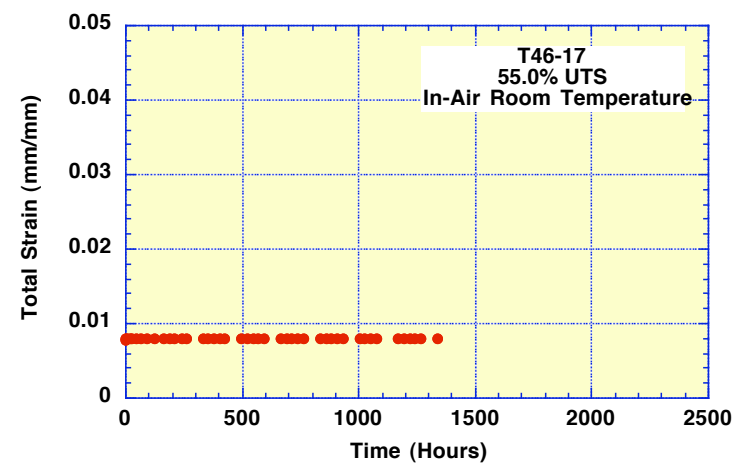

Total Strain vs Time

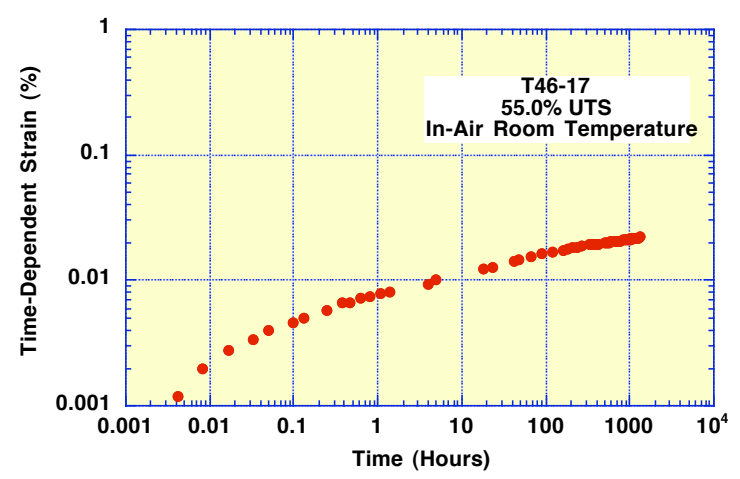

Time-Dependent Strain (Log Plot)

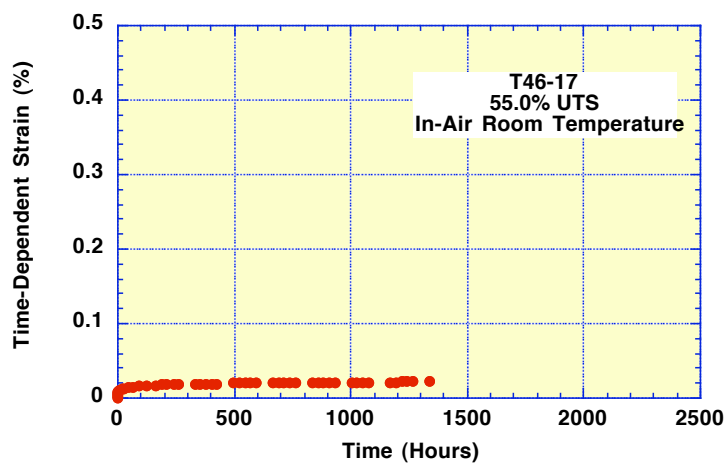

Time-Dependent Strain (Linear Plot)

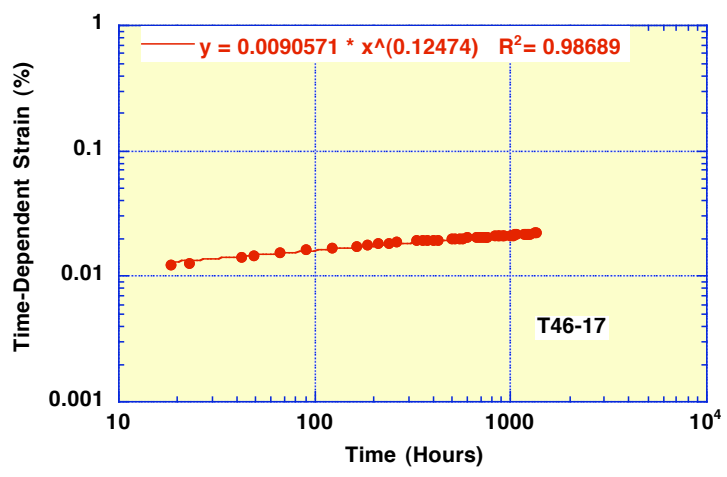

Power Law Fit. 
Specimen Number: T46-18

Load Level: $85.0 \%$ UTS

Environment: In-Air Room Temperature

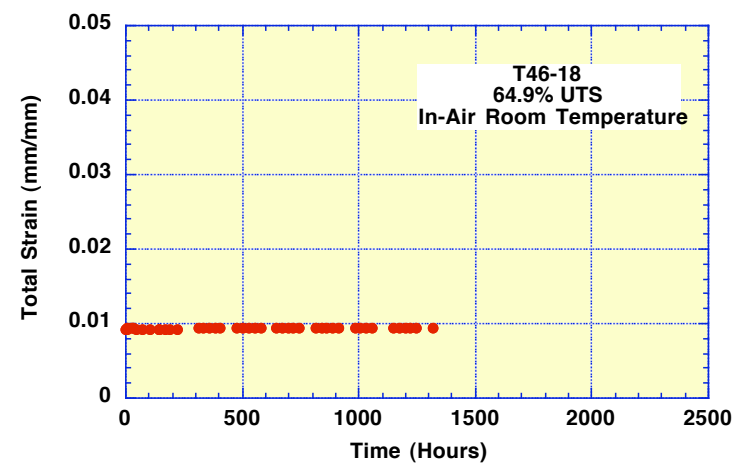

Total Strain vs Time

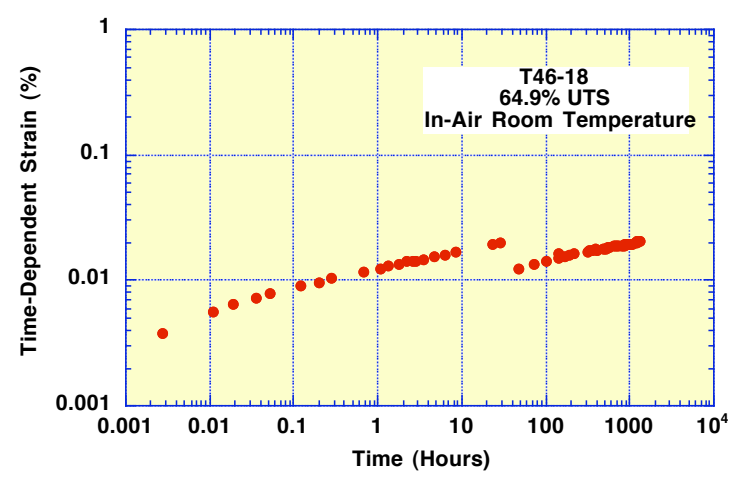

Time-Dependent Strain (Log Plot)

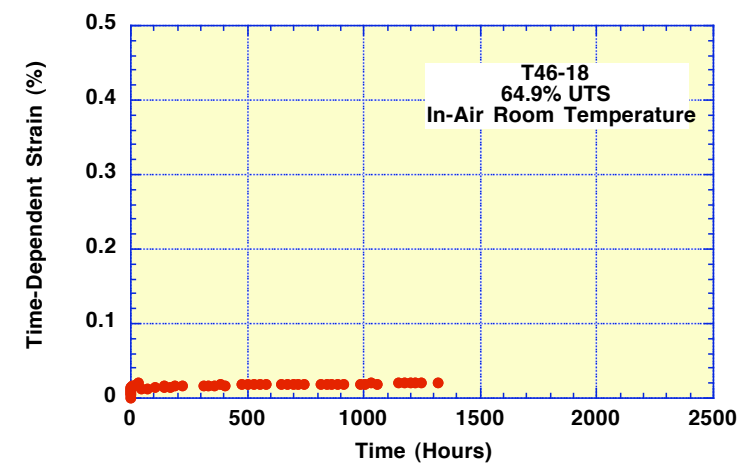

Time-Dependent Strain (Linear Plot)

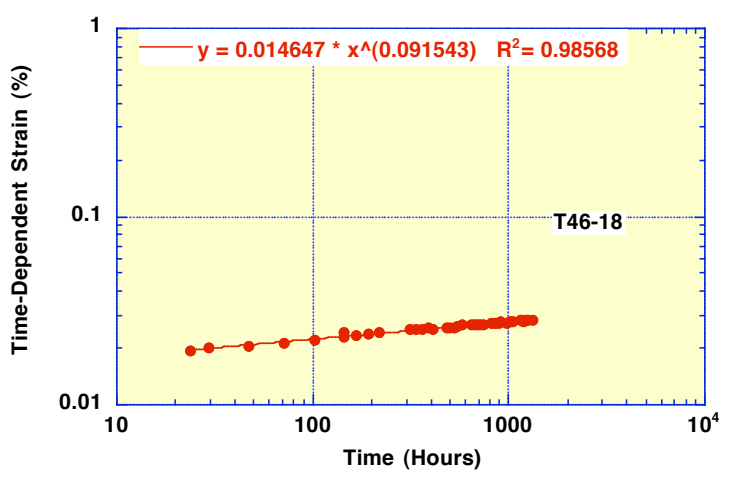

Power Law Fit. 
Specimen Number: T41-30

Load Level: $70.0 \%$ UTS

Environment: In-Air Room Temperature

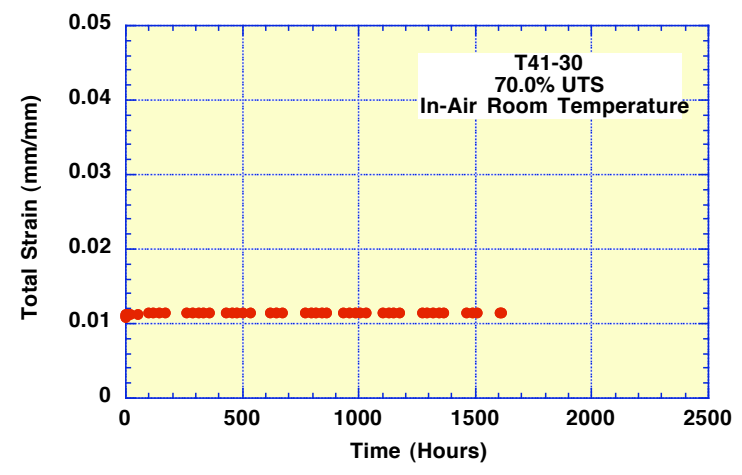

Total Strain vs Time

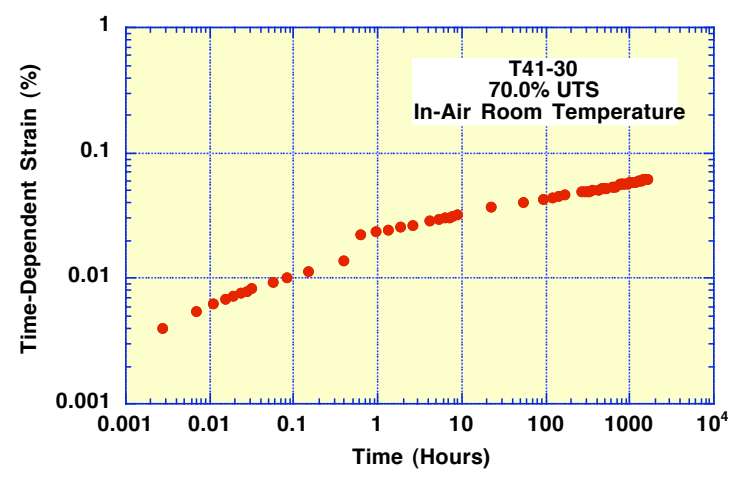

Time-Dependent Strain (Log Plot)

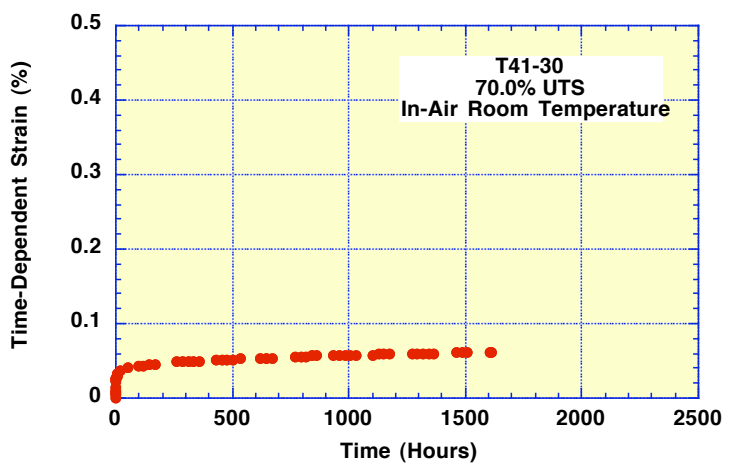

Time-Dependent Strain (Linear Plot)

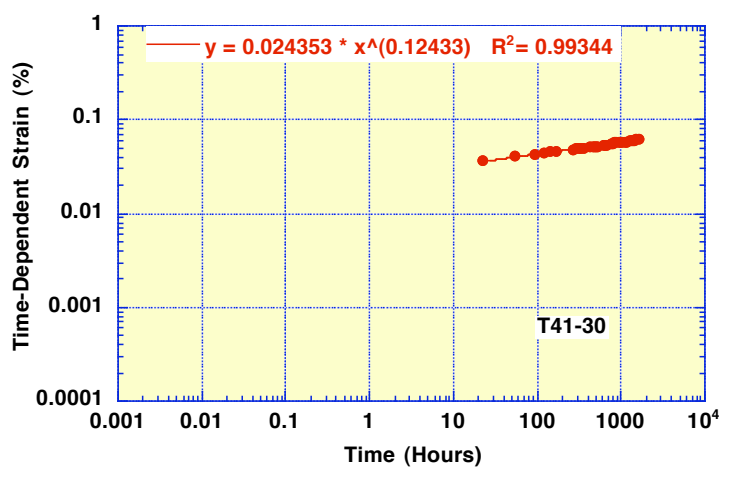

Power Law Fit. 


\section{Specimen Number: T41-41}

Load Level: $70.0 \%$ UTS

\section{Environment: In-Air Room Temperature}

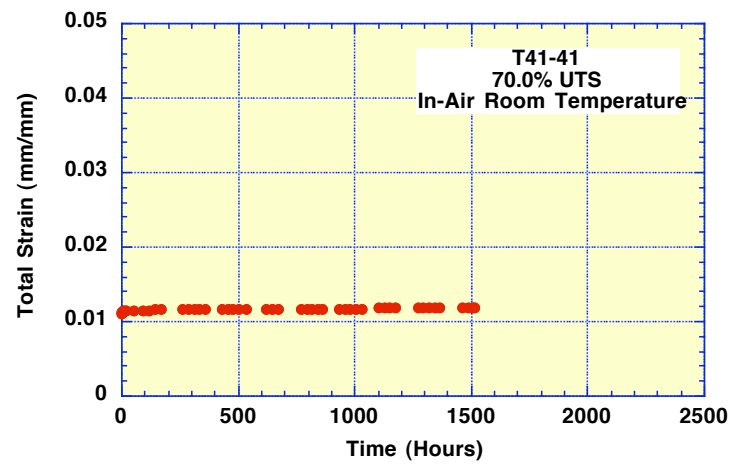

Total Strain vs Time

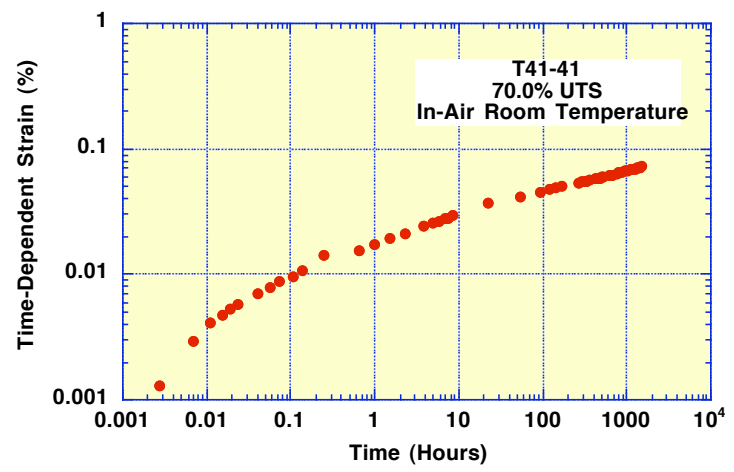

Time-Dependent Strain (Log Plot)

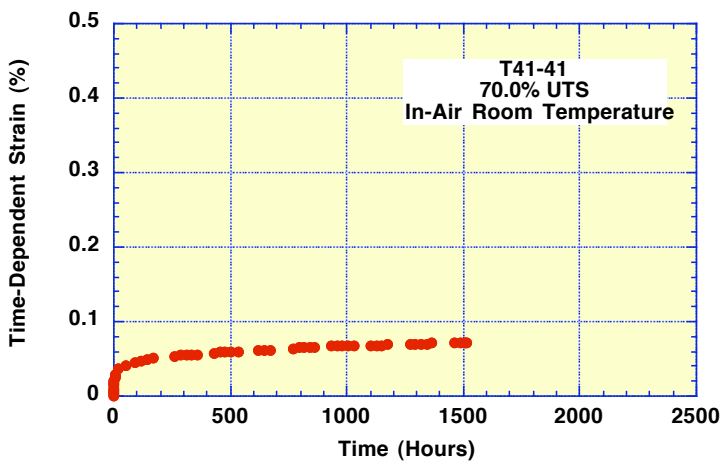

Time-Dependent Strain (Linear Plot)

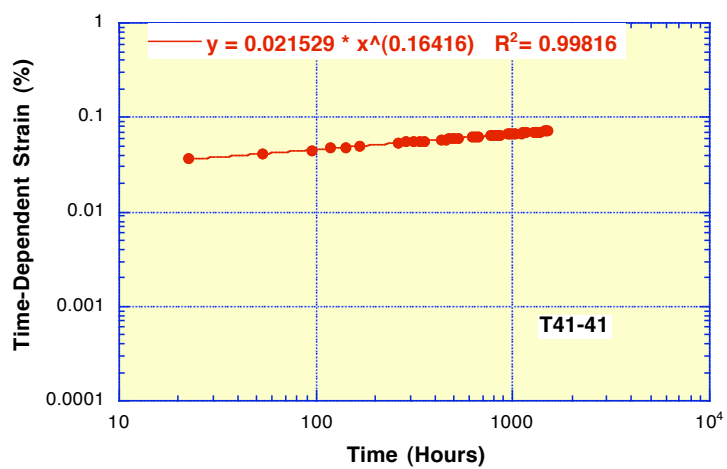

Power Law Fit. 
Specimen Number: T39-42

Load Level: $69.9 \%$ UTS

Environment: In-Air Room Temperature

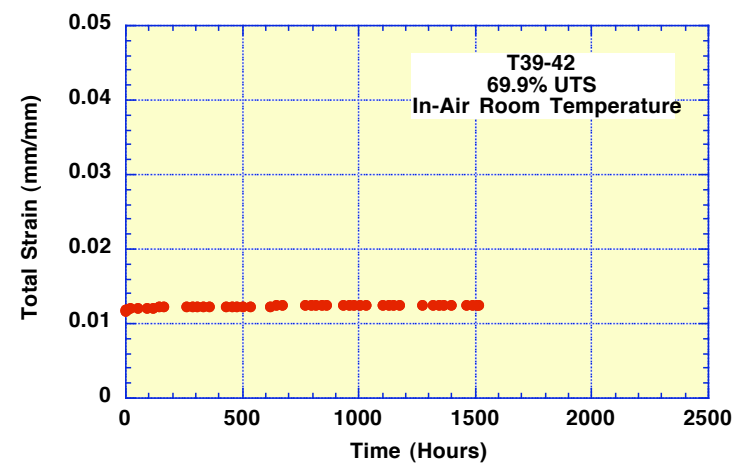

Total Strain vs Time

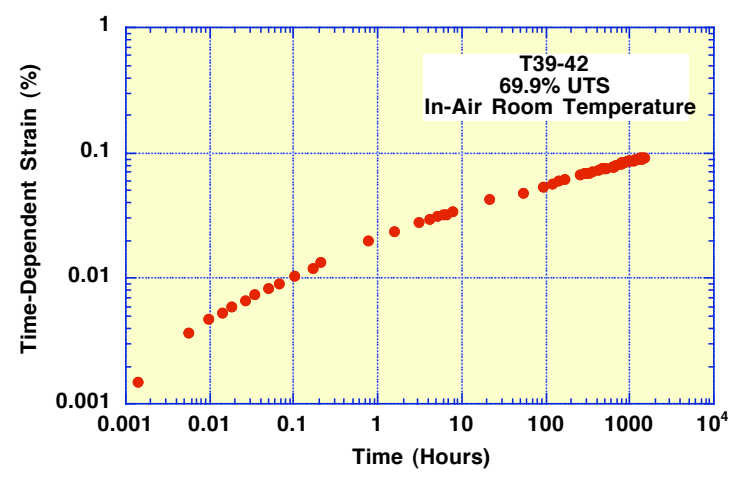

Time-Dependent Strain (Log Plot)

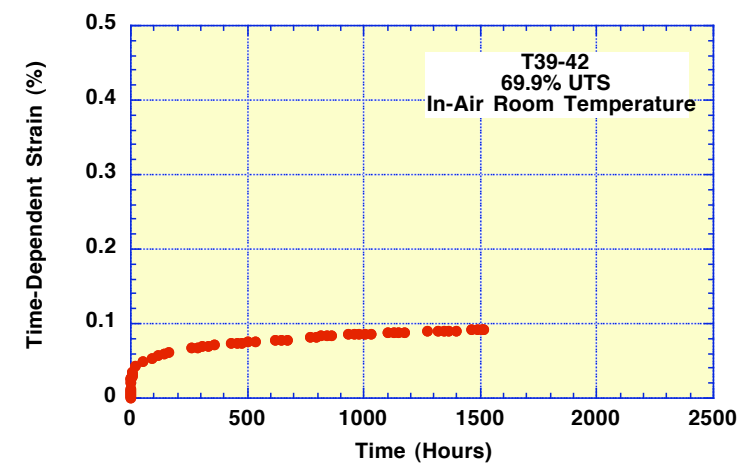

Time-Dependent Strain (Linear Plot)

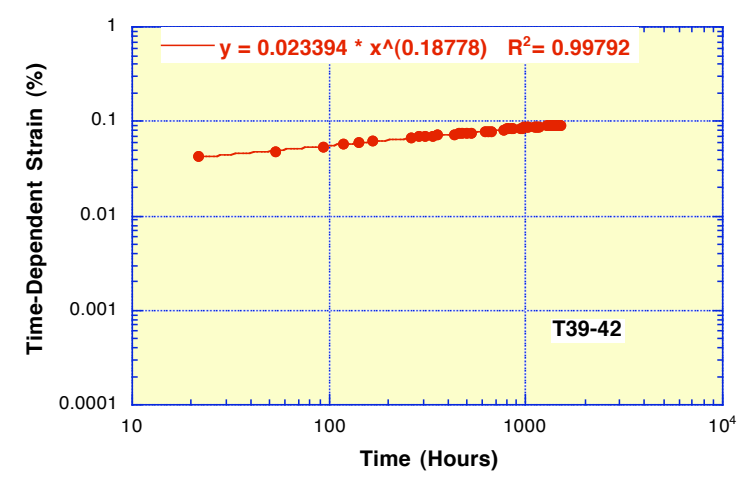

Power Law Fit. 


\section{Specimen Number: T41-31}

Load Level: $85.0 \%$ UTS

\section{Environment: In-Air Room Temperature}

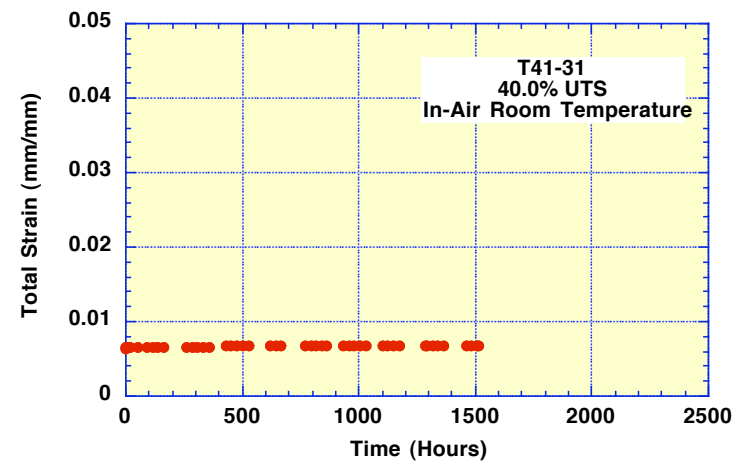

Total Strain vs Time

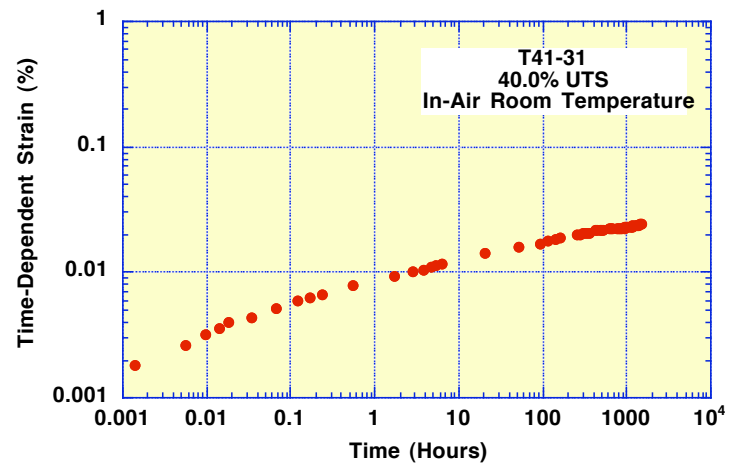

Time-Dependent Strain (Log Plot)

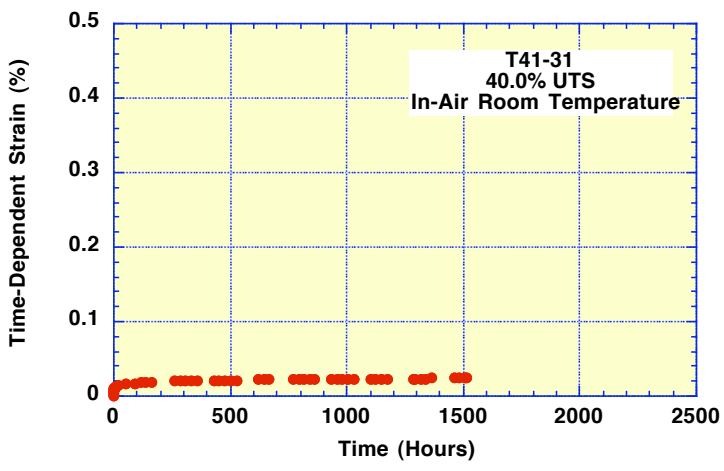

Time-Dependent Strain (Linear Plot)

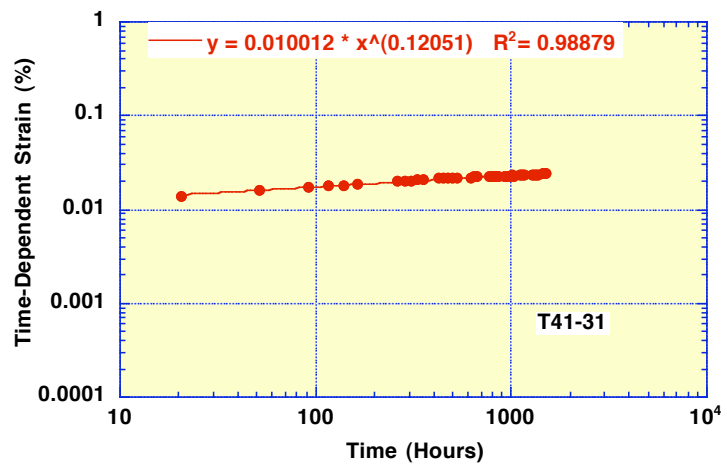

Power Law Fit. 
Specimen Number: T41-29

Load Level: $85.0 \%$ UTS

Environment: In-Air Room Temperature

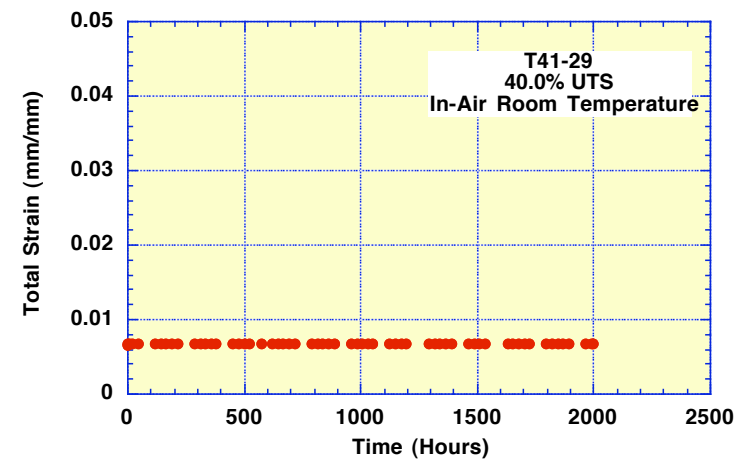

Total Strain vs Time

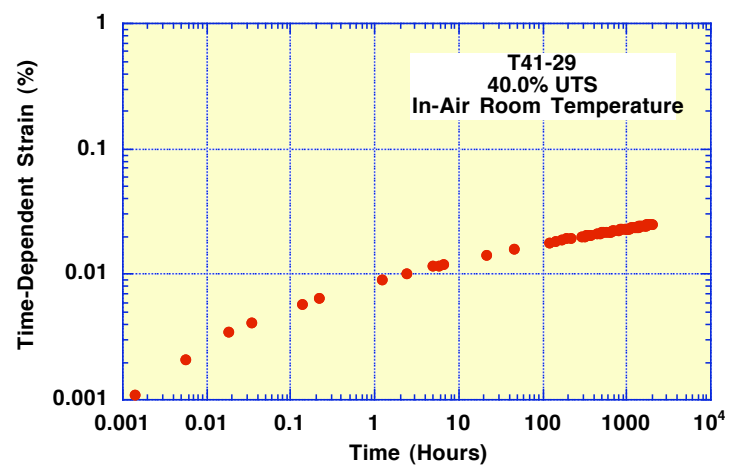

Time-Dependent Strain (Log Plot)

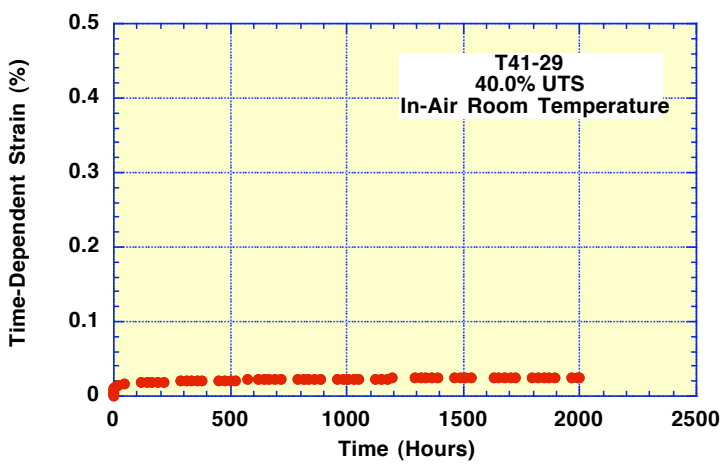

Time-Dependent Strain (Linear Plot)

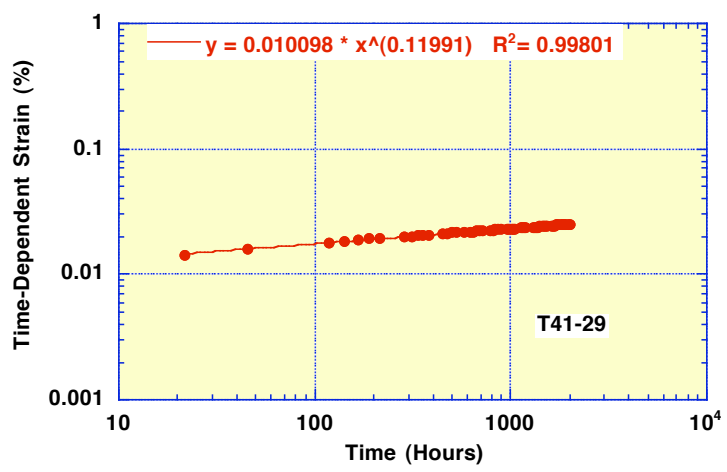

Power Law Fit. 


\section{Specimen Number: T41-21}

Load Level: $80.0 \%$ UTS

Environment: In-Air $70^{\circ} \mathrm{C}$

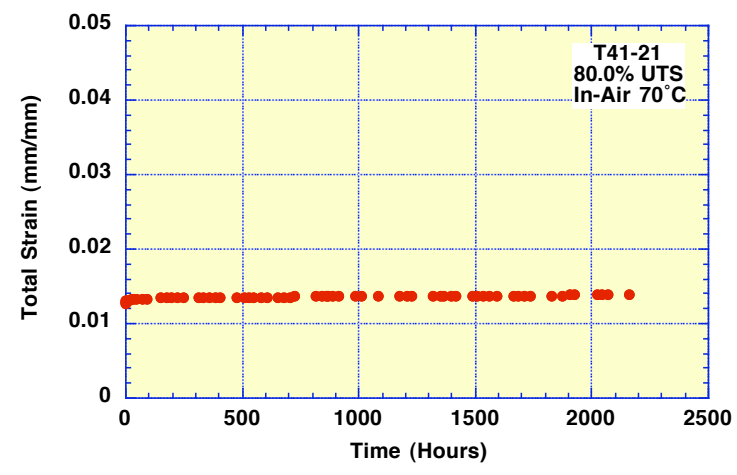

Total Strain vs Time

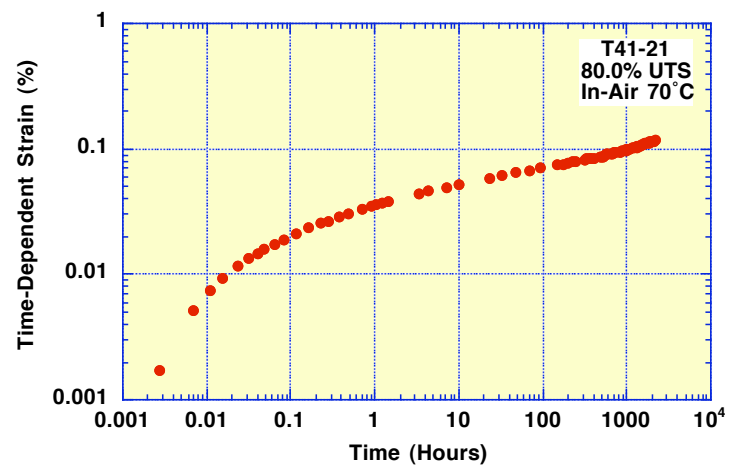

Time-Dependent Strain (Log Plot)

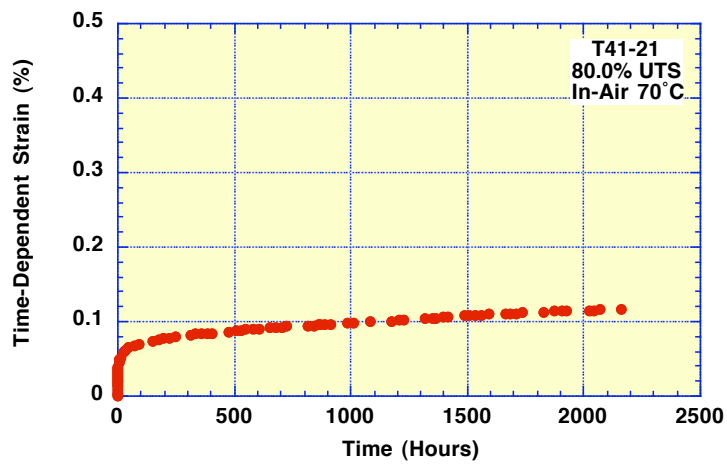

Time-Dependent Strain (Linear Plot)

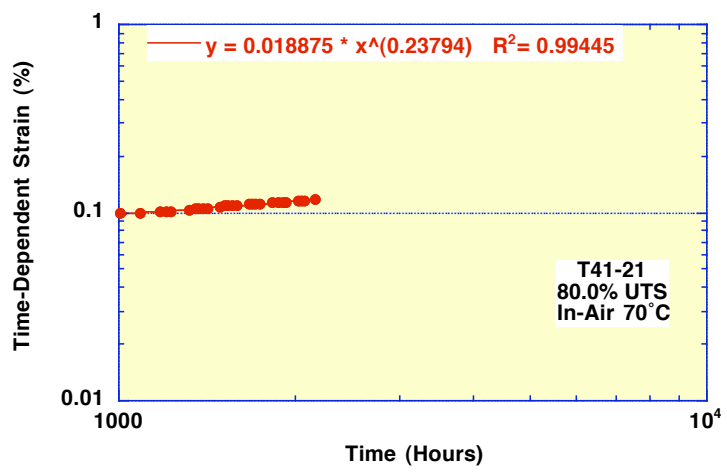

Power Law Fit. 


\section{Specimen Number: T41-14}

Load Level: $60.0 \%$ UTS

Environment: In-Air $70^{\circ} \mathrm{C}$

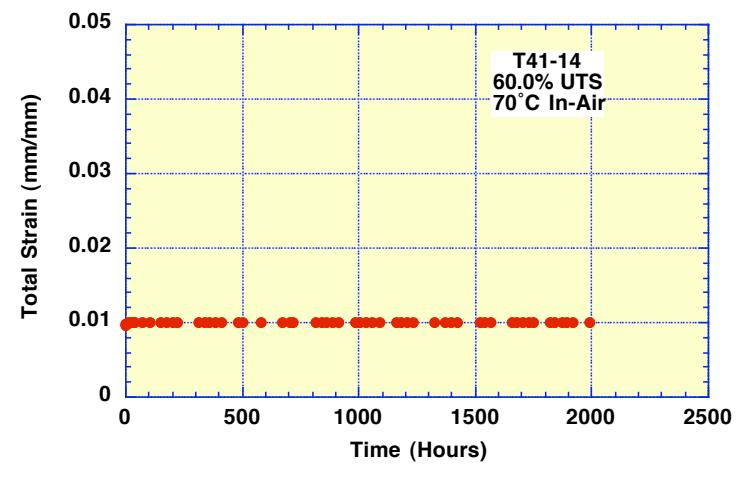

Total Strain vs Time

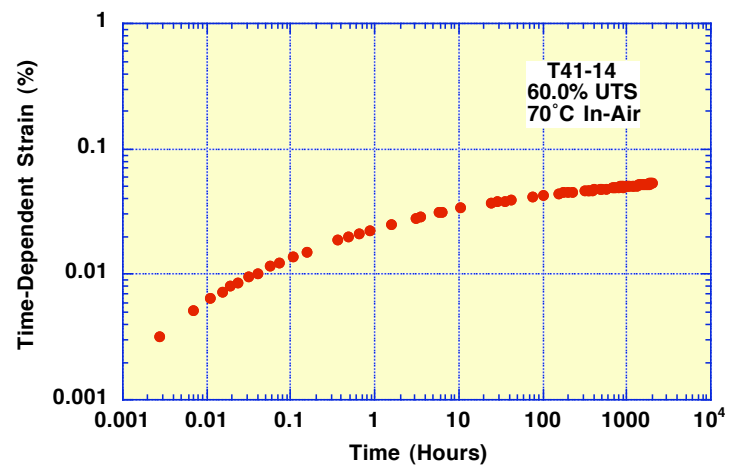

Time-Dependent Strain (Log Plot)

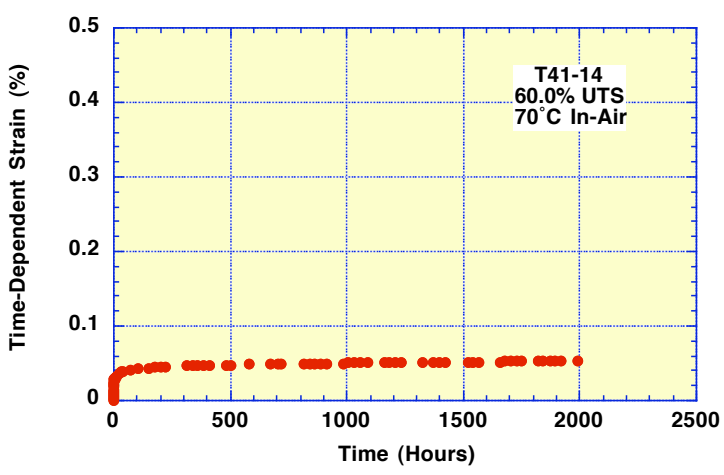

Time-Dependent Strain (Linear Plot)

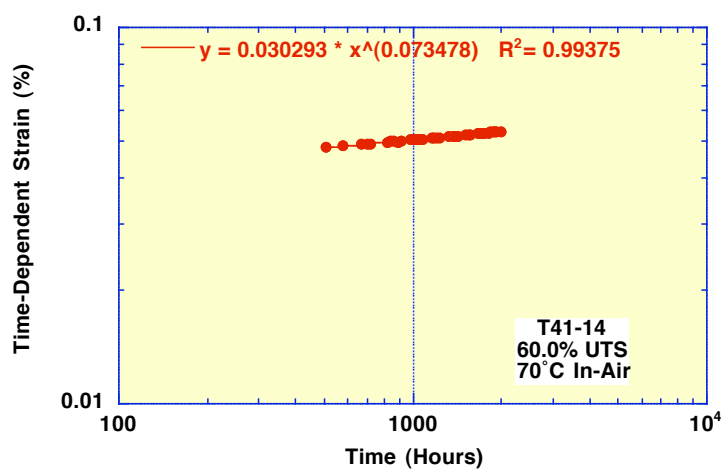

Power Law Fit. 


\section{Specimen Number: T41-12}

Load Level: $85.0 \%$ UTS

Environment: In-Air $70^{\circ} \mathrm{C}$
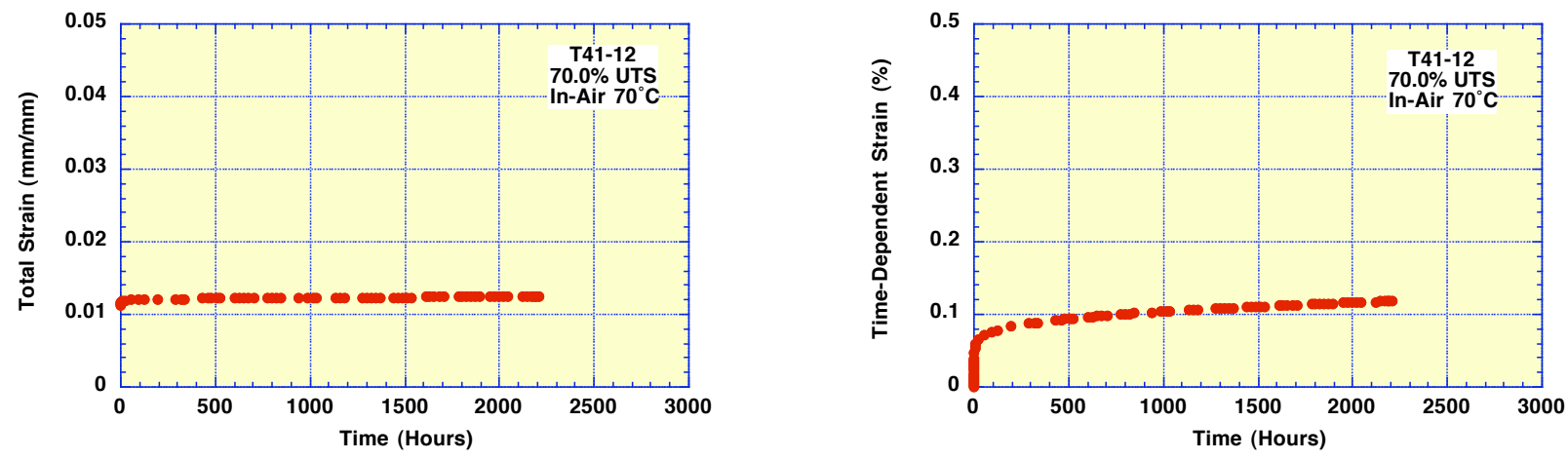

Total Strain vs Time

Time-Dependent Strain (Linear Plot)
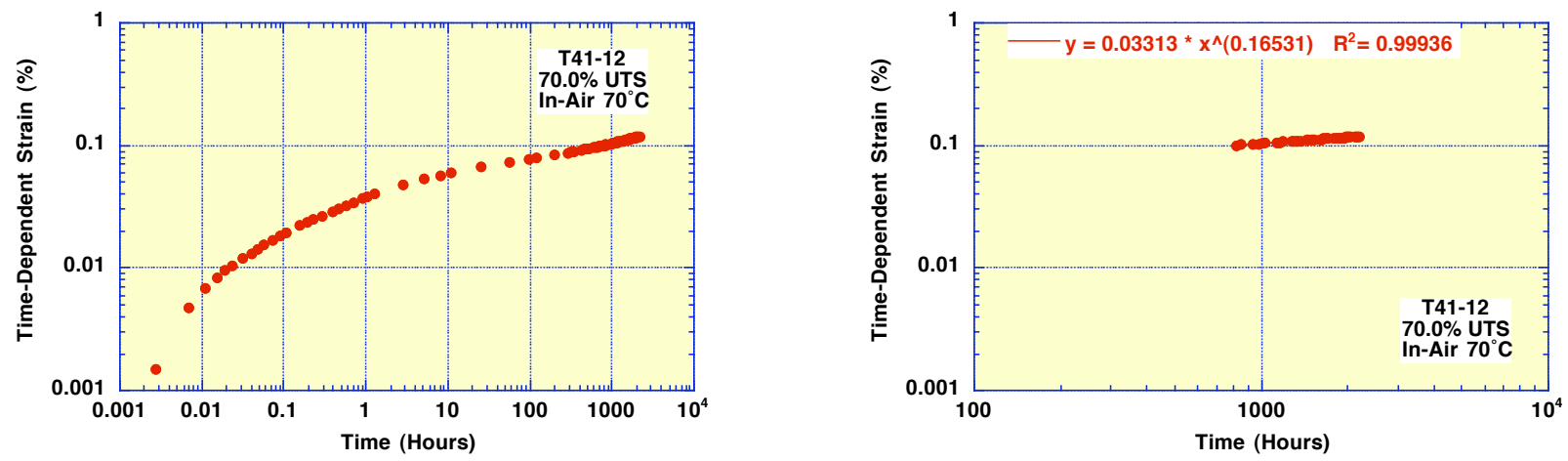

Time-Dependent Strain (Log Plot)

Power Law Fit. 


\section{Specimen Number: T41-51}

Load Level: $49.8 . \%$ UTS

Environment: In-Air $70^{\circ} \mathrm{C}$

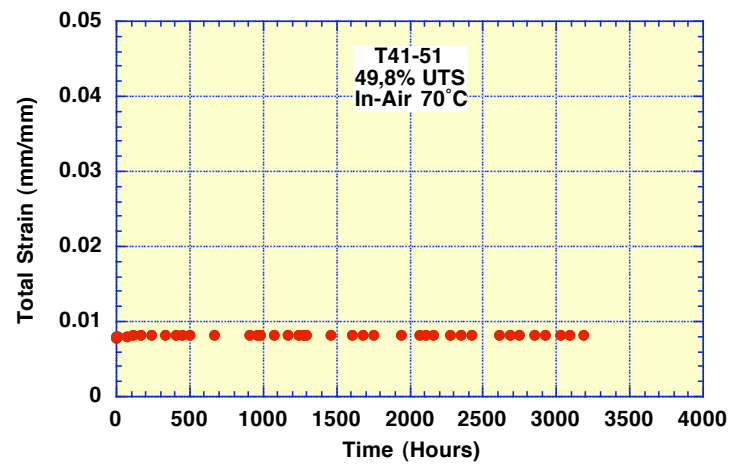

Total Strain vs Time

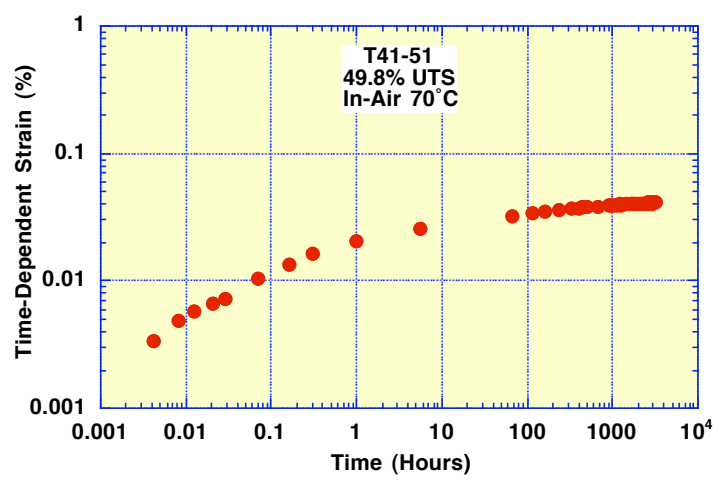

Time-Dependent Strain (Log Plot)

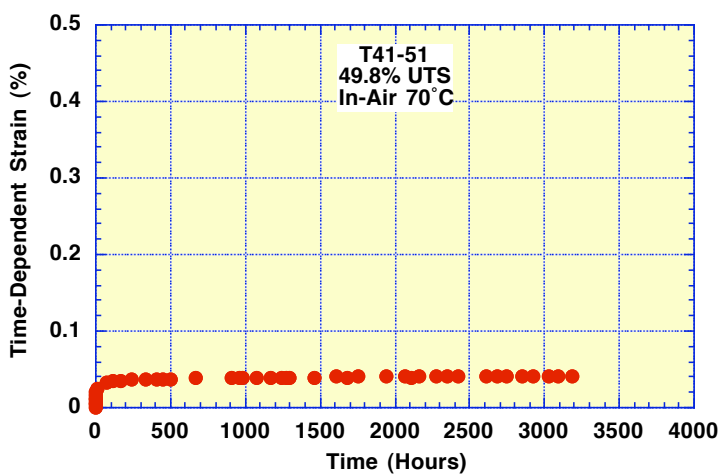

Time-Dependent Strain (Linear Plot)

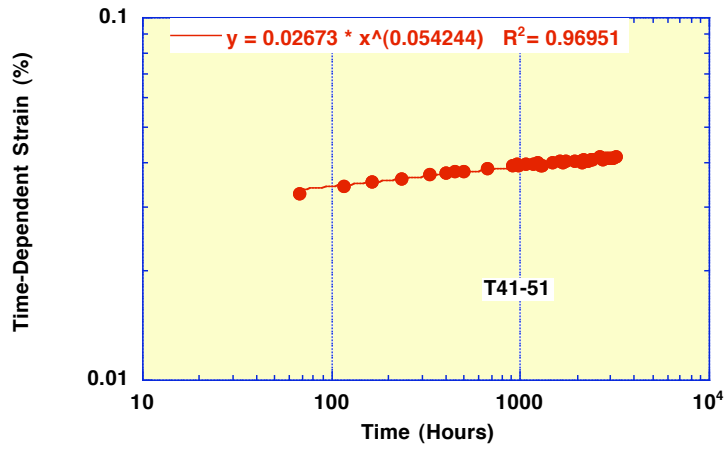

Power Law Fit. 


\section{Specimen Number: T41-19}

Load Level: $80.0 \%$ UTS

Environment: In-Air $90^{\circ} \mathrm{C}$

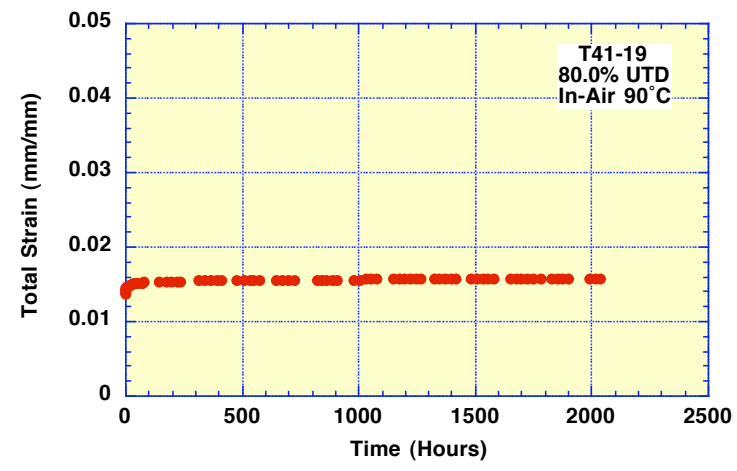

Total Strain vs Time

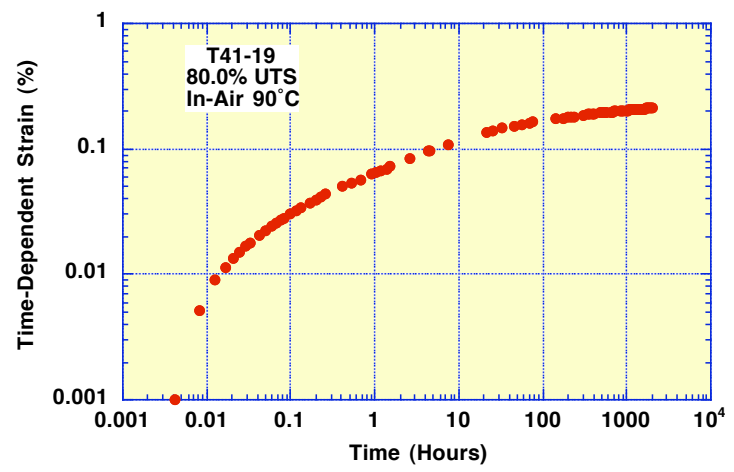

Time-Dependent Strain (Log Plot)

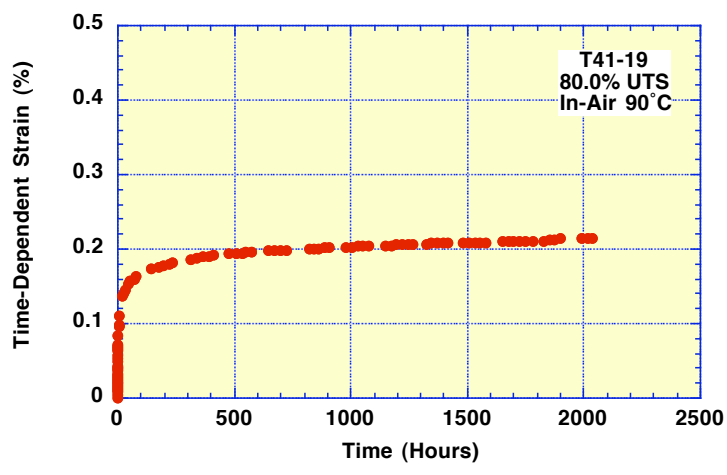

Time-Dependent Strain (Linear Plot)

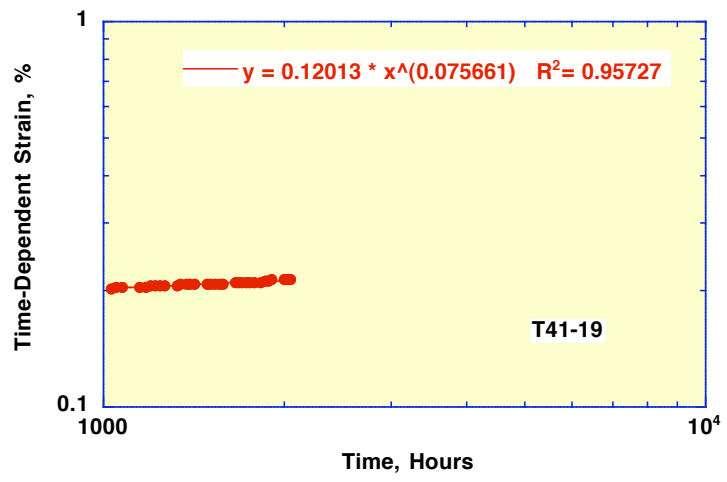

Power Law Fit. 


\section{Specimen Number: T41-13}

Load Level: $70.0 \%$ UTS

Environment: In-Air 90C

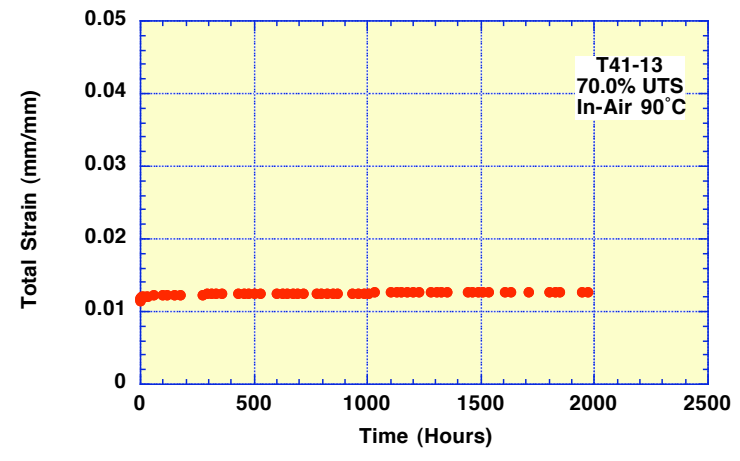

Total Strain vs Time

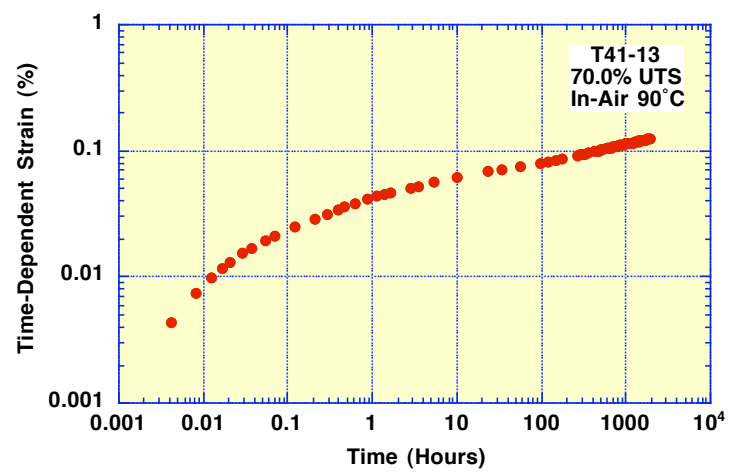

Time-Dependent Strain (Log Plot)

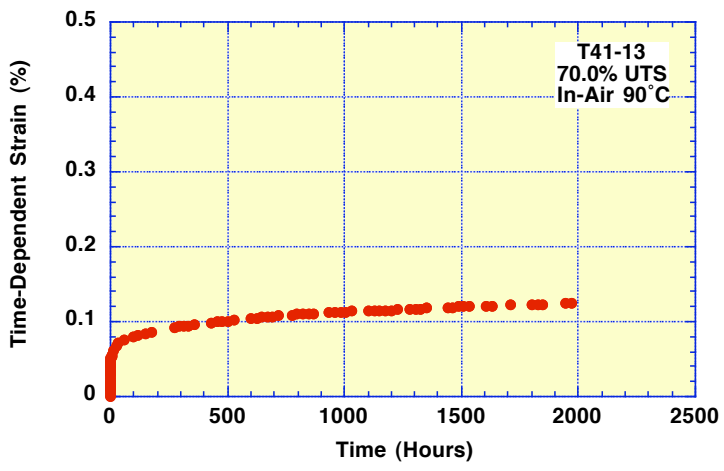

Time-Dependent Strain (Linear Plot)

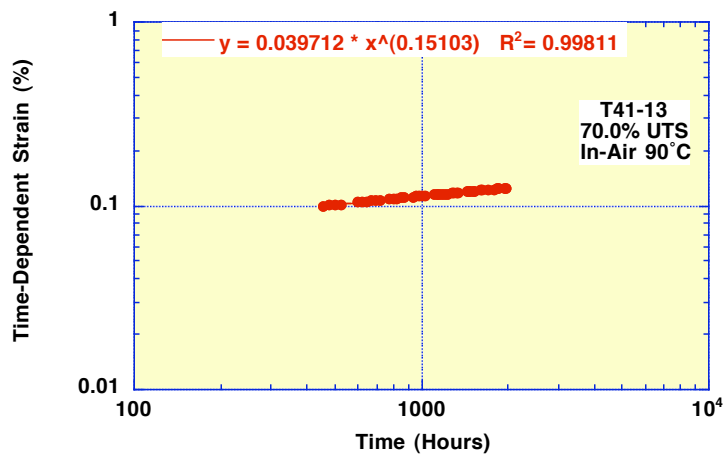

Power Law Fit. 
Specimen Number: T41-20

Load Level: $70.0 \%$ UTS

Environment: In-Air $90^{\circ} \mathrm{C}$

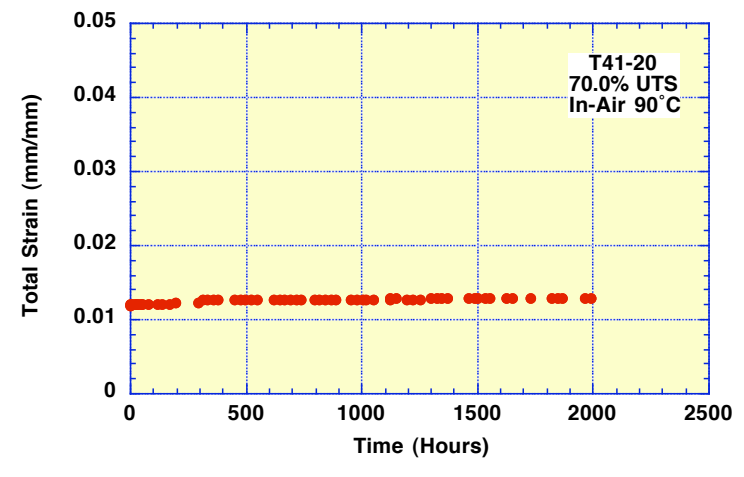

Total Strain vs Time

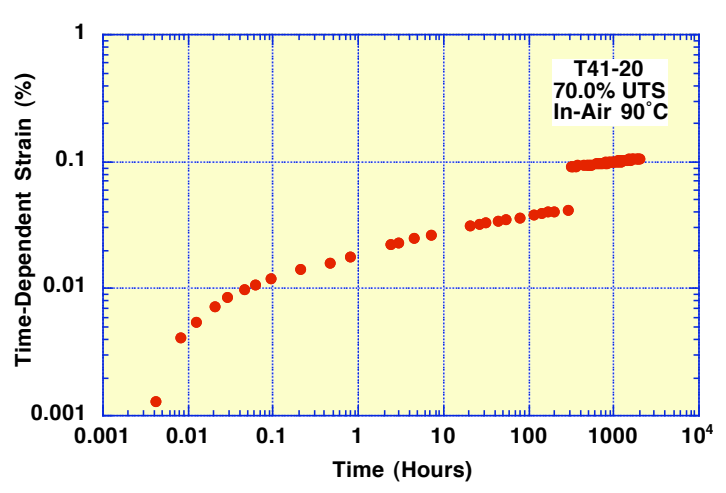

Time-Dependent Strain (Log Plot)

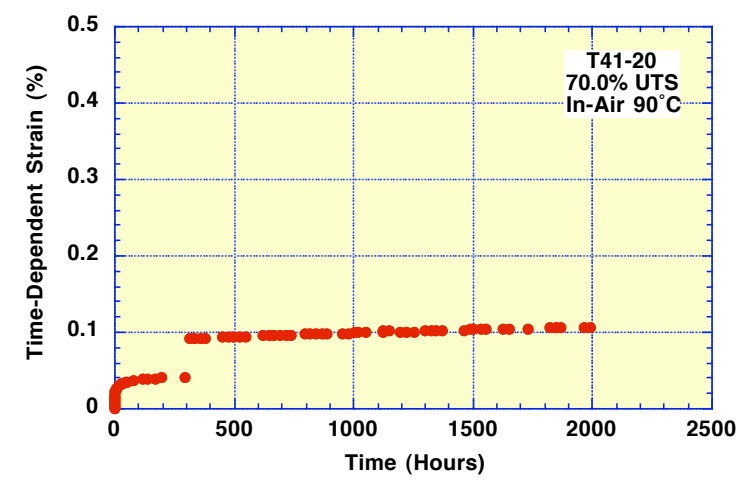

Time-Dependent Strain (Linear Plot)

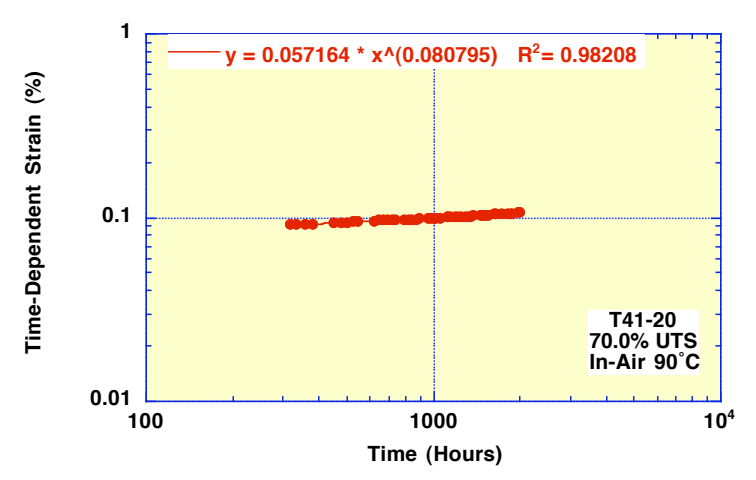

Power Law Fit. 


\section{Specimen Number: T41-10}

Load Level: $80.0 \%$ UTS

Environment: In-Air $90^{\circ} \mathrm{C}$

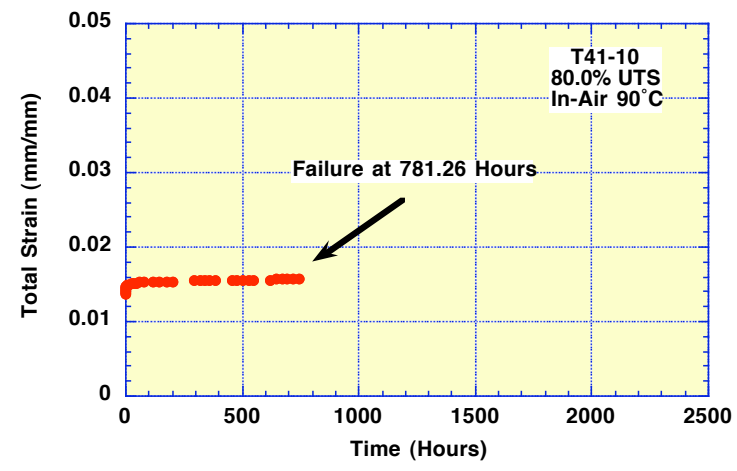

Total Strain vs Time

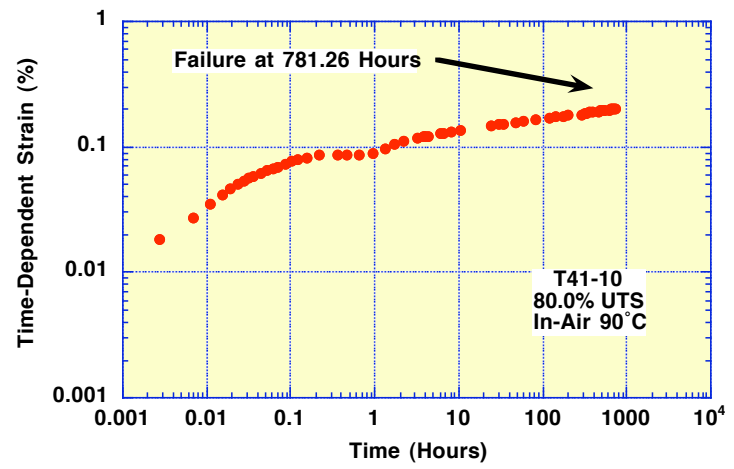

Time-Dependent Strain (Log Plot)

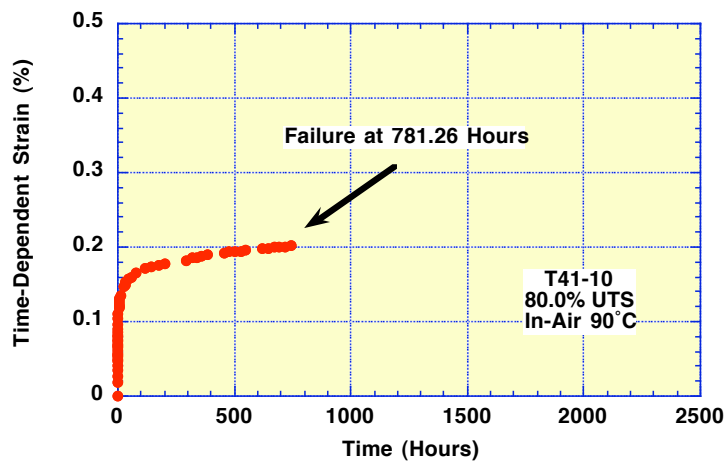

Time-Dependent Strain (Linear Plot)

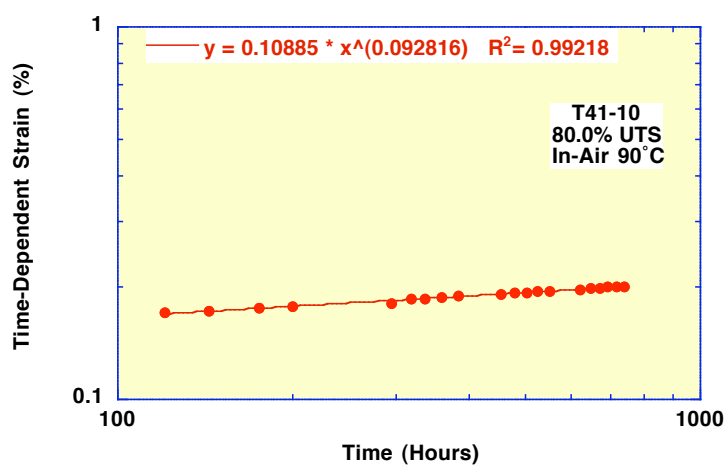

Power Law Fit. 
Specimen Number: T23-49

Load Level: $77.4 \%$ UTS

Environment: In-Air $120^{\circ} \mathrm{C}$

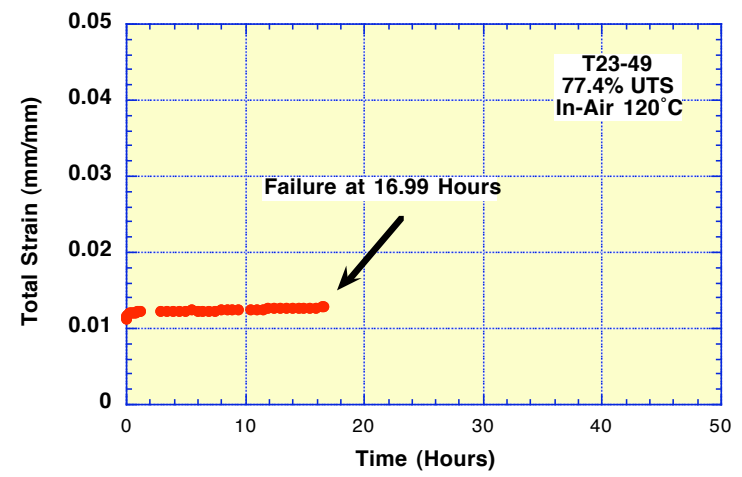

Total Strain vs Time

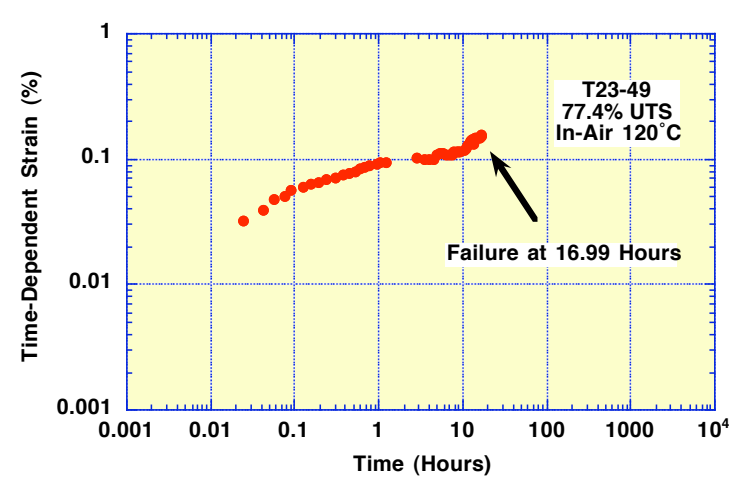

Time-Dependent Strain (Log Plot)

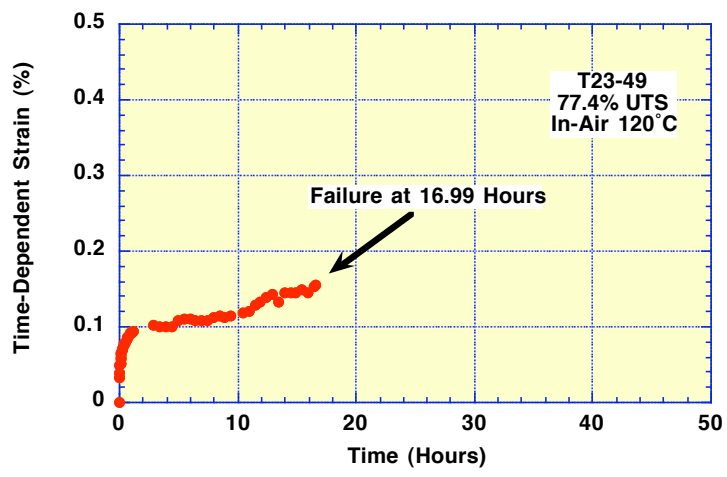

Time-Dependent Strain (Linear Plot)

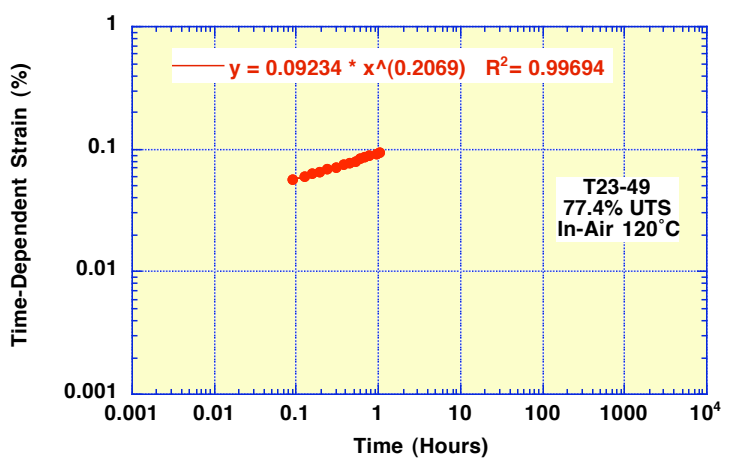

Power Law Fit. 
Specimen Number: T23-50

Load Level: $74.6 .0 \%$ UTS

Environment: In-Air $120^{\circ} \mathrm{C}$

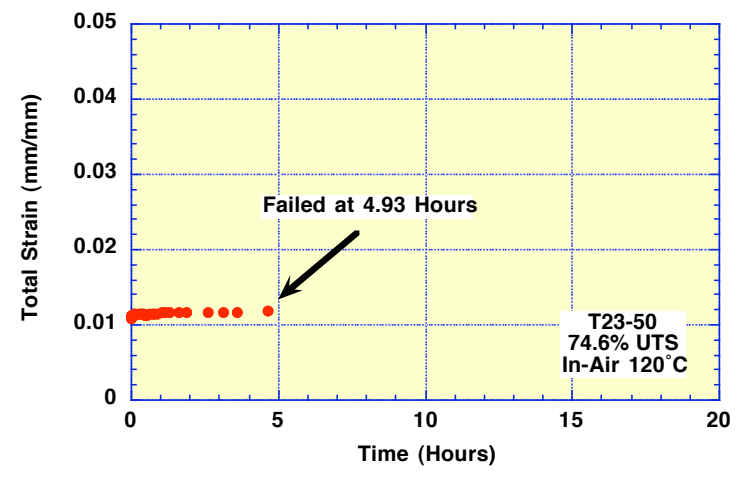

Total Strain vs Time

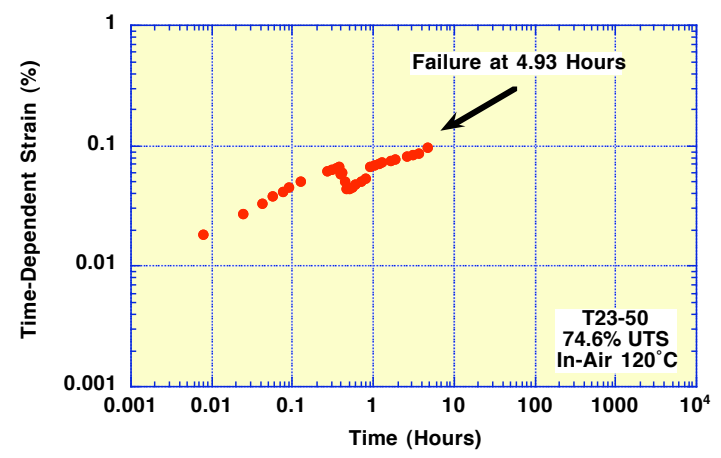

Time-Dependent Strain (Log Plot)

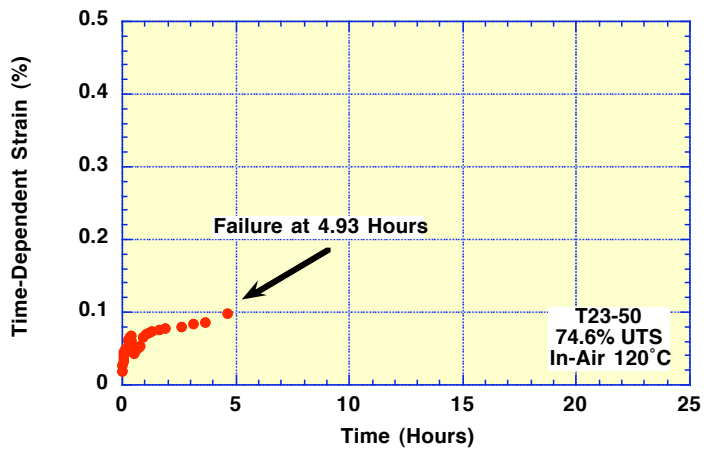

Time-Dependent Strain (Linear Plot)

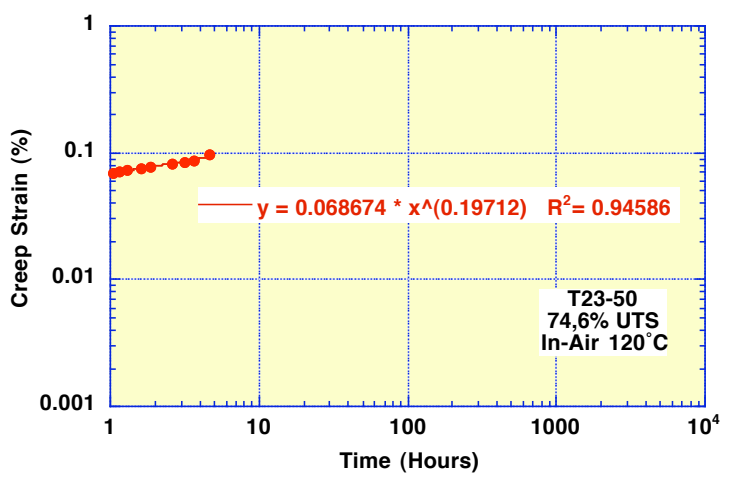

Power Law Fit. 


\section{Specimen Number: T31-38}

Load Level: $85.0 \%$ UTS

Environment: In-Air $90^{\circ} \mathrm{C}$

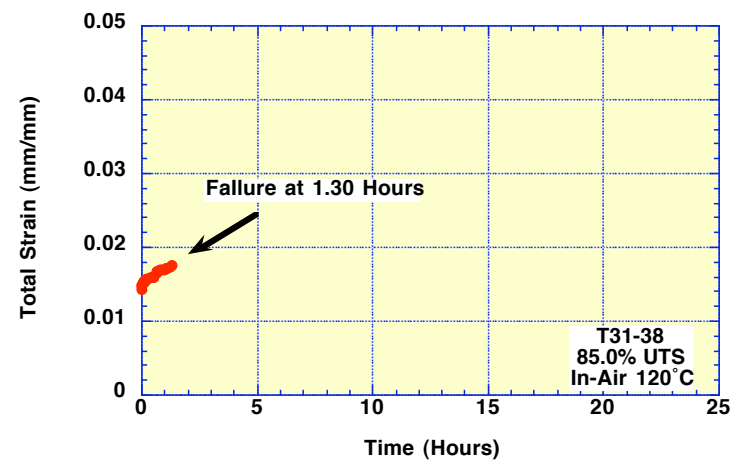

Total Strain vs Time

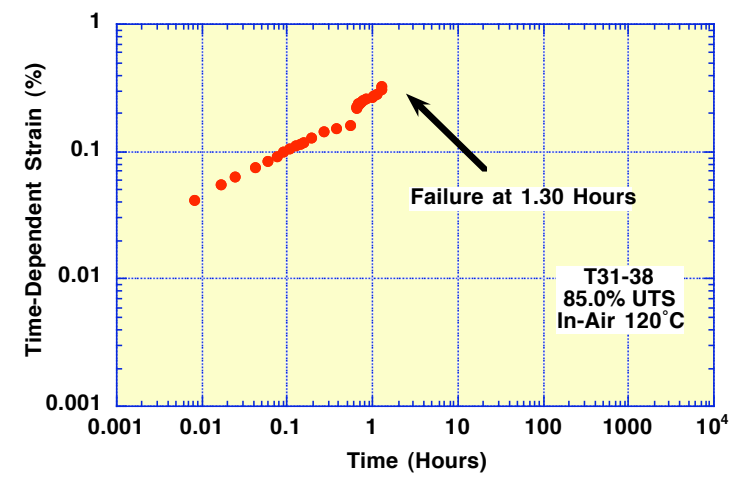

Time-Dependent Strain (Log Plot)

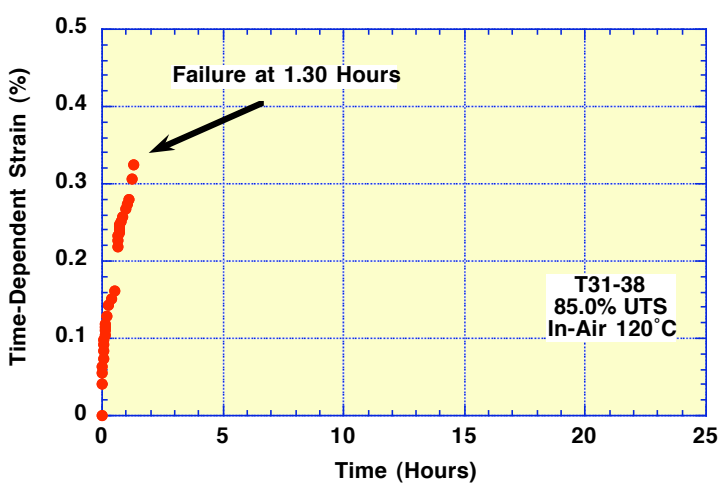

Time-Dependent Strain (Linear Plot)

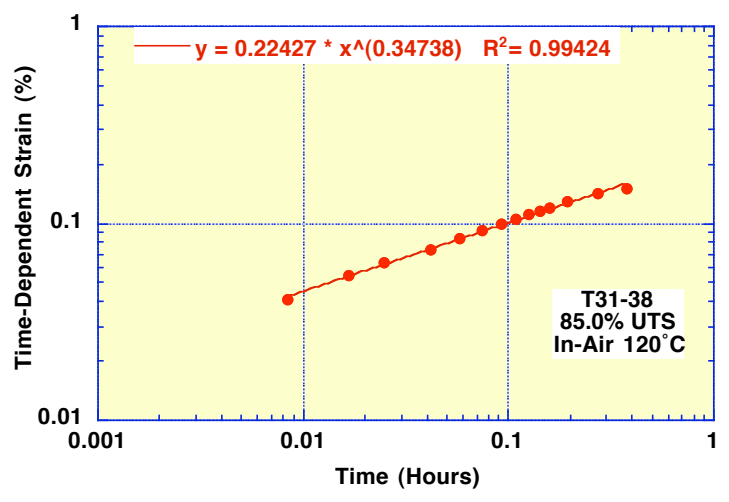

Power Law Fit. 


\section{Specimen Number: T31-40}

Load Level: $80.0 \%$ UTS

Environment: In-Air $120^{\circ} \mathrm{C}$

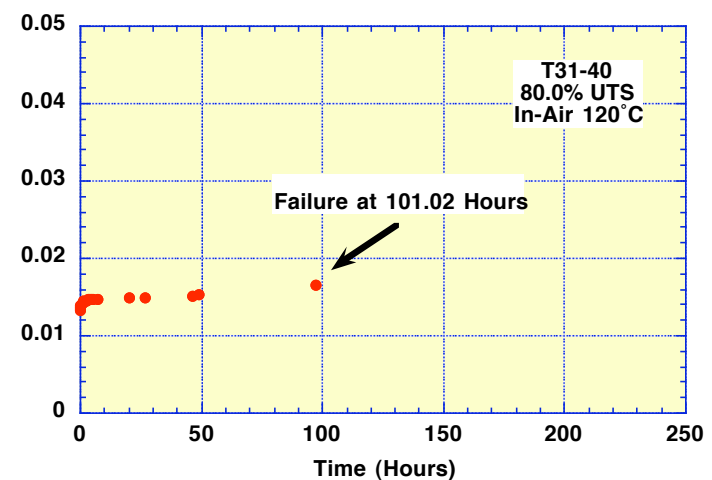

Total Strain vs Time

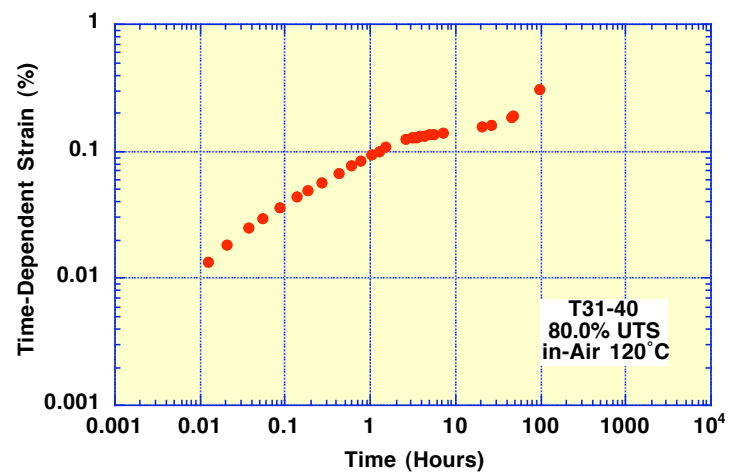

Time-Dependent Strain (Log Plot)

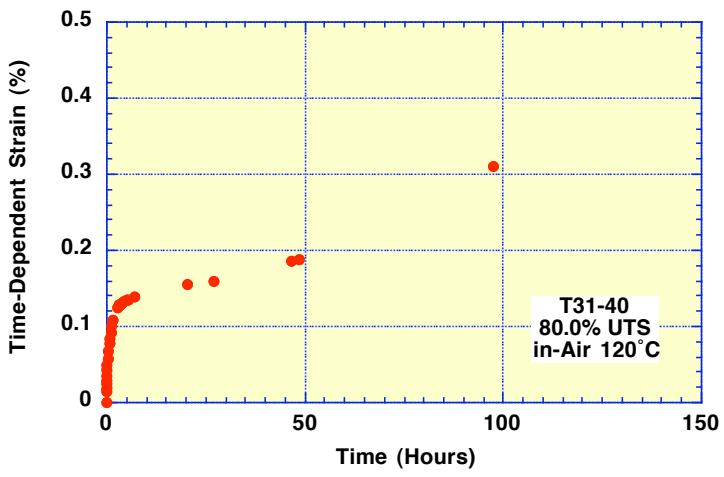

Time-Dependent Strain (Linear Plot)

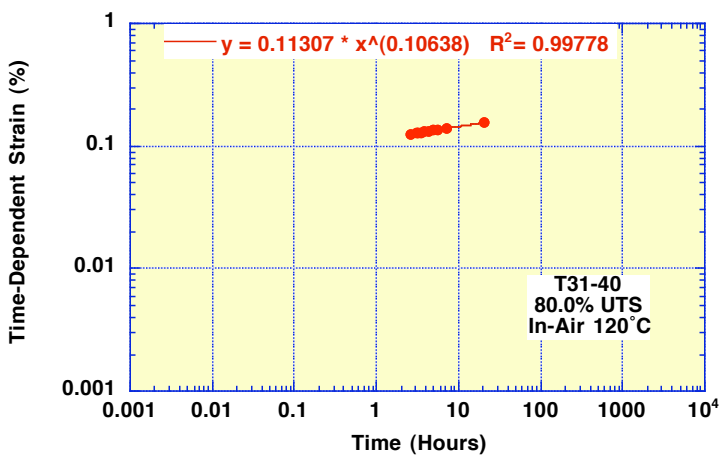

Power Law Fit. 


\section{Specimen Number: T31-39}

Load Level: $85.8 \%$ UTS

Environment: In-Air $120^{\circ} \mathrm{C}$

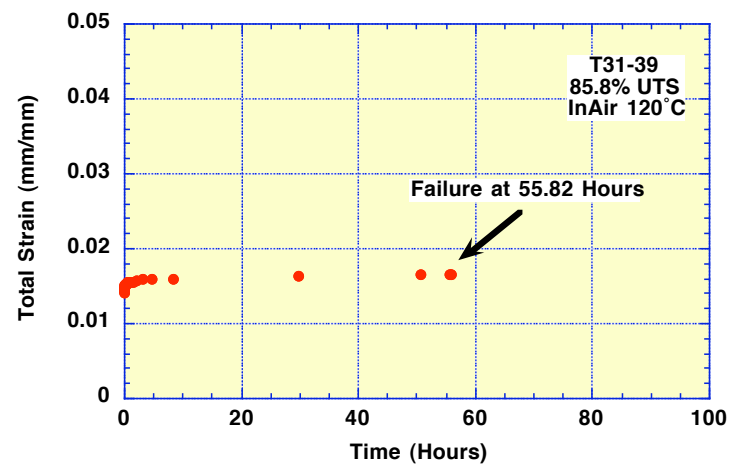

Total Strain vs Time

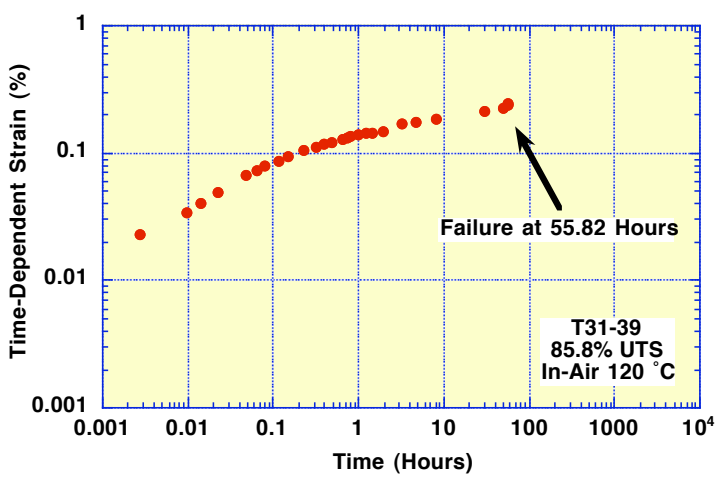

Time-Dependent Strain (Log Plot)

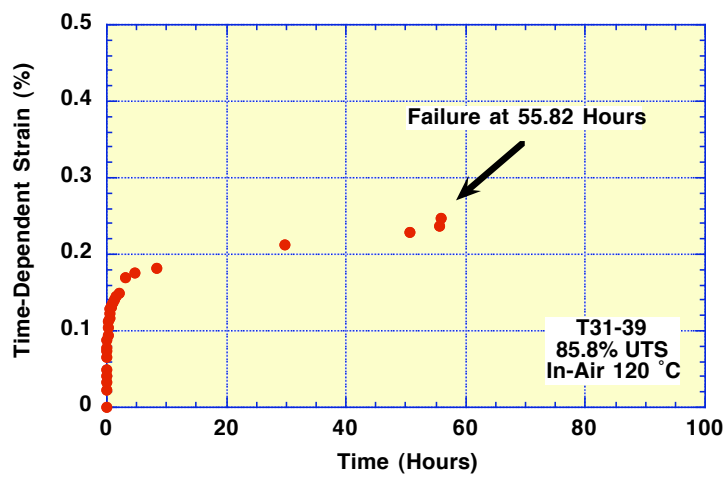

Time-Dependent Strain (Linear Plot)

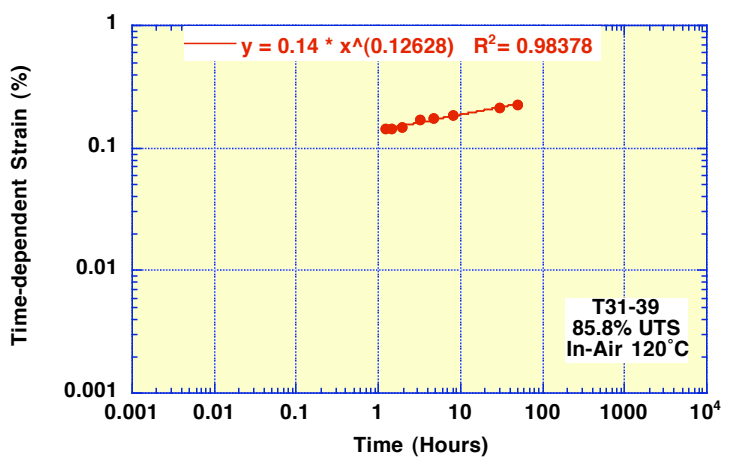

Power Law Fit. 


\section{Specimen Number: T31-44}

Load Level: $75.0 \%$ UTS

Environment: In-Air $120^{\circ} \mathrm{C}$

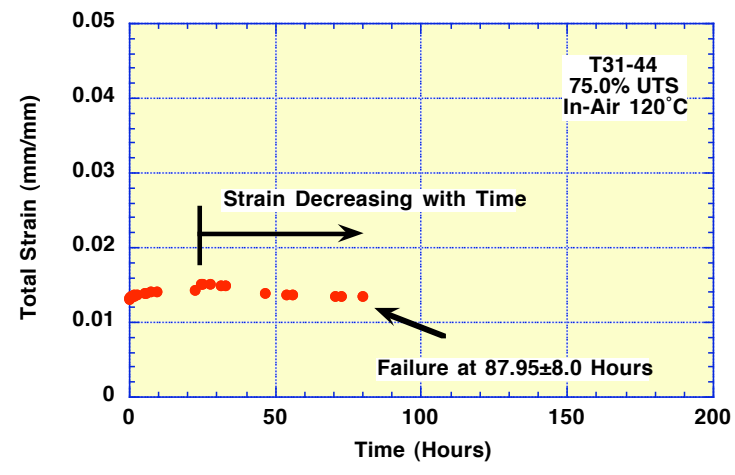

Total Strain vs Time

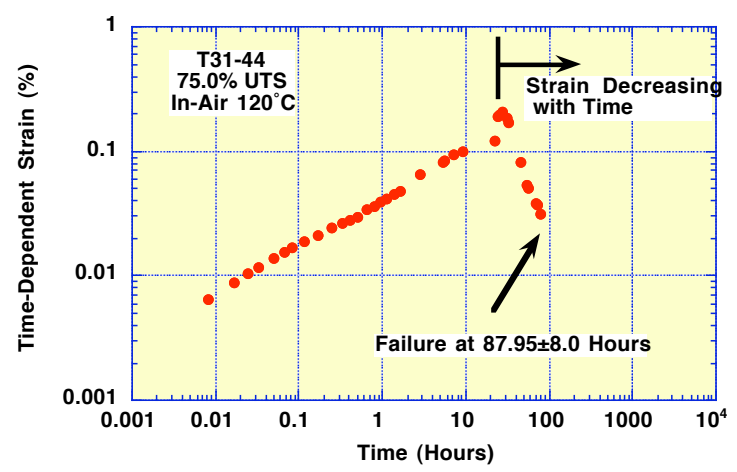

Time-Dependent Strain (Log Plot)

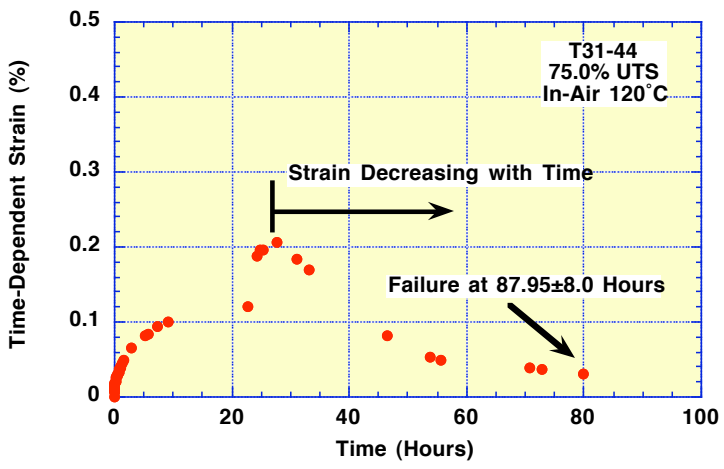

Time-Dependent Strain (Linear Plot) 


\section{Specimen Number: T41-8}

Load Level: $75.0 \%$ UTS

Environment: In-Air $120^{\circ} \mathrm{C}$

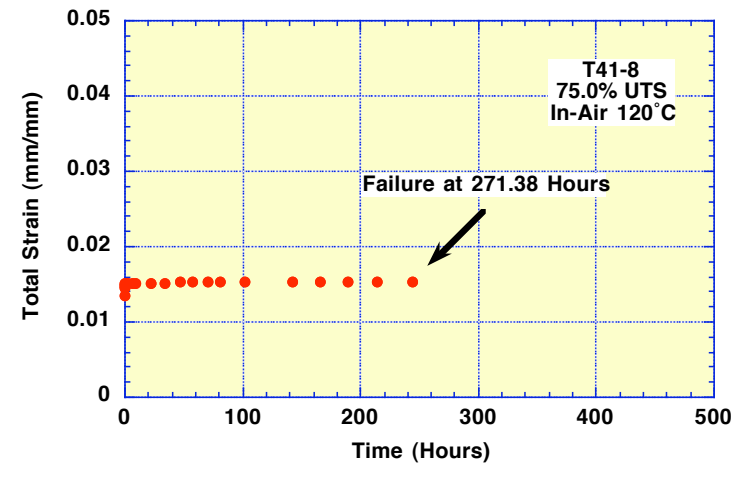

Total Strain vs Time

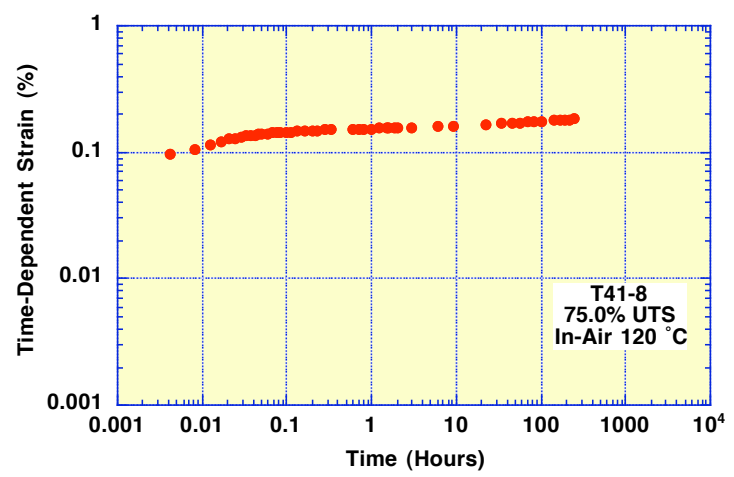

Time-Dependent Strain (Log Plot)

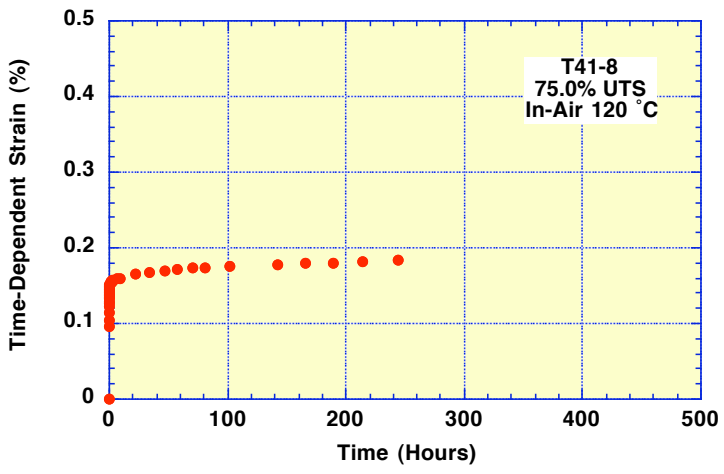

Time-Dependent Strain (Linear Plot)

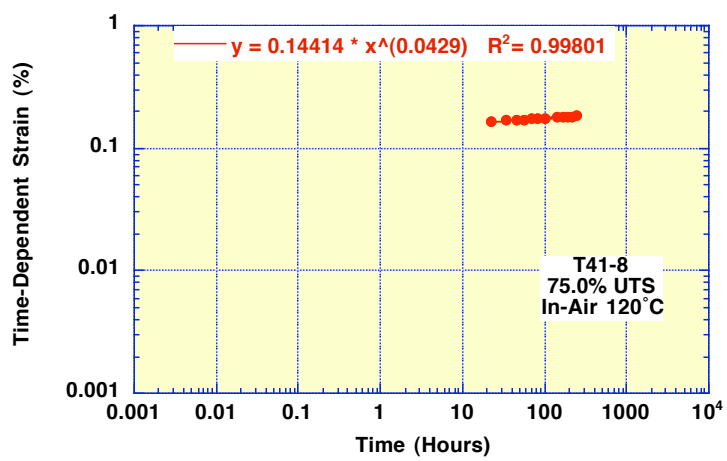

Power Law Fit. 
Specimen Number: T31-2

Load Level: $72.0 \%$ UTS

Environment: In-Air $120^{\circ} \mathrm{C}$

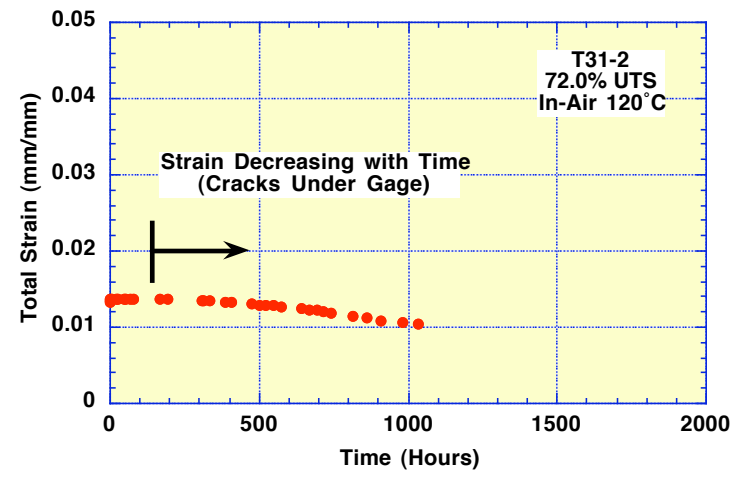

Total Strain vs Time 
Specimen Number: T31-4

Load Level: $72.0 \%$ UTS

Environment: In-Air $120^{\circ} \mathrm{C}$

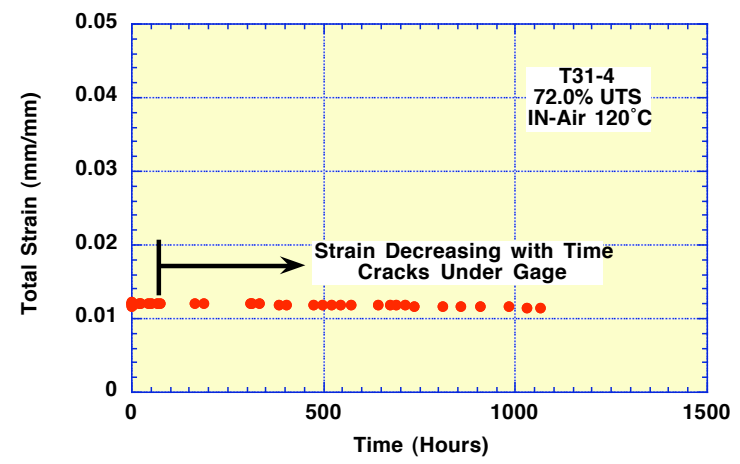

Total Strain vs Time 
Specimen Number: T31-22

Load Level: $69.9 \%$ UTS

Environment: In-Air $120^{\circ} \mathrm{C}$

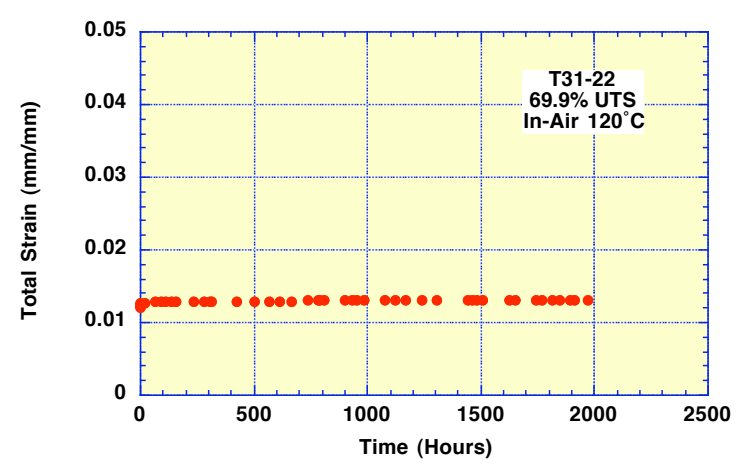

Total Strain vs Time

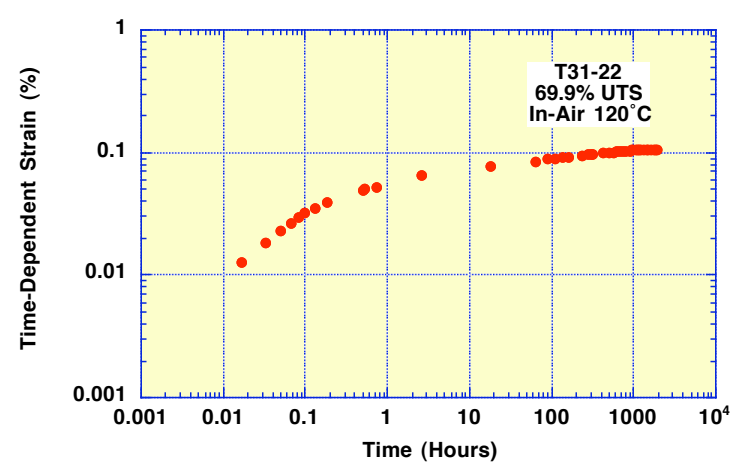

Time-Dependent Strain (Log Plot)

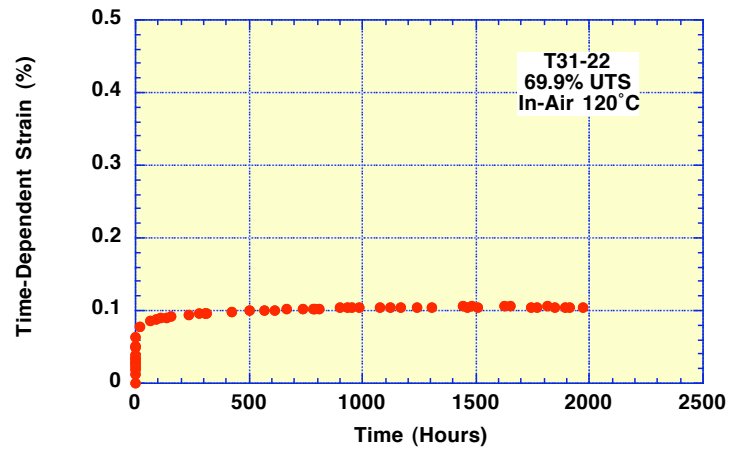

Time-Dependent Strain (Linear Plot)

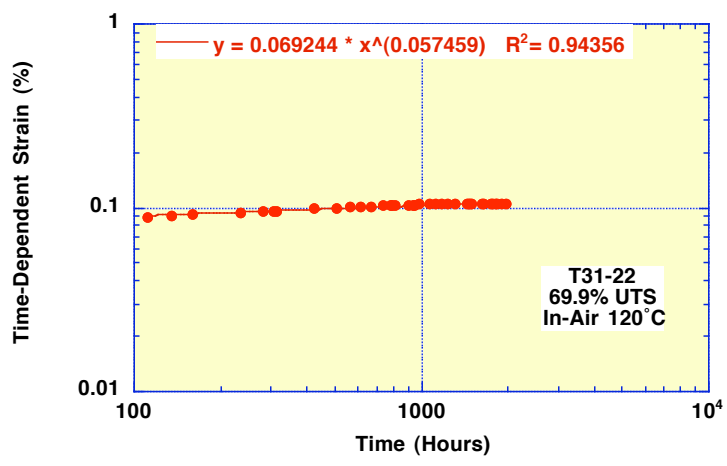

Power Law Fit. 
Specimen Number: T31-33

Load Level: $\mathbf{7 5 . 0 \%}$ UTS

Environment: In-Air $120^{\circ} \mathrm{C}$

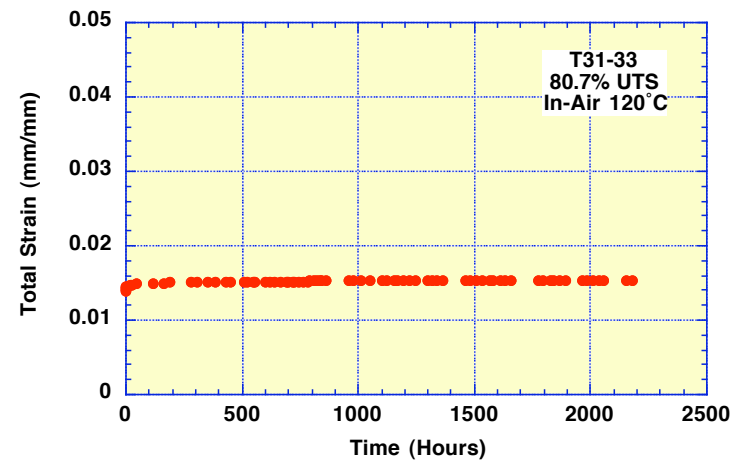

Total Strain vs Time

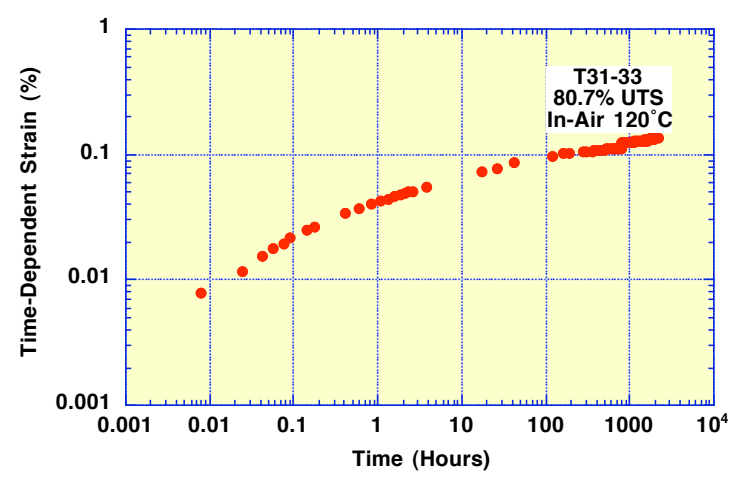

Time-Dependent Strain (Log Plot)

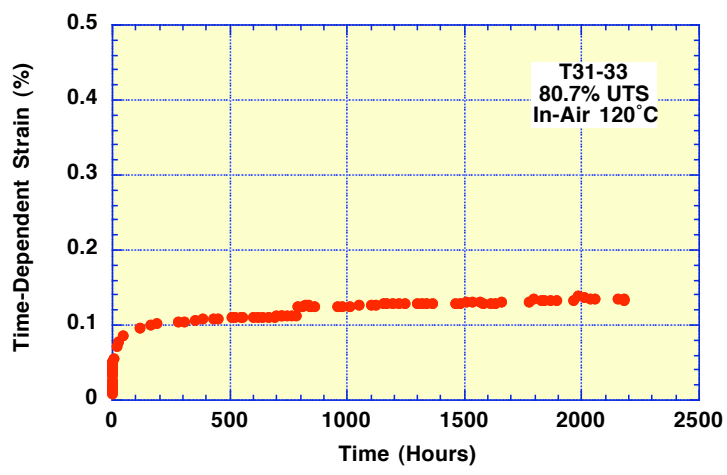

Time-Dependent Strain (Linear Plot)

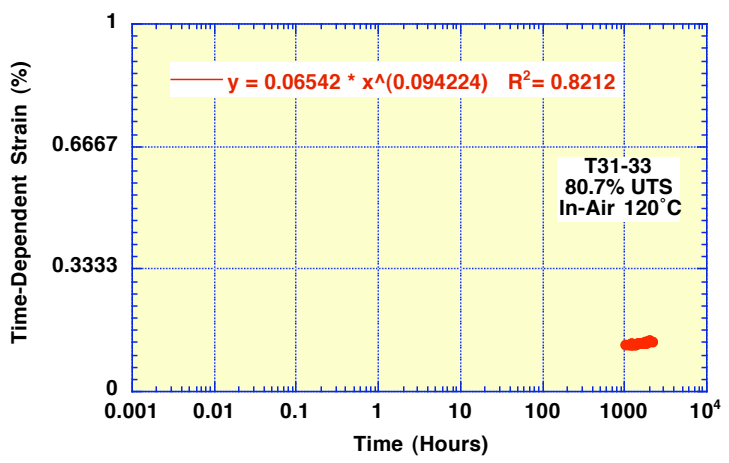

Power Law Fit. 


\section{Specimen Number: T31-43}

Load Level: $80.0 \%$ UTS

Environment: In-Air $120^{\circ} \mathrm{C}$

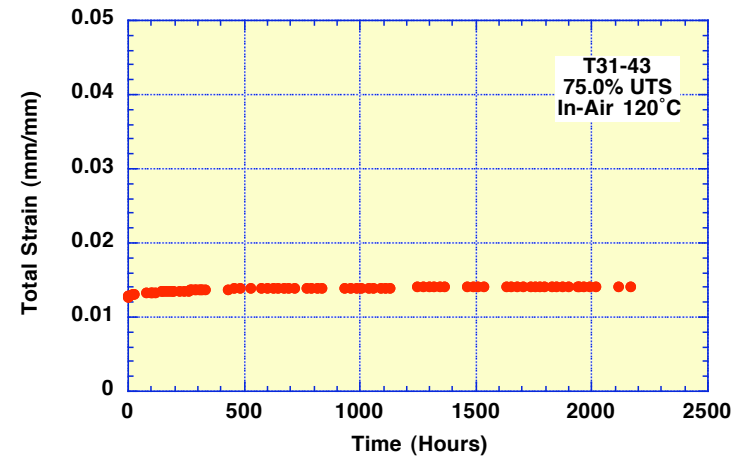

Total Strain vs Time

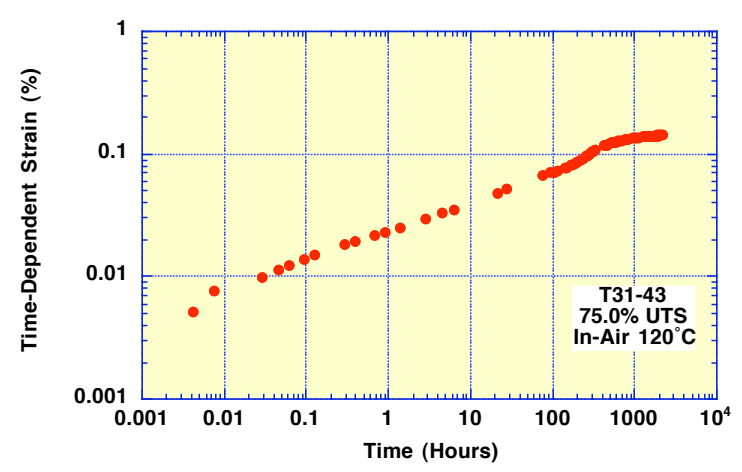

Time-Dependent Strain (Log Plot)

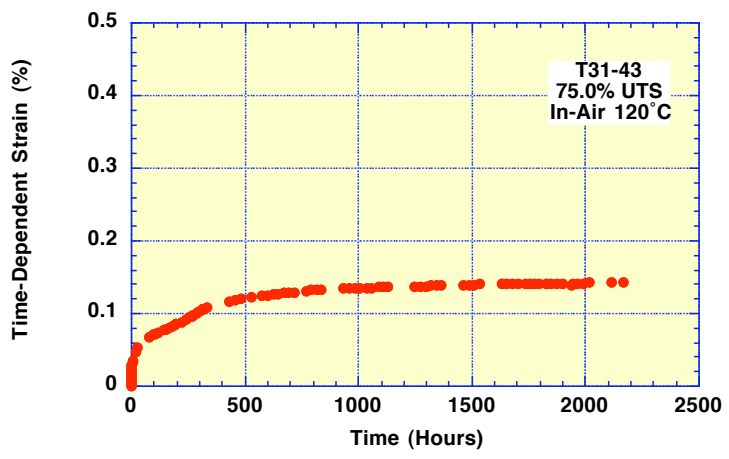

Time-Dependent Strain (Linear Plot)

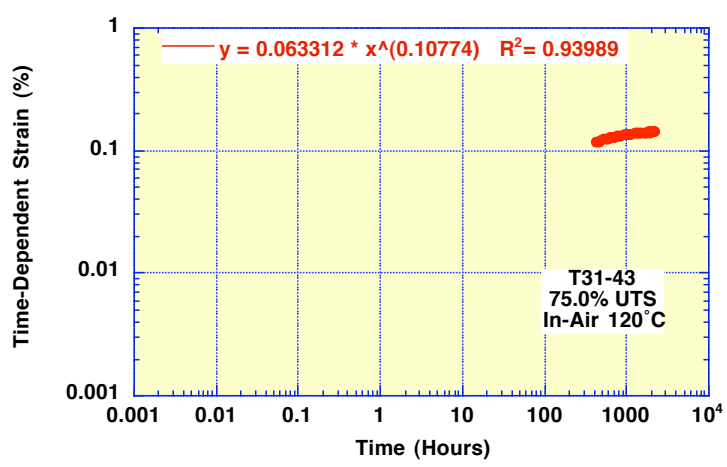

Power Law Fit. 


\section{Specimen Number: T31-42}

Load Level: $70.0 \%$ UTS

Environment: In-Air $120^{\circ} \mathrm{C}$

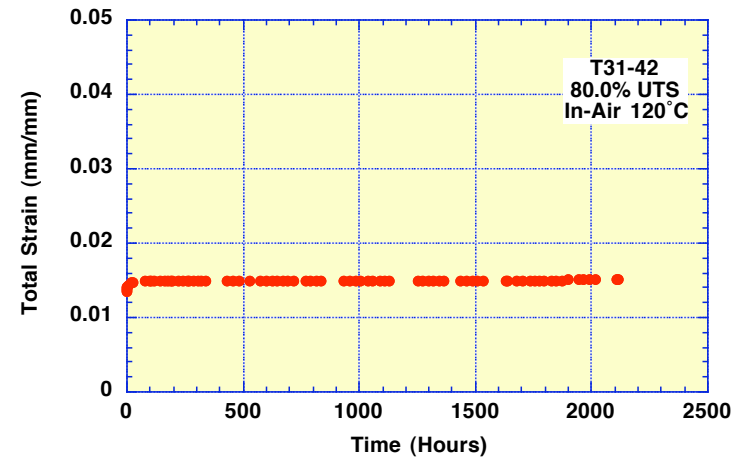

Total Strain vs Time

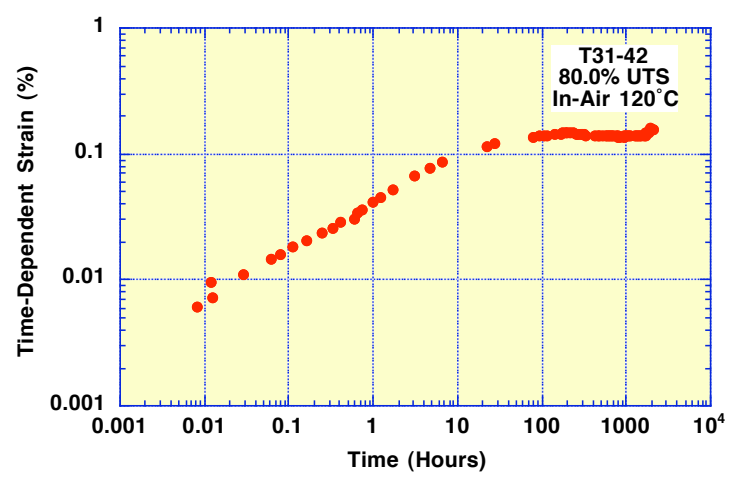

Time-Dependent Strain (Log Plot)

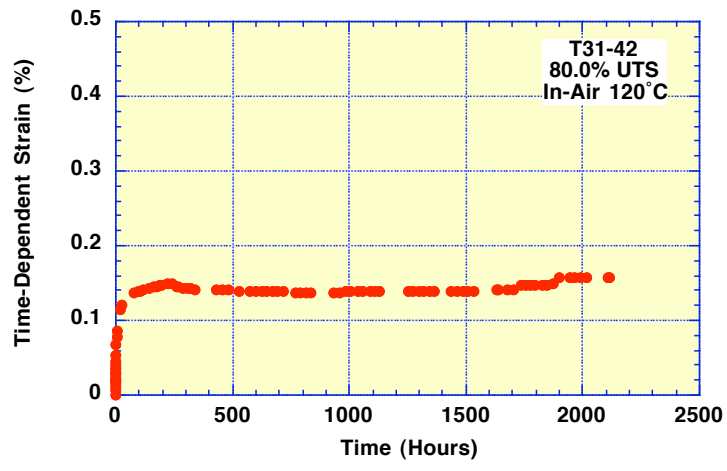

Time-Dependent Strain (Linear Plot)

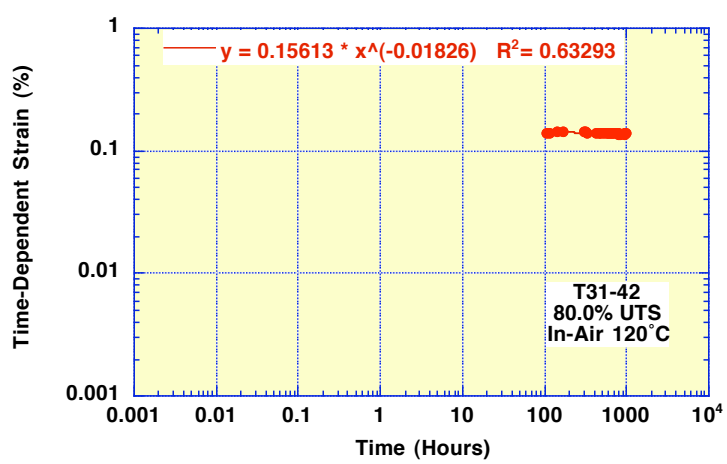

Power Law Fit. 
Specimen Number: T41-4

Load Level: $70.0 \%$ UTS

Environment: In-Air $120^{\circ} \mathrm{C}$

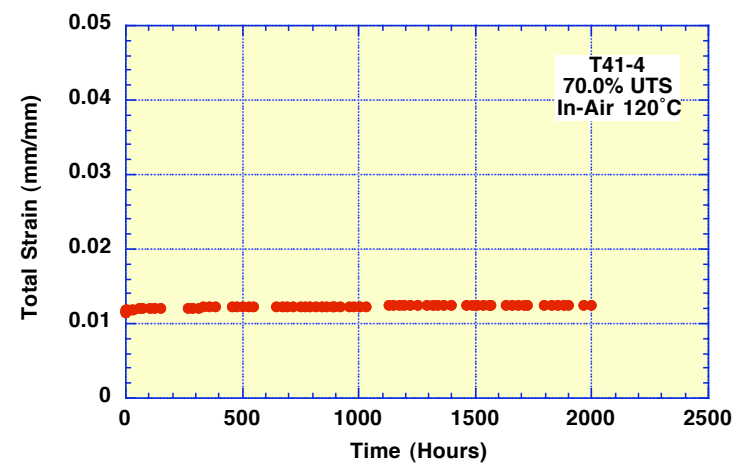

Total Strain vs Time

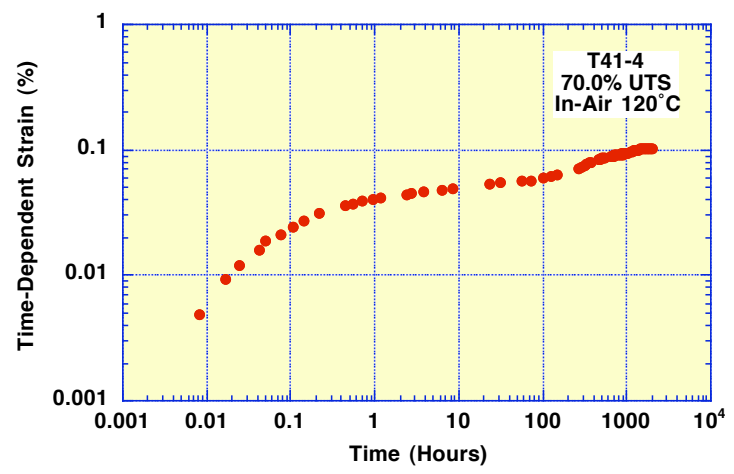

Time-Dependent Strain (Log Plot)

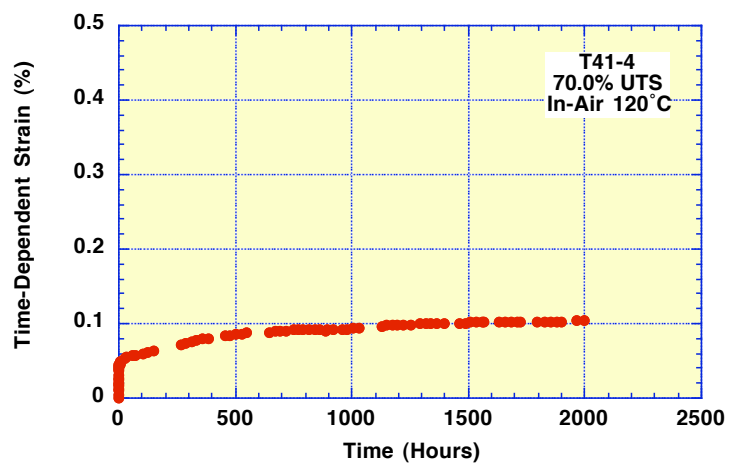

Time-Dependent Strain (Linear Plot)

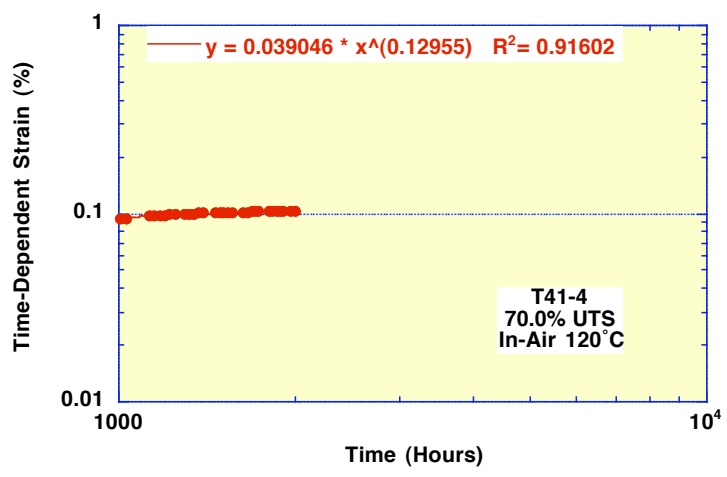

Power Law Fit. 
Specimen Number: T41-5

Load Level: $60.0 \%$ UTS

Environment: In-Air $120^{\circ} \mathrm{C}$

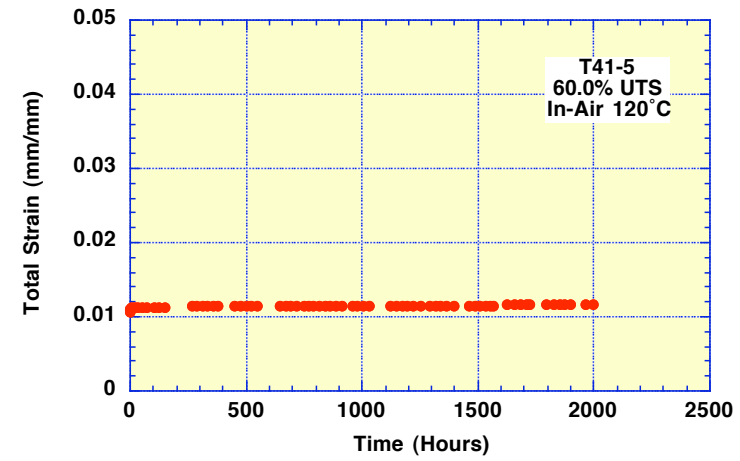

Total Strain vs Time

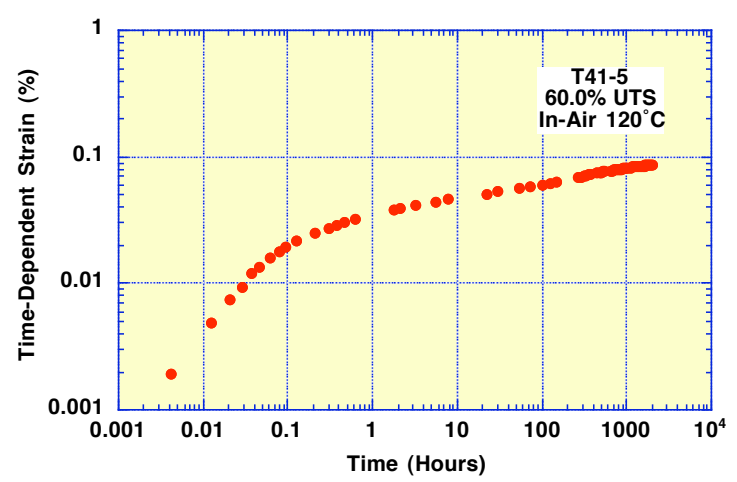

Time-Dependent Strain (Log Plot)

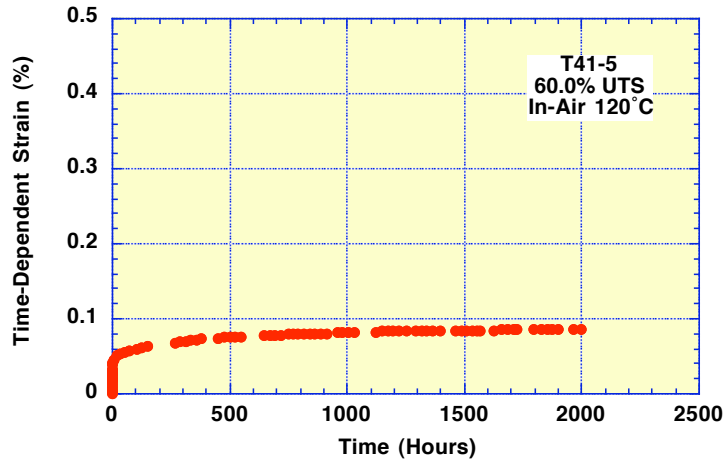

Time-Dependent Strain (Linear Plot)

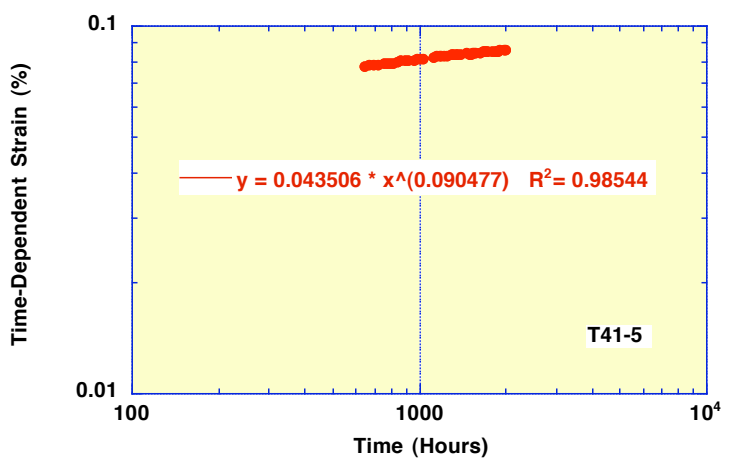

Power Law Fit. 
Specimen Number: T41-6

Load Level: $60.0 \%$ UTS

Environment: In-Air $120^{\circ} \mathrm{C}$

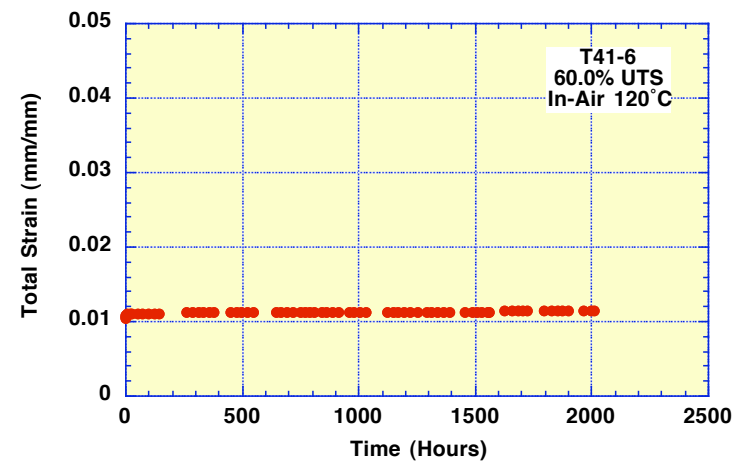

Total Strain vs Time

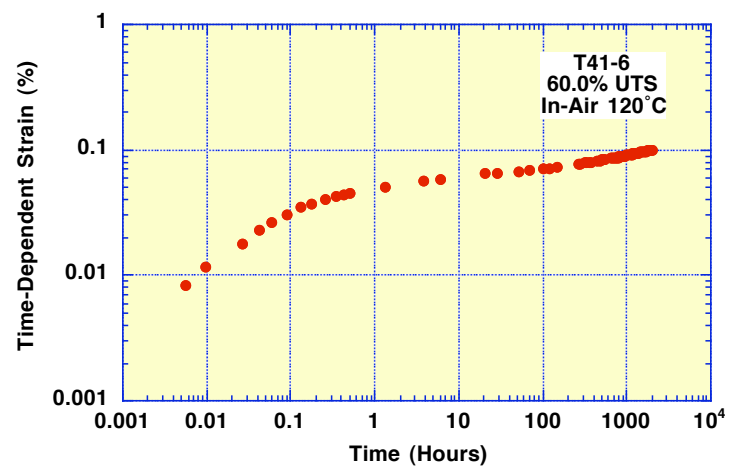

Time-Dependent Strain (Log Plot)

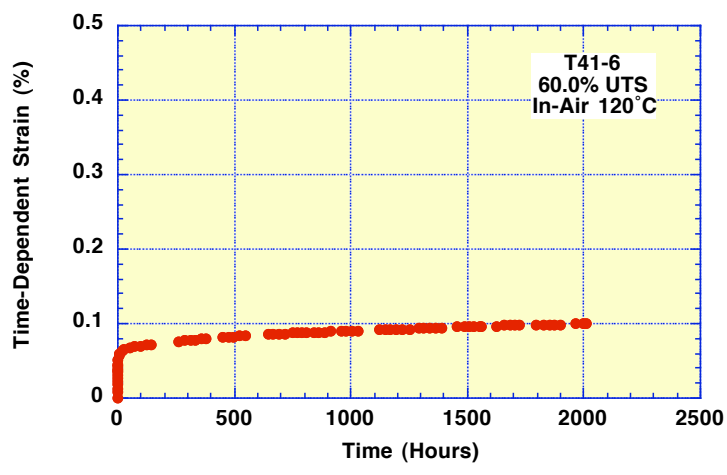

Time-Dependent Strain (Linear Plot)

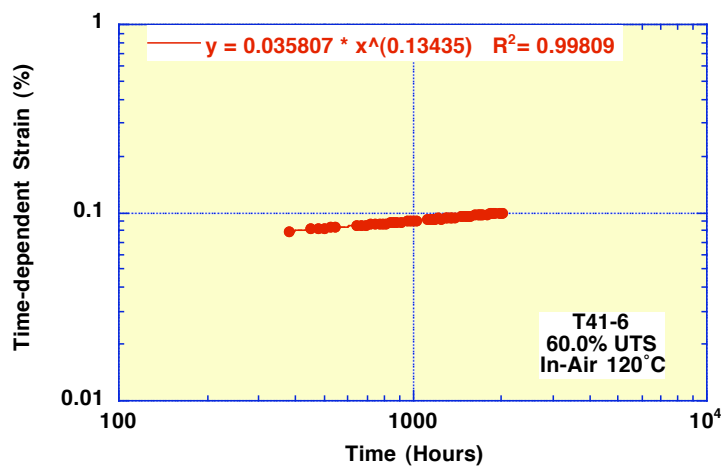

Power Law Fit. 


\section{Specimen Number: T41-7}

Load Level: $50.0 \%$ UTS

Environment: In-Air $120^{\circ} \mathrm{C}$

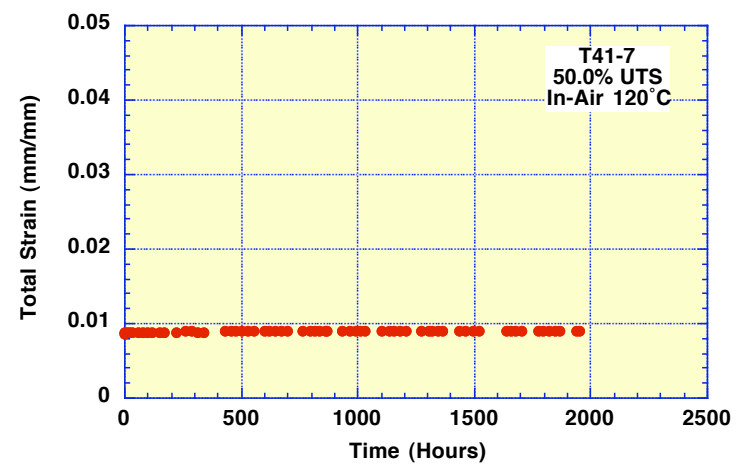

Total Strain vs Time

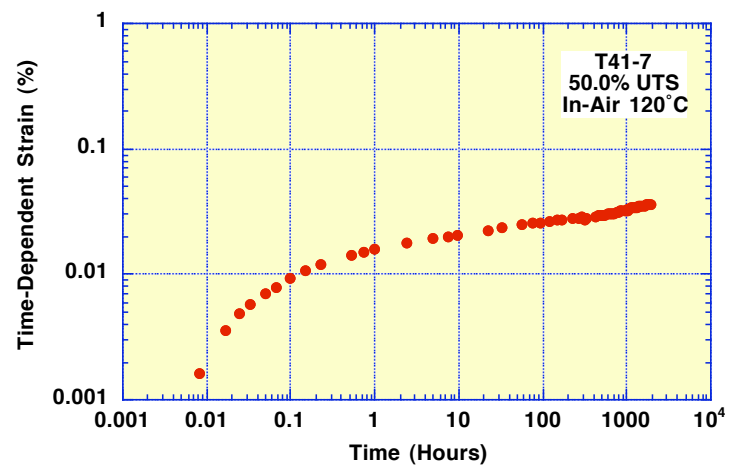

Time-Dependent Strain (Log Plot)

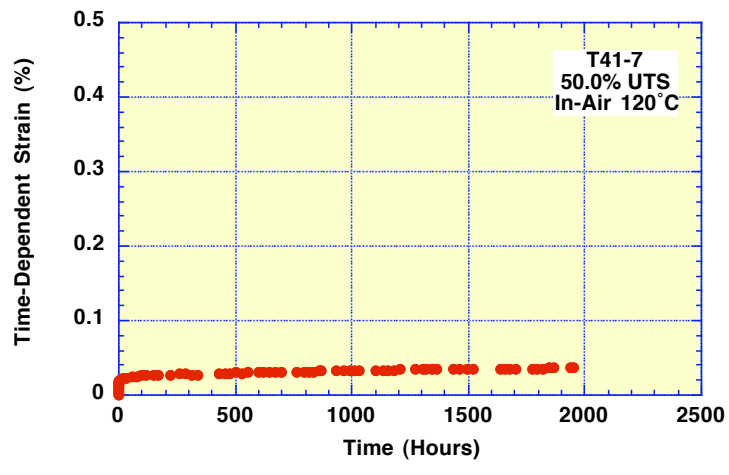

Time-Dependent Strain (Linear Plot)

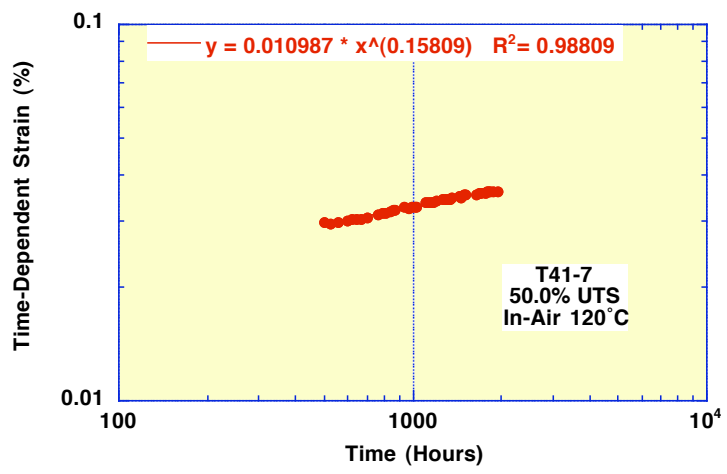

Power Law Fit. 
Specimen Number: T41-9

Load Level: $70.0 \%$ UTS

Environment: In-Air $120^{\circ} \mathrm{C}$

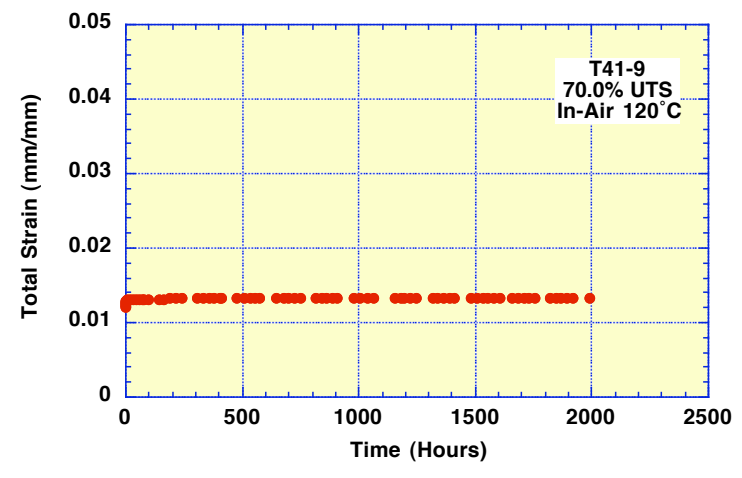

Total Strain vs Time

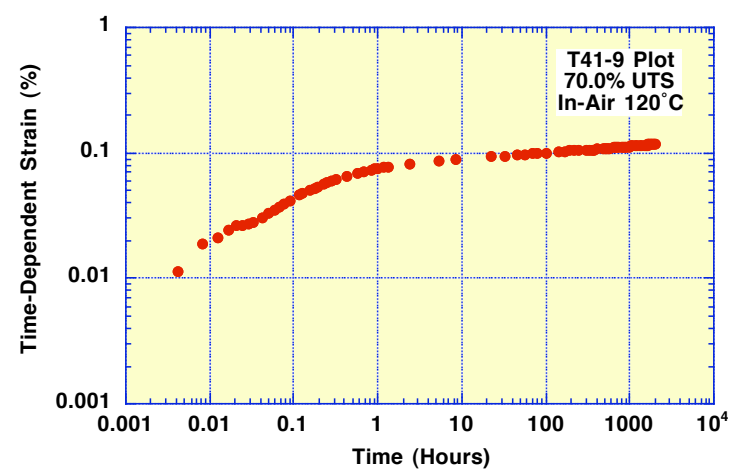

Time-Dependent Strain (Log Plot)

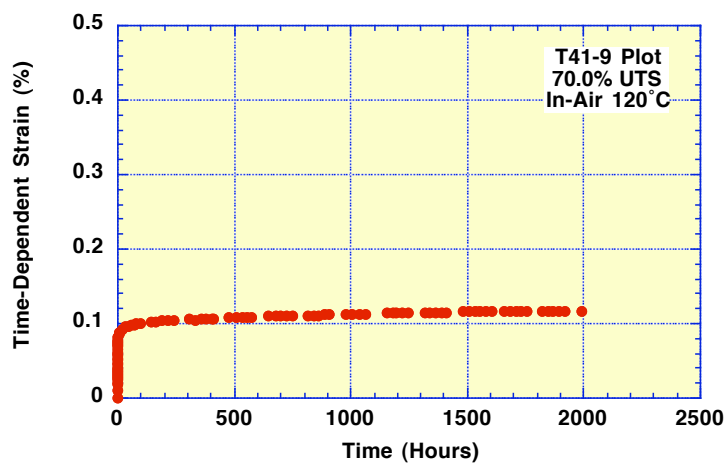

Time-Dependent Strain (Linear Plot)

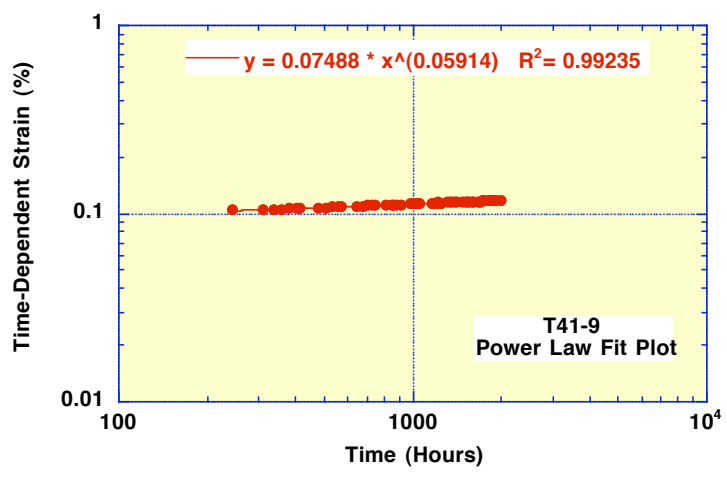

Power Law Fit. 


\section{Specimen Number: T41-15}

Load Level: $40.0 \%$ UTS

Environment: In-Air $120^{\circ} \mathrm{C}$

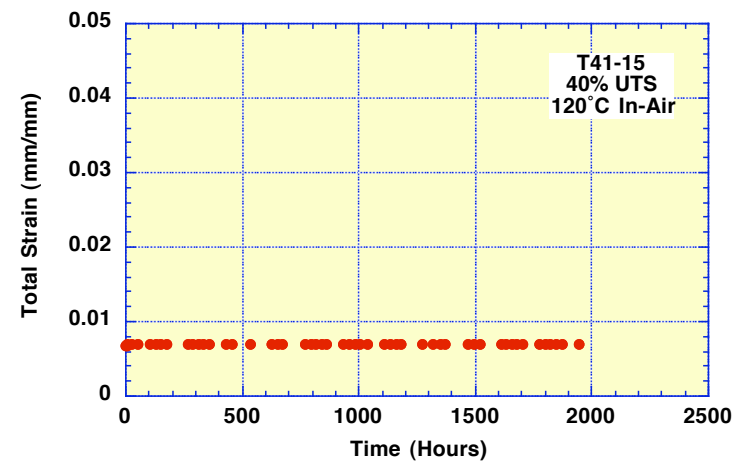

Total Strain vs Time

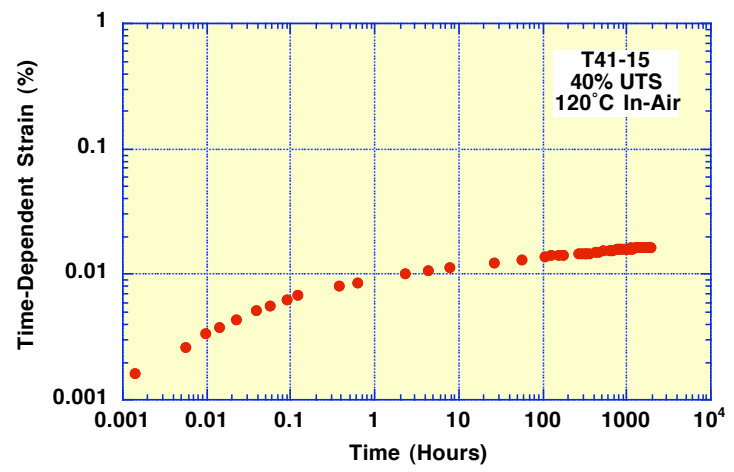

Time-Dependent Strain (Log Plot)

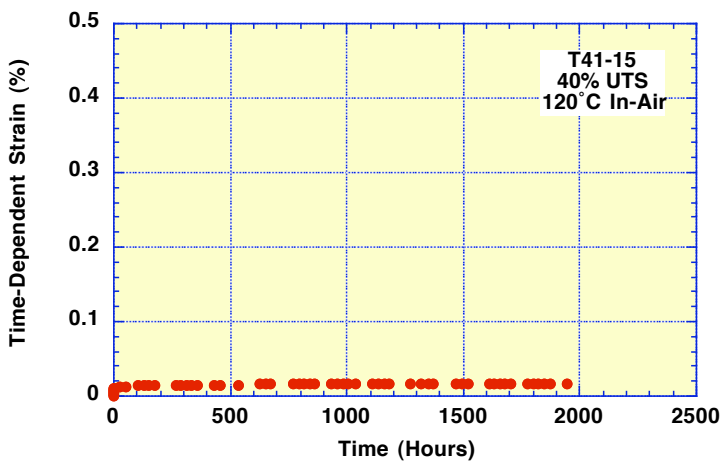

Time-Dependent Strain (Linear Plot)

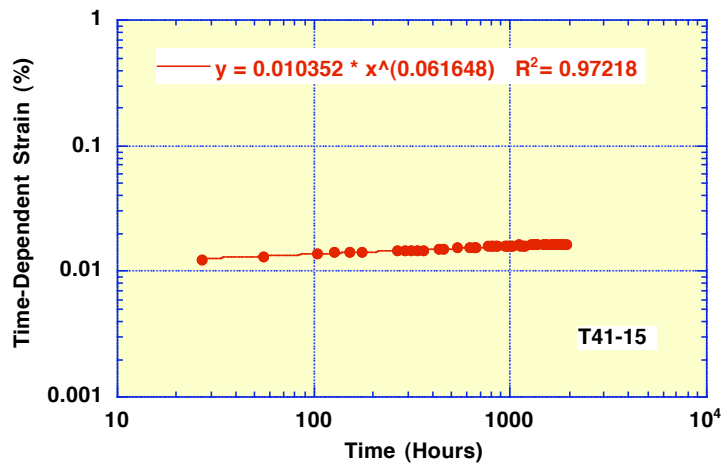

Power Law Fit. 


\section{Specimen Number: T41-23}

Load Level: $50.0 \%$ UTS

Environment: In-Air $120^{\circ} \mathrm{C}$

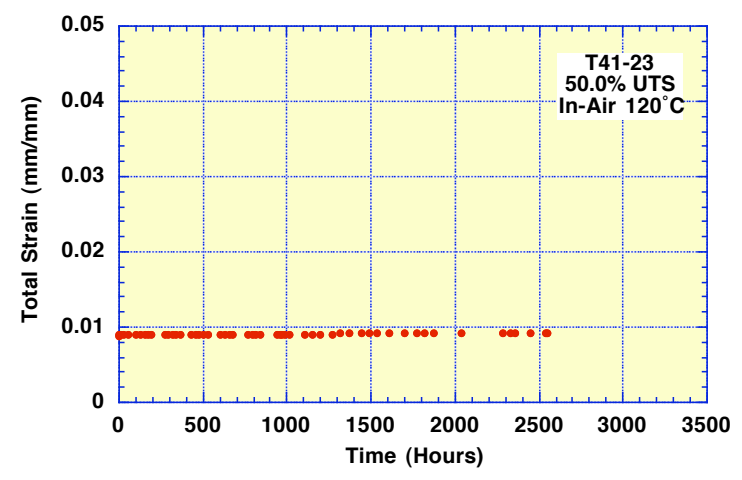

Total Strain vs Time

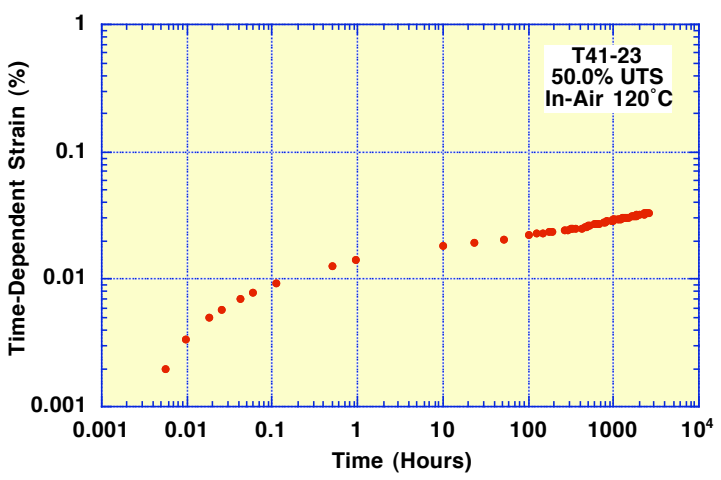

Time-Dependent Strain (Log Plot)

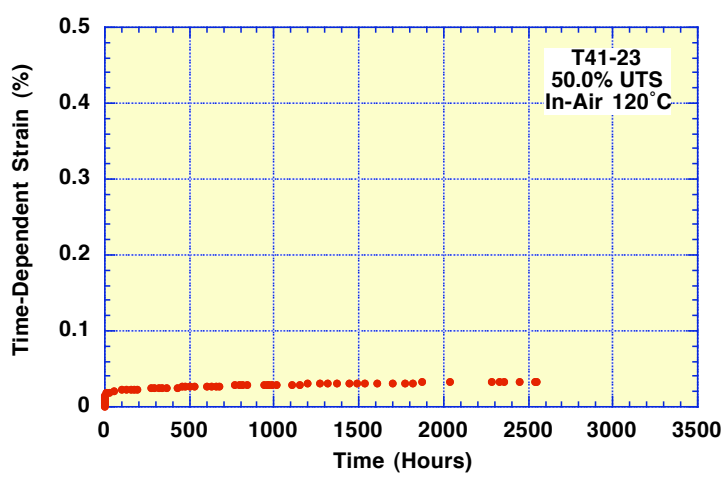

Time-Dependent Strain (Linear Plot)

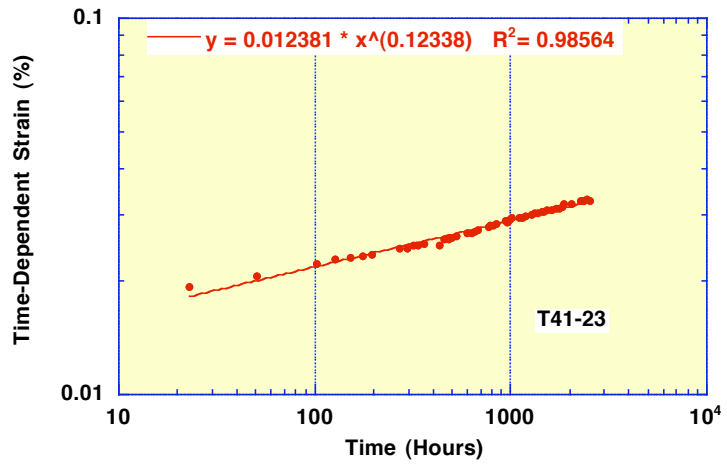

Power Law Fit. 
Specimen Number: T41-16

Load Level: $85.0 \%$ UTS

Environment: In-Air $120^{\circ} \mathrm{C}$

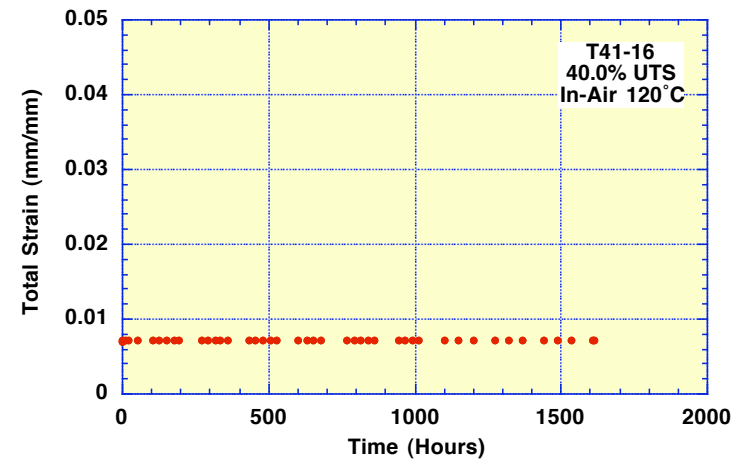

Total Strain vs Time

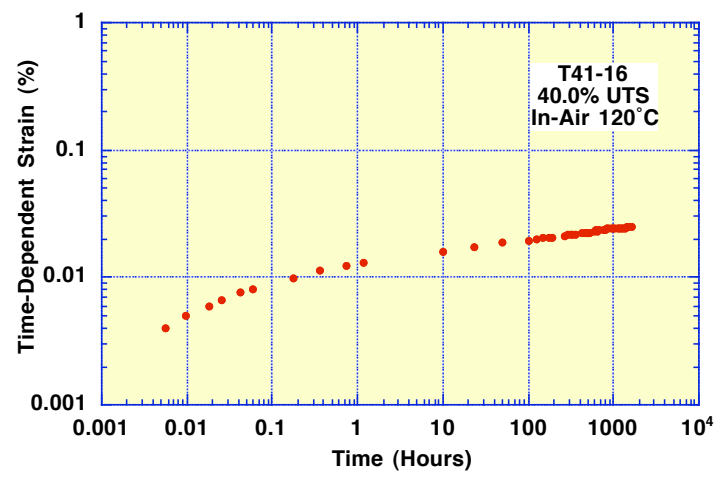

Time-Dependent Strain (Log Plot)

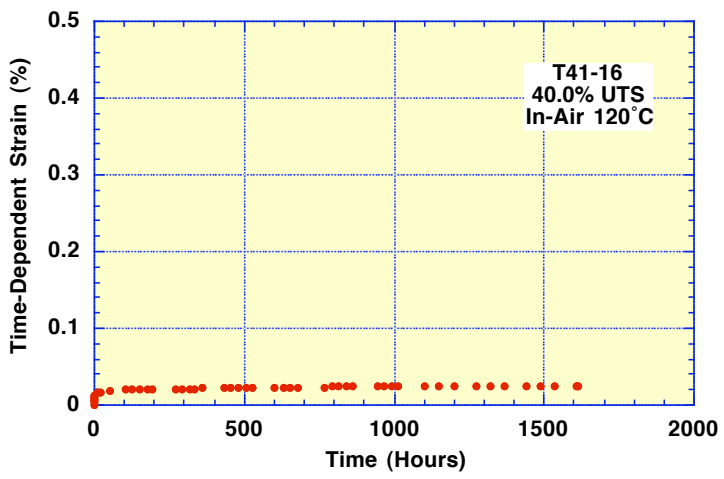

Time-Dependent Strain (Linear Plot)

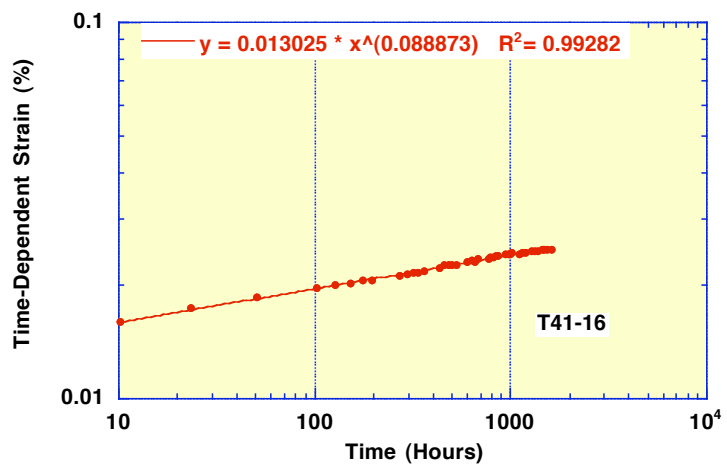

Power Law Fit. 


\section{Specimen Number: T39-10}

Load Level: $70.0 \%$ UTS

\section{Environment: Distilled Water Room Temperature}

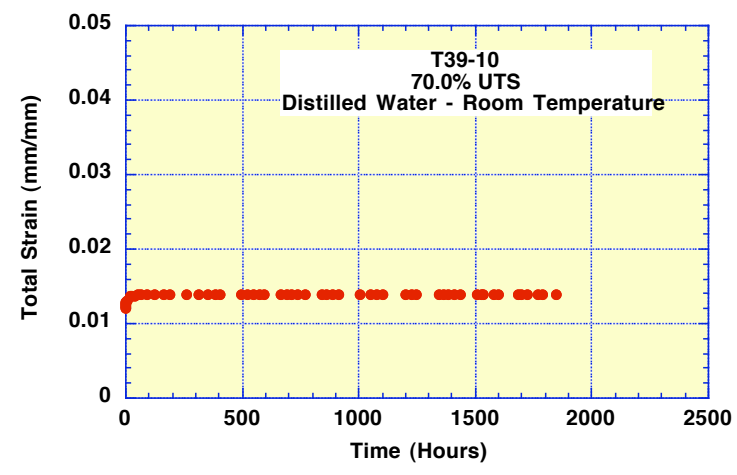

Total Strain vs Time

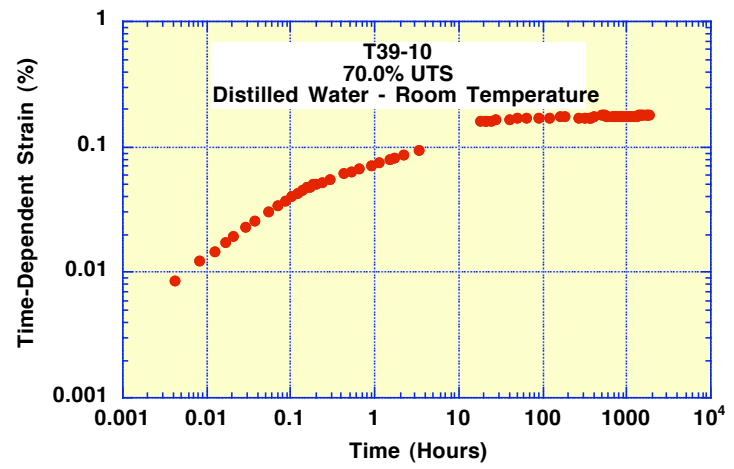

Time-Dependent Strain (Log Plot)

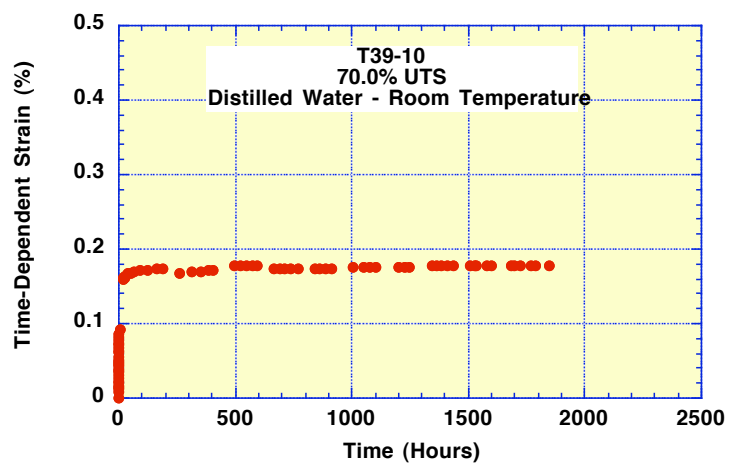

Time-Dependent Strain (Linear Plot)

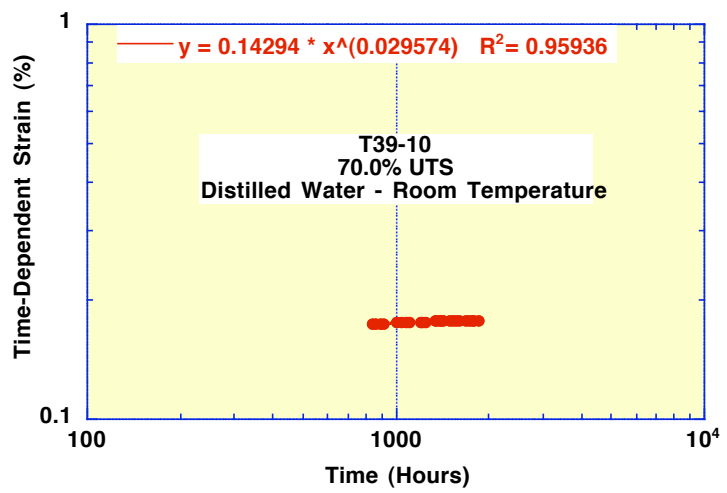

Power Law Fit. 


\section{Specimen Number: T39-11}

Load Level: $60.0 \%$ UTS

\section{Environment: Distilled Water Room Temperature}

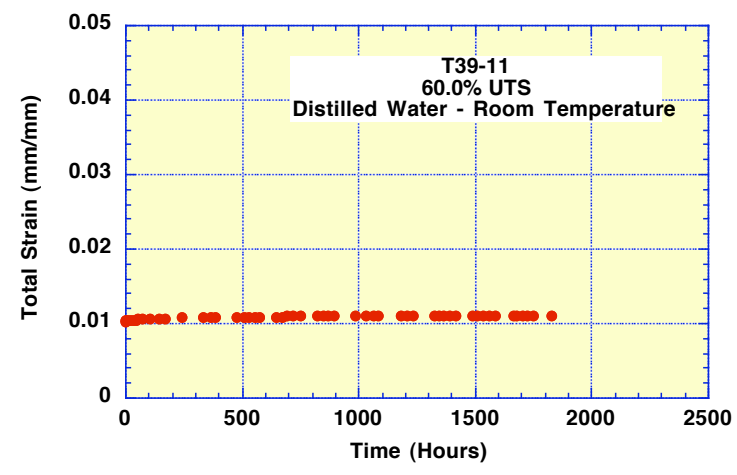

Total Strain vs Time

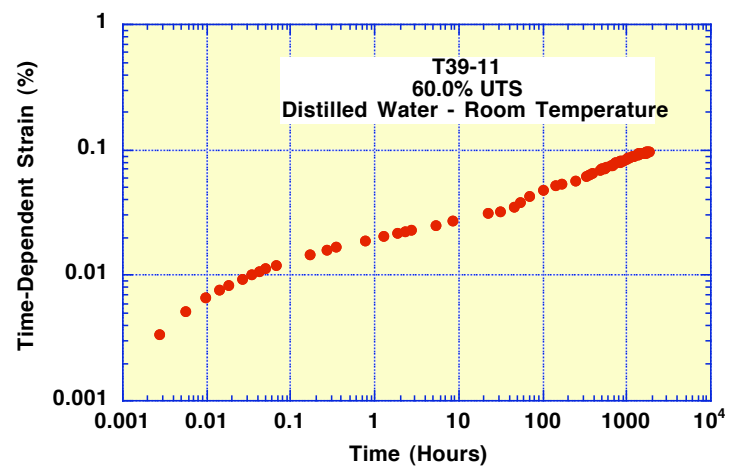

Time-Dependent Strain (Log Plot)

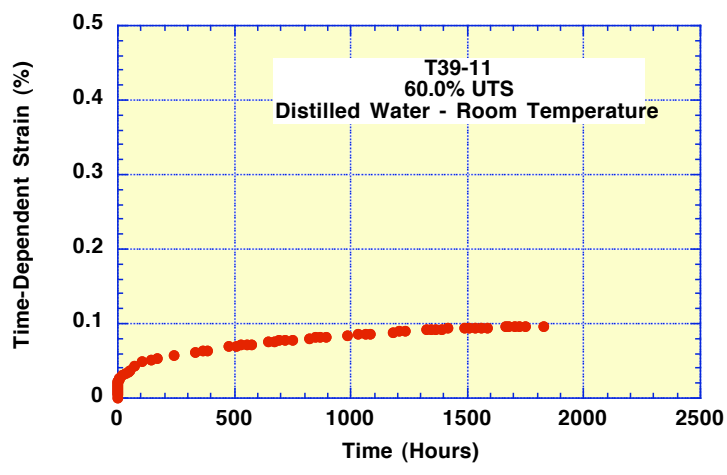

Time-Dependent Strain (Linear Plot)

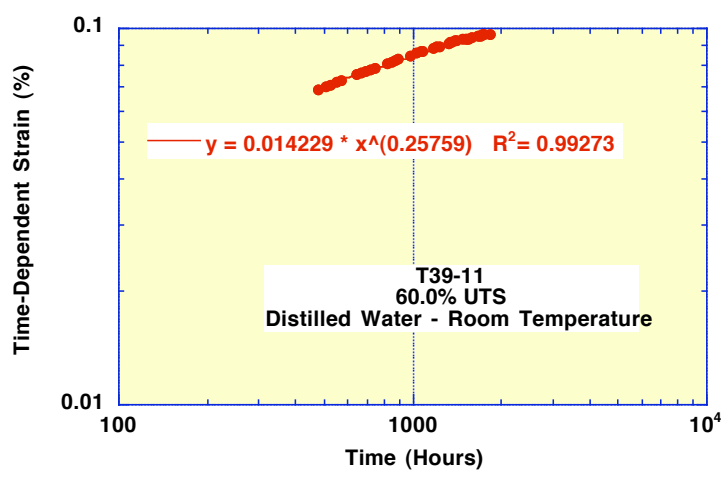

Power Law Fit. 


\section{Specimen Number: T39-12}

Load Level: $50.0 \%$ UTS

Environment: Distilled Water Room Temperature

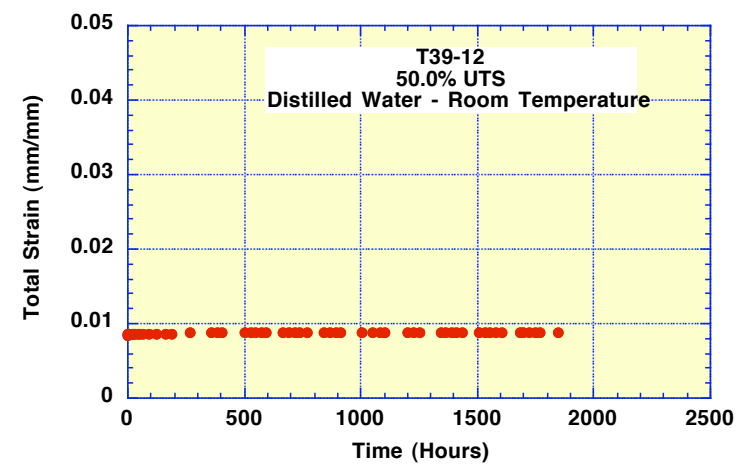

Total Strain vs Time

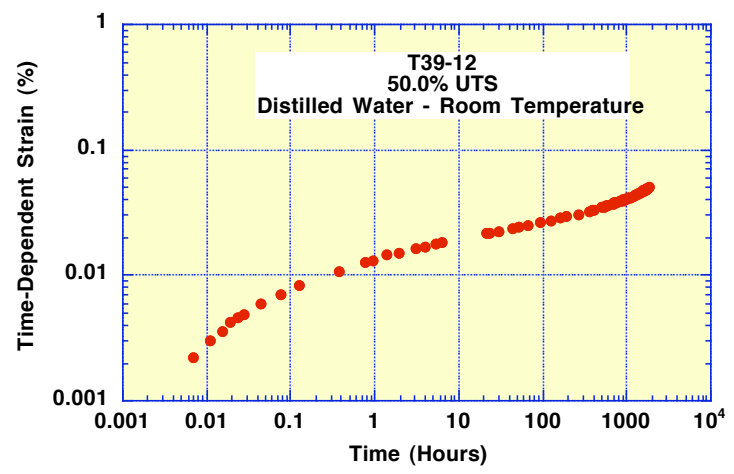

Time-Dependent Strain (Log Plot)

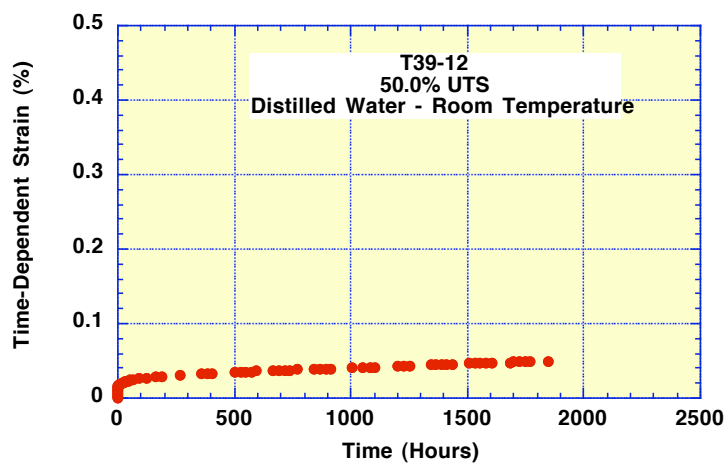

Time-Dependent Strain (Linear Plot)

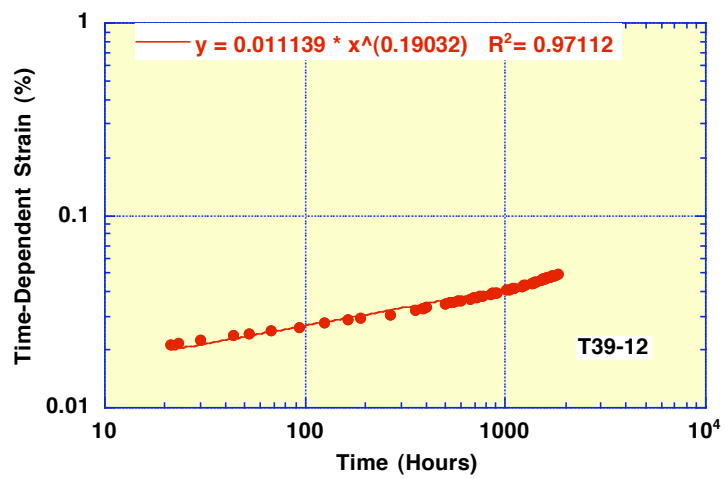

Power Law Fit. 
Specimen Number: T39-38

Load Level: $60.0 \%$ UTS

Environment: Distilled Water Room Temperature

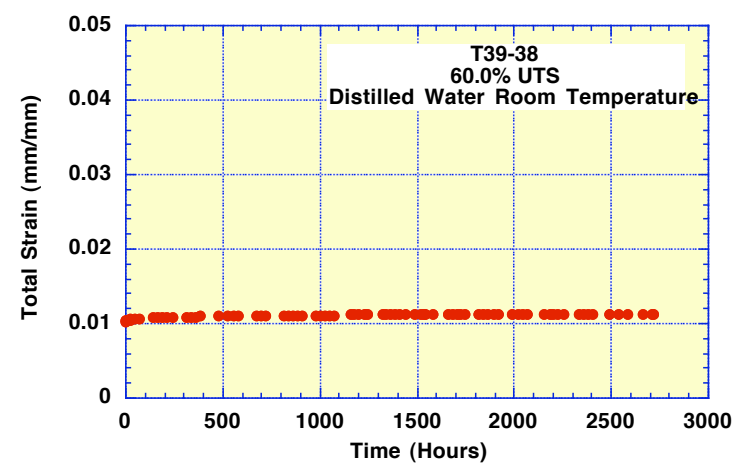

Total Strain vs Time

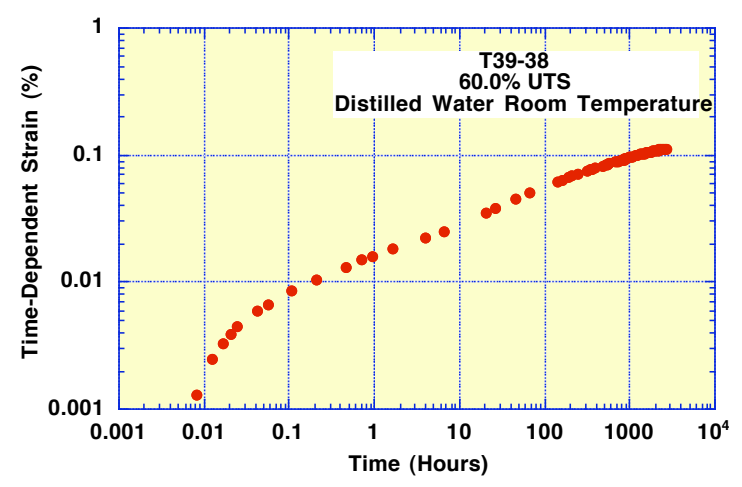

Time-Dependent Strain (Log Plot)

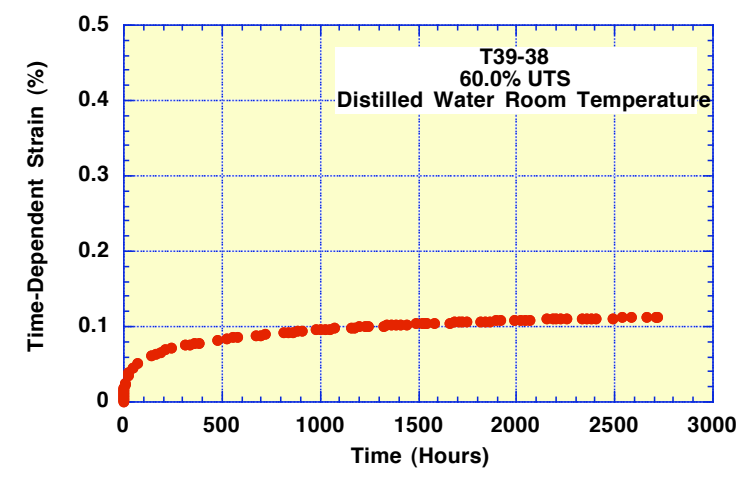

Time-Dependent Strain (Linear Plot)

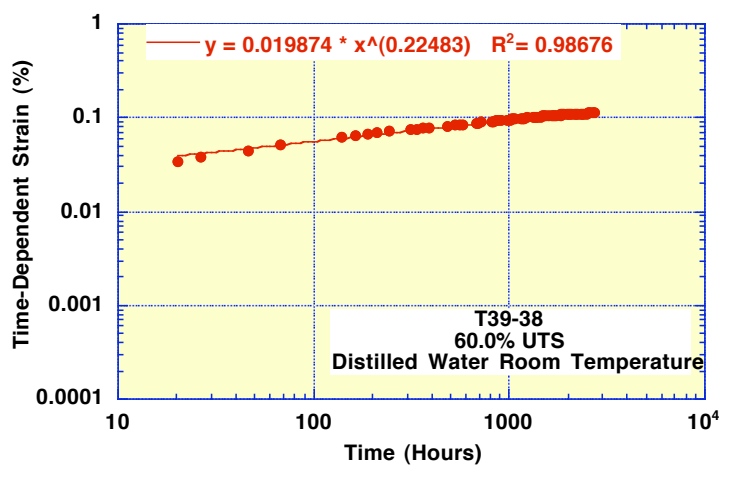

Power Law Fit. 
Specimen Number: T39-39

Load Level: $79.9 \%$ UTS

Environment: Distilled Water Room Temperature

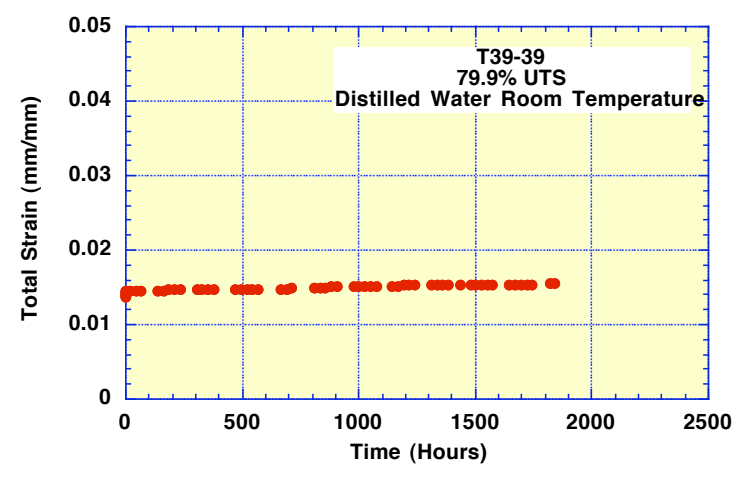

Total Strain vs Time

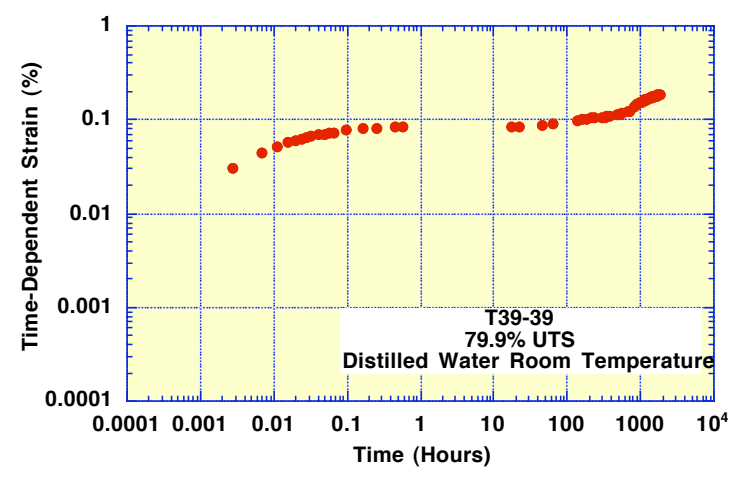

Time-Dependent Strain (Log Plot)

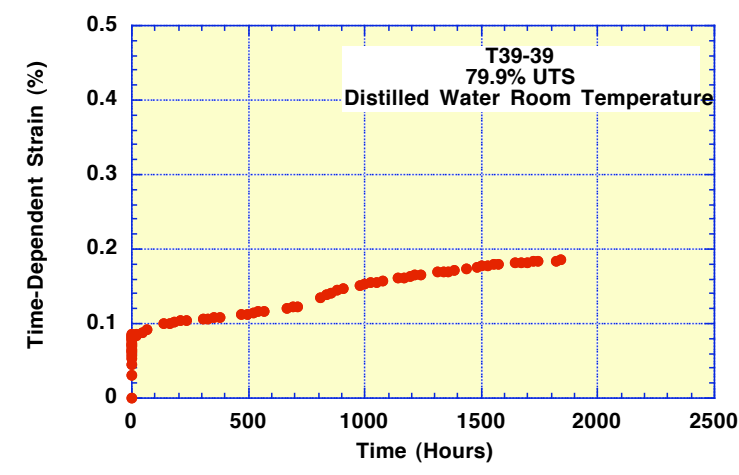

Time-Dependent Strain (Linear Plot)

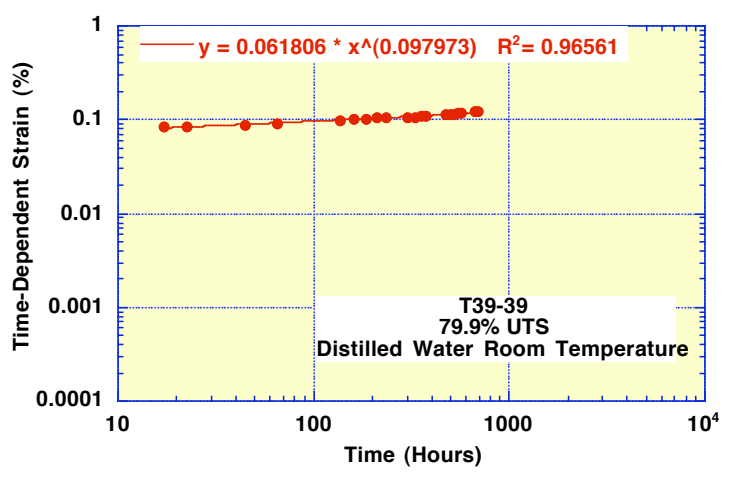

Power Law Fit. 
Specimen Number: T39-40

Load Level: $\mathbf{7 5 . 0 \%}$ UTS

Environment: Distilled Water Room Temperature

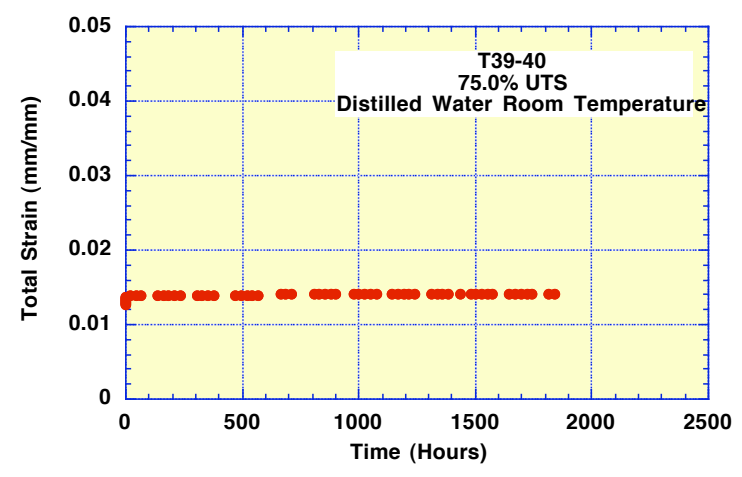

Total Strain vs Time

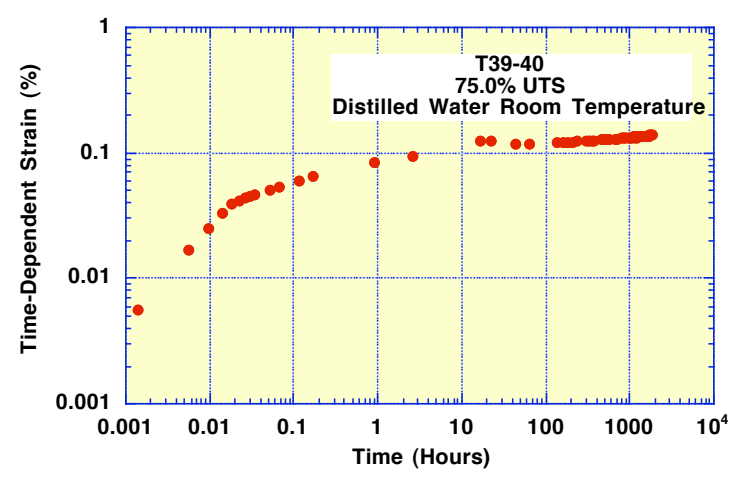

Time-Dependent Strain (Log Plot)

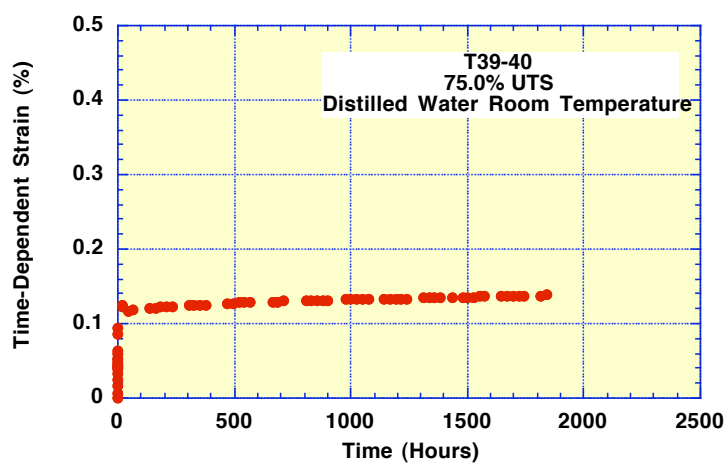

Time-Dependent Strain (Linear Plot)

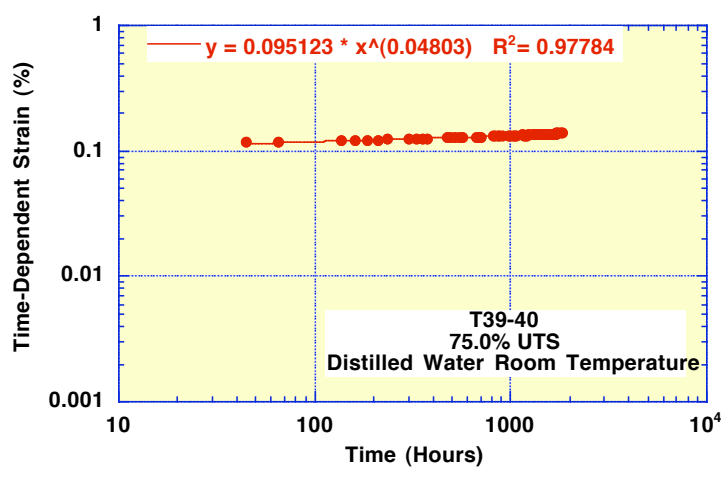

Power Law Fit. 
Specimen Number: T39-50

Load Level: $40.0 \%$ UTS

Environment: Distilled Water Room Temperature

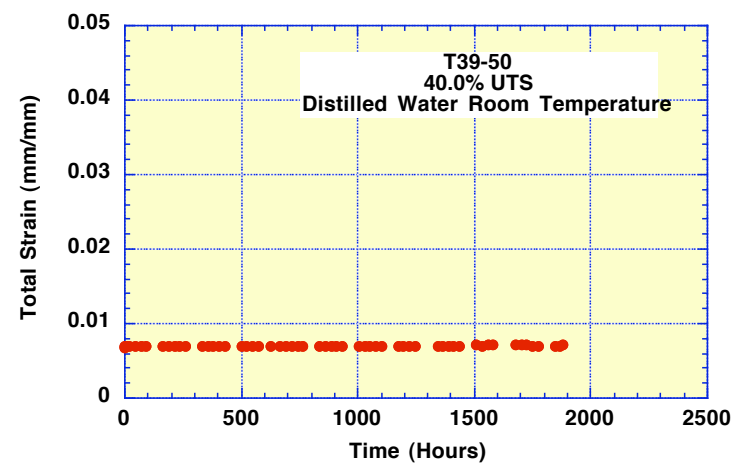

Total Strain vs Time

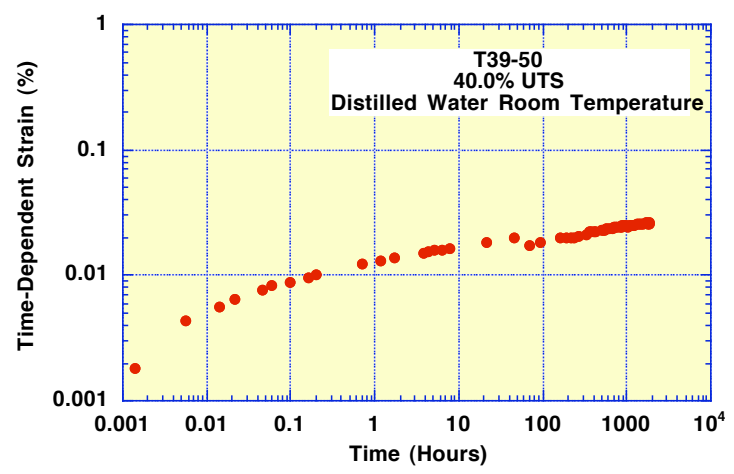

Time-Dependent Strain (Log Plot)

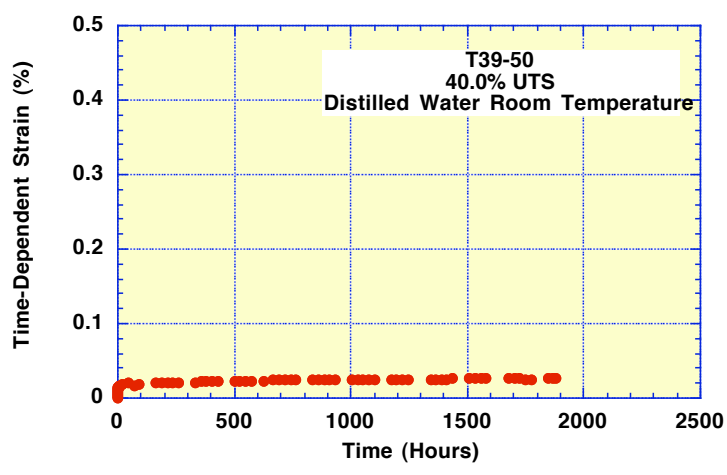

Time-Dependent Strain (Linear Plot)

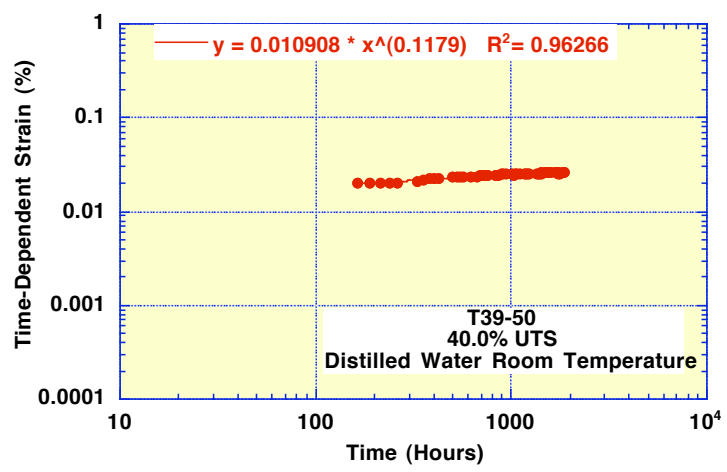

Power Law Fit. 


\section{Specimen Number: T39-41}

Load Level: $69.9 \%$ UTS

\section{Environment: Distilled Water Room Temperature}

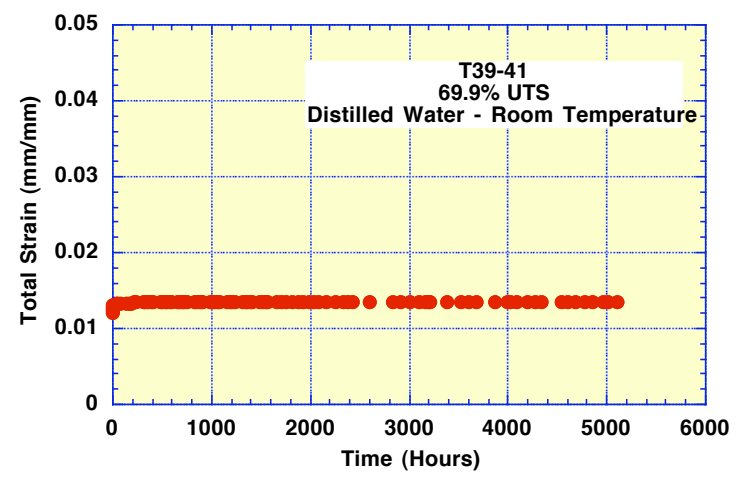

Total Strain vs Time

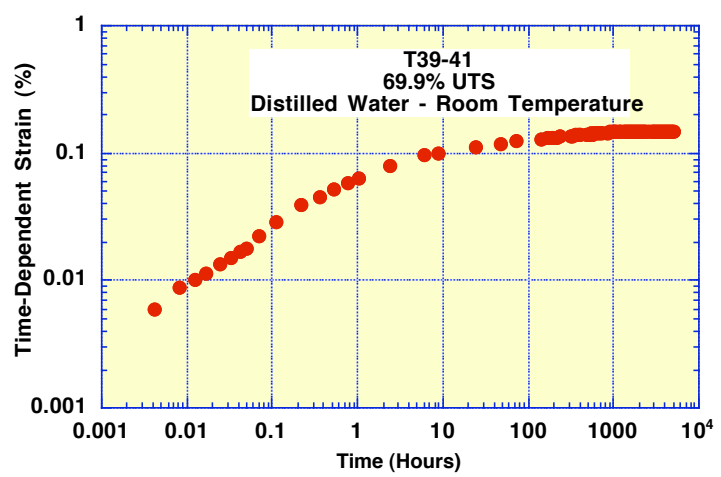

Time-Dependent Strain (Log Plot)

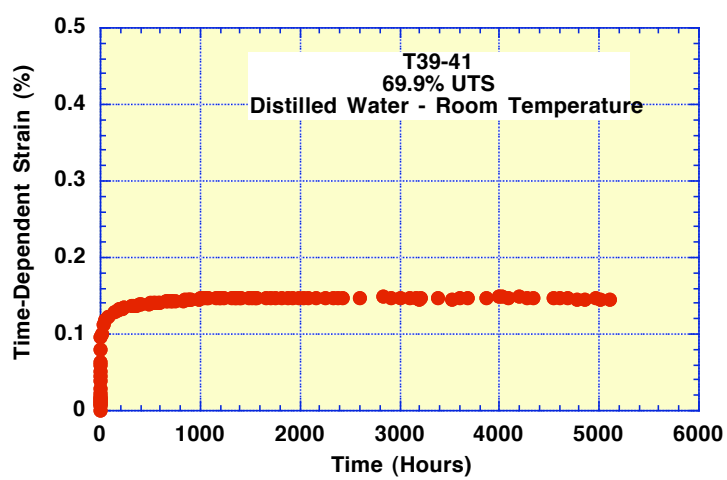

Time-Dependent Strain (Linear Plot)

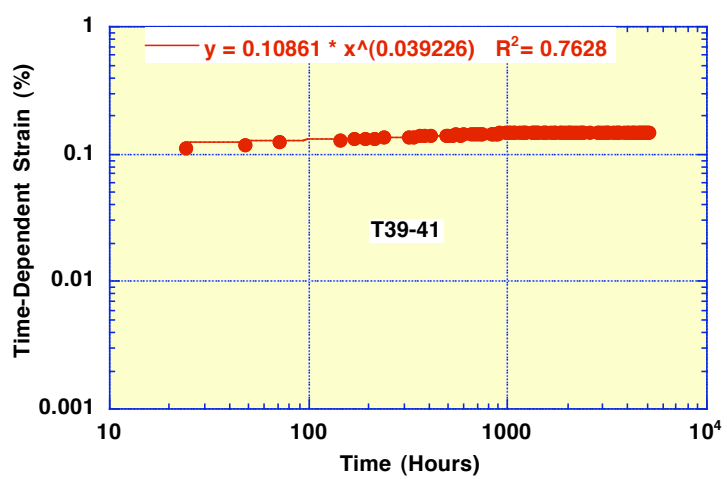

Power Law Fit. 
Specimen Number: T39-44

Load Level: $50.0 \%$ UTS

Environment: Distilled Water Room Temperature

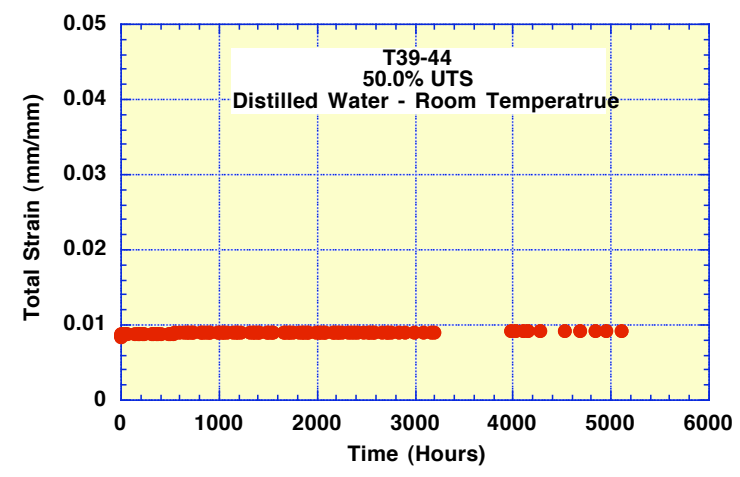

Total Strain vs Time

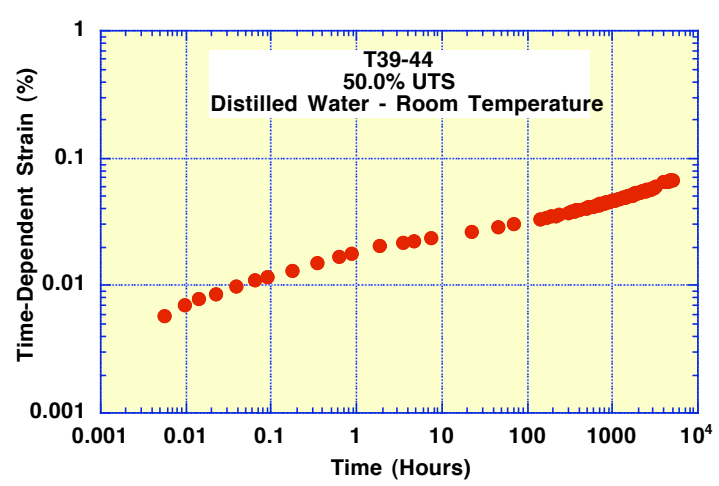

Time-Dependent Strain (Log Plot)

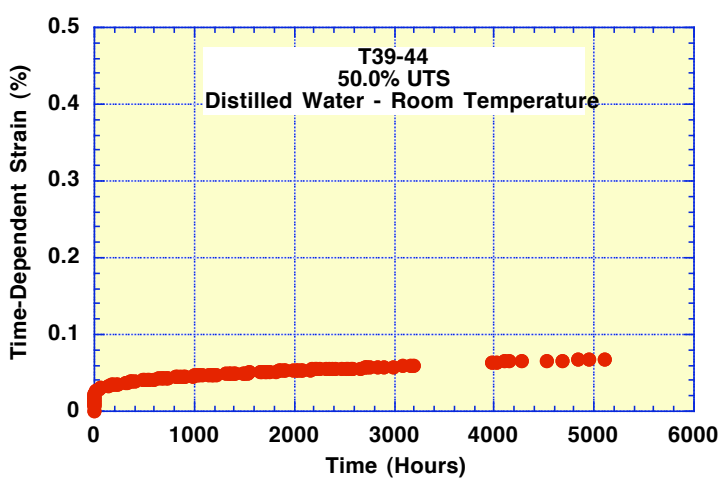

Time-Dependent Strain (Linear Plot)

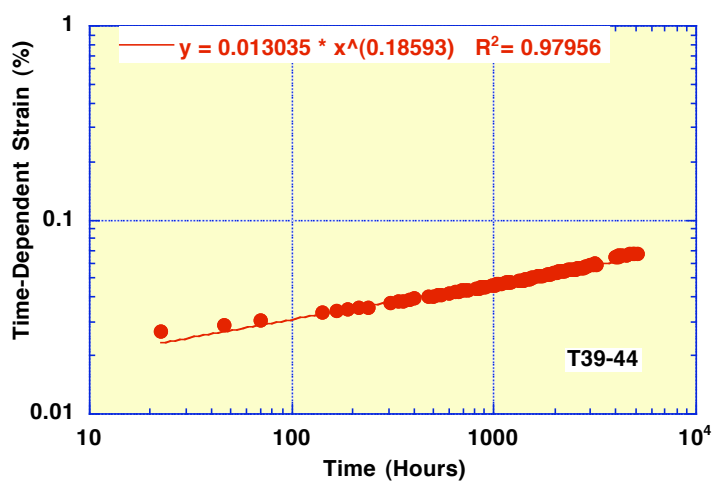

Power Law Fit. 
Specimen Number: T39-43

Load Level: $40.0 \%$ UTS

Environment: Distilled Water Room Temperature

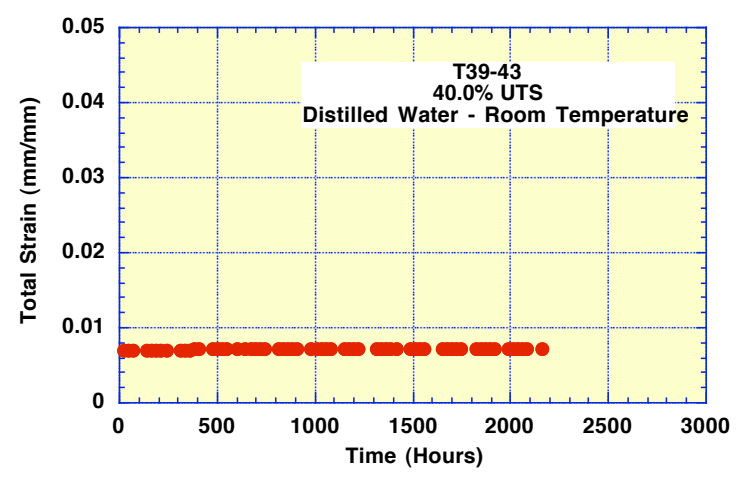

Total Strain vs Time

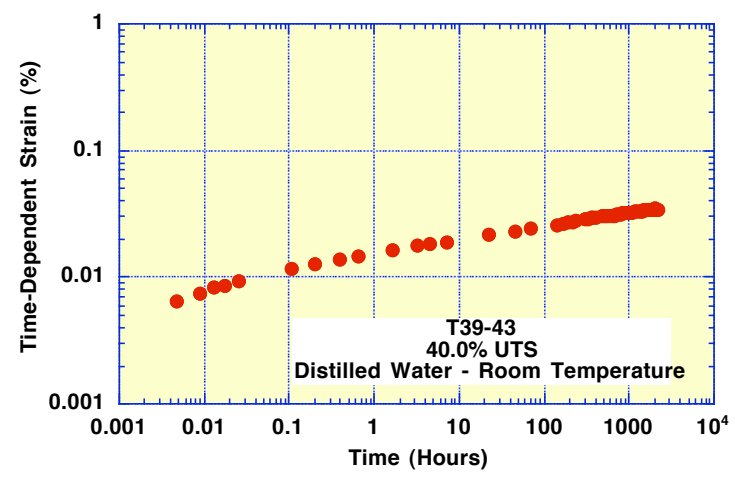

Time-Dependent Strain (Log Plot)

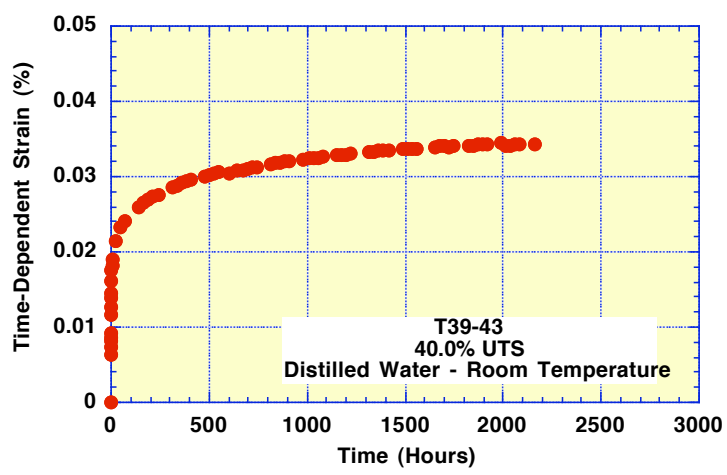

Time-Dependent Strain (Linear Plot)

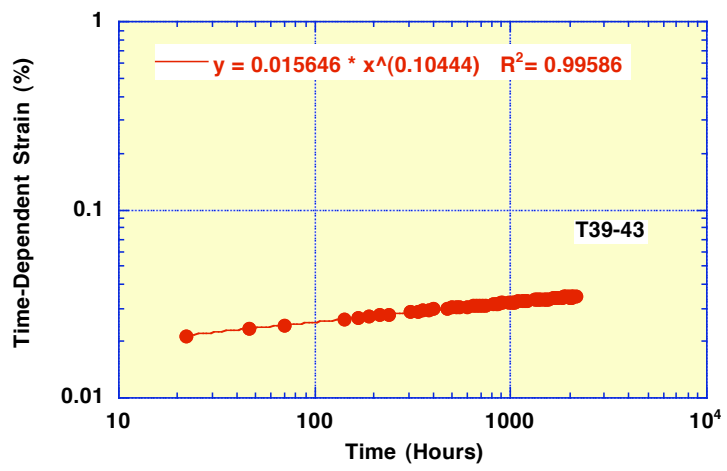

Power Law Fit. 


\section{Specimen Number: T41-36}

Load Level: $76.5 \%$ UTS

Environment: Distilled Water Room Temperature

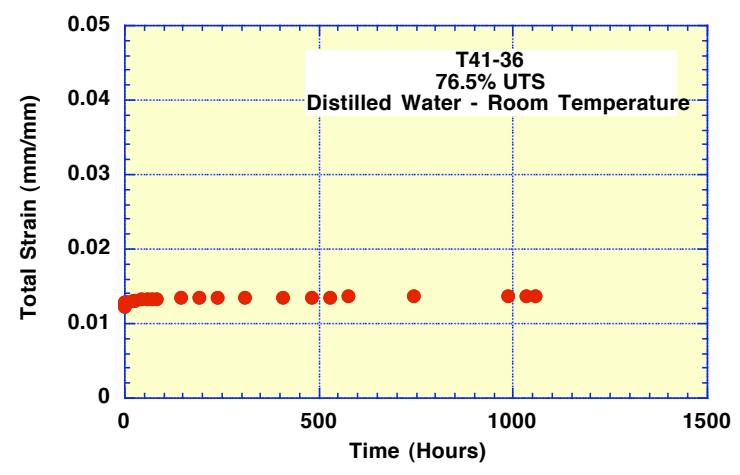

Total Strain vs Time

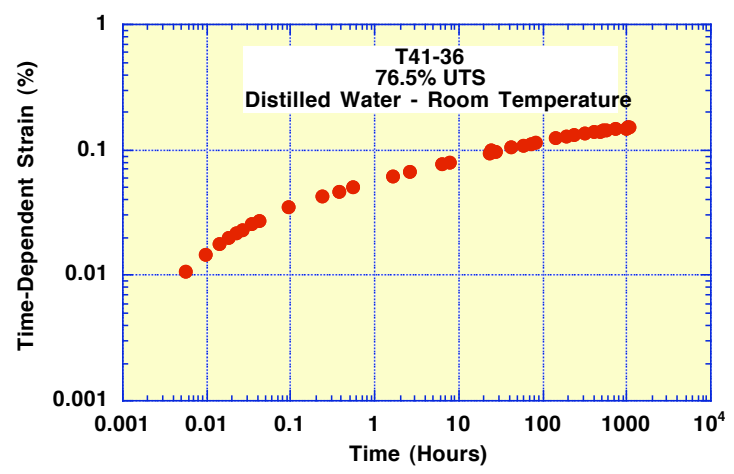

Time-Dependent Strain (Log Plot)

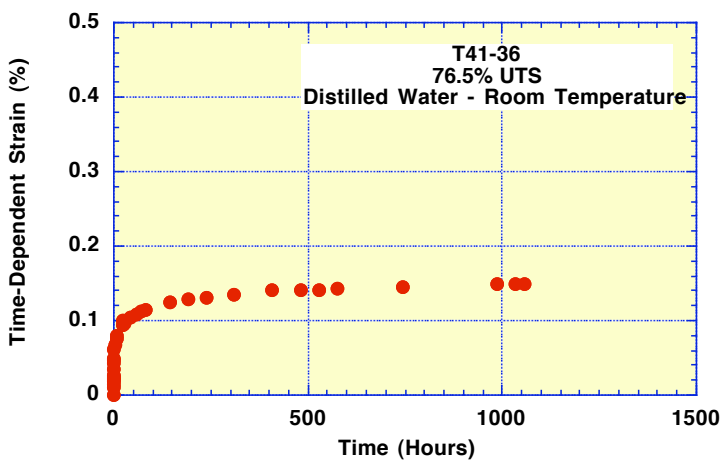

Time-Dependent Strain (Linear Plot)

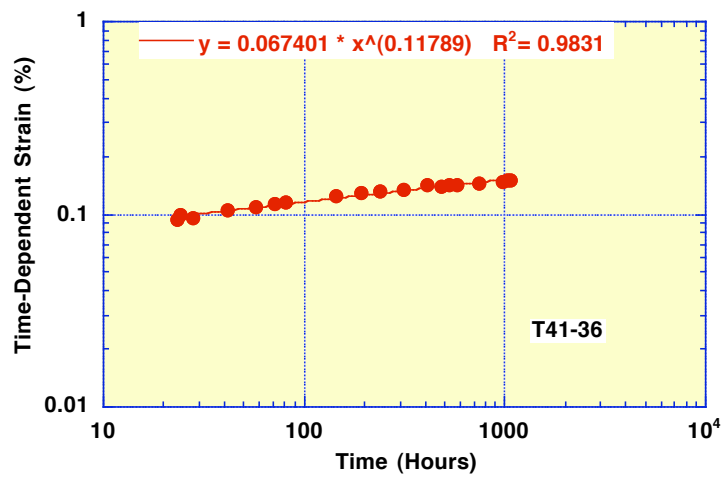

Power Law Fit. 
Specimen Number: T41-35

Load Level: $70.0 \%$ UTS

Environment: Distilled Water Room Temperature

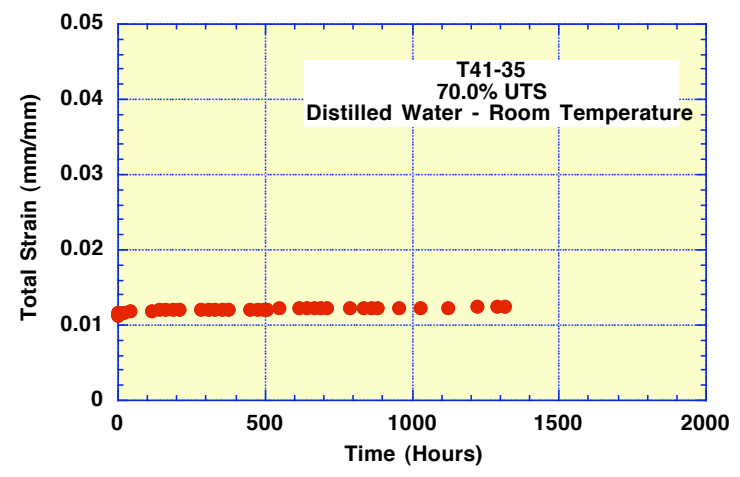

Total Strain vs Time

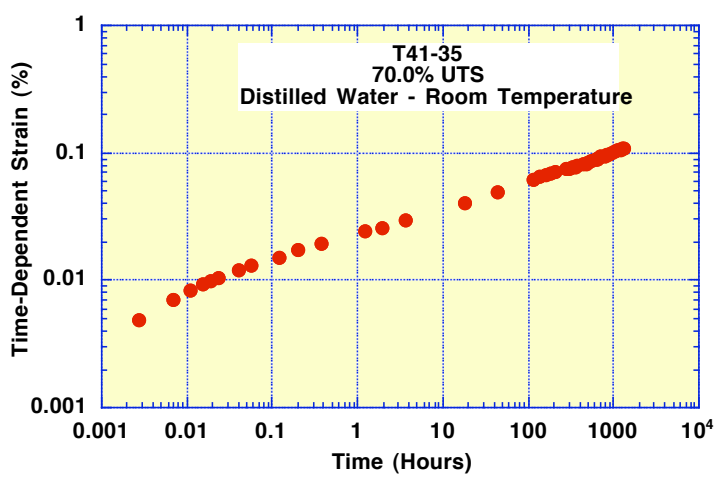

Time-Dependent Strain (Log Plot)

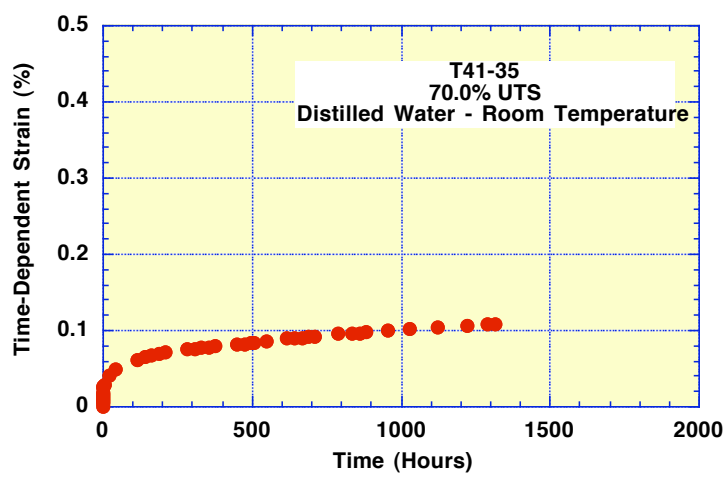

Time-Dependent Strain (Linear Plot)

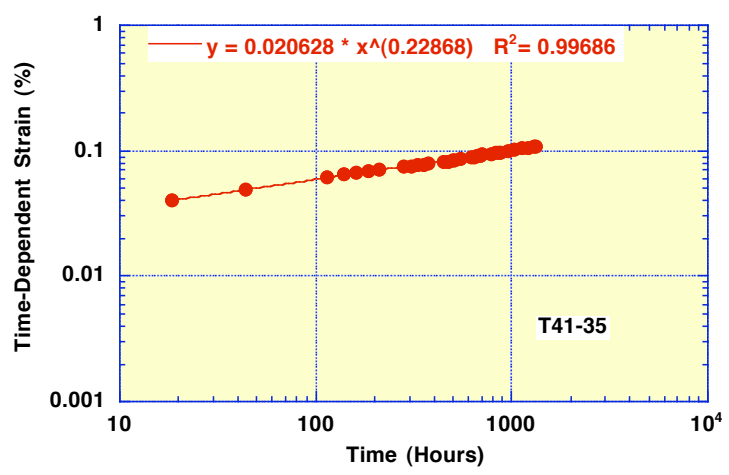

Power Law Fit. 
Specimen Number: T41-37

Load Level: $60.0 \%$ UTS

Environment: Distilled Water Room Temperature

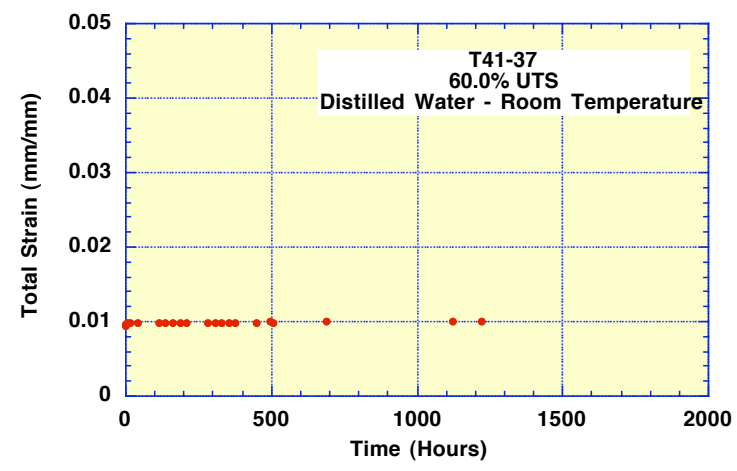

Total Strain vs Time

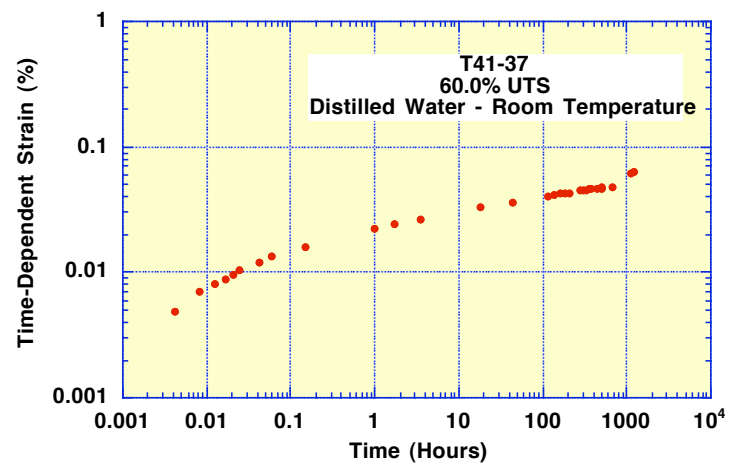

Time-Dependent Strain (Log Plot)

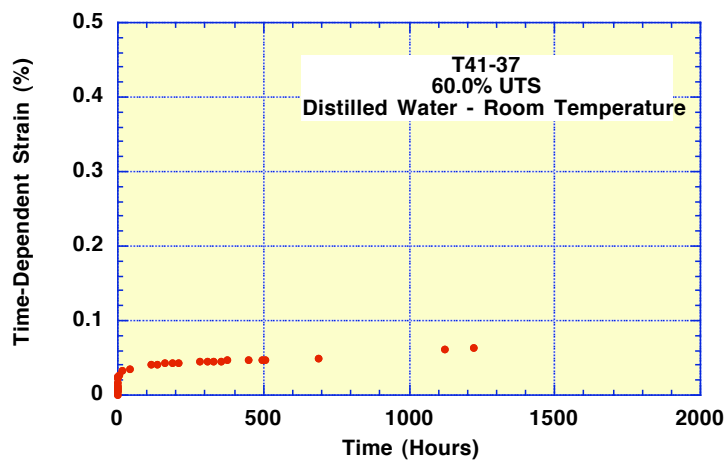

Time-Dependent Strain (Linear Plot)

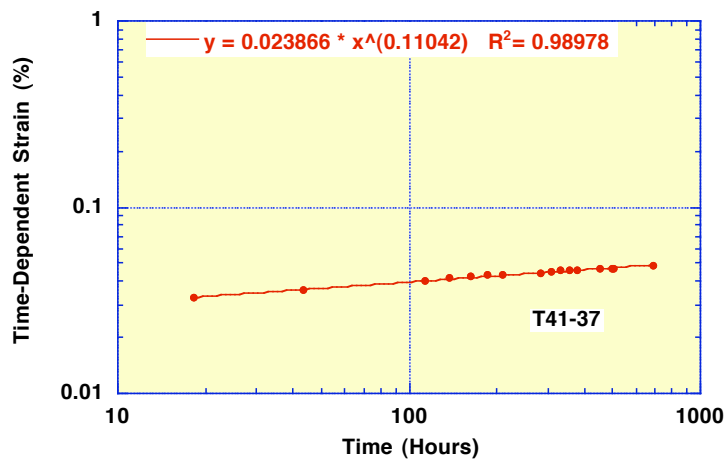

Power Law Fit. 
Specimen Number: T41-28

Load Level: $30.0 \%$ UTS

Environment: Distilled Water Room Temperature

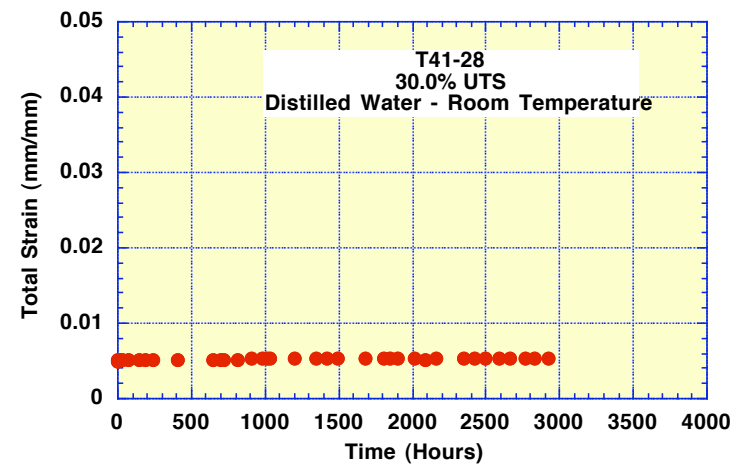

Total Strain vs Time

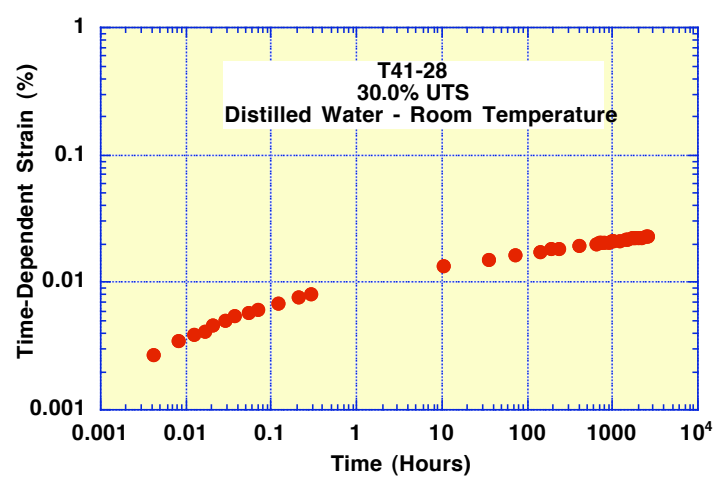

Time-Dependent Strain (Log Plot)

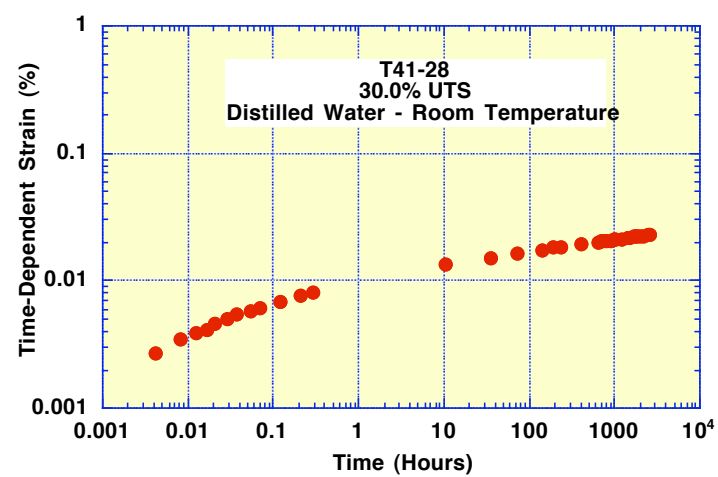

Time-Dependent Strain (Linear Plot)

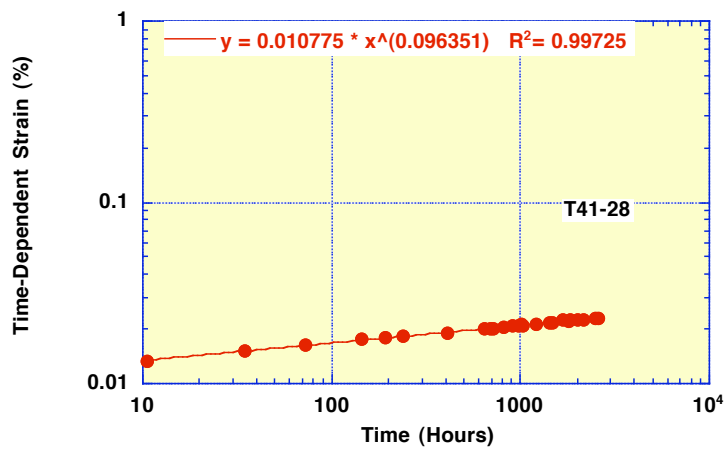

Power Law Fit. 


\section{Specimen Number: T41-48}

Load Level: $30.0 \%$ UTS

Environment: Distilled Water Room Temperature

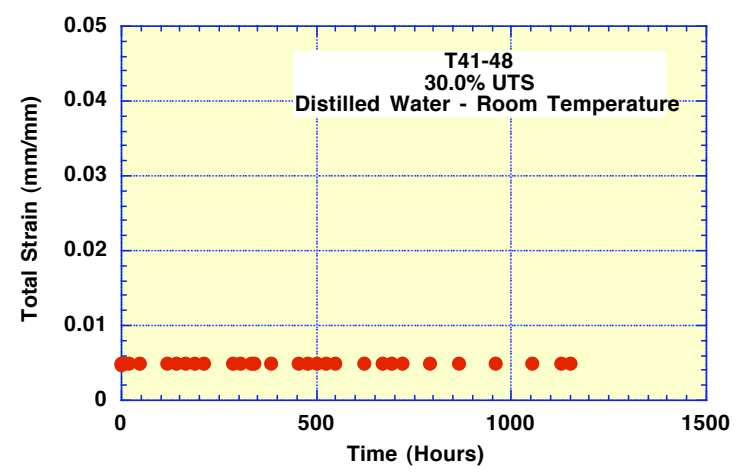

Total Strain vs Time

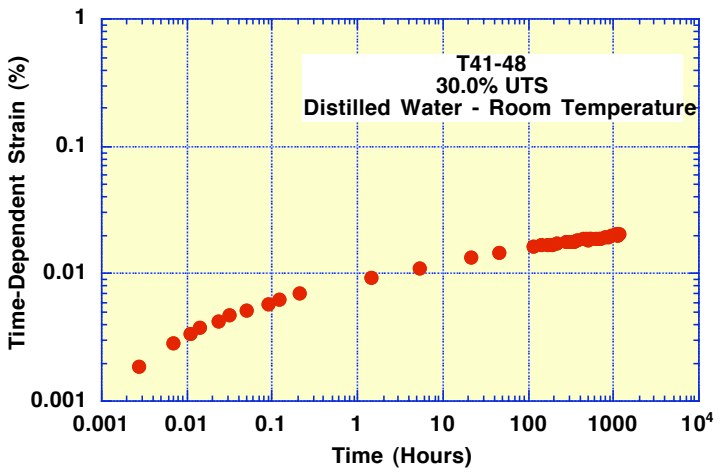

Time-Dependent Strain (Log Plot)

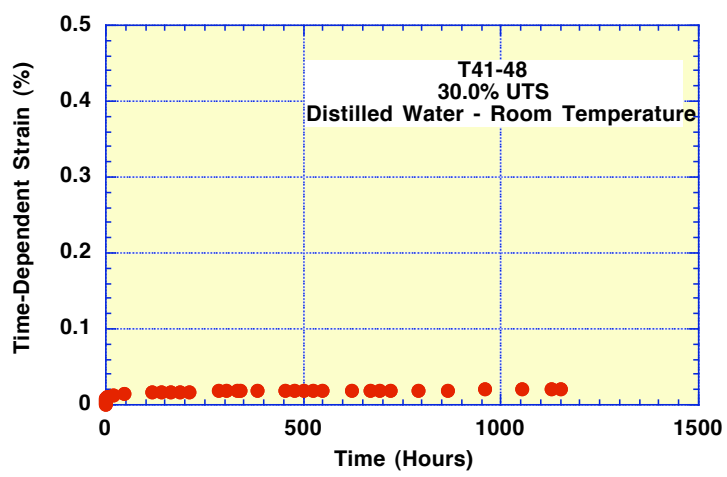

Time-Dependent Strain (Linear Plot)

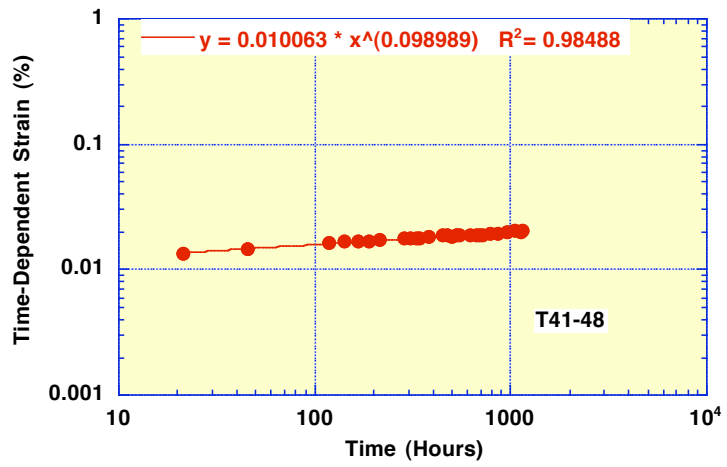

Power Law Fit. 
Specimen Number: T39-7

Load Level: $79.9 \%$ UTS

Environment: Windshield Washer Fluid Room Temperature

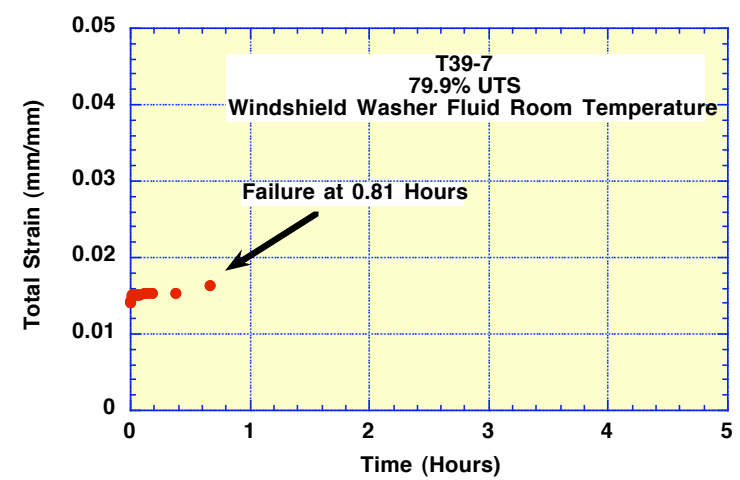

Total Strain vs Time

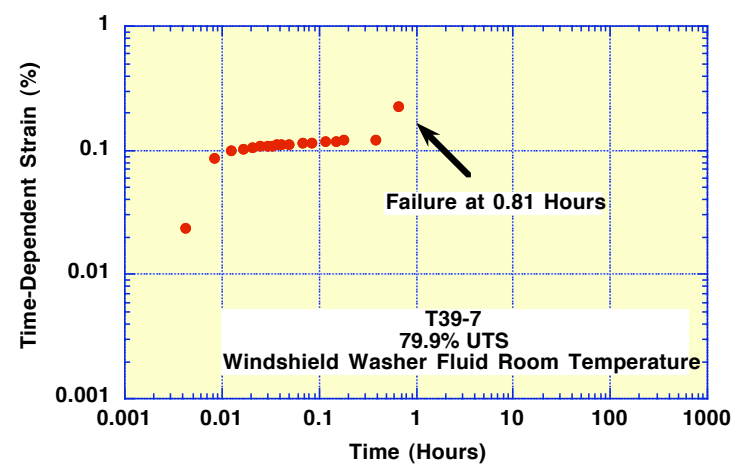

Time-Dependent Strain (Log Plot)

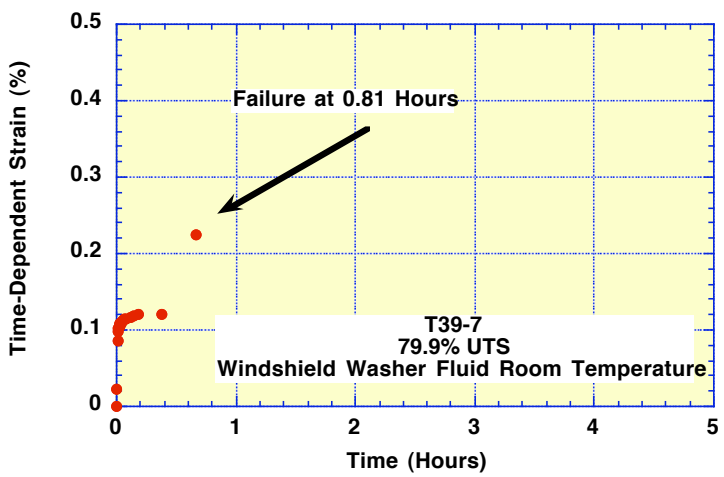

Time-Dependent Strain (Linear Plot) 
Specimen Number: T39-24

Load Level: $40.0 \%$ UTS

Environment: Windshield Washer Fluid Room Temperature

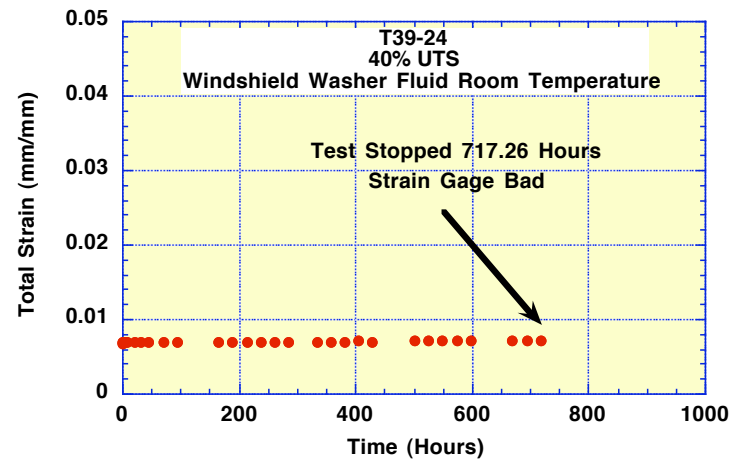

Total Strain vs Time 
Specimen Number: T39-23

Load Level: $50.0 \%$ UTS

Environment: Windshield Washer Fluid Room Temperature

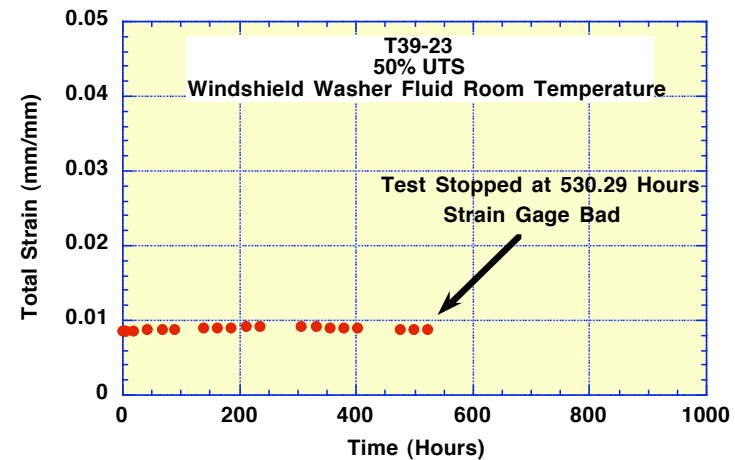

Total Strain vs Time 
Specimen Number: T39-51

Load Level: $40.0 \%$ UTS

Environment: Windshield Washer Fluid Room Temperature

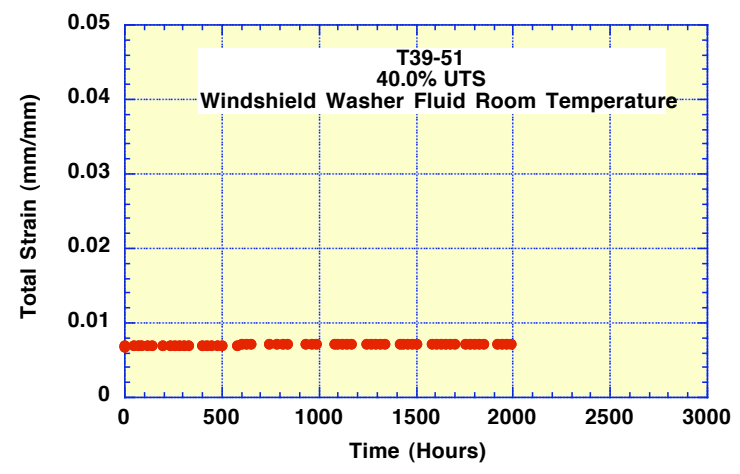

Total Strain vs Time

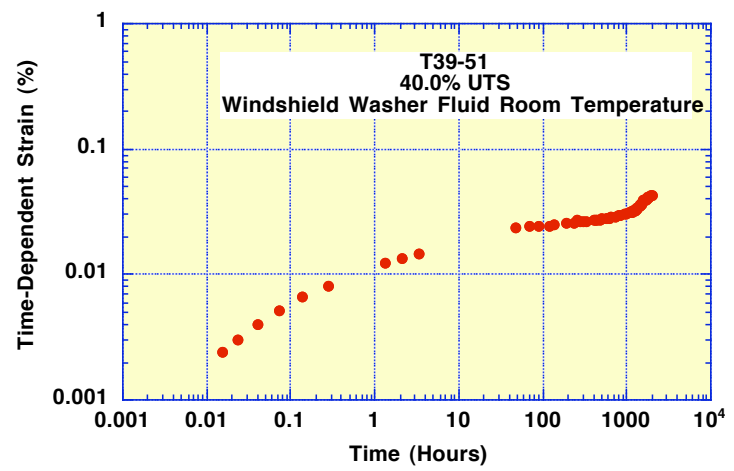

Time-Dependent Strain (Log Plot)

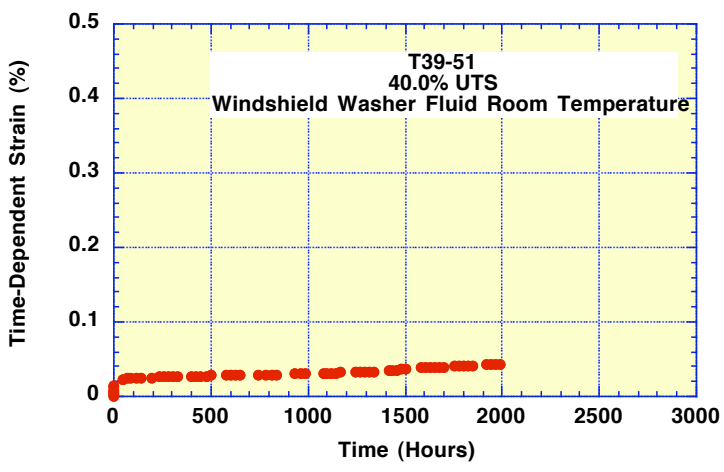

Time-Dependent Strain (Linear Plot)

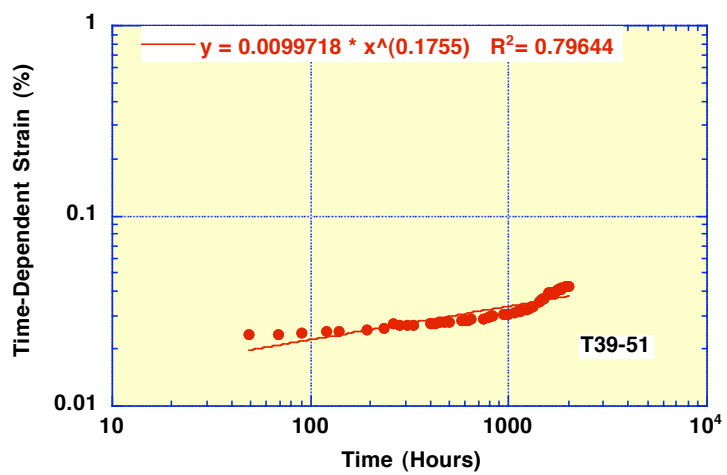

Power Law Fit. 
Specimen Number: T39-47

Load Level: $40.0 \%$ UTS

Environment: Windshield Washer Fluid Room Temperature

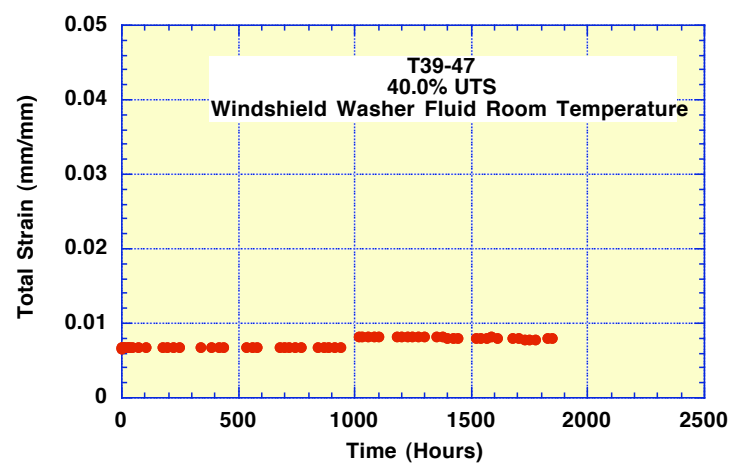

Total Strain vs Time

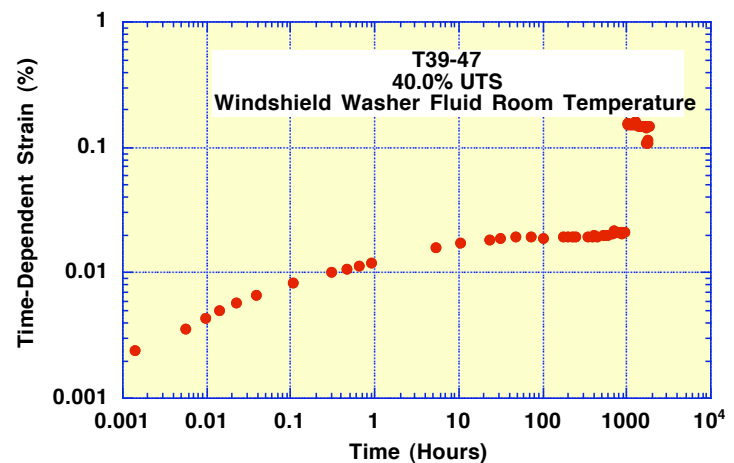

Time-Dependent Strain (Log Plot)

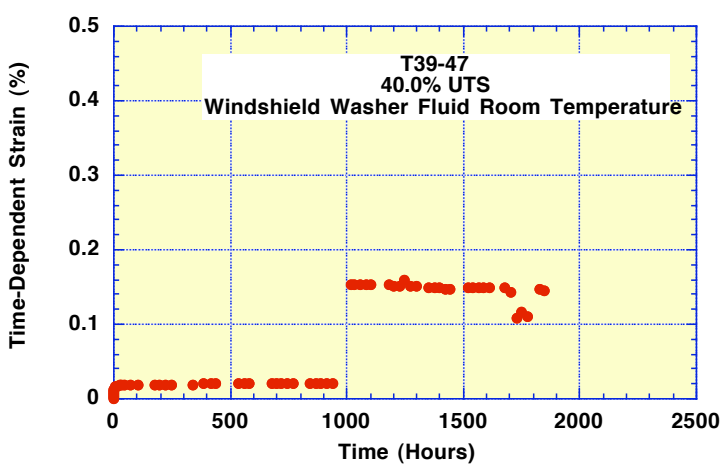

Time-Dependent Strain (Linear Plot)

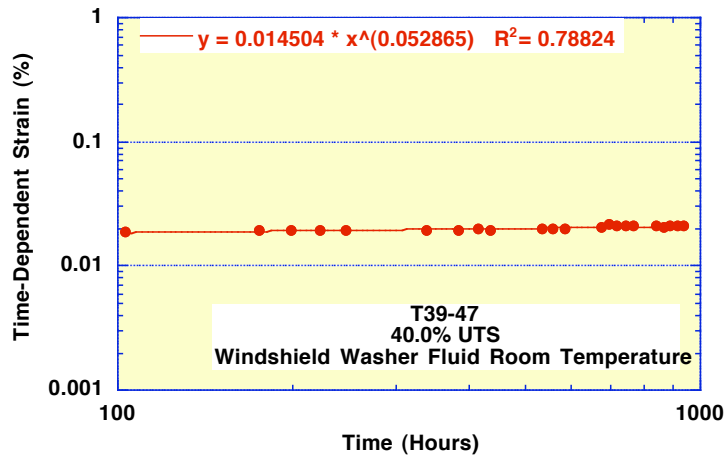

Power Law Fit. 
Specimen Number: T39-49

Load Level: 69.9\% UTS

\section{Environment: Windshield Washer Fluid Room Temperature}

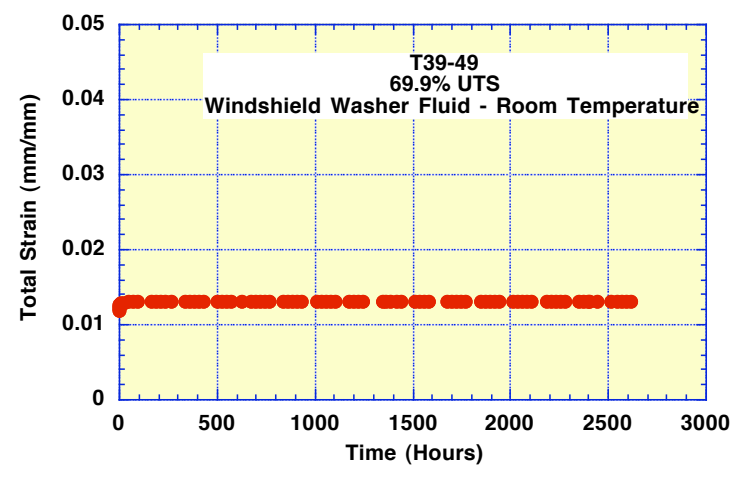

Total Strain vs Time

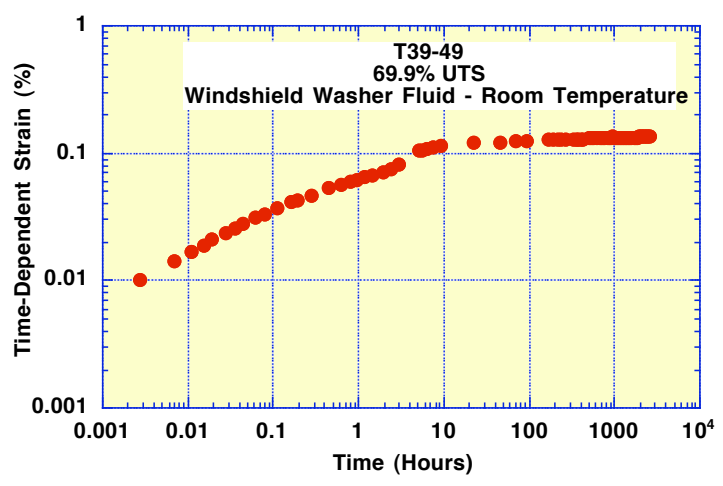

Time-Dependent Strain (Log Plot)

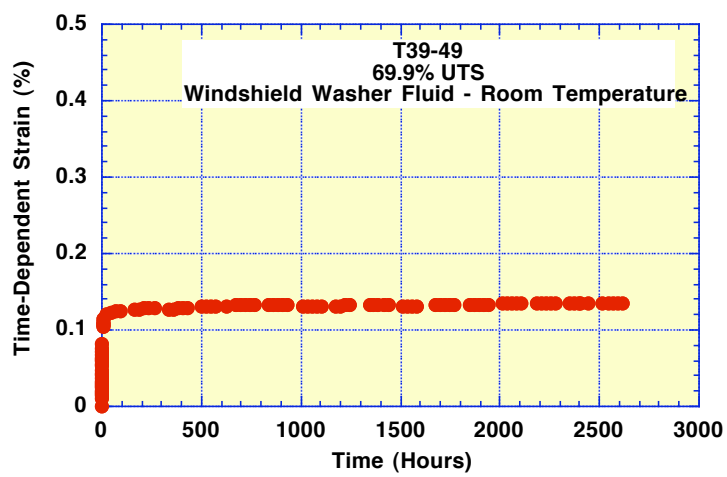

Time-Dependent Strain (Linear Plot)

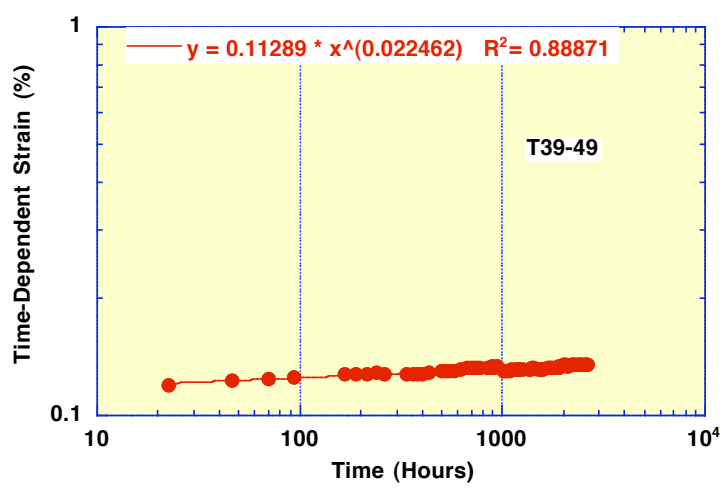

Power Law Fit. 
Specimen Number: T39-8

Load Level: $70.3 \%$ UTS

Environment: Windshield Washer Fluid Room Temperature

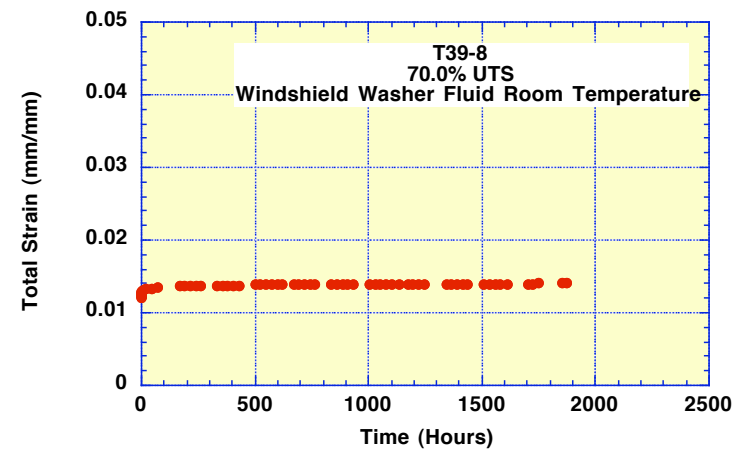

Total Strain vs Time

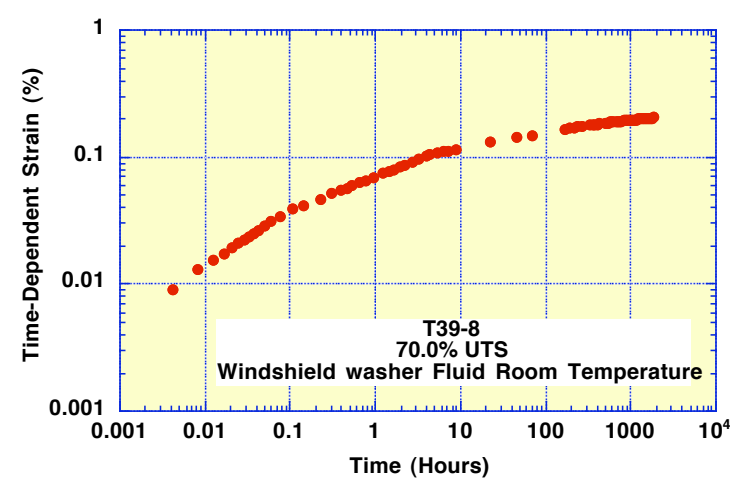

Time-Dependent Strain (Log Plot)

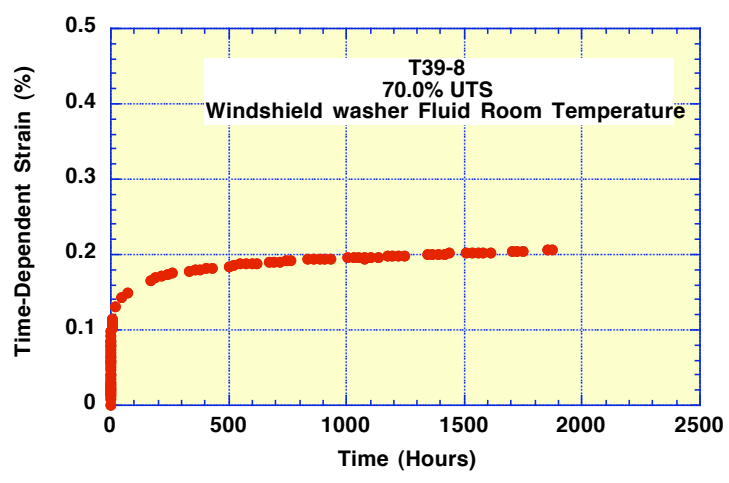

Time-Dependent Strain (Linear Plot)

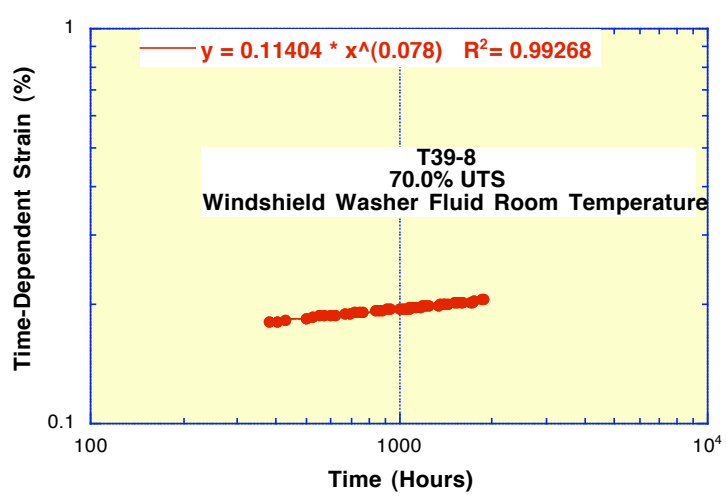

Power Law Fit. 
Specimen Number: T39-36

Load Level: $60.0 \%$ UTS

Environment: Windshield Washer Fluid Room Temperature

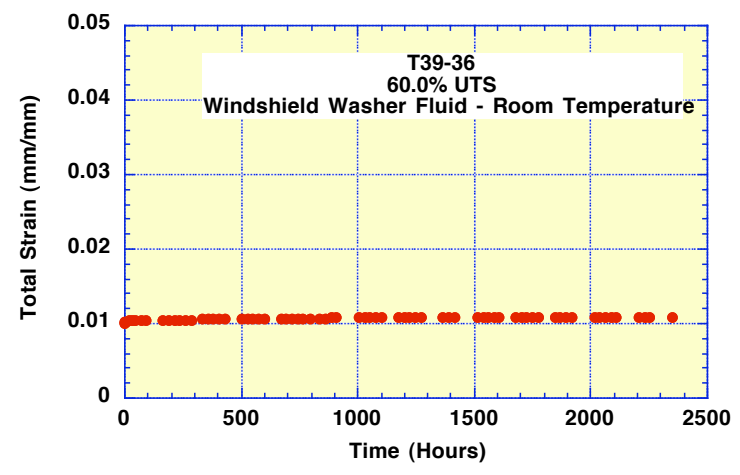

Total Strain vs Time

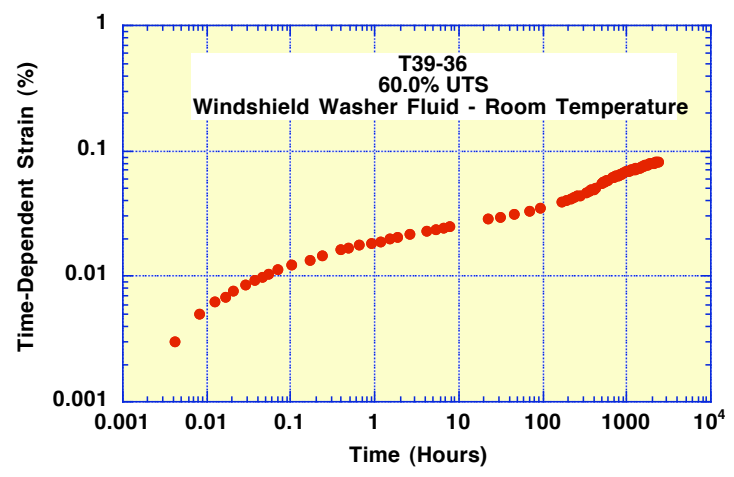

Time-Dependent Strain (Log Plot)

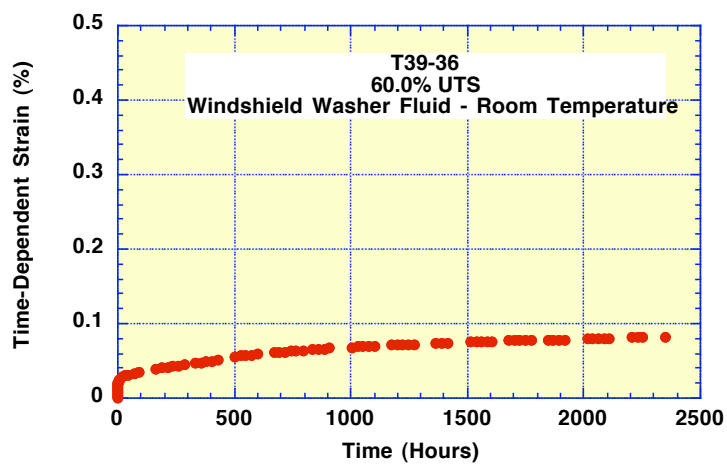

Time-Dependent Strain (Linear Plot)

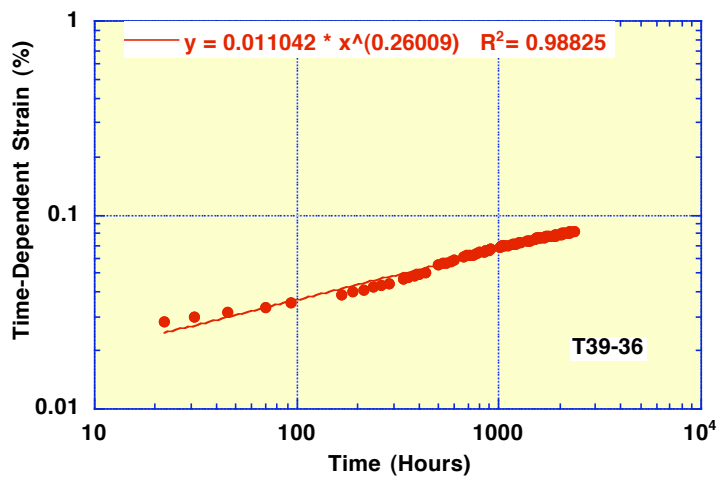

Power Law Fit. 
Specimen Number: T39-35

Load Level: $50.0 \%$ UTS

Environment: Windshield Washer Fluid Room Temperature

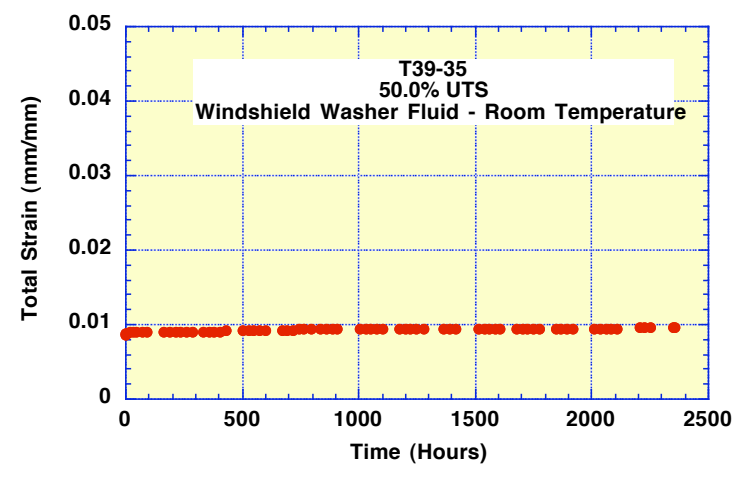

Total Strain vs Time

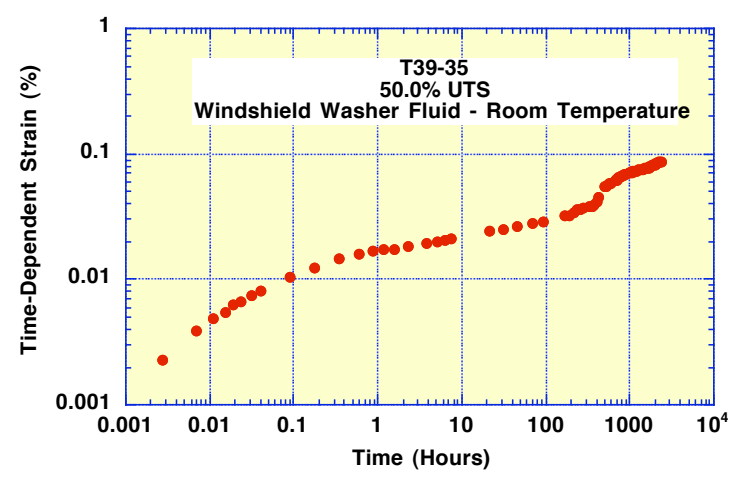

Time-Dependent Strain (Log Plot)

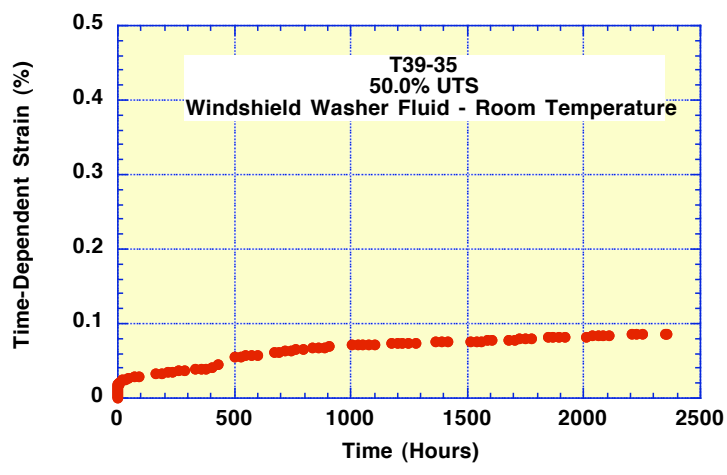

Time-Dependent Strain (Linear Plot)

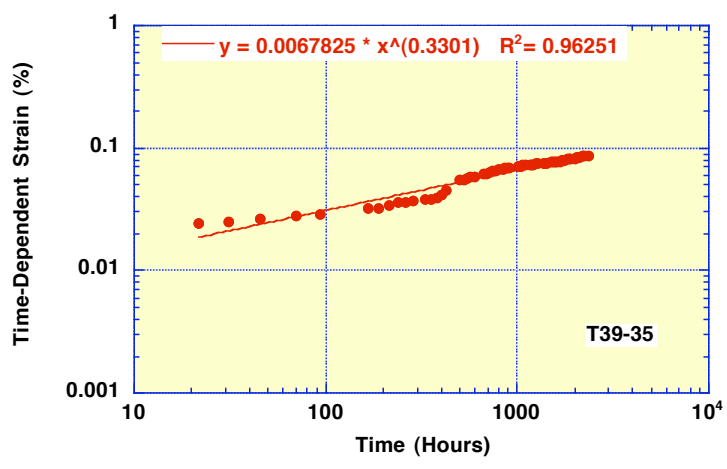

Power Law Fit. 
Specimen Number: T41-32

Load Level: $50.0 \%$ UTS

Environment: Windshield Washer Fluid Room Temperature

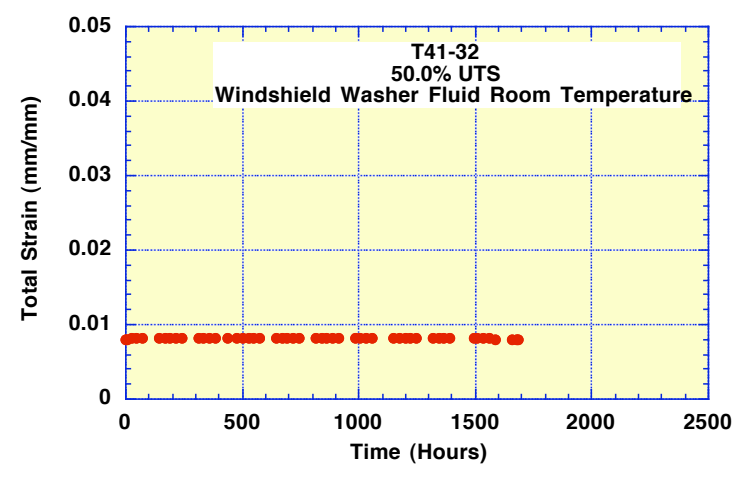

Total Strain vs Time

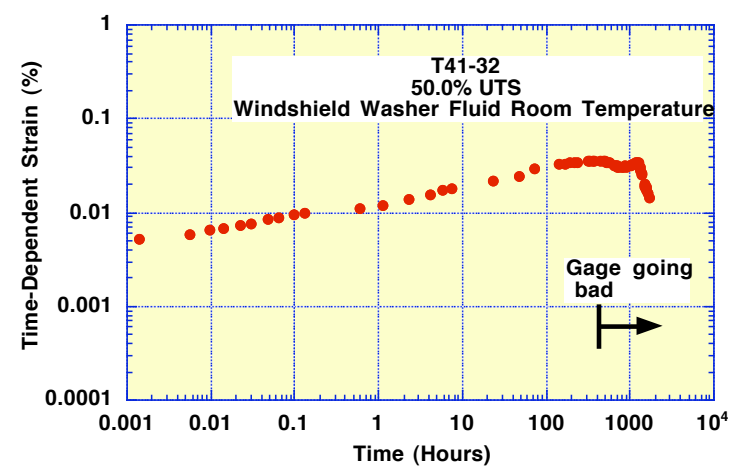

Time-Dependent Strain (Log Plot)

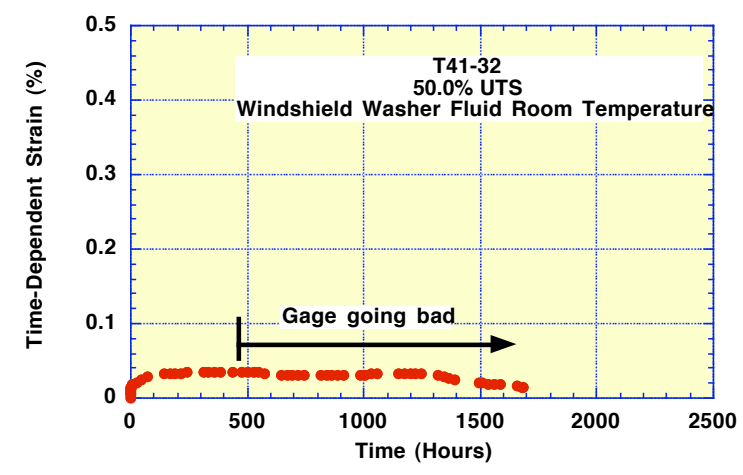

Time-Dependent Strain (Linear Plot)

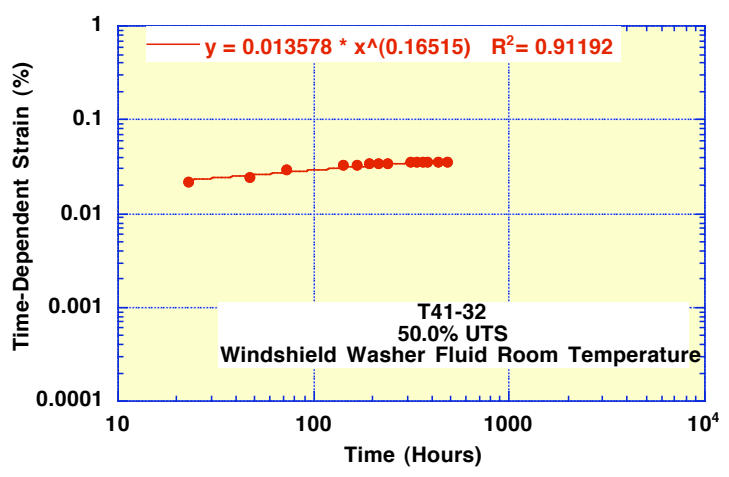

Power Law Fit. 
Specimen Number: T41-43

Load Level: $60.0 \%$ UTS

\section{Environment: Windshield Washer Fluid Room Temperature}

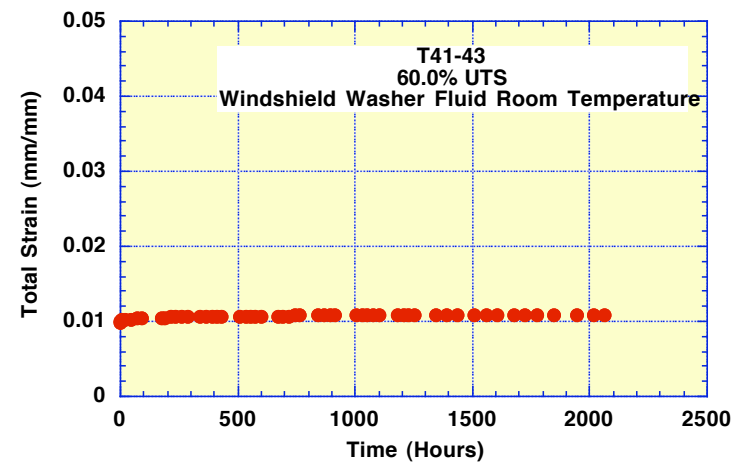

Total Strain vs Time

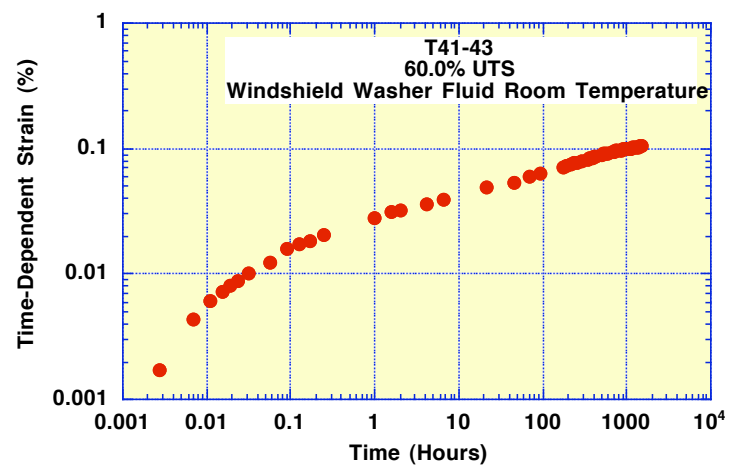

Time-Dependent Strain (Log Plot)

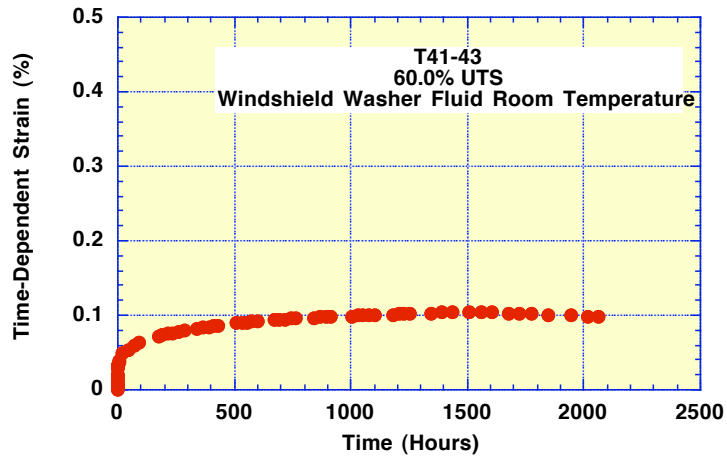

Time-Dependent Strain (Linear Plot)

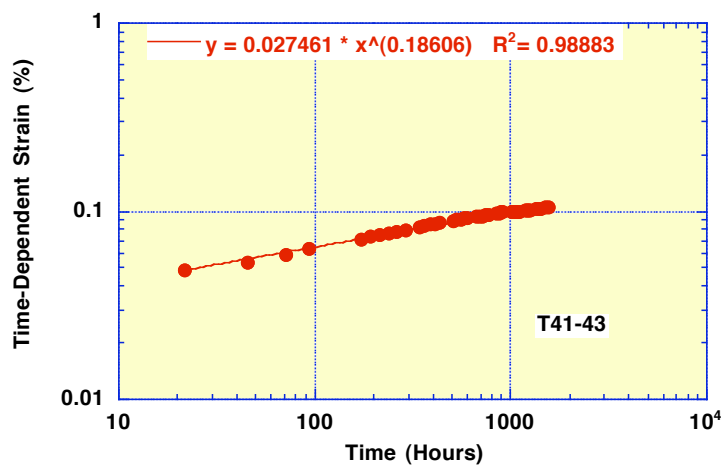

Power Law Fit. 


\section{Specimen Number: T41-45}

Load Level: $40.0 \%$ UTS

Environment: Windshield Washer Fluid Room Temperature

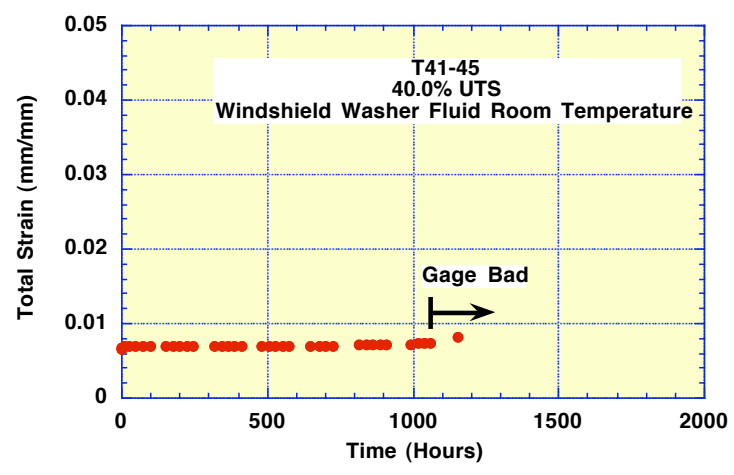

Total Strain vs Time

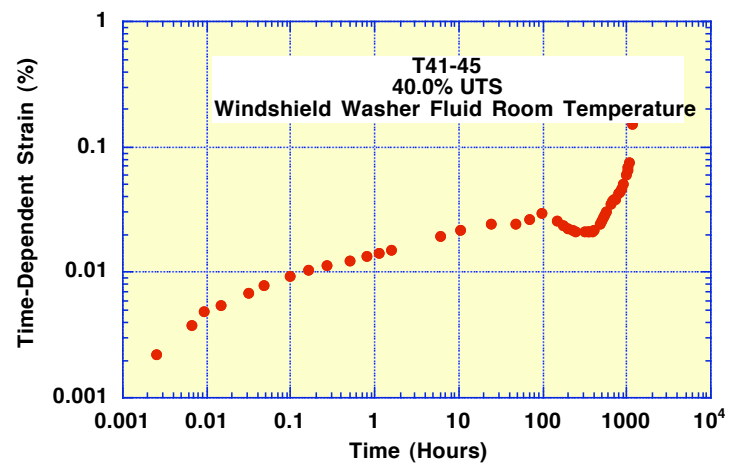

Time-Dependent Strain (Log Plot)

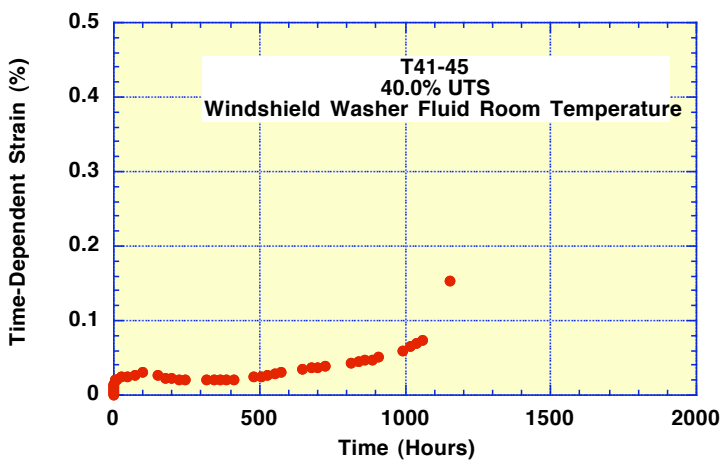

Time-Dependent Strain (Linear Plot) 
Specimen Number: T41-46

Load Level: $50.0 \%$ UTS

Environment: Windshield Washer Fluid Room Temperature

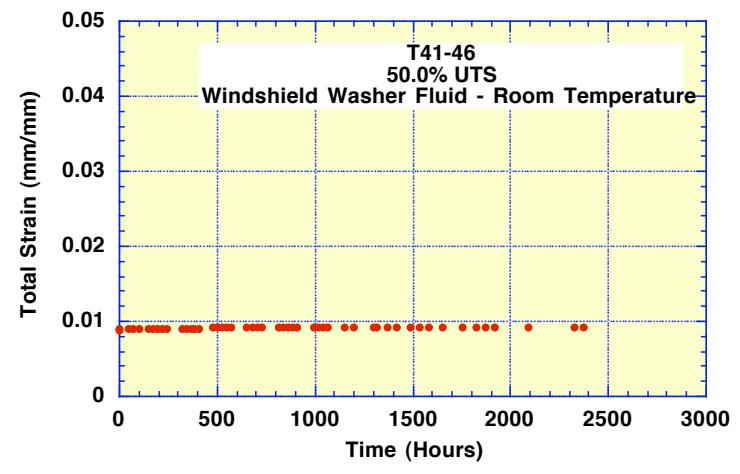

Total Strain vs Time

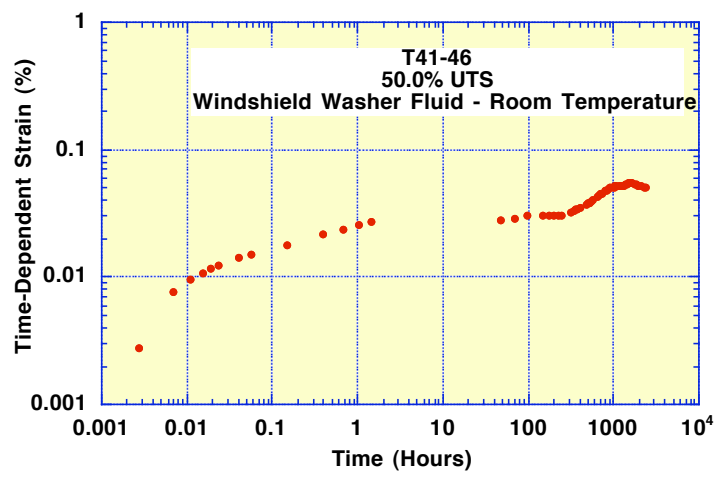

Time-Dependent Strain (Log Plot)

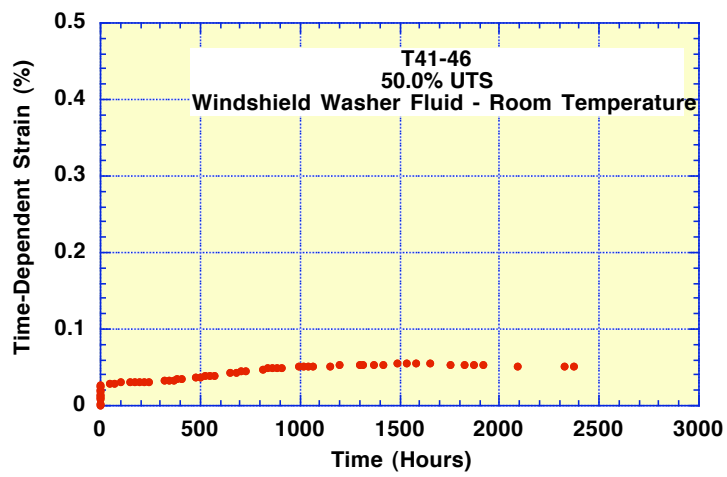

Time-Dependent Strain (Linear Plot)

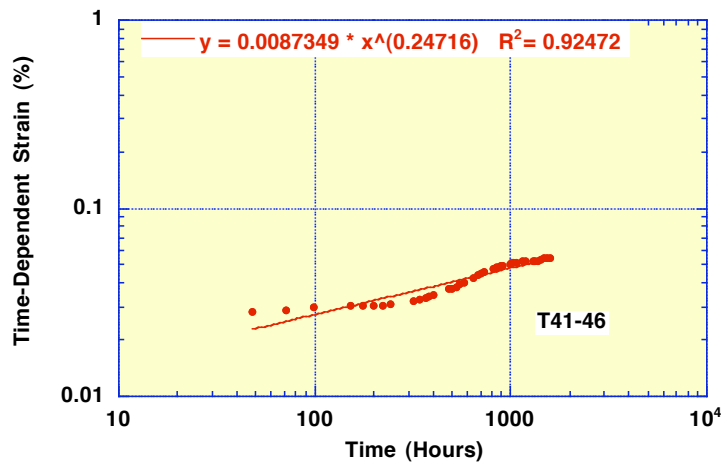

Power Law Fit. 
Specimen Number: T41-50

Load Level: $75.0 \%$ UTS

Environment: Windshield Washer Fluid Room Temperature

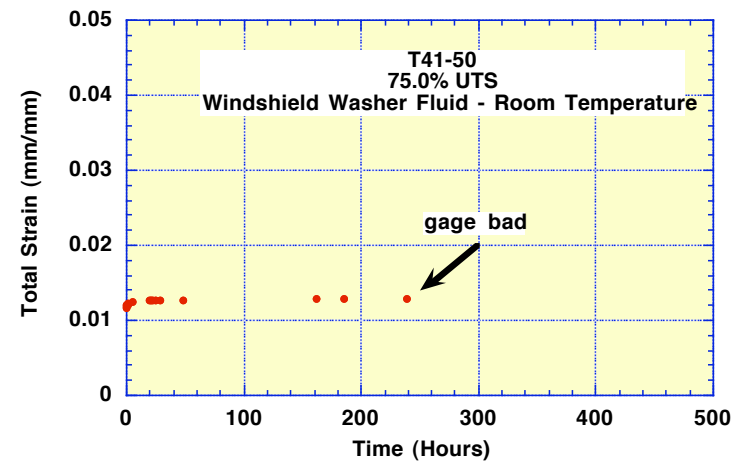

Total Strain vs Time

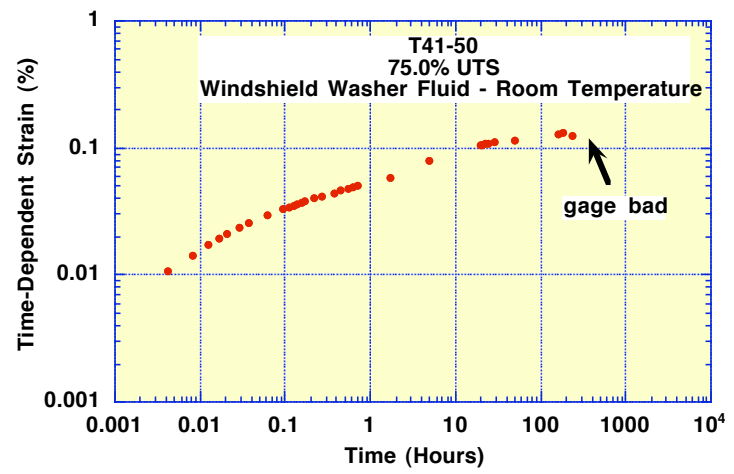

Time-Dependent Strain (Log Plot)

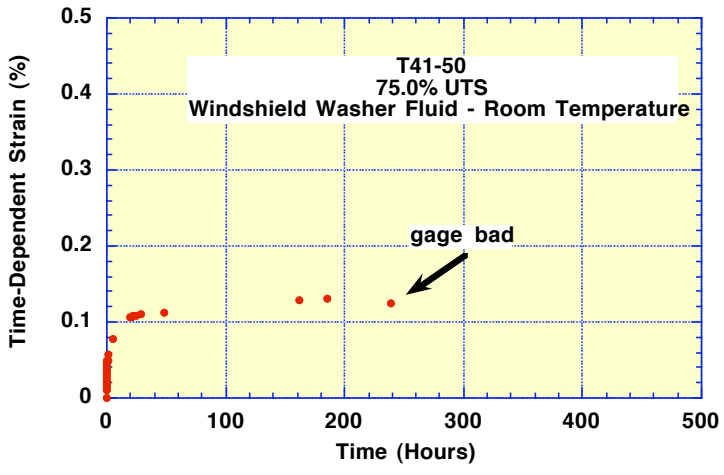

Time-Dependent Strain (Linear Plot) 
Specimen Number: T41-38

Load Level: $80.0 \%$ UTS

Environment: Windshield Washer Fluid Room Temperature

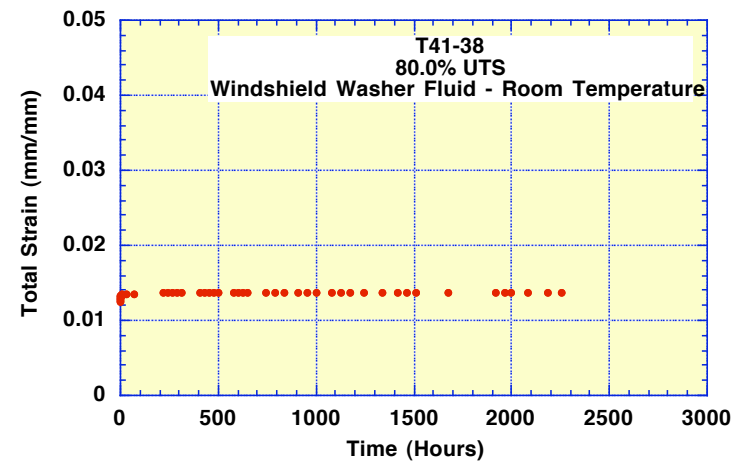

Total Strain vs Time

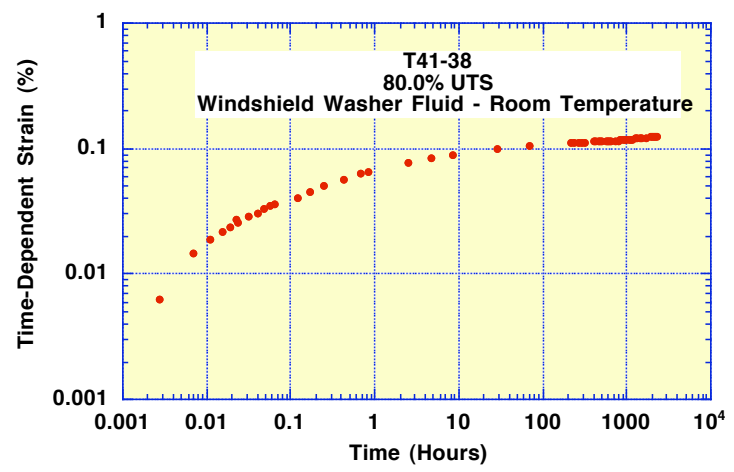

Time-Dependent Strain (Log Plot)

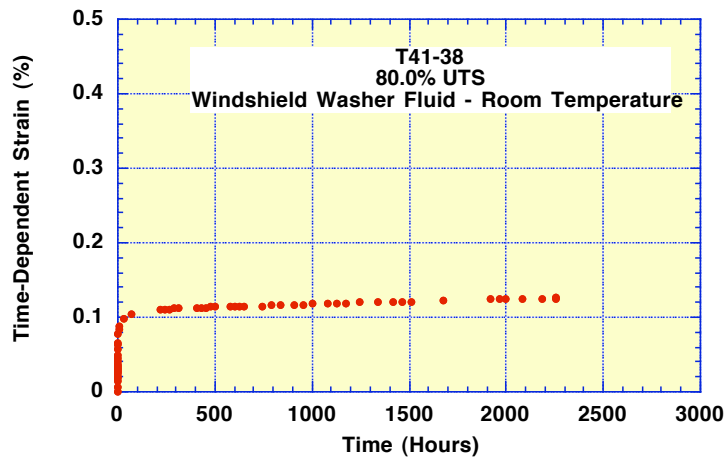

Time-Dependent Strain (Linear Plot)

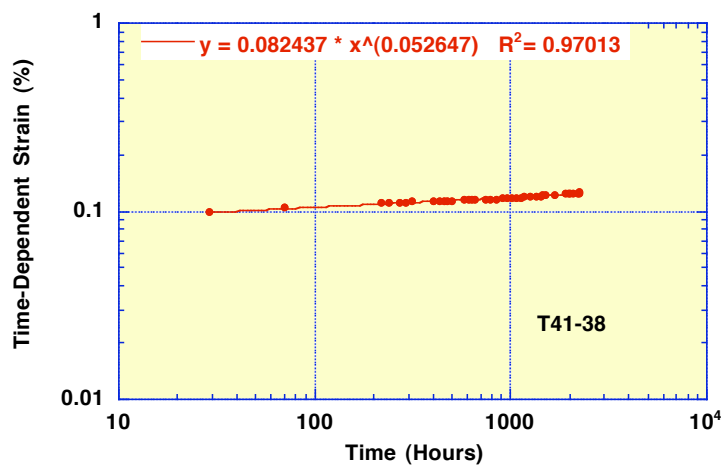

Power Law Fit. 


\section{Specimen Number: T41-49}

Load Level: $75.0 \%$ UTS

Environment: Windshield Washer Fluid Room Temperature

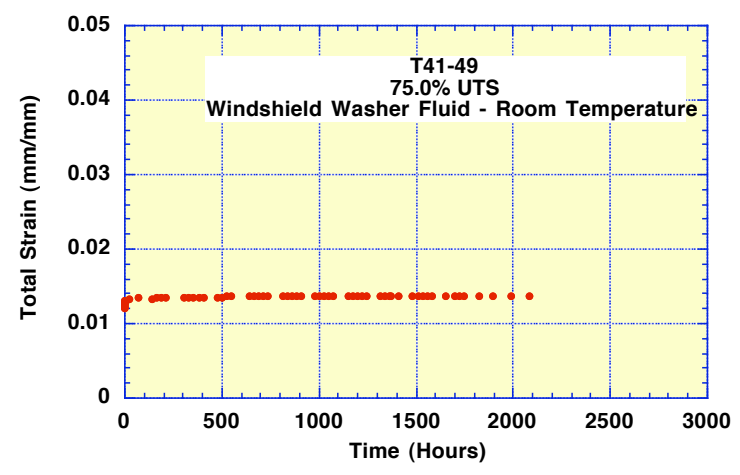

Total Strain vs Time

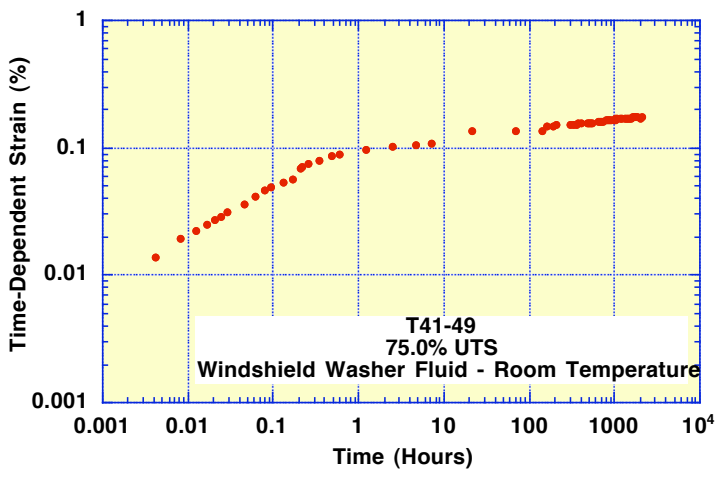

Time-Dependent Strain (Log Plot)

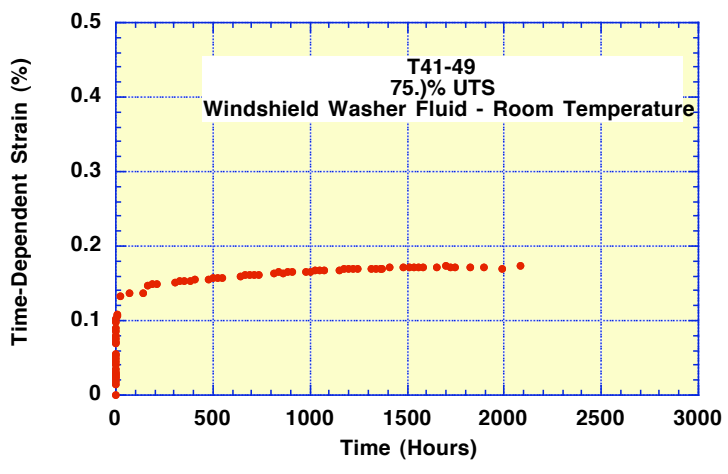

Time-Dependent Strain (Linear Plot)

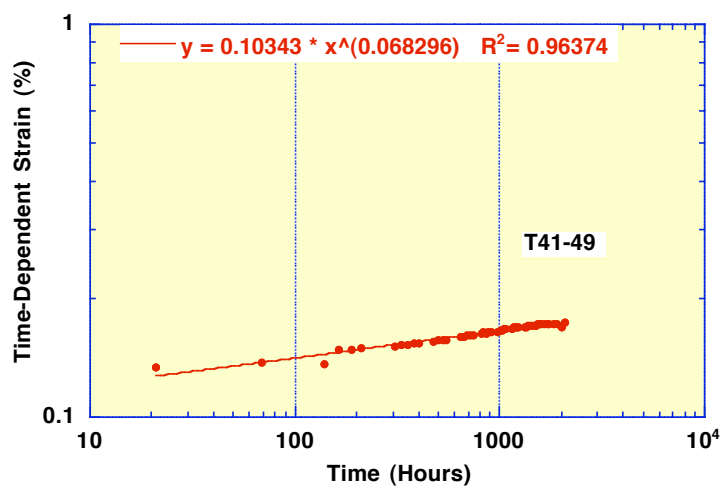

Power Law Fit. 
Specimen Number: T41-39

Load Level: $80.0 \%$ UTS

Environment: Windshield Washer Fluid Room Temperature

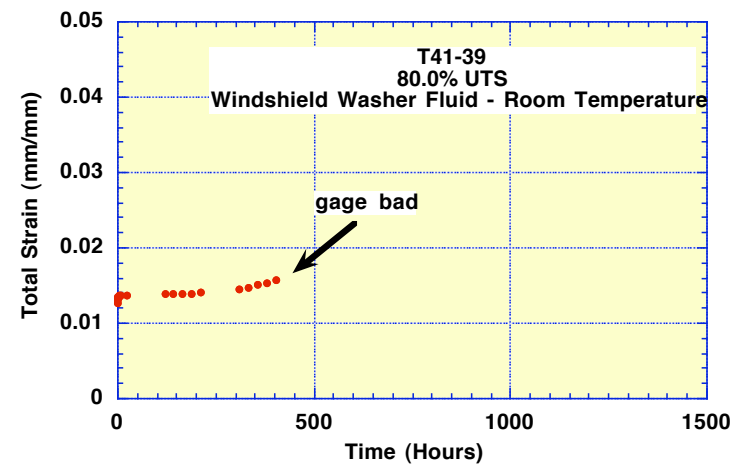

Total Strain vs Time

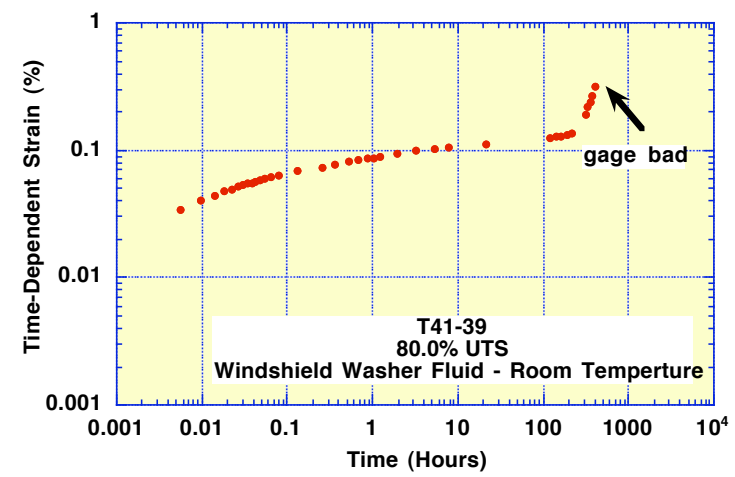

Time-Dependent Strain (Log Plot)

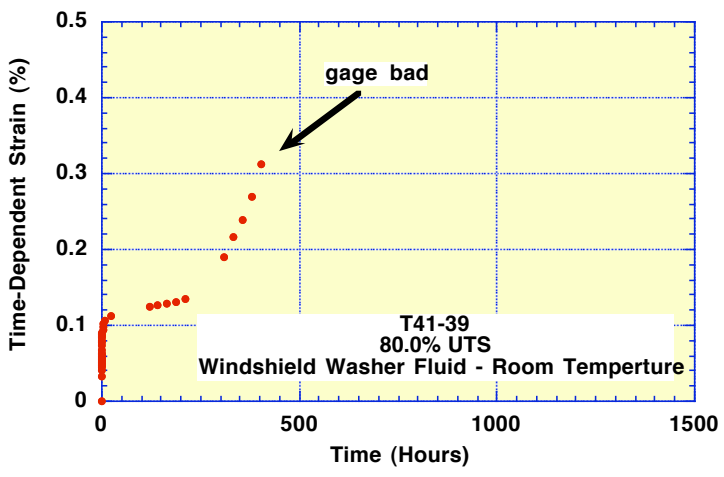

Time-Dependent Strain (Linear Plot) 
Specimen Number: T41-25

Load Level: $30.3 \%$ UTS

Environment: Windshield Washer Fluid Room Temperature

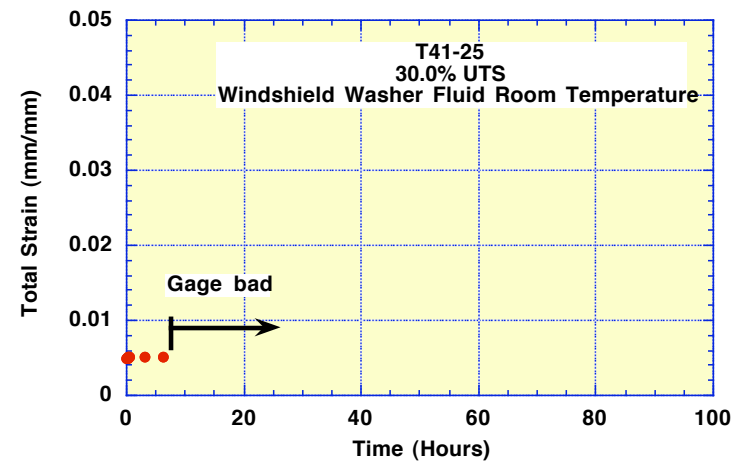

Total Strain vs Time

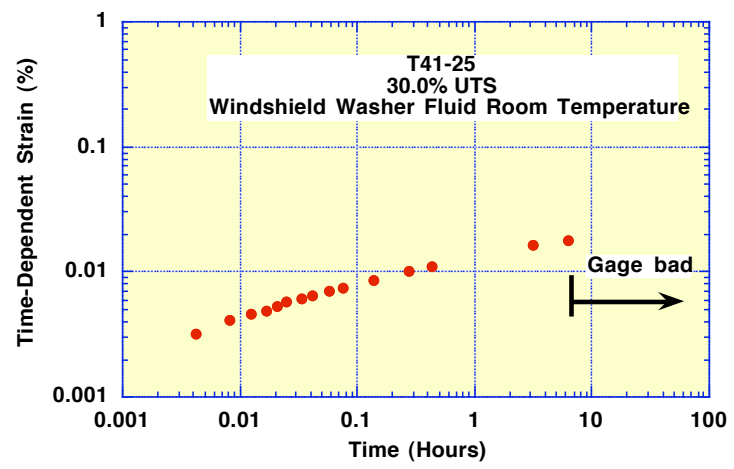

Time-Dependent Strain (Log Plot)

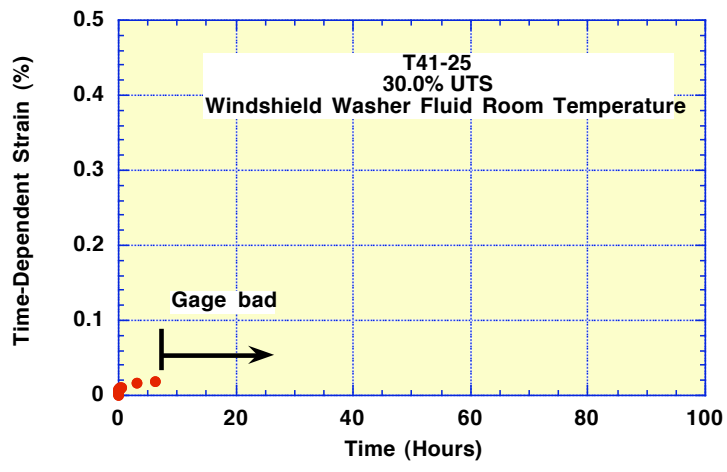

Time-Dependent Strain (Linear Plot) 




\section{Appendix G}

Summary of Creep Post-Test Tensile Property Results 

Appendix G Creep Post-Test Tensile Property Results

Environment: In-Air Room Temperature

\begin{tabular}{|c|c|c|c|c|c|c|c|c|c|c|c|}
\hline \multirow{2}{*}{$\begin{array}{l}\text { Specimen } \\
\text { Number }\end{array}$} & \multirow{2}{*}{$\begin{array}{l}\text { Load as } \\
\% \text { UTS }\end{array}$} & \multirow{2}{*}{$\begin{array}{c}\text { Creep Test } \\
\text { Duration, } \\
\text { Hours }\end{array}$} & \multicolumn{3}{|c|}{ Ultimate Tensile Strength } & \multicolumn{3}{|c|}{ Tensile Modulus of Elasticity } & \multicolumn{3}{|c|}{ Tensile Failure Strain } \\
\hline & & & $\begin{array}{c}\text { Plaque Avg., } \\
\mathrm{MPa}\end{array}$ & $\begin{array}{l}\text { Post-Creep } \\
\text { Test, MPa }\end{array}$ & $\begin{array}{c}\text { Change, } \\
\%\end{array}$ & $\begin{array}{c}\text { Specimen Initial } \\
\text { Stiffness., } \\
\text { GPa }\end{array}$ & $\begin{array}{c}\text { Post-Creep } \\
\text { Test, GPa }\end{array}$ & $\begin{array}{c}\text { Change, } \\
\%\end{array}$ & $\begin{array}{c}\text { Plaque Avg., } \\
\%\end{array}$ & $\begin{array}{l}\text { Post-Creep } \\
\text { Test, \% }\end{array}$ & $\begin{array}{c}\text { Change, } \\
\%\end{array}$ \\
\hline T41-29 & 40.0 & 2000 & 575 & 545 & -5.16 & 37.225 & 34.819 & -6.46 & 1.714 & 2.32 & 35.36 \\
\hline $\mathrm{T} 41-30$ & 70.0 & 1614 & 575 & 582 & 1.17 & 33.564 & 35.439 & 5.59 & 1.714 & 1.639 & -4.38 \\
\hline T41-31 & 40.0 & 1516 & 575 & 569 & -1.06 & 37.811 & 35.143 & -7.06 & 1.714 & 2.37 & 38.27 \\
\hline T41-41 & 70.0 & 1516 & 575 & 556 & -3.22 & 37.632 & 35.832 & -4.78 & 1.714 & - & - \\
\hline T39-42 & 69.9 & 1516 & 600 & 594 & -0.96 & 30.475 & 34.819 & 14.25 & 1.666 & 1.937 & 16.27 \\
\hline T31-1 & 80.6 & 3244 & 589 & 546 & -7.37 & 29.579 & 32.157 & 8.72 & 1.751 & 1.814 & 3.60 \\
\hline T31-19 & 74.4 & 1559 & 589 & 541 & -8.21 & 32.971 & 35.170 & 6.67 & 1.751 & 1.685 & -3.77 \\
\hline T31-24 & 74.9 & 2686 & 589 & 599 & 1.64 & 33.984 & 36.363 & 7.00 & 1.751 & 1.825 & 4.23 \\
\hline T31-25 & 85.0 & 1891 & 589 & 575 & -2.32 & 32.902 & 37.025 & 12.53 & 1.751 & 1.902 & 8.62 \\
\hline T31-28 & 79.9 & 1873 & 589 & 582 & -1.18 & 32.847 & 35.094 & 6.84 & 1.751 & 1.691 & -3.43 \\
\hline T31-31 & 85.0 & 2015 & 589 & 569 & -3.47 & 32.274 & 34.536 & 7.01 & 1.751 & 1.694 & -3.26 \\
\hline T31-34 & 90.0 & 151 & 589 & 616 & 4.58 & 30.433 & 34.170 & 12.28 & 1.751 & 1.841 & 5.14 \\
\hline $\mathrm{T} 31-35$ & 70.0 & 1633 & 589 & 563 & -4.34 & 33.791 & 35.101 & 3.88 & 1.751 & 1.717 & -1.94 \\
\hline T31-36 & 70.0 & 1559 & 589 & 567 & -3.81 & 33.481 & 35.101 & 4.84 & 1.751 & 1.806 & 3.14 \\
\hline T31-46 & 60.0 & 1515 & 589 & 601 & 2.00 & 35.536 & 36.508 & 2.74 & 1.751 & 1.777 & 1.48 \\
\hline T31-47 & 60.0 & 1174 & 589 & 590 & 0.16 & 34.681 & 35.563 & 2.54 & 1.751 & 1.825 & 4.23 \\
\hline T31-48 & 50.0 & 2065 & 589 & 603 & 2.36 & 34.095 & 34.943 & 2.49 & 1.751 & 1.665 & -4.91 \\
\hline T31-50 & 85.0 & 2135 & 589 & 629 & 6.73 & 34.426 & 35.811 & 4.03 & 1.751 & 1.744 & -0.40 \\
\hline $\mathrm{T} 31-51$ & 87.5 & 2019 & 589 & 627 & 6.44 & 32.964 & 34.253 & 3.91 & 1.751 & 1.887 & 7.77 \\
\hline T31-52 & 50.0 & 1175 & 589 & 627 & 6.49 & 31.874 & 34.750 & 9.02 & 1.751 & 1.879 & 7.31 \\
\hline T31-53 & 60.0 & 2032 & 589 & 597 & 1.34 & 33.812 & 34.750 & 2.77 & 1.751 & 1.844 & 5.31 \\
\hline T46-3 & 80.0 & 1683 & 541 & 555 & 2.55 & 37.376 & 38.287 & 2.43 & 1.434 & 2.172 & 51.46 \\
\hline T46-6 & 55.0 & 1800 & 541 & 553 & 2.22 & 35.998 & 37.004 & 2.80 & 1.434 & 1.378 & -3.91 \\
\hline T46-7 & 75.0 & 1540 & 541 & 556 & 2.84 & 36.921 & 38.176 & 3.40 & 1.434 & 1.608 & 12.13 \\
\hline T46-8 & 65.0 & 2615 & 541 & 551 & 1.92 & 36.177 & 36.701 & 1.45 & 1.434 & 1.539 & 7.32 \\
\hline T46-12 & 65.0 & 2598 & 541 & 515 & -4.84 & 36.384 & 37.507 & 3.09 & 1.434 & 1.5 & 4.60 \\
\hline T46-14 & 40.0 & 2856 & 541 & 564 & 4.28 & 36.653 & 36.956 & 0.83 & 1.434 & 1.367 & -4.67 \\
\hline T46-15 & 40.0 & 1339 & 541 & 502 & -7.20 & 36.308 & 36.404 & 0.27 & 1.434 & 1.665 & 16.11 \\
\hline T46-17 & 55.0 & 1340 & 541 & 532 & -1.58 & 35.632 & 36.494 & 2.42 & 1.434 & 2.415 & 68.41 \\
\hline T46-18 & 65.0 & 1320 & 541 & 528 & -2.42 & 35.625 & 36.908 & 3.60 & 1.434 & 1.434 & 0.00 \\
\hline
\end{tabular}


Appendix G Creep Post-Test Tensile Property Results

Environment: In-Air Elevated Temperature

\begin{tabular}{|c|c|c|c|c|c|c|c|c|c|c|c|c|}
\hline \multirow{2}{*}{$\begin{array}{l}\text { Specimen } \\
\text { Number }\end{array}$} & \multirow{2}{*}{$\begin{array}{l}\text { Load as } \\
\% \text { UTS }\end{array}$} & \multirow{2}{*}{$\begin{array}{c}\text { Test } \\
\text { Temperature' } \\
{ }^{\circ} \mathrm{C}\end{array}$} & \multirow{2}{*}{$\begin{array}{c}\text { Creep Test } \\
\text { Duration, } \\
\text { Hours }\end{array}$} & \multicolumn{3}{|c|}{ Ultimate Tensile Strength } & \multicolumn{3}{|c|}{ Tensile Modulus of Elasticity } & \multicolumn{3}{|c|}{ Tensile Failure Strain } \\
\hline & & & & $\begin{array}{c}\text { Plaque Avg., } \\
\text { MPa }\end{array}$ & $\begin{array}{c}\text { Post-Creep } \\
\text { Test, MPa }\end{array}$ & $\begin{array}{c}\text { Change, } \\
\%\end{array}$ & $\begin{array}{l}\text { Specimen Initial } \\
\text { Stiffness., } \\
\text { GPa }\end{array}$ & $\begin{array}{c}\text { Post-Creep } \\
\text { Test, GPa }\end{array}$ & $\begin{array}{c}\text { Change, } \\
\%\end{array}$ & $\begin{array}{c}\text { Plaque Avg., } \\
\%\end{array}$ & $\begin{array}{l}\text { Post-Creep } \\
\text { Test, } \%\end{array}$ & $\begin{array}{c}\text { Change, } \\
\%\end{array}$ \\
\hline T41-12 & 70.0 & 70 & 2209 & 575 & 616 & 7.11 & 5.137 & 4.865 & -5.29 & 1.714 & 1.650 & -3.73 \\
\hline T41-14 & 60.0 & 70 & 1993 & 575 & 653 & 13.54 & 5.127 & 4.977 & -2.93 & 1.714 & 1.791 & 4.49 \\
\hline T41-21 & 80.0 & 70 & 2162 & 575 & 623 & 8.32 & 5.200 & 5.491 & 5.60 & 1.714 & 2.634 & 53.68 \\
\hline T41-13 & 70.0 & 90 & 1969 & 575 & 617 & 7.38 & 5.117 & 4.325 & -15.48 & 1.714 & 1.923 & 12.19 \\
\hline T41-19 & 80.0 & 90 & 2040 & 575 & 552 & -4.05 & 4.977 & 5.462 & 9.74 & 1.714 & 2.448 & 42.82 \\
\hline T41-20 & 70.0 & 90 & 1989 & 575 & 582 & 1.22 & 5.067 & 5.446 & 7.48 & 1.714 & - & - \\
\hline T41-4 & 70.0 & 120 & 1997 & 575 & 514 & -10.66 & 36.59 & 30.90 & -15.56 & 1.714 & 1.567 & -8.58 \\
\hline T41-5 & 60.0 & 120 & 1996 & 575 & 583 & 1.38 & 34.04 & 28.56 & -16.10 & 1.714 & 1.961 & 14.41 \\
\hline T41-6 & 60.0 & 120 & 2012 & 575 & 540 & -6.12 & 34.91 & 33.26 & -4.72 & 1.714 & 1.717 & 0.18 \\
\hline T41-7 & 50.0 & 120 & 1949 & 575 & 578 & 0.57 & 35.14 & 33.51 & -4.65 & 1.714 & 1.811 & 5.66 \\
\hline T41-9 & 70.0 & 120 & 1994 & 575 & 590 & 2.61 & 34.61 & 31.27 & -9.64 & 1.714 & 1.864 & 8.75 \\
\hline T41-15 & 40.0 & 120 & 1945 & 575 & 652 & 13.44 & 35.42 & 35.48 & 0.18 & 1.714 & 1.651 & -3.68 \\
\hline T41-16 & 40.0 & 120 & 1611 & 575 & 660 & 14.81 & 35.32 & 37.17 & 5.23 & 1.714 & 2.49 & 45.27 \\
\hline T31-02 & 72.0 & 120 & 2834 & 589 & 614 & 4.28 & 34.55 & 32.17 & -6.88 & 1.751 & 1.829 & 4.45 \\
\hline T31-05 & 75.6 & 120 & 3308 & 589 & 612 & 3.86 & 35.10 & 32.52 & -7.35 & 1.751 & 1.783 & 1.83 \\
\hline T31-22 & 69.9 & 120 & 1970 & 589 & 561 & -4.77 & 36.51 & 33.77 & -7.52 & 1.751 & 1.706 & -2.57 \\
\hline T31-33 & 80.7 & 120 & 2183 & 589 & 620 & 5.28 & 36.06 & 31.90 & -11.53 & 1.751 & 1.837 & 4.91 \\
\hline T31-42 & 80.0 & 120 & 2116 & 589 & 596 & 1.15 & 36.03 & 32.75 & -9.11 & 1.751 & 1.667 & -4.80 \\
\hline T31-43 & 75.0 & 120 & 2116 & 589 & 591 & 0.40 & 36.22 & 32.81 & -9.42 & 1.751 & 2.3 & 31.35 \\
\hline
\end{tabular}


Appendix G Creep Post-Test Tensile Property Results

Environment: Distilled Water or Windshield Washer Fluid Room Temperature

\begin{tabular}{|c|c|c|c|c|c|c|c|c|c|c|c|c|}
\hline \multirow{2}{*}{$\begin{array}{c}\text { Specimen } \\
\text { Number }\end{array}$} & \multirow{2}{*}{$\begin{array}{l}\text { Load as } \\
\% \text { UTS }\end{array}$} & \multirow{2}{*}{\begin{tabular}{|c|} 
Fluid \\
Environment
\end{tabular}} & \multirow{2}{*}{$\begin{array}{c}\text { Creep Test } \\
\text { Duration, } \\
\text { Hours }\end{array}$} & \multicolumn{3}{|c|}{ Ultimate Tensile Strength } & \multicolumn{3}{|c|}{ Tensile Modulus of Elasticity } & \multicolumn{3}{|c|}{ Tensile Failure Strain } \\
\hline & & & & $\begin{array}{l}\text { Plaque Avg., } \\
\text { MPa }\end{array}$ & $\begin{array}{l}\text { Post-Creep } \\
\text { Test, MPa }\end{array}$ & $\begin{array}{c}\text { Change, } \\
\%\end{array}$ & $\begin{array}{c}\text { Specimen Initial } \\
\text { Stiffness., } \\
\text { GPa }\end{array}$ & $\begin{array}{l}\text { Post-Creep } \\
\text { Test, GPa }\end{array}$ & $\begin{array}{c}\text { Change, } \\
\%\end{array}$ & $\begin{array}{c}\text { Plaque Avg., } \\
\%\end{array}$ & $\begin{array}{l}\text { Post-Creep } \\
\text { Test, \%a }\end{array}$ & $\begin{array}{c}\text { Change, } \\
\%\end{array}$ \\
\hline T39-10 & 70.0 & DW & 1848 & 600 & 564 & -6.04 & 34.75 & 27.95 & -19.56 & 1.666 & 1.896 & 13.81 \\
\hline T39-11 & 60.0 & DW & 1828 & 600 & 533 & -11.24 & 35.51 & 29.16 & -17.88 & 1.666 & 2.228 & 33.73 \\
\hline T39-38 & 60.0 & DW & 2715 & 600 & 572 & -4.73 & 35.05 & 28.12 & -19.75 & 1.666 & 2.090 & 25.45 \\
\hline T39-39 & 79.9 & DW & 1842 & 600 & 529 & -11.78 & 36.08 & 30.87 & -14.45 & 1.666 & 1.542 & -7.44 \\
\hline T39-43 & 40.0 & DW & 2161 & 600 & 564 & -5.97 & 34.77 & 32.93 & -5.29 & 1.666 & 1.815 & 8.94 \\
\hline T39-50 & 40.0 & DW & 1878 & 600 & 545 & -9.17 & 34.89 & 32.64 & -6.44 & 1.666 & 1.971 & 18.31 \\
\hline T41-32 & 50.0 & WWF & 1687 & 575 & 601 & 4.53 & 34.89 & 37.34 & 6.57 & 1.714 & 2.780 & 62.19 \\
\hline T41-45 & 40.0 & WWF & 1326 & 575 & 572 & -0.54 & 34.06 & 38.16 & 10.75 & 1.714 & 2.297 & 34.01 \\
\hline T39-08 & 70.3 & WWF & 1875 & 600 & 550 & -8.26 & 35.37 & 29.04 & -17.91 & 1.666 & 1.927 & 15.67 \\
\hline T39-23 & 50.0 & WWF & 530 & 600 & 556 & -7.29 & 35.18 & 32.68 & -7.11 & 1.666 & 2.058 & 23.53 \\
\hline T39-24 & 40.0 & WWF & 717 & 600 & 565 & -5.90 & 35.05 & 33.21 & -5.25 & 1.666 & 1.837 & 10.26 \\
\hline T39-25 & 79.9 & WWF & 1611 & 600 & 528 & -12.06 & 34.77 & 29.77 & -14.38 & 1.666 & 1.728 & 3.72 \\
\hline T39-26 & 69.9 & WWF & 798 & 600 & 567 & -5.47 & 34.98 & 28.42 & -18.75 & 1.666 & 1.857 & 11.46 \\
\hline T39-28 & 50.0 & WWF & 190 & 600 & 568 & $\begin{array}{l}-5.39 \\
\end{array}$ & 34.52 & 32.54 & -5.75 & 1.666 & 2.074 & 24.49 \\
\hline T39-35 & 50.0 & WWF & 2357 & 600 & 586 & -2.42 & 34.63 & 32.76 & -5.40 & 1.666 & 2.022 & 21.37 \\
\hline T39-36 & 60.0 & WWF & 2353 & 600 & 545 & -9.09 & 35.09 & 30.87 & -12.04 & 1.666 & 1.830 & 9.84 \\
\hline T39-47 & 40.0 & WWF & 1847 & 600 & 601 & 0.10 & 36.43 & 34.85 & -4.33 & 1.666 & 1.420 & -14.77 \\
\hline T39-51 & 40.0 & WWF & 1991 & 600 & 593 & -1.13 & 34.77 & 33.36 & -4.05 & 1.666 & 1.987 & $\begin{array}{l}19.27 \\
\end{array}$ \\
\hline
\end{tabular}





\section{ORNL/TM-2006/011}

\section{INTERNAL DISTRIBUTION}

$\begin{aligned} 1-2 . & \text { R. L. Battiste } \\ 3 . & \text { R. G. Boeman } \\ 4-8 . & \text { J. M. Corum } \\ \text { 9. } & \text { M. S. Davenport } \\ \text { 10. } & \text { D. L. Erdman } \\ \text { 11. } & \text { J. G. Hansen } \\ \text { 12. } & \text { C. Janke } \\ \text { 13. } & \text { L. D. Klett } \\ \text { 14. } & \text { V. Kunc } \\ \text { 15. } & \text { E. Lara-Curzio }\end{aligned}$

\author{
16-20. D. J. Naus \\ 21. R. E. Norris \\ 22. P. A. Sklad \\ 23. J. M. Starbuck \\ 24. C. D. Warren \\ 25. Y. J. Weitsman \\ 26. Central Research Library \\ 27. ORNL Laboratory Records-RC \\ 28. ORNL Laboratory Records-OSTI
}

\section{EXTERNAL DISTRIBUTION}

29. M. Abdallah, Hexcel Carbon Fibers, Research and Technology, P.O. Box 18748, Salt Lake City, UT 84118-0748

30-34. J. A. Carpenter, U.S. Department of Energy, Office of Freedom Car and Vehicle Technologies, 1000 Independence Ave, SW, Washington, DC 20585-0121

35. M. Ciliberti, Ticona, 2600 N. Opdyke Road, Auburn Hills, MI 48326

36. M. M. Fisher, American Plastics Council, 1300 Wilson Boulevard, Suite 800, Arlington, VA 22209

37. R. B. Freeman, The Budd Company, 1515 Atlantic Boulevard, Auburn Hills, MI 48326

38. R. Gjerde, Textron Automotive Company, 100 Brady Road, Americus, GA 31709

39-488. L. Berger, Automotive Composite Consortium, General Motors, 30500 Mound Road, Mail Code 480-106-710, Box 9055, Warren, MI 48090-9055

49. J. M. Henshaw, Department of Mechanical Engineering, The University of Tulsa, 600 S. College Avenue, Tulsa, OK 74104-3189

50. G. A. Holmes, National Institute of Standards and Technology, Bldg. 224, Room B116, Mail Stop: Room B108, Gaithersburg, MD 20899

51. S. H. Johnson, BP Amoco Polymers, Inc., 4500 McGinnis Ferry Road, Alpharetta, GA 300053914

52. A. Fatz, National Composite Center, 2000 Composite Drive, Kettering, OH 45420

53. T. D. Seagrave, Bayer Corporation, 100 Bayer Road, Pittsburgh, PA 15205

54. M.T. Smith, Energy Materials, MSIN K2-03, 902 Battelle Blvd., Richland, WA 99352

55. L. V. Smith, Washington State University, School of Mechanics and Materials Engineering, Pullman, WA 99164-2920

56. J. Spruiell, University of Tennessee, 424 Dougherty Engineering Building, 1512 Middle Drive, Knoxville, TN 37996-2200

57. X. J. Xin, Department of Mechanical and Nuclear Engineering, Kansas State University, 338 Rathbone Hall, Manhattan, KS 66506-5205

58. S. J. Winckler, Cyclics Corporation, 747 Pierce Road, Clifton Park, NY 12065 
